\title{
THE CHERRIES OF NEW YORK
}




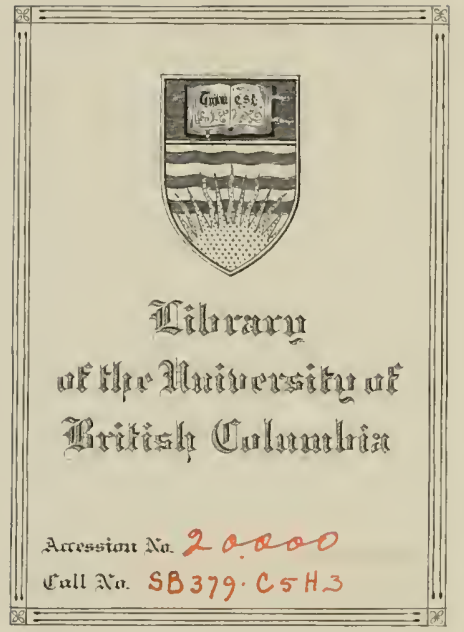



Digitized by the Internet Archive in 2010 with funding from University of British Columbia Library 







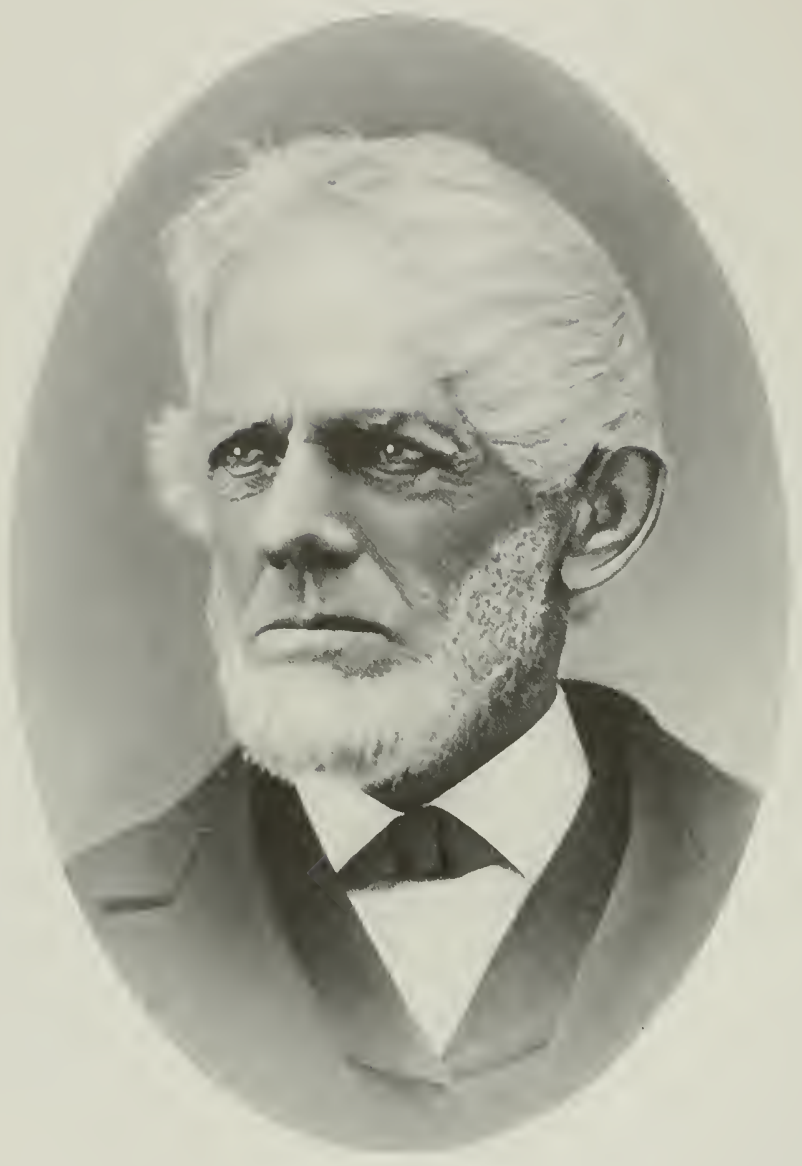

CHARLES DOWNING 


\title{
State of New York-Department of Acriculture
}

Twenty-second Annual Report-Vol. 2-Part II

\section{THE \\ CHERRIES OF NEW YORK}

\author{
BY \\ U. P. HEDRICK
}

ASSISTED BY

G. H. HOWE

O. M. TAYLOR

C. B. TUBERGEN

R. WELLINGTON

Report of the New York Agricultural Experiment Station for the Year 1914

II 


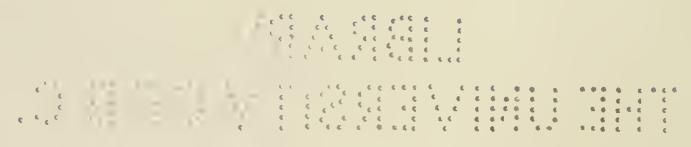




\section{NEW YORK AGRICULTURAL EXPERIMENT STATION, Geneva, N. Y., January 12, 1915}

To the Honorable Board of Control of the New York Agricultural Experiment Station:

Gentlemen:- I have the honor to transmit herewith the manuscript copy for Part II of the 33d Annual Report of this Station. This contribution is the fourth monograph on the fruits of New York State, prepared under your direction by the Horticulturist of this institution and his associates.

The cherry, which this manuscript discusses, is undoubtedly most widely grown of the tree-fruits of the State; for within easy reach of every rural housewife - in orchard or garden, along roadside or lane - the "pie cherry" will be found; and many a lawn, even in village or city, is graced by the stately trees which bear the delicious Yellow Spanish or Black Tartarian. In many parts of the State, also, cherry growing is an industry of much commercial importance, with orchards exceeded in value by those of the apple and peach alone.

Because of its widespread popularity and commercial importance the cherry well merits treatment in this place in the series of monographs. It is hoped and believed that the growers and lovers of the fruit will appreciate and utilize to good advantage the result here presented of years of painstaking work by the authors. The discussions are based not alone on Station experience with hundreds of the thousand or more varieties described, but as well upon the collected observations of many cherry growers and the expressed judgments of the leading pomologists who have been interested in this fruit.

W. H. JORDAN, Director 



\section{PREFACE}

This is the fourth of the monographs on the fruits of temperate North America published by the New York Agricultural Experiment Station. The nature and purposes of these treatises have been set forth in the prefaces of preceding volumes, but a summary of the purposes, with needed emphasis on several, is given for the convenience of all readers and the enlightenment of those who may not have the first three books.

The Cherries of New York contains an historical account of cultivated cherries, the botany of this fruit, a statement of its present economic status in America, descriptions of all known varieties of cherries, the synonymy and bibliography of the species and varieties, and biographical sketches of the persons who have contributed materially to cherry culture in America. The most important varieties are illustrated in colors. Everything that was thought would be helpful in breeding cherries has been included, and special search has been made for such material. So, too, whatever was thought to be of interest to students of ecology and of plant distribution has been added.

In the monographs on grapes and plums it was necessary to devote much space to the botanical relationship of these fruits since each contains more than a score of species under cultivation, some of which are scarcely known and most of which are extremely variable. The botany of cultivated cherries is comparatively simple and has been made plain by botanical writers. Yet the contemplation of the several species from a horticultural standpoint adds something, we believe, to the botany of cherries, especially as concerns the forms of the Sweet Cherry and the Sour Cherry which have been variously treated by botanists.

As compared with their congeners, especially the plums, the economic species of cherries are remarkably well delimited, showing far less responsiveness to environment and having seemingly less inherent variation, so that there need be little confusion in botanical classification. On the other hand varieties are so similar that it is only with the greatest difficulty that closely related sorts are distinguished and there is great confusion in the synonymy, the chief task of the present work being to distinguish the true names from the synonyms of the varieties described.

In The Cherries of New York, as in the preceding fruit books from this 
Station, effort has been made to give as accurately as possible the region in which the species and varieties grow best and to set forth fully the local prejudices of the fruits. Such knowledge cannot but be of value in determining the factors which govern the distribution of plants. The establishment of community relationships and description of plant communities now constitute an important part of botany on the one side and of geography on the other. No phenomena give better expression of the climate and the soil of a region than plant communities. When monographs of several of the fruits of temperate North America shall have been completed, with statements of likes and dislikes of the fruits and their varieties as to climate and soil, material should be available to establish plant communities from which can be drawn valuable generalizations.

All, howsoever interested in pomology, are dependent upon descriptions of fruits. A well-made description of a fruit, to one mentally equipped to interpret it, is second only, in the study of pomology, to having the fruit itself. With but few exceptions the descriptions of the major varieties are made first hand from cherries growing on the Station grounds, though in many cases fruits from different localities have been compared with those home-grown.

Since there are fewer varieties of cherries than of plums, it has been possible to describe and illustrate a greater proportion of the sorts under cultivation than in the book on plums, yet a selection has had to be made of the worthiest of the many kinds. The choice of sorts for full descriptions and color-plates has been determined: (I) By the present value of the variety; (2) the probable value if the variety be a novelty; (3) by the value of the data to the cherry breeder; (4) because of historical value - to show what the trend of cherry evolution has been; (5) to show the relationships of species and varieties. The varieties not illustrated nor fully described are divided into two further groups in accordance with the same considerations.

In botanical nomenclature the code adopted by the International Botanical Congress, held at Vienna in 1905, has been used. In the use of horticultural names we have followed somewhat closely the rules of the American Pomological Society, though in many cases strict observance of these rules, poor at best, would have added to rather than lessened the confusion in horticultural nomenclature and, therefore, they have been honored in the breach rather than in the observance. 
The references given are those that have been of use in ascertaining the history, the economic status, or the description of the variety that follows - no more, no fewer. These constitute a very small proportion of the references that have been read - a tremendous task involving two or three years' work for several persons.

So, too, it has been a herculean task to search out the synonyms of cherries. French, German, English and American books on pomology overflow with such synonyms and all in a state of "confusion worse confounded." An enormous amount of work has been done in trying to bring order out of this confusion. Many of the synonyms of varieties have been given in times past because of adaptations to local environment. Such naming of ecologic forms is not an unmixed evil, since it draws attention to variable varieties and characters which otherwise might be overlooked.

Under the ferment of Mendelian and De Vriesian ideas we seem to be at the beginning of an era of great improvement of plants. There have never been well-directed efforts to improve fruits, yet something has been done with all. Now, when there is an onrush of new discoveries in plantbreeding, seems to be a particularly opportune time to tell all that can be learned about how cherries have been brought from their wild state to their present perfection. This we try to do in giving the origin and history of varieties, especially as to parentage and manner of origin, though such information is scant and very fragmentary.

As in the previous fruit books some prominence is given in foot-notes to biography. A knowledge of the career of those who have been giants in their day in the development of any industry is most helpful to the best understanding, indeed, is almost indispensable to the fullest comprehension, of the industry. The short foot-notes, it is hoped, will serve to give some conception of what the master builders in pomology were like in training, character, and methods of work. From the reception which these sketches in former fruit books have received, the writers feel that the considerable expenditure of time and thought that these biographical notices have required is amply justified and that the effort to give credit due and some small honor to the promoters of pomology has been well worth while.

For aid in the preparation of The Cherries of New York I am especially indebted to those whose names appear on the title page, to my associate, Mr. R. D. Anthony, for reading proof; to the Station editor, Mr. F. H. 
Hall, who has had charge of the proof reading; to Zeese-Wilkinson Company, New York City, who have had an especially difficult task in making the color-plates and who have done the work well; and to the J. B. Lyon Company, Albany, New York, for their painstaking work in printing the book.

$$
\text { U. P. HEDRICK, }
$$

IIorticulturist, New York Agricultural Experiment Station. 


\section{TABLE OF CONTENTS}

PAGE

Preface. . . . . . . . . .

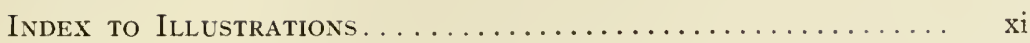

Chapter I. - Cultivated Cherries............. I

Chapter II.- The History of Cultivated Cherries........ 39

Chapter III. - Cherry Culture.............. 65

Chapter IV.- Leading Varieties of Cherries. . . . . . . . . 97

Chapter V.- Minor Varieties of Cherries........... 205

Bibliography, References and Abbreviations. . . . . . . . 337

INDEX. . . . . . . . . . . . . . . . . . 347 


\section{INDEX TO ILLUSTRATIONS}

Portrait of Charles Downing..................... Frontispiece FACING PAGE

Авbesse d'Otgnies. . . . . . . . . . . . . . . . . . . . 98

ArCH DukE................................ IOO

Bing. ............................. I04

Black Tartarian........................... I 8

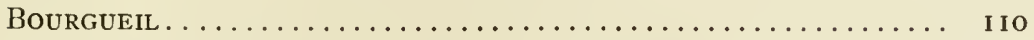

Brusseler Braune......................... II

Carnation . ............................. I I 4

CoE............................... I 20

Double Natte............................. I 24

DownER............................... 126

Dyehouse............................... I 26

EAGLE............................. I 28

EARly Purple............................. I 30

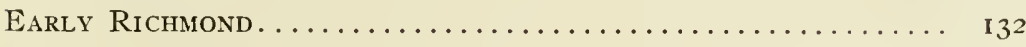

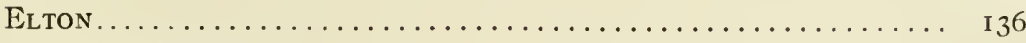

EMpress Eugenie............................. I 38

ENGLISH MoRELlo.......................... I 4 .

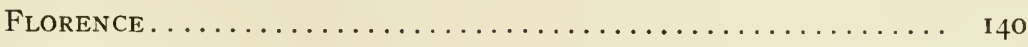

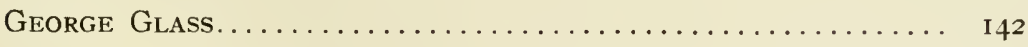

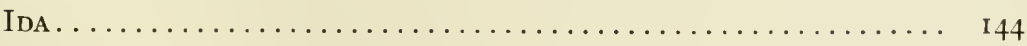

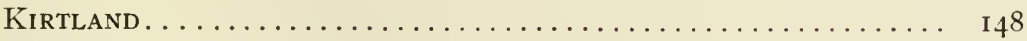

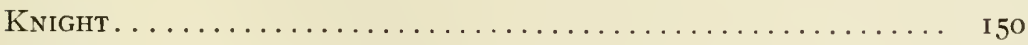

LAMBERT . . . . . . . . . . . . . . . . . .

LARGE MONTMORENCY ...................... I 54

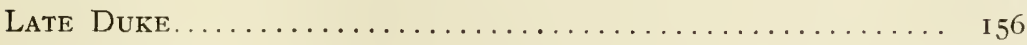

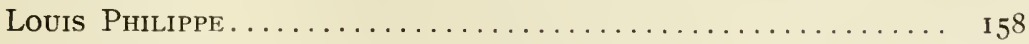

MAY DukE............................... I64

MEZEL . . . ........................... 68

MontMoREnCY.......................... I 70

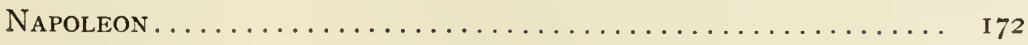

Nouvelle Royale......................... 174 
Olivet. 176

OSTHEIM 178

Prunus a vium (Double Flowering), Blossoms of........... 30

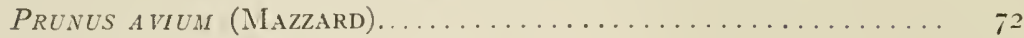

PRUYUS AVIUM (MAZZARD), Blossoms of.............. 68

PrLnes a Vium (Yellow Spanish), Blossoms of.............. 28

Prunus a VIU. X Prunus cerasts (Reine Hortense), Blossoms of. 32

Prunl's Cerasus (Amarelle Group), Blossoms of........... 24

Prunus cerasus (Morello Group), Blossoms of ............ 26

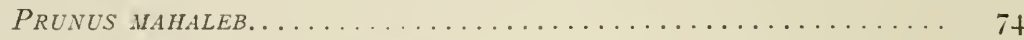

PRUNUS MAILALEB, Blossoms of . . . $\ldots \ldots \ldots \ldots \ldots \ldots \ldots \ldots \ldots \ldots$

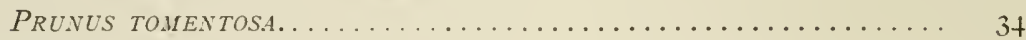

REINE HoRTENSE. . . . . . . . . . . . . . . . . . . . I 80

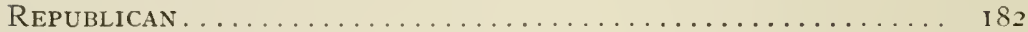

RockPORT ............................ I 82

Royal DukE.......................... I $8_{t}$

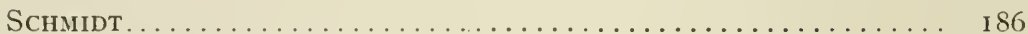

Short-Stem MontMorency .................... I 88

SKLANKA. .......................... I 88

SUdA. . . . . . . . . . . . . . . . . . . . . $\ldots 2$

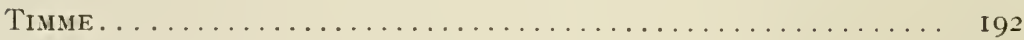

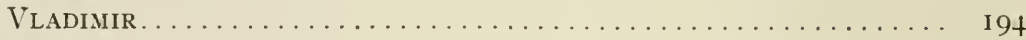

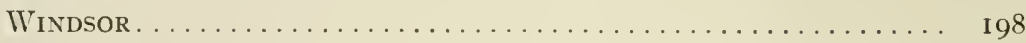

Wood .................................... 200

YELLOW SPANISH............................ 202 


\title{
THE CHERRIES OF NEW YORK
}

\author{
CHAPTER I \\ CULTIVATED CHERRIES \\ CHERRIES AND THEIR KINDRED
}

The genus Prunus plays a very important part in horticulture. It furnishes, in temperate climates, the stone-fruits, plants of ancient and modern agriculture of which there are a score or more commonly cultivated and at least as many more sparingly grown for their edible fruits. Of these stone-fruits the species of cherries rank with those of the plum and the peach in commercial importance while the several botanical groups of the apricot and almond are less important, but hardly less well-known, members of this notable genus. Prunus is of interest, too, because the history of its edible species follows step by step the history of agriculture. The domestication of its fruits from wild progenitors, most of which are still subjects of common observation, illustrates well the influences and conditions under which plants have generally been brought into domestication. The genus is also of more than ordinary note because the number of its economic species is being increased almost yearly by new-found treasures from North America and Asia, not varieties but species, which promise under future domestication still further to enrich horticulture.

The plum and the peach surpass the cherry in diversity of flavor, aroma, texture, color, form and size, characters which make fruits pleasant to the palate and beautiful to the eye; but the cherry, perhaps, plays a more important part than the plum or the peach in domestic economy. It has fewer prejudices as to soil and climate, hence is much more widely distributed and is more easily grown, being better represented in the orchards and gardens in the regions where the three fruits grow. The cherry, too, fruits more quickly after planting, ripens earlier in the season and its varieties are more regular in bearing and usually more fruitful - characters that greatly commend it to fruit-growing people. Probably it is the most popular of all fruits for the garden, dooryard, roadside and small orchard. All in all, while adorning a somewhat humbler place in pomology, it is more generally useful than the showier and more delicate plum and peach. 
Though placed by most botanists in the same genus, each of the stonefruits constitutes a natural group so distinct that neither botanist nor fruitgrower could possibly take one for another as the trees and fruits of the different groups are called to mind. But there are outstanding forms which seem to establish connections between the many species and the several groups of fruits and through these outliers the characters are so confounded in attempting to separate species that it becomes quickly apparent that there are few distinct lines of cleavage within the genus. For several centuries systematists have disputed as to whether the stone-fruits fall most naturally into one, two, or three genera - indeed have not been able to agree as to whether some species are plums or cherries, or others apricots or plums. Hybridization between the cultivated divisions of the genus - unquestionably it has taken place in nature as well - has added to the perplexities of classification. Accepting, then, for the present at least, the very artificial classification which, rather paradoxically, places in one genus a number of fruits commonly thought of as quite distinct, let us briefly note the characters which best distinguish cherries from their congeners.

The cherry is nearest of kin to the plum. These two are roughly separated from the other cultivated members of the genus to which they belong by bearing their fruits on stems in fascicles while the others are practically stemless and are solitary or borne in pairs. The fruits of plums and cherries are globular or oblong, succulent and smooth or nearly so. Peaches, apricots, nectarines and almonds are more sulcate than plums and cherries and the almond has a drier flesh, splitting at maturity to liberate the stone; and, with the exception of nectarines and a few varieties of apricots, all are very pubescent. The stones of cherries and plums are smooth, or nearly so, while those of the other fruits are sculptured and pitted, though those of the apricot are often somewhat plum-like.

Cherries are separated from plums by their smaller size and distinctive color of skin, juice and flesh; by the texture and distinct flavor of the flesh; by growth in corymbose rather than umbelliferous fascicles; by the more globular stone; and by the arrangement of the leaves in the bud. Leaves of the plum are usually convolute, or rolled up, in the bud, while those of the cherry are conduplicate, or folded lengthwise along the midrib.

We have been discussing the cherries of common cultivation - the Sweet Cherry and Sour Cherry of the orchards, the fascicled cherries to which the botanists give the group name, Cerasus. But there is another group, the Padus cherries, well worthy of brief mention. The most note- 
worthy representatives of Padus are the bird cherry (Prumus padus) of the Old World and the choke cherry (Prunus virginiana) of the New World. These Padus cherries are distinguished botanically in having their flowers borne in racemes, that is, in long clusters of which those nearest the base of the shoot open first - rather than in the short-clustered fascicles of the Cerasus group. The cherries are small and almost or quite black. The Padus cherries are but sparingly cultivated but undoubtedly they are capable of some improvement under more thorough cultivation.

\section{DISTRIBUTION OF CULTIVATED CHERRIES}

The cherry is one of the most commonly cultivated of all fruits and the many varieties of its several forms encircle the globe in the North Temperate Zone and are being rapidly disseminated throughout the temperate parts of the Southern Hemisphere. For centuries it has been, as we shall see in the history of the species, one of the most valuable fruitproducing trees of Europe and Asia - an inhabitant of nearly every orchard and garden as well as a common roadside tree in temperate climates in both continents. From Europe, as a center of distribution, the cherry has played an important part in the orcharding in temperate regions of other continents. In North America varieties of the cherry are grown from Newfoundland to Vancouver Island on the north, to the Gulf of California, Texas and Florida on the south, yielding fruit in a greater diversity of soils and climates in Canada and the States of the Union than any other tree-fruit.

The Sour Cherry is very cosmopolitan, thriving in many soils; is able to withstand heat, cold and great atmospheric dryness, if the soil contain moisture; and, though it responds to good care, it grows under neglect better than any other tree-fruit. The Sour Cherry, too, is rather less inviting to insects and fungi than most other stone-fruits, being practically immune to the dreaded San José scale. On the other hand the Sweet Cherry is very fastidious as to soils, is lacking in hardiness to both heat and cold and is prey to many insects and subject to all the ills to which stone-fruits are heir; it is grown at its best in but few and comparatively limited areas, though these are very widely distributed.

\section{USES OF THE CHERRY}

The cherry is a delectable early-summer fruit, especially grateful as a refreshing dessert and much valued in cookery, when fresh, canned, pre- 
served or dried, for the making of pies, tarts, sauces and confections. During the last few years, in America at least, the consumption of cherries has been enormously increased by the fashion of adding preserved cherries, as much for ornament as to give flavor, to many drinks and ices. The great bulk of the cherry crop now grown in America for commercial purposes is canned, the industry being more or less specialized in a few fruit regions. The demand for cherries for canning seems to be increasing greatly but unfortunately it calls for but few varieties, the Montmorency being the sort sought for among the Sour Cherries, while the hard-fleshed varieties of the Bigarreau type are in greatest demand among the Sweet Cherries.

The cherry, while a very common fruit in nearly all agricultural regions of America, does not hold the place in American markets as a fresh fruit that it does in the towns and cities of Europe. The great abundance of strawberries, raspberries, currants, gooseberries, dewberries, blackberries, as well as early varieties of tree fruits, makes keener here than abroad the competition in the fruit markets during cherry time. The fact, too, that market fruits in America are shipped long distances, for which the cherry is not well adapted, helps to explain the relatively small regard in which this fruit has been held for commercial purposes in the fresh state. In recent years, however, both Sweet Cherries and Sour Cherries, the former in particular, have been sent to the markets in far greater abundance, the impetus to their market value being due to a better product - better varieties, hence greater demand - and to greatly improved facilities for shipping and holding for sale.

In Europe several liqueurs are very commonly made from cherries both for home and commercial uses. Such is not the case in America, where, except in very limited quantities in which unfermented cherry juices are used in the home, this fruit is not used in liqueur-making. In some of the countries of Europe, wine is made from the juice; a spirit, kirschwasser, ${ }^{1}$ is distilled from the fermented pulp as an article for both home and commerce; and ratafias and cordials are very generally flavored with cherries. In the Austrian province of Dalmatia a liqueur or cordial called maraschino ${ }^{2}$ is made by a secret process of fermentation and distil-

\footnotetext{
${ }^{1}$ Kirschwasser as a commercial article is made chiefly on the upper Rhine from the wild black Sweet Cherry (Prunus avium). In its manufacture, fruit - flesh and kernels - is mashed into a pulp which is allowed to ferment. By distillation from this fermented pulp a colorless liqueur is obtained.

${ }^{2}$ Maraschino is a liqueur, or cordial, made from the fruit and leaves of the small, sour, black Marasca cherry. The product comes chiefly from Zara, the capital of the Austrian province of Dalmatia, where it has been made and exported for over 200 years. Such accounts of the process of making maraschino
} 
lation. This liqueur is imported in America in considerable quantities to flavor preservatives in which the home-grown cherries are prepared for use in various drinks and confections. No attempts have been made to grow the Marasca cherry on a commercial scale in America but undoubtedly it could be grown and, with the process of making maraschino discovered, an important use would be developed for cherries - all the more to be desired since the foreign maraschino is now grossly adulterated and imitated in this country. Both the fruits and seeds of cherries, especially of the Mahaleb, are steeped in spirits for food, drink and medicinal purposes. An oil used in making perfumes for scenting soaps and confectionery is also extracted from the seeds of the Mahaleb because of which use this species is often called the "Perfumed Cherry."

In the old herbals and pomologies much is made of the value of cherries for medicinal purposes. The fruit was supposed to be a sovereign remedy for various ailments of the digestive tract as well as for nervous disorders

as have become public seem to agree that the liqueur is a distillation of a compote made from the fruit and young leaves. When ripe the cherries are picked early in the morning and sent at once to the distillery where the stones are extracted by machinery. The leaves are cut, pressed and added to the fruit with sugar and alcohol. This mixture is allowed to ferment for six months or thereabouts and from it is then distilled maraschino. It is then stored in cellars for three years before being placed on the markets. In both Europe and America there are many imitations of the maraschino liqueur in which neither fruit nor foliage of the Marasca nor any other cherry has any part.

According to the Dalmatians all attempts to improve the Marasca cherry by culture have failed. They say, too, that it will not thrive elsewhere than in Dalmatia. Under culture, the fruits and leaves lose their distinctive aroma and taste as they do on any but the native soil of the variety. The poorer, sparser and more rocky the ferruginous soil, the wilder the tree, the smaller and sourer the cherries, the better the maraschino liqueur - so the present makers say.

Since considerable quantities of cherries are put up in America in maraschino, or its imitation, and the manufacture of such products is a growing industry, the following ruling by the Board of Food and Drug Inspection of the United States Department of Agriculture, taken from Food Inspection Decision I4I, is of interest to growers, canners and users of cherries:

"In considering the products prepared from the large light-colored cherry of the Napoleon Bigarreau, or Royal Anne type, which are artifically colored and flavored and put up in a sugar sirup, flavored with various materials, the Board has reached the conclusion that this product is not properly entitled to be called 'Maraschino Cherries,' or 'Cherries in Maraschino.' If, however, these cherries are packed in a sirup, flavored with maraschino alone, it is the opinion of the Board that they would not be misbranded, if labeled 'Cherries, Maraschino Flavor,' or 'Maraschino Flavored Cherries.' If these cherries are packed in maraschino liqueur there would be no objection to the phrase 'Cherries in Maraschino.' When these artificially colored cherries are put up in a sirup flavored in imitation of maraschino, even though the flavoring may consist in part of maraschino, it would not be proper to use the word 'Maraschino' in connection with the product unless preceded by the word 'Imitation.' They may, however, be labeled to show that they are a preserved cherry, artificially colored and flavored.

"The presence of artificial coloring or flavoring matter, of any substitute for cane sugar, and the presence and amount of benzoate of soda, when used in these products must be plainly stated upon the label in the manner provided in Food Inspection Decisions Nos. 52 and 104." 
and epilepsy. The astringent leaves and bark, or extracts from them, were much uscd by the ancients in medicine and are still more or less employed both as home remedies and in the practice of medicine as mild tonics and sedatives. One of the active chemicals of the leaf, seed and bark is hydrocyanic acid to which is largely due the peculiar odor of these structures. A gum is secreted from the trunks of cherry trees, known in commerce as cerasin, which has some use in medicine and in various trades as well, especially as a substitute and as an adulterant of gum arabic.

At least three cultivated cherry trees produce wood of considerable value. The wood of the cherry is hard, close-grained, solid, durable, a handsome pale red, or brown tinged with red. Prumus avium, the Sweet Cherry, furnishes a wood which, if sufficient care be taken to season it, is of much value in cabinet-making and for the manufacture of musical instruments. Prumus mahaleb is a much smaller tree than the former but its wood, as much as there is of it, is even more valuable, being very hard and fragrant and dark enough in color to take on a beautiful mahoganylike polish. In France the wood of the Mahaleb cherry is held in high esteem, under the name Bois de St. Lucie, in cabinet-making and for toys, canes, handles and especially for the making of tobacco pipes. In Japan the wood of Prumus pseudocerasus is said to be in great demand for engraving and in makjng the blocks used in printing cloth and wall-paper. In America the wood of the orchard species of cherries is seldom used for domestic purposes, that of the wild species being so much more cheaply obtainable and serving all purposes quite as well.

To people who know it only for its fruit, the cherry does not appear particularly desirable as an ornamental. But wild and cultivated cherries furnish many beautiful trees in a genus peculiar for the beauty of its species. The color and abundance of the flowers, fruits and leaves of the cultivated cherries and the fact that they are prolific of forms with double flowers, weeping, fastigiate or other ornamental habits, make the several species of this plant valuable as ornamentals. Besides, they are vigorous and rapid in growth, hardy, easy of culture, comparatively free from pests and adapted to a great diversity of soils and climates. Both the ornamental and the edible cherries are very beautiful in spring when abundantly covered with flowers, which usually open with the unfolding leaves, as well as throughout the summer when overspread with lustrous green foliage and most of them are quite as conspicuously beautiful in the autumn 
when the leaves turn from green to light and dark tints of red. All will agree that a cherry tree in full fruit is a most beautiful object. In the winter when the leaves have fallen, some of the trees, especially of the ornamental varieties, are very graceful and beautiful, others are often picturesque, and even the somewhat stiff and formal Sweet Cherries are attractive plants in the garden or along the roadside.

Very acceptable jellies, sauces and preserves are made from several of the wild cherries in the Padus group. The peasantry of the Eastern Hemisphere have in times of need found them important foods as have also the American Indians at all times. The fruits of some of the species of Padus are quite commonly used in flavoring liqueurs and on both continents are sometimes fermented and distilled into a liqueur similar to kirschwasser. The bark of different parts of the trees of this group is valuable in medicine - at least is largely used. The trees of several species form handsome ornamentals and some of them are in commerce for the purpose. Prumus serotina, one of the group, because of the strength of its wood and the beautiful satiny polish which its surface is capable of receiving, is a valuable timber tree of American forests. For the products of the members of this group, as just set forth, the domestication of some of the species of Padus might well be pushed.

\section{LITERATURE OF THE CHERRY}

Despite the important part they have played in orcharding since the domestication of fruits in temperate zones, as shown by their history and their present popularity, pomological writers have singularly neglected cherries. There are relatively few European books devoted to them and in America, while there are treatises on all others of the common tree-fruits, the cherry alone seems not to have inspired some pomologist to print a book. Neither are the discussions in general pomologies as full and accurate as for other fruits. The reason for this neglect is that the cherry, until the last decade or two, has scarcely been a fruit of commerce, having been grown almost entirely for home use or at most for the local market. As a result of this neglect of the cherry by students of pomology, we have no authoritative nor serviceable system of classification of the varieties of cherries and the nomenclature of this fruit is in an appalling state of confusion, as a glance at the synonymy of some of the older varieties discussed in The Cherries of New York will show. 


\section{AMELIORATION OF THE CHERRY}

The amelioration of the cherry has been in progress almost since the dawn of civilization, yet few men have directed their efforts toward the improvement of this fruit. The histories of the varieties described in The Cherries of New York show that nearly all of them have come from chance seedlings. Possibly there has been little interest in improving cherries because this fruit is comparatively immutable in its characters.

In spite of the fact that there are a great number of varieties, I, I 45 being described in The Cherries of New York, this of all stone-fruits is most fixed in its characters. The differences between tree and fruit in the many varieties are less marked than in the other fruits of Prunus and the varieties come more nearly true to seed. Though probably domesticated as long ago as any other of the tree-fruits, the cherry is now most of all like its wild progenitors. The plum is very closely related to the cherry but it has varied in nature and under cultivation much more than the cherry and in accordance with different environments has developed more marked differences in its species to endure the conditions brought about by the topographical and climatic changes through which the earth has passed. Under domestication more than twice as many orchard varieties of the plum have come into being as of the cherry. In spite of this stability, there are ample rewards in breeding cherries to those who will put in practice rightly directed efforts to improve this fruit - a statement substantiated by the histories of some of the best varieties, described later in this text, which were originated through what was passing as current coin in plant-breeding before the far better methods of the present time, brought about by Mendel's discovery, came into being.

The cherry, as the histories of its many diverse kinds show, has been improved only through new varieties. There is no evidence, whatever, to show that any one of the several hundred cherries described in this text has been improved by selection as a cumulative process, or, on the other hand, that any one of them has cumulatively degenerated. Of varieties cultivated for their fruits there are no records of mutations either from the seed or from bud, though of the ornamental cherries not a few have arisen as bud-mutations, as, for example, the several double-flowered cherries and those of weeping or fastigiate habit of growth and the many sorts with abnormally colored foliage. Since improvement depends upon the bringing into being of new cherries it becomes highly important to know 
how the varieties we are dealing with in The Cherries of New York have come into existence. The following is a summary of their manner of origin:-

No case is recorded in The Cherries of New York of a variety known to have come from self-fertilized seed.

The seed parent is given for 6I varieties. The statements as to seed parents are probably accurate, for a man planting cherry seeds would record the name of the seed parent correctly if he knew it.

The seed and pollen parents of twenty of the cherries described in this work are given. Sixteen of these are hybrids originating with Professor N. E. Hansen of South Dakota, leaving but four sorts the parents of which were known before the recent work of Professor Hansen.

No cherry cultivated for its fruit is reported to have come from a sport or a bud-mutation.

Cherries arising from seed sown without knowledge of either parent or from natural seedlings are put down as chance seedlings; of these there are 147 .

The origin of 917 of the varieties here described is unknown.

The total number of cherries under discussion is $\mathbf{1}, \mathbf{1} 45$.

To improve the cherry the breeder must know the material with which he is working. The following is a brief discussion of the characters of this fruit to be found in the technical descriptions of species and varieties.

\section{TREE AND FRUIT CHARACTERS OF THE CHERRY}

Species of cherries have very characteristic trees. The merest glance at the tree enables one to tell the Sweet Cherry, Prunus avium, from the Sour Cherry, Prumus cerasus. The first named is the larger of the two, especially reaching a greater height, is pyramidal in shape, with branches erect and bearing much less foliage than the Sour Cherry. The Sweet Cherry often lives for a century or more - the Sour Cherry attains but the three score years and ten of man. Prunus cerasus is easily distinguished from Prunus avium by its comparatively low, roundish and never pyramidal head. So, too, many of the varieties of either of these two species are readily told in the orchard by the size or habit of the plant. Other species are either shrubby or tree-like and their varieties may often be identified from the spaciousness or dwarfness of its trees. Size is rather more variable than other gross characters because of the influence of environment - food, moisture, light, isolation, pests and the like - yet 
size in a plant, or in the parts of a plant, is a very reliable character when proper allowances have been made for environment.

Habit of growth, unlike size, varies but little with changing conditions and thus becomes a most important means of distinguishing species and varieties and not infrequently sets the seal and sign of desirability for an orchard cherry. More than any other character, habit of growth gives what is called "aspect" to a cherry tree. Thus, a species or a variety may be upright, spreading, round-topped, drooping or weeping in habit of growth; the head may be open or dense and may be formed by a central shaft with several whorls of branches or by three or four trunk-like stems each with its scaffolding branches. The trees may grow rapidly or slowly and may be long-lived or short-lived. The trunks may be short and stocky, or long and slender, straight or crooked, gnarled or smooth, these characters often determining whether a cherry is manageable or unmanageable in the orchard.

The degree of hardiness is a very important diagnostic character for groups of cherries and often wholly indicates their value for agriculture. Thus, the varieties of Prunus avium are but little hardier than the peach while those of Prunus cerasus are as hardy or hardier than the apple. The range of varieties as to hardiness falls within that of the species and it is interesting to note that in Europe, where the wild Prunus avium is very common, in the many centuries since the fruit has been under domestication, a cultivated variety hardier than the wild Sweet Cherry has not been developed. Cherries are designated in the technical descriptions as hardy, half-hardy and tender.

Productiveness, age of bearing, and regularity of bearing are distinctive and valuable characters of orchard cherries but not of wild cherries. The care given the tree greatly influences fruitfulness, yet the quantity of fruit produced is often a helpful means of identifying a variety and is a character that must always be considered by the plant-breeder. Age of bearing and regularity of bearing are most important characters with the pome fruits, the apple, in particular, but while worth considering with the drupes are of relatively little value, all drupaceous fruits coming in bearing at about the same time for the species and all bearing regularly, as a rule, unless interfered with by some outside agency preventing the setting or causing the dropping of fruit.

Immunity and susceptibility to diseases and insects are valuable taxonomic characters of both species and varieties of cultivated cherries. 
Thus, the varieties of Prumus cerasus are very susceptible to black knot (Plowrightia morbosa), while those of Prumus avium are almost immune. On the other hand, Prunus avium is an inviting prey to San José scale (Aspidiotus perniciosus), while Prunus cerasus is but little injured, indeed, seldom attacked; Prunus mahaleb appears to be almost wholly immune to the powdery mildew (Podosphaera oxyacanthae), while Prunus avium and Prunus cerasus are much attacked, though Wood, a variety of Prumus arium, is almost immune. The English Morello, a variety of Prumus cerasus, is very subject to leaf spot (Cylindrosporium padi), while Montmorency, of the same species, is nearly immune. These examples can be multiplied many times by references to the discussions of varieties, and represent only observations on the grounds and in the neighborhood of this Station. They serve to show the great importance, to the fruitgrower, the plant-breeder and the systematist, of natural resistance to disease and insects.

Both the outer and the inner bark have considerable value in determining species but are of little importance in identifying varieties and have no economic value to the fruit-grower and hence but little to the breeder. Smoothness, color, thickness and manner of exfoliation are the attributes of the outer bark to be noted, while the color of the inner bark is the only determinant and that relatively unimportant. In young trees the bark of the cherry of all species is smooth, glossy or even brilliant; but later it becomes uneven, scaly and dull, usually ash-gray but varying in all of these characters to an extent well worth noting for taxonomic purposes. Cherries, in common with most trees, have a lighter colored bark in cold than in warm regions, and in dry than in wet areas.

Branches and branchlets are very characteristic in both species and varieties. The length, thickness, direction, rigidity and the branching angle are valuable determining characters and very stable ones, changing but little even with marked variations of soil and climate. Thus, a Sweet Cherry tree can be told from a tree of the Sour Cherry, or the English Morello can be distinguished from Montmorency by branch characters as far as the outlines of the trees are discernible. Few cherries bear spines but all are more or less spurred and these spurs are quite characteristic even in varieties. With the branchlets the length of the internodes should be considered and their direction, whether straight or zigzag; also color, smoothness, amount of pubescence, size and appearance of the lenticels, the presence of excrescences, are all to be noted in careful study though 
all are more or less variable, pubescence especially so, this character being too often relied upon in descriptions by European botanists and pomologists.

Leaf-buds vary greatly in different species in size, shape, color of the buds and of their outer and inner scales and in the outline of the scales. The angle at which the bud stands out from the branchlet is of some taxonomic value. Vernation, or the disposition of the leaf-blade in the bud, is a fine mark of distinction in separating the cherry from other stone-fruits and while all cherry leaves are supposed to be conduplicate, that is, folded by the midrib so that the two halves are face to face, yet there are slight but important differences in the conduplication of the leaves in both species and varieties. The manner of bearing buds whether single, in pairs, or in rosettes - must be taken into account, with species at least, and differences in shape and position of leaf and fruitbuds must be noted.

Leaves in their season are very evident and either collectively or individually are valuable determinants of species and varieties. Fruitgrowers take little note of leaves, however, though they should be taken into practical account, since their size and number often indicate the degree of vigor. The variability of leaves is usually within limits easily set and occurs most often in young plants, in extremes of soil and climate, and on very succulent growths or water-sprouts. Leaf-size is the most variable character of this organ but is yet dependable in separating several species, as, for example, Prunus avium from Prunus cerasus, the leaves being very much larger in the former than in the latter species. Leaf-forms are very constant in species and varieties, hence especially valuable in classification.

Much care has been taken to illustrate accurately the size and form of cherry leaves in the color-plates in this text but it is impossible to reproduce by color-printing the tints of the leaves, though these are quite constant in both species and varieties.

Other characters of leaves taken into account in describing cherries are thickness, roughness, and pubescence, all of which are somewhat variable, being greatly influenced by climate and soil. Quite too much stress is laid upon the value of pubescence on leaves in determining groups, unless comparisons can be made between plants growing in the same habitat. Possibly more important than any other part of the leaf-blade, in the study of species at least, is the margin. This in the cherry is 
always serrated and often sub-serrated. These serrations are best studied at the middle of the sides of the leaves, those at the base and apex often being crowded or wanting.

The petiole may be used to good advantage in distinguishing both species and varieties. Thus, in consequence of the great length and slenderness of the petiole of leaves of Sweet Cherries, the leaves are always more or less drooping, while those of the Sour Cherry are usually erect by reason of the petiole being short and strong. The color of the petiole is said by some to be correlated with that of the fruit - a statement that needs verification. The pubescence of the petiole must be noted.

The position, size, shape and color of the glands on cherry leaves must be noted as they are fairly constant guides. They are usually on the petiole at the base of the leaf but are sometimes on the leaf itself. The glands are commonly given as globular or reniform in shape but there are often intermediate forms the shape of which is hard to classify.

Stipules in this plant have considerable taxonomic value, having some distinguishing marks not possessed by the leaves. Cherry leaves springing from dormant leaf-buds have very small stipules, sometimes so minute as hardly to be seen, but on the current year's growth the stipules are larger, being largest at the tip of the branchlet. There is considerable difference in the size of these organs in varieties of the same species. Stipules of the cherry are nearly always borne in pairs. The small stipules, appearing with the first leaves, drop, at this Station, about the middle of June while those accompanying the later leaves on the wood growth of the current year remain until in July, there being a difference in varieties as to how long they remain. All stipules are deeply toothed and bear glands of varying color and shape on the serrations, the characters of both serrations and glands offering some distinguishing marks for species and varieties.

The flowers of cherries are very characteristic, as a study of the colorplates of blossoms will show, furnishing a wholly distinctive mark of species and helping to distinguish varieties. The flowers are hermaphrodites and are borne in more or less dense, corymbose clusters. Individual flowers in species and varieties vary in size, shape, color and odor. The peduncles are long or short, as the case may be; the corolla furnishes distinctions in size, shape and color of petals; the calyces are chiefly distinguished by their glands and the amount and character of the pubescence; while stamens and pistils offer differences in size, color of their different 
parts and in the number of stamens. In plums the reproductive organs differ greatly in ability to perform their functions, some varieties being self-sterile. In New York there seem to be no marked differences in fecundity in cherries nor are there so frequently the malformations of reproductive organs which are found in plums. The season of flowering is a fine mark of distinction between species and varieties, a fact well brought out by the chart on pages $80-8 \mathrm{I}$.

Of all organs, the fruit of the cherry is most responsive to changed conditions and hence most variable, yet the fruits furnish very valuable taxonomic characters in both botany and pomology. In pomology, in particular, the fruits must be closely studied. Size, shape, color, bloom, stem, cavity, apex, suture and skin are the outward characters of which note must be made; while the color, aroma, flavor and texture of the flesh are usually very characteristic. Both species and varieties are well distinguished by the time of ripening though there is much variation in ripening dates. The keeping quality is scarcely taken into account with cherries but varies a great deal, chiefly in accordance with firmness of the flesh. The flesh of cherries, as in all drupaceous fruits, clings to the stone or is wholly or partly free - a character of interest both to the systematist and to the fruit-grower. The color of the juice, whether colorless or red, is a plain and certain dividing line in both species and varieties.

The pits of cherries are rather more lacking in distinction than in other stone-fruits, plums for example, yet they must be accounted of considerable value in determination and for this reason have been included in all of the color-plates of varieties. Cherry-pits from individual trees are almost lacking in differences except in size but between species and varieties show many distinctions not only in size but in shape, surfaces, grooves and ridges, in the ends and more or less in the seeds within. Cherries of any variety grown on poor soils or in incongenial climates tend to have large stones and little flesh, while the pits are smaller and there is more flesh with the opposite extremes in environment. As will be pointed out in the discussion of the group of cherries known as the Dukes, many varieties have pits with shrunken and abortive seeds coming, as we think, from the hybrid origin of these cherries.

The several pages given to the discussion of the characters of cherries are in preparation for a proper understanding of the classifications and descriptions of species and varieties. We are now ready for the classifcation of the species of cherries which contribute or may contribute forms 
for cultivation either for their fruits or as stocks upon which to grow edible cherries. The following is a brief conspectus of the edible species of Prunus followed by a fuller conspectus of the sub-genus Cerasus to which cherries belong.

\section{A CLASSIFICATION OF CULTIVATED CHERRIES}

The genus Prunus is variously delimited and divided by systematic botanists. A simple, and from a horticultural point of view, a very satisfactory classification, is to put almonds and peaches in one sub-genus (Amygdalus), cherries in a second (Cerasus), plums and apricots in a third (Euprunus), and to place the racemose cherries and cherry-laurels, usually considered in Prunus, in another genus, Padus. In this division of Prunus into three sub-genera we may assign to each the following characters.

A. Leaves convolute, $i$. $e$, rolled in the bud (showing best in the opening buds). ${ }^{1}$

Euprunus. Plums and apricots.

A.A. Leaves conduplicate, $i . e$., folded lengthwise along the midrib in the bud.

B. Fruit more or less dry and hirsute; if juicy or glabrous the blossoms appear long before the opening of the leaves; fruits without stems.

Amygdalus. Almonds and peaches.

B.B. Fruit always juicy and usually glabrous; blooms appearing with the leaves.

Cerasus. Cherries.

Of these several divisions we are here concerned only with Cerasus, to which belong all fascicled cherries, the racemose, or Padus, cherries as yet having little or no value as esculents. The genus Prunus is from year to year being enlarged by the discovery of new species, the additions to Cerasus in particular being numerous. Thus, a decade ago, botanists placed in this sub-genus, at the outside, not more than a score of species but Koehne, the most recent monographer of Cerasus, describes I 19 species. Of Koehne's species at least a dozen are more or less cultivated for their fruits and a score or more are grown as ornamentals.

The following species are listed by Koehne: ${ }^{2}$

\footnotetext{
${ }^{1}$ The leaves are conduplicate in vernation in a few species of American plums; these species are intermediate between plums and cherries.

${ }^{2}$ The species are given as classified by Koehne, Plantae Wilsonianae Pt. 2:237-271. 1912. The liberty has been taken of changing the form of Koehne's citations to conform to that used at this Station. For the sake of brevity some of the citations of the original author have been omitted. Space does not permit the publication of Koehne's system of classification. This may be found in Plantae Wilsonianae Pt. 2:226-237. 1912 .

Conservative botanists will hardly accept all of Koehne's species, in describing which the author tells us he labored under the difficulty of paucity of material and that as more material comes to hand there
} 


\section{SPECIES OF CHERRIES}

Div. I. T Y P O C E R A S U S Koehne.

Sect. 1. CREMAST OSEPAL U M Koehne.

Subsect. 1. MAHALEB Koehne.

Cerastis sect. Mahaleb Roemer. Fani. Nat. Syn. 3:79. 1847.

Prunus subgen. Cerasus sect. MIahaleb Koehne. Deutsche Dendr. 305. 1893.

Ser. I. Eumahaleb Koehne.

I. Prunus mahaleb Linnaeus. $S p$. Pl. 472 . 1753. Europe, Western Asia.

Ser. 2. Paramahale b Koehne.

2. Prunus mollis Walpers. Rep. 2:9. Western North America.

3. Prunus emarginata Walpers. Rep. 2:9. Western North America.

Cerasus californica Greene. Fl. Francis 1:50.

4. Prunus pennsylvanica Linnaeus. Syst. ed I3 Suppl. 252. Eastern North America.

Subsect. 2. EUCERASUS Koehne.

Prunus sect. Eucerasus Koehne. Deutsche Dendr. 306. 1893.

5. Prunus fruticosa Pallas. Fl. Ross. 1:19. 1784. Europe to Siberia.

6. Prunus acida C. Koch. Dendr. 1:112. 1869. Southern Europe.

7. Prunus cerasus Linnaeus. $S p$. Pl. $47+$. 1753. Europe, Western Asia.

8. Prunus avium Linnaeus. Fl. Svec, ed 2:165. 1755. Europe, Western Asia.

Subsect. 3. PHYLLOMAHALEB Koehne.

Ser. 1. Aphanadenium Koehne.

9. Prunus maximowiczii Ruprecht. Bul. Acad. Sci. St. Pétersburg 15:131. 1857.

Prunus bracteata Franchet \& Savatier. Enum. Pl. Jap. 2:329. 1879.

Prunus apetala Zabel. Mitt. Deutsch. Dendr. Ges, 13:60 (not Franchet \& Savatier) 1904. Amur, eastern Manchuria, Korea, Saghalin, Japan from Hokkaido to Kiushiu.

Prunus maximowiczii aperta Komarow. Act. Hort. Petrop. 22:5, 48. 1904. Manchuria from the Ussuri through Kirin to Mukden and northern Korea

10. Prunus pulchella Koehne. Plant. Wils. Pt. 2:197. 1912. Western Hupeh. Ser. 2. Macradenium Koehne.

I1. Prunus conadenia Koehne. l. c. 197. Western Szechuan.

12. Prunus pleiacerasus Koehne. l. c. 198. Western Szechuan.

13. Prunus macradenia Koehne. l.c. 199. Western Szechuan.

14. Prunus discadenia Koehne. l. c. 200. Western Hupeh.

15. Prunus szechuanica Batalin. Act. Hort. Petrop. 14:167. 1895. Szechuan. Subsect. 4. PHYLLOCERASUS Koehne.

16. Prunus tatsienensis Batalin. Act. Hort. Petrop. 14:322. 1897. Szechuan.

Prunus tatsienensis adenophora (Franchet) Koehne. Plant. Wils. Pt. 2:238. 1912.

Prunus maximowiczii adenophora Franchet. Pl. Delavay. 195. 1889. Yunnan.

Prunus tatsienensis stenadenia Koehne. Plant. Wils. Pt. 2:201. 1912. Western Szechuan.

17. Prunus variabilis Koehne. l. c. 20I. Western Hupeh.

18. Prunus pilosiuscula (Schneider) Koehne. l. c. 202.

Prunus tatsienensis pilosiuscula Schneider. Fedde Rep. Nov. Sp. I:66. 1905. Western Hupeh and Szechuan.

19. Prunus polytricha Koehne. Plant. Wils, Pt. 2:204. 1912. Western Hupeh.

20. Prunus rebderiana Koehne. l. c. 205. Western Hupeh.

21. Prunus venusta Koehne. l. c. 239. Western Hupeh.

22. Prunus litigiosa Schneider. Fedde Rep. Nov. Sp. 1:65. 1905. Hupeh.

Prunus litigiosa abbreviata Koehne. Plant. Wils. Pt. 2:205. 1912. Western Hupeh.

23. Prunus clarofolia Schneider. Fedde Rep. Nov. Sp. 1:67. 1905. Szechuan.

must, therefore, be revisions. These species are provisionally accepted in The Cherries of New York under the belief that botany and horticulture are best served by giving names freely so that all forms to which reference may need to be made may thus be better identified.

The botanical student of Cerasus is referred to Schneider's comprehensive discussion of Prunus in his Handbuch der Laubholzkunde 1:589-637. 1906 and 2:973-993; also Koehne's monographs of Cerasus, Sargent, C. S., Plantae Wilsonianae Pt. 2:197-271. 1912. Profitable though it might be, space does not permit in The Cherries of New York a botanical discussion of other than the species cultivated for their fru its. 
Subsect. 5. PSEUDOMAHALEB Koehne.

24. Prunus yunnanensis Franchet. Pl. Delavay. 195. 1889. Yunnan.

25. Prunus macgregoriana Koehne. Plant. Wils. Pt. $2: 240$. I 912 . Western Hupeh.

26. Prunus henryi (Schneider) Koehne. l. c. 240.

Prunus yunnanensis henryi C. K. Schneider. Fedde Rep. Nov. Sp. 1:66 (in part) 1905. Yunnan.

27. Prunus neglecta Koehne. Plant. Wils. Pt. 2:2+1. 1912.

Prunus yunnanensis henryi C. K. Schneider. Fedde Rep. Nov. Sp. 1:66 (in part) I905. Yunnan.

Subsect. 6. LOBOPETALUM Koehne.

Ser. I. HeTEROCALyx Koehne.

28. Prunus scopulorum Koehne. Plant. Wils. Pt. 2:241. I9I2. Western Hupeh.

29. Prunus glabra (Pampanini) Koehne.

- Prunus hirtipes glabra Pampanini. Nuov. Giorn. Bot. Ital. 17:293. 1910; 18:122. I911. Hupeh.

30. Prunus involucrata Koehne. Plant. Wils. Pt. 2:206. 1912. Western Hupeh.

31. Prunus hirtipes Hemsley. Jour. Linn. Soc. 23:218. 1887.

32. Prunus schneideriana Koehne. Plant. Wils. Pt. 2:242. 1912. Chekiang.

33. Prunus duclouxii Koehne. l. c. 2ł2. Yunnan.

34. Prunus ampla Koehne. Plant. Wils. Pt. $2: 243$. 1912. Szechuan.

35. Prunus malifolia Koehne. l. c. 207. Western Hupeh.

Prunus malifolia rosthornii Koehne. l.c. 243 . Szechuan.

Ser. 2. Cyclaminium Koehne.

36. Prunus cyclamina Koehne. Plant. Wils. Pt. 2:207. I912. Western Hupeh.

Prunus cyclamina biflora Koehne. l. c. 243. Western China.

37. Prunus dielsiana Schneider. Fedde Rep. Nov. Sp. 1:68. 1905.

"P. szechuanica, var.?" or "P. szechuanica dielsiana Schneider," $l$. $c_{.}$, not $P$. szechuanica Batalin.

Hupeh.

Prunus dielsiana laxa Koehne. Plant. Wils. Pt. 2:208. 1912. Western Hupeh.

Prunus dielsiana conferta Koehne. l. c. 244. Western Hupeh.

38. Prunus plurinervis Koehne. l. c. 208. Western Szechuan.

39. Prunus rufoides Schneider. Fedde Rep. Nov. Sp. I:55. I905. Szechuan.

40. Prunus hirtifolia Koehne. Plant. Wils. Pt. 2 :209. 1912. Western Szechuan. Sect. 2. P S E U D O C E R A S U S Koehne.

Prunus subgen. Cerasus sect. Yamasakura Koidzumi. Tokyo Bot. Mag. 25: I83. I9II.

Subsect 7. HYPADENIUM Koehne.

41. Prunus glandulifolia Ruprecht \& Maximowicz. Mém. Sav. Ëlr. Acad. Sci. St. Pétersburg 9:87 (Prim. Fl. Amur.) 1859. Amur.

Subsect. 8. SARGENTIELLA Koehne.

42. Prunus pseudocerasus Lindley. Trans. Hort. Soc. Lond. 6:90, 1826. Cultivated in China. Cerasus pseudocerasus G. Don. Loudon Hort. Brit. 200. 1830.

Prunus sieboldii Koidzumi. Tokyo Bot. Mag. 25: 184. 1911.

Prunus pseudocerasus sieboldii Maximowicz. Bul. Acad. Sci. St. Pétersburg 29: 102,

Prunus paniculata Ker. Bot. Reg. 10: t. 800. 1824, not Prunus paniculata Thunberg.

Cerasus paniculata De Candolle. Prodr. 2:539. 1825 .

Cerasus sieboldtii Carrière. Rev. Hort. 37 r. 1866.

Prunus sieboldii Wittmack. Gartenf. 51:272. 1902.

Prunus pseudocerasus serrulata sieboldtii Makino. Tokyo Bot. Mag. 22:102. 1908?

Prunus serrulata serrulata sieboldtii Makino. l. c. 23:74. I909.

Prunus pseudocerasus typica sieboldii Koidzumi. l. c. $\mathbf{1} 82$.

Prunus psendocerasus flore roseo pleno Koehne. (Horticultural)

Prunus pseudocerasus naden Koehne. (Horticultural)

Prunus pseudocerasus watereri Koehne. l. c. 172.1909.

Cerasus wattererii, cited by Lavallée Icon. Arb. Segrez. II9. I885, as a synonym under Cerasus pseudocerasus?

Cerasus watereri Goldring. Garden 33: 4 I6, fig. p. 420. I888?

Prunus serrulata serrulata wattererii Makino. Tokyo Bot. Mag. 23:75. 1909? (Horticultural)

Prunus pseudocerasus virescens Koehne.

Prunus donarium Siebold. Rijks-Herbarium, Leyden.

43. Prunus paracerasus Koehne. Fedde Rep. Nov. Sp. 7:133. I909. Japan. (Horticultural)

44. Prunus serrulata Lindley. Trans. Hort. Soc, London $7: 138.1830$.

Prunus cerasus flore simplici Thunberg. Fl. Jap. 20r. 1784.

Prunus donarium Siebold. Verh. Balav. Genoot. I2: No. 1. 68 (Syn. Pl. Oecon.) I827.

Prunus jamasakura Siebold. l. c. $\mathbf{1 8 2 7 .}$ 
Cerasus serrulata G. Don. Loudon ITort. Brit. 480.1830.

Prunus puddum Miquel. Ann. Mus. Lugd.-Bat. 2:90, (in part, not Wallich) 1865.

Prunus pseudocerasus jamasakura glabra Makino. Tokyo Bot. Mag. 22:93. 1809.

Prunus pseudocerasus jamasakura pracox Makino. l. c. 98. I908.

Prunus pseudocerasus jamasakura glabra pracox Makino. l. c. I13.

Prunus pseudocerasus serrulata glabra Makino. l. c. 101.

Prunus pseudocerasus spontanea hortensis Koidzumi. l.c. 23:183. I909.

Prunus cerasus flore pleno Thunberg. Fl. Jap. 201. 1784 .

Prunus serrulata Lindley. cf. supra.

Cerasus serrulata G. Don. Loudon Arb. Brit. 2:701, fig. 407. 1833.

Cerasus pseudocerasus Lavallée. Icon. Arb. Segrez. 119, t. 36. 1885, (ubi citatur: Cerasus maeda h.).

Prunus pseudocerasus serrulata glabra fugenzo Makino. Tokyo Bot. Mag. 22:73. 1908.

Prunus serrulata serrulata fugenzo rosea Makino. l. c. 23:74. 1909.

Prunus jamasakura elegans glabra Koidzumi. l. c. 25:185. I9II.

Prunus jamasakura speciosa Koidzumi. l. c. 186. Japan, Korea.

Prunus serrulata albida (Makino) Koehne.

Prunus psetudocerasus hortensis flore simplici albo Maximowicz. Bul. Acad. Sci. St. Pétersburg $29: 102$.

Prunus psendocerasus Stapf. Bot. Mag. 131: t. 8012. 1905.

Prunus pseudocerasus serrulata sieboldii albida Makino. Tokyo Bot. Mag. 22: 102. 1908.

Prunus serrulata serrulata albida Makino. l. c. 23:74. 1909.

Prunus serrulata yashino Koehne. Mitt. Deutsch. Dendr. Ges. 18:167. 1909.

Prunus pseudocerasus yoshino Koehne. (Horticultural)

Prunus serrulata lannesiana (Carrière) Koehne. Milt. Deutsch. Dendr. Ges. I8: 167. 1909.

Cerasus lannesiana Carrière. Rev. Hort. 198. 1872.

Prunus pseudocerasus hortensis flore simplici carneo Maximowicz. Bul. Acad. Sci. St. Pélersburg 29: 102.

Prunus serrulata serrulata lannesiana Makino. Tokyo Bot. Mag. 23:74. 1909.

Prunus jamasakura speciosa nobilis Koidzumi. l. c. 25:187. 1911.

Prunus serrulata kriegeri Koehne. Gartenfl. 52:2 (nomen nudum) 1902.

Cerasus pendula kriegeri F. Späth ex Koehne.

Prunus serrulata grandiflora A. Wagner. Gartenfl. 52:169, t. 1513a. I903.

Prunus pseudocerasus horlensis flore pleno viridi Maximowicz. Bul. Acad. Sci. St. Pétersburg 29:102.

Prunus pseudocerasus serrulata glabra viridiflora Makino. Tokyo Bot. Mag. 22:102. 1908.

Prunus serrulata serrulata viridiflora Makino. l. c. 23:74. 1909.

Cerasus donarium Siebold. Rijks-Herbarium, Leyden.

Prunus pseudacerasus ukon Koehne. (Horticultural)

Prunus serrulata ochichima Koehne. Mitt. Deutsch. Dendr. Ges. 18:169. 1909.

Prunus serrulata serrulata fugenzo, 2. alborosea Makino. Tokyo Bot. Mag. 23:74. 1909.

Prunus pseudocerasus ochichima Koehne. (Horticultural)

Prunus pseudocerasus shirofugen Koehne. (Horticultural)

Prunus serrulata hisakura Koehne. Gartenfl. 51:2, t. 1494 b. 1902.

Cerasus caproniana flore roseo pleno Van Houtte. Fl. des. Serres 21:141, t. 2238. 1875 .

Cerasus serratifolia rosea Carrière. Rev. Hort. 889, t. fig. B. 1877 .

Prunus pseudocerasus hortensis flore semipleno roseo Maximowicz. Bul. Acad. Sci. St. Pitersburg II: 699. I 883.

Prunus pseudocerasus hisakura Koehne. (Horticultural)

Prunus pseudocerasus benifugen Koehne. (HorticulturaI)

Prunus pseudocerasus "New Red." Koehne. (Horticultural)

Prunus serrulata "W. Kou." Koehne. (Horticultural)

Prunus iamasakura speciosa nobilis donarium Koidzumi. Tokyo Bot. Mag. 25:187. 1911 .

Prunus serrulata veitchiana Koehne. Fedde Rep. Nov. Sp. 9:122. 1911.

Cerasus pseudocerasus "James Veitch." Gartenfl.51:497. 1902. (Horticultural)

Prunus serrulata mucronata Koehne. Mitt. Deuisch. Dendr. Ges. 18:170. 1909.

Prunus pseudocerasus hortensis flore pulcherrimo pleno candido Maximowicz. Bul. Acad. Sci. St. Pilersburg 29: 102.

Prunus cerasus flore roseo pleno Koehne. (Horticultural)

Prunus serrulata flore pleno Koehne. (Horticultural)

Prunus serrulata shidare-sakura Koehne. Mitt. Deutsch. Dendr. Ges. I8:170. 1909.

Prunus pseudocerasus hortensis flore carneo suffuso Maximowicz. Bul. Acad. Sci. St. Pétersburg $29: 102$.

Prunus pseudocerasus shidare-sakura Koehne. (Horticultural)

44 x 88 ? Prunus affinis Makino. Prunus pseudocerasus jamasakura $\mathbf{x}$ incisa? Makino. Tokyo Bot. Mlag. 22:99. 1908. Japan. 
45. Prunus sargentii Rehder. Mitt. Deutsch. Dendr. Ges. 17:159. 1908.

Prunus puddum Miquel. Ann. Mus. Lugd. Bat. 2:90 (in part, not Wallich) 1865.

Prunus pseudocerasus sachalinensis F. Schmidt. Mém. Acad. Sci. St. Pétersburg sér. 7, 12: No. 2. I24. Prunus pseudocerasus spontanea Maximowicz. Bul. Acad. Sci. St. Pétersburg 29: 102.

Prunus mume crasseglandulosa Miquel. Rijks-Herbarium, Leyden.

Prunus pseudocerasus Sargent. Garden and Forest 10: 462 , fig. 58 (not Lindley) 1897.

Prunus Sp. Zabel. Beissner, Schelle \& Zabel Handb. Laubholz-Ben. 24I. I903.

Prunus pseudocerasus borealis Makino. Tokyo Bot. Mag. 22:99. 1908.

Prunus serrulata borealis Makino. l. c. 23:75. 1909.

Prunus pseudocerasus spontanea Koidzumi. l. c. 182.

Prunus jamasakura elegans compta Koidzumi. l. c. 25:186. I911.

Prunus jamasakura borealis Koidzumi. l. c. 187. Korea, Saghalin, Japan.

46. Prunus tenuiflora Koehne. Plant Wils. Pt. 2:209. 1912. Western Hupeh.

47. Prunus wildeniana Koehne. l. c. 249. Hupeh.

48. Prunus leveilleana Koehne. l. c. 250 . Korea.

49. Prunus sontagiæ Koehne. l. c. 250. Korea.

50. Prunus mesadenia Koehne. l. c. 250. Nippon.

51. Prunus parvifolia (Matsumura) Koehne. l. c. 25 I.

Prunus pseudocerasus parvifolia Matsumura. Tokyo Bot. Mag. 15:101. 1901.

Prunus pseudocerasus typica parrifolia Koidzumi. l. c. 23:182. 1909.

Prunus jamasakura elegans parvifolia Koidzumi. l.c. 25: 186. I911. Japan.

Prunus parvifolia aomoriensis Koehne. Plant. Wils. Pt. 2:251. 1912. Northern Nippon.

52. Prunus concinna Koehne. l.c. 2 I0. Western Hupeh.

53. Prunus twymaniana Koehne. l. c. 2 II. Western Szechuan.

Subsect. 9. CONRADINIA Kochne.

54. Prunus conradinæ Koehne. Plant. Wils. Pt. 2:211. 1912. Western Hupeh.

55. Prunus helenæ Koehne. l. c. 212 . Western Hupeh.

56. Prunus saltuum Koehne. l. c. 213. Western Hupeh.

57. Prunus pauciflora Bunge. Mím. Ëtr. Acad. Sci. St. Pëtersburg 2:97 (Enum. Pl. Chin. Bor.) 1835. Chili.

58. Prunus sprengeri Pampanini. Nuov. Giorn. Bot. Ital. 18:230. I9I I. Hupeh.

59. Prunus yedœnsis Matsumura. Tokyo Bol. Mag. 15: 100. 1901. Cultivated in the gardens of Tokyo. Subsect. ro. SERRULA Koehne.

6o. Prunus majestica Koehne. Plant. Wils. Pt. 2:252. 1912.

Prunus puddum Franchet. Pl. Delavay. 197 (not Roxburgh following Brandis) 1889.

Prunus cerasoides tibetica Schneider. Fedde Rep. Nov. Sp. 1:54 (in part) 1905. Yunnan.

6r. Prunus serrula Franchet. Pl. Delavay. 196. 1889. Yunnan.

Prunus serrula tibetica (Batalin) Koehne. Plant. Wils. Pt. 2:213. I912. Western Szechuan. Subsect. II. PUDDUM Koehne.

62. Prunus campanulata Maximowicz. Bul. Acad. Sci. St. Pitersburg 29. 103.

Prunus cerasoides Koidzumi. Tokyo Bot. Mag. 23:181 (in part, not D. Don) 19o9. Fokien. Cultivated in Japan.

63. Prunus hosseusii Diels. Fedde Rep. Nov. Sp. 4:289. I907. Siam.

64. Prunus cerasoides D. Don. Prodr. Fl. Nepal. 239. 1825.

Prunus silvatica Roxburgh. Hort. Beng. 92. I814.

Cerasus phoshia Hamilton. De Candolle Prodr. 2:535. 1825.

Cerasus puddum Seringe. De Candolle Prodr. 2:537. 1825.

Prunus puddum Roxburgh. Forest Fl. Brit. Ind. 194. 1874. Nepal.

65. Prunus rufa Steudel. Nomencl. Bot. 2:404. I841. Cerasus rufa Wallich. Cat. No. 721. 1829. Eastern Himalaya.

66. Prunus trichantha Koehne. Plant. Wils. Pt. $2: 254.1912$.

Prunus rufa Hooker. Fl. Brit. Ind. 2:3I4 (in part) 1878. Eastern Himalaya. Subsect. I2. MICROCALYMMA Koehne.

67. Prunus herincquiana Lavallée. Plant. Wils. Pt. 2:214. I912. Western Hupeh.

Prunus herincquiana biloba (Franchet) Koehne. Western Hupeh.

Prunus biloba Franchet in Herb. Paris. China.

68. Prunus subhirtella Miquel. Ann. Mus. Lugd.-Bat. 2:91. I 865 .

Prun us subhirtella oblongifolia Miquel. l. c.

Prunus incisa Maximowicz. Bul. Sci. Acad. St. Pétersburg 29:99.

Prunus pendula ascendens Makino. Tokyo Bot. Mag. 7:103. 1893?

Prunus herincquiana ascendens Schneider. Ill. Handb. Laubholzk. I:608. 1906. 
Prunus ilosakra subhirtella Koidzumi. Tokyo Bot. Mag. 23:180. I908. Japan. Prunus subhirtella fukubana Makino. Tokyo Bot. Mag. 22: rr8. I908.

Prunus itosakra ascendens amabilis Koidzumi. l. c. 23:18r. 1909?

69. Prunus pendula Maximowicz. Bul. Acad. Sci. St. Pétersburg 29:98.

Prunus itosakura Siebold. Verh. Batav. Genoot. 12: No. 1. 68. 1830.

Cerasus pendula flore roseo Siebold. Cat. 5:31. 1863, Maximowicz.

Cerasus pendula rosea Dombrain. Floral Mag. 10. t. 536. 1871. ,

Prunus subhiriclla pendula Tanaka. Useful Pl. Jap. 153, fig. 620. 1895.

Cerasus itosakura Siebold. Herb., Maximowicz. l.c.

Cerasus herincquiana Lavallée. Icon. Arb. Segrez. II7. 1885.

Prunus miqueliana Schneider. Ill. Handb. Laubholak. I:609 (not Maximowicz) I906.

Prunus herincquiana Schneider. l. c. 608.

Cerasus pendula Siebold in herb., Koehne. l. c.

Prunus cerasus pendula flore roseo Koehne. l. c. (Horticultural)

Prunus itosakra pendula Koidzumi. Tokyo Bot. Mag. 23:180. 1909. Japan.

7o. Prunus taiwaniana Hayata. Jour. Coll. Sci. Tokyo 30:87. r9Ir. Formosa.

71. Prunus microlepis Koehne. Plant. Wals. Pt. 2:256. r912. Hondo.

Prusus microlepis ternata Koehne. l. c. 256 . Hondo.

Subsect. 13. CERASEIDOS (Siebold \& Zuccarini) Koehne.

Ceraseidos Siebold \& Zuccarini. Abl. Akad. Münch. 3:743 t. 5. 1843.

Ser. I. Phyllopodium.

72. Prunus setulosa Batalin. Act. Hort. Petrop. 12:165. 1892. Eastern Kansu.

73. Prunus phyllopođa Koehne. Plant. Wils. Pt. 2:257. 1912. Northern Shensi.

74. Prunus canescens Bois. l. c. 215. Western Hupeh.

75. Prunus veitchii Koehne. l. c. 257. Western Hupeh.

Ser. 2. Droserina.

76. Prunus giraldiana Schneider. Fedde Rep. Nov. Sp. 1:65. 1905. Northern Shensi.

77. Prunus droseracea Koehne. Plant. Wils. Pt. 2:215. 1912. Western Szechuan.

Ser. 3. Oxyodon.

78. Prunus trichostoma Koehne. 1.c.216. Western Szechuan.

79. Prunus latidentata Koehne. l. c. 217. Western Szechuan.

8o. Prunus micromeloides Koehne. l. c. 2 I8. Western Szechuan.

81. Prunus oxyodonta Koehne. l. c. 218. Western Szechuan.

82. Prunus glyptocarya Koehne. l. c. 219. Western Szechuan.

83. Prunus podadenia Koehne. l.c. 258. Western China.

84. Prunus lobulata Koehne. l. c. 220. Western Szechuan.

85. Prunus stipulacea Maximowicz. Bul. Acad. Sci. St. Pétersburg II:689. I883. Kansu.

86. Prunus pleuroptera Koehne. Plant. Wils. Pt. 2:22r. 19г2. Western Szechuan.

87. Prunus zappeyana Koehne. l. c. 221. Western Hupeh.

Prunus zappeyana? subsimplex Koehne. l. c. 222. Western Hupeh.

88. Prunus incisa Thunberg. Fl. Jap. 202 . 1784.

Cerasus incisa Loiseleur. Nowveau Duhamel 5:33. 1812.

Ceraseidos apetala Miquel. Ann. Mus. Lugd.-Bat. 2:93 I865 (in part). Japan.

Ser. 4. Euceraseidos.

89. Prunus caudata Franchet. Pl. Delavay. I96. ז889. Yunnan.

90. Prunus iwagiensis Koehne. Plant. Wils. Pt. 2:259. 1912. Hondo.

91. Prunus nipponica Matsumura. Tokyo Bot. Mag. 15:99. rgor.

Prunus miqueliana Koidzumi. l. c. 23:184 (not Maximowicz) 1909.

Prunus ceraseidos Maximowicz. Bul. Acad. Sci. St. Pitersburg 29:103.

Prunus a petala typica Schneider. Ill. Handb. Laubholzk. 1:608. I906. Japan.

92. Prunus autumnalis Koehne. Plant. Wils. Pt. 2:259. 1912.

Prunus subhirtella autumnalis Makino. Tokyo Bot. Mag. 22:117. I908. Hondo.

93. Prunus kurilensis Miyabe. Tokyo Bot. Mag. 24:11. I910.

Prunus ceraseidos kurilensis Miyabe. Mem. Boston Soc. Nat. Hist. 4:226 (Fl. Kurile Isl.) I 890.

Prunus incisa kurilensis Koidzumi. Tokyo Bot. Mag. 23:184. 1909.

94. Prunus nikkoensis Koehne. Plant. Wils, Pt. 2:260. I912. Japan.

95. Prunus miqueliana Maximowicz. Bul. Acad. Sci. St. Pétersburg I1:692 (not Schneider) 1883. Japan.

96. Prunus tschonoskii Koehne. Plant. Wils. Pt. 2:261. 1912.

Prunus ceraseidos Maximowicz. Bul. Acad. Sci. St. Pétersburg 29: 103.

Prunus apetala iwozana Schneider. Ill. Handb. Laubholzk. 1:608. 1906. Japan. 
97. Prunus apetala (Siebold \& Zuccarini) Franchet \& Savatier. Enum. Pl. Jap. 2:329. I879 (not Zabel, cf. P. maximowicsii, No. 9).

Ceraseidos apetala Siebold \& Zuccarini. Abh. Akad. Münch. 3:743. t. 5. I843.

Prunus ceraseidos Maximowicz. Bul. Acad. Sci. St. Pétersburg 29:103. Japan.

Ser. 5. Amblyodon.

98. Prunus gracilifolia Koehne. Plant. Wils. Pt. 2:223. 1912. Western Hupeh.

99. Prunus rossiana Koehne. l. c. 223. Western Hupeh.

Div. II. M I C R O C E R A S U S (Spach, Roemer) Koehne.

Cerasus sect. Microcerasus Spach. Hist. Vig. I:423. I834.

Microcerasus Webb. Phytogr. Canar. 2:19. 1836-40.

Sect. I. S P I R A E O P S I S Koehne.

Subsect. I. MYRICOCERASUS Koehne.

100. Prunus pumila Linnaeus. Mant. Pl. 75. 1767. Eastern North America.

101. Prunus besseyi Bailey. Bul. Cor. Ex. Sta. 70:261. 1894. Eastern North America. Subsect. 2. SPIRAEOCERASUS Koehne.

102. Prunus dictyoneura Diels. Bot. Jahrb. 36, Beibl. 82, 57. 1905. Shensi.

103. Prunus humilis Bunge. Mém. Étr. Acad. Sci. St. Pétersburg 2:97 (Enum. Pl. Chin. Bor.) 1833. Prunus salicina Lindley. Trans. Hort. Soc. Lond. 7:239. 1830.

Prunus bungei Walpers. Rep. 2:9 (not Moris) 1893. China.

104. Prunus glandulosa Thunberg. Fl. Jap. 202. I 784 .

Anygdalus pumila Linnaeus. Mant. $1: 74 . \quad 1767$.

Cerasus glandulosa Loiseleur. Nouv. Duhamel 5:33. 1825.

Prunus glandulosa glabra Koehne. Plant. Wils. Pt. 2:263. 1912.

Prunus japonica glandulosa Maximowicz. Bul. Soc. Nal. Mosc. 54:13. 1879. Japan.

Prunus glandulosa glabra alba Koehne. Plant. Wils. Pt. 2:263. I912.

Prunus japonica Lindley. Bot. Reg. 8:t. 1801. 1835.

Prunus glandulosa glabra rosea Koehne. Plant. Wils. Pt. 2:263. 1912.

Prunus japonica typica flore roseo Maximowicz, in sched.

Prunus ja ponica flor. simp. Tanaka. Useful Pl. Jap. 153, fig. 621. 1895.

Prunus japonica glandulosa Matsumura. Tokyo Bot. Mag. 14:136. I900. Japan.

Prunus glandulosa glabra albiplena Koehne. Plant Wils. Pt. 2:264. I9r2.

Cerasus japonica multiplex Seringe. De Candolle Prodr. 2:539 (in part) 1 825 .

Prunus japonica flore pleno Siebold \& Zuccarini. Fl. Jap. 1:172 t. 90 f. III. (in part) 1826.

Prunus japonica Oudemans. Neerlands Plantentuin t. 2. 1865.

Prunus japonica flore albo pleno Lemaire. Ill. Hort. 5: t.183. 1858.

Prunus japonica Maximowicz. Bul. Soc. Nat. Mosc. 54 . 14 (in part) 1879.

Prunus japonica multiplex Makino. Tokyo Bot. Mag. 22:72 (in part) 1908. Japan.

Prunus glandulosa purdomii Koehne. Plant. Wils. Pt. 2:264. 1912. Northern China.

Prunus glandulosa trichostyla Koehne. l. c. 224.

Prunus glandulosa trichostyla faberi Koehne. l. c. 224.

Prunus japonica J. Hutchinson. Bot. Mag. 135: t. 8260 (not Thunberg) 1909. Shantung.

Prunus glandulosa trichostyla paokangensis (Schneider) Koehne. Plant. Wils. Pt. 2:264. I912.

Prunus japonica packangensis Schneider. Fedde Rep. Nov. Sp. I:53. 1905. Western Hupeh.

Prunus glandulosa trichostyla sinensis (Persoon) Koehne. Plant. Wils. Pt. 2:265. I9I2.

Amygdalus indica nana Plukenett. Phytogr. I: t. II. f. 4 (I69I, new edit. 1769).

Prunus sinensis Persoon. Syn. 2:36. 1807.

Cerasus japonica Seringe. De Candolle Prodr. 2:539 (in part) I825.

Prunus japonica flore pleno Siebold \& Zuccarini. Fl. Jap. I: 172 t. 90 f. II I. (in part) I 826.

Prunus japonica Maximowicz. Bul. Soc. Nat. Mosc. 54: It (in part) 1883. Northern Shensi.

Prunus glandulosa salicifoli (Komarov) Koehne. Plant. Wils. Pt. 2:265. 1912.

Prunus japonica salicifolia Komarov. Act. Hort. Petrop. 22:754. 1904. Shing-king.

105. Prunus pogonostyla Maximowicz. Bul. Soc. Nat. Mosc. 54: I I. 1879.

Prunus formosana Matsumura. Tokyo Bot. Mag. 15:86. I90I.

Prunus pogonostyla globosa Koehne. Plant. Wils. Pt. 2:265. 1912. Formosa.

Prunus pogonostyla obovata Koehne. l. c. 265. Formosa.

106. Prunus japonica Thunberg. Fl. Jap. 201 . 1784.

Prunus japonica japonica Maximowicz. Bul. Soc. Nat. Mosc. 54:12. I 879.

Prunus japonica typica Matsumura. Tokyo Bot. Mag. 14:135. I9oo.

Prunus japonica eujaponica Koehre. Plant. Wils. Pt. 2:266. I912.

Prunus japonica eujaponica fauriei Koehne. l. c. 266. Japan.

Prunus japonica eujaponica oldhamii Koehne. l. c. 266. Hupeh. 
Prunus japonica gracillima Koehne. l. c. 266.

Prunus japonica gracillima thunbergii Kochne. l. c. 266.

Prunus japonica thunbergii Koehne. Fedde Rep. Nov. Sp. 8:23. 1910. Cultivated in the Spāth Arboretum near Berlin, received from St. Petersburg.

Prunus japonica gracillima engleri Koehne. Plant. Wils. Pt. 2:266. 1912.

Prunus japonica engleri Koehne. l.c. 266. Manchuria.

Prunus japonica gracillima minor Koehne. l. c. 267. Cultivated in the Späth Arboretum, Berlin.

Prunus japonica gracillima sphaerica (Carrière) Koehne. l. c. 267.

Prunus japonica sphaerica Carrière. Rev. Hort. 468, fig. 163. 1890.

Prunus japonica kerii (Steudel) Koehne. Plant. Wils. Pt. 2:267. I9r2.

Prunus japonica Ker-Gawler. Bot. Reg. 1: t. 27. 1815.

Amygdalus pumila Sims. Bot. Mag. 47: t. 2176.1820.

Prunus kerii Steudel. Nomencl. Bot. ed. 2, 403. I841, which cites "Cerasus" japonica Ker-Gawler.

Prunus japonica typica flore pleno Zabel. Beissner, Schelle \& Zabel Handb. Laubholz-Ben. 238. 1903.

Chekiang. Cultivated in England.

? Prunus praecox Carrière. Res. Horl. 488 , fig. I 42, 143. 1892. Originated from sowings of Prunus japonica sphaerica and supposed to be Prun us japonica X domestica.

107. Prunus nakaii Léveillé, Fedde Rep. Nov. Sp. 7:198. 1909. Korea.

108. Prunus carcharias Koehne. Plant. Wils. Pt. 2:267. 1912. Szechuan.

Sect. 2. A M Y G D A L O CER A S U S Koehne.

Cerasus sect. Microcerasus Spach.

Microcerasus Webb. Phytogr. Canar. 2:19 (1836-50); Schneider Ill. Handb. Laubholzk. 1:601. 1906.

Prunus subgen. Microccrasus Focke. Engler \& Prantl Natürl. Pflanzenfam. 3:3, 54. 1888.

Prunus sect. Trichocerasus et subgen. Microcerasus Koehne. Deutsche Dendr. 302, 306. 1893.

109. Prunus tomentosa Thunberg. Fl. Jap. 203. 1784. - Siebold \& Zuccarini Fl. Jap. I:51, t. 22.1826. Japan, western and northern China.

Prunus tomentosa spaethiana Koehne. Plant. Wils. Pt. 2:269. 1912. Cultivated in European gardens.

Prunus tomentosa graebneriana Koehne. l. c. 269. Cultivated near the Botanic Garden, BerlinDahlem.

Prunus tomentosa insularis Koehne. l. c. 269. Japan. Cultivated in Japan.

Prunus tomentosa souliei Koehne. l. c. 269. Szechuan.

Prunus tomentosa kashkarovii Koehne. l. c. 269. Tibet.

Prunus tomentosa endotricha Koehne. l. c. 225. Western Hupeh.

Prunus tomentosa breviflora Koehne. l. c. 270 . Northern Shensi.

Prunus tomentosa trichocarpa (Bunge) Koehne. Plant. Wils. Pt. 2:270. 1912.

Prunus trichocarpa Bunge. Mím. Ëtr. Acad. Sci. St. Pétersburg 2:96 (Enum. Pl. Chin. Bor.) I 833. Northern China.

Prunus tomentosa tsuluensis Koehne. Plant. Wils. Pt. 2:270. 1912. Northern Shensi.

Prunus tomentosa heteromera Koehne. l. c. 270. Szechuan.

110. Prunus batalinii (Schneider) Koehne. l. c. 270.

Prunus tomentosa, (?) Batalinii Schneider. Fedde Rep. Nov. Sp. 1:52. 1905. Szechuan.

IIt. Prunus cinerascens Franchet. Nouv. Arch. Mus. Paris, sẻr. 2, 8:216 (Pl. David. II. 34) I885. Western Szechuan.

I12. Prunus jacquemontii (Edgeworth) Hooke. Fl. Brit. Ind. 2:3I4. I878. Afghanistan, Northwestern Himalaya, Tibet.

I13. Prunus incana (Pallas) Steven. Mém. Soc. Nat. Mosc. 3:263. I812. Armenia, Georgia, Himalaya?

Cf. Cerasus hippophaeoides Bornmüller. Oester. Bot. Zeit. 49:15. 1899. Cappadocia.

114. Prunus griffithii (Boissier) Schneider. Ill. Handb, Laubholzk. I:606. I906. Afghanistan.

115. Prunus prostrata Labillardière. Icon. Pl. Syr. I:15, t. 6. I791. Southern Europe, Crete, Algier, Western Asia to Persia and Syria.

Cf. Prunus bifrons Fritsch. Sitz. Akad. Wien ror: pt. r. 636, t. 3, fig. 1. 1892. Himalaya?

II6. Prunus brachypetala (Boissier) Walpers. Ann. I:272. 1848-49. Southern Persia.

117. Prunus microcarpa C. A. Meyer. Verz. Pfl. Caucas. Casp. 166. 1831. Caucasia, Northern Persia.

Cf. Cerasus tortuosa Boissier \& Haussknecht. Boissier Fl. Or. 2:647. 1872. Antilibanon, Cappadocia, Kurdistan.

I18. Prunus verrucosa Franchet. Ann. Sci. Nat. sér. 6, 16:280. I883. Turkestan.

Cf. Prunus calycosus Aitchison \& Hemsley. Trans. Linn. Soc. 3:61, t. 8. 1888. Afghanistan.

119. Prunus diffusa (Boissier \& Haussknecht) Schneider. Ill. Handb. Laubholak. I:606. Igo6. Southwestern Persia. 
The geographical distribution of these cherries is most interesting. ${ }^{1}$ From North America come but five species of cherries but two of which, Prunus besseyi and Prunus pumila, furnish food and these two as yet are but sparingly grown; all five, however, are more or less used as stocks.

Greene $^{2}$ has described, in addition to the five accepted ones, eleven new species of true cherries from the far west of the type of Prunus emarginata, some of which at least have furnished food to the Indians, miners and trappers and may have horticultural possibilities for the desert regions in which they are found either for fruit or as stocks.

From the western portion of the Old World, including all of Europe, northern Africa, Asia Minor, Persia, Turkestan and Afghanistan come I4 species. From this region, though the number of species as compared with East Asia is small, we have all of the cultivated esculent cherries, if possibly Prunus tomentosa be excepted. Though nearly all of the species of this large territory are found - possibly all originated there - in the southeastern part of Europe and the adjoining southwestern part of Asia, yet they seem, with one or two exceptions, to be quite distinct from the species of the eastern half of the Old World - the Himalaya Mountains separating the two regions. It is probable that when west central Asia has been as well explored botanically as the east central part of the continent, many new species will be added to Prunus and its sub-genus Cerasus.

It is in the eastern half of the Old World that the cherry flora is richest. More than 100 of the II 9 species of Cerasus recognized by Koehne are found in the Himalaya Mountains and the region to the east including Japan and the Kuril Islands. Yet out of all of this wealth of raw material only Prumus tomentosa has been truly domesticated as an esculent though possibly a score of these species are well-known ornamentals. Of the Ioo eastern Asiatic species about 75 belong to China - the remainder to

${ }^{1}$ Koehne bas presented the results of a careful study of the distribution of cherries in Mitt. Deutsch. Dendr. Ges. 168-183. 1912.

${ }^{2}$ Greene (Proc. Biol. Soc. Wash. 18:55-60. 1905), preferring Cerasus to Prunus as a generic name for racemose cherries, gives the following new species: Cerasus californica (Fl. Francis, 50. I89I) from the hills of middle western California; Cerasus crenulata from the Mongolian Mountains, New Mexico; Cerasus arida inhabiting the borders of the desert at the eastern base of the San Bernardino Mountain, California; Cerasus prunifolia found in the mountains of Fresno County, California; Cerasus rhamnoides collected at Mud Springs, Amador County, California; Cerasus kelloggiana from the middle Sierra Nevada Mountains in California; Cerasus padifolia collected in the foothills near Carson City, Nevada; Cerasus obliqua described from a single specimen from Oroville, California; Cerasus parviflora known only from Mt. Shasta, California; Cerasus obtusa from the arid interior of southeastern Oregon; and Cerasus trichopetala found at Columbia Falls, Montana. The type specimens of these eleven species are in the National Herbarium at Washington. 
Formosa, Siam and Japan with its islands. Happily these Chinese cherries are being introduced, but a few at a time, it is true, to Europe and America and it can hardly be otherwise than that they will enrich horticulture as they are domesticated, hybridized or used as a consort upon which to grow the cherries now known to cultivation. In particular, it may be expected that cherries for the cold north and the bleak plains of our continent will be evolved from the Asiatic species better suited to these regions than the cultivated cherries we now grow.

The number and diversity of the species of cherries which this brief review of Cerasus shows to exist suggest that our cultivated cherry flora is but begun. There can be no question but that others of these species than the few that have been domesticated will yield to improvement under cultivation and furnish refreshing fruits. It is just as certain that new types, as valuable perhaps as the hybrid Dukes we now have, can be produced through hybridization. In North America, we have no satisfactory stock for cultivated Sweet and Sour Cherries. Both of the stocks now commonly used, the Mazzard and the Mahaleb, as we shall see, have weaknesses that unfit them for general use. Surely out of the great number of forms we have just listed a better stock than either of the two named can be found. No doubt, too, many of these new species, even though they do not furnish food, will prove valuable timber or ornamental trees.

We are ready now for a more detailed discussion of the cultivated species of cherries.

PRUNUS CERASUS Linnaeus.

1. Linnaeus Spec. Pl. 474 . 1753.

P. austera. 2. Ehrhart Beitr. 5: 160. 1790.

P. acida. 3. Ehrhart l.c. 1790 .

P. aestiva. 4. Salisbury Prodr. 356. 1796.

P. plena. 5. Poiret, in Lamarck Enc. Méth. Bot. 5:671. 1804.

P. rosea. 6. Poiret, in Lamarck l.c. 1804 .

P. Juliana. 7. Reichenbach Fl. Germ. Exc. 643. 1832, not Poiret in Lamarck, 1805.

P. hortensis. 8. Persoon Syn. Pl. 2:34. I807.

P. Marasca. 9. Reichenbach Fl. Cerm. Exc. 644. 1832.

P. oxycarpa. 10. Bechstein Forst. Bot. $5: 424$. 1843.

P. vulgaris. Ir. Schur Enunt. Pl. Transsilv. 954. 1866.

Cerasus vulgaris, 12. Miller Gard. Dict. ed. 8:No. I. 1768.

C. hortenses. 13. Miller l. c. No. 3. 1768.

C. acida. 14. Borkhausen, in Roemer Arch. Bot. I: II , 38. 1796.

C. austera. 15. Borkhausen, in Roemer l. c. 1796.

C. Caproniana. 16. De Candolle Fl. Fran. ed. 3, 4:8 42 . 1805.

C. nicotianaefolia. 17. Hort. ex De Candolle Prodr. 2:536. 1825 . 


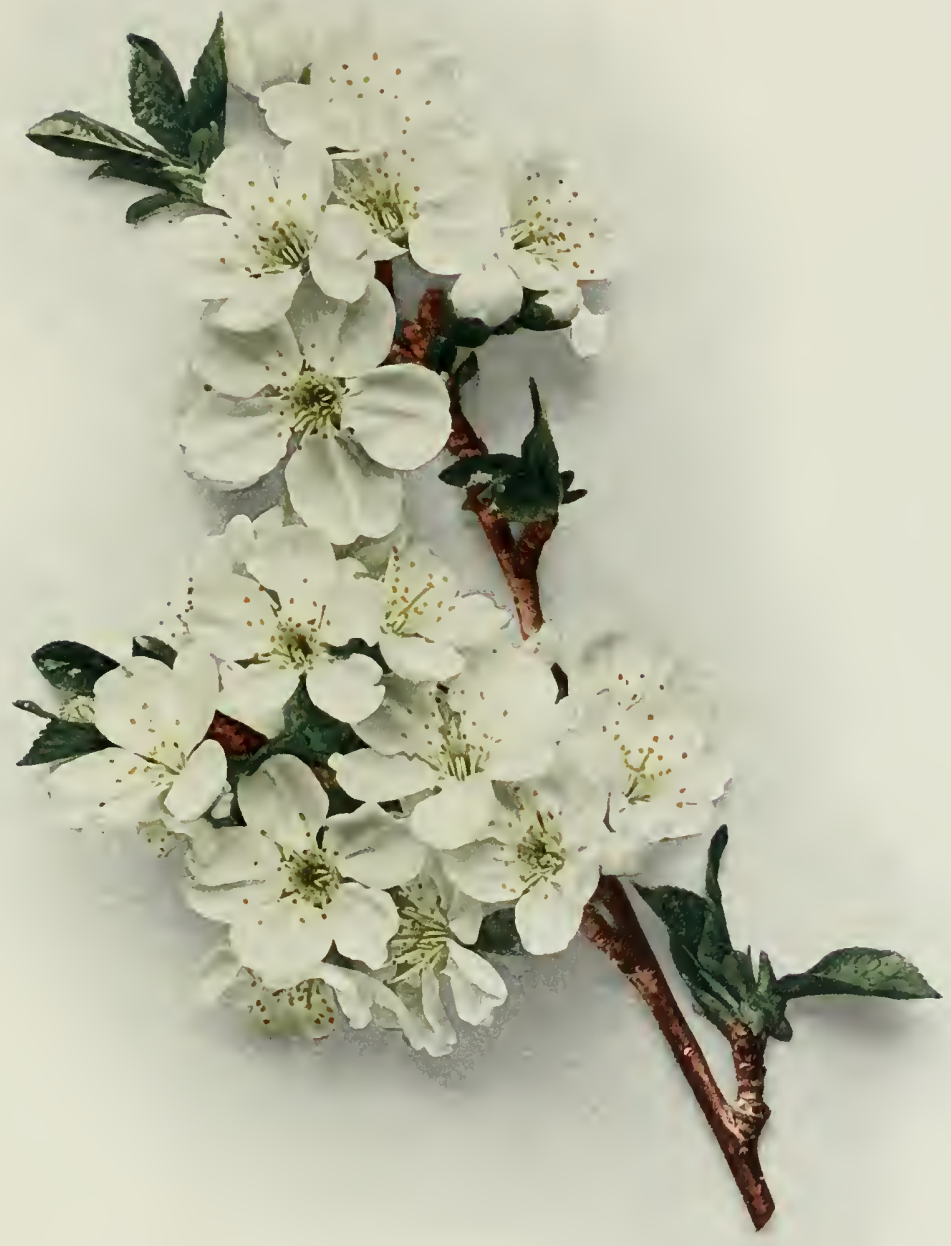



C. bigarella. 18. Dumortier Fl. Belg. 91. 1827.

C. effusa. 19. Host Fl, Austr. 2:6. 1831.

C. Marasca, 20. Host l. c. 1831 .

C. Bungei. 21. Walpers Rep. 2:9. I843.

C. Heaumiana. 22. Roemer Syn. Rosifl. $69 . \quad 1847$.

C. tridentina. 23. Roemer l. c. 76.1847.

C. Rhexii. 24. Hort. Gall, ex Van Houtte Fl. Serres, sér. 2, 7: 159.1868.

C. cucullata. 25. Hort. ex Koch Dendrol. 1:6. I869.

Tree low, reaching a height of twenty to thirty feet, diffuse, open-headed, roundtopped or spreading, often without a central leader; trunk at maturity a foot in diameter; bark reddish-brown overlaid with ashy-gray, smooth or sometimes roughened; branches spreading, slender and more or less drooping; branchlets slender and willowy, glabrous, reddish-brown becoming darker and overspread with ashy-gray; lenticels small, numerous, conspicuous, raised.

Leaves resinous at opening, more or less erect, very numerous, three to four inches long and from one-half to two inches wide, obovate to oval, folded upward, thick and firm in texture; tupper surface dark green, smooth, the lower surface paler green, with more or less pubescence; apex taper-pointed or acute, base abrupt or acute; margins finely serrate, often doubly so, teeth tipped with small, dark glands; petioles from a half-inch to two inches long, slender, grooved, with a few hairs on the upper surface, tinged with red; glands from one to four, usually small, variously colored, globose or reniform, usually at the base of the blade; stipules small, lanceolate, narrow, finely serrate, early caducous.

Winter-buds small, short, obtuse or pointed, plump and free, arranged singly or in clusters; leaf-scars usually prominent; flowers appearing with or after the leaves, showy, an inch across, white; borne in dense or scattered, very scaly clusters and in twos, threes and fours on one-year-old wood; pedicels from a half to an inch and a half in length, slender, green and glabrous; calyx-tube obconic, glabrous, green or tinged with red; calyx-lobes broadly obtuse or acute, glabrous on both surfaces, reflexed, margin serrate, faintly red; petals white, roundish or oval to obovate, entire or crenate, sessile or nearly so; stamens about thirty, filaments one-fourth of an inch in length; anthers yellow; pistils about as long as the stamens, glabrous.

Fruit roundish-oblate or cordate, sides slightly compressed, about three-fourths of an inch in diameter; suture lacking or indistinct; cavity well marked, usually abrupt; apex usually depressed; color from light to dark red; dots numerous, small, russet, more or less conspicuous; stem slender, from a half-inch to two inches in length, glabrous, without bloom; skin usually separating readily from the pulp; flesh dark red, with dark colored juice or pale yellow with colorless juice, tender, melting, sprightly, more or less acidulous, sometimes astringent; stone free or more or less clinging, roundish, pointed or blunt, smooth, less than a half inch in diameter; ventral suture usually ridged, sometimes smooth.

The numerous synonyms of Prunus cerasus indicate the state of confusion which prevails in the scientific nomenclature of the Sour Cherry. Yet the names given are scarcely a tithe of those that have been discarded or superseded for a whole or a part of this species by botanists. Happily, 
there is no language in which there is a possibility of confusing the Sour Cherry with the other two or three species of cultivated cherries if the common names be used. That men, learned or unlearned, speaking in their mother tongues distinguish species of cherries so readily by their common names, is ample excuse for not attempting to give in a pomological work all of the Latin names of the Sour Cherry that have been used by the many men who have at one time or another attempted to classify the plants in Prunus. Those here published are from boanists who have contributed most to the knowledge of the species.

Prunus cerasus is the Sour Cherry, or Pie Cherry, of many languages grown and esteemed in temperate climates the world over and probably the most widely distributed of all tree fruits. The species is found truly wild, as we have set forth in detail in the following chapter, in southwestern Asia and southeastern Europe. It is a frequent escape from cultivation, multiplying from seed distributed by birds or human agencies or growing from suckers which spring so freely from the roots as to make the species unfit for a stock in orchard work. The number of cultivated varieties of Prunus cerasus listed in The Cherries of New York is 270. Sour Cherries cultivated for their fruits constitute two distinct groups, each of which is again divided into many varieties. The two groups vary more or less in both tree and fruit but have a constant difference only in a single, very easily distinguished character - the juice in the fruits of one is red, in the other it is colorless.

The cherries with colorless juice are the Amarelles, from the Latin for bitter, a term probably first used by the Germans but now in general use wherever these cherries are grown, though the English often designate them as Kentish cherries and the French as Cerisier Commun. These Amarelles are pale red fruits, more or less flattened at the ends. Despite the derivation of the name Amarelle, they have less bitterness than the other group of varieties of the Sour Cherry. They are also less acid than the darker colored cherries and are therefore more suitable for eating out of hand while the dark colored cherries are almost exclusively culinary fruits. The common representatives of this group are Early Richmond, Montmorency and the various cherries to which the word Amarelle is affixed, as the King Amarelle and the Späte Amarelle.

The second group, varieties with reddish juice and usually with very dark fruits which are more spherical or cordate in shape than the Amarelles, comprises the Morellos of several languages or the Griottes of 


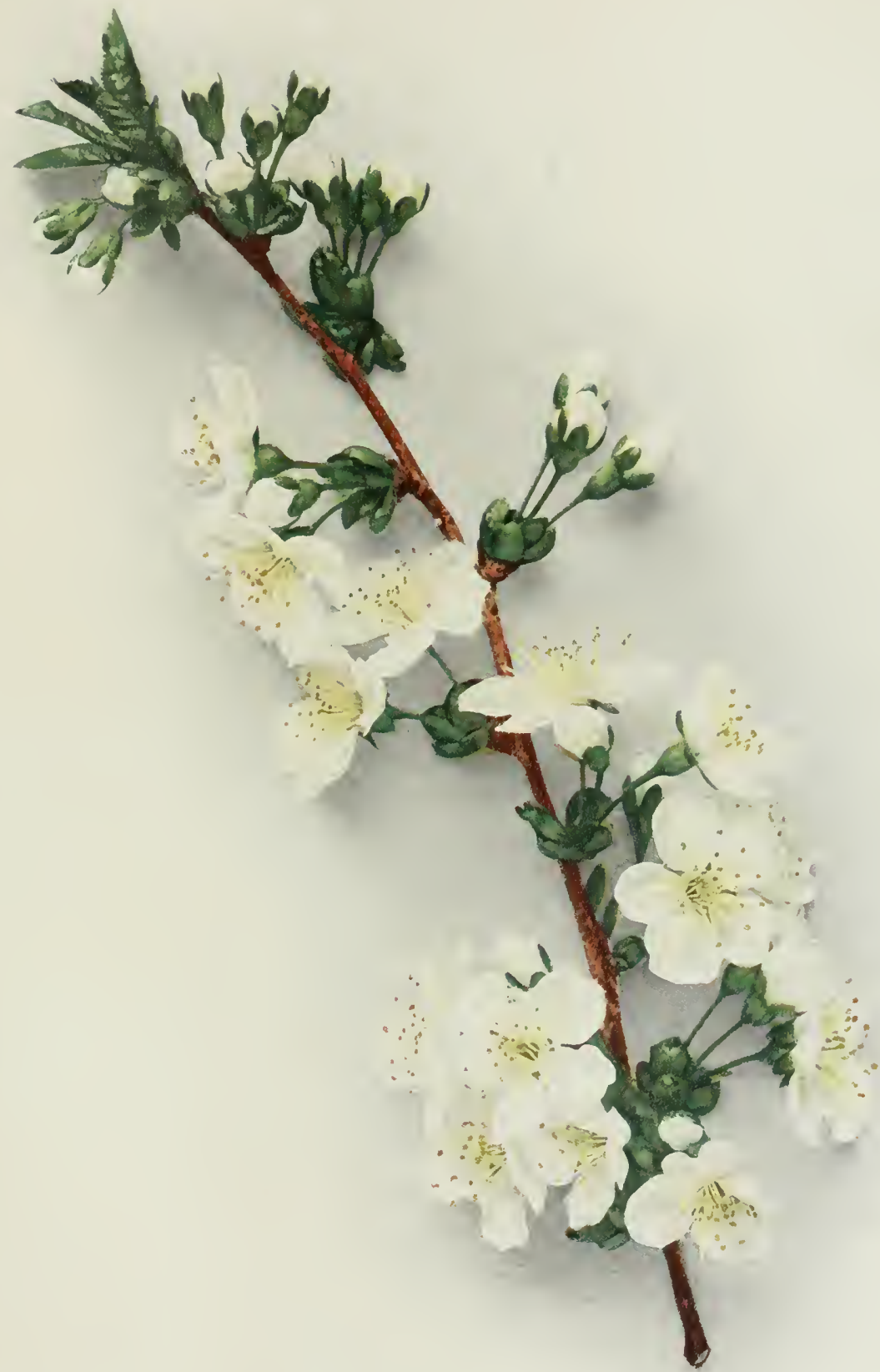



the French. The first of these terms has reference to the color, the word Morello coming from the Italian meaning blackish while Griotte, from the French, probably is derived through agriotte from aigre, meaning sharp, in reference to the acidity of these cherries. Weichsel is the German group name for these cherries, rather less commonly used than the other two terms. The trees of the Morello-like varieties are usually smaller, bushier and more compact than those of the Amarelles. The branches, as a rule, are more horizontal, often drooping, are less regularly arranged and are more slender. The leaves, in typical varieties, are smaller, thinner, a darker green and are pendant while those of the Amarelles are either inclined to be upright or horizontal; the leaves are also toothed less deeply and more regularly. These differences in the leaves are well shown in the color-plates of the varieties of the two groups. There are differences, also, in the inflorescence and the floral organs in the extreme types but these disappear in the varieties that connect the two forms. The typical varieties of this group are English Morello, Ostheim, Olivet, Brusseler Braune, Vladimir and Riga.

Attempts to give precise distinctions between the fruits and trees of the two groups fail because the varieties constituting them hybridize freely making it impossible, with the more or less blended characters, to classify accurately. The group name indicates but little more than whether the cherries have a colored or a colorless juice - a distinction well worth while for the fruit-grower.

Ehrhart called Sour Cherries with colorless juice Prunus acida and those with dark colored juice Prunus austera. To some extent botanists have followed Ehrhart's designations. Linnaeus thought the two groups sufficiently distinct to be botanical varieties of the species and denominated the cherry with colorless juice Prunus cerasus caproniana and the one with colored juice Prunus cerasus austera.

A third division of the species is the Marasca cherry from which is made maraschino, a distilled liqueur much used in Europe as a drink and in Europe and America in the manufacture of maraschino cherries. The Marasca cherry is a native of the province of Dalmatia, Austria, where the trees grow wild and are now sparingly cultivated. In I83 I Host gave this form the name Cerasus marasca and a year later Reichenbach described it as Prunus marasca. Botanists now very generally include it in the species under discussion and Schneider ${ }^{1}$ makes it a botanical variety,

\footnotetext{
I Schneider, C. K. Handb. Laubh. 1:61 5. 1906.
} 
Prunus cerasus marasca, a disposition which we believe to be the best. The Marasca cherries differ from the other cultivated forms chiefly in the greater vigor of the trees, relatively finer serrations of the leaves, longer stipules and a more compact inflorescence. The fruits are much smaller than in the common Sour Cherries, are deep red or almost black in color and have intensely red flesh and juice. The cherries are very acid with a bitter taste that gives flavor to the maraschino made from them.

Besides these divisions of the species cultivated for their fruits botanists describe several botanical forms which either have no horticultural value or are cultivated exclusively as ornamentals. It is not necessary to discuss these in a pomological work. Of these botanical derivatives of Prunus cerasus, Schneider enumerates nine and three hybrids between this and other species. ${ }^{1}$

PRUNUS AVIUM Linnaeus.
I. Linnaeus $F l$. Suec, ed. 2:165. 1755 .
P. nigricans. 2. Ehrhart Beitr. 7: 126. 1792.
P. varia. 3. Ehrhart l. c. 127. 1792.
P. sylvestris. 4. Persoon Syn. Pl. 2:35. 1807.
P. dulcis. 5. Miller ex Reichenbach Fl. Germ. Exc. 644. I832.
Cerasus nigra. 6. Miller Gard. Dict. ed. 8: No. 2. 1768.
C. Avium. 7. Moench Méth. 672. 1794.
C. varia. 8. Borkhausen, in Roemer $A$ rch. I., 2:38. 1796.
C. Juliana. 9. De Candolle Fl. Fran. 4:483. 1805.
C. duracina. 10. De Candolle l. c. I 805 .
C. rubicunda. 11. Bechstein Forstb. 160, 335. I 810.
C. intermedia. 12. Host Fl. Austr. 2:7. 1831, not Loisel. in Duham. 1812.
C. decumana. 13. Delaunay ex Seringe, in De Candolle Prodr. 2:536. 1825.
C. macrophylla. 14. Sweet Hort. Brit, ed. 1: 485.1827.
C. dulcis. 15. Borkhausen ex Steudel Nom. Bot. ed. sec., I:331. I8to.
C. pallida. I6. Roemer Syn. Rosifl. 69. 1847.
C. heterophylla. I7. Hort, ex Koch Dendrol. I: 106. 1869.
C. asplenifolia. 18. Hort. ex Koch l. c. 1869.
C. salicifolia, 19. Hort, ex Koch l. c. I869, not Ser. in De Candolle. I 825.

Tree reaching a height of thirty to forty feet, vigorous, upright-spreading, opentopped, semi-hardy, usually with a central leader; trunk a foot or more in diameter roughened; branches rather stocky, smooth, dull ash-gray, with few small lenticels; branchlets thick, long, with long internodes, grayish-brown, smooth, with small, inconspicuous lenticels.

Leaves resinous at opening, more or less drooping, numerous, four to six inches long, two to three inches wide, strongly conduplicate, oblong-ovate, thin; upper surface dark green, rugose or sometimes smooth; lower surface dull green, more or less pubescent; apex acute, base more or less abrupt; margin coarsely and doubly serrate, glandular; petiole

${ }^{1}$ Schneider, C. K. Handb. Laubh. I :1906; 2:1912. 


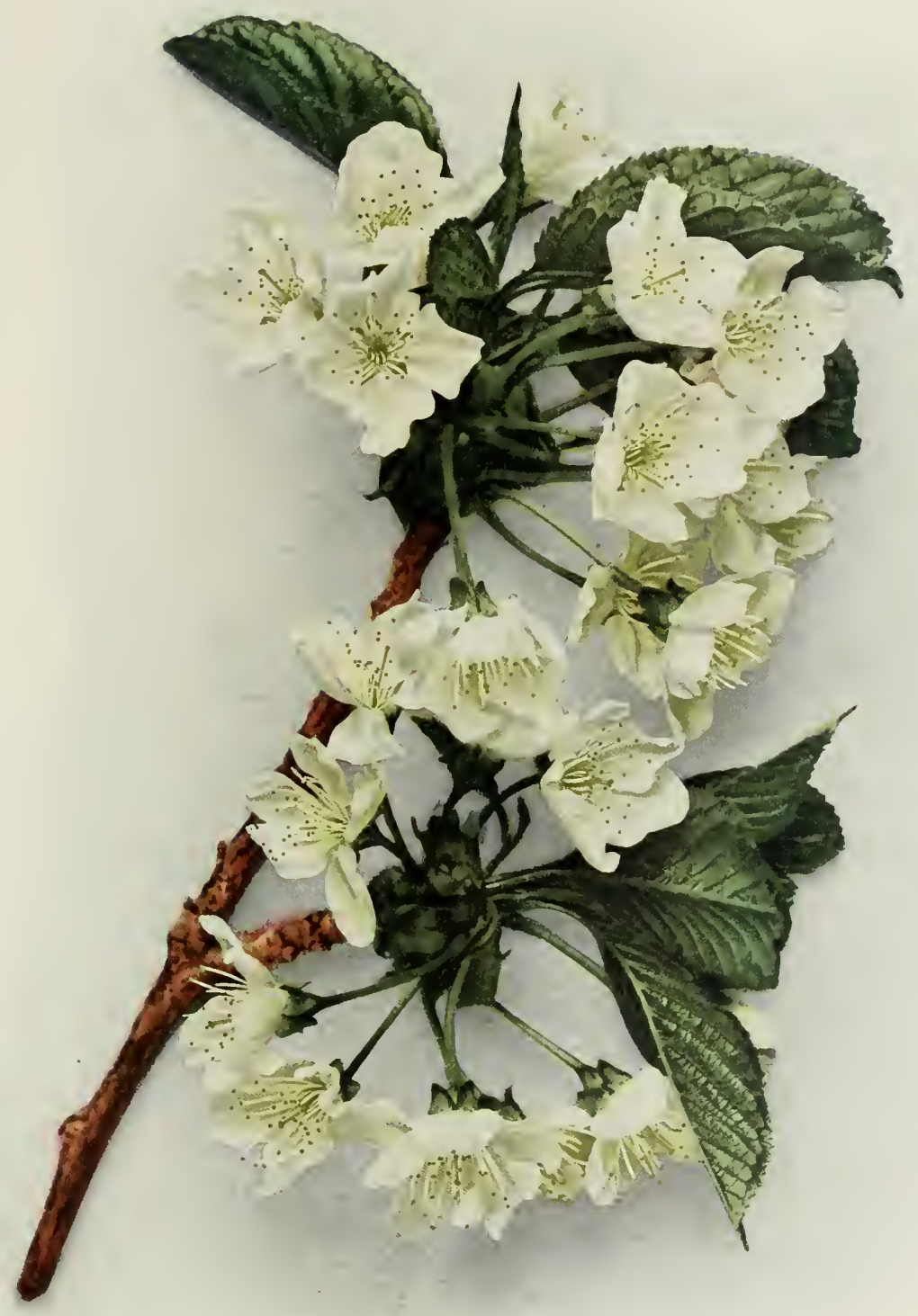

PRLYLS IITI (YELLOW SPANISH) 

one and three-fourths inches long, slender, dull red, with from one to three small, globose, reddish glands on the stalk; stipules small, lanceolate, finely serrate, early caducous.

Buds rather small, of medium length, pointed, appressed or free, arranged singly or in small, scaly clusters at the tips of branchlets or on short spurs; leaf-scars prominent; blooming with or after the leaves; flowers white, one and one-quarter inches across; in clusters of two or three; pedicels one inch long, slender, glabrous; calyx-tube green or with a faint red tinge, brownish-yellow within, campanulate; calyx-lobes faintly tinged with red, long, acute, margin serrate, glabrous within and without, reflexed; petals oval, entire or crenate, tapering to a short, blunt claw; stamens nearly one-half inch long, thirty-five or thirty-six; anthers yellow; pistil glabrous, shorter than the stamens.

Fruit ripening in early July; about an inch in diameter, cordate; cavity deep, wide, abrupt; suture a line; apex roundish or pointed; color ranging from yellow through red to purplish-black; dots numerous, small, russet, inconspicuous; stem tinged with red, one and one-half inches long, adherent to the fruit; skin toughish, adherent to the pulp; flesh yellow, red, or dark purple with colorless or colored juice, tender to firm, sweet; stone semi-clinging, three-eighths of an inch long, not as wide as long, elliptical, flattened, blunt, with smooth surfaces.

Through its cultivated varieties Prunus avium is everywhere known in temperate climates as the Sweet Cherry. In the wild state it is variously called Mazzard, Bird, Wild, Crab and the Gean cherry. It is not as hardy a species as Prumus cerasus and is, therefore, less generally grown but still is a favorite orchard, dooryard and roadside plant in all mid-temperate regions. It refuses to grow, however, in the warmest and coldest parts of the temperate zones. Wherever the species thrives as an orchard plant it is to be found growing spontaneously along fences and roadsides and in open woods from seeds distributed by birds. The fruits of these wild Sweet Cherries are usually small and the flesh thin and dry, often unpalatable; but, on the other hand, trees are sometimes found as escapes from cultivation which rival in their products the orchard-grown cherries. It is from reverted seedlings that the description of the species herewith given has been made. The number of cultivated varieties of Prunus avium listed in The Cherries of New York is 549.

The habitat of the species and its history as a cultivated plant are given in the following chapter. A further point of horticultural interest as regards its habitat is that wherever found truly wild, as in its original home in southern and central Europe and Asia Minor, it is to be found in moderately dry, calcareous soils and seldom in the shade, preferring always warm, sunny sites, as gravelly or stony hillsides. These predilections cling to the species in its cultivated varieties. Prumus avium differs from Prunus cerasus in an important horticultural character as 
the two species grow spontaneously - the former suckers from the root little or not at all, making it a suitable plant for a stock in orchard work, while the latter suckers so much as to make it unfit for use as a stock.

Prunus avium is variously divided by botanists and pomologists. Whatever distinct forms of the species may exist in the wild state, they are now interminably confused by hybridization under cultivation. It is impossible to divide the species into botanical varieties from the characters of the horticultural varieties, as many botanists have attempted to do. The species can be roughly divided into two pomological groups, the distinguishing character being the texture of the flesh.

Sweet Cherries with soft, tender flesh form one group known by pomologists under the French group name Guigne or the English Gean. These are also the Heart cherries of common parlance. These softfruited cherries may again be divided into dark colored varieties with reddish juice and light colored sorts with colorless juice. Typical light colored Geans are Coe, Ida, Elton and Waterloo; dark colored ones are Black Tartarian, Early Purple and Eagle. It is to this group of cherries that Linnaeus gave the varietal name Juliana and De Candolle the specific name Cerasus Juliana.

The second group is distinguished by the firm, breaking flesh of the fruits - the Bigarreaus of several languages, the name originally having reference to the diverse colors of the fruits. This group is further divisible in accordance with color of fruit and juice into black Bigarreaus and light Bigarreaus. Chief of the black cherries falling into this division are Windsor, Schmidt and Mezel; of the light ones, which are much more numerous, Yellow Spanish and Napoleon are representative sorts. Linnaeus called these hard-fleshed cherries Prunus avium duracina; De Candolle called them Cerasus duracina; K. Koch, Prunus avium decumana; and Roemer, Cerasus bigarella.

Besides these two orchard forms of Prunus avium several other horticultural forms, quite as distinct or even more so, are grown as ornamentals, some of which are listed as distinct species or as botanical varieties of Prunus avium. To add to the confusion, a number of Latinized garden names are more or less commonly applied to these ornamental Sweet Cherries. Schneider, ${ }^{1}$ in revising the genus Prunus, names four botanical forms of Prunus avium and two natural hybrids with other species.

I Schneider, C. K. Handb. Laubh. I: 1906; 2: 1912. 


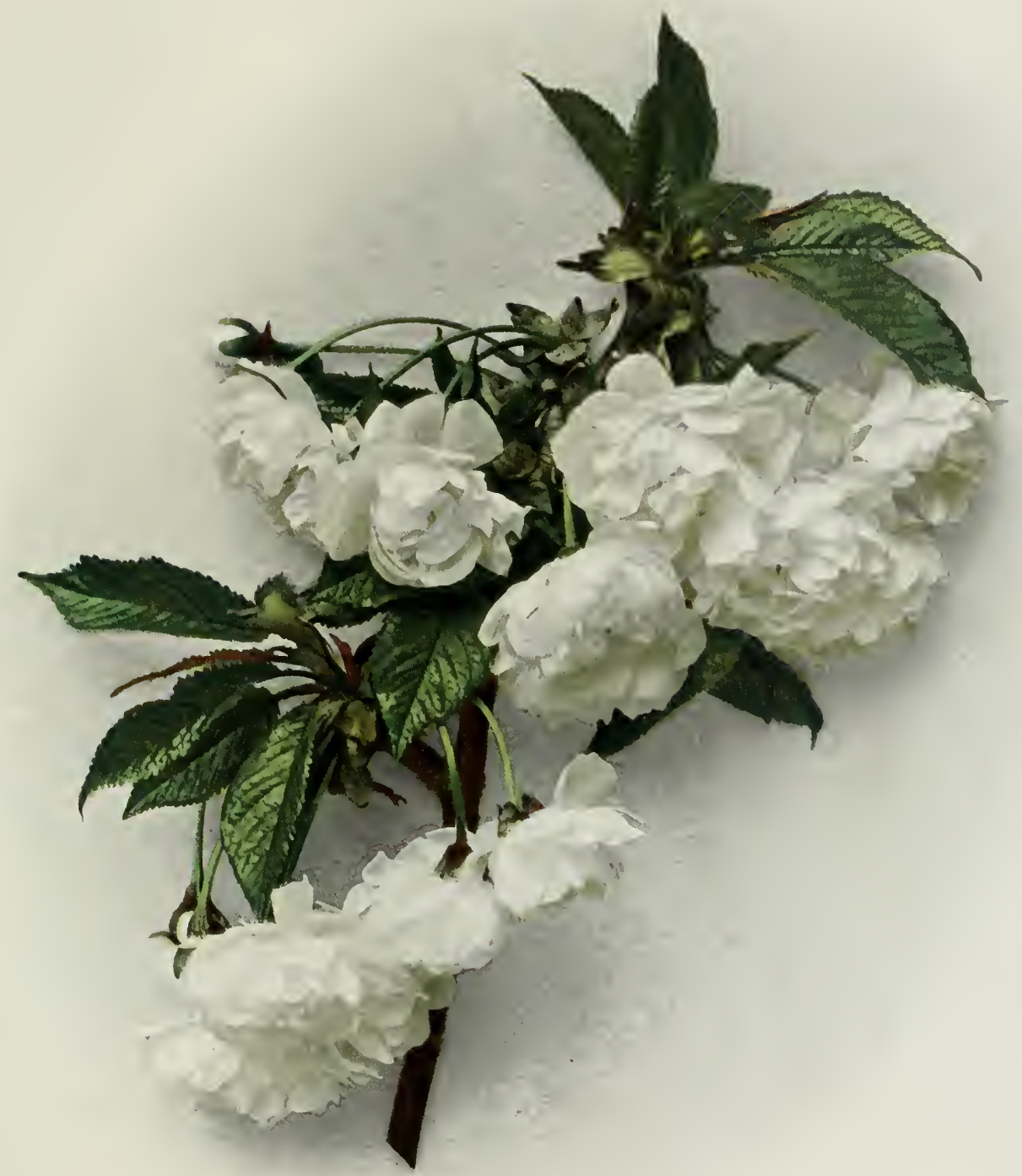

I'TIXI'IIIY (DOUBLE FLOWERING) 



\section{PRUNUS AVIUM $\times$ PRUNUS CERASUS}

The Duke cherries, long placed by most pomologists and botanists in a botanical variety of Prumus azium, are unquestionably hybrids between the Sweet Cherry and the Sour Cherry. A study of the characters of the varieties of the Duke cherries shows all gradations between Prumus cerasus and Prunus avium, though, in the main, they resemble the latter more than the former, differing from the Sweet Cherries most noticeably in having an acid flesh. Sterility is a common attribute of hybridism. In this respect the Dukes behave like most hybrids. In several Duke cherries all of the seeds collected at this Station are sterile; in others, most of them are sterile and in none are the seeds as fertile as in varieties known to be pure bred as to species. So, too, shrunken pollen grains indicate hybridity. A study of the pollen of the Duke cherries shows many grains, the greater proportion, to be abnormal, a condition not found in the pollen of varieties true to species. May Duke, Reine Hortense and Late Duke are the leading hybrid varieties.

There are dark colored Duke cherries with reddish juice and light colored sorts with uncolored juice, just as in the two parent species. May Duke is a typical variety with colored juice while Reine Hortense is probably the best-known cherry among these hybrids with uncolored juice. About 65 of the cherries listed in The Cherries of New York are "Dukes," or hybrids between the Sweet and the Sour Cherry.

The name Duke comes from the variety May Duke which is a corruption of Médoc, a district in the department of Geronde, France, from whence this variety came. The cherries of this group are known as Dukes only in England; in France the name Royale is similarily used.

These hybrid cherries have been placed in a distinct botanical group by several botanists. They constitute the Cerasus regalis Poiteau and Turpin (Traite des Arb. Fruit. 123); the Cerasus bigarella regalis Roemer (Syn. Monogr. 3:69); and the Prumus avium regalis Bailey (Cyc. Am. Hort. I453. 1901).

PRUNOS MAHALEB Linnaeus.

I. Linnaeus Sp. Pl. 474. 1753. 2. Bailey Cyc. Am. Hort. 3:1451. 1901. 3. Schneider Handb. Laubh. 1:617. 1906.

Cerasus mahaleb. 4. Miller Gard. Dict. ed. 8: No, 4. 1759.

Padus mahaleb. 5. Borkhausen Handb. Forstb. 2:1434. 1803.

Tree small, slender, vigorous, upright-spreading, open-topped; branches roughened, ash-gray over reddish-brown; branchlets numerous, slender and firm-wooded, with short internodes, dull gray, glabrous, with very numerous large, raised lenticels. 
Leaves numerous, an inch in length, one and one-fourth inches wide, ovate to obovate, thick, leathery; upper surface dark green, glossy, smooth; lower surface light green, slightly pubescent along the midrid; apex and base abrupt; margin finely crenate, with reddish-brown glands; petiole one-half inch long, slender, greenish, with none or with from one to three small, globose, greenish glands variable in position.

Buds small, short, obtuse, appressed or free, arranged singly as lateral buds and in clusters on small, slender spurs; flowers appearing late, after the leaves, small, averaging one-half inch across, white, fragrant; borne in clusters of six to eight scattered on a main stem an inch in length, with the terminal pedicels one-quarter inch long and basal pedicels one-half inch long; pedicels slender, glabrous, greenish; calyx-tube green, campanulate, glabrous; calyx-lobes narrow, entire, glabrous, reflexed; petals white, small, separated, ovate, tapering to short, narrow claws; filaments one-fourth inch long; pistil glabrous, about equal to the stamens in length.

Fruit matures about the middle of July; very small, one-fourth inch long, one-third inch wide, roundish-ovate; cavity shallow and abrupt; suture shallow or a mere line; apex roundish to slightly pointed, with stigma usually adherent; color black; stem slender, length of corymb about one and one-half inches; length of fruit-stem about one-quarter inch; skin thick, tough; flesh reddish-black, with scant reddish-black juice, tender and soft, very astringent, sour, not edible; stone free or nearly so, very small, averaging nine thirty-seconds inch long and seven thirty-seconds inch wide, ovate, slightly flattened, with pointed apex; ventral suture prominent.

Prumus mahaleb is now a wild inhabitant of all southern Europe as far north as central France, southern Germany, Austria-Hungary and eastward through Asia Minor and Caucasia to and within the borders of Turkestan. Wherever it grows spontaneously in the Old World it is said to prefer rocky, gravelly, sunny slopes and the climate in which the grape thrives best. Wild or cultivated, the Mahaleb is a shallow-rooted plant, a fact that must be taken into consideration in its use as a stock. Prunus mahaleb is a common escape from cultivation in eastern North America especially about the nursery centers of central New York.

The Mahaleb, or St. Lucie cherry, is of no importance to fruitgrowers for its fruit but as a consort with nearly all of the Sweet and Sour Cherries now being propagated in North America it becomes of prime importance and so receives botanical consideration here. According to Schneider, in the reference cited, there are several spontaneous forms of Prunus mahaleb and also several horticultural varieties grown as ornamentals. None of these, wild or cultivated, are of interest to fruitgrowers, unless, perchance some one of them should prove to be a better stock upon which to work orchard cherries. Mahaleb stocks are usually grown as seedlings but may also be propagated from root cuttings. 


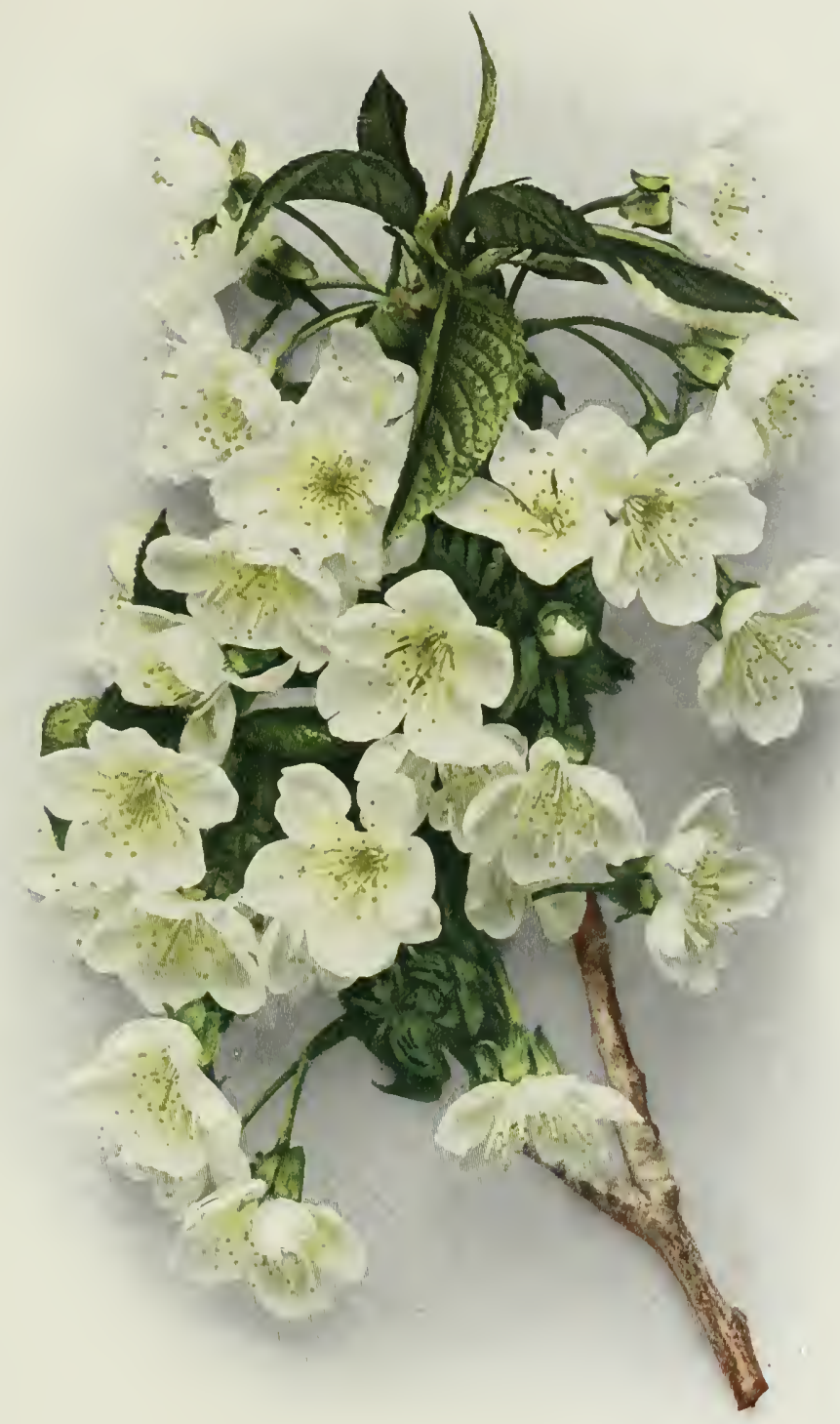

PRIYUS ITIU X PRTYTS CEIR IST'S (REINE HORTENSE) 

The wood of the Mahaleb tree is of value in cabinet making, possessing among other good qualities a pleasant and lasting odor. The leaves, too, are odoriferous and are more or less used in France in the manufacture of perfumes and in cookery to give savor to sauces.

PRUNUS TOMENTOSA Thunberg.

I. Thunberg Fl. Jap. 203. 1784. 2. Jack Garden \& Forest 5:580, fig. 99. 1892. 3. Bailey Cyc. Am. Hort. 3:1451. 1901. 4. Schneider Handb. Laubh. 1:601. I906. 5. Koehne Plantae Wilsonianae Pt. 2:268. 1912.

Cerasus tomentosa. 6. Wallich Cat. No. 715. 1829.

A dwarfish, bush-like plant attaining a height of ten or twelve feet, vigorous, densetopped, hardy; trunk and branches stocky; branches smooth, grayish-brown; branchlets many, of medium thickness and length, thickly overspread with short pubescence, with short internodes, roughish, with a few large, raised lenticels near the base.

Leaves numerous, two and one-eighth inches long, one and one-half inches wide, folded upward or flattened, broad-oval to obovate, velvety; upper surface dull, dark green, rugose; lower surface thickly pubescent, with a prominent midrib and veins; apex abruptly pointed; margin serrate; petiole three-sixteenths inch in length, reddish, pubescent, of medium thickness, with from twelve to fourteen small, globose, yellow glands, usually at the base of the blade.

Buds very small, short, pointed, free, arranged as lateral buds and in clusters on small, short spurs; leaf-scars not prominent; season of bloom early; flowers appear with the leaves, white, thirteenth-sixteenths inch across; borne singly or in pairs; pedicels short, thick, glabrous; calyx-tube reddish, campanulate, glabrous; calyx-lobes narrow, acute, serrate, slightly pubescent, erect; petals white, roundish-ovate, entire, with short claws; anthers tinged with red; pistil pubescent at the base, longer than the stamens, often defective.

Fruit matures in mid-season; a half-inch in diameter, roundish, slightly compressed; cavity deep, narrow, abrupt; suture shallow; apex depressed, with adherent stigma; color currant-red; dots numerous, small, grayish, obscure; stem thickish, one-eighth to onequarter of an inch in length, pubescent; skin thick, tender, adheres slightly to the pulp, covered with light pubescence; flesh light red, with light red juice, stringy, melting, sprightly, sour; good in quality; stone clinging, one-quarter of an inch long, one-eighth inch wide, oval, slightly pointed, with smooth surfaces.

The habitat of Prunus tomentosa is probably Central Asia though it is now to be found growing spontaneously in East Tibet and the Chinese provinces of Setschuan, Hupe, Kansu and perhaps Tochlii.

This shrub-like cherry is very generally cultivated in central, eastern and northern China and in Japan for its fruit and as an ornamental. It has been introduced into cultivation in many widely separated places in 
North America and appears to be promising for cold regions, both bud and wood withstanding perfectly the most rigorous climates of the United States. As it grows in America it is a bush and never a true tree. It is a twiggy, close-jointed plant, usually with many stems springing from the ground and these bearing branches quite to the base. Frequently these low-growing branches bend to the ground and take root forming new plants. The bushes are thickly clothed with leaves densely tomentose on the underside, in this respect and in shape, as well, very unlike the foliage of common cultivated cherries. The flowers appear in great abundance with the leaves, making a handsome ornamental; they are white, becoming rose-colored as they fall away. The fruit ripens in mid-season for cherries, setting profusely from the many blossoms. The cherries are a half-inch in diameter, bright currant-red, covered with inconspicuous hairs and contain a stone of medium size. They are pleasantly acid, very juicy and withal a decided addition to cultivated cherries. Prunus tomentosa seems a most promising plant for domestication and of particular merit for small gardens and cold regions.

Koehne, in his list of cherries, names ten botanical varieties of Prunus tomentosa. From this the species seems to be most variable and under cultivation would probably break up into many forms some of which might prove superior to the type species. Koehne's botanical varieties are given under the species on page 22 .

PRUNUS PUMILA Linnaeus.

I. Linnaeus Mant. Pl. 75. 1768. 2. Bailey Cor. Bul. Ex. Sta. 38:96. 1892. Bailey l. c. 70:260. 1894. 3. Bailey Cyc. Am. Hort. 3:1450. 1901.

P. Susquehanae. 4. Willdenow Enum. Pl. 519. 1809.

P. depressa. 5. Pursh Fl. Am. $1: 332$. 1814 .

$P$. incana. 6. Schweinitz Long's Expedition by Keating 2:387. 1824.

Cerasus glauca. 7. Moench Meth. 672. 1794.

C. pumila. 8. Nichaux Fl. Bor. Am. 2:286. 1803 .

C. depressa. 9. Seringe, in De Candolle Prod. 2:538. 1825 .

Plant a small shrub, five to eight feet in height, willow-like habit, weak, upright when young but becoming decumbent, slow-growing, hardy; trunk slender, smooth except for the raised lenticels; branches slender, smooth, twiggy, very dark, dull reddish-black with a tinge of gray; lenticels numerous, small, conspicuous; branchlets very slender, short, twiggy, with short internodes, dull grayish-brown, glabrous, with conspicuous, very small, raised lenticels.

Leaves hanging late in the season, small, averaging one and three-fourths inches long, one inch wide, flat, abruptly pointed, narrowly oblanceolate to obovate, thin; upper surface dark, dull green, smooth; lower surface light green, thinly pubescent on the 


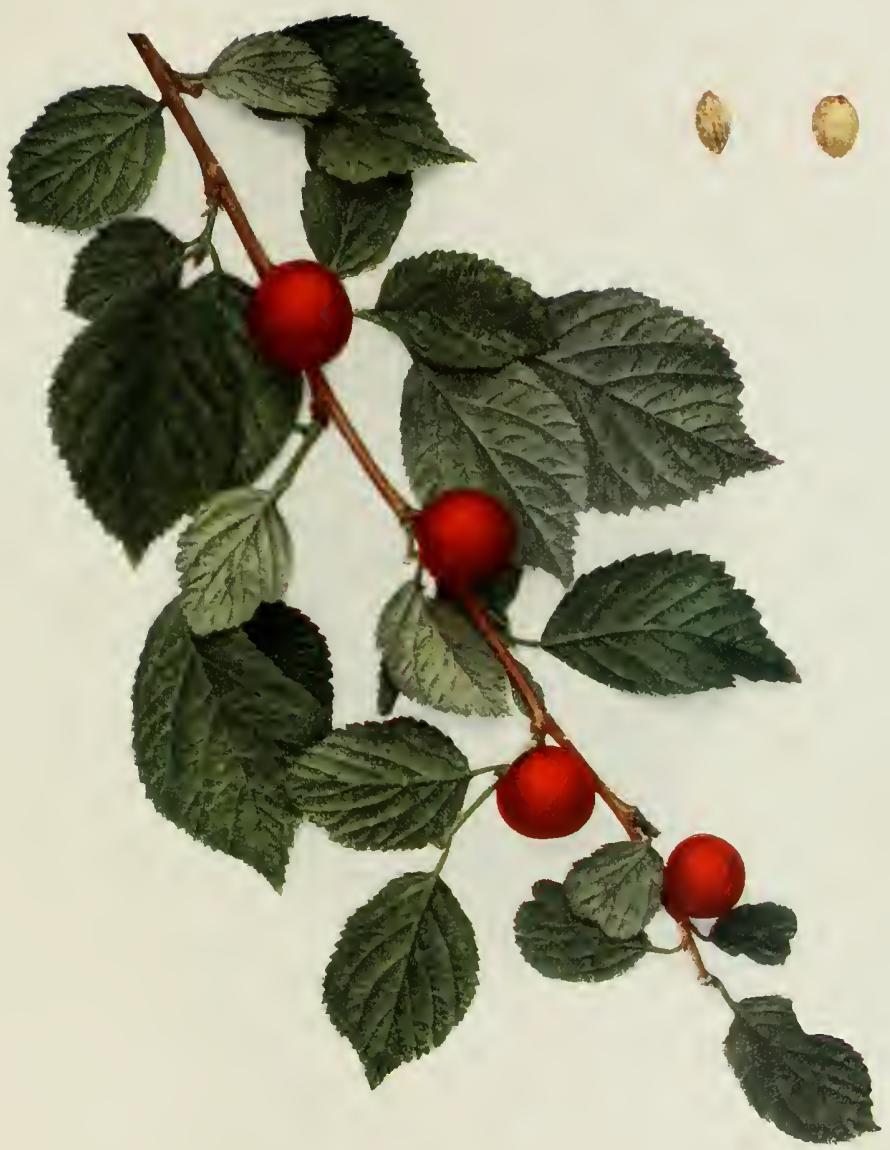

I'RI ICS TOYENTOSA 
. 
midrib and veins; midrib small, straight; veins very minute; margin serrate, teeth tipped with very small glands; petiole short, one-fourth inch in length, glandless.

Flowers small, in two-to five-flowered umbels, white, appearing with the leaves; pedicels slender, a half-inch in length. Fruit nearly round, pendulous, variable in color but usually purple-black, without bloom, nearly a half-inch in diameter; flesh thin, variable in quality but of ten sour and astringent; season late July; stone turgid, nearly round.

Prunus pumila, the Sand Cherry, or Dwarf Cherry, of eastern America, is found on sandy and rocky, inland shores from Maine to the District of Columbia and northwestward to the Lake of the Woods in Canada. In particular it is common on the sand dunes of the Great Lakes. Everywhere in the wild state it grows in light sands suggesting its use in arid soils and especially on poor soils in cold climates.

As yet there seem to be no named varieties of this cherry known to fruit-growers, its nearly related species, Prunus besseyi, offering greater opportunities to both the fruit-grower and the experimenter. Both the plants and fruits are so variable, the size, color and quality of the crop on some plants being quite attractive, that it is certain an opportunity to domesticate a worthy native plant is being overlooked. The species ought to have value, too, as a stock on which to work other cherries for sandy soils, dwarf trees and exacting climates.

PRUNUS CUNEATA Rafinesque.

1. Rafinesque $A n n$. Nat. I1. 1820, 2. Bailey Cor. Ex. Sta. Bul. 38:101. 1892. 3. Britton and Brown Ill. Flora 2:250. 1897. 4. Gray Man. Bot. ed. 7:498. 1908.

P. pumila cuneata. 5. Bailey Cyc. Am. Hort. 3:145I. I90I.

Prunus cuneata, sometimes called the Appalachian cherry, is not growing at this Station but is described in the references given as very similar to the Sand Cherry, differing in the following respects:

The plant is dwarfer but is more erect never having prostrate branches; the branches are smoother and lighter colored; the leaves are shorter, more oval, more obtuse, thinner, less conspicuously veined, teeth fewer and the points more appressed; the flowers are larger, petals broader and are borne on slightly curled stems in umbels of two to four; the fruit and stone in the two species are much the same, possibly averaging smaller in this species.

The habitat of Prunus cuneata is from Maine to North Carolina and northwest to Minnesota, being most commonly found in wet, stiff soils near lakes and bogs but often found on rocky hills if the soil be not too dry. 
It is doubtful if this cherry is as promising for cultivation as the foregoing species and not nearly as worthy attention as the next cherry.

PRUNUS BESSEYI Bailey.

1. Bailey Cor. Ex. Sta. Bul. 70:261. 1894. 2. Contrib. U. S. Nat. Herb. 3:156. 1895. 3. Bessey Neb. Hort. Soc. 26:168. 1895. Bessey l. c. 37:121. 1906. 4. Britton and Brown Ill. Flora 3:251. I 897 .

P. pumila Besseyi. 5. Waugh Vt. Ex. Sta. Rpt. 12:239. 1898-99. 6. Bailey Cyc. Am. Hort. 3:1451. 1901 .

Plant a small shrub, spreading or diffuse, one to four feet in height, open-centered, slow-growing, hardy; trunk slender, smooth; branches slender, smooth, very dark brownishblack, with numerous lenticels; branchlets slender, short, with short internodes, dull grayish-brown becoming almost black, smooth, glabrous, with conspicuous, small, raised lenticels.

Leaves hanging late, numerous, small, two and three-eighths inches long, one inch wide, thick, stiff, slightly folded upward or nearly flat; apex with a short taper-point, broadly lanceolate to nearly oval-lanceolate; upper surface dark green, glossy, smooth; lower surface very light green, not pubescent; midrib distinct, glabrous; veins small but distinct; margin serrate, teeth appressed, tipped with indistinct, sharp glands; petiole thick, three-eighths inch in length, glandless or with from one to two very small, light colored, globose glands on the petiole at the base of the leaf; stipules very prominent, almost leaf-like.

Flowers appearing with the leaves in sessile umbels, small, less than a half-inch across, white; fruit more than a half-inch in diameter, globose, sometimes oblong-pointed, yellowish, mottled or more often purple-black; variable in quality but always more or less astringent; ripening in early August; stone large, globose, slightly flattened.

The habitat of Prunus besseyi is not yet definitely bounded but it can, at least, be said that this species is to be found on the prairies from Manitoba and Minnesota to southern Kansas and westward into Montana, Wyoming and Utah. In its natural range it undoubtedly runs into that of Prumus pumila to the east, and Waugh, in the reference given, holds that the two species grade into each other and he, therefore, makes this a variety of the eastern species. Certainly Prunus pumila and Prunus besseyi are as distinct as are many other of the more or less indefinite species of this genus - few, indeed, are the species of Prunus that do not have outliers which overlap other types and, as we shall see, there are hybrids between this and species of other cherries, plums and even peaches and apricots, showing that the lines of demarcation between the members of this genus are difficult to define.

Although Prunus besseyi has received attention from horticulturists less than a quarter-century it has aroused much interest, best indicated 
by the fact that now a considerable number of varieties of the species are under cultivation and there are more than a score of hybrids disseminated in which it is one of the parents. Indians, trappers and early settlers have long used the wild fruit under the name of Western Sand Cherry, Bessey's Cherry and Rocky Mountain Cherry. Among pioneers this cherry was held in high esteem for sauces, pies and preserves and, where there was a dearth of cultivated cherries, was eaten with relish out of hand. The flesh is tender, juicy and, while astringent as commonly found, plants bearing aromatic and very palatable cherries are often found growing wild while some of the domesticated plants bear very well-flavored fruits. All speak of the Sand Cherry as wonderful in productiveness and as having remarkable capacity to withstand the vicissitudes of the exacting climate in which it grows. A valuable asset of Prunus besseyi is its great variability. Fruit from different plants varies in size, color and flavor suggesting that, under cultivation, amelioration will proceed rapidly. The plants of this species root freely from layers or root-cuttings and are therefore easily propagated and multiplied.

But it is in its hybrids that this western cherry has proved most valuable in horticulture. There are now hybrids under cultivation between this species and the Sand plum (Prunus augustifolia watsoni), the Hortulana plum (Prunus hortulana), the Simonii plum (Prunus simonii), the Japanese plum (Prunus triflora), the American plum (Prunus americana), the Cherry plum (Prunus cerasifera), the Sweet Cherry (Prunus aitum), the peach (Prunus persica), the apricots (Prunus armeniaca and Prunus mume), and the common plum (Prunus domestica). It would almost seem that this species is the "go-between" of the many and varied types of the genus Prunus. It is true that few of these hybrids yet shine as orchard plants but, given time, it seems certain that some will prove valuable in general horticulture and that many will be grown in the special horticulture of the northern Mississippi Valley and the adjoining plains to the west. Credit must be given to Professor N. E. Hansen of the South Dakota Experiment Station for most of our present knowledge of hybridism between this and other species. ${ }^{1}$

In his work with this species Hansen has also found that Prumus besseyi makes a very good stock for peaches, apricots, Japanese and native plums and that, while it does not so readily consort with the true cherries, yet

\footnotetext{
${ }^{1}$ See bulletins 87 (1904), 88 (1904), I08 (I908) and I30 (I9II) from the South Dakota Experiment Station, Brookings, S. D.
} 
it can be used as a stock for them. On the other hand larger fruits of the Sand Cherry can be grown when it is budded on stocks of the American plum, Prunus americana.

\section{MINOR SPECIES}

Besides these well-recognized species of cultivated cherries there are several others that play a much less conspicuous part in horticulture. Prunus fruticosa Pallas, the Dwarf Cherry of Europe, is much cultivated, more especially its botanical variety pendula, as an ornamental and somewhat for its fruit. According to Wilson, ${ }^{1}$ Prumus involucrata Koehne is grown for its fruit in the gardens of China; the fruits, he says, are "small and lacking in flavour." The fruits of Prumus emarginata Walpers are eaten by the Indians on the Pacific Coast and the early settlers used the species as a stock for orchard cherries. Prunus jacquemontii Hooker, the Dwarf Cherry of Afghanistan and Tibet, is occasionally in culture for its fruit and as a park plant; so also is another dwarf cherry from southwestern Asia, Prunus incana Steven. Prunus pseudocerasus Lindley, the Flowering Cherry of Japan, is a well-known ornamental the world over and in Japan is used as a stock for orchard cherries for which purpose, as we have suggested in the discussion of stocks, it ought to be tried in America.

${ }^{1}$ Wilson, E. H. A Naluralist in Western China 2:27. 1913. 


\section{CHAPTER II}

\section{THE HISTORY OF CULTIVATED CHERRIES}

\section{THE ANCIENT USE OF CHERRIES}

History casts no direct light upon the period when the cherry first came under cultivation. Undoubtedly primitive men in all parts of the North Temperate Zone enlivened their scanty fruit fare with wild cherries. Cultivated cherries, we know, had their origin in the Old World. But history tells us nothing of the period when Europe and Asia were unbroken forests inhabitated by savages who eked out a precarious subsistence by the pursuit of the chase and from meagre harvests of wild grains, fruits and vegetables. On these continents agriculture and rude civilization began in ages immemorial and cultivated plants diversified, enriched and adorned the landscapes long before the first written records. Our knowledge of how wild cherries have been remodeled into the orchard and garden varieties of to-day - of what the methods and processes of domestication have been - is, therefore, doubtful and limited, for the mind and hand of man had been deeply impressed upon the cherry long before the faint traditions which have been transmitted to our day could possibly have arisen.

The history of the cherry, then, goes back to primitive man. Direct proof of the ancient use of cherries is furnished by the finding of cherrypits of several species in the deposits of Swiss lake-dwellings, in the mounds and cliff-caves of prehistoric inhabitants of America and in the ancient rubbish-heaps of Scandinavian countries. There are but few regions in which cultivated cherries are grown in which the inhabitants in times of stress, or by choice in times of plenty, do not now use as food wild cherries, some species of which grow in abundance and under the most varied conditions, almost from the Arctic Circle to within a few degrees of the Tropic of Cancer in a belt encircling the globe. It is probable that all of the wild species which have furnished fruit to the aborigines or to the modern inhabitants of a region have been sparingly cultivated - at the very least if they possessed any considerable food value they have been more or less widely distributed by the hand of man. But, curiously enough, out of the score or more of species of which the fruit is used as food as the plants grow wild, but two may be said to be truly domesticated. These are the Sour, or Pie Cherry, Prunus cerasus, and the Sweet 
Cherry, Prunus avium, with the histories of which we are now to be concerned.

Pliny is generally accredited as the first historian of the cherry. Nearly eighteen and a half centuries ago he gave an account of the cherries of Rome with the statement that Lucullus, the Roman soldier and gourmet, had brought them to Rome 65 years before Christ ${ }^{1}$ from the region of the Black Sea. This particular in the account proves to be a good illustration of the adage that old errors strike root deeply. Though disproved beyond all question of doubt time and time again by botanists and historians, Pliny's inadvertence is still everywhere current in text-books, pomologies and cyclopaedias - a mis-statement started, repeated and perpetuated from medieval days when to be printed in Pliny was sufficient proof. That Lucullus brought to Italy a cherry and one which the Romans did not know there is no reason to doubt, but other cherries there must have been, not only wild but cultivated, of Prunus cerasus at least and probably of Prunus avium, and in comparative abundance long before Lucullus, returning from the war in Pontus with Mithridates, brought to Rome a cherry. With this brief mention of Pliny's inaccuracy, we pass to more substantial facts in the history of the cherry.

The domestication of one or the other of the two generally cultivated species of cherries followed step by step the changes from savagery to civilization in the countries of Europe and of western Asia. For, as one sorts the accumulated stores of botanical and historical evidence, it becomes quickly apparent that both the Sweet and the Sour Cherry now grow wild and long have done so in the region named and that, from the time tillage of plants was first practiced in the Old World, this fruit has been under cultivation, feeble, obscure, and interrupted by war and chase though its cultivation may have been. Certainly the history of the cherry is as old as that of agriculture in the southern European countries and is interwritten with it.

In beginning the history of a cultivated plant the first step is to ascertain where it grows spontaneously - where it may be found unplanted and unattended by man. This is the task now before us for Prunus cerasus and Prunus avium, discussing them in the order named.

\footnotetext{
${ }^{1}$ See quotation on page 45 .
} 


\section{THE ORIGIN OF CULTIVATED CHERRIES}

Prumus cerasus, of which the Montmorency is the commonest representative in America, is now to be found wild wherever Sour Cherries are much grown, for it is a favorite food of many birds which quickly scatter its seeds from centers of cultivation. Nearly all of the botanies of temperate regions in which agriculture is carried on name this cherry as an escape from cultivation into woods and hedgerows and along roadsides. The Sour Cherry, then, is now to be found truly wild in many parts of several continents. It is not so easy to say where the habitat and what the condition before the species was cultivated. But botany, archaeology, history and philology indicate that the original habitat of the Sour Cherry is southeastern Europe and the nearby countries in Asia.

After saying that this cherry has been found wild in the forests of Asia Minor, the plains of Macedonia, on Mount Olympus and in neighboring territories, De Candolle, however, limits its habitat to the region "from the Caspian Sea to the environments of Constantinople." as a wild plant this cherry must have spread over a far greater area. Even the broadest boundaries of the habitat of Prunus cerasus as set by De Candolle show over-caution. Thus, the Marasca cherry, a botanical variety of Prunus cerasus, is most certainly wild in the Province of Dalmatia on the Adriatic Sea in Austria; so, too, it is certain that this species is feral as far away from De Candolle's center of distribution as northern Austria and southern Germany and has been so for untold ages. It is safe to say that the original source of the Sour Cherry was the territory lying between Switzerland and the Adriatic Sea on the west and the Caspian Sea and probably somewhat farther north on the east. That is, our savage forefathers must have found this cherry in the region thus outlined, probably in a much more extended territory, into which it was brought in more or less remote times by agencies other than human from De Candolle's smaller area of origin.

It is easier to define the geographic range of the wild Sweet Cherry. Botanists very generally agree that Prunus avium as a wild plant inhabits all of the mainland of Europe in which the cultivated varieties of the species can be grown - that is, most of the continent south of Sweden and may be found wild well into southern Russia. The species is reported sparingly wild in northern Africa and is a very common wild plant in

${ }^{1}$ De Candolle, Origin of Cultivated Plants 207. 1885. 
southern Asia as far east as northern India. It must not be thought that the plant is everywhere abundant in the great area outlined as its habitat. To the contrary, the Sweet Cherry is an uncommon wild plant in Spain, Italy and other parts of southern Europe. All authorities agree that the region of greatest communal intensity for Prunus avium is between the Caspian and Black Seas and south of these bodies of water. It might suffice to say that from about these seas the Sweet Cherry came - that here grew the trunk from which branches were spread into other lands by birds and animals carrying the seeds from place to place. The most important fact to be established, however, is that this cherry has long grown spontaneously over a widely extended territory and may, therefore, have been domesticated in several widely separated regions.

\section{THE CHERRY IN GREECE; THE FIRST RECORD OF CULTURE AND THE NAME}

Having established the habitats of the two cultivated cherries we may next ask when and where their cultivation began. The domestication of plants probably began in China - certainly Chinese agriculture long antedates that of any other nation now in existence of which we have records. Agriculture in China, historians roughly approximate, goes back 4,000 years. But while the Chinese have many other species of cherry, as we have seen, some of which may be said to be partially domesticated, Prunus cerasus and Prunus avium are not found wild in China and were only in recent years introduced there as cultivated plants. Neither does the cherry of our civilization seem to have been known in the second great agricultural region of the world-Egypt and the extreme southwest of Asia. At least there are no words for the cherry in the languages of the peoples of that region and cherry pits have not been found with the remains of other plants in the tombs and ruins of Egypt, Assyria and Babylon. Nor does the cherry seem to have been cultivated in India until comparatively recent times.

These very brief and general statements show that cherries were not cultivated in the first agricultural civilizations and serve to fix the time and the place of the domestication of the cherry a little more definitely. Records of cherries as cultivated plants begin, so far as the researches of botanical historians now show, with Greek civilization though it is probable, for several reasons, that some cultivated cherries came to Greece from Asia Minor.

Theophrastus, to whom Linnaeus gave the title "Father of Botany," 
writing about 300 years before the Christian era in his History of Plants, is, according to botanical historians, the first of the Greek writers to mention the che ry. His statement is as follows:-

"The cherry is a peculiar tree, of large size, some attaining the height of twenty-four cubits, rather thick, so that they may measure two cubits in circumference at the base. The leaf is like that of the mespilus, rather firm and broader, the color of the foliage such that the tree may be distinguished from others at a good distance. The bark, by its color, smoothness and thickness, is like that of tilia. The flower [meaning, the cluster of flowers] is white, resembling that of the pear and mespilus, consisting of small [separate] flowers. The fruit is red, similar to that of diospyros [but what his diospyros was no one knows] of the size of a faba [perhaps nelumbo seed], which is hard, but the cherry is soft. The tree grows in the same situations as tilia; by streams." 1

From this passage we gather that the cherry Theophrastus knew was the Sweet Cherry, Prunus avium; the description shows it to be the same large, tall treee now naturalized in open woods and along roadsides in many parts of the United States. From the fact that Theophrastus describes the tree and the bark in more detail than the fruit we may assume that the cherry was more esteemed in ancient Greece as a timbertree than as a fruit-tree. Curiously enough the name the Greeks at this time used for the Sweet Cherry is now applied to Prumus cerasus, the Sour Cherry.

"Kerasos" was the Sweet Cherry in ancient Greece and from kerasos came cerasus, used by many botanists as the name of the genus. That the Sweet Cherry should by the use of avium be denominated the "bird cherry" is clear since birds show much discrimination between cherries, but why the Sour Cherry should be given the specific name cerasus, first applied to the Sweet Cherry, is not apparent.

Pages are written in the old pomologies and botanical histories as to the origin of the word cerasus. Pliny's statement that Lucullus called the cherry cerasus from the town from which he obtained it, Kerasun in Pontus, on the Black Sea, is, in the light of all who have since looked into the matter, a misconception. To the contrary, commentators now agree that the town received its name from the cherry which grows most abundantly in the forests in that part of Asia Minor. The name, according to all authorities, is very ancient - a linguistic proof of the antiquity of the cherry.

${ }^{1}$ Theophrastus, Book III, Chap. I3. 
To sum up, the cherry comes into literature first from Greece in the writings of Theophrastus. There can be but little doubt, however, but that it had been cultivated for centuries before Theophrastus wrote. Whether one or both of the two cherries were domesticated by the Greeks, beginning with their civilization, or whether cultivated cherries came to Greece from Asia Minor, is not now known. It is very probable that some of the several varieties grown in Greece came under cultivation through domestication of wild plants; others were introduced from regions farther east.

\section{THE SWEET CHERRY POSSIBLY THE PARENT OF THE SOUR CHERRY}

A digression may be permitted here to state a hypothesis suggested by De Candolle ${ }^{1}$ which should interest both fruit-growers and plantbreeders. De Candolle, while considering the two species of cultivated cherries to be now quite distinct, suggests that, since they differ essentially but little in their characters and since their original habitats were in the same region, it is probable that one species came from the other. $\mathrm{He}$ surmises, since Prunus avium is the commoner in the original home, is generally the more vigorous of the two, has spread much farther and probably at a much earlier date from the primal habitation in Asia Minor than Prumus cerasus, that the latter, the Sour Cherry, is derived from the Sweet Cherry. In the future breeding of cherries confirmatory evidence of such a relationship may be obtained though, should none be found, the negation should go for naught and the supposition can only remain an interesting and plausible hypothesis.

\section{THE CHERRY IN ITALY}

Pliny attempts to give the first full account of cultivated cherries and, even though among his statements are several inaccuracies, yet he may be said to have made a very good beginning of a flora of cultivated cherries for he names and describes ten varieties. The fact that there were as many as ten cherries in Italy at the time Pliny wrote, less than a century after the return of Lucullus from Pontus, is strong evidence that the cherry in Italy antedates Lucullus. Besides, it is hardly probable that Pliny knew and described all of the cherries to be found in the whole of his country. But even if these ten comprise the entire number, those who know how extremely difficult it is to introduce new plants in

\footnotetext{
${ }^{1}$ De Candolle, Alphonse Origin of Cultivated Plants 210. 1885.
} 
a country with the facilities we have in our day, will doubt that all of the cherries in Pliny's account could have been introduced in Italy 1900 years ago and have come under general cultivation, as according to Pliny they had, within the short space of a century. The following quotation, then, must be taken as an account of the cherries grown in Italy in the first century after Christ with little weight given to the historical evidence presented. ${ }^{1}$

"The cherry did not exist in Italy before the period of the victory gained over Mithridates by L. Lucullus, in the year of the City 68o. $\mathrm{He}$ was the first to introduce this tree from Pontus, and now, in the course of one hundred and twenty years, it has travelled beyond the Ocean, and arrived in Britannia even. The cherry, as we have already stated, in spite of every care, has been found impossible to rear in Egypt. Of this fruit, that known as the "Apronian" is the reddest variety, the Lutatian being the blackest, and the Caecilian perfectly round. The Junian cherry has an agreeable flavour, but only, so to say, when eaten beneath the tree, as they are so remarkably delicate that they will not bear carrying. The highest rank, however, has been awarded to the Duracinus variety, known in Campania as the "Plinian" cherry, and in Belgica to the Lusitanian cherry, as also to one that grows on the banks of the Rhenus. This last kind has a third colour, being a mixture of black, red, and green, and has always the appearance of being just on the turn to ripening. It is less than five years since the kind known as the "laurel-cherry" was introduced, of a bitter but not unpleasant flavour, the produce of a graft upon the laurel. The Macedonian cherry grows on a tree that is very small, and rarely exceeds three cubits in height; while the chamaecerasus is still smaller, being but a mere shrub. The cherry is one of the first trees to recompense the cultivator with its yearly growth; it loves cold localities and a site exposed to the north. The fruits are sometimes dried in the sun, and preserved, like olives, in casks."

How are the cherries described in the passage from Pliny related to those of modern culture? A score or more of commentators have tried to tell but when the comments are compared Pliny's disorder becomes confusion worse confounded. Here, as in his historical statements, Pliny seems to have prepared the ground for a fine crop of misunderstandings. The speculations as to what particular cherry each of the descriptions fits quickly show the futility of specification. A few generalizations only are warranted.

Thus, if we assume, as most commentators do, that Apronian, the

${ }^{1}$ Bostock and Riley Nat. History of Pliny 3:322. 1855. 
first of Pliny's varieties, was named after Apronius, a Roman praetor of Pliny's day, there is nothing to indicate the character of the cherry except the word "reddest" which means but little for it is no more possible to distinguish cherries by redness than by its blackness to tell a pot from a kettle.

It is as impossible to distinguish the second variety as the first. The name given is Lutatian, the variety having been dedicated, as all commentators agree, to Lutatius Catulus, a contemporary of Lucullus, revered by Romans for having rebuilt the capitol after it had been destroyed by fire. It is described as "being the blackest" but whether Prunus avium or Prunus cerasus, sweet or sour, who can tell?

The third variety is called the Caecilian cherry, which we are told is "perfectly round" - a character possessed in like degree by many cherries. The name, on the authority of Latin scholars, commemorates the Caecilius family, rich and powerful Romans, friends of Lucullus at the time he was promoting cherry culture.

We may be a little more certain of the identity of the fourth cherry, called the Junian, and said to have been possessed of " an agreeable flavor but only, so to say, when eaten beneath the tree, as they are so remarkably delicate that they will not bear carrying." Whether the name was given in honor of the Roman Republican, Junius Brutus, who died 42 A. D. or from Junius, the month of their ripening, cannot be said. The description, as practically all agree, fits very well the French Guigne or English Gean group of cherries. It is probable that "Guigne" is a perversion of " Junian."

There can be little question as to the cherry Pliny next describes, "the Duracinus variety" which he says has been awarded "highest rank" and to which he paid the compliment of giving it his own name, for he tells us that it is "known in Campania as the Plinian cherry." This hard-fleshed cherry of delectable quality can be no other than a Bigarreau - some protean Napoleon, Yellow Spanish, Windsor or the older Oxheart and Elkhorn.

The sixth cherry is the Lusitanian, which, if the translations read aright, the Belgians rank highest. Ancient Lusitania is modern Portugal and the Lusitanian cherry may be the Griotte of Portugal grown from time immemorial in that country. The identity of the variety is not so important in this passage as is the connection that Pliny establishes in cherry culture at this early time between Portugal, Italy and Belgium. 
By such tckens does our author cast doubt upon his statement that Lucullus had but yesterday, as it were, brought the cherry from Pontus. The seventh cherry is one "that grows on the banks of the Rhenus" (Rhine), further described as "being a mixture of black, red and green," and of having "always the appearance of being just on the turn to ripening." It is useless to add another guess to those of the many commentators as to what this tri-colored cherry from the banks of the Rhine may be.

The eighth description, that of the "laurel-cherry," applies to a graft and not to a variety. Of it, Pliny says, "It is less than five years since the kind known as the laurel-cherry was introduced, of a bitter, but not unpleasant flavor, the produce of a graft upon the laurel." It is barely possible that a cherry could be made to grow on a laurel five years but it is extremely doubtful, as all modern horticulturists who have tried it say, and it is impossible to have such a graft bear fruit. Pliny was misinformed.

The ninth and tenth of Pliny's cherries, the Macedonian and the Chamaecerasus, are probably one and the same, since but one cherry that could possibly answer to the descriptions given could have been in Italy at the time Pliny wrote. The cherry described, then, was almost beyond doubt Prunus fruticosa Pallas, a synonym of which is Prunus cl.rmaecerasus Jacquin, perpetuating the name used by Pliny. This is the European Dwarf Cherry, or Ground Cherry, which is now and was probably then a wild plant in parts of Italy and which is very well described by "a tree that is very small, and rarely exceeds three cubits in height."

We have accredited Pliny with having first described cherries in Italy and discredited his account of their introduction in his own country, but chiefly on inferential evidence. Just a few words of direct proof that the cherry was long in cultivation by the Romans before Lucullus and we have done with the introduction of the cherry into Italy and have filled another gap between Theophrastus and our own times. Marcus Terentius Varro (B. C. II7-27), one of the illustrious scholars of ancient Rome, sometimes called the father of Roman learning, in his eightieth year, as he tells us in his first chapter, wrote a book on farming - one, which, by the way, may be read with profit by modern farmers. ${ }^{1}$ In book I, chapter XXXIX, he tells when to graft cherries, discussing the process not as if it or the cherry were new or little known but as if the cherry were

\footnotetext{
${ }^{1}$ A very good translation of Varro on farming is one by Lloyd Starr-Best, published by G. Bell \& Sons, London. 1912.
} 
as commonplace as the other agricultural crops of the times. Varro effectually disproves Pliny to whose mis-statement we have given so much space only because for nearly 2000 years it has been generally accepted as the truth.

The gaps in the history of the cherry are long. Athenaeus, ${ }^{1}$ Tertullian, ${ }^{2}$ Ammianus, ${ }^{3}$ and St. Jerome, ${ }^{4}$ Roman writers of the Third and Fourth Centuries, mention cherries but chiefly to repeat and perpetuate Pliny's errors. It was not until the Sixteenth Century - a lapse of I 400 years - that an attempt was again made to describe in full cultivated cherries. Sometime in this century, Matthiolus (1487-1577), a Tuscan and one of the eminent naturalists not only of Italy but of the world in the Middle Ages, in translating and annotating the medical works of the Greek writer Dioscorides, made a list of the fruit-trees then grown in Italy. As the second descriptive list of cherries this contribution of Matthiolus might be worth reprinting were it not, as in Pliny, that but few of his varieties can be certainly made out. He does, however, make a number of additions to Pliny's list but space does not permit a consideration of these; especially since Gerarde, writing less than a century later in English, so well amplifies Matthiolus that we shall print his account.

\section{CHERRIES IN THE SIXTEENTH CENTURY}

Pliny mentions the cherry as growing in several countries and, by reading between lines, we may assume that cultivated cherries were distributed throughout all parts of Europe where agriculture was practiced, by Christ's time or shortly thereafter. Pliny speaks of the cherry in some connection with England, Germany, Belgium and Portugal. Surely we may assume that the cherry was being grown at the same time in at least the countries in Europe which are between or border on those named. But from Pliny to the Sixteenth Century the current of progress in cherry culture was immeasurably slow. In the intervening I60o years not a score of new cherries were brought under cultivation. Attention was probably given during these dark ages to this and to all fruits as species and as divisions of species which came nearly or quite true to seed. It was only in the refinements of horticulture and botany brought about by the herbalists that true horticultural varieties came into common cultivation.

\footnotetext{
1 Athenaeus Dipnosophiste Book II, Chap. XXXIV-V.

${ }^{2}$ Tertullian A pologeticum Chap. XI.

${ }^{3}$ Ammianus History of the Roman Emperors Book 22, Chap. XVI.

'St. Jerome Epistulae Book I, Letter XXXV.
} 
Thus, the first of the German herbals, the Herbarius, printed at Mainz in I49I, does not describe or even name varieties of cherries but groups them in the two species as Sweets and Sours, the statement running:" "The cherries are some sweet, some sour, like the wild apple; the sours bring to the stomach gas and make the mouth fresh (frisch), those too sweet or too sour are of little use." A wood-cut in this old herbal illustrates a Sour Cherry.

According to Müller, ${ }^{2}$ not until 1569 did the Germans attempt to give names to varieties, when, in a medical herbal, the Gart der Gesundheit, cherries were roughly divided into four groups: (I) The Amarellen, sour, dark red cherries with long stems. (2) The Weichselkirschen, red cherries with white juice and short stems. (3) The Süsskirschen, red or black Sweet Cherries with long stems. (4) "Beside these yet more " distinguished by their shape and the province in which they are grown. Not until well into the Eighteenth Century do the Germans seem to have given names to more than a few of the most distinct varieties of cherries. Yet the cherry was more largely cultivated in Germany, one, two, or three centuries ago, as it is now, than in any other European country. This, one readily gleans from what has been written on cherries in different countries and from the acknowledgments of foreign pomologists to those of Germany for most of what has been printed regarding cherries. Not only has the cherry been a favorite orchard plant in Germany but since the Sixteenth Century it has been largely planted along the public roads.

Of cherries on the continent, for this brief history, nothing more need be said. Most of the varieties that have been imported from Europe to America have come from England and we must, therefore, devote rather more attention to the history of the cherry in England than in other European countries.

\section{CHERRIES IN ENGLAND}

Cultivated cherries came to England with the Romans. Prunus avium is indigenous in Great Britain but probably no care worthy the name cultivation was given these wild trees by the ancient Britons. Pliny states that the cherry was carried from Rome to Britain before the middle of the First Century - meaning probably some improved variety. In no part of the world does the cherry take more kindly to the soil than in

\footnotetext{
${ }^{1}$ Quoted from Mūller, Hugo M. Obstzüchter 8:3. I9Io.

${ }^{2}$ Ibid.
} 
England and no doubt this fruit became firmly established in Kent, where the Romans settled, before the downfall of the southern invaders. With the expulsion of the Romans and the subsequent influx of barbarians, agriculture, especially gardening and fruit-growing, became almost a lost art but still it is not probable that the cherry was wholly lost to cultivation during the Teutonic invasions of Britain.

Fruit-growing could not have greatly prospered, however, in the centuries of strife with the barbarians which succeeded Roman rule in England; and a revival of cherry culture did not take place until the reintroduction of Christianity and the establishment of monasteries where, undisturbed by wars, the monks became notable horticulturists. They not only had opportunity in the comparative peace in which their lives were cast to grow fruit but many of them were men of superior intelligence and skill and from intercourse with the continental countries learned what plants were worth growing and how to grow them - the monasteries were the experiment stations of the times. Undoubtedly the monks in bringing to England treasures from the continent did not forget fruits and among them cherries.

Passing by a considerable number of references which could be cited to show that cherries of one kind and another were cultivated in Britain from at least as early a date as the Ninth Century, we come to the discussion of this fruit by the herbalists of the Sixteenth and Seventeenth Centuries. Of the three great English herbalists, Turner published his work in 1538; Gerarde's, printed in 1596, was revised and greatly improved by Johnson in I633; Parkinson's Paradisi in Sole Paradisus Terrestris, or Park-in-Suns Earthly Paradise - the author evidently a punster - was published in I629. All of these contain as full botanical and pomological discussions of cherries as knowledge then permitted.

It must not be thought, by those unacquainted with the plant-lore of the times, that the cherry received consideration only from the pens of Turner, Gerarde, and Parkinson. During the time covered by the lives of these three men a score or more of books were written in English on botany and pomology in which accounts were given of the cherry, all showing the esteem in which this fruit was held in England during and before the reign of Queen Elizabeth. Space permits comments on the account of the cherry given by but one of these Elizabethan herbalists, and of the several Gerarde's seems best suited to our purpose.

We have chosen Gerarde because he treats the cherry more fully 
than do the other writers of the period and because he was a compiler and a translator, having, as he quaintly says, " perused divers Herbals set fourth in other languages;" thus from Gerarde we obtain a conception of cherries growing on the continent as well as those growing in England. Students of the English herbals say that Gerarde translated, copied and adapted from Matthiolus, whose book we have noted, but more particularly from Dodoens who in 1554 published in Antwerp A History of Plants. These two worthies, in turn, had borrowed very freely from still more ancient writers - Theophrastus, Dioscorides, Columella and others. As might be suspected, errors centuries old were passed down, yet each new translation or compilation contains much added information and is far freer from error. In particular, Gerarde seems to have been a wise compiler and adapter and to have combined a large measure of first-hand practical knowledge with his borrowings from others. This is especially true of what he writes concerning cherries, a fruit with which he seems to have been very familiar.

The following is Gerarde's account, with interpolations by the author:

"The ancient Herbalists have set down four kinds of Cherry trees; the first is great and wild, the second tame or of the garden, the third hath sour fruit, the fourth is that which is called in Latin Chamaecerasus, or the dwarfe Cherry tree. The later writers have found divers sorts more, some bringing forth great fruit, others lesser; some with white fruit, some with blacke, others of the colour of black bloud, varying infinitely according to the clymat and country where they grow."

The four cherries which Gerarde says the "ancient herbalists have set down" are, it is easy to see: first, the wild Prunus avium; second, cultivated sweet varieties of Prunus avium; third, the sour Prunus cerasus; fourth, the Dwarf Cherry, Prunus fruticosa.

"The English Cherry tree groweth to a high and great tree, the body whereof is of a mean bignesse, which is parted above into very many boughes, with a barke somewhat smooth, of a brown crimson colour, tough and pliable; the substance or timber is also brown in the middle, and the outer part is somewhat white: the leaves be great, broad, long, set with veins or nerves, and sleightly nicked about the edges: the floures are white, of a mean bigness, consisting of five leaves, and having certain threds in the middle of the like colour. The Cherries be round, hanging upon long stems or footstalks, with a stone in the middest which is covered with a pulp or soft meat; the kernell thereof is not unpleasant to the taste, though somewhat bitter." 
This is Prunus avium, which is very generally wild in Britain - the Gean of the English.

"The Flanders Cherry tree differeth not from our English Cherry tree in Stature or form of leaves or floures, the only difference is, that this tree brings forth his fruit sooner and greater than the other, wherefore it may be called in Latine, Cerasus praecox, sive Belgica."

A cherry which "brings forth his fruit sooner and greater than the other " can be no other than one of the early varieties of the Sweet Cherry.

"The Spanish Cherry tree groweth up to the height of our common Cherry tree, the wood or timber is soft and loose, covered with a whitish scaly barke, the branches are knotty, greater and fuller of substance than any other Cherry tree; the leaves are likewise greater and longer than any of the rest, in shape like those of the Chestnut tree: the floures are like the others in form, but whiter of colour; the fruit is greater and longer than any, white for the most part all over, except those that stand in the hottest place where the sun hath some reflexion against a wall: they are also white within, and of a pleasant taste."

We have in this description a very good pen picture of Yellow Spanish, one of the Bigarreaus, of which there must have been several in common cultivation in Gerarde's time.

"The Gascoin Cherry tree groweth very like to the Spanish Cherry tree in stature, flours and leaves: it differeth in that it bringeth forth very great Cherries, long, sharp pointed, with a certain hollownesse upon one side, and spotted here and there with certain prickles of purple color as smal as sand. The taste is most pleasant, and excelleth in beauty."

Gascoin, sometimes "Gaskin" in England, is a corruption of Gascoigne, a name applied by the French to cherries produced in Gascony and said to have been brought to England by Joan of Kent when her husband, the Black Prince, was commanding in Guienne and Gascony. The variety is a very good Sweet Cherry, no doubt the one described in this text under the name Bleeding Heart.

"The late ripe Cherry tree groweth up like unto our wild English Cherry tree, with the like leaves, branches and floures, saving that they are sometimes once doubled; the fruit is small, round, and of a darke bloudy colour when they be ripe, which the French-men gather with their stalkes, and hang them up in their houses in bunches or handfulls against Winter, which the Physitions do give unto their patients in hot and burning fevers, being first steeped in a little warme water, that causeth them to swell and plumpe as full and fresh as when they did grow upon the tree. 
"The Cluster Cherry tree differeth not from the last described either in leaves, branches, or stature: the floures are also like, but never commeth any one of them to be double. The fruit is round, red when they be ripe, and many growing upon one stem or foot-stalke in clusters, like as the Grapes do. The taste is not unpleasant although somewhat soure."

These two cherries, one sees at once, are varieties of Prunus cerasus. The first, Gerarde identifies for us on a succeeding page as the Morello. He says of it: "The late ripe cherries which the Frenchmen keepe dried against the winter, and are by them called Morelle, and wee after the same name call them Morell Cherries.

"This Cherrie-tree with double floures growes up unto a small tree, not unlike to the common Cherrie-tree in each respect, saving that the floures are somewhat double, that is to say, three or foure times double; after which commeth fruit (though in small quantitie) like the other common Cherry.

"The double floured Cherry-tree growes up like unto an hedge bush, but not so great nor high as any of the others, the leaves and branches differ not from the rest of the Cherry-tree. The floures hereof are exceeding double, as are the flours of Marigolds, but of a white colour, and smelling somewhat like the Hawthorne floures; after which come seldome or never any fruit, although some Authors have said that it beareth sometimes fruit, which my selfe have not at any time seen; notwithstanding the tree hath growne in my Garden many yeeres, and that in an excellent good place by a bricke wall, where it hath the reflection of the South Sunne, fit for a tree that is not willing to beare fruit in our cold climat."

These two are double-flowered cherries, several of which seem to have been grown as ornamentals. Both belong to Prunus cerasus and as we gather rather better elsewhere than here, both are of the Amarelle type of tree.

"The Birds Cherry-tree, or the blacke Cherry-tree, that bringeth forth very much fruit upon one branch (which better may be understood by sight of the figure, than by words) springeth up like an Hedge tree of small stature, it groweth in the wilde woods of Kent, and are there used for stockes to graft other Cherries upon, of better tast, and more profit, as especially those called the Flanders Cherries: this wilde tree growes very plentifully in the North of England, especially at a place called Heggdale, neere unto Rosgill in Westmerland, and in divers other places about Crosbie Ravenswaith, and there called Hegberrie-tree: it groweth likewise in Martome Parke, foure miles from Blackeburne, and in Harward neere thereunto; in Lancashire almost in every hedge; the leaves and branches differ not from those of the wilde Cherry-tree: the floures grow 
alongst the small branches, consisting of five small white leaves, with some greenish and yellow thrums in the middle: after which come the fruit, greene at the first, blacke when they be ripe, and of the bignesse of Sloes; of an harsh and unpleasant taste.

"The other birds Cherry-tree differeth not from the former in any respect, but in the colour of the berries; for as they are blacke; so on the contrary, these are red when they be ripe, wherein they differ."

The cherries described in these two paragraphs, one black and one red, "that bringeth forth very much fruit upon one branch" and "groweth in the wilde woods" and "of an harsh and unpleasant taste" are of course the Prumus padus of Britain and most of Europe - not a true cherry but the racemose Bird Cherry, or Choke Cherry.

"The common blacke Cherry-tree growes up in some places to great stature: there is no difference between it and our common Cherry-tree, saving that the fruit hereof is very little in respect of other Cherries, and of a blacke colour."

This must be some wild Gean or Mazzard.

"The dwarfe Cherry-tree groweth very seldome to the height of three cubits: the trunke or body small, covered with a darke coloured blacke: whereupon do grow very limber and pliant twiggie branches: the leaves are very small, not much unlike to those of the Privite bush: the floures are small and white: after which come Cherries of a deepe red colour when they be ripe, of taste somewhat sharpe, but not greatly unpleasant: the branches laid downe in the earth, quickely take root, whereby it is greatly increased."

Here we have Prunus fruticosa very well described.

"My selfe with divers others have sundry other sorts in our gardens, one called the Hart Cherry, the greater and the lesser; one of the great bignesse, and most pleasant in taste, which we call Luke Wardes Cherry, because he was the first that brought the same out of Italy; another we have called the Naples Cherry, because it was first brought into these parts from Naples: the fruit is very great, sharpe pointed, somewhat like a man's heart in shape, of a pleasant taste, and of a deepe blackish colour when it is ripe, as it were of the colour of dried bloud."

Gerarde's Hart is probably one of the Heart cherries, while "Luke Wardes Cherry" is one of the oldest named Sweet Cherries known in England, having been mentioned by Parkinson and other of the herbalists as well as in this list.

"We have another that bringeth forth Cherries also very great, bigger than any Flanders Cherrie, of the colour of Jet, or burnished horne, 
and of a most pleasant taste, as witnesseth Mr. Bull, the Queenes Majesties Clockmaker, who did taste of the fruit (the tree bearing onely one cherry, which he did eat; but my selfe never tasted of it) at the impression hereof. We have also another, called the Agriot Cherry, of a reasonable good taste. Another we have with fruit of a dun colour, tending to a watchet. We have one of the Dwarfe Cherries, that bringeth forth fruit as great as most of our Flanders Cherries, whereas the common sort hath very small Cherries, and those of an harsh taste. These and many sorts more we have in our London gardens, whereof to write particularly would greatly enlarge our volume, and to small purpose: therefore, what hath beene said shall suffice. I must here (as I have formerly done, in Peares, Apples, and other such fruites) refer you to my two friends, Mr. John Parkinson, and Mr. John Millen, the one to furnish you with the history, and the other with the things themselves, if you desire them."

One can only roughly surmise as to what the cherries mentioned in this paragraph are with the exception of the Agriot which is, if the synonymy of several European pomologists be correct, the Griotte Commune, a sort supposed to have been brought from Syria by the crusaders and to have been recorded under the last name in France as early as I 485 .

The end of the Seventeenth Century saw a great revival of agriculture in all of its branches on the continent; in England the revival began with the fall of the commonwealth. From this time the progress of cherry culture has been so rapid and so great that it would be an endless task to give even a cursory view of it - a task unnecessary, too, for succeeding the herbalists a great number of botanies, pomologies and works on agriculture were published to many of which reference is still easy. Moreover, the histories of varieties in this text carry us back quite to the beginning of the Eighteenth Century.

There now remains for the history of the cherry but to sketch its introduction and culture in North America, an undertaking that can be done briefly and to the point, for the data are abundant, recent and reliable. Here, too, accounts of the origin of varieties and the development of the cherry may be looked for in the chapters which comprise the main part of the book.

\section{CHERRIES IN AMERICA}

The cherry was one of the first fruits planted in the fields cleared and enriched by our hardy American ancestry. From Canada to Florida the colonists, though of several nationalities and those from one nation 
often representing several quite distinct classes, were forced alike to turn at once to the cultivation of the soil as a means of subsistence. And while in all of the colonies the early settlers must have been busily engaged in the cultivation of cereals for the staff of life, in the South in growing cotton and tobacco for money and for purposes of barter, in the North in harvesting forest and fish products for bartering; yet the historians of the colonies notice so often and describe so fully and with such warmth of feeling the vegetables, flowers and fruits in the orchards and gardens of the New World that it is certain that the ground was tilled not only as a means of subsistence but because the tillers loved the luxuries of the land.

What fruit better adapted to the uses of colonists than the cherry? It possesses in a high degree, especially the Sour Cherry, the power of adaptation to new environment and thrives under a greater variety of conditions than any other of our fruits unless it be the apple, which it at least equals in this respect. The cherry is easily propagated; it comes in bearing early and bears regularly; of all fruits it requires least care gives the greatest returns under neglect; and the product is delectable and adapted to many purposes. We shall expect, then, in examining the early records of fruit-growing in America to find the cherry one of the first planted and one of the most widely disseminated of fruits.

\section{CHERRIES PLANTED BY THE FRENCH IN AMERICA}

While written records are lacking, the plantations of old trees and the development of cherry culture indicate that the French early planted cherries in Nova Scotia, Cape Breton, Prince Edward Island and in the early settlements on the St. Lawrence River. The cherry is a favorite fruit of the French and the venerable trees that survived on the sites of their settlements when the English came into possession of Canada are proof sufficient that the émigrés from Provence or Normandy, fruit districts of France from which many French settlers came, brought with them seeds of the cherry with those of other fruits. Peter Kalm in his Travels into North America in $177 \mathrm{I},{ }^{1}$ records the very general culture of all the hardy fruits in Canada and leaves the impression that such had been the case from the first settlements.

\footnotetext{
${ }^{1}$ Kalm, Peter Travels into North America 1771.
} 


\section{CHERRIES IN NEW ENGLAND}

The cherry came to New England with the first settlers. This we are told in all the records of early New England in which the conditions of the country are described and of it we have confirmatory proof in many enormous cherry trees, Sweet and Sour, both about ancient habitations and as escapes from cultivation in woods, fields and fence rows, all pointing to the early cultivation of this fruit. The early records are very specific. Thus, to quote a few out of an embarrassment of references: Francis Higginson writing in 1629 , after naming the several other fruits then under cultivation in Massachusetts, notes that the Red Kentish is the only cherry cultivated. ${ }^{1}$ In the same year, the I6th of March, 1629 , a memorandum of the Massachusetts Company shows that "Stones of all sorts of fruites, as peaches, plums, filberts, cherries, pear, aple, quince kernells" were to be sent to New England. ${ }^{2}$

These seeds, provided by the home company with forethought of the need of orchards in the colony, evidently produced fruit trees sufficient to supply both hunger and thirst; for John Josselyn, who made voyages to New England in 1638, I639 and 1663, writing of "New England's Rarities Discovered," says: ${ }^{3}$ "Our fruit Trees prosper abundantly, Apple-trees, Pear-trees, Quince-trees, Cherry-trees, Plum-trees, Barberrytrees. I have observed with admiration, that the Kernels sown or the Succors planted produce as fair and good fruit, without grafting, as the tree from whence they were taken: the Countrey is replenished with fair and large Orchards. It was affirmed by one Mr. Woolcut (a magistrate in Connecticut Colony) at the Captains Messe (of which I was) aboard the Ship I came home in, that he made Five hundred Hogsheads of Syder out of his own Orchard in one year. Syder is very plentiful in the Countrey, ordinarily sold for ten shillings a Hogshead.

"The Quinces, Cherries, Damsons, set the Dames a work, Marmalad and preserved Damsons are to be met with in every house. It was not long before I left the Countrey that I made Cherry wine, and so may others, for there are good store of them both red and black. Their fruit trees are subject to two diseases, the Meazels, which is when they are burned and scorched with the Sun, and lowsiness, when the woodpeckers jab holes in their bark: the way to cure them when they are lowsie is to bore a hole in the main root with an Augur, and pour in a quantity of Brandie or Rhum, and then stop it up with a pin made of the same Tree."

1 Mass. Hist. Soc. Collections Ist Ser. I: 118.

${ }^{2}$ Mass. Records I: 24.

${ }^{3}$ Mass. Hist. Collections 3 d Ser. 23:337. 
As early as I64I, a nursery had been started in Massachusetts and was selling among other trees those of the cherry. Troublesome pests had made their appearance, too, as may be seen from the following letter, probably from the first American nurseryman. The letter is written by George Fenwith of Saybrook, Connecticut, under date of May 6, I641, ${ }^{1}$ to Governor John Winthrop, Jr.

"I haue receaued the trees yow sent me, for which I hartily thanke yow. If I had any thing heare that could pleasure yow, yow should frely command it. I am prettie well storred with chirrie \& peach trees, \& did hope I had had a good nurserie of aples, of the aples yow sent me last yeare, but the wormes have in a manner distroyed them all as they came vp. I pray informe me if yow know any way to preuent the like mischiefe for the future."

These early plantations of cherries in New England were undoubtedly grown from seed; for buds, cions and trees could not have been imported unless the latter were brought over potted out as was not commonly done until a century and a half later - at least, the records make mention of seeds and not of trees as was the case just before and after the Revolutionary War. A statement left by one of the Chief Justices of Massachusetts, Paul Dudley, living at Roxbury, at as late a date as 1726, indicates that varieties were few. In a paper in the Philosophical Transactions $^{2}$ on agricultural conditions in Massachusetts, among many other interesting things, Justice Dudley says:

"Our apples are without doubt as good as those of England, and much fairer to look to, and so are the pears, but we have not got all the sorts. Our peaches do rather excel those of England, and then we have not the trouble or expence of walls for them; for our peach trees are all standards, and I have had in my own garden seven or eight hundred fine peaches of the Rare-ripes, growing at a time on one tree. Our people, of late years, have run so much upon orchards, that in a village near Boston, consisting of about forty families, they made near three thousand barrels of cyder. This was in the year I 72I. And in another town of two hundred families, in the same year I am credibly informed they made near ten thousand barrels. Our peach trees are large and fruitful, and bear commonly in three years from the stone. Our common cherries are not so good as the Kentish cherries of England, and we have no Dukes or Heart cherries, unless in two or three gardens."

\footnotetext{
1 Mass. Hist. Collections 4 th Ser. VI: 499.

${ }^{2}$ Abridgment 6:pt. II: 341, in Hist. Mass. Hort. Soc. 14-15. 1 829-1878.
} 
CHERRIES IN NEW YORK

Though settled at about the same time and having a more congenial climate, New York made progress in fruit-growing more slowly than Massachusetts. The early Dutch settlers in New York were transient traders and not home makers. Actual settlement with homes in view did not begin until after the historical bargain in which thrifty Peter Minuit had acquired Manhattan Island for \$24.00 and the country became New Amsterdam. But troublesome times followed under the rule of Minuit, Wouter Van Twiller and Kieft, quarrels and actual war, or the fear of it, with colonists to the north and south as well as with the savages, preventing the planting of orchards and farms until in 1647 when the reins of government were taken in hand by Peter Stuyvesant.

Governor Stuyvesant was a farmer as well as a soldier and there is something in history and much in tradition of the Bowery Farm, which flourished on the site of the present Bowery in New York. This farm was planted and tended by "Peter, the Headstrong" when he was not disputing with his burgomasters, watching the Yankees and fighting Swedes and Indians. The orchards and gardens, according to all accounts, were remarkably fine and were kept in a high state of cultivation. Stuyvesant founded the farm during the stormy times of his governorship but did not live on it until the English took possession of New Amsterdam in $166+$ when he retired to the land and devoted the eighteen remaining years of his life to agriculture. From the neighboring colonies and from abroad he brought many fruits, flowers, farm and truck crops. Fruits came to him also from Holland and were disseminated from his orchard up the Hudson.

The cherry was one of the fruits much grown by the Dutch. It would be wearisome and would serve little purpose even to attempt a cursory review of the literature of colonial days in New York showing the spread and the extent of fruit culture by the Dutch. Travel up the Hudson and its branches was easy and within a century after the settlement of New York by the Dutch, cherries were not only cultivated by the whites, according to the records of travelers, naturalists and missionaries, but were rudely tilled by the Indians.

For a long time after its introduction in New York, the cherry, in common with other fruits, was grown as a species - varieties and budded or grafted trees were probably not known. Fruit-growing as an industry began in New York and in America, with the establishment of a nursery 
at Flushing, Long Island, in $\mathrm{I} 730$, by Robert Prince, founder of the nursery which afterwards bccame the famous Linnaean Botanic Garden. At what date this nursery began to offer named cherries for sale cannot be said but advertisements appearing in 1767,1774 and 1794 show that budded or grafted named cherries were being offered for sale by the Princes. In I 804, William Prince, third proprietor of the famous Flushing nursery, prepared a list of the named cherries then under cultivation in America for Willich's Domestic Encyclopaedia, an English work which was being edited and made " applicable to the present situation of the United States" by Dr. James Mease. The following is Prince's list: ${ }^{1}$

"May Duke, ripe in May and June: long stem, round and red, an excellent cherry, and bears well.

"Black Heart, ripe in June: a fine cherry.

"White Heart (or Sugar Cherry) ripe in June: white and red.

"Bleeding Heart, ripe in June; a very large cherry of a long form and dark colour; it has a pleasant taste.

"Ox Heart, ripe in June: a large, firm, fine cherry.

"Spanish Heart, ripe in June.

"Carnation, ripe in July, it takes its name from its colour, being red and white, a large round cherry, but not very sweet.

"Amber, ripe in July.

"Red Heart, do.

"Late Duke, do.

"Cluster, planted more for ornament, or curiosity than any other purpose.

"Double Blossoms, ripe in July.

"Honey Cherry, do. small sweet cherry.

"Kentish cherry, ripe in July.

"Mazarine, do.

"Morello, do. and August; a red, acid cherry, the best for preserving, and for making cherry-brandy.

"Early Richmond Cherry. This fruit originated near Richmond in Virginia, and is the earliest cherry in America, and valuable on that account; it is the size of a May Duke, and resembles it in form.

"Red Bigereau, a very fine cherry, ripe in July, of a heart shape. shaped.

"White Bigereau, ripe in July and August: remarkably firm, heart

"Large Double Flowering Cherry. This tree produces no fruit but makes a handsome appearance in the spring, when it is covered with clusters of double flowers as large as the cinnamon rose; it differs from

${ }^{1}$ Willich Domestic Encyclopaedia 105. 1804. 
the common double flowering cherry which never forms a large tree, and has small pointed leaves.

"The three last were imported from Bordeaux in $\mathbf{I} 798$.

"Small Morello Cherry, called also Salem Cherry, because it came originally from Salem County, N. J., is cultivated by Mr. Cooper of that state, who values it highly. The fruit has a lively acid taste. The tree produces abundantly, and is the least subject to worms of any cherry trees.

"Mr. C. says that the Bleeding Heart suits a sandy soil, but that the May-duke will not flourish in it."

\section{CHERRIES IN THE SOUTH}

It would be interesting but hardly of sufficient profit to trace further the history of cultivated cherries in the states of the Atlantic seaboard. References to the cherry abound in the colonial records of Pennsylvania, New Jersey and Delaware but they bring out no facts differing materially from those abstracted from the records of the northern colonies. The Quakers and the Swedes in the states watered by the Delaware and the English in Maryland, Virginia and North Carolina, all early grew cherries as one of the easiest fruits to propagate and cultivate.

Space can be spared for but two brief quotations to show the condition of cherry culture in the South in Colonial days. The first is from Bruce's Economic History of Virginia. ${ }^{1}$

"In the closing years of the seventeenth century, there were few plantations in Virginia which did not possess orchards of apple and peach trees, pear, plum, apricot and quince. ${ }^{2}$ The number of trees was often very large. The orchard of Robert Hide of York ${ }^{3}$ contained three hundred peach and three hundred apple trees. There were twenty-five hundred apple trees in the orchard of Colonel Fitzhugh. ${ }^{4}$ Each species of fruit was represented by many varieties; thus, of the apple, there were mains, pippins, russentens, costards, marigolds, kings, magitens and bachelors; of the pear, bergamy and warden. The quince was greater in size, but less acidulated than the English quince; on the other hand, the apricot and plum were inferior in quality to the English, not ripening in the same perfection. ${ }^{5}$ Cherries grew in notable abundance. So great was the productive capacity of the peach that some of the landowners planted

\footnotetext{
${ }^{1}$ Bruce Economic History of Virginia I:468. I 895 .

${ }^{2}$ Glover Philo. Trans. Royal Soc. 1676-1678, vols. XI-XII, p. 628.

${ }^{3}$ Records of York Counly vol. 1694-1697, p. 71, Va. State Library.

- Letters of William Fitzhugh April 22, 1686.

'Glover Philo. Trans. Royal Soc. 1676-1678, vols. XI-XII, p. 628.
} 
orchards of the tree for the mere purpose of using the fruit to fatten their hogs; ${ }^{1}$ on some plantations, as many as forty bushels are said to have been knocked down to the swine in the course of a single season." 2

The second quotation is from Lawson's History of Carolina. ${ }^{3}$

"We have the common, red and black cherry, which bear well. I never saw any grafted in this country, the common excepted, which was grafted on an indian plum stock, and bore well. This is a good way, because our common cherry trees are very apt to put scions all around the tree for a great distance, which must needs be prejudicial to the tree and fruit. Not only our cherries are apt to do so, but our apples and most other fruit trees, which may chiefly be imputed to the negligence and unskillfulness of the gardner. Our cherries are ripe a month sooner than in Virginia."

\section{CHERRIES IN THE MIDDLE WEST}

At a surprisingly early date the cherry, with the apple, peach, pear and plum, was being grown far inland in the New World. Southeastern Michigan was settled in I 701 at Detroit and within a half-century settlements had been made at Vincennes, Indiana; Kaskaskia and Cahokia, Illinois; and at Saint Louis and several other points in Missouri. The orchards and gardens of the early French settlers in these states live in the traditions of all the settlements; but much more substantial evidence was to be found a century ago, and in the case of the apple and pear may still be found, in the venerable trees of all the tree-fruit in and about these old French posts. "The homes of these pioneers," so good an authority as Parkman tells us, "were generally placed in gardens surrounded by fruit trees of apples, pears, cherries and peaches." Were proof lacking of these early plantations, it might be assumed that people so fond of horticulture as the French would not long be unmindful of the value to themselves and their posterity of plantations of fruit trees.

\section{CHERRIES ON THE PACIFIC COAST}

The history of the cherry in America is not complete without some mention of its introduction, culture and the development of new varieties on the Pacific coast. Indeed, it is not too much to say that at no time nor at any place in its whole history has the cherry made greater advancement than during the last half-century in Oregon, California and Washington - naming the states in order of their contribution to cherry culture.

\footnotetext{
${ }^{1}$ Beverley History of Virginia p. 260.

${ }^{2}$ Glover Philo. Trans. Royal Soc. 1676-1678, vols. XI-XII, p. 628.

${ }^{3}$ Lawson History of Carolina 183. 1714. (Reprint of 1860.)
} 
At about the time the colonies were beginning their struggle with the mother country for independence, Franciscan monks were establishing missions in California. To these they brought seeds of fruits, grains, flowers and vegetables, as several historians of the missions tell us, and as the trees found by Americans a few decades later make certain as regards fruits. It is probable that by the close of the Revolutionary war all subtropical and temperate fruits of Europe were to be found cultivated in the missions of California. Among these, in an enumeration of the products of the missions, the cherry is listed by E. S. Capson. ${ }^{1}$ From its introduction at approximately the close of the Eighteenth Century, the cherry continued to be cultivated, at times more or less sparsely to be sure, until, by conquest in the war with Mexico, California passed into the possession of the United States. A new era in horticulture began in California soon after the influx of gold-seekers in 1849 , some of whom, noting the opportunities of fruit-growing, at once began the importation of seeds and plants.

Modern fruit-growing on the Pacific Coast, however, began in Oregon. The California Argonauts of ' 49 were much too busily engaged in digging gold to think of getting it indirectly by tilling the soil, whereas the men who were then crossing the plains from Missouri or sailing around the Horn from New England to Oregon were home-makers and true tillers of the soil. These early Oregonians were the forerunners in the zeal and enterprise which have made horticulture on this coast the marvel of modern agriculture. But one of the several early horticulturists of Oregon can be mentioned here, he deserving special mention by virtue of his work with cherries.

Until 1847 the few cultivated fruits to be found in Oregon were seedlings mostly grown by employees of the Hudson Bay Fur Company. In that year there was a notable importation of cultivated fruits across the plains - a venture which quickly proved pregnant with results in fruit harvests which have not ceased and give promise long to continue. Henderson Lewelling crossed the plains from Henry County, Iowa, and brought with him a choice selection of grafted fruits. These he transported in boxes of soil which he hauled in a wagon drawn by oxen. Arriving in Oregon late in the fall of 1847 he found that he had 300 trees alive which he planted at what is now Milwaukee, a few miles south of Portland on the east side of the Willamette River. Later, seeds were brought for

${ }^{1}$ History of California II I. $\mathbf{1 8 5 4 .}$ 
stocks, though for the cherry the wild species, Prunus emarginata and Prunus virginiana, were used and very successfully, until Mazzard and Mahaleb seeds could be obtained. In this travelling nursery, Lewelling brought to Oregon cherries of the Bigarreau, the English Morello and probably of several other types. The label of one of the cherries was lost and this unknown was renamed Royal Ann. Unfortunately, it was one of the best known of all cherries that for the time being lost its identity the Napoleon, which probably has been cultivated for three centuries and since I 820 has borne the name of the great General. With dogged perseverance the West Coast fruit-growers continue the name "Royal Ann " to the great confusion of systematic pomology.

But of chief import to cherry culture were the subsequent operations in the Lewelling nursery at Milwaukee. Lacking proper stocks, Seth Lewelling, who had succeeded Henderson in the nursery business, grew a great many cherries from seeds. From these he afterward selected and disseminated varieties that have made Oregon famous not only for what are probably the finest sweet cherries in the world but for a long list of new and desirable varieties - as Republican, Lincoln, Willamette Seedling and Bing. We call to mind no greater success in bringing into being new fruits from a few lots of seedlings than in the case of Lewelling and his cherries. Lewelling's work stimulated others to breed cherries and among many seedlings that have since been named in the Northwest the Lambert and Oregon are well worthy of mention.

The facts of time and place in the beginning of cherry culture which we have tried to set forth in this chapter have, we think, some historical and narrative interest. Yet, the main value of the facts are not in history and story. Rather, at least so we hope they will be interpreted, these brief records show what the crude material was out of which our present cultivated cherry flora has been developed; what the steps were in the domestication and development of the cherry; what economic purposes they have served; and who the peoples are and what the methods were in bringing the cherry to its present state of development. In a word, I the chapter will not have served the purpose for which it is mainly intended if it does not furnish facts and inspirations toward the further evolution of the cherry. 


\section{CHAPTER III}

\section{CHERRY CULTURE}

The magnitude of the cherry industry in the United States is not generally appreciated. This is because cherries are very largely grown in small home plantations and the product is either consumed at home and in local markets, or is sent to canning factories and is therefore disposed of without the display attending the production and marketing of fruits sold in the general market. The following figures from the last census show the importance of the industry. There were in 1909, according to the census taken in 1910, 11,822,044 bearing cherry trees in the United States and $5,621,660$ trees not of bearing age. The bearing trees bore 4,126,099 bushels of fruit valued at $\$ 7,231,160$. When this, the thirteenth census, was taken the cherry ranked fifth in commercial value among orchard fruits, being surpassed in the order named by the apple, peach, plum and pear.

The yield of fruit was 43.6 per centum greater in 1909 than in 1899 . This high percentage of increase has been brought about in several ways. The recent development of rapid transportation, refrigerator service and of marketing facilities has greatly stimulated the culture of this as of all other fruits in the United States. An increased demand for canned and preserved cherries has sprung up so that cherries are much more used now than formerly, the trade in preserved cherries for confections and various drinks in particular having greatly increased. Lastly, better care of orchards and better means of combating insects and fungi have increased the yields during the last decade.

Cherries are grown in greater or less quantities in every state in the Union but commercially the industry is confined to a few states having especial advantages in climate, soil and markets. In but six states, according to the last census, was the value of the cherry crop more than a halfmillion dollars, the states being: California \$951,654, Pennsylvania \$909,975, Ohio $\$ 657,406$, Michigan $\$ 590,829$, New York $\$ 5+4,508$, Indiana $\$ 508,516$. In New York in particular, recent plantings of this fruit have been so great that at this writing, July, I9I4, the figures given for this State could be increased by a quarter at the very least, and no doubt they could be largely increased also for California and Michigan. The great growth of the canning industry is most largely responsible for the large plantings of cherries in recent years in regions especially suited to this fruit. 
In the several states named, the cherry industry is further localized. Thus, in the 6I counties in New York, the cherry is grown largely in but I2, the number of trees in each of these being: Columbia 78,526, Niagara 61,786, Monroe 49,831, Ontario 36,394, Wayne 35,385, Erie 29,483, Onondaga 25,932, Seneca 27,063, Chautauqua 24,483 , Steuben 15,412 , Orleans $I_{4}, 682$ and Cayuga 14,319 . If the figures just given, the total number being 413,296 , are compared with the number of trees in the State, 674,000 , it will be seen that the industry is quite localized, two-thirds of the cherries being grown in 12 of the 61 counties, though the fact is brought out in the census that cherries are grown on 59,408 farms in New York, showing that this fruit is much grown for home use. Further figures of interest as regards New York are that the cherry crop in 1909 amounted to 271,597 bushels which sold for $\$ 544,508$. The plantings in the State cover in the neighborhood of 9,500 acres.

A canvass of the leading cherry-growers and nurserymen in the United States shows that, in all parts of the country excepting California, Oregon and Washington, Sour Cherries are much more commonly grown than Sweet Cherries. In New York at least 90 per cent of the cherry trees are of sour varieties and this proportion will hold for the region east of the Rockies. The leading commercial varieties of Sour Cherries, in order named, are Montmorency, Early Richmond and English Morello. No other variety is nearly as commonly grown as is even the least well known of these three. No one of the Duke cherries is mentioned as of commercial importance, but May Duke, Late Duke and Reine Hortense are frequently grown in home plantations.

Growers of Sweet Cherries are not nearly as closely in accord as to the best varieties as are those who grow sour sorts. The most popular Sweet Cherries in the East seem to be Windsor, Black Tartarian, Napoleon and Wood with a very insistent statement of the few who have tried it that Schmidt is better than any of these for the market. On the Pacific Coast honors go to Napoleon, which the Westerners continue to call Royal Ann despite the fact that it has been cultivated for three centuries and had been called Napoleon for nearly a half-century before Lewelling took it to Oregon in 1847 . Other popular sorts on the Pacific seaboard are Bing, Lambert and Republican - all western productions.

Rather more important than the information obtained from growers of cherry trees as to varieties was that as to the stocks on which cherries 
are grown in America. This brings us to a discussion of the whole subject of stocks for cherries.

\section{STOCKS FOR CHERRIES}

Cherries have been grown in America for over 200 years and for 50 years the crop has been important commercially. Yet despite the extent and the importance of the industry and the years it has been in existence, curiously enough so fundamental a question as the best stock upon which to grow cherries has not yet been settled; indeed, though cherries behave markedly different on the several stocks, interest as to which is the best seems but recently to have been aroused. Now there is a rather warm controversy as to which is the better of the two leading stocks, the Mazzard or the Mahaleb.

Fruit-growers on one side hold that the Mazzard is the best stock for all orchard varieties of this fruit while nurserymen controvert this view and say that the Mahaleb is at least a fit stock for sweet sorts and is the best one for Sour Cherries, and, moreover, that it is now impossible to grow cherries on Mazzard roots at prices that fruit-growers are willing to pay. Since no systematic attempts seem to have been made to determine the peculiarities and values of these two and other cherry stocks both sides dispute without many facts. Meanwhile, a fine crop of misunderstandings has grown up about the whole matter of cherry stocks. It is worth while to attempt to clear up some of the misunderstandings. The first step toward this end is to describe and give the botanical and horticultural relationships of the Mazzard and Mahaleb cherries to orchard cherries.

The Mazzard, as we have seen, is a common name, of uncertain origin, of the wild Sweet Cherry, Prunus avium, from which has come all cultivated Sweet Cherries. It is important to recall that the trees of the Mazzard reach a height of thirty or forty feet and the trunk often attains a diameter of eighteen or twenty inches. Other characters to be kept in mind are that the Mazzard lacks hardiness to cold but grows vigorously and is usually healthy, though susceptible to several fungi, one of which, the shot-hole fungus, Cylindrosporium padi, makes it a most difficult plant to grow in the nursery. Trees and fruit coming from the Mazzard used as a stock are very uniform, a fact easy to ascertain in New York where this stock has been largely used for nearly a century. The Mazzard is almost always grown from seed for stocks though suckers are occasionally useda poor practice. 
The Mazzard, or at least the Sweet Cherry, has probably been more or less used as a stock since the earliest cultivation of this fruit. The Greeks and Romans practiced budding and grafting centuries before Christ's time and when the cherry came to them as a domesticated fruit, at least three or four centuries before Christ, they undoubtedly made use of budding and grafting ${ }^{1}$ to maintain varieties and in the case of the Sour Cherry, if they had it, and they probably did, to avoid the suckers that spring from the roots of the trees. The literature of fruit-growing is scant and fragmentary during the Middle Ages but beginning with the herbals in the Sixteenth and Seventeenth Centuries there are many treatises on fruits and botany and in several of these the use of the wild Sweet Cherry, the Mazzard, is mentioned. ${ }^{2}$

In America the Mazzard as a stock probably came into use soon after the establishment of Prince's nursery at Flushing, Long Island, about I 730, budding and grafting seeming to have been little practiced in the New World before the founding of this nursery. ${ }^{3}$ The use of the Mazzard as a stock is mentioned probably for the first in Coxe's Fruit Trees, ${ }^{4}$ the

1 Varro (B. C. $117^{-27}$ ), as we have seen on page 47 , tells when to graft cherries and discusses the process as if grafting cherries were a common operation.

2 In The Country-Man's New Art of Planting and Grafting, written by Leonard Mascall, 1652, the writer says, "Sower Cherries . . . will grow of stones, but better it shall be to take of the small Cions which do come from the roots; then plant them.

"Ye must have respect unto the Healme Cherry, [a sweet cherry of the time] which is graft on the wild Gomire [Mazzard] which is another kind of great Cherry, and whether you do prune them or not, it is not materiall; for they dure a long time."

R. A. Austen, in his Treatise of Fruit Trees, 1653, writes, "Concerning Stocks fit for Cherry-trees, $I$ account the black Cherry stock (Mazzard) the best to graft any kind of Cherry upon. Yet some say the red Cherry stock is best for May-Cherries. But the black Cherry stocks are goodly straight Plants full of sap and become greater trees than the red Cherry trees."

John Reid, The Scots Gard'ner, I683, writes, "Dwarfe Cherries on the Morella, or on the common Red Cherrie. Or on that Red geen which is more Dwarffish than the black."

John Lawrence, The Clergyman's Recreation, 1714 , declared that, "Black Cherries (Mazzard) are the only Stocks, whereon to raise all, the several sorts of Cherries."

3 "The practice of grafting and inoculating in America is but of modern date. It was introduced by Mr. Prince, a native of New York, who erected a Nursery in its neighborhood about forty years ago. But since the late American revolution, others have been instituted in this and some other parts of the United States. Mr. Livingston has lately established one, not far from the city of New York, which can vie with some of the most celebrated ones in Europe. May he, and others, who have undertaken in that useful branch of business, meet with encouragement and success. Nothing in the extensive field of Horticulture can afford more agreeable amusement or yield more solid satisfaction and advantage." Forsyth on Fruit Trees, Albany, N. Y., I803:278.

4" The cherry is propagated by budding and ingrafting - from its disposition to throw out gum from wounds in the vessels of the bark, the former mode is most generally adopted. The heart cherries do not succeed well on any but the black Mazard stocks, but round or duke cherries do as well on Morello 


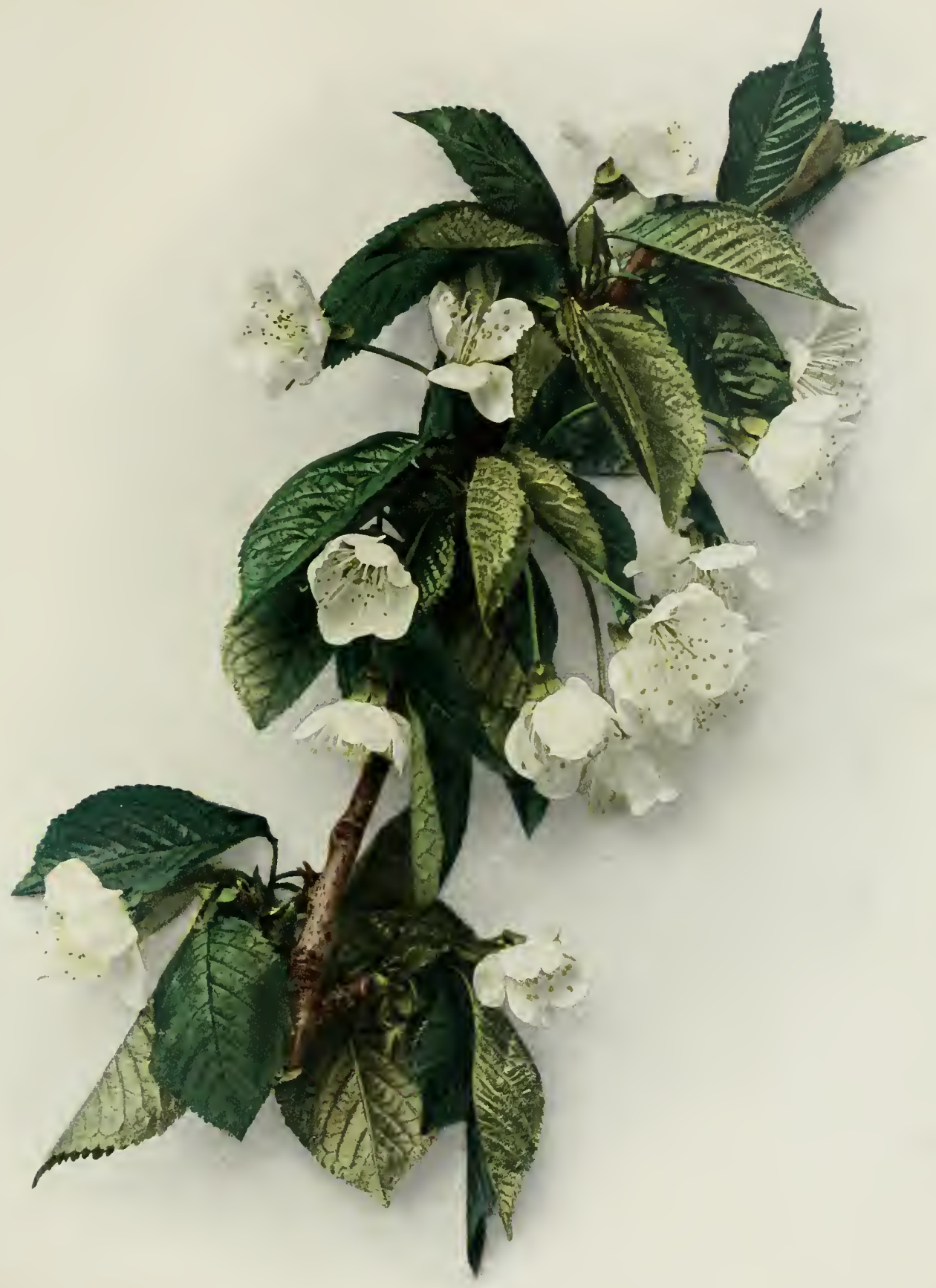



second American treatise on fruits, published in 1817 , and again in Thacher's American Orchardist, published in $1822 .^{1}$ Both authors, as the footnotes show, speak of the use of this stock as if it were in common use in American nurseries. Neither mentions the Mahaleb.

The Mahaleb, Prunus mahaleb, it will be remembered from the description previously given, is a bush or bush-like cherry, sometimes but not often attaining the height and port of a tree. The top is thick, with rather slender ramifying branches bearing small, green, smooth, glossy leaves, which resemble those of the apricot more than they do the leaves of either species of orchard cherries. The fruits are at first green, then yellowish, turning to red and at full maturity are shining, black and so hard, bitter and astringent as to be scarcely edible. This brief description of Prunus mahaleb shows that it is quite distinct from either our commonly cultivated Sweet Cherry, Prunus avium, or the Sour Cherry, Prunus cerasus, differing from either much more than the two edible species differ from each other. It is quite as far removed from the Sweet or the Sour Cherry botanically as the apple is from the pear, the quince, or the thorn and if anything more distantly related than orchard cherries are to plums. One would expect the wood structure of the Mahaleb to differ from that of Sweet or Sour Cherries very materially and that even if the union proved in budding or grafting wholly normal that there would be some difficulty in the proper passage of nutritive solutions between stock and cion. This cherry, as we have seen, is propagated almost entirely from seed though it may easily be grown from layers, cuttings and suckers. The American supply of Mahaleb stock comes from France.

The Mahaleb seems to have come into use as a stock for other cherries

stocks, which are often preferred from their being less liable to the cracks in the bark, from frost and sun on the south-west side; this injury may be almost effectually prevented by planting on the east side of board fences or buildings, or by fixing an upright board on the south-west side of each tree in open situations.

"The best stocks are raised from stones planted in the nursery. Stocks raised from suckers of old trees, will always generate suckers, which are injurious and very troublesome in gardens: diseases of old or worn out varieties, are likewise perpetuated by the use of suckers for stocks." Coxe Fruit Trees 1817:253.

1 "The cultivated cherry, when reared from the seed, is much disposed to deviate from the variety of the original fruit, and, of course, they are propagated by budding or grafting on cherry stocks: budding is most generally preferred, as the tree is less apt to suffer from oozing of the gum than when grafted. The stocks are obtained by planting the seeds in a nursery, and the seedlings are afterwards transplanted. Those kinds which are called heart cherries are said to succeed best on the black mazard stock; but for the round kind, the Morello stocks are preferred, on account of their being the least subject to worms, or to cracks in the bark, from frost and heat of the sun." Thacher American Orchardist 1822:2I 2. 
in France having been first mentioned for this purpose by Duhamel du Monceau in his Traite des Arbres Fruitiers in $1768 .^{1}$

Miller in his Gardener's Dictionary, I 75t, describes the Mahaleb cherry and says it was "Cultivated in 1714 by the Duchess of Beaufort." This seems to be the first mention of its culture in England though Gerarde in The Herball or Generall IIistorie of Plantes describes it. Neither mentions its use as a stock. In fact, it seems not to have been mentioned as a stock in England until I824 when Loudon in the Encyclopedia of Gardening speaks of it as "the most effectual dwarfing stock." ${ }_{2}$

It was not until after the middle of the Nineteenth Century that the Mahaleb came into use in America, none of the horticultural writers in the first half of the last century, as Cobbett, I803; McMahon, I806; Coxe, 1817; Thacher, I822; Prince, I828; Kenrick, 1833; Manning, I838; Thomas, I 846 ; Floy, I 846, nor Cole, I 849 , having mentioned the Mahaleb though nearly all speak of the Mazzard as the stock upon which cherries are budded. Downing, in 1845 , makes first mention of the Mahaleb as a stock in the New World; ${ }^{3}$ Thomas in his second edition, $185 \mathrm{I}$, recommends it as a stock to dwarf cherries; ${ }^{4}$ Barry, 1852 , says that Mahaleb stock is imported from Europe; ${ }^{5}$ while Elliott, in 1854 , also speaks of it as

1 "So the good species and their varieties are perpetuated and multiplied by grafting upon the Merisier, upon the Cerisier with round fruit, and upon the Cerisier de Sainte-Lucie [Mahaleb]. All the Cerisiers succeed well upon the Nerisier and it is the only subject which is suited to the high-headed trees. It has the advantage of not sending forth any or very few suckers. The Cerisier de Sainte-Lucie has the same advantage. It receives very well the graft of all species of cherries and adapts itself to the worst soils." Duhamel Traite des Arbres Fruitiers 1:197. 1768.

2 "Varieties of the cherry are continued by grafting or budding on stocks of the black or wild red cherries, which are strong shooters, and of a longer duration than any of the garden kinds. Some graft on the Morello for the purpose of dwarfing the tree, and rendering it more prolific; but the most effectual dwarfing stock is the mahaleb, which, however, will not succeed in the generality of soils in Britain. Dubreuil of Rouen recommends the wild cherry for clayey and light soils, and the mahaleb for soils of a light, sandy or chalky nature. The stones of the cultivated cherry are commonly, but improperly, substituted for those of the wild sort, as being more easily procured." Loudon Enc. of Gard. 1824:924.

3 "When dwarf trees are required, the Morello seedlings are used as stocks; or when very dwarf trees are wished the Perfumed Cherry, (Cerasus Nahaleb) is employed; but as standards are almost universally preferred, these are seldom seen here. Dwarfs in the nursery must be headed back the second year, in order to form lateral shoots near the ground." Downing Fruit Trees of America 1845: 164.

4 " The stocks used for this purpose (to dwarf cherries) are the "Perfumed Cherry" or Prunus Mahaleb, which also possesses the advantage of flourishing on heavy clay ground. The grafts will usually grow quite vigorously for two or three seasons, but they soon form dwarf, prolific bushes." Thomas Am. Fruit Cult. 1849:351.

5 " The principal stocks used for the cherry are the mazard for standard orchard trees, and the mahaleb for garden pyramids and dwarfs.

"The Mahaleb (Cerasus mahaleb) is a small tree with glossy, deep green foliage. The fruit is black, 


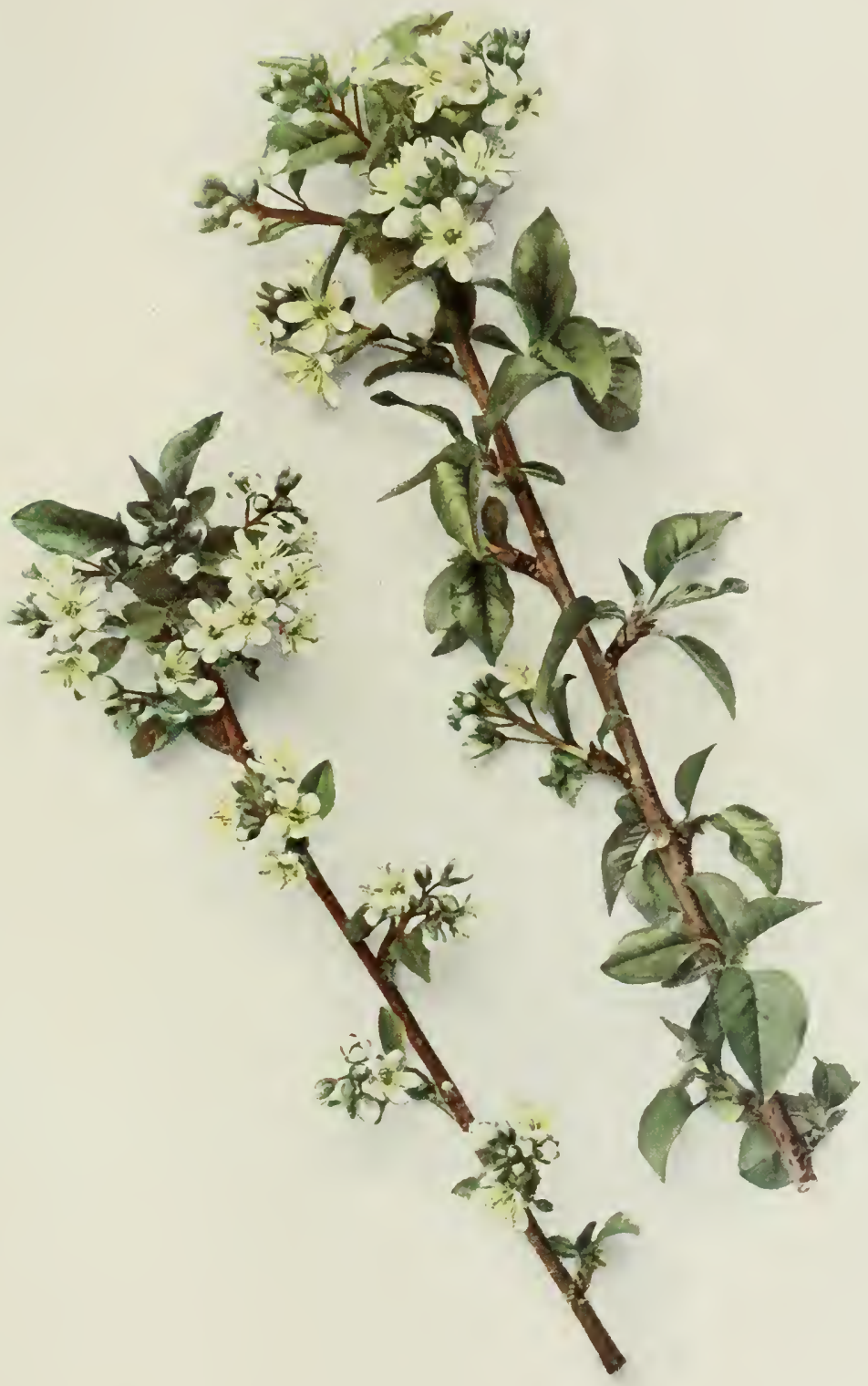



a dwarfing stock. ${ }^{1}$ From this date on the Mahaleb is mentioned in all American works on pomo ogy in which stocks for cherries are discussed.

Pains have been taken to show the exact date the Mahaleb began to be used as a stock in America. The quotations show that this was about I850. They show, too, that at first and for a long time its only use was as a dwarfing stock. But now the Mahaleb has almost wholly superseded the Mazzard as a stock for all Sweet and Sour Cherries. Not many cherries were propagated on the new stock until after 1860 when its use, if we may judge from the accounts of fruit-growing, began to be general and it grew so rapidly in favor that by $\mathbf{I} 880$ it was more popular than the Mazzard and in another decade had almost wholly taken the place of the latter. Probably 95 per centum of the cherries grown in this country are budded on the Mahaleb. Why has the Mahaleb supplanted the Mazzard? This is the question that immediately comes to mind and to the discussion of which we proceed.

There is no question but that it is much easier to grow cherry trees on Mahaleb stock in the nursery than on Mazzard and that usually a better looking tree can be delivered to the fruit-grower on the first-named stock. Seedlings of both stocks are imported from Europe and those of the Mahaleb are usually cheaper. These reasons are sufficient for the exclusive use of Mahaleb by nurserymen, and, were it certain that the Mahaleb is the best stock for the fruit-grower, all hands might forthwith renounce the Mazzard. In what respects is it easier to grow cherries on the Mahaleb in the nursery than on the Mazzard?

All know that the Sweet Cherry is a little difficult to grow - is capricious as to soils, climates, cultivation and pruning, and as to diseases and insects. The Mazzard now used for stocks has the faults of the species to which it belongs. The Mahaleb, on the other hand, is adapted to a greater diversity of soils; is hardier to either heat or cold; less particular about cultivation; will stand more cutting in the nursery if pruning be necessary; is less susceptible to aphids which in many parts of the United

\footnotetext{
about the size of a marrow-fat pea, and quite bitter. It blossoms and bears fruit when about three years old. It is considerably cultivated in many parts of Europe, as an ornamental lawn tree. There are very few bearing trees in this country yet; consequently nearly all the stocks used are imported, or grown from imported seeds." Barry The Fruit Garden 1851:115, I17.

1 "Dwarf Trees.-Are produced by propagating the Sweet or Duke varieties on the Mahaleb, or Morello roots. They should in all cases be worked just at the crown of the root, as it is there a union is best formed; and also, by means of pruning, (see page 30 ) they should be made to form heads branching immediately from the ground." Elliott $\mathrm{Fr}$. Book $1854: 185$.
} 
States trouble cherries in the nursery row; and, more to the point than all else, in New York at least, is not nearly as badly infested with the shothole fungus, Cylindrosporium padi, which often ruins plantations of Mazzard stock. Mahaleb stock, too, is more easily "worked" than the Mazzard both in the actual work of budding and in having a longer season for this nursery operation. Cherries on Mahaleb ripen their wood earlier than those on Mazzard and may thus be dug earlier in the fall.

Nurserymen and fruit-growers alike agree to this statement of the superior merits of the Mahaleb as a nursery plant. The facts set forth are matters of common observation - so well known that it is not necessary to verify them experimentally. A half-century of experience in America on many soils, in many climates and under widely varied conditions has demonstrated that it is easier to grow cherries in the nursery on the Mahaleb than on the Mazzard stock.

From experience in the orchard, fruit-growers have established several facts as to the relative value of Mazzard and Mahaleb stocks from their standpoint. These are:

I. Cherries on Mahaleb are hardier to cold than those on Mazzard stocks. This hardiness is due, in part at least, to the fact that cherry wood on Mahaleb ripens sooner than on Mazzard. This superior hardiness of the Mahaleb is evident in the nursery-row as well as in the orchard and is a matter of great importance in northern nursery regions. In this connection it should be said that the Mahaleb is not as hardy as might be wished and that there are, as we shall later show, still hardier stocks.

2. There is no question but that the Mahaleb is a dwarfing stock. It came into use and in Europe continues to serve almost the sole purpose of dwarfing varieties worked upon it. This retarding effect is not fully realized by American cherry-growers because for the first few years the diminution in size is not apparent and even at the close of a decade the difference in size is not as marked as it would be between standard and dwarf apples or pears of the same age.

3. Cherry-growers who have tried both stocks agree that most varieties come in bearing earlier on Mahaleb than on Mazzard stocks. From the known effects of dwarfing on other fruit trees this would be expected.

4. The size of the cherries is the same on trees grown on the two stocks. The claim is made that apples and pears are a little larger on dwarf trees and that when peaches and plums are dwarfed the fruit is 


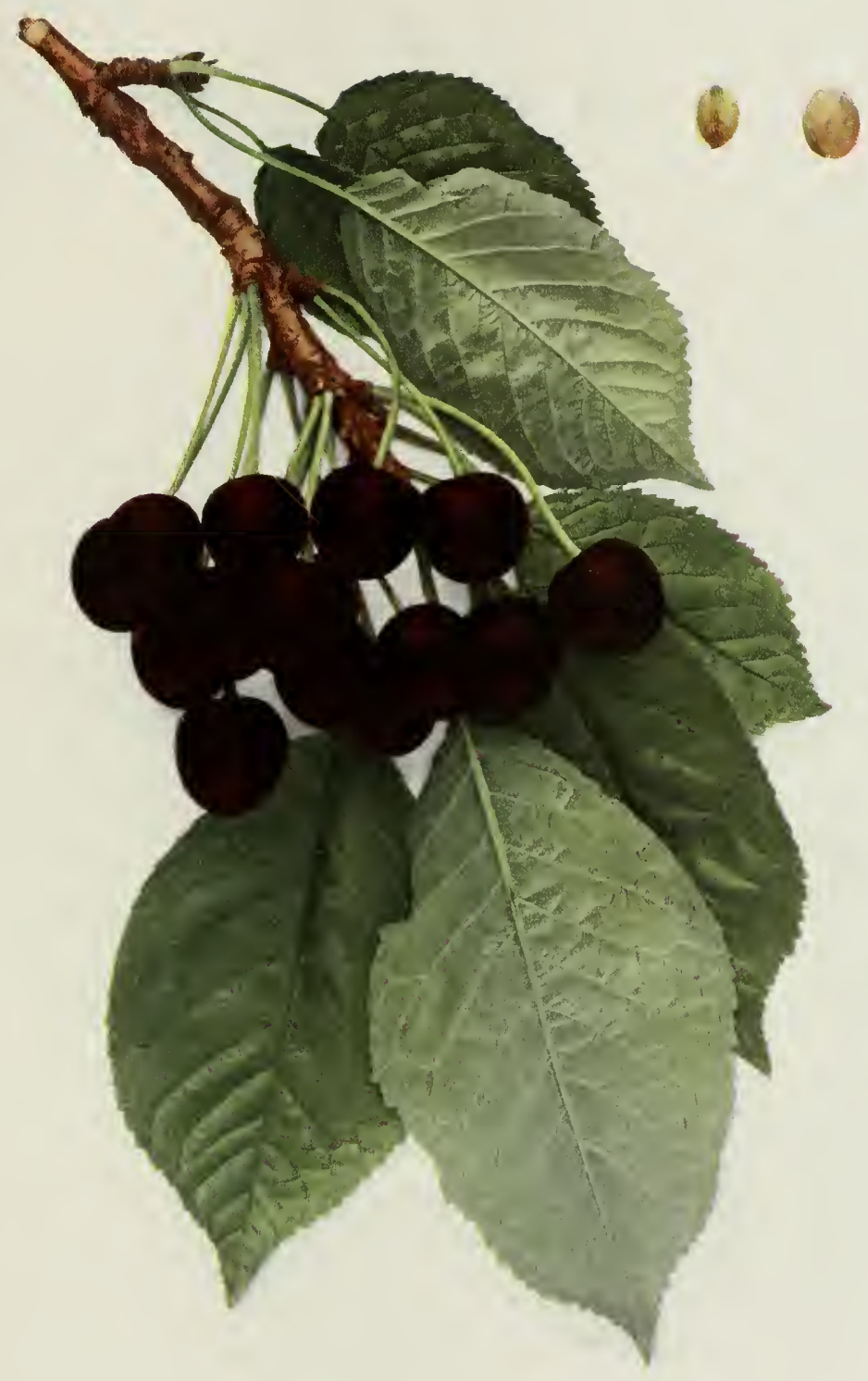

PIINTS IYIY (MAZZARD) 

smaller. No one seems to have seen or to have thought that there are differences in the size of cherries grown on Mazzard or Mahaleb stock.

5. Better unions are made with Mazzard than with the Mahaleb. This would be expected because of the close relationship of the Mazzard to orchard cherries.

6. The Mahaleb is probably the more cosmopolitan stock - will thrive on a greater diversity of soils than the Mazzard stock. In particular it is somewhat better adapted to sandy, light, stony, and arid soils that are not well adapted to growing cherries. Its root system is much nearer the surface of the ground and it is, therefore, better adapted to shallow soils than the Mazzard.

7. Though the evidence is somewhat conflicting on this point it is probable that cherries on Mazzard live longer than on Mahaleb. It may be that the frequent statements to this effect arise from the knowledge that dwarf fruit-trees are generally shorter lived than standard trees since there seem to be no records of actual comparisons.

8. Lastly, in climates where the cherry can be grown with reasonable certainty and in soils to which this fruit is adapted, varieties on Mazzard are more productive and profitable than on the Mahaleb stock. This seems to be the concensus of opinion among growers in the great cherry regions of California, Oregon, Washington, Michigan and New York.

Several other stocks have been more or less successfully used for cherries and a great number have never been tried that might make good stocks. In a country as diversified as ours and in a state as variable in soil and climate as New York and with the manifold varieties of Sweet and Sour Cherries, it is almost certain that under some conditions there are stocks more desirable than either Mazzard or Mahaleb. The resources of the cherry-grower in this direction are so great that in this account we can but briefly outline them, describing but a few of the many stocks that might be used.

In the colder parts of New York and of the United States, undoubtedly seedlings of Russian cherries would make hardy and in most other respects very desirable stocks. These Russian cherries, too, as a rule, come nearly or quite true to seed, making very good orchard plants on their own roots. Some of them, if not most of them, sprout rather badly - not so serious a fault as one might think, especially in a cultivated orchard. For budding over to other varieties only sour sorts should be used, taking for trial such varieties as Bessarabian, Brusseler Braune, Double Natte, George Glass, 
Lutovka, Early Morello, Ostheim and Vladimir. Probably most of these would dwarf standard varieties more or less but in no case is it to be supposed that they would have the dwarfing effect of Mahaleb. In the North Mississippi Valley some of these, especially of the Ostheim or Morello type, have been very successfully used as stocks.

The small, wild, red cherry locally known as the Bird, Pin and as the Pigeon Cherry, Prunus pennsylvanica, found from the Atlantic to the eastern slopes of the Coast Range on the Pacific in northern United States and southern Canada, is often used as a hardy stock. The writer has seen it so used in northern Michigan but from his observation can recommend it only for cold regions and as a makeshift since it dwarfs standard varieties and usually suckers badly. W. T. Macoun, Ottawa, Canada, Dominion Horticulturist, states that this stock is commonly used in the colder parts of Canada and with good results. This cherry is not as distantly related to orchard varieties as the Mahaleb and unites with Sour Cherries at least as readily as does the Mahaleb.

In the West and Northwest the Sand Cherry, Prumus pumila, is used very successfully in cold, dry regions as a stock for Sour Cherries. The following is a very good account of its behavior from the pen of the late Professor J. L. Budd, a pioneer cherry grower in the Middle West. ${ }^{1}$

"Those who have seen acres of the Sandy Cherry in the northwest loaded with fruit have not been ready to believe it a good stock for the cherry on account of its sprawling bushy habits of growth. But those who have watched its growth when young under culture on rich soil can comprehend the fact that it is as easy to work as the Mahaleb. As with the Mahaleb the seedlings grown in seed bed will be large enough to set in nursery row the next spring, and of good size for August budding. To illustrate its rapidity and uprightness of growth I will state that we rooted a few cuttings in plant house last winter. When set in nursery they had made a show of growth of from two to four inches, yet at budding time, the middle of August, they were fully as large, stocky and upright as the Mahalebs, and in all respects in as perfect condition for budding.

"This hardiest of all cherries is very closely related to our garden cherries, so nearly indeed that our botanists long ago decided that valuable crosses on it might be made.

"As yet its use for stocks is somewhat experimental, but we can say positively that it united well with our hardy sorts in budding, and it does not dwarf the sorts worked upon it to a greater extent during the first five years of growth than does the Mahaleb."

\footnotetext{
${ }^{1}$ Iow'a Sta. Bul. 10:425. 1890.
} 


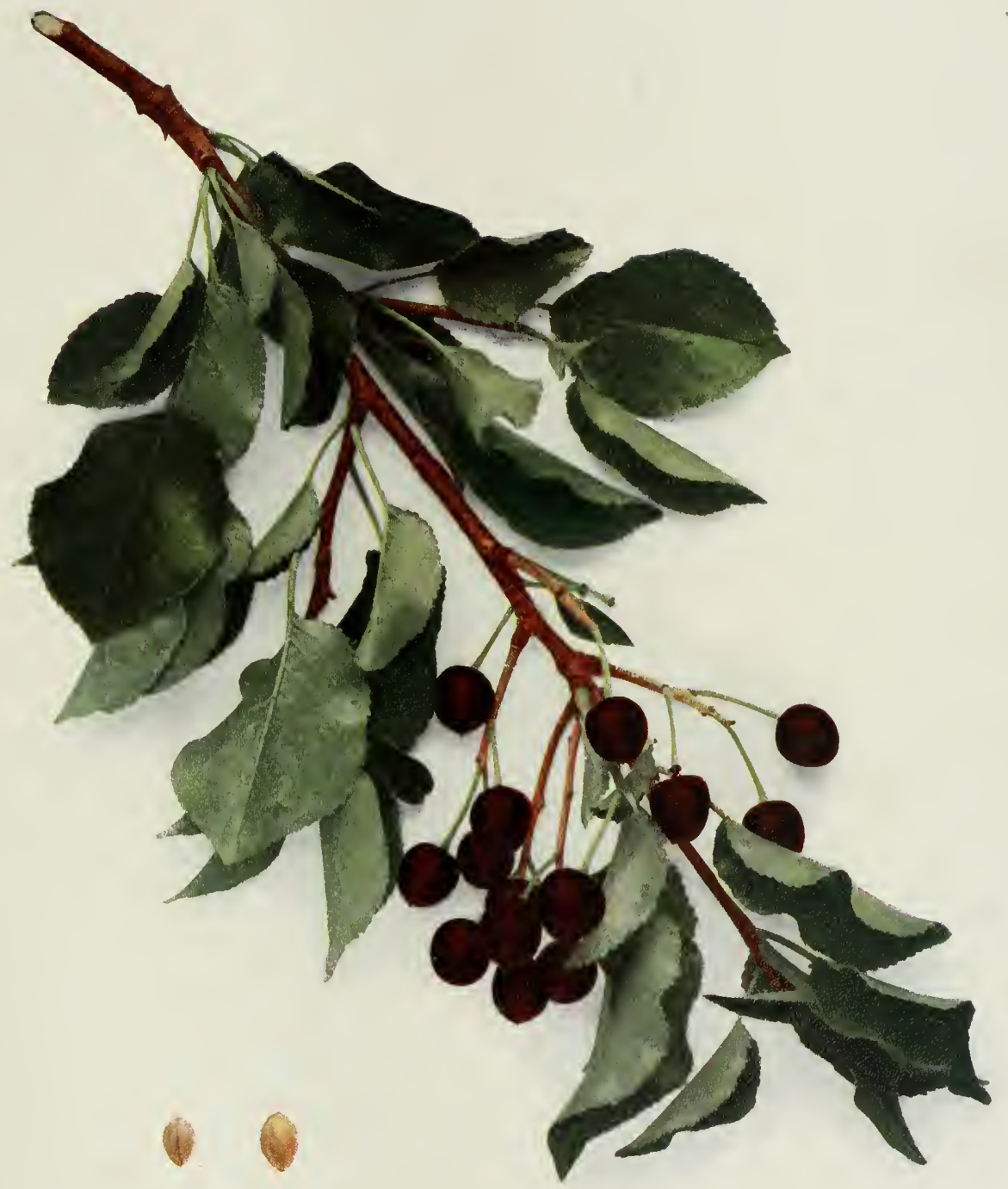



There are records of the Choke Cherry, Prunus virginiana, ${ }^{1}$ and of the Rum, or wild Black Cherry, Prunus serotina, having been used as stocks but these long-bunch, or racemose, cherries are so distantly related to the short-bunch, or fascicled, orchard cherries that it would seem that their use would be desirable only under great stress.

In Japan a horticultural variety of Prumus pseudocerasus is used as a stock. Of this cherry for this purpose, Professor Yugo Hoshino of the Tohoku Imperial University at Sapporo, Japan, writes as follows:

"You wish to know about the cherry stocks used in this country. It is very rare to use our common wild cherry as a stock for European cherries. In Hokkaido (Yozo Island), we commonly use the seedlings of European Sweet and Sour Cherries as stocks. But in the northern part of Japan proper (Main Island), it is a common practice to graft European cherries on a special kind of our cherry. This cherry has particular characters which fit it for propagation; namely, it roots very easily either from cuttings or by layering (mound). Its botanical position is not certain, but it is probable that it is a cultural variety of Pseudocerasus, especially bred for stock purposes. It is grown by nurserymen only and called DaiSakura. (Dai means stock: Sakura means cherry.) It has a somewhat dwarfing influence on cions and hastens their fruiting age."

This stock ought to be tried in America if, indeed, it is not already under cultivation from introductions made by the United States Department of Agriculture.

These are but a few of many cherries that have been or might be tried as stocks for orchard varieties. There are many species of cherries more closely related to the cultivated edible sorts than the Mahaleb. Many of the cherries from Asia, not now known to growers, will eventually find their way to America; a few have already been introduced by the United States Department of Agriculture; some of them can undoubtedly be used as stocks and from them we may hope to find a better stock than either the Mazzard or Mahaleb.

Cherries are now grown almost wholly as budded trees but they can be more or less readily root-grafted, depending upon the variety. Under some circumstances it might be profitable to propagate them by grafting. Usually it is necessary to use a whole root and to graft at the crown of the stock. Budd recommends this practice for Iowa, using Mazzard stock

1 Prunus virginiana was used as a stock in Oregon in 1850 as there were no other stocks available. The union was very good but the stock was condemned because of suckering. Seth Lewelling $N$. W. Horticulturist Nov. I 887 . 
but with the expectation that the cion will take root and eventually the tree will stand on its own roots. ${ }^{1}$ We cannot believe, however, that grafting can ever take the place of budding as a nursery practice or that it can be profitably used except in very exceptional cases.

Buds in propagating are usually taken from nursery stock, a practice of decades, and there is no wearing out of varieties. Old varieties have lost none of the characters accredited to them a century, or several centuries, ago by pomological writers. Nor does it seem to matter, in respect to trueness to type, whether the buds be taken from a vigorous, young stripling, a mature tree in the hey-day of life or some struggling, lichen-covered ancient - all alike reproduce the variety. The hypothesis that fruit-trees degenerate or, on the other hand, that they may be improved by bud-selection, finds no substantiation in this fruit. There seems to be no limit to the number of times its varieties can be propagated true to type from buds.

\section{CHERRY CLIMATES AND CHERRY SOILS}

Climate and soil have been the chief determinants of location for cherry-growing in New York. Both Sweet Cherries and Sour Cherries are profoundly influenced by the natural environment in which they are grown - Sweet Cherries rather more so than any other fruit, either climate or soil dictating whether they may or may not be grown.

The Sour Cherry is at home in a great variety of climates, the vagaries of weather affecting it but little. It is probably the hardiest to cold, in some of its varieties at least, of all our tree fruits, thriving almost to the Arctic Circle and from there southward, in some of its forms, quite to the limits of the Temperate Zone. The blossoming season is relatively late so that fruit-setting is seldom prevented by spring frosts. Yet, even with this hardy fruit, it is necessary to take thought of heat and cold in growing commercial crops; for spring frosts may wither the bloom or

1 " I will here say that one year with another we succeed as well in grafting on Mazzard roots as we do with pear on pear roots, and nearly as well as with apple on apple roots. In some cases since the appearance of the graft-box fungus our success has been more complete with the cherry than with the apple. This success is due to careful compliance with two main guiding rules, founded on the nature of cherry wood: (1) Keep the scions dry until used. If given an opportunity they will absorb water cnough to start the buds and form a callus at the base. In this condition they will fail to unite with the root. (2) After grafting, pack in boxes with sand or moss and store in a root cave, kept uniformly cool by opening at night and keeping closed during the day. If the buds start prior to the time of planting in nursery they will usually fail to grow. It may prove useful to add, that the sprouts from deeply set trces on Mazzard root will always be true to the varieties planted, and the surface roots can be utilized for root cuttings, as noted on a future page." Ia. Sta. Bul. 10: 424 . I890. 
summer heat and wind blast the crop if the orchard site be not well selected as regards local weather.

The Sweet Cherry, on the other hand, must be coddled in every turn of the season, in climatic requirements being particularly sensitive to heat and cold. This cherry stands with the peach in not being able to survive temperatures much below zero and in suffering greatly from spring frosts because of early blooming. It is even more susceptible to heat than the peach, and especially cannot endure long-continued heat, both fruit and foliage suffering. The Sweet Cherry is at its best in a warm, sunny, genial, equable climate. The Duke cherries, hybrids between the Sweet and the Sour species, in the matter of hardiness are midway between the hardy Sours and the tender Sweets though this is but a very general statement applying to the group as a whole and not to individual varieties. Some of these withstand cold and heat well while others are tender in either extreme.

Cherries are more at the mercy of moisture than of temperature conditions. Continued rain at blossoming time will almost surely prevent a proper setting of fruit; and the cherries crack, and brown-rot becomes exceedingly aggressive if there is wet weather in harvest time. Late summer rainfall to supply moisture to the trees is a matter of small concern to the cherry-grower, for growth begins early and the crop is off the trees before summer droughts usually begin. Where irrigation is practiced water for the cherry is safely supplied at most seasons of the year except when harvest is in swing at which time the cherries will swell and crack if there be too much water.

As with all fruits the direction, temperature and humidity of winds are factors which decree whether or not cherries can be grown profitably either in a locality or a region. A pocket in the hills filled with dead air or a wind-swept highland would be unsatisfactory extremes; for, in the first case, fungi, especially the dreaded brown-rot, would take too great toll, and, in the second, blossoms would be blasted or foliage frazzled and the fruit whipped. The harsh, drying winds of winter, too, would be disastrous to Sweet Cherry culture and if extreme, as on the Great Plains, wood and buds of Sour Cherries would suffer. Artificial wind-breaks have not been found profitable in the hilly and wooded East, entailing too many disadvantages, but if cherries be planted at all in the prairies of the Middle West, some protection from the winds must usually be provided.

The two species from which cultivated cherries come grow with proper vigor in quite different soils. The Sour Cherry and most of its hybrid 
offspring, the Dukes, may be made to grow in almost any arable soil, but the Sweet Cherry is fastidious - to be pleased only by particular soils.

Sour Cherry orchards in New York most excel on strong, even-tempered, loamy soils, naturally or artificially well drained yet retentive of moisture. There is possibly a shade of difference in favor of clay loams and some thriving plantations may be found on stiff clays having good depth and good drainage. Wet, sticky clays underlaid with a cold, clammy subsoil - a combination all too common in Central New York - furnish conditions which defy the best of care and culture.

Sweet Cherry orchards are found excelling on lighter, and less fertile soils than those we have described for the grosser feeding Sours. Growers of Sweet Cherries conceive a perfect soil for this fruit to be a naturally dry, warm, deep, free-working, gravelly or sandy loam. If the soil is not naturally dry, it must be made so by artificial drainage, for this fruit is most impatient of too much moisture or a root-run restricted by water. In Sweet Cherry soils, as will be surmised, it is difficult to supply humus yet this must be done either by cover crops or by manure to make the soil sufficiently retentive of moisture. Sweet Cherries can be grown on other soils than those under discussion but, for a large, firm, finely finished product for the markets, only the soils described are suitable.

The conditions of soil and climate, as we have briefly defined them, that favor cherry culture are to be found in several parts of New York. Briefly we may name and describe the cherry regions of the State as follows:

The undulating, maritime plains of Long Island, covered with a thick deposit of sand, are very well adapted to cherries where the soil is rich enough to come under the plow. The genial climate, with its rather heavy rainfall, is precisely that in which the cherry thrives, the region falling short in the poorness of the soil - a fault easily remedied, where there is good bottom, by manuring. Despite the fact that occasional trees and plantations show that this fruit thrives on Long Island the cherry is not much grown here, the industry needing some leader to show the way.

The valley of the Hudson from where the river leaves the mountains on the north to its entrance into the highlands of its lower stretch is admirably adapted to cherry-growing, both climate and soil meeting the requirements of this fruit. In parts of the valley the industry has been developed, Columbia County taking first place among the counties of the State, with its 78,526 trees in 1909. The product of this region goes chiefly to the great city market near at hand. Unfortunately the standard 
of cultivation is low in the Hudson Valley and the handling and marketing of the crop is also on a lower level than westward in the State. The cherry harvest is earlier here than elsewhere in New York, if we except the small crop of Long Island, an advantage, for prices usually fall rather than stiffen as the season advances.

The great basin in which lie the Central Lakes of New York is far famed for its Sour Cherry industry, the product going largely to canneries. Some Sweet Cherries are grown - more and more are being planted about these lakes; but the rich, heavy soils which mostly prevail hereabouts are more fit for varieties of the Sour Cherry; though the equable climate makes almost certain the Sweet Cherry crop on soils suited to its culture. Here, as elsewhere in the State, the acreage at this writing is greatly on the increase though it is doubtful if the advance will much longer weather the present depression in prices. All through this region, as in that to the north, the Sweet Cherry grows wild, thriving like the Biblical bay - seemingly a sheer gift of the soil and, like other gifts, generally neglected.

The high plain along the shore of Lake Ontario from the St. Lawrence River to the Niagara River, extending from the lake on the north from ten to fifteen miles inland, is the region of greatest possibilities for the cherry in New York. The climate of this great stretch of territory is nearly perfect for this fruit and the soils are sufficiently diversified to furnish a suitable habitat for any of the many varieties of either Sweet or Sour cherries. In the past there have been so many ups and downs in the cherry industry that fruit-growers in this favored belt have given more attention to other fruits but for the last decade, until the recent downward turn in the cherry market, the plantings have been greatly increased, both Sweet and Sour cherries finding favor.

Not unlike the Ontario shore in climate, but quite unlike it in its soils, is the shore of Lake Erie, the most westward topographical division of New York in which cherries are grown. The mainstay of this region is the grape, but, in seeking for a more diversified agriculture, Sour Cherry culture was introduced some twenty years ago and has become a thriving industry with prospects of continued growth. Here, as is so often the case in agriculture, credit must be given to some one leader for the development of a crop and the cherry orchards that dot the landscape for miles about the home of the late John Spencer speak eloquently of his leadership in this region. 
A necessary accompaniment to a discussion of climate is a statement of the dates of blooming of the various sorts of cherries; for often, through selection with reference to this life event of the plant, injurious climatal influences may be escaped at blooming-time. In the accompanying table averages of the blooming dates of varieties of cherries for the years just past, I9I 2 to I9I 4 , are given.

In making use of these dates, consideration must be given to the environment of the orchards at Geneva. The latitude of the Smith Astronomical Observatory, a quarter of a mile from the Station orchards, is $+2^{\circ} 52^{\prime}+6.2^{\prime \prime}$; the altitude of the orchards is from five hundred to five hundred and twenty-five feet above the sea level. The soil is a stiff and rather cold clay; the orchards lie about a mile west of Seneca Lake, a body of water forty miles in length and from one to three and one-half miles in width and more than six hundred feet deep. The lake has frozen over but a few times since the region was settled, over a hundred years ago, and has a very beneficial influence on the adjacent country in lessening the cold of winter and the heat of summer and in preventing early blooming.

The dates are those of full bloom. They were taken from trees grown under normal conditions as to pruning, distance apart, and as to all other factors which might influence the blooming period. An inspection of the table shows that there is a variation of several days between the time of full bloom of the different varieties of the same species. These differences can be utilized in selecting sorts to avoid injury from frost.

Table Showing Blooming Dates and Season of Ripenixg

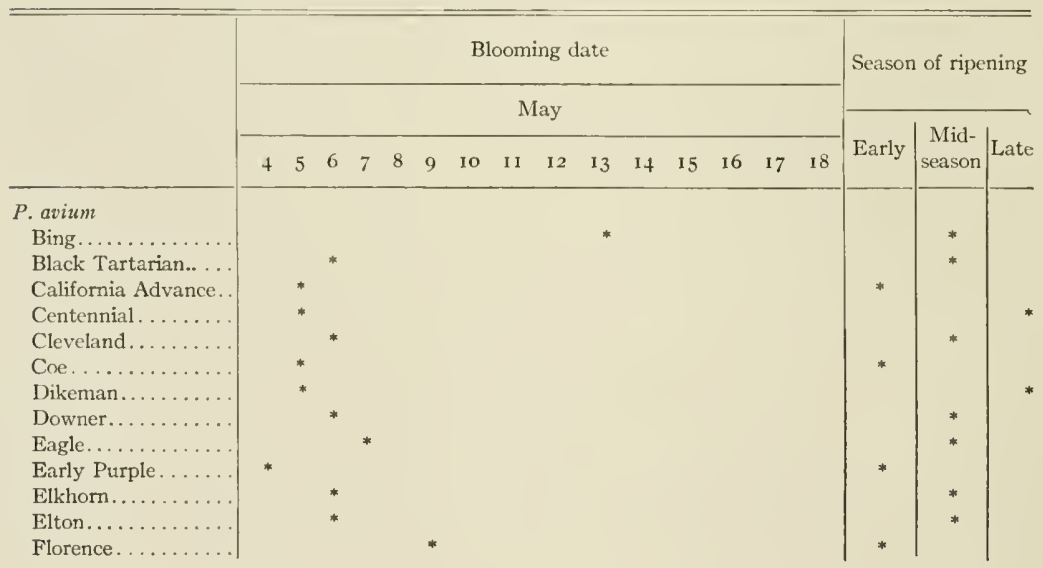


Table Showing Blooming Dates and Season of Ripening - Concluded

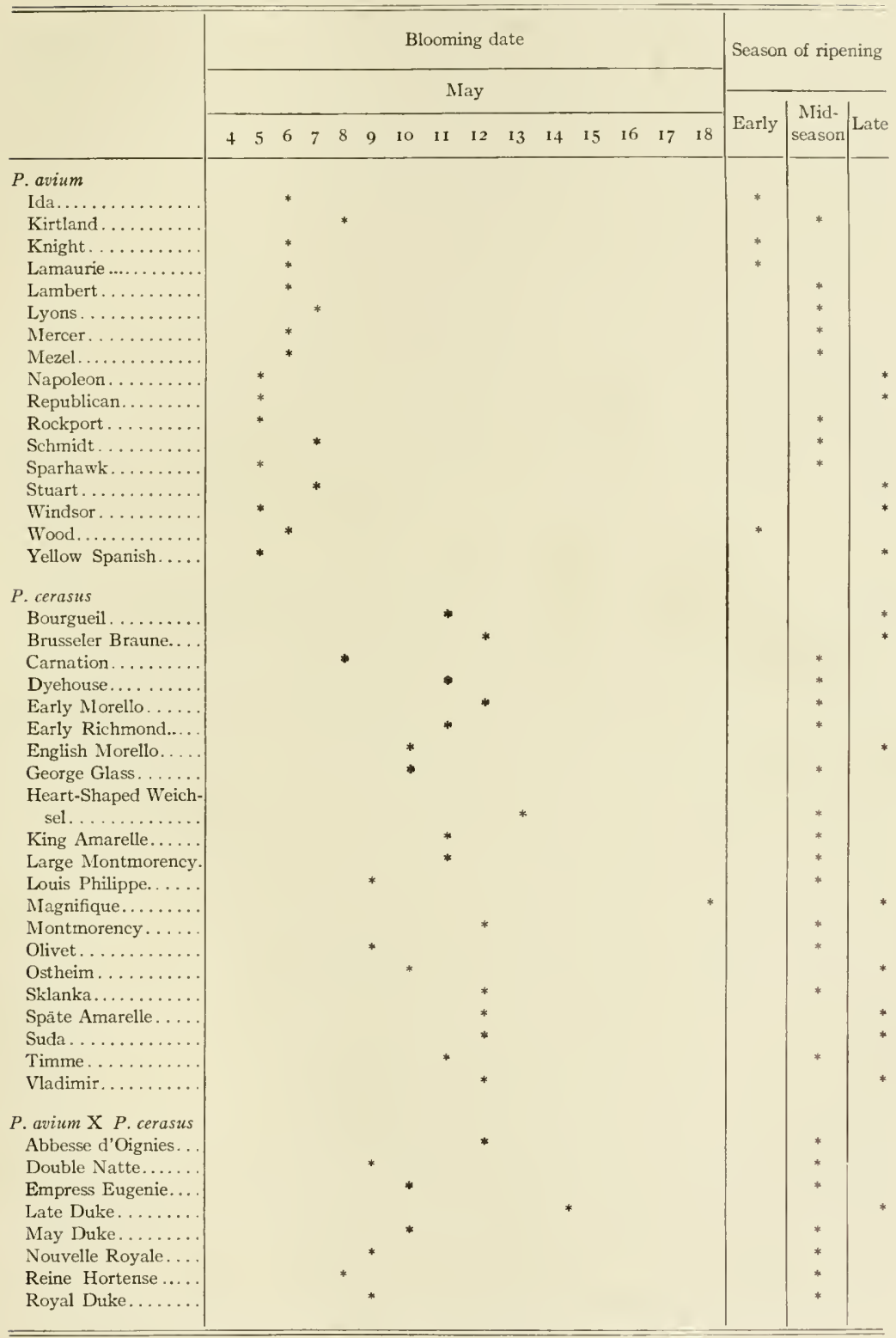




\section{THE POLLINATION OF CHERRIES}

We cannot complain in New York of much uncertainty in the setting of the cherry crop. Late spring frosts occasionally catch the blossoms of Sweet varieties but seldom those of the Sour sorts. Cold weather, especially if accompanied by wet weather, not unfrequently cuts short the cherry crop by preventing proper setting. There is, however, no general complaint of poor crops through self-sterility. In fact from the behavior of perfectly isolated trees in all parts of the State it would be premised that the cherry is most nearly self-fertile of all tree-fruits.

Yet there may be orchards or seasons in which cross-pollination cuts a figure, for Gardner ${ }^{1}$, of the Oregon Station, found in experiments carried on by him in various parts of Oregon that many varieties of Sweet Cherries in the Pacific Coast environment are self-sterile. The work seems to have been very carefully done and the conclusions are worth reprinting in full, bearing in mind that they would be much modified under New York conditions. Gardener found:

" I. All the varieties of the Sweet Cherry tested are self-sterile. This self-sterility is in no case due to a lack of germinability of the pollen produced. On the other hand, the pollen of each of the varieties studied is capable of producing a set of fruit on the variety or varieties with which it is inter-fertile. The list includes Bing, Black Republican, Black Tartarian, Coe, Early Purple, Elton, Knight, Lambert, Major Francis, May Duke, Napoleon, Rockport, Waterhouse, Willamette, Windsor, Wood.

" 2. Certain of these varieties - Bing, Lambert, and Napoleon are mentioned especially - are inter-sterile. Mixed plantings of these three varieties cannot be expected to set fruit unless the trees are within the range of influence of some other variety or varieties that are inter-fertile with them.

"3. Among those studied, Black Republican, Black Tartarian, and Waterhouse seem to be the most efficient pollenizers for this group of varieties.

" 4. Other good pollenizers that may be mentioned are: Elton, Wood, Coe, Major Francis, Early Purple. These, however, proved somewhat variable in their pollenizing abilities.

"5. Some of the seedling trees found in and about cherry orchards are efficient pollenizers for the three varieties - Bing, Lambert, Napoleon. Probably many of these seedling trees are efficient pollenizers, though the value of any particular seedling can be determined only by experiment or very careful observation.

${ }^{1}$ Gardner, V. R. Pollination of the Sweet Cherry, Ore. Sta. Bul. 116:36. I913 
"6. At least some members of the Duke group of cherries are capable of pollinating some of the Bigarreaus.

"7. At least some of the varieties of the Sour Cherry (P. cerasus) are capable of pollinating some of the Bigarreaus.

" 8. Inter-sterility of Sweet Cherry varieties is apparently not correlated with their closeness of relationship.

"9. The ability of a variety of cherry to set fruit is not entirely dependent upon the kind of pollen available. Environmental factors are important."

It is doubtful if New York cherry-growers will need to pay much attention to cross-pollination but, in case cherry trees are not setting full crops, and for no other apparent reason, the fertility of the blossoms may well receive attention. Should varieties be found self-sterile, sorts must be chosen which come into blossom at the same time, in which case the preceding table shows the sorts which bloom together or nearly enough so to make cross-pollination possible.

\section{CHERRY ORCHARDS AND THEIR CARE}

It is patent to the eye of every passer-by that cherry trees are commonly set too thickly in most of the orchards in New York. While close planting is a universal fault, the amount of room differs greatly in different cherry centers, depending mostly upon the custom in the community, though, as all confess, it should depend upon the variety and the soil. The very erroneous notion seems to have prevailed in setting the piantations now reaching maturity that a large return could be skimmed from a small area by close setting, Sour Cherries often being put only twelve feet apart each way and Sweet Cherries, considering their great size, even closer, at sixteen feet. Experienced growers now put such dwarf kinds as the Morellos at from sixteen to eighteen, the Montmorencies and their kind at eighteen to twenty-two; and the large growing Sweet Cherries at from twenty-four to thirty feet.

Cherries are usually planted two years from the bud. Spring is the season for setting, though the hardy Sour sorts might often be set advantageously in late autumn. The losses at setting time are greater with the cherry than with any other fruit, old hands in fruit-growing losing trees as well as beginners. An experiment at the Station shows that these losses are greatly mitigated by a change in the usual method of transplanting. The custom is to shorten-in all branches of transplanted fruittrees but this, with the cherry in particular, removes the largest and 
presumably the best nourished buds - certainly those from which would soonest develop the leaves so necessary to sustain the breath of life in the young plant and to give it a start. In the experiment at this Station it was found that, if the top of the young tree was reduced by thinning the branches instead of cutting all back, a much larger proportion of the trees would strike root and live through our parching summers.

Cherry trees in the past have been headed three or four feet above the ground but in new plantations they are now usually started lowerat half of the above distances. Two forms of top are in vogue, the spireshape and the vase-shape. Sour Cherries are almost universally grown with closed centers but some growers prefer the form of the vase for Sweet varieties, though the majority hold to trees with central trunks and many subsidiary branches. Little pruning is done in cherry orchards after the first two or three years, by which time the sapling has been shaped. Subsequent pruning consists in removing dead, injured or crowded branches and an occasional superfluous one. Heading-in finds little favor with experienced growers. These few statements indicate that the cherry, as now grown, is pruned but little, and that that little must be done very carefully, the pruning knife in the hands of a careless man being, with this fruit, " a sword in the hands of a child."

The general tuning-up in the cultivation of fruits during the past quarter-century has had its influence on cherry culture. Commercial orchards are no longer kept in sod and the clean, purposeful cultivation that has taken the place of grass has doubled the output of cherries, tree for tree, throughout the State, the difference in yield being especially noticeable in seasons when drought lies heavy on the land. Cultivation, as practiced by the best growers, consists of plowing the land in the spring and then frequently stirring the soil until the first of August, at which time a cover-crop is sown. If the soil is light, and therefore hungry and thirsty, the plowing should be done early and the cultivator kept constantly at work until cherry-picking. Cherry orchards often, without apparent cause, have an indefinable air of malaise - look dingy and unhappy - such require almost week-to-week cultivation to tide them over their period of indisposition.

Grain, as well as grass, is discountenanced in cherry orchards, but cultivated truck and farm crops in young plantations, or, under some conditions, small fruits, are looked upon as permissible and often pay for the keep of the young trees until they come into profitable bearing. 
Cover-crops are in common vogue in cherry orchards in New York and, since with this fruit they can be sown earlier in the season, are used to better advantage than in other orchards to furnish a full supply of humus and to provide nitrogen. Brown-rot, an annual scourge in most cherry orchards, takes less toll from trees cultivated and cover-cropped, these operations covering the mummied fruits and keeping the spores they carry from coming to light and life.

Cherry growers as a rule are not now using fertilizers for their crops. It would seem that this is not doing duty by the land; but it must be remembered that the cherry grows vigorously and that over-feeding may stimulate the growth too much, laying the orchard open not only to unfruitfulness but to winter injury of bud and tree. Among those who use fertilizers there is little accord as to what fertilizing compounds are best or as to what the results have been. There is common agreement, however, that Sour Cherries respond more generally to fertilizers than the Sweet sorts. Until there are carefully carried out fertilizer experiments with this fruit the vexatious problems of fertilization cannot be solved. Nitrate of soda seems to be a great rejuvenator in orchards laid down to grass. Whatever the cause, when leaves lack color and hang limp, this fertilizer is a sovereign tonic. Heavy dressings of stable manure are much used in grassed-over orchards, as they are, also, in such as have had none or but scant crops.

THE COMMERCIAL STATUS OF CHERRY-GROWING IN NEW YORK

Cherry growing is a specialist's business in which, under the best of conditions, there are more ups and downs than with other fruits. Because of the great profits that have come to a few in the years just past many growers have been drawn into the business in a small way or have planted an acreage beyond their means to manage. The inevitable depression that follows over-planting is, at this writing, at hand and spells ruin to some and disgust and discouragement in the industry to others. Perhaps no fruit can better be left to men of reserve capital than the cherry, and even with men of substance cherry-growing should largely be incidental to the culture of other fruits - an industry to fit in to keep land, labor and machinery employed.

Cherry trees begin to bear in the climate of New York when set from three to five years. The varieties of Prunus cerasus first produce profitable crops but, at from six to eight years from setting, both Sweet and 
Sour sorts are in full swing as money-making crops. The limits of profitable age are not set by the life of the tree but, rather, by its size. Thus, cherry trees of either of the species commonly cultivated are not infrequently centenarians but the profitable age of an orchard is not often more than from thirty to forty years. After this time the trees become large and the expense of caring for them and of picking the fruit becomes so great as to prevent profits. Moreover, disease, injuries and inevitable accidents will have thinned the ranks of trees until the orchard is below profit-making.

(mentry-picking begins in New York about the first of July, following the rush in harvesting strawberries, and lasts, if the orchard contains both Sweet and Sour varieties, from four to six weeks. Workers may in this way fill in a gap between small-fruits and other tree-fruits and the crop becomes one in which the grower may often take small profits to keep his help employed; though, in the long run, if the more or less frequent depressions can be weathered, the cherry may prove as profitable as other fruits.

The problem of labor is a most vexatious one under present conditions, it being impossible to obtain casual men laborers for cherry-picking and women and children are unsatisfactory, since the fruit must be carefully picked or both cherries and trees suffer. The problem is solved, unsatisfactorily in most cases, in various ways by different growers. Most of the crop is now picked by children in the teens under the eyes of men or women supervisors. In picking for the market the stem is left on and only the stem is touched by the fingers. Cherries for canning factories are less laboriously picked. The picking package is usually an eight-pound basket. The rate paid is one cent per pound. Pickers earn $\$ 1.50$ to $\$ 2.00$ per day in good seasons. Close watch is kept on pickers to prevent the breaking off of fruit-spurs, thereby destroying the succeeding year's crop, varieties fruiting in clusters suffering especially from carelessness in this respect. Cherries are picked a few days before full ripeness.

Cherries are sent to canneries in various packages but chiefly in half-bushel baskets or paper-lined bushel crates, the container being often supplied by the cannery. The six- and eight-pound baskets are the favored receptacles for Sour Cherries in city markets but the Sweet sorts are rather oftener sent in four-pound baskets and still more frequently in quart boxes. In the larger packages not much effort is made to make the fruit attractive but in the smaller ones, stemless and bruised cherries are thrown out and 
the package filled, stem down, with the best fruits. In fancy grades all of the fruit in the box is layered. The demands of the market, of course, determine the package and the manner of packing. Cherries are seldom stored longer than a few days at most in common storage and a week or two weeks in cold storage.

There is a marked difference in the shipping and keeping qualities of varieties of cherries, the sorts that keep longest and ship best, quite at the expense of quality, having the call of the markets. Undoubtedly this must remain so, though it is to be desired that local markets, at least, be supplied with the best, irrespective of handling qualities. A further factor that prevents the placing of choicely good cherries in distant markets at all times is brown-rot, to be discussed later, which more often attacks the juicy and usually the best-flavored varieties, oftentimes ruining the pack on the way to market - one of the most discouraging events incidental to cherry-growing.

Marketing machinery for cherries is at present very costly, inadequate and frequently sadly out of gear. The fruit passes first from the grower to a local buyer who ships to a center of consumption, transportation companies taking heavy toll on the way. Jobbers or commission companies, who in some cases receive the fruit direct from the grower, then distribute the crop to retailers in the consuming centers. Lastly, the retailer parcels out the quantities and the qualities demanded by the housewife. The whole business of selling the crop is speculative and the grower is fortunate to receive half of what the consumer pays and not infrequently has all of his pains for nothing or may even be forced to dip into his pocket for transportation. The perishableness of the product and the present defects of distribution go far to make the crop the hazardous one it is but all look forward to better times coming under an improved system of marketing.

Up to the present, it must be said, but little effort has been made in New York to ship far and to develop a trade in cherries other than at the canneries. The canners have until the last year or two taken the cream of the crop but with recent greatly increased plantings are now over-supplied. The average grower, possessing a mixture of mental inertia and business caution, has not sought other sources for the surplus fruit. Bolder and more energetic spirits are now developing new markets and opening up those to which other tree-fruits more generally go so that the present over-production may prove a blessing in disguise. The greatly 
increased demand, for Sour Cherries in particular, brought about by the development of markets in 1913-14, are most hopeful signs for the future of the cherry industry.

\section{CHERRY DISEASES}

Cherries, without preventive or remedial intervention, are at the mercy of two or three fungus diseases and sometimes several others are virulent, depending upon locality, season, weather and variety. One of these diseases, brown-rot, in spite of the great advances in plant pathology of recent years, is almost beyond the control of preventive or remedial measures. Happily, all the others yield better to treatment.

Brown-rot ${ }^{1}$ (Sclerotinia fructigena (Persoon) Schroeter), sometimes known as fruit-mold or ripe-rot, very frequently attacks flowers and shoots but is most conspicuous on the ripe or ripening cherries where its presence is quickly detected by a dark discoloration of the skin which is afterwards partly or wholly covered with pustule-like aggregations of gray spores. The decayed fruits usually fall to the ground but sometimes hang to the tree, becoming shriveled mummies, each mummy being a storehouse of fungus threads and spores from which infestation spreads to the next crop. The disease, in some seasons, like a withering blight, attacks twigs, flowers and leaves early in the spring doing great damage to the young growth and often wholly preventing the setting of fruit. The rot spreads with surprising rapidity on the fruits in warm, damp weather either before the fruit is picked or in baskets while being shipped or stored. Preventive remedies have so far met with but indifferent success; probably the best method of control is to destroy the mummy-like fruits and all other sources of infection either by picking them from the trees, or much better by plowing them under deeply. Varieties of cherries show various degrees of susceptibility to brown-rot. All Sweet Cherries are more subject to the disease than the Sour sorts. But with either of the two species there are great variations in the susceptibility of the varietal hosts - a matter specially noted in a later chapter in the discussion of varieties.

Another serious disease of the cherry, and probably the most striking one in appearance, is the black-knot ${ }^{2}$ (Plowrightia morbosa (Schweinitz) Saccardo), characterized by wart-like excrescences on shoots and branches.

\footnotetext{
${ }^{1}$ Smith, E. F. Peach Rot and Peach Blight, Journ. Myc. 5:123-134. 1889. Quaintance, A. L. The Brown Rot, etc., Ga. Sta. Bul. 50:237-269, figs. 1-9. I900.

${ }^{2}$ Farlow, W. G. The Black Knot, Bulletin Bussey Institution 440-453. 1876. Halsted, B. D. Destroy the Black Knot, etc., N. J. Sta. Bul. 78:1-14. 1891 .
} 
Black-knot looks more like the work of an insect than a fungus and was long supposed to be such even by those who were studying the trouble. The knots begin to form early in the summer and are of characteristic color and texture - dark green, soft and velvety, but in the fall, as the fungus ripens, the color changes to coal-black and the knots become hard and more or less brittle. The excrescences usually form on one side of a twig or branch so that death seldom follows quickly. The disease attacks both wild and cultivated plants in every part of this continent where cherries are grown but is epidemic only in the East, the cherry regions of the West being practically free from the disease. Up to the present time the fungus has not been found elsewhere than in America. Happily, black-knot may be controlled by cutting out the diseased wood. To completely eradicate the fungus, if it is especially virulent, however, the orchard must be gone over several times during a season. In New York the removal of black-knot is ordered by law, the results showing that when the law is obeyed, especially if there be hearty co-operation among growers, eradication is usually possible. Sweet Cherries are much less attacked by black-knot than the Sour sorts but the differences in immunity between varieties in either of the two species are not very marked - at least such is the case on the grounds of this Station where the disease is always present and is often very prevalent.

Exoascus cerasi Fuckel $^{1}$ is the cause of a very striking deformity of the cherry in Europe, both Prunus avium and Prunus cerasus being attacked. The disease has been reported in America but has not yet become virulent. The fungus attacks the branches, causing a clustering of the twigs in the form of a broom, giving it the name witches' broom. The leaves on the diseased twigs usually take on a crinkled shape and a reddish color. The malady may be readily prevented by the destruction of affected branches.

In common with other species of Prunus the foliage of cherries is attacked by several fungi which produce diseased spots on the leaves, the dead areas usually dropping out leaving holes as if punctured by shot. Thus we have "shot-hole fungus," "leaf-spot" and "leaf-blight" as effects of these diseases. Three fungi are in the main responsible for these leaf troubles; these are Cylindrosporium padi Karsten, ${ }^{2}$ Mycospharella

${ }^{1}$ Duggar, B. M. Fungous Diseases of Plants 185, fig. 68. 1909.

${ }^{2}$ Higgins, B. B. Contributions to the Life History and Physiology of Cylindrosporium on Stone Fruits, Am. Jour. Bol. I:145-173. 1914. 
cerasella Aderhold ${ }^{1}$ and Cercospora circumliscissa ${ }^{2}$ Saccardo. The ravages of these fungi are prevented by the proper use of bordeaux mixture and lime and sulphur, remedies which, however, must be used with some care to avoid spray injury. With these, as with other fungi, cultivation has a salutary effect as it destroys diseased leaves which harbor the fungi during their resting period.

Cherry leaves are often covered with a grayish powder which in severe cases causes them to curl and crinkle and sometimes to drop. This powdery substance consists of the spore-bearing organs of a mildew ${ }^{3}$ (Podosphara oxyacanthce De Bary). Powdery mildew is much more common on nursery stock than on fruiting trees and in New York is a serious pest on young cherry trees. In the nursery, injury may be prevented by the use of copper sprays or lime and sulphur, either of which is also an efficient preventive in the orchard but the mildew is seldom prevalent enough on orchard plants to require treatment.

Wherever cherries are grown in either the nursery or orchard, crown gall ${ }^{4}$ (Bacterium tumefaciens Smith and Townsend) has obtained a footing. In the North at least, it seldom greatly injures old trees, but if the galls girdle a nursery plant serious injury results. Therefore, badly infected young trees showing galls should not be planted. However, but little harm is liable to result under most conditions. When infected plants have been planted it has been found that galls vary greatly in duration, sometimes disappearing within a year or two and at other times persisting indefinitely. The tumor-like structures are usually at the collar of the plant and vary from the size of a pea to that of a man's fist, forming at maturity rough, knotty, dark-colored masses. Neither prevention nor cure has been discovered, though it is known that soils may be inoculated with the disease from infected stock and that, therefore, diseased trees should not be planted in soils virgin to the galls. It is probable that there are differences in the susceptibility of Sweet and Sour cherries to the fungus and that the varieties of the two species vary in their resistance

${ }^{1}$ Aderhold, R. Mycosphaerella cerasella n. spec., die Perithecienform von Cercospora cerasella Sacc. und ihre Entwicklung, Ber. d. deut. bot. Ges. 18:246-249. 1900.

2 Duggar, B. M. Fungous Diseases of Plants 314. I909. Pierce, N. B. A Disease of Almond Trees, Jour. Myc. $7: 66-67$, Pls. I1-14. I892.

${ }^{3}$ Duggar, B. M. Fungous Diseases of Plants 226. 1909.

1 Smith, E. F. and Townsend, C. O. A Plant Tumor of Bacterial Origin, Science 25:671-673. 1907. Toumey, J. W. Cause and Nature of Crown Gall, A riz. Sta. Bul. 33: I-6q, figs. 1-31. 190o. Hedgcock, G. C. Crown Gall, etc., U. S. Depl. Agr. Bur. Pl. Ind. Bul. 90:15-17, Pls. 3-5. 1906. 
but as yet no one seems to have reported on the differences in susceptibility of cherries to the disease.

The leaf-rust ${ }^{1}$ (Puccinia pruni-spinosce Persoon) of stone-fruits, occurring rarely on the fruit, sometimes attacks cultivated cherries and is a rather common disease of the wild Prunus serotina. This rust is troublesome only, however, in warm, moist climates. It is most apparent in the fall and is casily recognized through its numerous rust-colored sori on the underside of the leaves. Defoliation takes place in severe infestations. Either bordeaux mixture or lime and sulphur may be used as a preventive.

Old cherry trees are often attacked by a fleshy fungus or " toadstool ". (Polyporus sulphureus (Bulliard) Fries). This fungus is said to be worldwide in its distribution and to occur upon a large variety of trees. It is very striking in appearance, the clusters appearing during late summer or early autumn in large, shelving branches, the sporophores fleshy and of cheese-like consistency when young but becoming hard and woody with age. At first the "toadstools" are all yellow but later only the under surfaces are yellow while the upper surface is orange-red. The plants are more or less odoriferous, the odor increasing with age. Happily, the fungus is not very virulent but is often the cause of decay in the tree-trunkthe brown-rot of the wood of this and other orchard and forest plants. In localities where the fungus thrives it may usually be controlled by covering all wounds with tar or other antiseptic materials.

At least two other fleshy fungi have been found injuring cherries. These are Clitocybe parasitica Wilcox ${ }^{3}$ and Armillaria mellea Vahl., ${ }^{4}$ the latter the honey agaric, more or less abundant in both Europe and America. Both are associated with and are probably a cause of the root-rot of the cherry and other orchard fruits. Neither is a common enough pest in this country, however, to receive extensive description in texts on diseases of plants. Control measures are different in localities where fungi occur, consisting in the main of getting rid of stumps and roots in orchard lands and planting to field crops before using for orchard purposes. Infected trees should be removed or isolated by trenching about them.

${ }^{1}$ Scribner, F. L. Leaf Rust of the Cherry, etc., U. S. Dept. Agr. Rpt. 353-355, Pl. 3. 1887.

: Atkinson, Geo. F. Studies of Some Shade Tree and Timber Destroying Fungi, Cor. Agl. Exp. Sta. Bul. 193:208-21 ६. 1901. Schrenk, H. von. Div. Veg. Phys. and Path., U. S. Depl. Agl. 25: +0-52, Pls. II (in part), I3. I900.

${ }^{3}$ Wilcox, E. M. A Rhizomorphic Root-Rot of Fruit Trees, Okla. Agr. Exp. Sta. Bul. 49:1-32, Pls. I-11. I901.

${ }^{4}$ Duggar, B. M. Fungous Diseases of Plants 473. 1909. 
All stone-fruits suffer more or less from an excessive flow of gum. The name gummosis ${ }^{1}$ is generally applied to these troubles. Gumming is much more prevalent in the far West than in the East but is to be found wherever stone-fruits are grown. This excessive gumming is a secondary effect of injuries caused by fungi, bacteria, insects, frost, sunscald, and mechanical agencies. There is a good deal of difference in the susceptibilities of varieties and species to this trouble, the Sweet Cherry suffering much more than the Sour sorts and varieties of other species having hard wood suffering less than those having softer wood. There is less gummosis, too, on trees in soils favoring the maturity of wood; under conditions where sun and frost are not injurious; and, obviously, in orchards where by good care the primary causes of the diseases are kept out.

A number of diseases of the trunk arise from mechanical injuries from wind, sun, frost and hail. Few, indeed, are the fruit-growers whose trees are not occasionally damaged in one way or another in the vicissitudes of a trying climate. Very often these mechanical injuries are followed by fungal parasites or insects so as to make it difficult to distinguish the primary from the secondary trouble. There is a wide difference in the susceptibility of Prunus arium and Prunus cerasus to such injuries, the Sweet Cherry, with its softer wood, being much more easily injured by any and all stresses of weather than the Sour Cherry. In the main the elements cannot be combated but low heading of the trees is a preventive from sunscald, at least, and sometimes may have a favorable effect in preventing wind and frost injuries.

\section{CHERRY INSECTS}

Insects troubling cherries are numerous but hardly as destructive as with other tree-fruits. Entomologists list about to species of insects attacking cherries and about as many more occasionally attack the varieties of one or the other of the two cultivated species. The majority of these pests came with the tree from its habitat over the sea but several have come from the wild cherries of this continent.

Of the pests peculiar to the cherry alone, possibly the cherry fruit maggot $^{2}$ (Rhagoletis cingulata Loew) is, the country over, as troublesome as any. The adult insect is a small fly with barred wings which lays eggs

\footnotetext{
${ }^{1}$ Hedrick, U. P. Gumming of the Prune Tree, Ore. Sla. Bul. 45:68-72. 1897.

${ }^{2}$ Slingerland, M. V. Bul. Cor. Ag. Ex. Sta. I72: 1899.
} 
under the skin of the cherry in mid-summer. From these eggs small, whitish maggots about one-third of an inch long hatch and eat out a cavity in the ripening fruit. These maggots when full grown pupate in the ground and remain there until the following season. The only effective preventive or remedial measure to take against the pest in large orchards is to spray with a sweetened arsenical, but in small plantations chickens are fairly effective in scratching up and eating the pupating maggots.

The cherry fruit maggot is probably responsible for most of the "wormy" cherries in New York but the plum curculio is also a cause of "wormy" fruits and in some seasons is a most formidable pest. This curculio ${ }^{1}$ (Conotrachelus nenuphar Herbst) is a rough, grayish snout-beetle somewhat less than a quarter of an inch in length, so familiar an insect as scarcely to need further description. The female beetle pierces the skin of the young cherries and places an egg in the puncture. About this cavity she gouges out a crescent-shaped trench, this cut or sting being a most discouraging sign to the cherry-grower, for he well knows that from the eggs come, within a week or two, white and footless grubs which burrow to the stone and make "wormy fruit." Some of the infested cherries drop but many remain eventually to distract the housewife and those who eat cherries out of hand. Jarring the beetles from the trees, a method employed by plum-growers, is quite too expensive and ineffective for the cherry-grower and poisoning with an arsenate is the only practical means of combating the pest. Rubbish and vegetation offer hiding places for the insects and, therefore, cultivated orchards are freer from curculio than those laid down to grass. There are no curculio-proof cherries but, as with plums, the thin-skinned varieties are damaged most by the insect.

The grub of the plum curculio is easily distinguished from the cherry fruit maggot. This "worm " is the larva of a beetle, a true grub, footless and with a brownish, horny head while the cherry fruit maggot, the larva of a two-winged insect, is a true maggot like that which comes from the common house-fly and hardly to be distinguished from the apple maggot. It is important to be able to distinguish in wormy cherries the grub of the curculio from the cherry fruit maggot in order to know and understand the nature of the two enemies in combating them.

Another pest of this fruit is the cherry leaf-beetle (Galerucella cavicollis Le Conte) the larvae of which sometimes do much damage to cherry foliage. The adult insect is an oval, reddish beetle about one-fourth of

${ }^{1}$ Riley, C. V. An. Rpt. State Entom. Mo. 1:50-56. 1869; 3:1 I-29. 1871. 
an inch long with black legs and antennae. Both the adult and the larvae feed on the leaves and do much damage if abundant. Usually there are two broods, the insect pupating in the ground. Fortunately the pest is easily controlled with the arsenical sprays.

The cherry scale (Aspidiotus forbesi Johnson) is commonly found on this fruit and occasionally on others as well. To the unaided eye it is very similar to the well-known San José scale, differing chiefly in being lighter in color. The remedy is the same as for the San José scale, which we next discuss.

The dreaded San José scale ${ }^{1}$ (Aspidiotus perniciosus Comstock) is rather less harmful to cherries than to other tree-fruits and yet is sometimes a serious pest on Sweet Cherries. Sour Cherries are almost immune. The insect is now so well known in all fruit-growing regions that it needs no description. It is usually first recognized by its work, evidence of its presence being dead or dying twigs - oftentimes the whole tree is moribund. Examination shows the twigs or trees to be covered with myriads of minute scales, the size of a small pin-head, which give the infested bark a scurfy, ashy look. If the bark be cut or scraped a reddish discoloration is found. Leaves and fruit as well as bark are infested, the insidious pest, however, usually first gaining a foothold on the trunks or a large branch. Cherry-growers, in common with all fruit-growers, find the lime and sulphur solution the most effective spray in combating this insect.

Several other scale insects feed on the cherries and, now and then, become pestiferous; among these the following may be named: The European fruit lecanium ${ }^{2}$ (Lecanium corni Bouché) occasionally does a great deal of damage in New York and now and then destroys the whole crop in an orchard. The winter treatment for San José scale is used to control this pest, but usually such treatment is supplemented by a summer spray about July first with such contact sprays as whale oil soap and kerosene emulsion. The fruit pulvinaria (Pulvinaria amygdali Cockerell), the mealy bug (Pseudococcus longispinus Targioni), the scurfy scale (Chionaspis furfura Fitch), the West Indian peach scale (Aulacaspis pentagona Targioni), the Putnam scale (Aspidiotus ancylus Putnam), the walnut scale (Aspidiotus juglans-regice Comstock), Howard's scale (Aspidiotus howardii Cockerell), the European fruit scale (Aspidiotus ostreceformis Curtis), the red scale of California (Chrysomphalus aurantii Maskell), the

1 Marlatt, C. L. The San José or Chinese Scale, U. S. D. A. Bur. Ent. Bui. 62: 1-89. 1906.

${ }^{2}$ Lowe, V. H. The New York Plum Lecanium, N. Y. Sta. Bul. 136:583. 1897. 
oyster-shell scale (Lepidosaphes ulmi Linnaeus), and the soft scale (Coccus hesperidum Linnaeus), are all more or less common.

Several borers occasionally infest cherry trees of which the peach borer $^{1}$ (Sanninoidea exitiosa Say.) is the most troublesome. Larvae of the peach borer are frequently found in both Sweet and Sour Cherries, more particularly in Sweet Cherries, in eastern orchards. Fortunately this pest is not as rife with the cherry as with peaches and plums. Its work may be prevented by thorough cultivation, by mounding the trees and, according to some, by the use of a covering of tar or of obnoxious or poisonous washes. Usually preventive measures are not effective, however, and the borer must be destroyed - best done by digging it out with a knife and wire. Since the pest is easily discovered through the exudation of gum mixed with sawdust or excreta, close to the surface or just beneath the ground, its presence can be detected in time to prevent its doing much damage. The lesser peach borer ${ }^{2}$ (Sesia pictipes Grote \& Robinson) often attacks old or weakened cherry trees, working in the growing tissues of the trunk anywhere from the ground to the main branches. The worm is much like the common peach borer, known by all, but is smaller, rarely reaching the length of four-fifths of an inch when full grown. The flatheaded apple tree borer ${ }^{3}$ (Chrysobothris femorata Fabricius) is a common pest in wild cherries and sometimes seriously attacks the cultivated species. It is treated as is the peach borer.

The shot-hole borer ${ }^{4}$ (Eccoptogaster rugulosus Ratzeburg), though seldom injuring healthy trees, is very often a serious menace in old or decrepit cherry trees. It may be looked upon, however, as an effect rather than a cause. The peach bark-beetle ${ }^{5}$ (Phlcotribus liminaris Harris) is very similar in its work to the shot-hole borer and like it attacks only diseased and decrepit trees.

All cherry-growers are familiar with the small, dark green, slimy slugs which feed on the surface of the leaves of the cherry, possibly more common on the foliage of pears, eating out the soft tissues and leaving but the skeleton of the leaf. If the slugs are numerous the tree may be defoliated or if the leaves remain the foliage looks as if scorched. The adult of this slug is a sawfly (Caliroa (Eriocampoides) cerasi Linnaeus)

\footnotetext{
${ }^{1}$ Beutenmuller, W. Sesiidae of America, etc, 266-27I. 1901.

2Ibid. 29I-292. I90I.

${ }^{3}$ Riley, C. V. An. Rpt. State Entoml. Mo. I: $46-47 . \quad$ I869.

${ }^{4}$ Lowe, V. H. N. Y. Sta. Bul. 180:122-128. 1900.

${ }^{5}$ Wilson, W. F. The Peach-tree Bark-beetle, U. S. D. A. Bur. Ent. Bul. 68:9I-I08. 1909.
} 
which lays its eggs within the tissue of the leaves. Despite the fact that it is easily destroyed by any of the arsenical sprays or by dusting with lime this slug everywhere does much damage to cherries.

Wild cherries suffer severely from the tent caterpillar' (Malacosoma americana Fabricius) and occasionally cultivated trees are attacked. The arsenical sprays are fatal to the pest. The spring canker-worm ${ }^{2}$ (Paleacrita vernata Peck) and the fall canker-worm ${ }^{3}$ (Alsophila pometaria Harris), the white-marked tussock moth (Henerocampa leucostigma Smith and Abbot), the rusty tussock moth (Hemerocampa antiqua Linnaeus), and the definite-marked tussock moth (Hemerocampa definita Packard) are all occasional cherry pests and all succumb to poisonous sprays. The two now notorious European pests recently introduced into America, gypsy moth (Porthetria dispar Linnaeus) and the browntail moth (Euproctis chrysorrhcea Linnaeus), attack cherry trees in common with other deciduous trees and may often do considerable damage. Sometimes, but not often, the buds of the cherry are attacked by the bud-moth (Spilonota (Tmetocera) ocellana Schiffermüller), the caterpillars of which bind the young leaves together as they expand so that small, dead, brown clusters of foliage are to be seen here and there where the pests are at work. Spraying with arsenicals is effective if done just as the buds begin to open.

In sandy soils the cherry is sometimes attacked by hordes of the common rose-chafer (Macrodactylus subspinosus Fabricius), leaves, flowers and even the fruit suffering from the pest. It is a difficult insect to control but a spray of arsenate of lead with molasses is fairly effective. It is important to know that the insect does not often breed in ground kept in clean cultivation.

${ }^{1}$ Lowe, V. H. The Apple-tree Tent Caterpillar, N. Y. Sta. Bul. 152:279-293. 1898.

${ }^{2}$ Riley, C. V. An. Rpt. State Entom. Mo. 2:94-103. 1870.

${ }^{3}$ Ibid. 7:83-90. 1875 . 


\section{CHAPTER IV}

\section{LEADING VARIETIES OF CHERRIES}

\section{ABBESSE D'OIGNIES}

\section{Prunus avium $\times$ Prunus cerasus}

1. Mortillet Le Cerisier 2:182. I866. 2. Leroy Dict. Pom. 5:161, 162 fig. 1877. 3. Hogg Fruit Man. 276, 277. 1884. 4. Mich. Pom. Soc. Rpt. 329. 1888. 5. Budd-Hansen Am. Hort. Man. 2:284. 1903. 6. Ia. Sta. Bul. 73:62 fig. 1907. 7. N. Y. Sta. Bul. 385:307, 308, P1. 1914.

Abbesse d'Oignies has so many good characters that it is well worth trying commercially wherever cherries are grown in the United States. Curiously enough, it seems so far to have been tried only in the Middle West, Professor Budd having introduced it in Iowa from Russia in $\mathbf{1} 883$. In the unfavorable soil and climatic conditions of the Mississippi Valley, Abbesse d'Oignies grows as well as any cherry of its class, if we may judge from the accounts of it. We do not know of its having been tried elsewhere in the East than on our grounds and here we find it, in competition with practically all of the varieties of its class, one of the best of the Dukes. At this Station it does so well that we described it, in the reference given, as one of the noteworthy fruits in our collection. The trees are large, vigorous, hardy, fruitful and very free from fungus diseases. The cherries are large, dark red, of most excellent quality, combining the flavor of the Dukes with a firmer and yet tenderer flesh than the Montmorency. The high quality, handsome appearance and good shipping qualities of the fruit, combined with the splendid characters of the tree, ought to make Abbesse d'Oignies a very good commercial variety.

This cherry probably originated in Belgium about the middle of the Nineteenth Century. At least it was first listed in Belgian nursery catalogs in I854. It is now a greater or less favorite wherever cherries are grown in the Old World, Professor Budd having found it, as we have said, in 1883 , in Russia and immediately transported it to America.

Tree characteristically large and vigorous, upright-spreading, round-topped but with drooping branchlets, hardy, productive; trunk stocky, with shaggy bark; branches thick, smooth, ash-gray over reddish-brown, with many lenticels; branchlets short, with short internodes, brownish, roughened by transverse wrinkles and by numerous conspicuous, small, raised lenticels.

Leaves two and one-half inches wide, five and one-half inches long, folded upward, 
obovate, thick; upper surface glossy, dark green; lower surface light green, slightly pubescent, distinctly ribbed by the larger veins; apex taper-pointed, base acute; margin with small, black glands, coarsely and doubly serrate; petiole one and one-quarter inches long, thick, lightly tinged with red, grooved, with one or two small, globose, reddish-orange glands.

Buds rather long, pointed, free, arranged often in elongated clusters at the ends of long spurs; leaf-scars very prominent; season of bloom medium, averaging five days in length; flowers white, one and three-sixteenths inches across; borne in dense clusters at the ends of long spurs or spur-like branches, well distributed, varying from one to three; pedicels one-half inch long, glabrous, greenish; calyx-tube reddish, campanulate, glabrous; calyx-lobes tinged red, long, narrow, somewhat acuminate, glabrous within and without, reflexed; petals roundish-oval, entire, nearly sessile, with a broad, shallow notch at the apex; filaments one-quarter inch long; pistil glabrous, equal to the stamens in length.

Fruit late; three-fourths inch long, seven-eighths inch thick, roundish-oblate, slightly compressed; cavity of medium depth, wide, regular; suture a line; apex roundish, slightly depressed; color dark red; dots numerous, small, light russet, conspicuous; stem slender, one and one-half inches long, adhering to the fruit; skin tough; flesh yellowish-white, with colorless juice, slightly stringy, tender and soft, sprightly subacid; of very good quality; stone free, about three-eighths inch in diameter, roundish, turgid, slightly pointed, with smooth surfaces; ridged along the ventral suture.

\section{ARCH DUKE}

\section{Prunus avium $\times$ Prunus cerasus}

1. Parkinson Par. Ter. 571. 1629. 2. Rea Flora 205. 1676. 3. Prince Pom. Man. 2: 135. 1832. 4. Downing Fr. Trees Am. 189, 190. 1845. 5. Floy-Lindley Guide Orch. Gard. 97, 98. 1846. 6. Mag. Hort. 13:398 fig. 1847. 7. Elliott Fr. Book 203. 1854. 8. U. S. D. A. Rpt. 135. 1867. 9. Am. Pom. Soc. Cat. 12. 1871. 10. Hogg Fruit Man. 278, 279. 1884.

Griolle de Porlugal. 11. Duhamel Trait. Arb. Fr. 1:190, 191, Pl. XIII. 1768. 12. Leroy Dict. Pom. 5:297, 298 fig. 1877.

Portugiesischer Griottier Weichselbaum. 13. Kraft Pom. Aust. I:6, Tab. I6 fig. I. 1792.

Herzogskirsche. 14. Christ Handb. 670. 1797. 15. Christ Wörterb. 282. 1802. 16. TruchsessHeim Kirschensort. 371-376. 1819.

Portugiesische Griotte. 17. Christ Handb. 674. 1797.

Cerise Royale de Hollande. 18. Ann. Pom. Bclge. 1:81, Pl. 1853.

Cerise de Portugal. 19. Mortillet Le Cerisier 2:148 fig. 37, I 49, 150. 1866.

Parkinson, nearly three hundred years ago, thought the Arch Duke "one of the fairest and best of cherries." It is now, however, quite surpassed by several others of the Dukes. The concensus of opinion of those who have known the true fruit of this name is that either May Duke or Late Duke is better. We give it prominence only because of its worthy past and that it may be better distinguished from May Duke with which it is often confused. As compared with the last-named variety it is two weeks later; the tree is more vigorous but not as productive; and the branches 


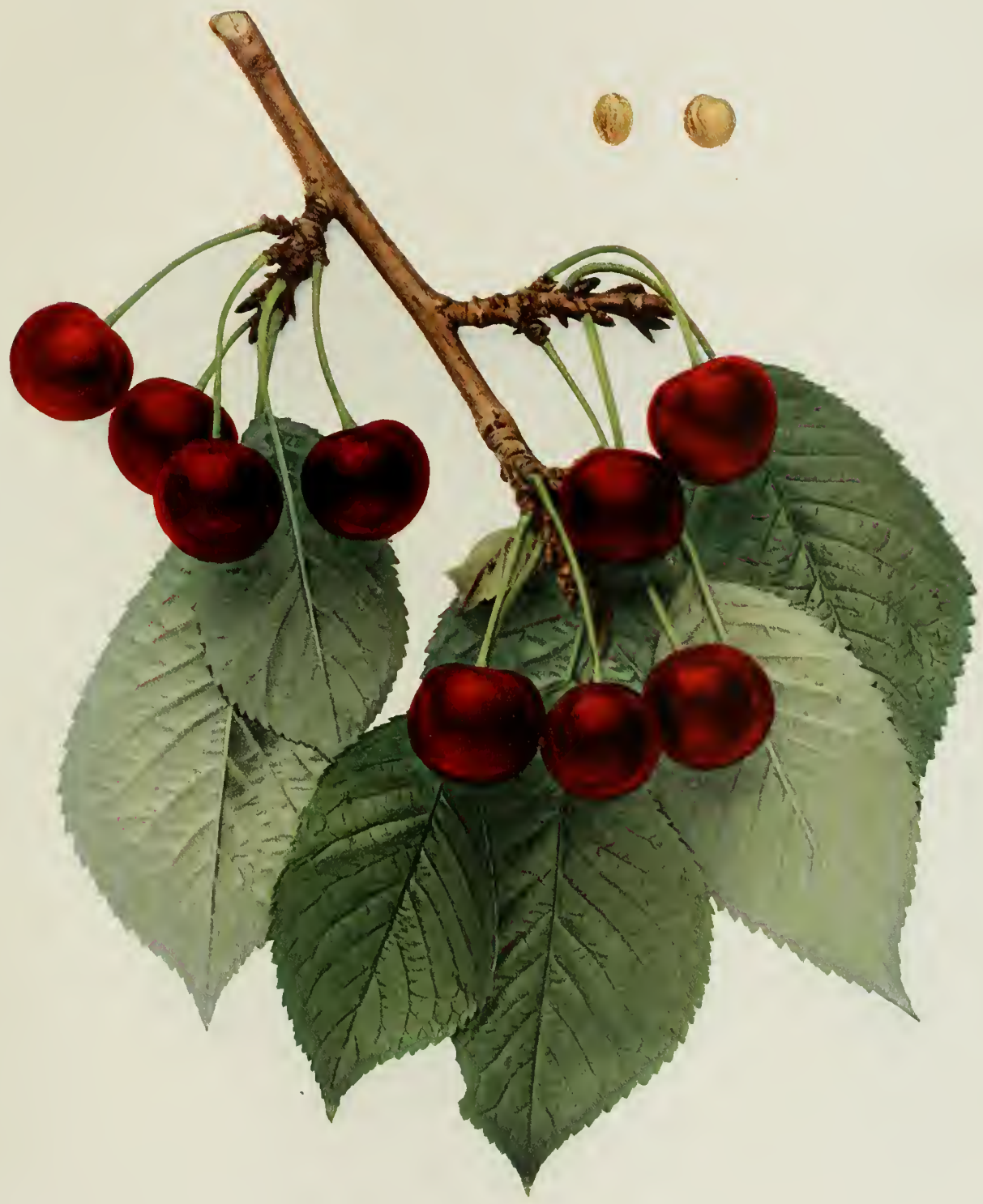



are larger, more divergent and more pendulous. The cherries are not as well flavored but are larger and have a shorter stalk.

This old English variety was first mentioned by Parkinson in Paradisus Terrestris, I629. For many years previous to the middle of the last century the true Arch Duke cherry was very scarce and was often confused with other varieties, some writers asserting that it was the May Duke; others, the Late Duke. In I 847 , however, the true Arch Duke cherry was discovered in the nurseries of Thomas Rivers, Sawbridgeworth, England, having been grown there, according to Mr. Rivers, by his ancestors for nearly a century. It was then found that the fruit was quite unlike that of either May Duke or Late Duke, though the habit of the tree was similar. It is not known when Arch Duke was introduced into America but the American Pomological Society placed it upon its fruit list in I87 I.

Tree medium in size, vigorous, somewhat upright, hardy, productive; trunk stocky, smooth; branches slender, long, smooth, reddish-brown, marked with considerable scarfskin, with numerous, rather large lenticels; branchlets of medium length, curved, with short internodes, brown mottled with ash-gray, smooth, glabrous, with few small, slightly raised, inconspicuous lenticels.

Leaves numerous, about two inches wide, three inches long, folded upward, shortoval to obovate, of medium thickness; upper surface dark green; lower surface light green, very slightly pubescent; apex acutely pointed; margin finely and doubly serrate, glandular; petiole one inch long, tinged with dull red, slender, with one or two, rarely three small, globose, brownish glands at the base of the blade.

Buds small, short, conical, plump, free, arranged singly as lateral buds or in clusters of variable size; leaf-scars rather prominent; season of bloom medium; flowers white, one and one-sixteenth inches across; borne in clusters of twos and threes; pedicels three-fourths inch long, rather slender, glabrous, greenish; calyx-tube with a faint tinge of red, obconic, glabrous; calyx-lobes with a trace of red, of medium length and breadth, acute, serrate, glabrous within and without, reflexed; petals roundish, entire, nearly sessile, the apex entire or with a shallow, wide notch; anthers yellowish; filaments three-sixteenths inch long; pistil glabrous, longer than the stamens.

Fruit matures in mid-season; one and one-eighth inches in diameter, obtuse-cordate, slightly compressed, flattened at the extremities; cavity of medium depth, narrow, somewhat obtuse; suture distinct; apex flattened or depressed; color light red becoming dark red or almost black at full maturity; dots numerous, of medium size, russet, rather inconspicuous; stem slender, one and one-half inches long, rather stout at its point of insertion in the fruit, adherent to the fruit; skin moderately thick; flesh light to dark red, firm, crisp, slightly astringent at first, becoming a very pleasant subacid at full maturity, juicy, good to very good in quality; stone semi-clinging, seven-sixteenths inch long, three-eighths inch wide, oval, compressed, with smooth surfaces. 


\section{BALDWIN}

\section{Prunus cerasus}

I. Kan. Hort. Soc. Rpt. 23:81. 1898. 2. Kan. Hort. Soc. Cherry, The, 15, 16, Pl. 1900. 3. Ia. Sta. Bul. $73: 63$. 1903. 4. Am. Pom. Soc. Cat. 27. 1909.

Baldwin is supposed to have grown from a sprout of a stock on which Early Richmond had been budded on the farm of S. J. Baldwin, Seneca, Kansas. The Early Richmond bud was in some manner broken off and the sprout, springing from the stock, was allowed to grow and first fruited in I89I. On the grounds of this Station Baldwin trees which came fairly direct from the originator turned out to be Olivet. The published descriptions that can be found are so scant and fragmentary that we cannot make out whether the variety is really distinct or, as in the case of our trees, is Olivet renamed. The variety has been rather widely disseminated in the Middle West but has not shown much merit either for home or for commercial orchards in the rather lengthy probationary period it has had in the East. The American Pomological Society added Baldwin to its fruit list in I909. The description we give is a compilation.

Tree vigorous, upright, round-topped; leaves large, broad; flowers white, changing to pink.

Fruit ripens early; usually borne in pairs; large, round; stem of medium length, rather thick; color very dark red, yet almost transparent; flavor slightly acid, yet considered one of the sweetest and richest of the Morello class.

\section{BADMANN MAY}

\section{Prunus avium}

I. Downing Fr. Trees Am. 168 fig. 60. 1845. 2. Am. Pom. Soc. Cat. 74. 1862. 3. Hogg Frtuit MIan. 279. 1884.

Frühe Maiherzkirsche. 4. Kraft Pom. Aust. I:1, Tab. 1. 1792. 5. Truchsess-Heim Kirschensort. 140, 141, 142. 1819. 6. Ill. Handb. 49 fig., 50. 1860. 7. Mathieu Nom. Pom. 348, 349. 1889.

Süsse Maiherzkirsche. 8. Christ Handb. 662. 1797.

May Bigarreau. 9. Kenrick Am. Orch. 234. 1841. I0. Mag. Hort. 7:288. 1841. I1. Cultivator N. S. 4:280 fig. I. 1847. 12. Hovey Fr. $A m$. I:55, 56, Pl. 185 I.

Guigne Précoce de Mai. 13. Mortillet Le Cerisier 2:54 fig. 2, 55, 56. 1866. 14. Mas Pom. Gen. II: 5 I, 52, fig. 26. 1882 .

Bigarreau Baumann. 15. Leroy Dict. Pom. 5:176 fig., 177. 1877.

Guigne de Mai. 16. Soc. Nat. Hort. France Pom. 102 fig., 103. 1904.

Baumann May is an early Sweet Cherry which at one time held high place among its kind but a century of culture proved that it had little value except for extreme earliness and it is now but sparingly or not at all grown either in America or abroad. If the variety could be obtained it 


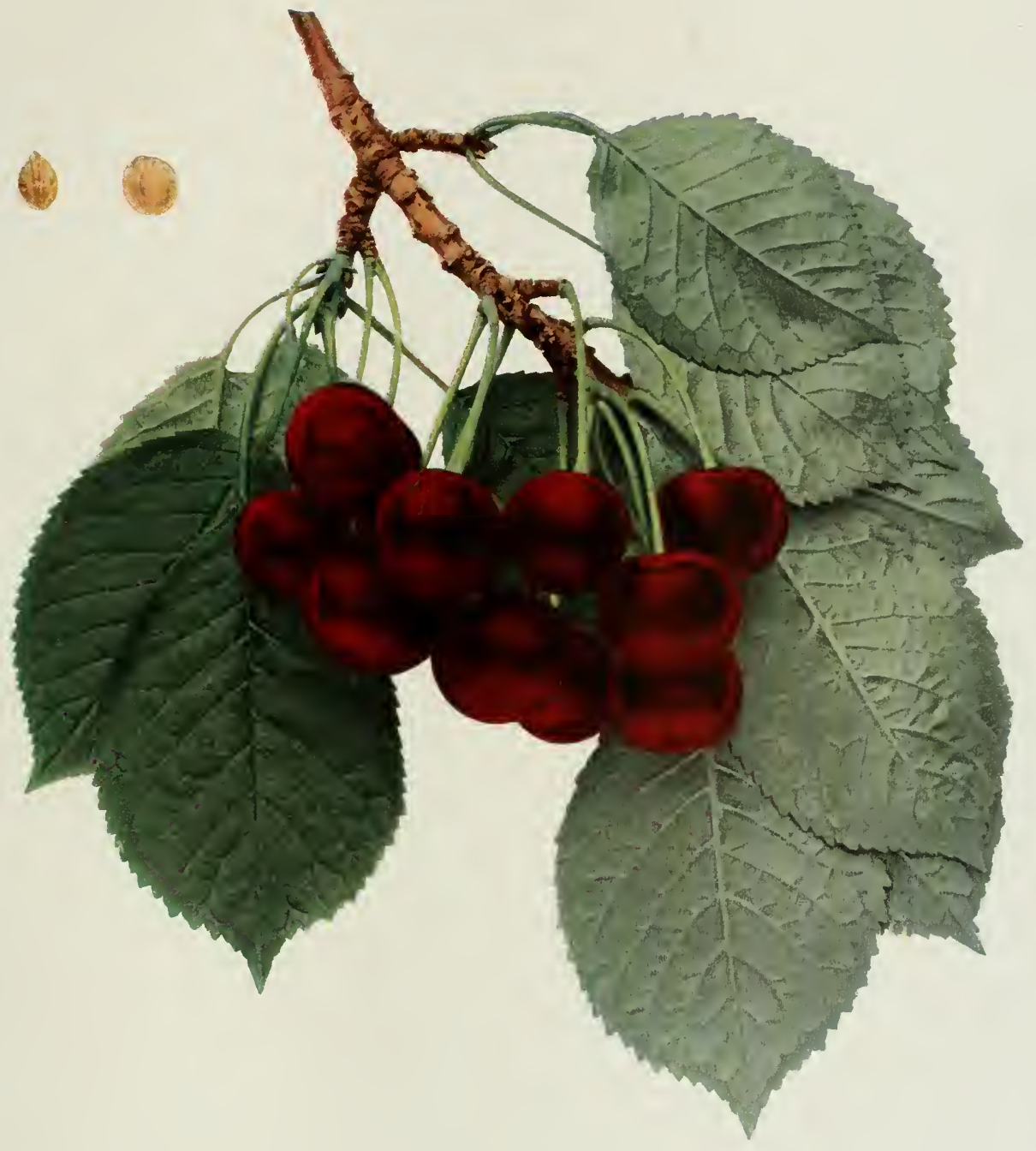

ARCH DUKE 

might be worth growing for breeding work because of its earliness and great productiveness. At one time this variety was rather largely grown in central and western New York and specimens of it must yet remain in this region.

From the latter part of the Eighteenth Century, when we first find an account of this variety in Kraft's Pomona Austriaca, to the last of the Nineteenth, writers have described Baumann May under many different names. From all accounts it originated toward the latter part of the Eighteenth Century, in Germany. From Germany it was introduced into Alsace where F. J. Baumann, a nurseryman at Bollweiler, grew it in his nursery under the name Bigarreau Baumann and disseminated it throughout the French provinces. The cherry was received in America, with several others, by Colonel M. P. Wilder of Boston, Massachusetts, from Messrs. Baumann, about the year 1838. The American Pomological Society listed the variety, in $\mathbf{1 8 6 2}$, in its fruit catalog as Bauman's May but dropped it again in $\mathbf{1} 87 \mathbf{I}$. The following description is a compilation:

Tree vigorous, somewhat spreading, regular in form, compact, very productive; branches stocky, nearly horizontal but often curved downward; branchlets with short internodes, reddish-brown nearly covered with silver-gray scarf-skin; leaves medium to large, dark green, ovate-oblong, coarsely and deeply serrate; petiole rather short, with two large, reniform glands near the base of the leaf; buds large, ovate; flowers of medium size, opening very early.

Fruit matures very early; medium to rather small, ovate-cordate, angular, irregular in outline; color dark red becoming nearly black when fully ripe; stem one and threequarters inches long, rather thick; flesh purplish-red, with abundant juice, soft and tender, sweet, well flavored; of good quality; stone medium in size, roundish-ovate.

\section{BESSARABIAN}

Prunus cerasus

I. Ia. Agr. Col. Bul. 53. 1885. 2. Ia. Sta. Bul. 2:38. 1888. 3. Ibid. 19:549. 1892. 4. Can. Exp. Farm Bul. 17:6. 1892. 5. Mich. Pom. Soc. Rpt. 24. 1894. 6. U. S. D. A. Pom. Rpt. 39, 40. 1895. 7. Am. Pom. Soc. Cat. 17. 1897. 8. Del. Sta. An. Rpt. 12:122, 123 fig. 8, 124. 1900. 9. Wash. Sta. Bul. 92:12. I910.

By general consent Bessarabian has a place in home orchards in the colder parts of the Mississippi Valley and the Great Plains. It is very hardy and is said to thrive even under neglect - standing as much abuse as a forest tree. As compared with standard commercial cherries of the East the fruit is distinctly inferior in size and quality, being hardly fit to eat out of hand, and is sour and astringent even when cooked. The trees, though hardy and healthy, are dwarfish and not productive because of the 
smallness of the cherries. It is an early cherry but the fruit hangs long. The variety is said to root well from cuttings, which, if true, might make it worth while trying as a stock. Bessarabian is a variant of English Morello, the fruit of which sort greatly excels it wherever the trees can be equally well grown.

This variety was brought to America from Russia about 1883 , by Professor J. L. Budd of Ames, Iowa, who believed it to belong to a race of cherries originally found in central Asia.

Tree of medium size, upright, becoming somewhat spreading, compact, healthy, unproductive, very hardy; branches somewhat drooping, long, slender; leaves abundant, medium to small, oval, coarsely serrate, dark green, broad, flat; glands few, usually on the stalk at the base of the leaf.

Fruit matures medium early, remaining on the tree a long time in good condition; medium in size, roundish-oblate to cordate, irregular, bright red becoming dark red; stem long, varying from one and three-fourths to two inches in length, slender, curved; skin tenđer; flesh light to dark red, with abundant colored juice, variable in firmness, sprightly sub-acid becoming milder when fully ripe; fair in quality; stone variable in size, roundish-oval, semi-clinging.

\section{BIGARREAU PÉLISSIER}

\section{Prunus avium}

I. Soc. Nat. Hort. France Pom. 92 fig., 93. 1904. 2. Cat. Cong. Pom. France 30 fig. 1906.

Pélissiers Knorpelkirsche. 3. Proskauer Obstsort. 57. 1907.

This variety originated in France as a chance seedling about 1883 and fruited first in I89I. It was introduced a few years later by M. Auguste Pélissier, a nurseryman at Château-Renard, Bouches-du-Rhône, France. Although not yet well established even in France, this cherry is considered promising for market, because of its firm flesh, handsome appearance, high quality and good tree-characters. It is included among the major varieties in The Cherries of New York that the attention of American cherry-growers may be called to it. As yet it seems not to have been tried in this country. The following description is compiled:

Tree upright, vigorous, very productive; branches rather long, large, bearing large, oval leaves; flowers large, semi-open; blooming season early.

Fruit matures from early June to the last of June; large or very large, obtuse-cordate, slightly depressed at the apex, with a shallow yet distinct suture; stem short, thick; skin rather thick, firm, yellowish almost entirely overspread with vivid red which becomes darker at maturity but often showing streaks of clear red; flesh fine-grained, firm, juicy, red with streaks of white, sweet, aromatic; quality good to very good; stone of medium size, oval, with a pronounced suture. 


\section{BING}

\section{Prunus avium}

1. U. S. D. A. Rpt. 262, Pl. 4 fig. a. 1892. 2. Wash. Bd. Hort. Rpt. 126, 128. 1893. 3. Am. Pom. Soc. Cat. 24. 1899. 4. W. N. Y. Hort. Soc. Rpt. 112. 1900. 5. Ibid. 26. 1904. 6. Am. Pom. Soc. Rpt. 192. 1907. 7. Wickson Cal. Fruits 187. 1908. 8. Am. Pom. Soc. Cat. 26. 1909. 9. Wash. Sta. Bul. 92:23. 1910 .

Bing is one of the best of the several very good cherries from the Pacific Northwest. But few Sweet Cherries equal it in size and attractiveness and none surpass it in quality, so that it may be said to be as good as any of the dessert cherries. It is, too, a very good shipping fruit, ranking with the best of the Bigarreaus, to which group it belongs, as a cherry for distant markets. Another quality commending the variety is that it hangs well on the trees and the crop ripens at one time so that the harvest consists of but one picking. While many cherry-growers speak well of the trees, unfortunately we cannot do so from their behavior on the grounds of this Station. They have not been as vigorous, as healthy or as productive as cherry trees should be in a commercial variety of first rank. The cause, however, may be in the location rather than in the variety, for in an orchard but a few miles distant Bing does much better than on these grounds. The variety, though comparatively new, is no longer on probation. It has a niche in the cherry flora of the country, deserving a place in the collection of every amateur by virtue of its splendid fruit. When it is happy in soil and climate, Bing is bound to be one of the leading commercial cherries.

Seth Lewelling of Milwaukee, Oregon, the originator of several of our finest cherries, grew Bing from the seed of Republican in I 875. The variety was named after a Chinese workman. In I 899 the American Pomological Society placed the variety on its fruit list.

Tree large, vigorous, erect becoming upright-spreading, rather open, productive; trunk and branches thick, smooth; branches brownish with numerous, small lenticels; branchlets thick, long, with long internodes, greenish-brown, smooth, pubescent, with small, raised, conspicuous lenticels.

Leaves abundant, large, folded upward, ovate to obovate of medium thickness; upper surface dark green, smooth; lower surface light green, pubescent; apex abruptly pointed, or acute, base abrupt; margin slightly serrate, glandular; petiole long, pubescent, thickish, tinged red, with from one to three large, reniform, reddish glands on the stalk.

Fruit matures in mid-season or later; very large, one inch in diameter, broadly cordate, somewhat compressed, slightly angular; cavity deep, of medium width, abrupt, regular; suture a dark line; apex roundish or slightly depressed; color very dark red, 
almost black; dots small, russet, inconspicuous; stem variable in thickness, one and onefourth inches long; skin of medium thickness, tough, adherent to the pulp; flesh purplishred with dark purple juice, rather coarse, firm, very meaty, brittle, sweet; of very good quality; stone semi-free, large, ovate to oval, blunt, with smooth surfaces.

\section{BLACK GUIGNE}

\section{Prunus avium}

I. Prince Pom. Man. 2:112. I832.

Scheur-Kers. 2. Knoop Fructologie 2:36, 43. 1771.

Frühe Schwarze Herakirsche. 3. Christ Wörterb. 274. 1802.

Guigne Bigaudelle. 4. Prince Pom. Man. 2:113. 1832.

Coburger Maiherzkirsche. 5. Ill. Handb. 51 fig., 52. 1860. 6. Oberdieck Obst-Sort. 377. I88I. 7. Lauche Deut. Pom. III:No. I, P1. 1882.

Guigne Noire Commune. 8. Leroy Dict. Pom. 5:328, 329 fig., 33o. 1877.

Noire Hâtive de Cobourg. 9. Mas Pom. Gen. I1:123, 124, fig. 62. 1882.

There is much confusion in the history of this old cherry. It undoubtedly originated in France and in that part of the country later conquered by the Germans, though Mas, in his Pomologie Générale, mentioned it as probably of German origin. In the time of Louis XIII this variety was known as the Guigne Noire Commune and was cultivated quite extensively in France and northern Italy. It was esteemed both for its earliness and its fine quality and was known as Guigne Guindoulle by the peasants of central France and by the Tuscans in Italy as Corbini because of the color of its skin. Black Guigne, Black Heart, and Early Purple, which, while similar in many characters, are entirely distinct, have been badly confused by both French and German writers and it is only with the greatest difficulty that the three can be separated. While this cherry was formerly considered of worth in Continental Europe, it is scarcely recognized there now and was probably never brought to America. The following description is compiled from European fruit-books :

Tree very large, round-topped, spreading, irregular in outline, productive; branches long, large, straight, brownish, mottled with gray scarf-skin; internodes long and unequal; leaves large, oval or oblong, acuminate; margin irregularly serrate; petiole long, slender, with large glands; blooming season late; flowers small.

Fruit matures the last of June to the middle of July, usually attached in pairs but sometimes in threes; medium to large in size, obtuse-cordate; color bright reddish-black changing to deep purple; suture indistinct; stem slender, inserted in a deep, broad cavity; skin thin, tender; flesh dark purple, with abundant colored juice, half-tender, somewhat stringy, sweet yet sprightly, pleasantly flavored; quality good; stone small, oval. 


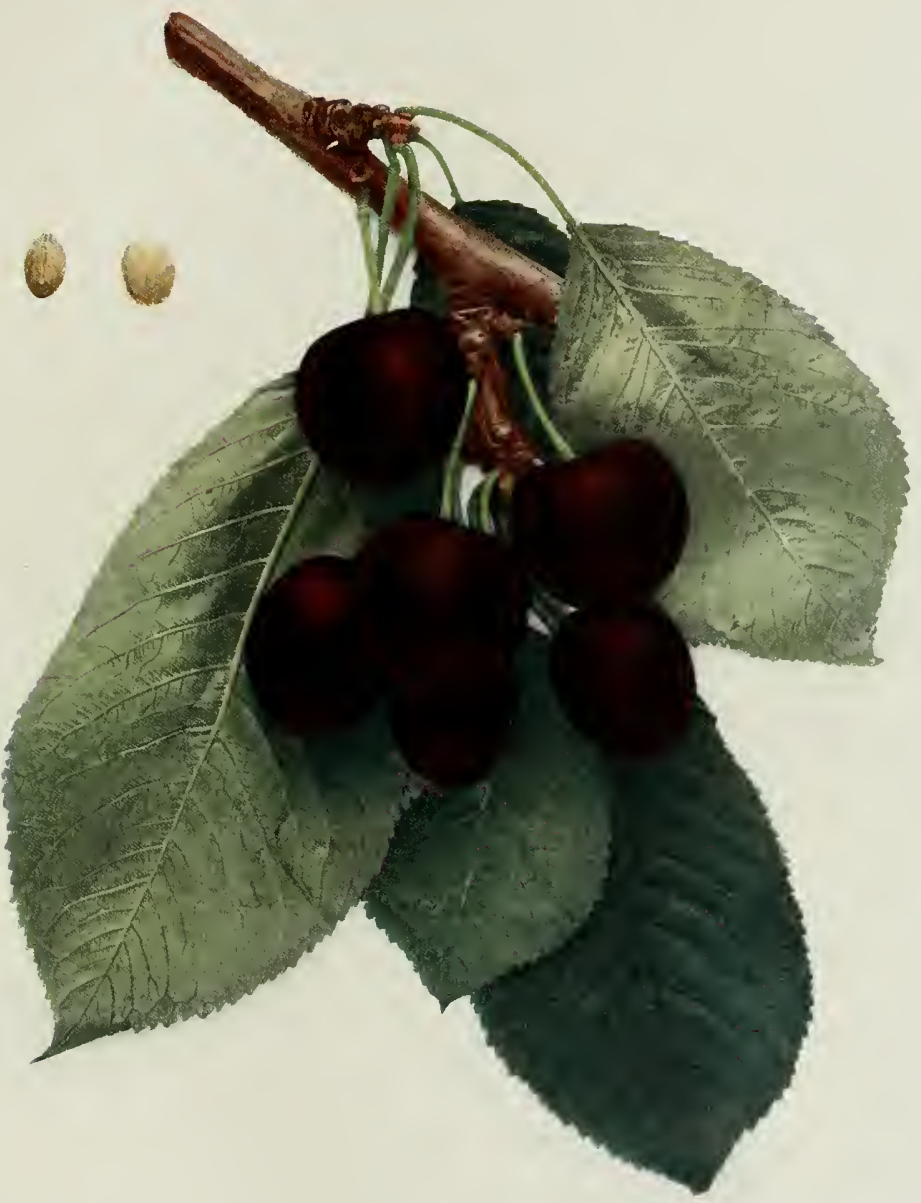





\section{BLACK HAWK}

\section{Prunus avium}

1. Horticulturist 6: 360,361 fig. 1851. 2. Am. Pom. Soc. Rpt. 45, 235. 1854. 3. Elliott Fr. Book 190 fig. 1854. 4. Hooper W. Fr. Book 258, 270, 271. 1857. 5. U. S. D. A. Rpl. 382. 1875.

Épervier Noir, 6. Mas Pom. Gen, II:41, 42, fig. 21. 1882 .

Despite the fact that Black Hawk was lauded by the horticulturists in the middle of the last century as one of the best of all black Sweet Cherries, it is now almost unknown. According to the older pomologists it was unsurpassed for eating out of hand but was only mediocre in all other characters of either fruit or tree. In particular it was surpassed in many ways by the better-known Eagle which fills about the same place in cherry culture. The variety was very popular in southern Ohio about Cincinnati where many trees may still be found and where it is still more or less planted. Possibly because of the excellent quality of the fruit, the amateur might well try a tree or two. The description is compiled.

Black Hawk originated with Professor J. P. Kirtland of Cleveland, Ohio, sometime previous to I 845 . It is one of the best of the many seedlings fruited by him. The American Pomological Society in I $85+$ named this sort as one of the promising new fruits and it still remains on the fruitlist of this organization.

Tree large, vigorous, spreading, round-topped, resembling Yellow Spanish in habit, productive, healthy; branches stout, smooth, dark reddish-brown, straight; branchlets slender, with short internodes.

Leaves large, folded upward, obovate, rather thick; upper surface dark green; lower surface pale green; apex abruptly pointed; margin coarsely and deeply serrate; petiole short, stout, bright red, with two or more orange-red, reniform glands.

Buds of medium size, rather short, free; flowers small or medium in size; pedicels long, very slender; calyx-lobes straight, finely serrate, obtuse; petals roundish, broadly and deeply notched at the tip.

Fruit matures about the middle of June, a few days later than Black Tartarian; medium to large, obtuse-cordate, surface uneven, sides compressed; cavity deep, broad, abrupt, nearly regular; color glossy, dark purplish-black changing to almost black at complete maturity; stem usually thick but often variable, of medium length; skin thick, adhering to the pulp; flesh purplish-black, tender, with abundant colored juice, aromatic, well flavored, sweet; of very good quality; stone of medium size, with uneven surfaces.

\section{BLACK HEART}

\section{Prunus avium}

1. Rea Floro 205. 1676. 2. Prince Pom. Mon. 2:115. 1832. 3. Downing Fr. Trees Am. 169 fig. 1845. 4. Am. Pom. Soc. Rpl. 195. 1854. 50 Thompson Gord. Ass't 526. 1859. 6. Am. Pom. Soc. Cot. 74. 1862 . 
Guignier à Fruit Noir. 7. Duhamel Trait. Arb. Fr. I:158, 159, 160, Pl. I fig. I. 1768.

Frühe Schwarze Herzkirsche. 8. Truchsess-Heim Kirschensort. I16-I19. 1819. 9. Mathieu Nom. Pom. 340, 349. 1889.

Guigne Noire Ancienne. Io. Mortillet Le Cerisier 2:66 fig. 7, 67, 68. 1866.

Bigarreau Noir d'Espagne. I1. Leroy Dict. Pom. 5:223 fig., 224. 1877.

Although one of the oldest cherries under cultivation, Black Heart is still largely grown the world over. Prince, in $\mathrm{I} 832$, said that it was more widely cultivated in the United States than any other variety and Downing, in 1845 , said Black Heart was then better known than any other cherry in the country. While neither of these two statements would hold for Black Heart now, it having long since passed its heyday of popularity, it is still, because of the fruitfulness of the tree and the high quality and beauty of the fruit, a variety of much merit. Black Heart fails in the commercial fruit growing of nowadays, as compared with the cherry culture of the fruit connoisseurs of a generation ago, because it does not meet market demands, failing to do so through two defects: it does not ship well and when brown-rot is rife it quickly succumbs to this fungus. It is, too, now difficult to obtain the variety true to name, the trees at this Station, as an example, in several attempts, turning out untrue, which forces the use of a compiled description in this text.

This cherry was mentioned by John Rea in 1676 but there can be no doubt but that it originated many years previous to this date. Probably it is the cherry mentioned by Robert Dodonée, a naturalist of Malines, Belgium, in $\mathbf{1 5 5 2}$. When or by whom it was introduced to America is not known but it was being grown here very early in the Nineteenth Century and ever since has been considered a valuable variety for general planting. Nearly every nurseryman throughout the United States lists Black Heart, a fact attesting its popularity. The American Pomological Society placed Black Heart on its catalog of fruits in I862, a place which it has since retained.

Tree large, very vigorous, tall, wide-spreading, productive; branches stout, brownish, mingled with yellow, mottled with gray scarf-skin; lenticels numerous, small.

Leaves very large, oblong, waved, acuminate, nearly flat; upper surface dark green; margin deeply and coarsely serrate; petiole of medium length, lightly tinged with red, with greenish glands.

Buds large, oval, pointed; season of bloom early or very early; flowers medium in size; petals roundish, imbricated.

Fruit matures early, season long; large, obtuse-cordate, somewhat compressed; cavity broad; suture deep; surface somewhat irregular; color dark purple becoming black; stem one and three-fourths inches long, siender; skin slightly shrivelled; flesh dark red, firm 
to very firm becoming tender at full maturity, with abundant colored juice, sweet; good in quality; stone large, roundish-ovate; dorsal suture deep.

\section{BLACK TARTARIAN}

\section{Prunus avium}

1. Truchsess-Heim Kirschensort. 130-132. 1819. 2. Pom. Mag. 1:44, Pl, 1828. 3. Lond. Hort. Soc. Cat. 55. 1831. 4. Prince Pom. Man. 2:II3, IIt. 1832. 5. Proc. Nat. Con. Fr. Gr. 52. $18+8$. 6. Dochnahl Führ. Obstkunde 3:21. 1858. 7. Ill. Handb. 61 fig., 62. 1860. 8. Leroy Dict. Pom. 5:228, 229 fig., 230. 1877. 9. Mathieu Nom. Pom. 377, 378. 1889. I0. Cai. Cong. Pom. France 37. 1906.

Ronald's Large Black Heart. II. Forsyth Treat. Fr. Trees 42, 43. 1803.

Guigne Noire à Gros Fruit. 12. Cat. Cong. Pom. France 36.1906.

Tartarian. 13. Am. Pom. Soc. Cat. 26. 1909.

Black Tartarian is probably the favorite dooryard and roadside Sweet Cherry in New York and ranks second or third among commercial cherries in the State, as it probably does for the whole region east of the Mississippi. It is known by all who grow or eat cherries. The preeminently meritorious characters which give it so high a place in cherry culture are: first, and most important, the elasticity of its constitution whereby it adapts itself to widely different soils and climates; second, the fruitfulness, healthfulness and robustness of the trees which also bear regularly, live to an old age and grow to a prodigious size, oftentimes attaining a diameter of two feet; third, this variety is comparatively free from the worst of cherry diseases, brown-rot; lastly, the cherries, though not as large as some similar sorts, are tempting to the eye through their rotund form and glossy black color and are a delight to the palate, the handsome purplish-red flesh being firm and crisp, yet juicy, with a sweet, rich flavor which all agree gives the quality the rank of "very good to best." It is a virile variety and from it have come several promising seedlings and it is one of the parents of a number of cross-bred cherries. Black Tartarian is earlier than most of the Sweet Cherries with which it must compete - under most conditions a help in marketing. Unfortunately it is a little too soft to handle well in harvesting and marketing or to hold its shape as a canned product. Its small size is also against it for the canner's trade. The several defects noted prevent Black Tartarian from taking first rank in commercial orchards but for the home plantation it is one of the best.

Black Tartarian came originally from Russia. It was introduced into England in 1794 from Circassia, by Hugh Ronalds of Brentford, Middlesex, as Ronald's Large Black Heart. Two years later, John Fraser introduced a variety, a native of Crimea, which he purchased in St. Petersburg, as 
Fraser's Black Tartarian. This turned out to be the same as the cherry from Circassia. Some go farther back and say that Black Tartarian was carried to Russia from Spain, thence to England. It owes its introduction into this country to William Prince of Flushing, Long Island, probably in the early part of the Nineteenth Century. It was recognized in 1848 and placed on the schedule of fruits at the National Convention of Fruit Growers which later became the present American Pomological Society. The variety still retains a place among the recommended cherries but under the name Tartarian. The variety quickly became popular in America, finding a place in every orchard and in the lists of all nurserymen. Some nurserymen claim to have superior strains of the old variety; as, Green's Tartarian and Black Tartarian Improved. Comparisons show no differences. Black Russian, listed by some firms, is probably Black Tartarian as it is used many times as a synonym by foreign writers.

Tree characteristically large, vigorous, upright, vasiform, productive; trunk of medium thickness, smooth; branches smooth, reddish-brown, slightly overspread with ash-gray, with large lenticels; branchlets rather long, brown almost entirely overspread with ashgray, smooth, glabrous, with inconspicuous, slightly raised lenticels.

Leaves numerous, five and one-half inches long, two and one-half inches wide, folded upward, obovate to elliptical, thin; upper surface dark green, rugose; lower surface light green, slightly pubsecent; apex acute, base abrupt; margin varies from serrate to crenate; petiole two inches long, thick, tinged with red, with a few hairs, with from one to three reniform, reddish glands of medium size usually on the stalk.

Buds pointed or obtuse, plump, free, arranged singly as lateral buds, or in small clusters on spurs of variable length; leaf-scars very prominent; season of bloom medium; flowers white, one and one-fourth inches across, borne in scattering well-distributed clusters in twos and threes; pedicels one inch long, slender, glabrous, greenish; calyx-tube faintly tinged with red, campanulate, glabrous; calyx-lobes with a trace of red, long, broad, obtuse, glabrous within and without, reflexed; petals roundish, entire, with short, blunt claws; anthers yellowish; filaments nearly one-half inch long; pistil glabrous, shorter than the stamens.

Fruit matures early; less than one inch in diameter, cordate, compressed; cavity intermediate in depth and width, flaring; suture indistinct; apex pointed and slightly depressed; color purplish-black; dots numerous, small, russet, obscure; stem slender, one and one-half inches long, adherent to the fruit; skin thin, separating readily from the pulp; flesh purplish-red, with dark colored juice, firm, meaty, crisp, pleasant flavored, mild, sweet; of very good quality; stone free, ovate, slightly flattened and oblique, with smooth surfaces.

\section{BLEEDING HEART}

Prunus avium

I. Rea Flora 205. 1676. 2. Forsyth Treat. Fr. Trees 42. 1803. 3. Floy-Lindley Guide Orch. Gard. I04. I846. 4. Elliott Fr. Book $215 . \quad 1854$. 


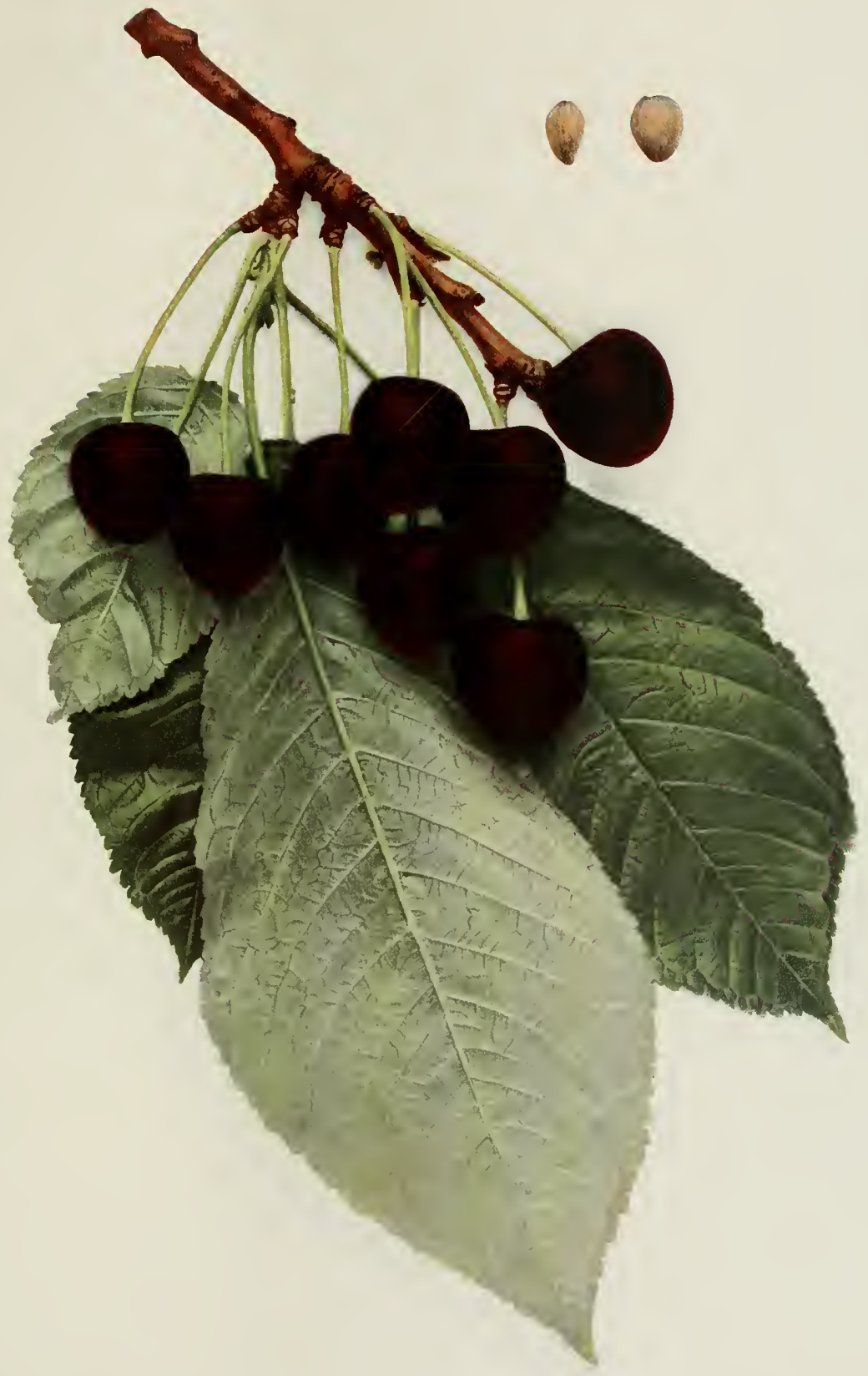

BLACK TARTARIAN 

Gascoigne. 5. Parkinson Par. Ter. 571, 572. I629. 6. Gerarde Herball I504. 1636. 7. Hogg Fruit Man. 298. 1884 .

Red Heart. 8. Rea Flora 206. 1676. 9. Brookshaw Hort. Reposit. 2: I83, Pl. 96 fig. I. I 823.

Blutherzkirsche. Io. Truchsess-Heim Kirschensort. 224, 225, 226. I8I9.

Gascoigne's Heart. II. Downing Fr. Trees Am. I74. $18+5$.

Blutrothe Molkenkirsche. 12. Dochnahl Führ. Obstkunde 3:29. 1858.

Guigne Rouge Hâtive. 13. Leroy Dict. Pom. 5:338 fig., 339. 1877.

Bleeding Heart goes back almost as far as the history of cultivated cherries. It is only of historical interest now and this chiefly because it has been the parent of many sorts of present worth. According to the old writers it took highest rank in the cherry lists of a century and more ago by virtue of its high quality and handsome appearance, the name being indicative of color and form. So far as can be made out at this late date the variety has been grown but little or not at all in America, the description here given coming from old pomologies.

This, like the preceding sort, is a cherry of several names, having been mentioned first by Parkinson in I629 as the Gascoign Cherry. In England three different names have been applied to this variety, Gascoigne, Red Heart and Bleeding Heart. At least there seems to be little doubt that the Bleeding Heart and Red Heart listed by John Rea in 1676 were the Gascoign of Parkinson and Gerarde.

Tree of largest size, very vigorous, not very productive; branches numerous, large, long, diverging, brownish-red, mottled with gray scarf-skin; leaves very large, oblong, acuminate; margin crenate; petiole thick, long, reddish, with well-developed glands; blooming season early.

Fruit matures the latter half of July; usually in pairs, large, elongated heart-shaped, with pointed apex; color bright red changing to dark red, somewhat mottled; stem two inches long, slender; flesh reddish, rather tender although firm, with abundant juice, highly flavored, sweetish; good in quality; stone large, oblong.

\section{BOURGUEIL}

\section{Prumus cerasus}

Cerise de Bourgueil. I. Mortillet Le Cerisier 2:205. 1866 .

Montmorency de Bourgueil. 2. Mas Le Verger 8:123, 124, fig. 60. 1866-73. 3. Leroy Dict. Pom. $5: 364,365$ fig. 1877 .

Bourgueil is a variant form of Montmorency hardly differing enough in fruit from Large Montmorency to be distinguished from it and yet since it seems to be more productive than the last-named sort it is possibly worth adding to the cherry flora of the country. The variety, it must be remembered, is still on probation, but if trees true to name can be obtained 
it is worth planting in small numbers where growers want a cherry of the Montmorency type.

This variety was found by a Doctor Bretonneau about 1844 in Bourgueil, Indre-et-Loire, France. It is known by the name of the finder as well as that of the locality in which it originated and through having the same place of origin is often confused with Cerise Rouge Pale. The United States Department of Agriculture received this variety in 1905 from Ferdinand Jamin, Bourg-la-Reine, Seine, France, and in turn forwarded it to this Station where it has been fruiting for the past few seasons. Nurserymen do not as yet offer it for sale and it is doubtful if it is known in more than a few places in America.

Tree vigorous, upright-spreading, vasiform, productive; branches slender, smooth, reddish-brown partly covered with ash-gray, with numerous lenticels; branchlets slender, long, brown, with some ash-gray, smooth, with numerous inconspicuous, raised lenticels.

Leaves numerous, four inches long, two inches wide, folded upward, obovate to ovate, thick; upper surface dark green, smooth; lower surface light green, pubescent along the veins; apex and base variable in shape; margin doubly crenate; petiole one inch long, thick, with a dull tinge of red, pubescent, with none or with from one to three globose, yellow or brownish glands on the base of the blade.

Buds small, short, variable in shape, plump, free, arranged singly as lateral buds and on short spurs in clusters variable in size; leaf-scars prominent; season of bloom late; flowers white, one and one-fourth inches across; borne in scattering, well-distributed clusters, usually in threes; pedicels short, one-half inch long, glabrous, greenish; calyxtube faintly tinged with red, campanulate, glabrous; calyx-lobes with a trace of red, broad, serrate, glabrous within and without, reflexed; petals crinkled, roundish, entire, sessile, with apex entire; filaments one-fourth inch long; pistil glabrous, equal to the stamens in length.

Fruit matures in mid-season; three-fourths inch long, one inch wide, nearly oblate, somewhat compressed; cavity deep, wide, medium flaring, regular; suture indistinct; apex roundish to flattened; color bright red; dots small, russet, inconspicuous; stem stout, one and one-eighth inches long, adherent to the fruit; skin tender, free; flesh yellowishwhite with colorless juice, tender and melting, sprightly, sour; of good quality; stone free, large, roundish-ovate, pointed, with smooth surfaces, tinged with red, with a prominent ventral suture.

\section{BRUSSELER BRAUNE}

\section{Prunus cerasus}

1. Christ Handb. 676. 1797. 2. Christ Wörterb. 288. 1802. 3. Truchsess-Heim Kirschensort. 533-536. 1819. 4. Dochnahl Führ. Obstkunde 3:63, 64. 1858. 5. Mathieu Nom. Pom. 333, 341. 1889. 6. Am. Pom. Soc. Cat. 24. 1899. 7. Del. Sta. An. Rpt. 12:124, 125, fig. 8. 1900.

Brüsselsche Bruyn. 8. Krüitz Enc. 75, 76. 1790.

Zweite Grösser Herakirschweichsel. 9. Kraft Pom. Aust. 1:9, Tab. 22 fig. I. 1792.

Ratafia. 10. Hogg Fruit Man. 309, 3 10. I884. 


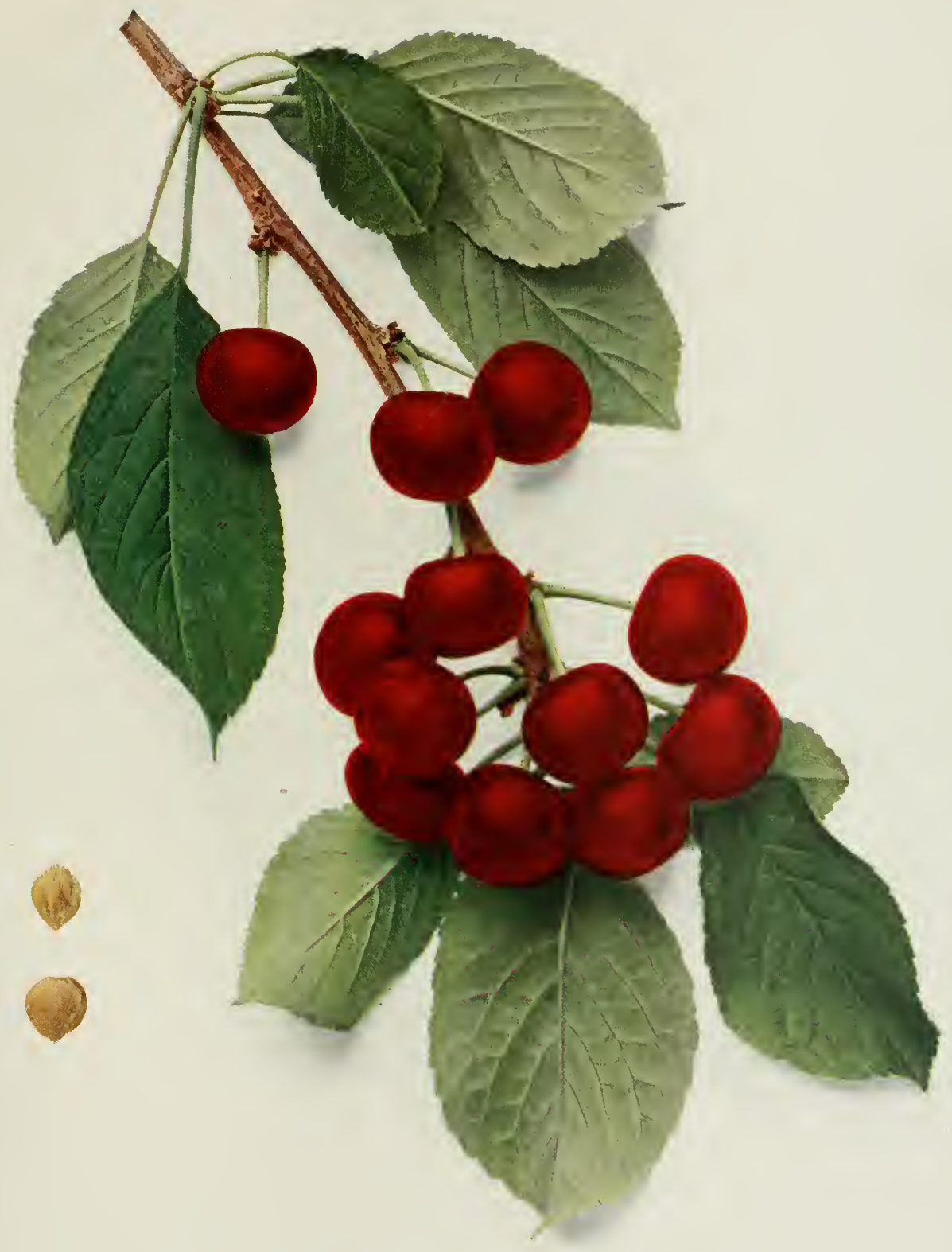

BOURGUEIL 

From the standpoint of commercial cherry culture, Brusseler Braune has little value. The trees are uncertain in bearing; the cherries are small, sour, and astringent; and, worse than the faults named, the crop ripens very unevenly. It is of the English Morello type but in New York, at least, is far inferior to this well-known sort. Brusseler Braune has been much advertised for cold climates but there are many better cherries that stand cold nearly or quite as well and are better in both tree and fruit characters and, in particular, that will not vex the souls of growers by ripening so unevenly. The variety has two marked peculiarities: the leaves on the two-year-old wood are very small and the fruit-stems bear a small leaflet at their base. These leaflets on the fruit-stem would have to be removed in marketing the crop - another serious defect.

No doubt Brusseler Braune originated in Holland but there is nothing definite as to the time though Truchsess, a German, writes of having received it in $\mathbf{I} 785$ as Brüsselsche Bruyn. The synonyms of this variety are more or less confused with those of English Morello. This cherry was brought to America in I 883 by the late J. L. Budd with several other varieties. In the collection of trees sent out from the original importation, of which this was one, or from trees budded from them, were Griotte du Nord, Large Long Late, Shadow Amarelle, Lutovka, George Glass, Orel No. 27 , or Gibb, and Bessarabian. Unfortunately the varieties were badly mixed and much confusion has resulted. It is not impossible that the first three are synonyms but the Lutovka, George Glass, Bessarabian and possibly the Gibb are distinct varieties. In I 895, this Station recommended a new cherry for trial for home and market and distributed buds throughout the state under the name Lutovka. Later it was found that an error had been made regarding the trees sent us as Lutovka, they being the Brusseler Braune. The American Pomological Society added Brusseler Braune to its fruit catalog list in I 899 but dropped it in 1909.

Tree of medium size, vigorous, upright-spreading but with drooping branchlets, dense, round-topped, unproductive; trunk and branches smooth, stout; branches brownish, overspread with ash-gray, with numerous small lenticels; branchlets slender, with short internodes, nearly covered with ash-gray, smooth, glabrous, with small, lightly raised, inconspicuous lenticels.

Leaves three and one-half inches long, one and three-fourths inches wide, folded upward, obovate, thick, grooved along the midrib; upper surface very dark, dull green; lower surface light green, pubescent; apex taper-pointed, base acute; margin finely and doubly serrate; petiole one and one-eighth inches long, tinged with dull, dark red, grooved along the upper surface, with from one to four small, globose, yellowish-green glands. 
Buds pointed, plump, free, arranged as lateral buds and in clusters on scattering, short spurs; leaf-scars prominent; season of bloom late; flowers one inch across, white; borne in scattering clusters in threes and fours; pedicels one and one-eighth inches long, slender, glabrous, greenish; calyx-tube furrowed, tinted with red, obconic, glabrous; calyxlobes with a trace of red, acuminate, serrate, glabrous within and without, reflexed; petals oval to obovate, entire, nearly sessile, with a shallow, wide notch at the apex; filaments one-fourth inch long; pistil glabrous, equal to the stamens in length.

Fruit matures very late; nearly one inch in diameter, although variable in size, roundish-cordate, slightly compressed; cavity of medium depth, narrow, abrupt; suture very shallow, indistinct; apex roundish, with a small depression at the center; color light red changing to dark red as the season advances; dots numerous, small, dark russet, inconspicuous; stem two and one-fourth inches long, with small leaflets at the base, strongly adherent to the fruit; skin thin, tender, separates readily from the pulp; flesh dark red, with dark colored juice, tender and melting, somewhat astringent, sour; of fair quality; stone nearly free when fully mature, fifteen-thirty-seconds inch long, roundishoval, rather plump, blunt-pointed; surfaces smooth; ventral suture slightiy enlarged near the base.

\section{BUNTE AMARELLE}

\section{Prunus cerasus}

I. Truchsess-Heim Kirschensort. 652-655. 1819. 2. Ia. Hort. Soc. Rpt. 330. 1885. 3. Ia. Sta. Bul. 2:40. 1888. 4. Budd-Hansen Am. Hort. Afan. 2:272. 1903 .

So far Bunte Amarelle has found a place only in the trying cherry climate of Iowa and neighboring States. It is not attractive enough in appearance, good enough in quality, or certain and fruitful enough in bearing to compete with other Amarelles, to which group this variety belongs. Its saving grace is extreme hardiness of tree, though vigor and health help make it somewhat desirable in cold, prairie regions of the Mid-West where cherry growing is more or less precarious. There has been much uncertainty as to the true variety and we have had to discard the trees on the Station grounds and compile a description.

This variety probably originated in Germany in the latter part of the Eighteenth Century. Truchsess, a German, in 1819, called the cherry Bunte Amarelle because of its variegated color before full maturity. The variety was introduced from Poland to America sometime previous to I 885 and has usually gone under the name of Amarelle Bunte. From all accounts Professor J. L. Budd of Ames, Iowa, the authority on these hardy cherries during his time, had two different cherries under the name Amarelle Bunte; for in his report at the Iowa Horticultural Society in $188_{5}$, he mentioned a variety under that name as being a large, dark purple and nearly sweet sort which could not have been the true Bunte Amarelle of Truchsess. 


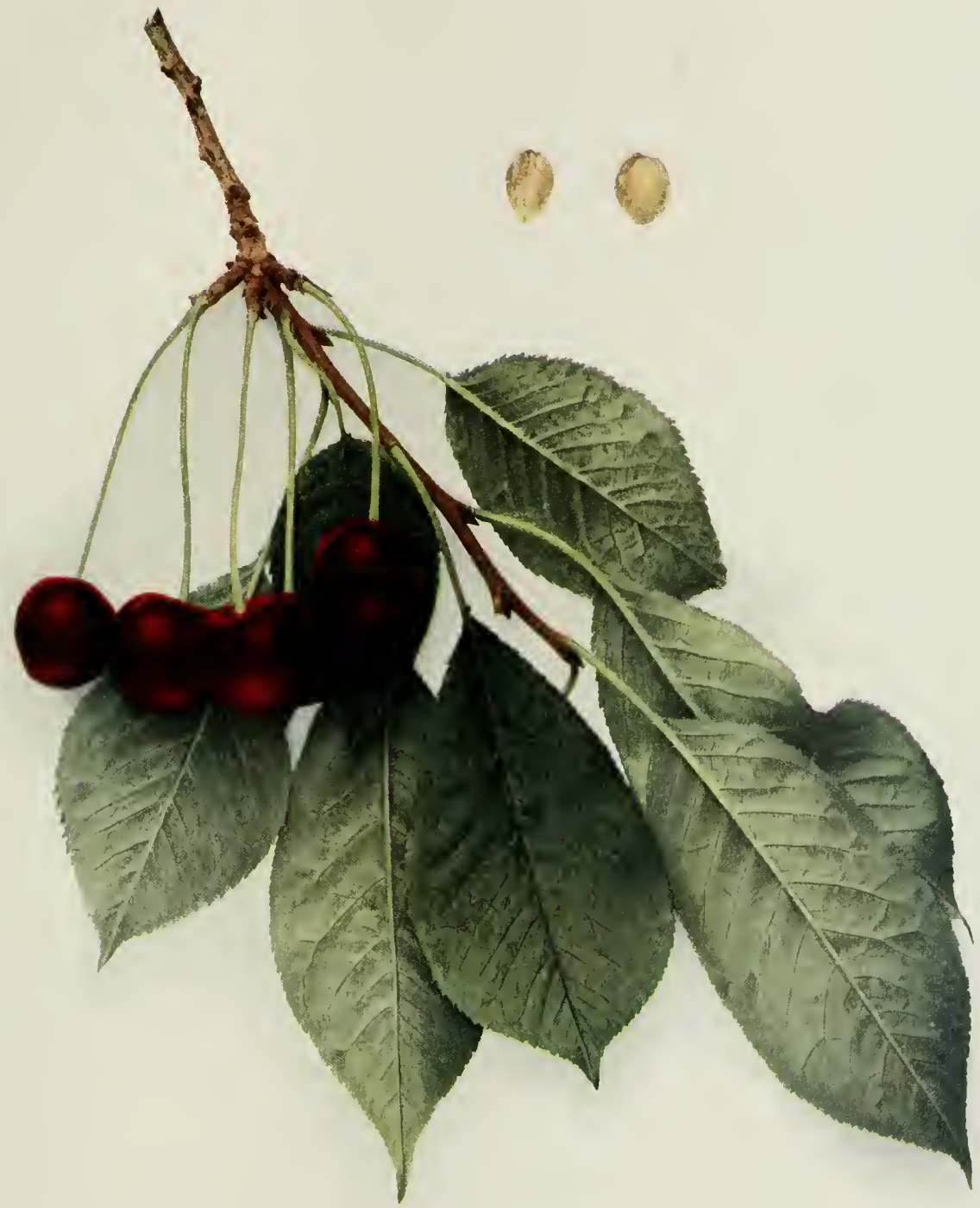



Budd and Hansen in 1903 described a variety which agrees very closely with the true variety of Truchsess which we herewith describe.

Tree vigorous, upright, hardy; foliage large, coarse.

Fruit matures the second week in June; medium to large, roundish, flattened at the base; cavity variable in depth; suture shallow, indistinct; apex depressed; color yellow overspread with light red; stem green, straight, rather slender, one and one-half to two inches long; flesh slightly colored, juicy, firm but tender, pleasantly subacid; very good in quality; stone variable in size, broad.

\section{CALIFORNIA ADVANCE}

\section{Prunus avium}

I. Wickson Cal. Fruits 289, 292. 1889. 2. Wash. Sta. Bul. 92:25. 1910.

Adrance. 3. Am. Pom. Soc. Rpt. I3o. I 897.

Ulatis. 4. Mich. Sta. Bul. 177:32. 1899.

California Advance is a Sweet Cherry, one of the "Hearts " of common parlance, distinguished and worth growing only because it is extra early, though when fully ripe it is of very good quality. It is usually described as a cherry of "large size" but on the grounds of this Station the cherries run small, as they are occasionally reported elsewhere to do, suggesting that the variety requires good care and a choice cherry soil for a finely finished product. On these grounds the variety seems to be preeminently free from fungus diseases but the robin and other birds take greater toll from it than from almost any other cherry, beginning their harvest long before the fruit is fit for human fare. California Advance might well be planted in a small way for a local market in New York, or a tree or two for home use, but it has no place in large numbers in this State.

California Advance came from a seed of Early Purple sown by W. H. Chapman of Napa, California, the seedling being saved because the cherries were larger and ripened earlier than those of its parent. It has sometimes been confused with the Chapman cherry, of somewhat similar characteristics, which also originated in Napa, but the two are quite distinct.

Tree large, vigorous, upright-spreading, dense, productive; trunk and branches stout, smooth; branchlets of medium thickness, brownish-bronze partly covered with ash-gray, glabrous; leaves numerous, five and one-half inches long, two and one-half inches wide, long-obovate to elliptical, thin, medium green, slightly rugose; margin serrate, glandular; petiole nearly two inches long, slender, tinged with red, pubescent along the upper side and with a shallow groove, with from two to four large, reniform, reddish glands, usually on the stalk; buds large, obtuse or pointed, plump, arranged singly as lateral buds or in clusters of variable size on numerous short spurs; leaf-scars prominent; season of bloom early; flowers one and one-eighth inches across; pistil equal to the stamens in length. 
Fruit ripens very early, season averaging eleven days; about three-fourths inch in diameter, roundish-cordate, compressed; color purplish-black; stem of medium thickness, often one and one-half inches long, adherent to the fruit; skin thin, tender, separates from the pulp; flesh reddish, with dark red juice, meaty, tender, mild, sweet; of very good quality; stone semi-clinging, three-eighths inch by eleven-thirty-seconds inch in size, roundishoval, compressed, oblique, with smooth surfaces.

\section{CARNATION}

\section{Prunus cerasus}

I. Rea Flora 205. 1676. 2. Langley Pomona 86, Pl. 16 fig. 3. 1729. 3. Forsyth Treat. Fr. Trees 42. 1803. 4. Coxe Cult. Fr. Trees 251, 1817. 5. Prince Pom. Man. 2:138, 139. 1832. 6. Downing Fr. Trees Am. 194 fig. 83. 1845. 7. Thompson Gard. Ass't 529. 1859. 8. Am. Pom. Soc. Cat. 74. 1862. 9. Mas Le Verger 8:91, 92, fig. 44. 1866-73. 10. Hogg Fruil Man. 289. 1884.

Cerise d'Orange. II. Knoop Fructologie 2:36, 4I. 177 I.

Rothe Oranienkirsche. 12. Krünitz Enc. 55, 56. 1790. 13. Truchsess-Heim Kirschensort. 456-463. 1819. 14. Ill. Handb. 175 fig., 176. 1860.

Carnation is a conspicuous cherry because of its beautiful color - red, a little variegated with white or yellow, hence the name. It is one of the Amarelles, similar to Montmorency except in color in which character it is more pleasing than the better-known sort. The stone separates from the pulp very readily leaving the flesh unusually bright and clean. Because of their sprightly refreshing flavor, the cherries are pleasing to the palate, as well as attractive to the eye. Unfortunately the trees are but moderately vigorous and fruitful and these qualities count so heavily against it as a commercial cherry that Carnation cannot be more than a fruit for amateurs unless under exceptional conditions. For a home plantation, however, it would be hard to name a better cherry of its kind.

Carnation is another of the choicely good, old cherries, being first mentioned by John Rea in 1676 and later by Langley in 1729 . Having been cultivated for so long and disseminated among so many growers who kept meagre records in early days, this sort became badly confused with other varieties, especially with the "Cerisier à gros fruit rouge-pale," men-

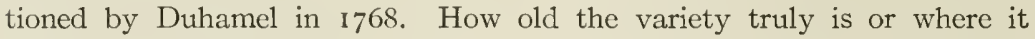
originated cannot be said. Carnation seems to have been first mentioned in America by William Coxe in I8I 7 and a few years later it was growing on the grounds of William Prince, Flushing, New York. Since that time it has been quite widely disseminated throughout the United States but is grown less extensively now than formerly. The American Pomological Society, in I 862, placed Carnation on its list of recommended fruits where it still holds a place. 


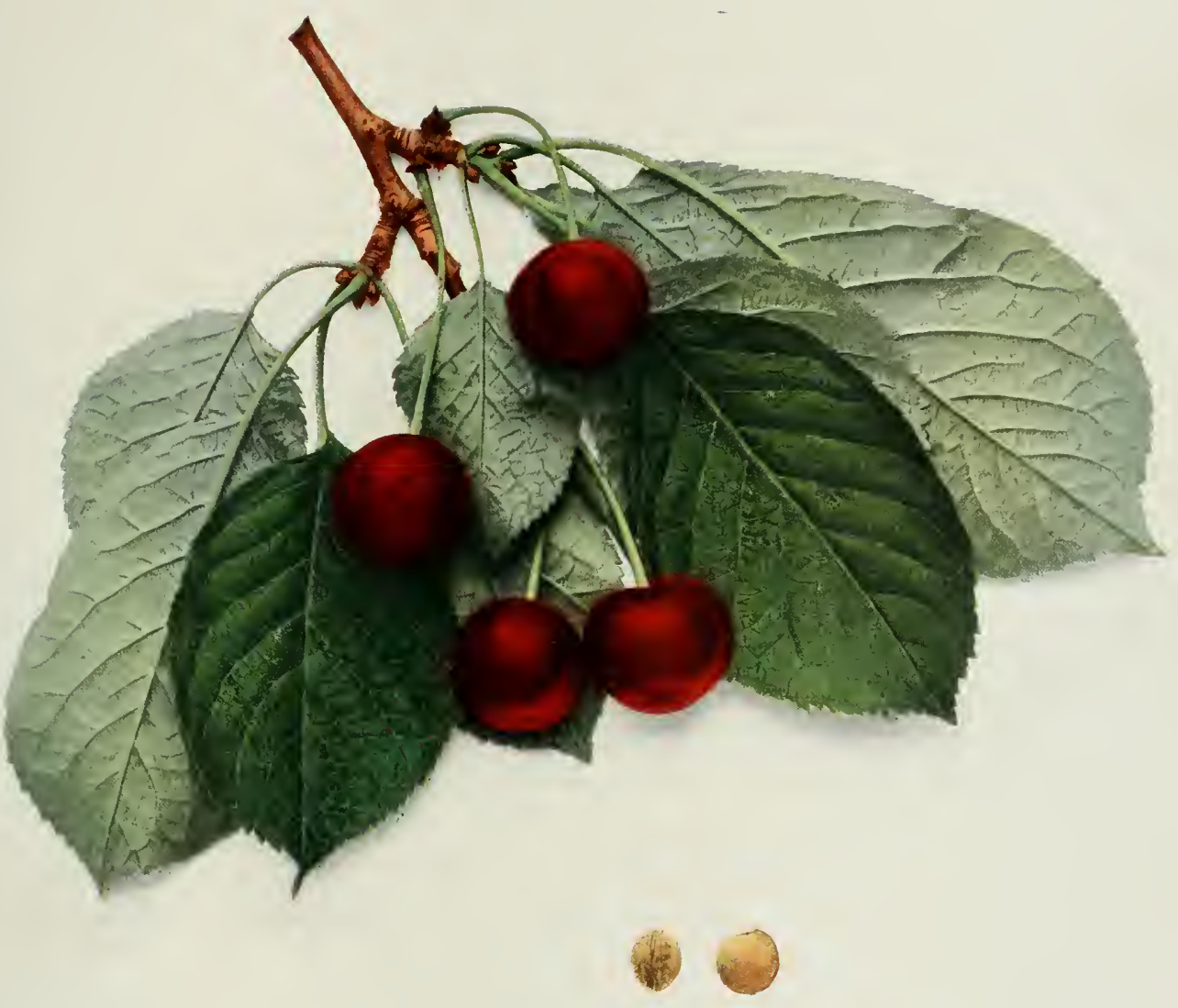



Tree medium in size, spreading, becoming drooping, not very productive; trunk intermediate in thickness; branches reddish-brown overspread with ash-gray, with numerous lenticels variable in size; branchlets brown or ash-gray, smooth, with numerous conspicuous, raised lenticels.

Leaves very numerous, four inches long, two inches wide, folded upward, oval to obovate, thin; upper surface dark green, roughened; lower surface dull, light green, thinly pubescent; apex acute; margin finely and doubly serrate, glandular; petiole two inches long, slender, dull red on the upper surface, with one or two large, reniform, reddish glands on the stalk.

Buds small, short, obtuse, plump, free, arranged singly as lateral buds, or in small clusters on numerous, short spurs; season of bloom late; flowers white, one and one-fourth inches across; borne in scattered clusters in twos and threes; pedicels one inch long, of medium thickness, glabrous, green; calyx-tube light reddish-green, campanulate, glabrous; calyx-lobes tinged with red, of medium length, broad, acute, glabrous within and without, reflexed; petals roundish-oval, entire, with short, broad claws, the apex notched; filaments in four series, the longest averaging one-half inch in length; pistil glabrous, shorter than the stamens.

Fruit matures in mid-season or later; three-fourths of an inch long, one inch in thickness, roundish-oblate, compressed; cavity deep, abrupt; suture indistinct; apex flattened or with a deep depression; color medium to dark red; dots numerous, small, russet, inconspicuous; stem one and one-half inches long, adherent to the fruit; skin tender, separating readily from the pulp; flesh yellowish-white, with abundant colorless juice, tender and melting, sprightly; of very good quality; stone free, nearly one-half inch in diameter, roundish, blunt, with smooth surfaces.

\section{CENTENNIAL}

\section{Prunus avium}

1. Am. Pom. Soc. Rpt. 17, 159. 1885. 2. Wickson Cal. Fruits 289. 1889. 3. Am. Pom. Soc. Cat. 24. $\quad$ I 899 .

In California, Centennial is passing from the period of probation to one of general acceptance as a standard variety. Unfortunately it has not been well tested in the East but trees growing in a commercial orchard at Geneva show the variety to be a close competitor, in this instance at least, with its parent, Napoleon, the mainstay of Sweet Cherry growers in New York. In some respects it quite surpasses Napoleon. It is larger, sweeter and better flavored and has a smaller pit. The trees fall short of those of its well-known parent, however, in being less fruitful. Even more serious defects are, in the orchard under observation, that Centennial cracks and is less successful in resisting brown-rot than Napoleon though it surpasses many other well-known sorts in these respects. The two varieties under comparison may be further distinguished by the more 
oblate fruits of Centennial, by a more mottled color and by the pits which are longer and more pointed in the newer variety. Centennial is recommended for home orchards and experimentally for commercial plantations.

Centennial is a seedling of Napoleon grown by Henry Chapman, Napa, California. It came in fruit in 1876 but was not introduced until 1885, Leonard Coates of Napa, California, being the introducer. Despite its many merits, Centennial did not win a place on the fruit list of the American Pomological Society until I 899.

Tree large, vigorous, upright-spreading, open-topped, productive; trunk thick, roughish; branches stout, smooth, brownish, with many large lenticels; branchlets thick, with internodes of medium length.

Leaves numerous, large, flattened, long-oval to obovate, thick; upper surface dark green, rugose; lower surface pale green, thinly pubescent; apex taper-pointed; margin coarsely serrate, with small and inconspicuous glands; petiole one and one-fourth inches long, pubescent, tinged with red, with from two to four large, reniform, greenish-red, flattened glands, usually on the stalk.

Buds large, long, pointed, plump, free, arranged singly as lateral buds or in small clusters on short spurs; leaf-scars prominent; blooming season about the middle of May; flowers one and one-fourth inches across, usually arranged in twos and threes; pedicels variable in length averaging one and one-eighth inches, slender, glabrous, greenish; calyxtube faintly tinged with red, obconic, glabrous; calyx-lobes long, acute, glabrous on both surfaces, reflexed; petals oval, entire, tapering to short, narrow claws, with a slightly crenate apex; anthers greenish; filaments one-eighth inch long, shorter than the petals; pistil glabrous, equal to the stamens in length.

Fruit matures the last week in June, length of season rather short; very large, shortcordate, compressed; cavity deep, wide; suture distinct, broad, shallow; apex roundish or slightly depressed; color amber-yellow, speckled and overlaid with crimson; dots whitish, inconspicuous; stem thick, one and one-fourth inches long, adherent to the pulp; skin thin, tender, cracks badly, adherent to the pulp; flesh whitish, with colorless juice, meaty, crackling, sprightly, sweet; of very good quality; stone semi-clinging, three-eighths inch in length, eleven-thirty-seconds inch in width, ovate, plump, oblique, with smooth surfaces; ridged on the ventral suture.

\section{CHOISY}

\section{Prunus avium $\times$ Prunus cerasus}

Cerisier à Fruit Ambré, à Fruit Blanc. I. Duhamel Trait. Arb. Fr. I:185, I86, I87, Pl. XI. I768.

Schöne von Choisy. 2. Truchsess-Heim Kirschensort. 452-455. 18rg. 3. Mathieu Nom. Pom. 333, 334, 376.1889 .

Belle de Choisy. 4. Pom. Mag. 1:42, PI. 1828. 5. Prince Pom. Man. 2:137. 1832. 6. Cultivator I0: 150 fig. 1843. 7. Downing Fr. Trees $A m$. 190 fig. 79. 1845. 8. Poiteau Pom. Franc. 2: No. 27, P1. 1846. 9. Am. Pom. Soc. Rpt. 37, 38, 102. 1852. Io. Ann. Pom. Belge I:63, fig. 2. I853. I1. Elliott Fr. Book 189. 1854. I2. Am. Pom. Soc. Cat. 74. 1862. I3. Mortillet Le Cerisier 2:169, 170 fig. 45 , 171, 172. I866. I4. Mas Le Verger 8: I 13, I1 4, fig. 55. 1866-73. I5. Hogg Fruit Mon. 276, 280. I884. 16. Soc. Nat. Hort. France Pom. 80 fig., 81. 1904. 17. Cat. Cong. Pom. France 18. 1906. 
It seems to be the consensus of opinion of a score or more of European and American pomologists who have known Choisy that it is the handsomest and most delicious of all Duke cherries - one of the very best of all dessert cherries. In it are delicately combined the richness of the Sweet Cherry and the sprightliness of the Sour Cherry. Unfortunately, while it bears early and regularly, the trees are seldom fruitful. As an offset to unfruitfulness, however, the trees are vigorous, hardy and healthy. The cherries keep and stand the wear and tear of marketing as well as those of any other Duke. Its qualities all commend it for the home orchard and for a local market. In particular it may be recommended for cold climates where a true Sweet Cherry is not quite hardy, this hybrid being nearly as hardy as the other parent, the Sour Cherry. Unfortunately suitable specimens of this beautiful cherry could not be obtained for a color-plate and the description has had to be compiled in part.

Duhamel describes two amber-colored cherries, one of which is listed by Leroy as Belle de Choisy. The Cerise Blanche, or Cerise Ambrée (Grosse), according to Leroy, was cultivated in Central France as early as 1628 and in 1667 Merlet wrote of it as the most curious and rare of all cherries. Kenrick, American Orchardist, I832, lists a variety, Ambrée, which according to Floy-Lindley's and Duhamel's descriptions must be Choisy. Some writers, however, say that Choisy was first grown by M. Gondouin, a gardener for Louis XV, in $\mathrm{I} 760$, at the village of Choisy near Paris. The American Pomological Society, in its report for 1852 , mentioned this variety as having promise and ten years later listed it in the Society's fruit catalog where it has since remained.

Tree large, vigorous, spreading, somewhat open, hardy, but moderately productive; branches thick, of a clear grayish color with brownish-red tips; lenticels very numerous, large, roundish.

Leaves numerous, very broad, obovate, rather abruptly pointed; upper surface shining dark green, deeply and regularly serrate to rather dentate.

Buds large, thick, conical, clear brown somewhat covered with gray; season of bloom rather early; flowers white, large, numerous, borne in large clusters; petioles short, scarcely an inch in length; petals broadly round, edges dentate; calyx-lobes short, large; pistil longer than the stamens.

Fruit matures in some localities just before May Duke, in others just after that variety, ordinarily ripe, however, at the end of June; usually attached in pairs, large, roundish to somewhat oval, flattened toward the base; cavity shallow, wide; suture shallow, indistinct; apex depressed; color attractive bright red mottled with yellow and amber; stem thick at the base, one and one-half to two inches long, generally forking at about one-half 
inch from the base; skin thin, somewhat firm, semi-transparent showing the netted texture of the pulp beneath; flesh pale amber, with abundant colorless juice, tender, melting, sweet, pleasant flavor; very good in quality; stone medium to small, roundish, pointed at the apex; dorsal suture indistinct; surfaces nearly smooth.

\section{CLEVELAND}

Prunus avium

I. Horticulturist 2:60 fig. 1847-48. 2. Elliott Fr. Book 191 fig., 192. 1854. 3. Am. Pom. Soc. Cat. 74. 1862. 4. Mortillet Le Cerisier 2:131. 1866.

Knorpelkirsche von Cleveland. 5. Ill. Handb. 45 fig., 46.1867.

Cleveland is a Bigarreau which falls so far short of its near kin, as it grows in New York at least, as not to be worth planting except as an early cherry of its type - earliness being its one saving asset. The cherries closely resemble Rockport in size, color, shape and flavor, are in no way better than that somewhat mediocre sort and are even more subject to brown-rot. It ripens with Black Tartarian and can never compete in orchard or market with that sort. Possibly Cleveland has too much merit to be wholly neglected yet it certainly is not worth planting in New York unless in a locality where it does exceptionally well and when an early cherry of its kind is wanted.

Cleveland is said by its introducer, Professor J. P. Kirtland, to be a seedling from Yellow Spanish. Its close similarity to Rockport suggests that it may have come from a pit of that variety. It was brought out in I 842 but was not adopted by the American Pomological Society for its fruit list until I 862. Despite rapidly passing popularity it is still on this list.

Tree of medium size and vigor, upright-spreading, open, very productive; trunk of medium diameter and smoothness; branches smooth, reddish-brown partly overspread with ash-gray, with many small lenticels; branchlets slender, brown partly overspread with ash-gray, smooth, with numerous small, inconspicuous lenticels.

Leaves numerous, five inches long, two and one-half inches wide, folded upward, obovate to long-elliptical, thin; upper surface medium green, slightly rugose; lower surface light green, lightly pubescent; apex acute, base abrupt; margin coarsely and doubly serrate, glandular; petiole often two inches long, reddish, rather slender, hairy, grooved, glandless or with from one to four reniform, reddish glands, usually on the stalk.

Buds small, short, pointed, plump, free, arranged singly as lateral buds or in clusters of variable size on rather short spurs; leaf-scars prominent; flowers white, one and onefourth inches across; borne in scattered clusters, usually in twos; pedicels three-fourths inch long, glabrous, greenish; calyx-tube green, tinged with red, light green within, broadly campanulate, glabrous; calyx-lobes tinged with red, broad, acute, glabrous within and 
without, reflexed; petals roundish, entire, with short, broad claws, notched and crinkled at the apex; filaments in four series, the longest averaging one-half inch in length; pistil glabrous, shorter than the stamens.

Fruit matures early; about three-fourths of an inch in diameter, cordate, compressed, with an irregular surface; cavity wide, flaring, irregular; suture shallow, indistinct; apex somewhat obtusely-pointed; color light red overspreading yellow; dots numerous, small, yellowish, obscure; stem slender, one and one-half inches long, adherent to the fruit; skin thin, tender, separating readily from the pulp; flesh light yellow, with colorless juice, tender and melting, sweet; of good quality; stone clinging, large, one-half inch long, oval, flattened at the base, plump, with smooth surfaces.

\section{CLUSTER}

\section{Prunus cerasus}

1. Parkinson Par. Ter. 572, fig. 10. 1629. 2. Gerarde Herball 1505 fig. 6. 1636. 3. Prince Pom. Man. 2:132, I33. 1832. 4. Downing Fr. Trees Am. 194 fig., 195. 1845. 5. Hogg Fruit Man. 290. $188+$.

Flanders Cluster. 6. Ray Hist. Plant. 1539. 1688.

Cerisier à Bouquet. 7. Duhamel Trait Arb. Fr. 1:176, 177, 178, Pl. VI. 1768. 8. Poiteau Pom. Franc. 2: No. 16, P1. 1846. 9. Nas Le Verger 8: 47,48 , fig. 22. I866-73.

Tros-Kers. 10. Knoop Fructologie 2:43. $177 \mathrm{t}$.

Trauben oder Bouquet Amarelle. II. Truchsess-Heim Kirschensort. 62I-629. 1819. I2. Dochnahl Führ. Obstkunde 3:70, 71. 1858. 13. Mathieu Nom. Pom. 340. 1889.

Griolte à Bouquet. 14. Leroy Dict. Pom. 5:278, 279 fig., 280, 28I, 1877.

Cluster is a curiosity, characterized by fruits borne in clusters at the extremity of a single peduncle. The pistils vary from one to a dozen, setting from one to five perfect fruits in the cluster or from eight to twelve as the trees become older. The variety is little known in America but is well known in Europe, having first been described by Daléchamp in 1586 , according to Leroy. Its origin is uncertain. Parkinson speaks of it as Flanders Cluster, in I629, and as it was cultivated in Germany before I6I3 and nearly as soon in Switzerland it may be assumed that either South Germany or Flanders is its native home. It appears under several names in European fruit books, the terms trochet, bouquet, buschel, and trauben all signifying that the fruits are borne in clusters and usually referring to this variety. The Cerisier à Trochet of Duhamel is probably a distinct variety. The fruit has little value and is cultivated chiefly as a curiosity. The following description is compiled:

Tree small and bushy, moderately vigorous, dense, productive; branches numerous, long, slender, somewhat curved, drooping and often breaking under a load of fruit; internodes long; leaves small, oblong, acuminate; margin doubly serrate; petiole thick, short, rigid, with small, roundish, conspicuous glands; blooming season late; flowers small. 
Fruit matures the last of June, attached in twos or threes, with from two to eight fruits per cluster; variable in size, roundish, flattened at the extremities; suture prominent; color clear red becoming darker at maturity; skin tough, transparent; stem long, inserted in a deep cavity; flesh nearly white, transparent, with abundant juice which is usually uncolored but sometimes tinged red, very tender, sour, yet agreeable; quality fair; stone small, roundish, compressed.

\section{COE}

Prunus avium

I. Am. Pom. Soc. Cat. 26. 1909.

Coe's Transparent. 2. Horticulturist 2:71, 72 fig. 1847-48. 3. Am. Pom. Soc. Cat. 211.1856. 4. Mortillet Le Cerisier 2:87 fig., 88. 1866. 5. Culk. \& Count. Gent. 36:326. 1871. 6. Thomas Guide Prat. 15, 206. 1876.

Guigne Có́. 7. Leroy Dict. Pom. 5:319 fig., 320. 1877.

Coe's Bunte Transparent. 8. Mathieu Nom. Pom. 3+3. 1889.

Even earlier and certainly better than Cleveland, which we have just discussed, is Coe, long known as Coe's Transparent. This is the first of the light-colored cherries to ripen and is a splendid fruit in quality and appearance. The color-plate shows this variety very well - possibly too well, since one of its defects is variability in color, the variant usually being very light colored and not as attractive as the type. A second defect is that the fruit runs rather small. The tree-characters are in the main very good. The variety can be distinguished, as a rule, by the large, spreading tree and to a lesser extent by its hardiness, vigor, healthfulness and fruitfulness. Coe is worthy of a place in every home plantation, in orchards for local markets and in favored localities as an early cherry for the general market.

Curtis Coe of Middletown, Connecticut, grew this variety early in the Nineteenth Century from a pit of what he supposed to be Ox Heart. The American Pomological Society included Coe in its list of recommended fruits in 1856.

Tree large, vigorous, upright-spreading, open, very productive; trunk stocky, shaggy; branches thick, smooth, dark reddish-brown overlaid with ash-gray, with many raised lenticels; branchlets stout, short, brown nearly covered with gray, smooth, glabrous, with numerous small, conspicuous, raised lenticels.

Leaves numerous, four and one-fourth inches long, two and one-fourth inches wide, folded upward or flattened, long-elliptical to obovate, thin; upper surface medium green; lower surface light green, thinly pubescent; apex acute, base abrupt; margin coarsely serrate, with small, black glands; petiole one and three-fourths inches long, thick, tinged with red, grooved, hairy, with from one to three large, reniform, greenish-yellow or reddish glands on the stalk. 


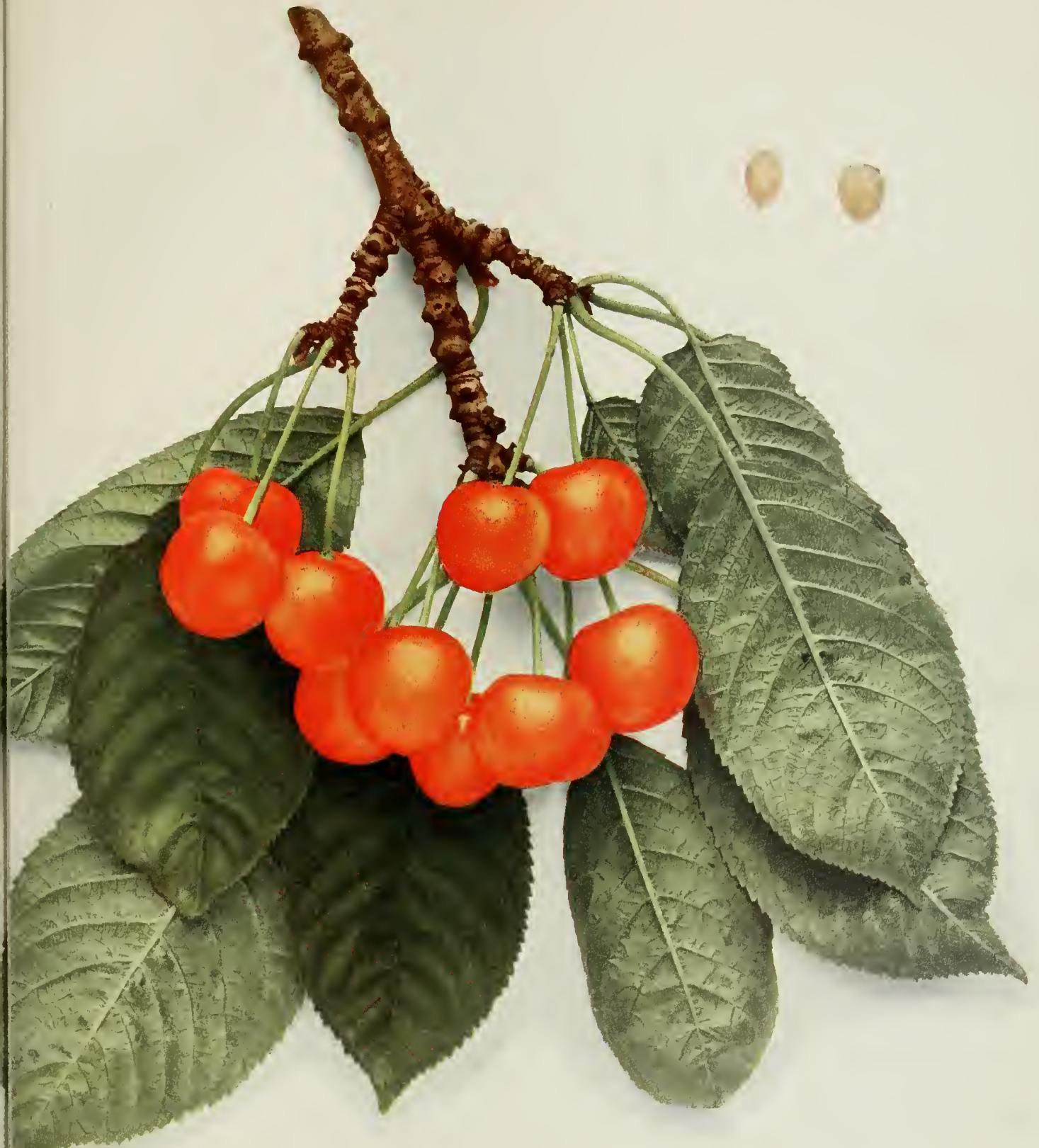



Buds large, long, conical, plump, free, in clusters on spurs variable in length; leafscars very prominent; season of bloom intermediate; flowers one and one-fourth inches across, white; borne in dense clusters, thickly distributed over the tree in twos and threes; pedicels one inch long, slender, glabrous, green; calyx-tube green, broadly campanulate, glabrous; calyx-lobes tinged with red, broad, obtuse, glabrous within and without, reflexed; petals roundish, entire, with a shallow notch at the apex; filaments one-quarter inch long; pistil glabrous, equal to the stamens in length.

Fruit matures early; nearly one inch in diameter, roundish-cordate, slightly compressed; cavity regular, abrupt; suture indistinct; apex blunt-pointed or slightly depressed; color pale amber faintly mottled with red; dots small, light yellow, inconspicuous; stem slender, one and one-half inches long, adherent to the fruit; skin thin, of medium toughness, separating from the pulp; flesh pale yellow, with colorless juice, tender, meaty, mild, sweet; good to very good in quality; stone semi-free or free, one-half inch long, less than one-half inch wide, roundish, somewhat flattened, blunt, with smooth surfaces; ridged along the ventral suture.

\section{DIKEMAN}

\section{Prunus avium}

I. Del. Sta. Bul. 35:16, 17 fig. 1897 .

Dikeman has some merit as a very late Sweet Cherry but here its usefulness ends. The cherries are too small and the pits too large for this variety to have great worth. The tree is somewhat remarkable for its spreading habit and stout branches. Plant-breeders seeking for a very late sort might well choose Dikeman as a parent.

Two very similar cherries, with a variation in the spelling, pass under this name. Late in the Eighteenth Century there appeared a cherry on the Dyckman farm near New York City. Some thought it to be identical with Black Tartarian; others said it was distinct and called it Dyckman. It was never more than of local note. Some few years ago the late S. D. Willard of Geneva introduced the Dikeman cherry from the farm of George B. Dikeman, Oceana County, Michigan. This variety often goes under the name Dykeman but from the information at hand we feel certain that Dikeman is the correct spelling. On our grounds this variety and Black Tartarian, although similar, are two distinct sorts, the Dikeman being later, firmer and a clingstone.

Tree large, vigorous, broadly-spreading, open-topped, productive; trunk and branches thick, smooth; branches reddish-brown covered with ash-gray, with numerous lenticels which are variable in size; branchlets short, brown, partly covered with ash-gray, smooth, glabrous, with inconspicuous, slightly raised lenticels.

Leaves numerous, four and one-half inches long, two and one-fourth inches wide, folded upward, obovate to long-elliptical, thin; upper surface medium green, slightly rugose; 
lower surface light green, faintly pubescent; apex acute, base abrupt; margin coarsely and doubly serrate; petiole about one and one-half inches long, tinged with red, with a few hairs, with from one to four reniform, reddish glands, usually on the stalk.

Buds large, pointed, plump, free, arranged singly as lateral buds or in clusters variable in size on short spurs; leaf-scars prominent; season of bloom intermediate; flowers white, one and three-eighths inches across; borne in scattering clusters, in ones, twos or threes; pedicels one and one-fourth inches long, glabrous, greenish; calyx-tube tinged with red, campanulate, glabrous; calyx-lobes with reddish tinge, broad, acute, glabrous within and without, reflexed; petals roundish, entire, nearly sessile, with a shallow notch at the apex; filaments one-half inch long; pistil glabrous, shorter than the stamens.

Fruit matures late; about three-fourths of an inch in diameter, cordate; cavity wide, flaring; suture shallow, indistinct; apex slightly pointed, with a small depression at the center; color purplish-black; dots numerous, small, dark russet, inconspicuous; stem siender, one and one-fourth inches long, adherent to the fruit; skin thin, tender, adherent to the pulp; flesh dark red, with dark colored juice, very meaty, crisp, mild, somewhat aromatic, sweet; of good quality; stone clinging, longer than wide, ovate, flattened, with smooth surfaces, somewhat marked with a reddish tinge.

\section{DOUBLE GLASS}

\section{Prunus avium $\times$ Prunus cerasus}

I. Truchsess-Heim Kirschensort. 440-451, 487-490, 689. 1819. 2. Dochnahl Führ. Obstkunde 3:51. 52. 1858. 3. Ill. Handb. 163 fig., 164. 1860. 4. Mich. Hort. Soc. Rpt. 329. I888. 5. Ia. Hort. Soc. Rpt. 80. 189o. 6. Can. Exp. Farm Bul. 17:7. 1892. 7. Budd-Hansen Am. Hort. Man. 2:274. 1903. Amarelle Double de Verre. 8. Mortillet Le Cerisier 2:197-201, fig. 55. 1866. Great Cornelian. 9. Hogg Fruit Man. 299. 1884.

Glass. Io. Ia, Sta. Bul. 73:70. 1903.

Double Glass is a Duke, a hybrid more nearly resembling the Sweet Cherry than the Sour Cherry. The trees grow remarkably well in nursery and orchard and their behavior so pleased growers when the variety was brought to notice that it became for a time quite the vogue. But the trees turned out to be unproductive and the cherries so mediocre that the variety rapidly passed through its heyday of popularity. The fruits are curiously marked, the suture being so deep as to make them appear double - hence the name. The variety has no value where sweet sorts are hardy but possibly might find a niche somewhere in regions where a more tender Sweet Cherry cannot be grown.

This variety, of ancient and unknown origin, dates back at least to I792 when Truchsess received it from Christ under the names Grosse Frühkirsche and Englische Erzherzogskirsche, both of which were incorrect, the first because it was not characteristic since the fruit did not ripen early, and the second because it denoted a class of dark-fleshed cherries. In 
France, Double Glass has long been cultivated under the name Amarelle Double de Verre. The variety was brought to America from Russia in 1883 by Professor J. L. Budd. While grown for a time in the Central States it was never highly regarded and has now nearly passed from cultivation. The following description is a compilation:

Tree large, vigorous, upright-spreading becoming divergent with age, usually hardy, rather unproductive; branchlets thick, reddish-brown; leaves healthy, small to medium, ovate, with serrated margins; buds large, prominent.

Fruit matures the latter part of June; usually large, roundish-oblate, with a very deep suture; color light red becoming much darker at maturity; stem long, thick; skin thin, tough, translucent; flesh yellowish, with abundant uncolored juice, firm, tender, sprightly; good in quality; stone medium in size, roundish.

\section{DOUBLE NATTE}

\section{Prumus cerasus}

I. Truchsess-Heim Kirschensort. 538, 539. 1819. 2. Hogg Fruit Man. 292. 1884. 3. Mich. Hort. Soc. Rpt. 327. 1888. 4. Ia. Sta. Bul. 73:67. 1903.

Cerise van der Nat. 5. Knoop Fructologie 2:41. $177 \mathrm{I}$.

Kirsche von der Nalle. 6. Krünitz Enc. 69, 70. 1790. 7. Truchsess-Heim Kirschensort. 539-542. 1819. 8. Ill. Handb. 509 fig., 5 10. 1861 .

Budd's importations of Russian cherries, to which reference is so often made in this text, brought forth almost universal praise for any and all of the foreign sorts. Cultural tests soon demonstrated, however, that most of the varieties were comparatively worthless; Double Natte is one of these. It is a very mediocre cherry of the Morello group in nowise equal to English Morello except when earliness is a prime requisite, this sort being one of the earliest of the Morellos. In flavor it is equal to English Morello but is no better. At Geneva the trees are seldom very fruitful. From the eulogistic reports of its behavior in the Middle West it would seem that it was better adapted to Iowa, for instance, than for New York.

This variety was first mentioned by Knoop, the Dutch pomologist, in $177 \mathrm{I}$ - origin not given. Some years ago Professor J. L. Budd also imported from Russia a cherry under the name Riga No. I8. This cherry has been grown as a separate variety under the name Riga but the descriptions of it are all identical with those of Double Natte and there can be no doubt but that they are one and the same.

Tree large, vigorous, upright-spreading, open-topped, somewhat vasiform, productive; trunk and branches smooth; branches brown nearly covered with ash-gray, with a few large lenticels; branchlets long, with short internodes, brown partly covered with ash-gray, smooth, with a few very large, raised lenticels. 
Leaves numerous, three and three-eighths inches long, one and three-fourths inches wide, folded upward, short-obovate, thick, stiff; upper surface glossy, slightly rugose; lower surface pale green, thinly pubescent; apex sharp-pointed, tapering toward the base; margin coarscly serrate, glandular; petiole thick, dull red, grooved on the upper surface, nearly one inch long, glandless or with one or two small glands at the base of the blade.

Buds conical or pointed, plump, free, arranged singly as lateral buds and in small clusters on spurs; leaf-scars inconspicuous; season of bloom intermediate; flowers white, one and one-fourth inches across; borne in scattering clusters in twos and threes; pedicels one inch long, slender, glabrous, greenish; calyx-tube with a faint reddish tinge, campanulate, glabrous; calyx-lobes tinged red, long, acute, glabrous within and without, reflexed; petals obovate, entire, tapering to short, narrow claws, with a broad but shallow notch at the apex; filaments about one-fourth inch long; pistil glabrous, shorter than the stamens.

Fruit matures early; three-fourths of an inch in diameter, cordate to conical, compressed; cavity somewhat abrupt, regular; suture deep, distinct, often extending entirely around the fruit; apex depressed; color dark red; dots numerous, small, brownish, obscure; stem slender, one and three-fourths inches long, adheres strongly to the fruit; skin thin, tough, separating readily from the pulp; flesh dark red, with reddish juice, tender and melting, sprightly, sour; good to very good in quality; stone nearly free, longer than wide, nearly round, slightly flattened, with smooth surfaces; somewhat ridged along the ventral suture.

\section{DOWNER}

Prunus avium

1. Kenrick $A m$. Orch. 218, 1835. 2. Hovey $F r, A m .2: 93,94$, P1. 1851.

Downer's Red Heart. 3. Kenrick Am. Orch. 276. 1832.

Downer's Late. 4. Proc. Nat. Con. Fr. Gr. 52. 1848. 5. Ann. Pom. Belge 2:65, Pl. 1854.

Guigne Tardive de Downer. 6. Mortillet Le Cerisier 2:95 fig., 96, 97. 1866.

Downer is a Sweet Cherry, one of the so-called "Hearts" much prized by those who know it as a late cherry delicately and richly flavored. Possibly it is the best of the late Sweet Cherries. Several defects keep it from being of any considerable worth; it thrives only in the choicest soils; the trees are often unhealthy as well as lacking in vigor; the flesh is thin and the stone is large; and, though the cherries set abundantly, the yield is small because the fruits are small. So, while the variety is almost indispensable in a home orchard, ripening after almost all of the dessert cherries have gone, Downer has small place in a commercial plantation. It should be said further in its favor, however, as a commercial fruit, that it stands harvesting and shipping very well.

Downer takes the name of Samuel Downer, Dorchester, Massachusetts, who grew it some time before 1832 when it first found a place in pomological works. It was included by the American Pomological Society in its 


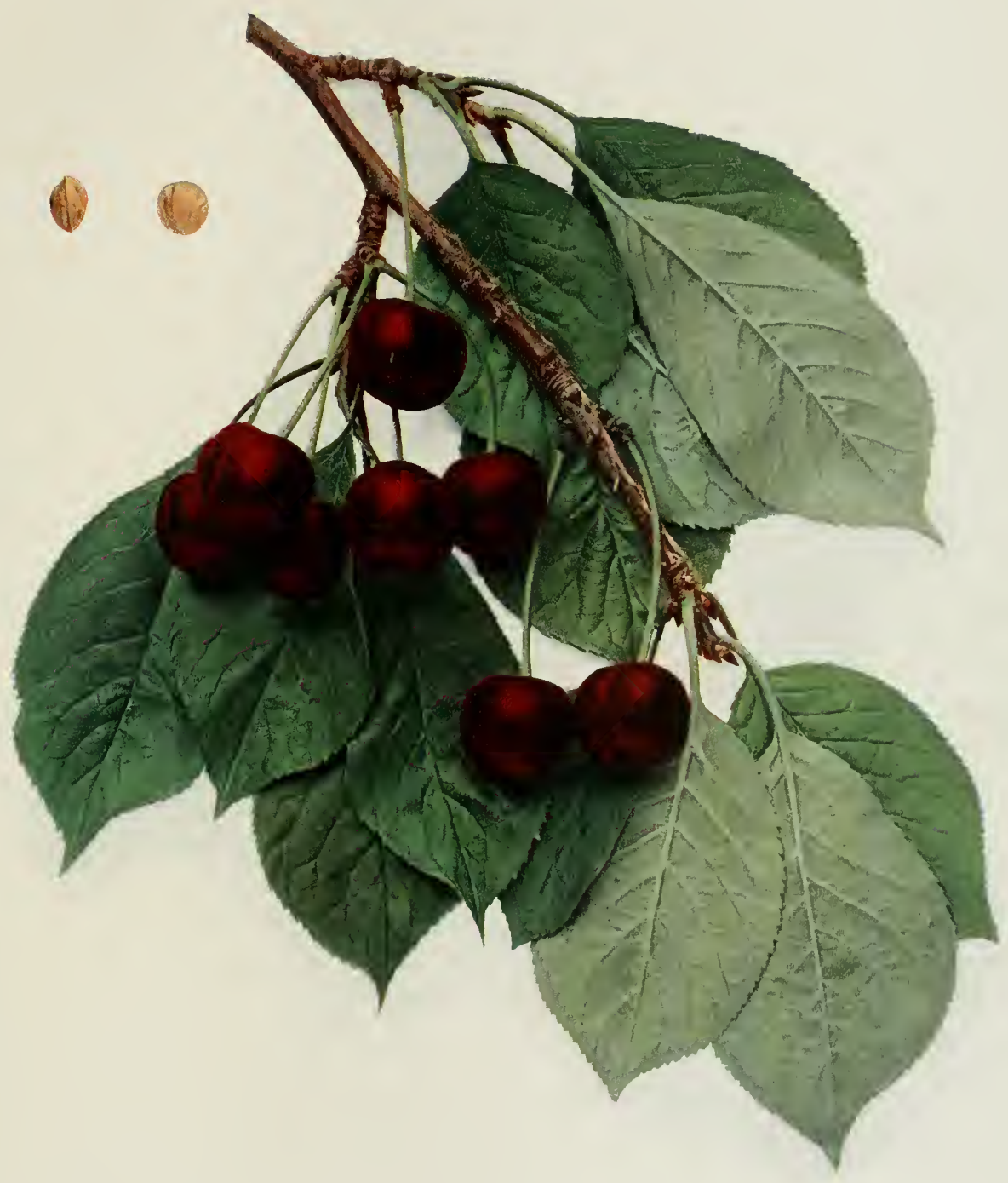



schedule of fruits in 1848 as Downer's Late. It now appears as Downer with Downer's Late Red as a synonym in accordance with the rules of the Society.

Tree large, vigorous, upright-spreading, dense-topped, productive; trunk thick, with shaggy bark; branches thick, roughened, dark brown overspread with dark gray, with numerous large lenticels; branchlets slender, long, brown partly covered with ash-gray, smooth, with inconspicuous, raised lenticels.

Leaves numerous, three inches long, one and three-fourths inches wide, folded upward, obovate, rather stiff; upper surface dark green; lower surface light green, hairy along the veins; apex acute, base abrupt; margin doubly serrate, glandular; petiole one inch long, thick, dark red, grooved, glandless or with from one to three large, globose or reniform glands on the stalk.

Buds small, except the terminals which are large, pointed, plump, free, arranged singly as lateral buds, or in small clusters on short spurs; leaf-scars prominent; flowers white, one and one-fourth inches across; borne in thin clusters in ones and in twos; pedicels variable in length often one inch long, glabrous; calyx-tube faintly tinged with red, campanulate, glabrous; calyx-lobes tinged with red, acuminate, glabrous within and without, reflexed; petals roundish, entire, somewhat sessile, with a shallow notch at the apex; pistil glabrous, nearly equal to the stamens in length, often defective.

Fruit matures among the latest; three-fourths of an inch in diameter, roundishcordate, slightly compressed; cavity very shallow, flaring; suture obscure; apex variable in shape usuaily somewhat pointed; color light to dark red frequently showing an amber background on the shaded side; dots numerous, small, russet, inconspicuous; stem one and three-fourths inches long, adherent to the fruit; skin tough, separating from the pulp; flesh pale yellow, with colorless juice, somewhat stringy, tender, with soft flesh, mild and pleasant, sweet when fully ripe; good to very good in quality; stone large, free, ovate, flattened, with smooth surfaces; somewhat ridged along the ventral suture.

\section{DYEHOUSE}

\section{Prunus cerasus}

I. Horticulturist 25: 176, 177. 1870. 2. Downing Fr. Trees Am. 3rd App. 161. 1881. 3. Am. Pom . Soc. Cat. 17. 1897.

Dyehouse is conspicuous among cherries for its earliness and for the beauty of its fruit. Early Richmond is the standard early cherry yet Dyehouse is a week earlier, just as attractive in appearance and equally well flavored. It is near of kin to Early Richmond but the two may be distinguished by the difference in time of ripening and by its brighter, clearer color, greater opaqueness, more highly colored juice and slightly smaller size. Possibly this cherry would supersede the better-known Early Richmond were it not for the defect in size and for the further faults of being less productive and more capricious to environment, as it fails to 
thrive in localities where the older sort is quite at home. It is a worthy rival of Early Richmond, however, and ought to be grown both for home and commercial purposes far more than it is.

To H. T. Harris of Stamford, Kentucky, belongs the honor of introducing this well-known cherry. Although its parentage is unknown, it is almost certain that a Mr. Dyehouse, Lincoln County, Kentucky, raised the tree from a pit sixty or more years ago. At the time of its introduction its characteristics were not clearly drawn and many believed it to be the Early Richmond. In time, however, differences were shown, as we have set forth in the preceding paragraph. It was added to the fruit list of the American Pomological Society in 1897.

Tree small, vigorous, spreading, with drooping branchlets, dense, round-topped, productive; trunk and branches slightly roughened; branches reddish-brown covered with dark ash-gray, with large, elongated, raised lenticels; branchlets slender, willowy, variable in length, brown overspread with ash-gray, smooth, with a few small, inconspicuous lenticels.

Leaves numerous, three inches long, one and one-half inches wide, slightly folded upward, obovate to long-oval; upper surface very dark green, smooth; lower surface light green, with a few hairs along the midrib; apex acute, base variable in shape; margin finely serrate, with small, dark glands; petiole one-half inch long, tinged with dull red, with a few hairs along the grooved upper surface, with from one to three small, globose, greenish-yellow glands at the base of the blade.

Buds small, short, obtuse, plump, free, arranged singly and in clusters on short spurs; leaf-scars prominent; season of bloom intermediate; flowers one inch across, white; borne in dense but well-distributed clusters, usually at the ends of spur-like branches, in twos, threes or fours; pedicels one and one-half inches long, glabrous, greenish; calyx-tube green, obconic, glabrous; calyx-lobes tinged with red, serrate, glabrous within and without, reflexed; petals roundish-obovate, entire, almost sessile, with entire apex; filaments onefourth inch long; pistil glabrous, nearly equal to the stamens in length.

Fruit matures early; more than one-half inch in diameter, oblate, slightly compressed; cavity of medium depth, narrow, abrupt, regular; suture indistinct; apex flattened, with a small depression at the center; color dark red; dots numerous, small, obscure; stem one inch long, adhering to the pulp; skin thin, tough; flesh light yellowish-white, with pinkish juice, tender, sprightly, tart; of very good quality; stone nearly free, ovate, slightly flattened, with smooth surfaces; somewhat ridged along the ventral suture.

\section{EAGLE}

\section{Prunus avium}

1. Mich. Sta. Bul. 104:84. 1894. 2. Am. Pom. Soc. Cat. 17. 1897.

Black Eagle. 3. Prince Treat. Hort. 3I. 1828. 4. Pom. Mag. 3:127, P1. 127. 1830. 5. Kenrick Am. Orch. 274, 275. 1832. 6. Downing Fr. Trees Am. 170 fig. 62. 1845. 7. Floy-Lindley Guide Orch. 


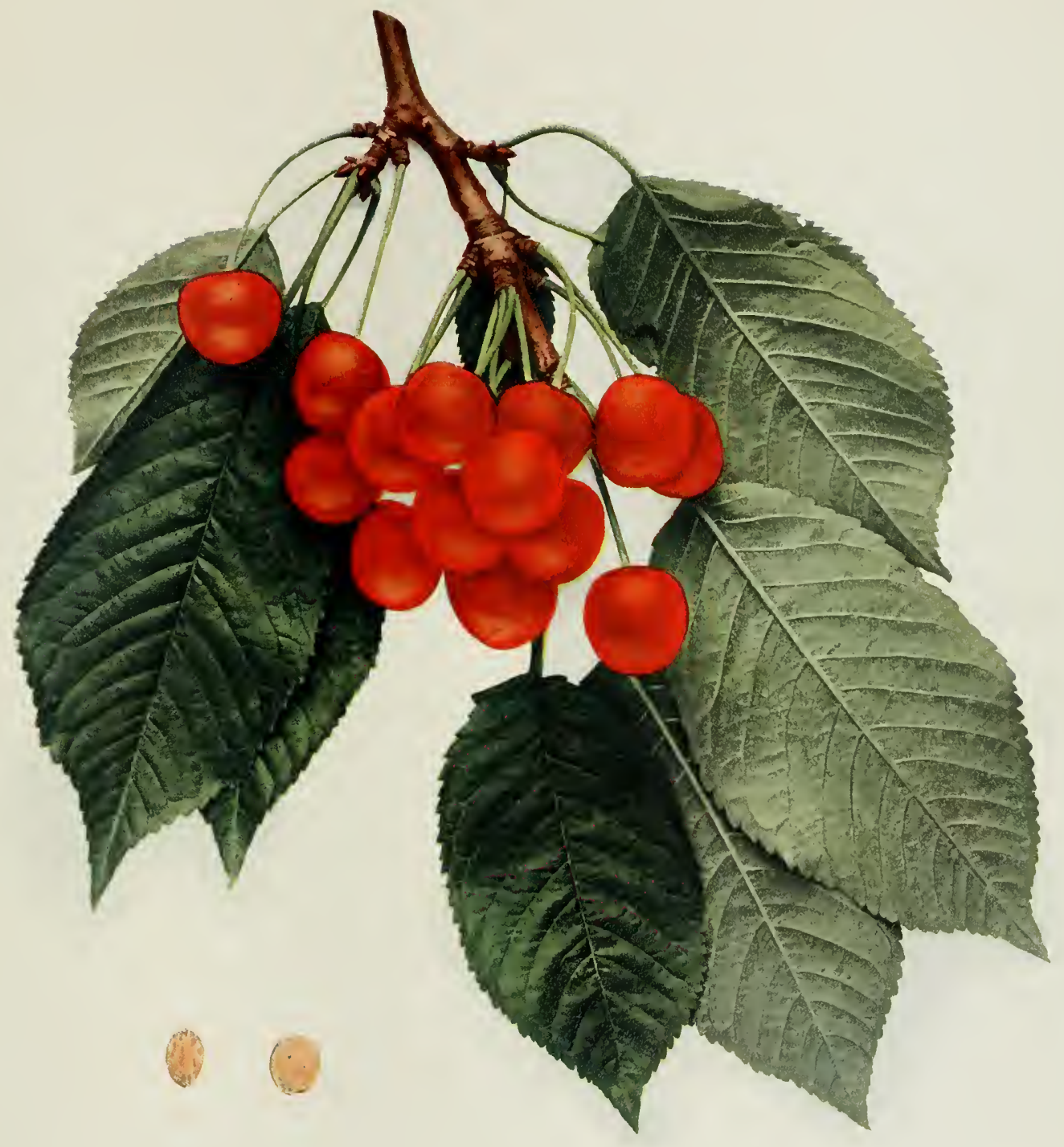





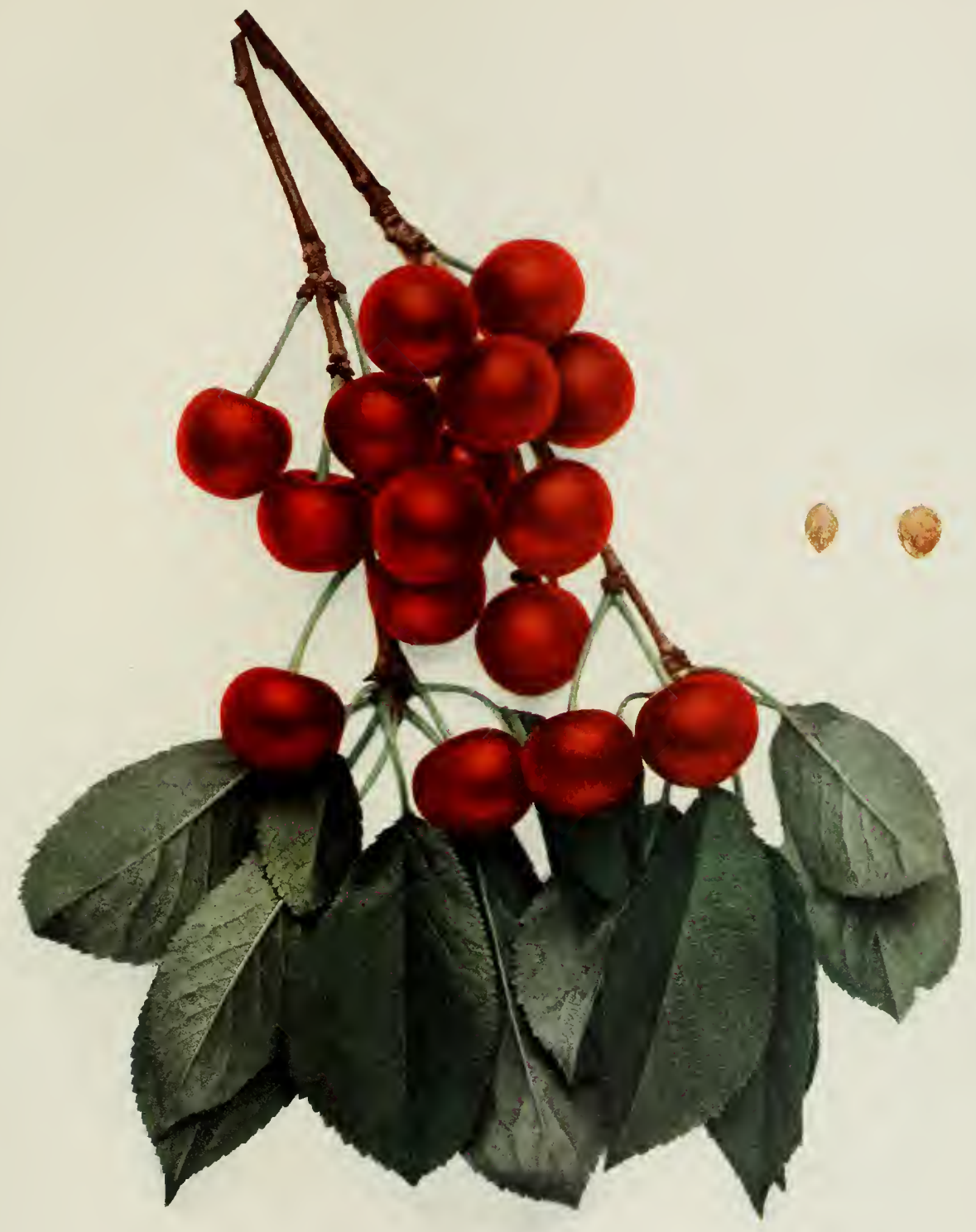

DYEHOUSE 

Gard. 102. 1846. 8. Mag. Hort. 14:386, 387 fig. 37. 1848. 9. Proc. Nat. Con. Fr. Gr. 52. 1848. 10. Hovey Fr. Am. 1:85, Pl. I851. I1. Horticulturist N. S. 4:287. I854. 12. Am. Pom. Soc. Rpt. 108, 186. 1856. 13. Mortillet Le Cerisier 2:77-79, fig. I2. I866. I4. Mas Pom. Gen. II:83, 84, fig. 42. I882. 15. Hogg Fruit Man. 285, 286. I884. I6. Cornell Sta. Bul. 98:49I fig. 86. I 895 .

We hesitatingly follow the American Pomological Society in calling this variety Eagle when it has so long been known as Black Eagle, the name given it by the great pomologist, Knight. Were this choicely good cherry larger in size, it would still be a prime favorite with growers for in many respects it is one of the best varieties of its species. Its flavor is excellent; the trees are usually fruitful; it ripens at a good time in the cherry season, just after Black Tartarian; the cherries are less liable to crack than many of its rivals; and the trees are as hardy, healthy and vigorous as those of any Sweet Cherry. Some complain that the trees do not bear well at first but are productive only with age. But, after all, it is its high quality that gives Eagle so much merit that it ought not to be forgotten - makes it worth a place in every home orchard and commends it highly to commercial growers of cherries who want a finely finished product for either local or general market. The fruit-stems of this variety are characteristically long.

Eagle was grown about 1806 by Sir Thomas Andrew Knight at Downton Castle, Wiltshire, England, by fertilizing the Bigarreau of the old writers, our Yellow Spanish, with pollen of the May Duke. The correctness of the parentage as given has been questioned because of its inherited characteristics. But if the May Duke is a hybrid between a Sweet and a Sour, a pure Sweet offspring is not an impossibility. In I823, Honorable John Lowell of Massachusetts received Eagle from Knight. Prince mentioned this cherry in his Treatise of Horticulture, I 828 , but the exact date of its introduction into New York is unknown. In I 848 it was placed on the list of fruits adopted by the National Convention of Fruit Growers and since then it has been retained on the fruit list of the American Pomological Society.

Tree large, vigorous, upright-spreading, dense, unproductive at first but improving with age; trunk and branches thick, smooth; branches reddish-brown partly covered with ash-gray, with numerous small lenticels; branchlets thick, brownish partly corered with light ash-gray, the surface slightly ribbed and with small, raised, inconspicuous lenticels.

Leaves numerous, five inches long, two and one-half inches wide, folded upward, long, obovate to elliptical, thin; upper surface dark green, rugose; lower surface light green, thinly pubescent; apex variable in shape; margin coarsely and doubly serrate, with 
dark glands; petiole nearly two inches long, tinged with red, with a few hairs, with from two to four reniform, brownish glands usually on the stalk.

Buds large, conical or pointed, plump, free, arranged singly as lateral buds and in clusters on spurs of medium length; leaf-scars prominent; season of bloom medium; flowers white, one and one-eighth inches across; borne in scattered clusters in twos and threes; pedicels one inch long, slender, glabrous, greenish; calyx-tube green faintly tinged with red, campanulate; calyx-lobes with a trace of red, obtuse, glabrous within and without, reflexed; petals irregular-oval, crenate, with short, blunt claws and with a crenate apex; anthers yellowish; filaments one-fourth inch long; pistil glabrous, equal to the stamens in length.

Fruit matures in mid-season; nearly one inch in diameter, oblate, somewhat cordate, compressed; cavity regular, flaring; suture a faint groove; apex pointed or slightly depressed; color dark red almost black; dots small, russet, medium in number, obscure; stem slender, two inches long; skin thin, tender; flesh dark red, with wine-colored juice, meaty, tender, crisp, pleasant flavored, mild, sweet; very good to best in quality; stone free except along the ventral suture, rather small, ovate, slightly flattened, blunt, with smooth surfaces; ridged along the ventral suture.

\section{EARLY MAY}

Prunus fruticosa

I. Langley Pomona 86, Pl. 17 fig. 2. I729. 2. Prince Pom. Man. 2:131. 1832. 3. Downing Fr. Trees Am. 479. 1869. 4. Hogg Fruit Man. 295. 1884.

May. 5. Parkinson Par. Ter. 571. 1629.

Cerisier Nain à Fruit Rond Précoce. 6. Duhamel Trait. Arb. Fr. I:168, 169, 170, Pl. III. 1768.

Frühe Zwergweichsel. 7. Truchsess-Heim Kirschensort. 492-498. 1819. 8. Mathieu Nom. Pom. 349, 350, 372. 1889 .

A marell-Weichsel. 9. Dochnahl Führ. Obstkunde 3:57, 58. $185^{8}$.

Précoce de Montreuil. 10. Mas Le Verger 8: I41, I42, fig. 69. 1866-73.

Griottier Nain Précoce. Ir. Leroy Dict. Pom. 5:293 fig., 294. 1877.

As the only cultivated representative of the European Dwarf Cherry, Early May should be of especial interest to cherry-growers. It is a true dwarf variety, the trees seldom attaining a height of more than six or seven feet. Both tree and branches are very flexible so that Early May is well adapted to the wall-training of European countries. It has further value in its earliness, being the earliest of all cherries. It is doubtful whether the variety can now be obtained in America but it ought to be reintroduced both for the fruit and because it is a handsome ornamental. Early May has several characters to recommend it to plant-breeders. The description herewith given is compiled from European fruit-books.

Pliny in his Natural History mentions the Macedonian and the Chamaecerasus cherries, both of which we now believe to have been Prunus fruticosa, the European Dwarf Cherry. Early May, according to European 


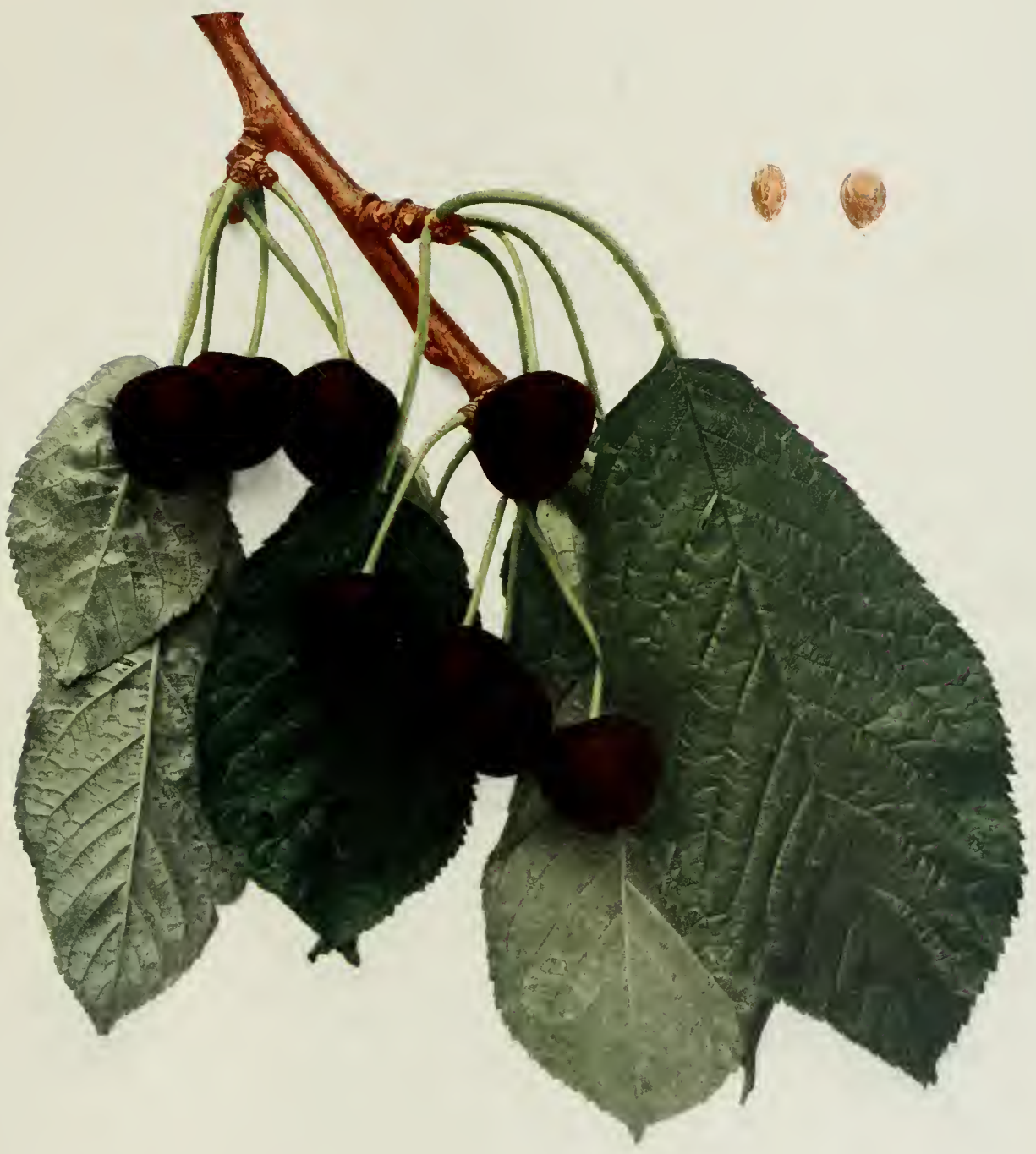

EAGLE 

botanists, is a variety of this dwarf species and may be the identical cherry that Pliny described. Following Pliny it was mentioned by Estienne, a Frenchman, in 1540 , by Knoop, the Dutch pomologist, in I $77 \mathrm{I}$, by Parkinson, the English herbalist, in I629, and, as the references show, by most pomologists since. The names May and Early May have been applied to several varieties, and especially in the West to the Early Richmond but all are distinct and ought not to be confused with this, the true variety.

Tree very small, rather weak; branches numerous, slender, somewhat curved, flexible, branchlets slender, pendant; leaves abundant, very small, obovate or oblong, acuminate; margin irregularly and deeply serrate; petiole short, slender, without glands; blooming season very early; flowers small; petals oval.

Fruit matures very early, usually attached in pairs; small, roundish, slightly flattened; suture indistinct; color bright red becoming dark red at full maturity; stem one inch long, slender, set in a small, regular cavity; skin thin; flesh yellowish-white, sometimes tinged red under the skin, tender, juicy, brisk but pleasant subacid; quality fair; stone very small, roundish.

\section{EARLY MORELLO}

\section{Prunus cerasus}

I. Del. Sta. An. Rpt. 12:118. 1900. 2. Budd-Hansen Am. Hort. Man. 2:275. I903. Orel No. 23. 3. Hich. Hort. Soc. Rpt. 327. 1888. 4. Ia. Sta. Bul. 73:68, 77 fig. 17. 1903.

This, which we think is the true Early Morello, is worthy an extended description in The Cherries of New York chiefly because there are several cherries of this name. The confusion results in much vexation to cherrygrowers in the West where, only, these cherries have been planted. The full description should make clear at least the character of the variety which is being grown at this Station as Early Morello. About all that can be said of the variety as it grows here is that the trees are hardy, healthy. vigorous, fruitful and regular in bearing. The cherries show the variety to be of the Amarelle group but are such as to make it far inferior to Montmorency and other well-known Amarelles. The name is misleading, as the variety has little in common, in tree or fruit, with the true Morellos.

The cherry described here as Early Morello was introduced by Professor J. L. Budd from Orel, Russia, as Orel No. 23. It has proved very productive and hardy throughout the West and resembles Early Richmond, though smaller, a trifle darker, less acid and a week later. A dark-fleshed variety from Erfurt, Prussia, was sent out from Rosedale, Kansas, where it is known as Early Morello. This, and one by D. U. Reed, Blue Springs, Nebraska, appear to be very similar to the Northwest, or Wier No. 29. 
Tree of medium size and vigor, upright-spreading, very productive; trunk rather thick, shaggy; branches with numerous large lenticels; branchlets slender, short; leaves two and three-fourths inches long, one and one-half inches wide, thick, stiff, dark green, rather glossy, smooth; margin finely and doubly serrate, with small, dark glands; petiole glandless or with from one to three small, globose, brown or yellowish glands variable in position; buds small, short, obtuse, in small clusters at the ends of slender, branchlike spurs; leaf-scars prominent; season of bloom late; flowers one inch across; pistil equal to or slightly longer than the stamens, sometimes defective.

Fruit matures in mid-season; about three-fourths of an inch in diameter, oblate, compressed; color attractive dark red; stem one inch long, adhering to the fruit; skin thin, tender, separating from the pulp; flesh light yellow, with pinkish juice, tender and melting, sprightly, tart; of very good quality; stone free, ovate, flattened, slightly pointed, with smooth surfaces, somewhat tinged with red.

\section{EARLY PURPLE}

Prunus avium

I. Am. Pom. Soc. Cat. 26. 1909.

Purple Cherry. 2. Ray Hist. Plant. 1540. 1688.

Early Purple Guigne. 3. Cullivator N. S. 4:280 fig. 2. 1847. 4. Hovey Fr. Am. I:93, 94, Pl. 1851. 5. Am. Pom. Soc. Rpt. 55. 1852. 6. Am. Pom. Soc. Cat. 211. 1856. 7. Mas Le Verger 8:129, 130, fig. 63. 1866-73. 8. Mortillet Le Cerisier 2:57 fig. 3, 58, 59. 1866. 9. Horticulhurist 25:71 fig. 1870. 10. Leroy Dict. Pom. 5:334, 335 fig., 336. 1877. 11. Hogg Fruit Man. 295. 1884. 12. Guide Prat. 6, 193. 1895.

Purple Guigne. 13. Elliott Fr. Book 195 fig. 1854.

Early Purple is a valuable cherry on account of its earliness, its attractive color and high quality. The trees bear well and regularly after having become established in the orchard. The variety has the reputation of being a poor grower in the nursery and as a young tree in the orchard but with age it takes on vigor and at all times is as healthy as those of any Sweet Cherry. More than most cherries, this variety responds to good care and a choice cherry soil - a warm, free-working loam being best. A rather unusual and serious defect of this variety is that the fruit-spurs are easily broken during picking and the crop of the next season thereby cut short. Another fault is that it is the favorite food of the robin where this, the worst of all cherry pests, abounds. The cherries of this variety do not attain their rich purple color until full maturity is reached. Hogg, the English pomologist, maintains that Early Purple does better on the Mahaleb than on the Mazzard stock. No home collection should be without this variety and it can often be profitably grown as an early cherry for the local market.

Early Purple is the Early Purple Guigne of most fruit-books, the 


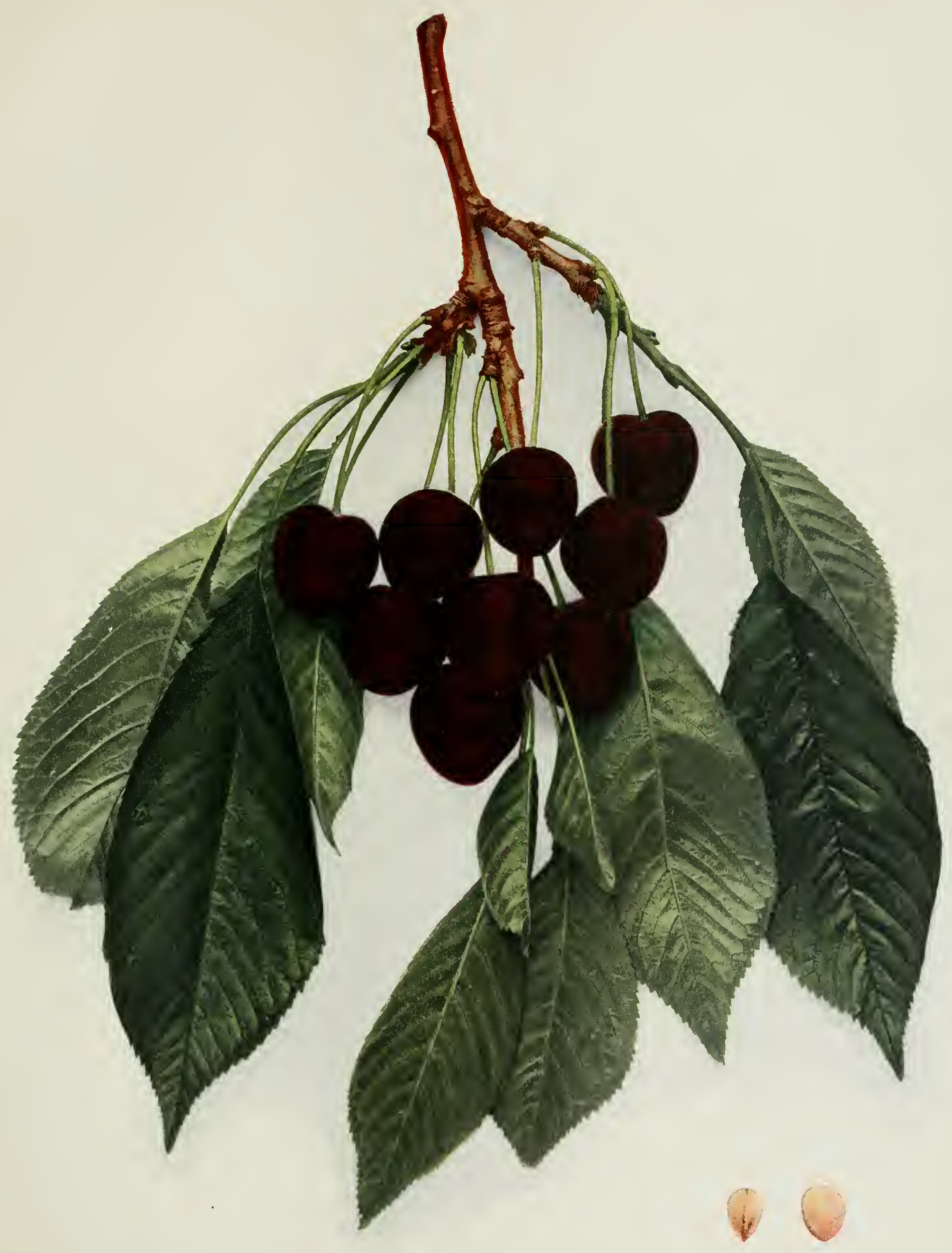

EARLY PURPLE 

name having been shortened by the American Pomological Society, though, since the variety goes back to the Early Purple of Ray in 1688, the name here used has the right of precedence. As to what the origin and history of the variety were before Ray mentioned it, we can find no record. Early Purple was brought to America over a hundred years ago. According to Elliott, eastern growers received it directly from England, while in the West it was brought over by a party of German emigrants, under the name "German May Duke" and as such it is still much grown in localities in the Central West. In I 852, the American Pomological Society listed Early Purple as one of the promising new fruits and later, in 1856 , it was given a place, which it has since retained, on the Society's catalog of fruits recommended for general cultivation.

Tree large, vigorous, upright-spreading, open-topped, very productive; trunk thick, smooth; branches smooth, reddish-brown partly covered with ash-gray, with large lenticels; branchlets short, brown partly covered with ash-gray, roughened, with a few small, inconspicuous lenticels.

Leaves numerous, four inches long, one and three-fourths inches wide, folded upward, oval to obovate, thin; upper surface dark green, rugose; lower surface light green, very lightly pubescent; apex and base acute; margin finely serrate, with small, dark colored glands; petiole one and three-fourths inches long, slender, tinged with red, with few hairs, with two or three small, globose, reddish glands on the stalk.

Buds variable in size and shape, rather long, plump, free, arranged singly as lateral buds and in small clusters on spurs variable in length; season of bloom early; flowers white, one and one-fourth inches across; borne in scattering clusters, usually in twos; pedicels characteristically long, often one and one-fourth inches, slender, glabrous; calyxtube with a faint tinge of red, campanulate; calyx-lobes tinged with red, long, acute, serrate, glabrous within and without, reflexed; petals broadly oval, serrate, with short, blunt claws and a shallow, notched apex; filaments one-fourth inch long; pistil glabrous, shorter than the stamens.

Fruit matures very early; one inch in diameter, cordate, slightly compressed; cavity regular; suture a faint line; apex pointed; color purplish-black; dots numerous, small, grayish, obscure; stem tinged with red, slender, nearly two inches long, adhering to the fruit: skin thin, tender, separating readily from the pulp; flesh dark reddish-purple, with dark colored juice, tender, melting, mild, sweet; of very good quality; stone free except along the ventral suture, rather large, broadly oval, compressed near the apex, with smooth surfaces.

\section{EARLY RICHMOND}

\section{Prunus cerasus}

I. Thacher Am. Orch. 217. 1822, 2. Prince Pom. Man. 2:142. 1832. 3. Elliott Fr. Book 194, 195 fig. 1854. 4. Am. Pom. Soc. Cat. 12. 1871. 5. Del. Sta. An. Rpt. 12:115 fig., i16. 1900.

Flanders. 6. Parkinson Par. Ter. 571, 1629. 
Kentish. 7. Miller Gard. Kal. 154. 1734. 8. Truchsess-Heim Kirschensort. 660, 661. 1819. 9. Downing Fr. Trees Am. 196 fig., 197. 1845. 10. Am. Pom. Soc. Cal. 74. 1862. 11. Mas Le Verger $8: 25,26$, fig. 11 . $1866-73$.

Cerisier Hâtif. 12. Duhamel Trait. Arb. Fr. 1:170, 171, Pl. IV. 1768. 13. Truchsess-Heim Kirschensort. 657, 658, 691. 1819. 14. Poiteau Pom. Franc. 2: No. 13, Pl. 1846. 15. Leroy Dict. Pom. 5:343, 344 fig., 345. 1877.

Cerise de Volger. 16. Knoop Fructologie 2:36, 43. $177 \mathrm{I}$.

Frühzeitige Amarelle. 17. Truchsess-Heim Kirschensort. 616-618. 1819. 18. Dochnahl Führ. Obstkunde 3:70. 1858.

Early Griotte. 19. Prince Pom. Man. 2:131, 132. 1832.

French. 20. Quebec Pom. \& Fr. Gr. Soc. Rpt. 122, 123. 1906.

Early Richmond has long been the leading Sour Cherry of its season - the first of its kind in the markets. It is not a remarkable variety in its fruit-characters, the cherries being but medium in size, mediocre in quality and not handsomer than other Amarelles with which it belongs. It is, however, a very good culinary fruit and when well ripened may be eaten out of hand with relish by those who like the refreshing acidity of a Sour Cherry. Though not in nearly as great demand for canning as Montmorency it still makes a very good canned product, being used more than it otherwise would be to prolong the canning season because of its earliness. Before cherries were largely canned for the markets, Early Richmond was much used in making dried cherries, the product, rightly cured, making a delicious sweetmeat which would keep for several months. The cherries are remarkable for the tenacity with which the stone clings to the stem. It is the tree in which the Early Richmond particularly surpasses. It thrives in varied soils and climates from the St. Lawrence to the Carolinas and from the Atlantic to the Pacific - possibly the most cosmopolitan of all cherries - and everywhere vigorous, healthy and fruitful. For the many purposes for which it may be used and because of the characters of the tree, Early Richmond is indispensable in every home and commercial orchard for an early cherry. After Montmorency it is more largely grown than any other cherry, Sweet or Sour, in New York.

Early Richmond is the old Kentish of English writers, confused more or less with the different Montmorencies. Whether or not this variety was introduced into Kent, England, by the Romans and became thus early the Kentish or whether it came from Flanders or Holland where it was called Cerise de Volger, is not now certain. Probably, however, it is one of the many seedlings of the Cerise Commune, as are the Montmorencies, and was first known as Cerisier Hâtif. Early in the Sixteenth Century the gardener of Henry VIII made extensive plantings in Kent 


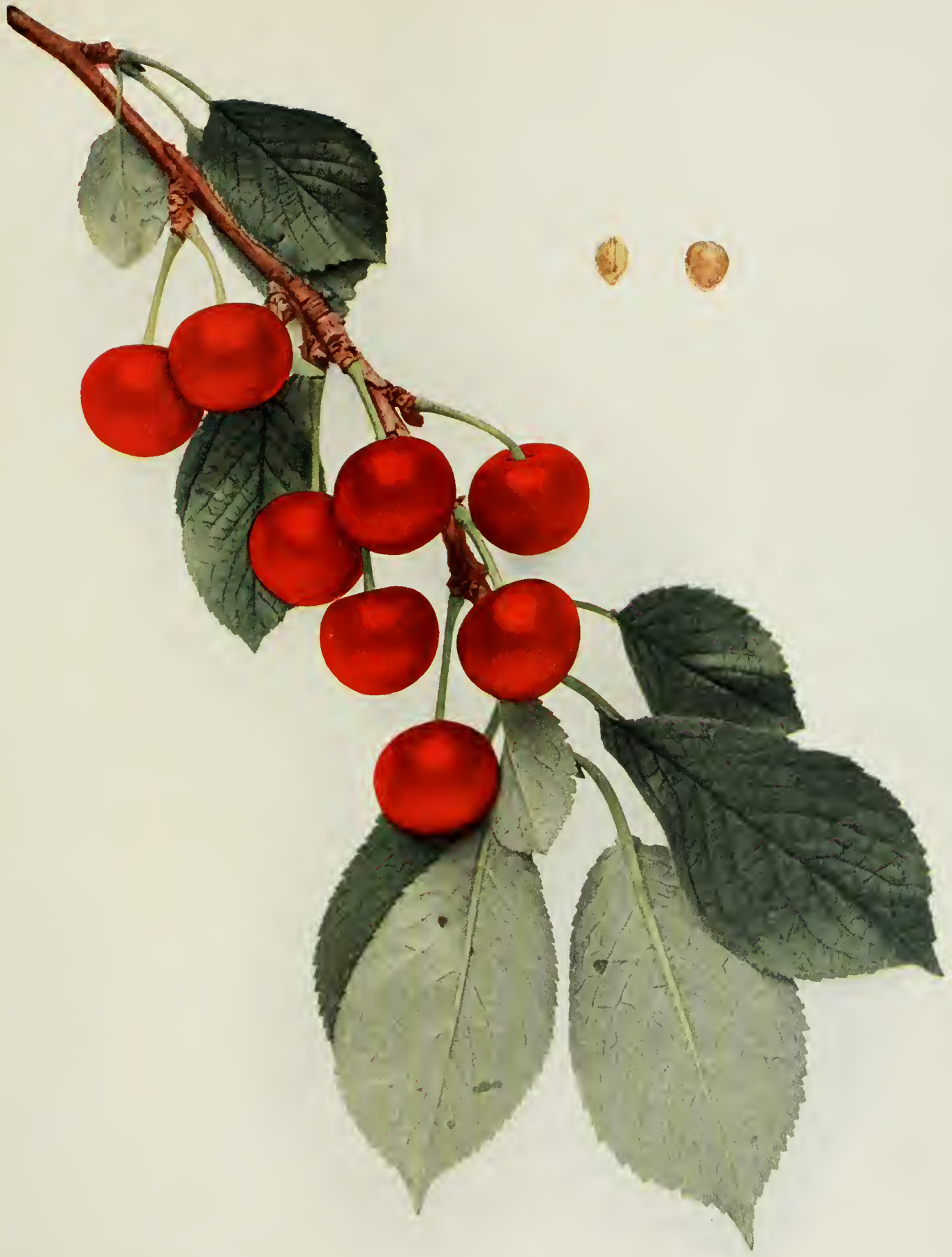


inconspicuous; stem slender, one inch long, adherent to the fruit; skin thin, rather tough, separating from the pulp; flesh pale yellow, with light pinkish juice, stringy, tender and melting, sprightly, pleasant flavored; good to very good in quality; stone free, small, roundish-ovate, slightly pointed, with smooth surfaces; somewhat roughened along the ventral suture.

\section{ELKHORN}

\section{Prunus avium}

1. Prince Pom. Man. 2:117. 1832. 2. Elliott Fr. Book 213. 1854. 3. Am. Pom. Soc. Cat. 24. 1899 .

John Tradescantes Cherrie. 4. Parkinson Par. Ter. 574. 1629.

Hertogs-Kers. 5. Knoop Fructologie 2:36, 40. $177 \mathrm{I}$.

Grosse Schwarze Knorpelkirsche. 6. Truchsess-Heim Kirschensort. 180-192. 1819. 7. Dochnahl Führ. Obstkunde 3:36. 1858. 8. Ill. Handb. 89 fig., 90. 1860. 9. Lauche Deut. Pom. III: No. 6, Pl. 1882. 10. Mathieu Nom. Pom. 357, 358. 1889.

Tradescant's Black Heart. 11. Downing Fr. Trees Am. 188 fig., 189. 1845. 12. Thompson Gard. Ass't 526. 1859. 13. Am. Pom. Soc. Cat. 74. 1862.

Gros Bigarreau Noir. 14. Mortillet Le Cerisier 2:108-111, fig. 24. 1866. 15. Leroy Dict. Pom. 5:224, 225 fig., 226. 1877.

St. Margaret's Cherry. I6. Flor. \& Pom. 105, P1. 5ł2. 1881.

Elkhorn has served its day and is now being rapidly superseded by other cherries of the Bigarreau group to which it belongs. It was valued by the old pomologists because of the large size of the fruit, the firm flesh, late ripening, rich flavor, and because it hangs well on the tree long after maturity. But it fails in competition with other Bigarreaus in bearing cherries quite variable in size, in the diminishing size of the fruit as the trees attain age and more than all else in being but moderately productive. The bark of the trunk and main branches is so heavily overspread with gray as to make this a distinguishing mark. The fruit, too, is distinct in appearance by reason of the irregular surface of the skin. The variety possesses no characters, as it usually grows, to make it worth planting either for home or market.

The history of this old cherry was almost hopelessly confused by the early horticulturists by the vast number of names they used for it, many of which belonged to other varieties. Elkhorn is supposed to have been raised by John 'Tradescant, gardener to Charles I of England, under the name Tradescant's Black Heart. Of this cherry, John Parkinson in I629 says: "John Tradescantes Cherrie is most usually sold by our Nursery Gardiners, for the Archdukes cherrie, because they have more plenty thereof, and will better be increased, and because it is so faire and good a cherrie that it may be obtruded without much discontent: it is a reasonably good bearer, a faire great berrie, deepe coloured, and a little 
pointed." It is not known when or how Elkhorn got to America. The first cherry-grower in this country to mention it was William Prince, in 1832, who says that his father noticed the variety growing in a garden next to a hotel in Maryland about 1797 and brought cions of it to New York afterwards propagating and selling it under the name Elkhorn given to the cherry by the hotel proprietor. Elkhorn was at one time very popular and well disseminated throughout the United States and is sold now by a large number of nurserymen either under the name Tradescant's Black Heart or as Elkhorn. In I862, the American Pomological Society listed in its fruit catalog Tradescant's Black Heart but dropped it in 1877 . In I 899 this Society placed the variety in its catalog under the name Elkhorn and it still remains on its list of recommended fruits. From its history it is apparent that this cherry is rightly called Tradescant or Black Heart or by some combination of these terms but Elkhorn has been adopted by the American Pomological Society, is everywhere in common use on this continent and is so distinctive that we choose for this text the newer name.

Tree large, very vigorous, upright, open-topped, moderately productive; trunk stocky, smooth; branches stout, smooth, with numerous small lenticels, reddish-brown heavily overspread with ash-gray; branchlets thick.

Leaves numerous, three and three-fourths inches long, two and one-fourth inches wide, short-oval to obovate, thin; upper surface medium green, roughish; lower surface dull, light green, lightly pubescent; apex acute; margin coarsely serrate, glandular; petiole with from one to three raised glands of medium size, variable in shape, usually on the stalk.

Fruit matures in late mid-season; three-fourths of an inch in diameter, cordate to conical, slightly compressed; cavity deep, wide, flaring; suture indistinct; apex roundish or pointed, with a slight depression at the center; color purplish-black; dots numerous, small, dark russet, inconspicuous; stem one and three-eighths inches long, adhering to the fruit; skin thin, tender, adhering somewhat to the pulp; flesh a characteristically dark purplish-red, with very dark colored juice, meaty, firm, crisp, mild, sweet; of good quality; stone semi-free, ovate, flattened, slightly pointed, with smooth surfaces, tinged with red.

\section{ELTON}

Prunus avium

1. Lond. Hort. Soc. Cat. 49. 1831. 2. Prince Pom. Man. 2:121, 122. 1832. 3. Pom. Mag. 2:92, $\mathrm{P}_{1}$ 1839. 4. Downing Fr. Trees Am. 186 fig. 77. 1845. 5. Proc. Nat. Con. Fr. Gr. 52. 1848. 6. Am. Pom. Soc. Rpt. 75. 1850. 7. Am. P^m. Soc. Cat. 54. 1852. 8. Elliott Fr. Book 194 fig. 1854. 9. Thompson Gard. Ass't 528. 1859. 10. Ill. Handb. 105 fig., to6. I860. 11. Mortillet Le Cerisier 2:91 fig. 17, 92, 93. 1866. 12. Downing Fr. Trees Am. 463 fig. 1869. 13. Leroy Dict. Pom. 5:196, 197 fig. 1877.

Flesh Coloured Bigarreau. I4. Prince Pom. Man. 2:128. 1832. 15. Downing Fr. Trees Am. 182 fig. 74. 1845. 16. Leroy Dict. Pom. 5:192, 193 fig. 1877. 
Elton has been freely recommended and widely cultivated in Europe and America for the past century and probably no cherry has given more general satisfaction. The variety is distinguished by the form, color, flesh and flavor of its fruit. The cherries are oblong-heart-shaped - possibly too much drawn out for best appearance and often too oblique; the color, very well shown in the color-plate, is most attractive and makes up for any defect in shape - a dark red mottled with amber, very bright, clear and glossy; the flesh, a little too soft to ship well, is delicate and most pleasing to the palate; the flavor is peculiarly rich and luscious being hardly surpassed by that of any other cherry. The trees may be as readily told as the fruit, by the unusually dark red color of the petioles of the leaves. The branches are stout and bear the crop thickly placed close to the wood and in prodigious quantities. Unfortunately it has a fault which in America, at least, makes it almost unfit for a commercial plantation. Brown-rot, the scourge of the Sweet Cherry, attacks this variety more aggressively than almost any other sort and for this reason, while its merits can hardly be too highly spoken of, Elton must remain for most part a variety for the home orchard. The tree, perfect in most respects, is a little tender to cold. Leroy, the French pomologist, thinks it does better on Mahaleb than on the Mazzard stock.

This is another cherry from Thomas Andrew Knight, the great English pomologist. Knight fruited it first about I 806, the tree coming from a pit of Yellow Spanish, the paternal parent being White Heart. From the first it took a high place in English and continental pomology as it did also in America upon being brought here in 1823. The variety is everywhere known and grown in America and is for sale by many nurserymen. Elton was one of the fruits to receive attention at the first meeting of the American Pomological Society in 1848 , and in 1852 was put on the list of recommended fruits where it still remains.

Tree large, vigorous, upright-spreading, open-topped, very productive; trunk thick, smooth; branches smooth, reddish-brown covered with ash-gray, with small lenticels; branchlets long, brown partly covered with ash-gray, smooth, with inconspicuous, raised lenticels, intermediate in number and size.

Leaves numerous, five and one-half inches long, two and one-half inches wide, folded upward, long-obovate to elliptical, thin; upper surface dark green, rugose; lower surface light green, thinly pubescent; apex acute, base abrupt; margin doubly serrate, with small, dark glands; petiole two inches long, heavily tinged with red, with a few scattering hairs along the upper surface, with from two to four reniform or globose, reddish-brown glands on the stalk. 


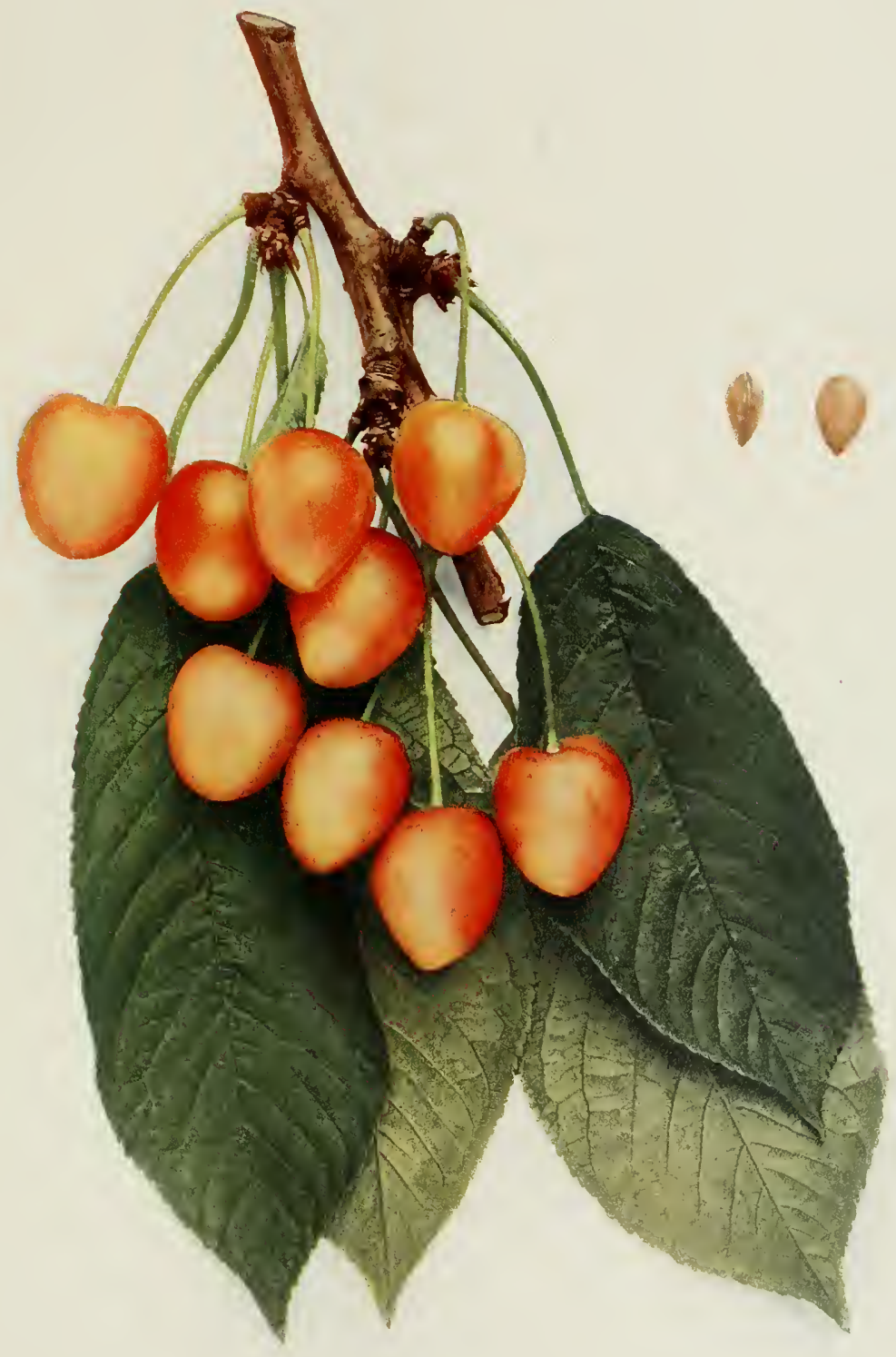

ELTON 

Buds large, long, pointed, plump, free, arranged singly as lateral buds and on very short spurs variable in size; leaf-scars prominent; mid-season in blooming; flowers onc and one-half inches across, white; borne in twos and threes; pedicels one inch long, slender, glabrous, greenish; calyx-tube green, campanulate, glabrous; calyx-lobes tinged with red, long, broad, acute, serrate, glabrous within and without, reflexed; petals roundish, entire, nearly sessile, with a shallow notch at the apex; filaments about one-half inch long; pistil glabrous, shorter than the stamens.

Fruit matures early; about one inch long, three-fourths inch wide, cordate to conical. somewhat compressed and oblique; cavity rather abrupt, regular; suture indistinct; apex distinctly pointed; color dark red with an amber tinge, faintly mottled; dots numerous, small, light yellow, obscure; stem slender, one and three-fourths inches long; skin thin, tender, separating from the pulp; flesh white with a tinge of yellow, with colorless juice, slightly stringy, tender, very mild, sweet; of good quality; stone free except along the ventral suture, one-half inch long, long-ovate, slightly flattened, with smooth surfaces; somewhat ridged along the ventral suture.

\section{EMPRESS EUGENIE}

\section{Prunus avium $\times$ Prumus cerasus}

1. Gard. Mon. 7:277. 1865. 2. Mortillet Le Cerisier 2:159 fig. 4 I, 160. 1866. 3. Mas Le Verger 8:5, 6, fig. I. 1866-73. 4. Pom. France 7: No. 10, Pl. 10. 1871. 5. U. S. D. A. Rpt. 383.1875. 6. Am. Pom. Soc. Cat. 20. 1877. 7. Leroy Dict. Pom. 5:348 fig., 349. 1877. 8. Hogg Fruit Man. 296, 297. 1884. 9. Gaucher Pom. Prak. Obst. No. 78, P1. 29. 1894.

Eugenie. 10. Am. Pom. Soc. Cat. 22. 1883.

This old French cherry, for many years largely advertised and widely sold in America, does not thrive in the New World as well as the reports say it does in the Old World. The two faults that condemn it, as it grows here, are that the cherries ripen very unevenly making several pickings necessary and the trees are so small that, though loaded with fruit, the total yield is not large. Lesser faults are that the cherries are not uniform in shape and are borne thickly in close clusters so that when brown-rot is rife this variety suffers greatly. The short stem, too, prevents easy picking. To offset these faults Empress Eugenie has to its credit the reputation of being about the most refreshing and delicious Duke. In a home plantation where the unevenness in ripening can be utilized to prolong the season and where dwarfness may not be undesirable, Empress Eugenie may well find a place.

This cherry appeared in 1845 as a chance seedling on the grounds of M. Varenne at Belleville, near Paris, France. It first fruited about i $85^{\circ}$ and four years later the Horticultural Society of Paris placed it, under the name Impératrice Eugénie, on its list of recommended fruits. M. A. Gontier, a nurseryman at Fontenay-aux-Roses introduced it to commerce 
in I855. Empress Eugenie soon became quite generally disseminated throughout Europe and was considered nearly as good as May Duke, with which it has occasionally been confused. It must have been brought to America towards the beginning of the last quarter of the Nineteenth Century and here it gradually became widely distributed until today it is found in all the leading cherry plantations and is propagated by a large number of nurserymen throughout the United States. The American Pomological Society added this cherry to its fruit catalog list in 1877 under the name Empress Eugenie. In 1883 this name was shortened to Eugenie under which term it has since appeared in the Society's catalog. In The Cherries of New York we have not adopted the shortened name as, by such a change, all trace is lost of the person after whom the cherry was christened.

Tree small, not very vigorous, upright, becoming round-topped, very productive; trunk slender, roughish; branches slender, much roughened, reddish-brown partly covered with ash-gray, with numerous small lenticels; branchlets with short internodes, brown slightly covered with ash-gray, smooth except for the numerous small, conspicuous, muchraised lenticels.

Leaves numerous, three and one-half inches long, one and three-fourths inches wide, folded upward, obovate, thick; upper surface dark green, slightly rugose; lower surface light green, thinly pubescent; apex abruptly pointed, base variable in shape; margin doubly serrate, with small, dark glands; petiole three-fourths of an inch long, tinged with red, with a few hairs along the upper surface, glandless or with one or two small, globose, greenish-yellow or reddish glands, usually at the base of the blade.

Buds obtuse, plump, free, arranged singly as lateral buds and on long or short spurs, in clusters variable in size; leaf-scars obscure; blooming in mid-season; flowers one and one-fourth inches across, white; borne in very dense clusters, in threes and fours; pedicels one inch long, glabrous, greenish; calyx-tube with a faint tinge of red, obconic, glabrous; calyx-lobes with a trace of red, acute, glabrous within and without, reflexed; petals roundish, entire, with short but distinct claws; apex nearly entire; filaments one-fourth inch long; pistil glabrous, equal to the stamens in length.

Fruit matures in mid-season; three-fourths of an inch in diameter, roundish-conic to oblate-conic, compressed; cavity narrow; suture very shallow, indistinct; apex flattened or depressed; color dark red; dots numerous, small, dark russet, obscure; stem one and one-fourth inches long, adherent to the fruit; skin tough, separating from the pulp; flesh pale red, with pinkish juice, tender, meaty, sprightly, pleasant flavored, tart; of good quality; stone semi-clinging, small, ovate, flattened, somewhat oblique, with smooth surfaces.

\section{ENGLISH MORELLO}

Prunus cerasus

I. Parkinson Par. Ter. 572. 1629. 2. Langley Ponzona 85. 1729. 3. Christ Handb. 677. 1797. 4. Lond. Hort. Soc. Cat. 54. 1831. 5. Downing Fr. Trees Am. 197, 198 fig. 18+5. 6. Am. Pom. Soc. Cat. 74. 1862. 7. Hogg Fruit Man. 306, 307. 1884. 8. Am. Pom. Soc. Cat. 27. 1909. 


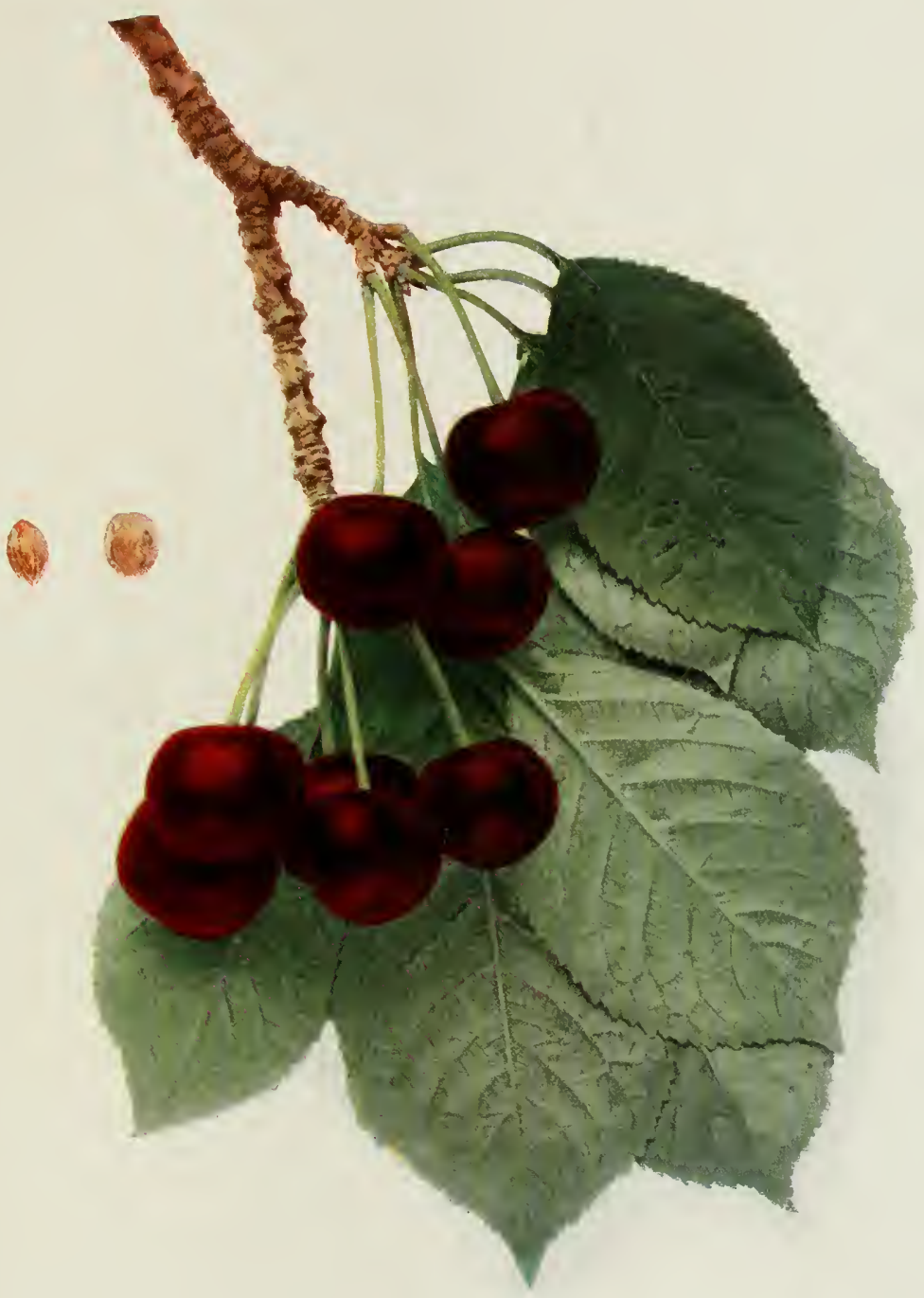

EMPRESS EUGENIE 
Grosse Cerise à Ratafia. 9. Duhamel Trait. Arb. Fr. 1:189. 1768.

Grosse Lange Lothkirsche. Io. Truchsess-Heim Kirschensort. 599, 600, 601. 1819. 11. Mich. Hort. Soc. Rpt. 326. 1888. 12. Nathieu Nom. Pom. 356, 357. 1889.

Large Morello. 13. Prince Pom. Man. 2:144. 1832.

Ratafia Griotte. 14. Prince Pom. Man. 2:147. 1832. 15. Poiteau Pom. Franc. 2: No, 17, Pl. 1846. 16. Leroy Dict. Pom. 5:299, 300 fig., 301. 1877.

Northern Griotte. 17. Prince Pom. Man. 2:146. 1832. 18. Poiteau Pom. Franc. 2: No. 18, Pl. 1846. 19. Mortillet Le Cerisier 2:188 fig., 189, 190. 1866. 20. Pom. France 7: No. 15, Pl. 15. I871. 21. Thomas Guide Prat. 18, 195. 1876. 22. Ia. Hort. Soc. Rpt. 331. 1885.

Colorado Morello. 23. Rogers Cat. 18. 1900.

English Morello is the best of all its group and is the standard late Sour Cherry in North America, occupying at the close of the season the place held by Montmorency in mid-season for home, market and cannery. It is not a table fruit and can hardly be eaten out of hand until it loses some of its astringency and acidity by thorough ripening. In any way the cherries are prepared by cooking, however, it is one of the best, culinary processes giving the fruits a rich, dark wine color, very attractive in appearance, and a most pleasant, sprightly, aromatic flavor. The fruit is handsome in appearance, bears harvesting and shipping well, is resistant to brown-rot and hangs long on the trees after ripening, often until the last of August if robins can be kept away. Once seen, one may always know the trees. They are small, round-headed, with branches that distinctly droop. To be sufficiently productive an English Morello orchard must be closely set; for, though the trees are vigorous and productive for their size, they are too dwarf to yield heavily. The trees are hardy but not always healthy and are not adapted to as great a diversity of soils as might be wished. The variety distinctly fails in its tree-characters. The demand for English Morello has recently decreased and it is doubtful if it ever regains its popularity of a decade ago. There is a place for a late cherry which English Morello now fills but not sufficiently well.

All of the early pomologists describe a Morello or a Morella but no one of them definitely gives its place of origin. The concensus of opinion is that it originated in either Holland or Germany from whence it was introduced into England and later into France. The early German writers listed a Grosse Lange Lothkirsche which is English Morello. Preceding them, Duhamel described the Grosse Cerise à Ratafia "as one praised for confitures and preserving," which is probably this cherry. Leroy believed English Morello to be the cherry that Mortillet brought to Paris from Holland calling it Griotte du Nord though he thought the variety had been grown in France for many years previous but under another name. 
It is possible that the term Du Nord originated through its being widely grown as an espalier demanding a northern exposure, rather than as some have thought, because it came from northern Germany. In 1862 English Morello was put on the fruit list of the American Pomological Society where it still remains. Wragg is thought to be identical with this cherry by some and, if not, it differs but little. Northern Griotte and Grosse Lange Lothkirsche, introduced by Budd from Russia, are English Morello. Morris, or Colorado Morello, put out by John Morris of Golden, Colorado, once thought to be distinct, is also English Morello.

Tree small, upright-spreading, with drooping branchlets, dense-topped, productive; trunk slender, rough; branches slender, smooth, dark brown overlaid with dark ash-gray, with numerous small lenticels; branchlets slender, willowy, with short internodes, brownish, smooth, with numerous conspicuous, small, slightly raised lenticels.

Leaves numerous, two and three-fourths inches long, one and one-half inches wide, folded upward, obovate to oval; upper surface dark green, smooth; lower surface light green; apex acute, base variable in shape; margin finely serrate, with small, dark glands; petiole one-half inch long, tinged with dull red, grooved, with from one to three small, globose or reniform, greenish-yellow glands at the base of the blade.

Buds small, short, obtuse, plump, free, arranged singly as lateral buds; leaf-scars obscure; season of bloom late; flowers one inch across, white; borne in scattering clusters in twos and threes; pedicels nearly one inch long, glabrous, greenish; calyx-tube with a faint tinge of red, somewhat campanulate, glabrous; calyx-lobes with a trace of red. obtuse, serrate, glabrous within and without, reflexed; petals distinctly veined, roundish, crenate, sessile, with crenate apex; filaments one-fourth of an inch long; pistil glabrous, shorter than the stamens.

Fruit matures very late; about three-fourths of an inch in diameter, sometimes running larger, roundish-cordate, slightly compressed; cavity shallow, narrow, flaring, regular; suture a shallow groove; apex roundish, with a small depression at the center; color very dark red becoming almost black; dots numerous, small, dark russet, conspicuous; stem slender, one inch long, adhering well to the fruit; skin thin, tender, separating from the pulp; flesh dark red, with dark colored juice, tender and melting, sprightly, tart; of good quality; stone free, small, ovate, slightly flattened and pointed, with smooth surfaces, slightly tinged with red.

\section{FLORENCE}

\section{Prunus avium}

1. Prince Treat. Hort. 29. 1828. 2. Kenrick Am. Orch. 277. 1832. 3. Downing Fr. Trees Am. 187. 1845. 4. Thomas Amt. Fruit Cult. 365. 1849. 5. Am. Pom. Soc. Cal. 22. 1885.

Knevelt's Late Bigarreau. 6. Lond. Hort. Soc. Cat. 46.1831.

Bigarreau de Florence. 7. Leroy Dict. Pom. 5:204 fig., 205. 1877.

Florence Heart. 8. Bunyard-Thomas Fr. Gard. 43. 1904.

Florence is a Bigarreau so similar to Yellow Spanish as to be hardly worth planting, since it is, all and all, surpassed by its better-known rival. 


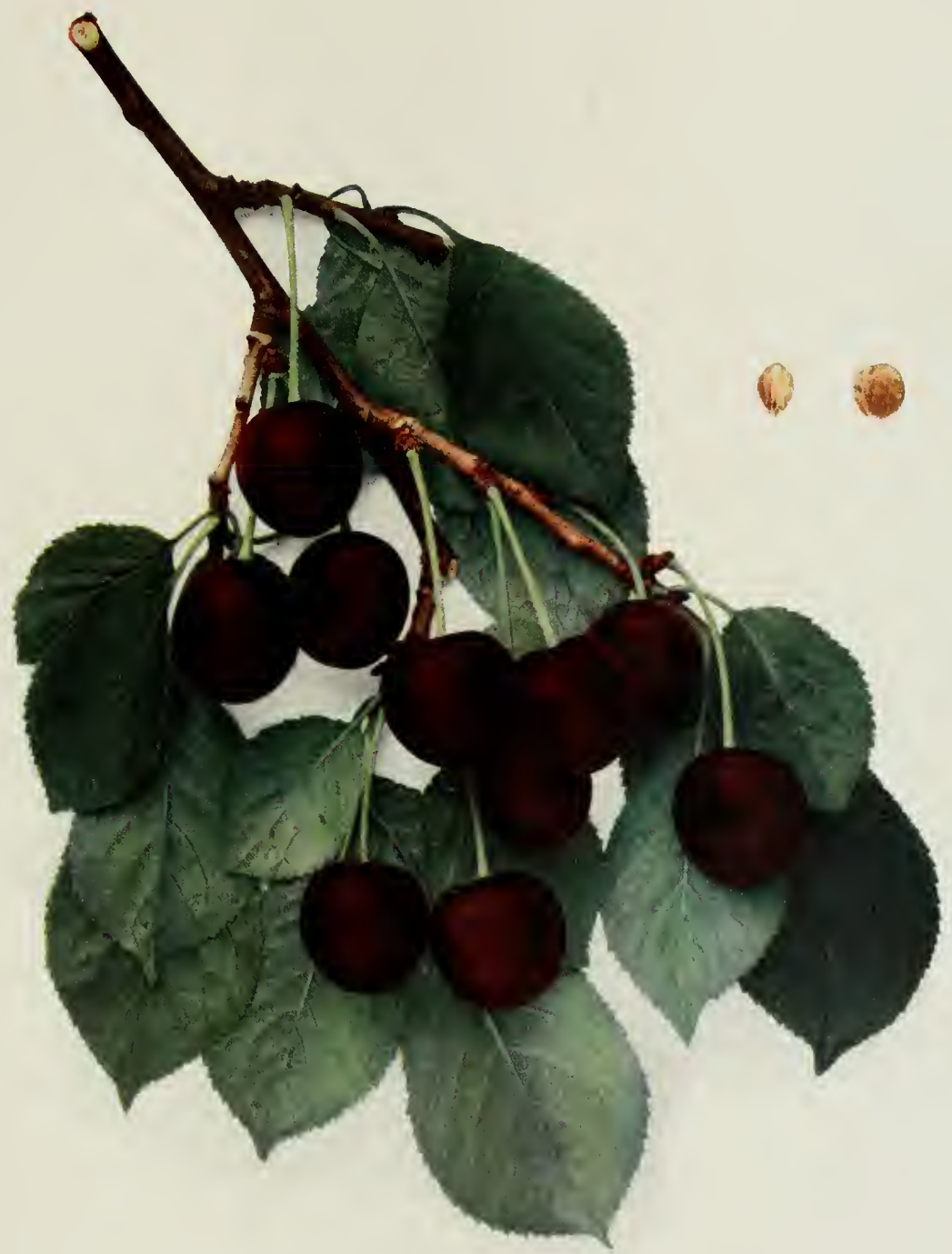





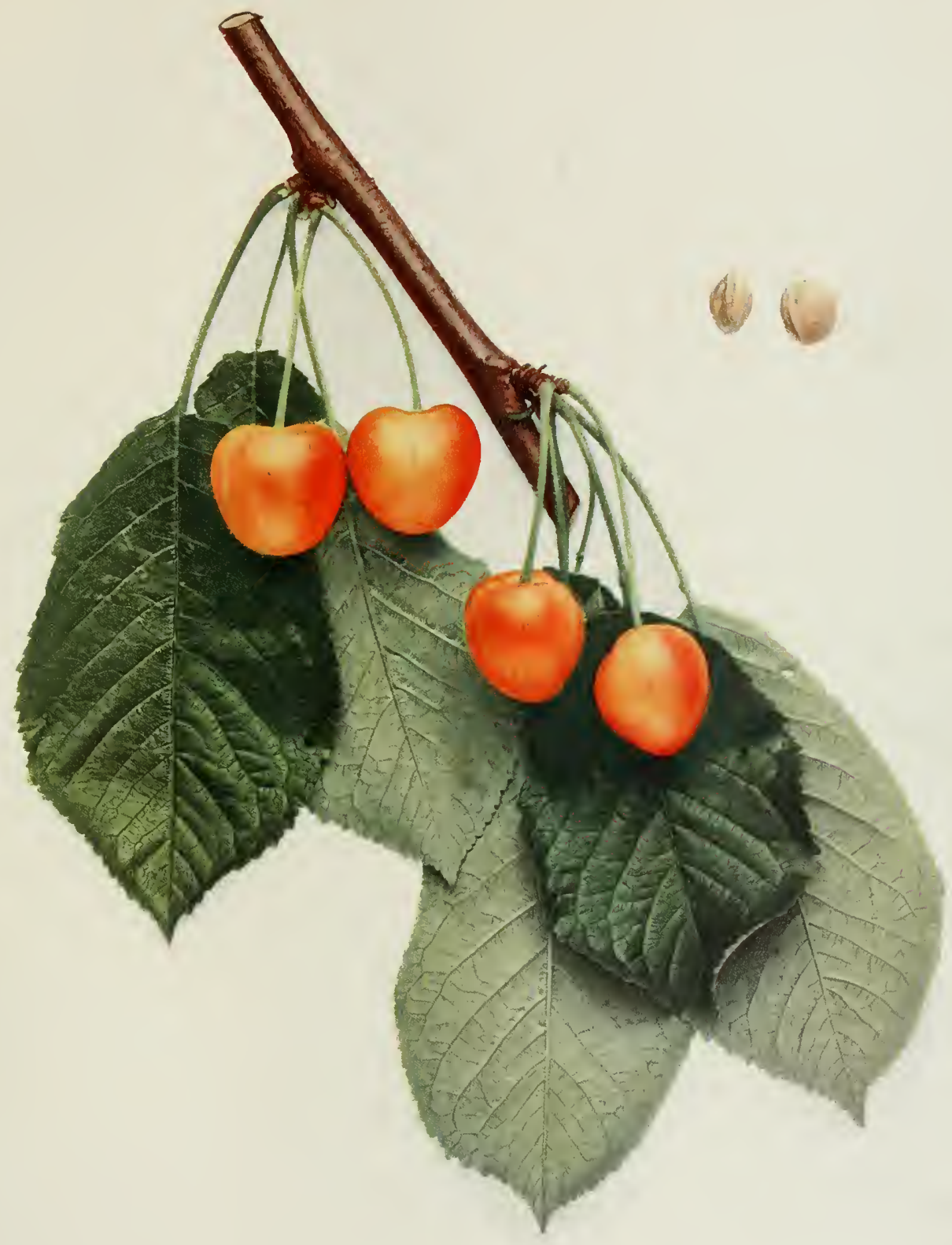

FLORENCE 

The fruit hangs on the tree in edible condition an almost phenomenal length of time which has given rise to much divergence of opinion as to its season, some pomologists rating it as early, others as mid-season and still others as late. At Geneva the trees of this variety are not as healthful, vigorous or as fruitful as those of Yellow Spanish, with which it must compete, nor are the cherries quite as fine in appearance or quality.

This variety was found in Florence, Italy, early in the Nineteenth Century by John Houblon, who took it to England from whence it was brought to America. It found a place in 1885 on the fruit list of the American Pomological Society where it remained until I89I, when it was discarded, with quite sufficient reason.

Tree vigorous, upright, open-topped, productive; trunk and branches thick, smooth; branches reddish-brown partly overspread with ash-gray, with numerous lenticels; branchlets thick, long, brown partly covered with ash-gray, smooth, with inconspicuous, raised lenticels.

Leaves numerous, variable in size, averaging four and one-fourth inches long, two and one-fourth inches wide, folded upward, long-oval to obovate, thin; upper surface rather dark green, rugose; lower surface dull light green, thinly pubescent; apex acute, base abrupt; margin coarsely and doubly serrate, glandular; petiole one and three-fourths inches long, thick, pubescent, dull red, with from two to four large, reniform, reddish glands on the stalk.

Buds pointed, plump, free, arranged as lateral buds and grouped in large clusters on numerous short spurs; season of bloom intermediate; flowers one and one-fourth inches across, white; borne in dense clusters in twos and threes; pedicels three-fourths of an inch long, slender, glabrous, greenish; calyx-tube green, obconic, glabrous; calyx-lobes greenish, acute, glabrous within and without, reflexed; petals broad-obovate to oval, entire, with very short, blunt claws, distinctly notched at the apex; filaments nearly one-half inch long; pistil glabrous, usually shorter than the stamens.

Fruit matures early; one inch in diameter, cordate, compressed; cavity deep, wide; suture very shallow; apex somewhat pointed; color reddish over an amber background, marked with indistinct, whitish spots and streaks; dots numerous, small, whitish, inconspicuous; stem one and one-half inches long, adherent to the fruit; skin thin, separating from the pulp; flesh yellowish-white, with colorless juice, tender, meaty, crisp, sprightly, sweet; of very good quality; stone clinging, cordate, flattened, blunt, with roughish surfaces; enlarged along the ventral suture.

\section{GEORGE GLASS}

Prunus cerasus

1. Mich. Hort. Soc. Rpt. 328, 329. 1888. 2. Ia. Hort. Soc. Rpt. 79. 1890. 3. Mich. Hort. Soc. Rpt. 245. 1894. 4. Ia. Sta. Bul. 31:34I. 1895. 5. Del. Sta. An. Rpt. 12:125. 19oo. 6. Budd-Hansen Am. Hort. Man. 2:276, 277. 1903. 7. Ia. Sta. Bul. 73:70. 1903. 
George Glass has been widely heralded as a desirable variety in the Middle West but in New York, where it has passed through a rather lengthy probationary period, practically all who have tried it are ready to declare it worthless. It is of the Amarelle group and cannot compete with the many good varieties of its kinship, as the Early Richmond or the several Montmorencies. Its season is between Early Richmond and Montmorency. As compared with the last-named variety, the standard Sour Cherry, the fruit of George Glass is smaller, sourer, less attractive in appearance and the trees are far less fruitful. Possibly the trees are more hardy, this character commending it for the colder parts of the Mississippi Valley.

The origin of this variety is uncertain but it is supposed to have been introduced into Iowa by immigrants from northeastern Germany. In American collections it has often been confused with Brusseler Braune and Bessarabian and by some is declared to be identical with the latter sort. It is supposed to be a cross between a Duke and a Morello cherry.

Tree large, vigorous, upright-spreading, rather open, hardy, appears unproductive; trunk thick; branches thick, roughened, with numerous conspicuous, raised lenticels; leaves numerous, four inches long, two inches wide, obovate, thick, stiff, dark green; petiole three-fourths of an inch long, tinged with red, with a few hairs along the upper surface, with one or two small, globose, reddish-orange glands, usually at the base of the blade; buds intermediate in size and length; leaf-scars prominent; season of bloom intermediate; flowers one and one-fourth inches across; borne in dense clusters.

Fruit matures in mid-season; three-fourths of an inch long, one inch wide, oblate, compressed; cavity deep; color light red changing to dark red; stem one and one-eighth inches long, adherent to the fruit; skin separating from the pulp; flesh yellowish-white, with abundant colorless juice, stringy, tender and melting, rather mild for a sour cherry; good to very good in quality; stone free, roundish or slightly oblate, plump, blunt, with smooth surfaces; ventral suture prominent.

\section{HEART-SHAPED WEICHSEL}

\section{Prunus cerasus}

I. Truchsess-Heim Kirschensort. 573-577. 1819. 2. Dochnahl Führ. Obstkunde 3:60, 61, 1858. 3. Mich. Hort. Sac. Rpt. 328. 1888. 4. Wash. Sta. Bul. 92:17. 1910.

Herzförmige Sauerkirsche. 5. Christ Wörterb. 288. 1802.

Heart-Shaped Griotte. 6. Prince Pom. Man. 2:149. I832. 7. Mas Le Verger 8:103, I04, fig. 50. 1866-73.

This Sour Cherry, of the Morello group, is too poor in quality to recommend it for any purpose. The fruit is scarcely edible until dead ripe and even then is too puckering to eat out of hand with relish. The cherries 


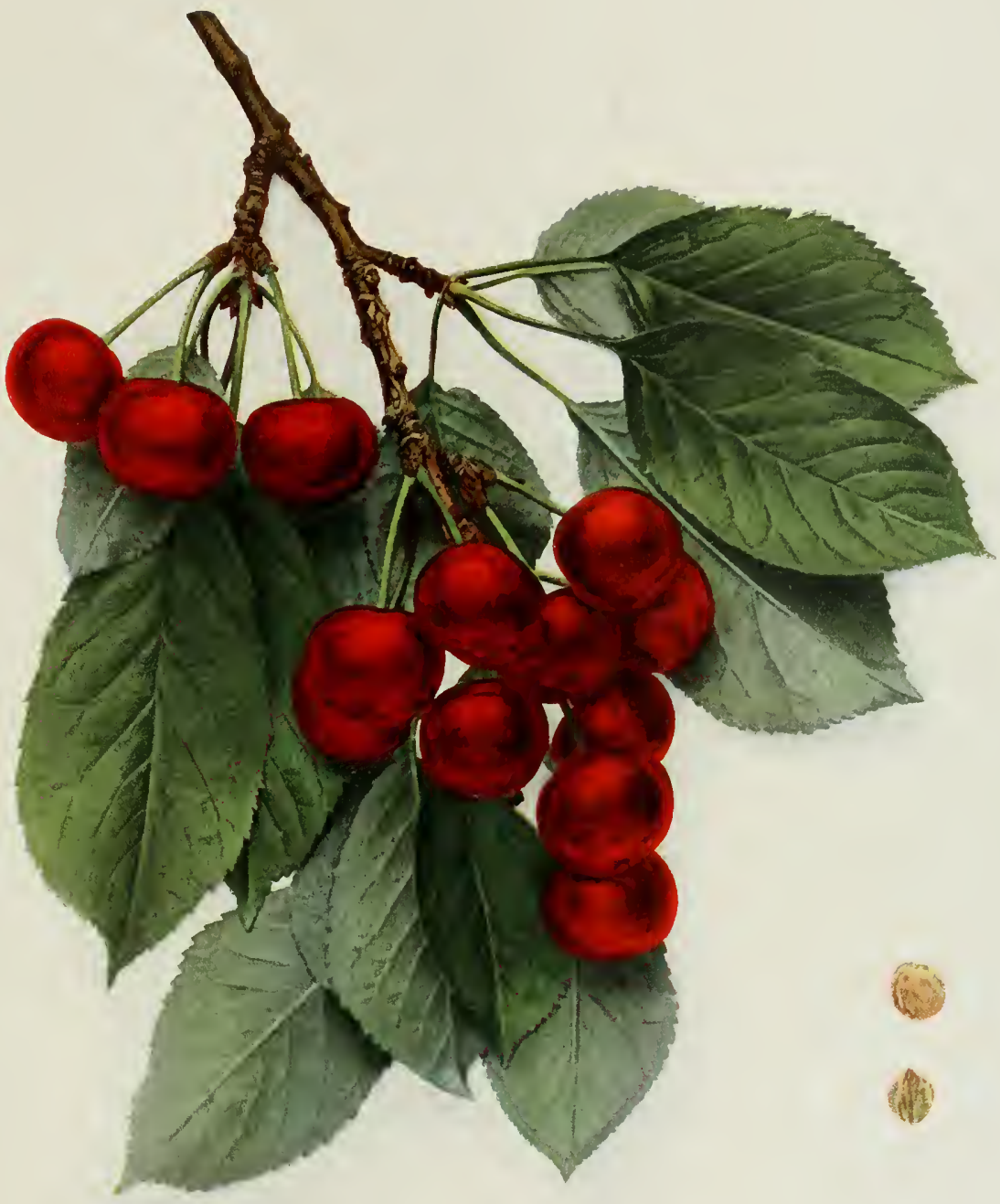

GEORGE GLASS 

are very attractive, being large for the kind, heart-shaped, of a handsome, clear, glossy dark purple color and very uniform in all characters. The tree is conspicuous because of its symmetrical shape, large size, round head and its many branches and branchlets. The leaves are characteristically small, as are the flowers, which are further distinguished by very narrow petals. The tree is hardy and productive and quite worth a place on a lawn as an ornamental if not in the garden for its fruit. The variety has several characters to commend it to plant-breeders.

This variety came to light in written records in the early part of the Nineteenth Century in German fruit-books under the name Saure Herzkirsche or Herzkirschweichsel and was highly recommended for its fine flavor. Professor J. L. Budd of Iowa, in one of his European trips, was impressed with its symmetrical habit of growth and its abundant foliage where he found it growing in eastern Europe as a lawn tree. $\mathrm{He}$ included it among his importations but it has not proved valuable in the New World.

Tree large, vigorous, upright-spreading, open-topped, unproductive; branches rather slender, smooth except for the large, conspicuous lenticels; branchlets slender, long; leaves numerous, two and three-fourths inches long, one and three-eighths inches wide, obovate to oval, thin, dark green, smooth; petiole over one-half inch long, tinged with red, with from one to three small, globose, greenish-yellow or brownish glands at the base of the blade; buds intermediate in size and length, usually obtuse; season of bloom late; flowers one inch across; borne in scattered clusters; filaments one-fourth inch long; pistil slightly shorter than the stamens, often defective.

Fruit matures in mid-season; about three-fourths of an inch in diameter, roundishconic, slightly compressed; color very dark, dull red; stem slender, one and one-fourth inches long, adhering to the fruit; skin thin, tough; flesh very dark red, with dark winecolored juice, tender, rather meaty, very astringent, sour; of poor quality; stone nearly free, small, ovate, flattened, pointed, with roughish and colored surfaces.

\section{HILDESHEIM}

\section{Prunus avium}

I. Prince Pom. Man. 2:131, 1832. 2. Elliott Fr, Book 196. 1854.

Guignier à Fruit Rouge Tardif. 3. Duhamel Trait. Arb. Fr. 1:162. 1768.

Agathe. 4. Knoop. Fructologie 2:37. 177 I.

Doppelttragende Kleine Rothe Spätkirsche. 5. Truchsess-Heim Kirschensort. 281, 282, 283. I819.

Hildesheimer Ganz Späte Knorpelkirsche. 6. Truchsess-Heim Kirschensort. 321, 322, 323. 1819.

Late Red Guigne. 7. Prince Pom. Man. 2:113. 1832.

Bigarreau Tardif de Hildesheim. 8. Downing Fr. Trees Am. 184. 1845.

Merveille de September. 9. Elliott Fr. Book 2 I0. 1854.

Belle Agathe de Novembre. 10. Ann. Pom. Belge 3:9, P1. 1855. 
Hildesheimer Späte Knorpelkirsche. II. Ill. Handb. I39 fig., 140. 1860.

Kratos Knorpelkirsche. I2. Ill. Handb. 59 fig., 60.1867.

Schöne Agathe. 13. Ill. Handb. 63 fig., 64. 1867.

Bigarreau de Fer. 14. Leroy Dict. Pom. 5:199, 200 fig. 1877.

Belle Agathe. 15. Mas Pom. Gen. 11:99, 100, fig. 50. 1882.

Bigarreau de Hildesheim. 16. Hogg Fruit Man. 282. 1884.

This variety, one of the oldest, has been called by a great number of names by European writers. The cherry mentioned by Duhamel, in I 768 , as a late Guigne with red fruit, otherwise known as Guigne de Fer, can be no other than Hildesheim. The exact origin of the variety has never been known, though it is supposed to have sprung up in the neighborhood of Hildesheim, Prussia. It was brought to America early in the Nineteenth Century, probably by William Prince. With it came some of the numerous foreign names. It seems certain that Late Red Guigne mentioned by Prince was Hildesheim. Ripening late and being small and of rather undersirable texture, Hildesheim did not meet with much favor in America, never being widely disseminated, and has long since passed from cultivation. This variety, under the name Belle Agathe, was propagated in Belgium by M. Thiery about $185^{2}$ and for some time was supposed to be a separate sort. The following description is compiled:

Tree very large, vigorous, upright, hardy, an annual bearer, unproductive while young producing good crops later; branches thick, large, long, straight; leaves numerous, of medium size, oval or elongated-oval, acuminate; margin finely and regularly serrate; petiole slender, rather short, tinged red, with large, flattened glands; blooming season early.

Fruit matures very late, usually attached in fives but sometimes in threes and fours; small to medium, roundish-cordate, flattened on one side, somewhat irregular; color yellowish, mottled and marbled with dark red; stem two inches long, slender, somewhat curved; skin thick; flesh pale yellow, slightly tinged with red at the pit, firm, somewhat stringy, rather dry, with uncolored juice, pleasant flavored, sweet; quality good; stone medium to large, with reddish surface, long, compressed.

\section{IDA}

Prunus avium

I. Gard. Mon. 20:270, 271. 1878. 2. Downing Fr. Trees Am. 3rd App. 162. 1881. 3. Am. Pon. Soc. Cat. 26. 1909.

Ida is a handsome, large, light red cherry resembling Napoleon in shape and Rockport in color, but differing from both in having soft flesh which places it among the Hearts rather than the Bigarreaus. Because of beauty of the fruit, earliness and good tree-characters, Ida promises to become a 


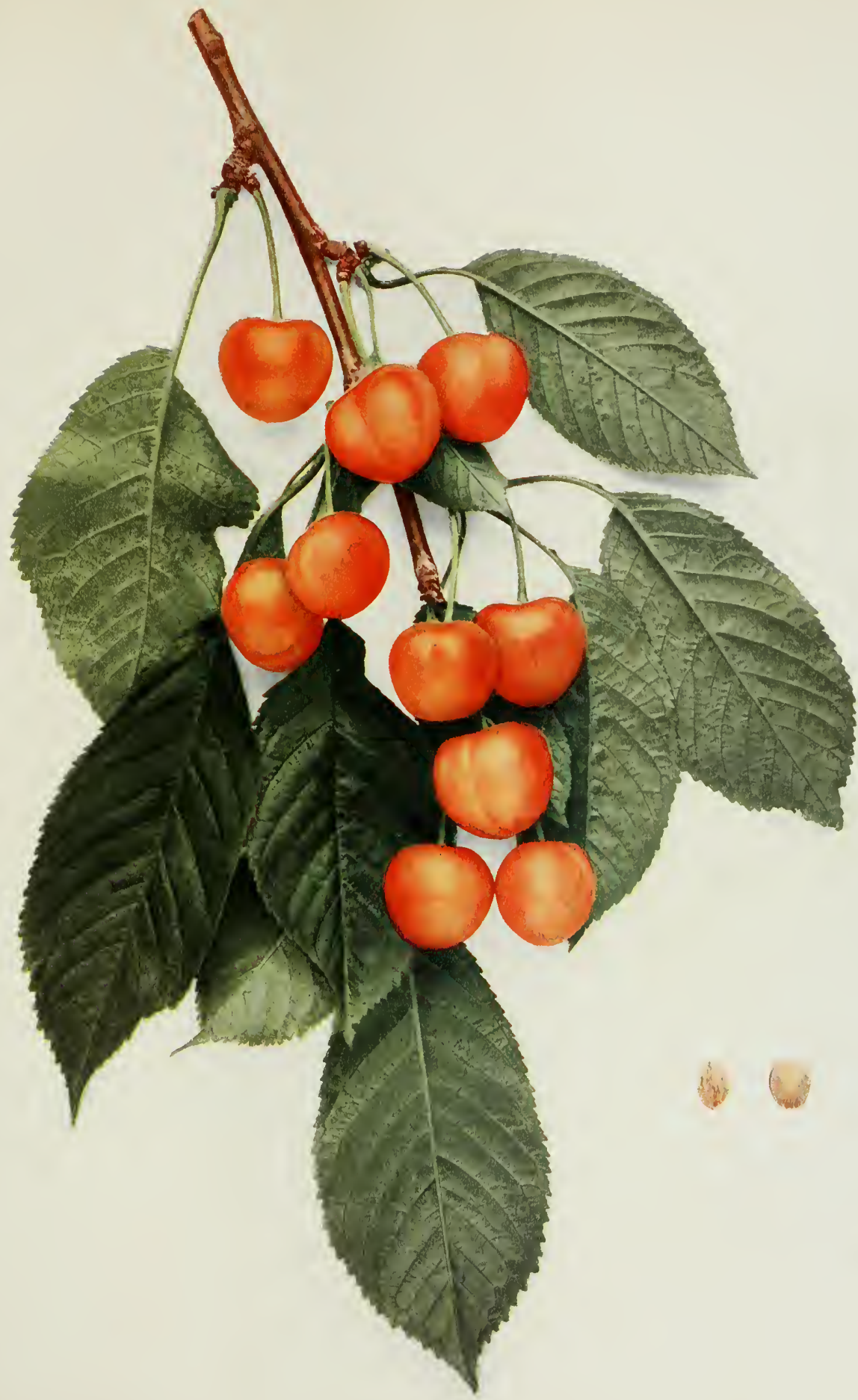



rather general favorite in home orchards though it falls short of several others of its near of kin in flavor and flesh-characters. It can never take a high place among commercial kinds because the cherries are too soft to handle well, show bruises plainly, are somewhat susceptible to brown-rot and come when better cherries are plentiful. The trees are vigorous, hardy and bear full crops regularly and in various environments. The variety is readily told by the upright habit of growth and by the large lenticels on trunk and branches. Ida has been very well tried as a commercial variety in this State but in the ups and downs of the industry has not held its own with other sorts and can be recommended only for home plantations.

E. H. Cocklin of Shepherdstown, Pennsylvania, grew this variety as a seedling of Cocklin's Favorite, another of his cherries. The cherry was named after his daughter, Ida. It seems to have proved worthy of general culture, as it is now listed by many nurserymen. The American Pomological Society placed Ida on its fruit list in 1909.

Tree large, vigorous, upright, open-topped, somewhat vasiform, very productive; trunk stout; branches very stocky, smooth, light ash-gray over brown, with large, muchraised lenticels; branchlets very stout, short, brown partly covered with ash-gray, roughish, with a few raised lenticels.

Leaves five and one-half inches long, two and one-half inches wide, folded upward, elliptical to obovate, thin; upper surface dark green, smooth; lower surface light green, pubescent along the midrib and larger veins; apex taper-pointed, base acute; margin doubly crenate, with small, black glands; petiole two and one-fourth inches long, thick, tinged with red, somewhat hairy along the grooved upper surface, usually with two large, reniform, reddish glands on the stalk.

Buds large, long. pointed, plump, free, arranged singly as lateral buds and in dense clusters on numerous short spurs, also with many small, round, lateral leaf-buds on the secondary growth; leaf-scars not prominent; blooming in mid-season; flowers white, one and one-fourth inches across; borne in clusters usually in twos; pedicels three-fourths of an inch long, glabrous, greenish; calyx-tube green, whitish within, campanulate, glabrous; calyx-lobes with a tinge of red, acute, reflexed; petals roundish, entire, dentate at the apex, nearly sessile; filaments nearly one-half inch long; pistil glabrous, shorter than the stamens.

Fruit matures early; three-fourths of an inch in diameter, cordate, slightly compressed; cavity deep, flaring, regular; suture a distinct line; apex variable in shape; color amber overspread with light red, mottled; dots numerous, rather large, yellowish, somewhat conspicuous; stem one and one-half inches long; skin thin, separating readily from the pulp; flesh whitish, with colorless juice, tender and melting, mild, sweet; of good quality; stone free or semi-free, roundish, slightly flattened, blunt, with smooth surfaces; with distinct ridges along the ventral suture. 


\section{JEFFREY DUKE}

\section{Prunus avium $\times$ Prunus cerasus}

1. Lond. Hort. Soc. Cat. 52. 1831. 2. Mag. Hort. 9:204. 1843. 3. Downing Fr. Trees Am. 190. 191. 1845. 4. Am. Pom. Soc. Cat.74. 1862. 5. Mas Pom. Gen. 11:119, 120, fig.60. 1882. 6. Hogg Fruit Man. 302. 188 4.

Royale. 7. Duhamel Trait. Arb. Fr. 1:193, 194, P1. XV. 1768. 8. Truchsess-Heim Kirschensort. 482-484. 1819. 9. Leroy Dict. Pom. 5:386, 387 fig., 388 . 1877.

Königliche Süssweichsel. 10. Truchsess-Heim Kirschensort. 427-429. 1819. 11. Ill. Handb. 73 fig., 74. 1867 .

Jeffrey's Royal. 12. Floy-Lindley Guide Orch. Gard. $99.18+6$.

Royale Hâtive. 13. Mortillet Le Cerisier 2:134-138, fig. 32.1866.

This old variety, which has almost passed from cultivation, may have had its origin in France about the middle of the Eighteenth Century, though more likely it originated in England much earlier. Leroy mentions a Royale cherry which was introduced from England to France about 1730 and was first grown by M. le Normand in the garden of Louis XV. The name Royale was first used by the French about 1735 from the fact that it was grown in the royal gardens and since that time this name has clung to the variety in most of the French plantations. According to English writers, the variety was brought to notice in England by Jeffrey, proprietor of the Brompton Nursery at Brompton Park, England, and from that time it was known as Jeffrey's Duke. English pomologists maintain that Jeffrey renamed the old Cherry Duke of England, giving it his name. Jeffrey Duke appeared on the American Pomological Society's fruit catalog list in 1862 but was dropped in 1871 . It is doubtful if the variety can now be found in America. The following description is compiled from the authors given in the references:

Tree large, vigorous, very upright, unusually compact, slow-growing, productive; branches very numerous, stocky, straight, thickly set with fruit-spurs; internodes short; branchlets very short; buds closely set; leaves numerous, medium in size, oval or obovate, acuminate; margin finely and irregularly serrate; petiole short, slender, with small, flattened or globose glands; blooming season late; flowers small, very open.

Fruit matures in mid-season, usually attached in pairs; medium in size, roundish, slightly flattened at the apex and base; suture a well-marked line; color lively red becoming dark red or almost black when fully ripe; stem slender, inserted in a moderately broad, deep cavity; skin thin; flesh firm but tender, yellowish-amber, with abundant colored juice, slightly stringy, highly flavored; good in quality; stone small, roundish, tinged with red. 


\section{KING AMARELLE}

\section{Prunus cerasus}

1. Christ Wörterb. 293. 1802. 2. Truchsess-Heim Kirschensort. 610-615. 1819. 3. Liegel Syst. Anleit. 174. 1825. 4. Ill. Handb. 533 fig., 534. 1861. 5. Lauche Deut. Pom. III: No. 23, PI. 1882. 6. Am. Gard. 9:264. 1888. 7. Can. Exp. Farm Bul. 2nd Ser 3:62. 1900. 8. Ia. Sia. Bul. 73:72. 1903. 9. Am. Pom. Soc. Cat, 27. 1909 .

King's Cherry. Io. Rea Flora 205. 1676.

King Amarelle is an old European cherry that has taken on new life in America. It is of the Early Richmond type, differing from this standard Amarelle in bearing fruit a little earlier, lighter in color and with a longer stem. The fault which all but condemns the variety as a commercial cherry is the small size of the fruit, the cherries running smaller than those of Early Richmond which, in its turn, is rather too small. The tree is very like that of Early Richmond - quite as vigorous and productive, the same in size and shape and, if anything, a little more hardy. The variety is told from afar in blossoming-time by the peculiar distribution of the flowerclusters, which are numerous and dense but always separated by several inches or a foot of bare wood. King Amarelle can never displace Early Richmond but might be tried where a somewhat hardier cherry is wanted or it might be planted as a substitute where the better-known sort fails.

This variety, of old and uncertain origin, sprang up in France about the same time as the Montmorencies and became confused with them. In both fruit and tree-characters, however, King Amarelle is very different from the Montmorencies, being more like Early May but ripening later and making a larger tree. The cultivation of King Amarelle never became extended in Europe because of the inferior quality of the fruit and poor tree-characters. Professor J. L. Budd brought the variety to America from Russia about I883. The Royal Amarelle, grown on the Canadian Experiment Station grounds in 1900 , is undoubtedly King Amarelle. The American Pomological Society placed it on its list of recommended fruits in 1909.

Tree of medium size and vigor, upright-spreading, open-topped, very productive; trunk roughish; branches rather slender, smooth, reddish-brown overlaid with dark ashgray; branchlets slender, of medium length, with short internodes, brown partly covered with ash-gray, smooth, with numerous conspicuous, small, raised lenticels.

Leaves three and one-half inches long, one and one-half inches wide, folded upward, obovate, somerwhat glossy, thick; upper surface dark green, rugose; lower surface light green, with a few scattering hairs; apex acute, base abrupt; margin finely and doubly 
serrate, with small, dark glands; petiole one inch long, somewhat slender, lightly tinged with red, with a few hairs on the grooved upper surface and with from one to three small, g-obose, greenish-yellow glands at the base of the blade.

Buds small, short, obtuse, very free, arranged singly as lateral buds and in clusters on few, short spurs; leaf-scars prominent; season of bloom intermediate; flowers white, one and one-fourth inches across; borne in dense clusters usually in threes; pedicels over one-half inch long, glabrous, greenish; calyx-tube with a tinge of red, obconic, glabrous; calyx-lobes faintly tinged with red, acute, serrate, glabrous within and without, reflexed; petals somewhat obovate, entire, with an entire apex; filaments one-fourth inch long; pistil glabrous, equal to the stamens in length.

Fruit matures early; three-fourths inch in diameter, roundish-oblate, compressed; cavity regular, somewhat abrupt; suture indistinct; apex roundish or flattened; color bright red; dots numerous, small, light russet, rather conspicuous; stem one inch long, adhering to the fruit; skin thin, tender, separating from the pulp; flesh pale yellow, with colorless juice, tender and melting, sprightly; fair to good in quality; stone free, ovate, somewhat flattened, pointed, with smooth surfaces, faintly tinged with red; ridged along the ventral suture.

\section{KIRTLAND}

\section{Prunus avium}

I. Am. Pom. Soc. Sp. Rpt. 22, 1904-05.

Kirtland's Mary. 2. Horticulturist 2:123, 124 fig. 21. 1847-48. 3. Thomas Am. Fruit Cult. 365 . 1849. 4. Cole Am. Fr. Book 23r. I849. 5. Am. Pom. Soc. Rpt. 39. 1852. 6. Ibid. 235. I854. 7. Elliott Fr. Book I98 fig. 1854. 8. Hooper W. Fr. Book 262, 263. 1857. 9. Mas. Le Verger 8:55, 56, fig. 26. I 866-73.

Mary. 10. Hogg Fruit Man. 69, 86, 87. I866.

In the collection of cherries at this Station, Kirtland stands among the best of the Bigarreaus in quality of fruit - in fact is hardly surpassed in richness and delicacy of flavor. The fruit, too, as may be seen from the color-plate, is handsome, the cherries resembling the well-known Napoleon but being a little darker in color. The flesh is firm and meaty and stands handling well and also resists the brown-rot as well as any other cherry. With these splendid qualities of fruit, Kirtland would long ago have been one of the standard commercial cherries were its tree-characters better. Wherever tried, the complaint comes that the trees lack vigor and can be grown successfully only on choice cherry soils and under the best of care. With these faults the variety can be recommended only for home orchards and for local markets where there is demand for a very early Bigarreau, since this variety ripens before most other cherries of its kind.

Kirtland was grown in 1842 by Professor J. P. Kirtland of Cleveland, Ohio, and ranks foremost in quality and appearance of all the seedlings raised by this well-known cherry-breeder. The American Pomological 


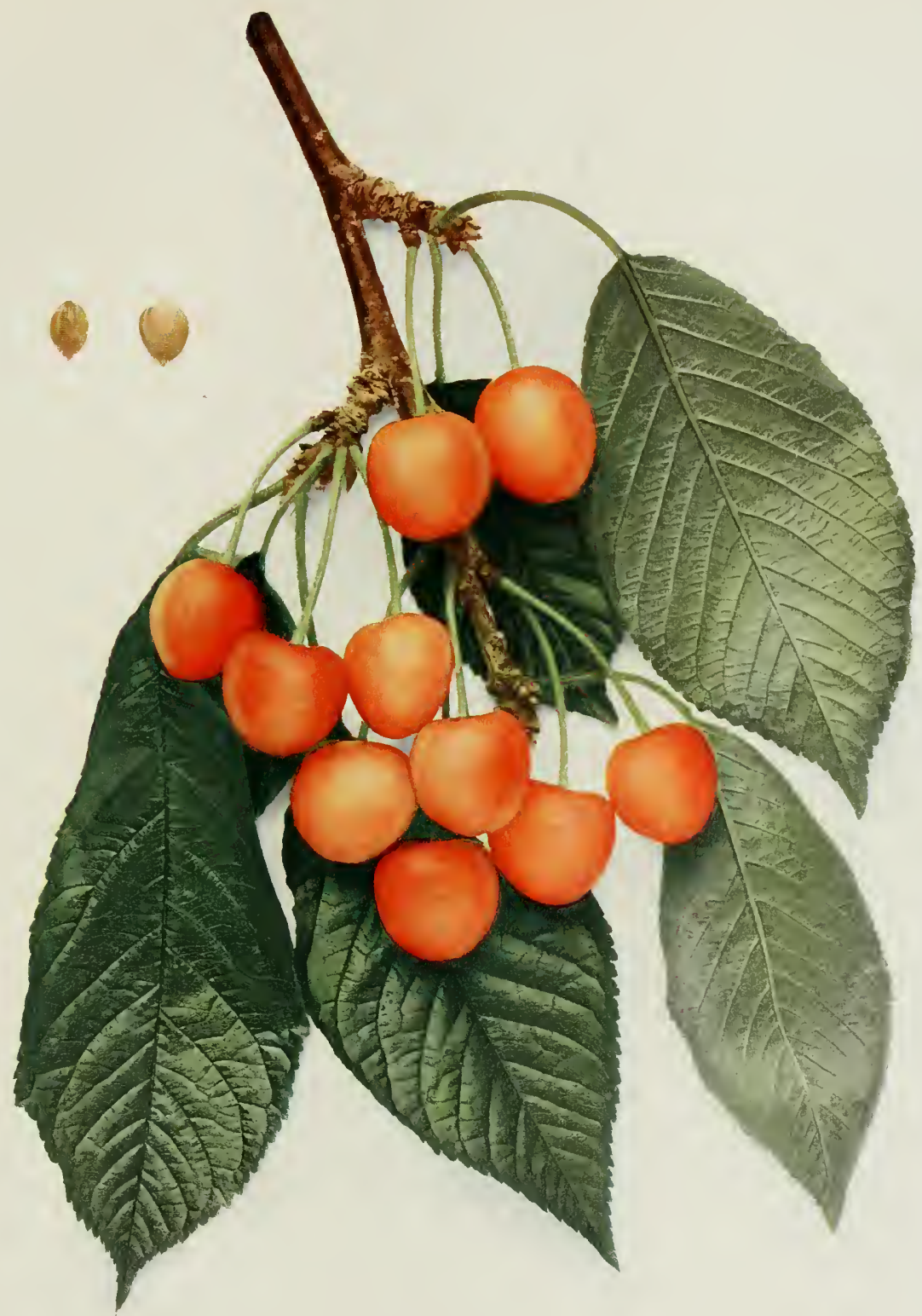


Society, in 1852 , mentioned this sort as deserving of further trial and, in I 854 , listed it among the varieties of promising fruits. Elliott, in his Fruit Book, noted this cherry under the name Kirtland's Mary, in honor of Professor Kirtland's daughter, and classed it as a variety worthy of general cultivation. Hogg, in I866, dropped the name Kirtland and listed it as Mary, while in the American Pomological Society's Special Report for 1905 it is called Kirtland. According to the rules of pomological nomenclature, Hogg was correct in holding the name Mary but, since there is another Mary and no worthy sort bearing the name of so eminent a horticulturist as Professor Kirtland, this Station follows the American Pomological Society in the use of Kirtland.

Tree small, rather weak, upright-spreading, open-topped, productive; trunk and branches slender, smooth; branches reddish-brown partly overspread with ash-gray, with numerous lenticels; branchlets thick, brown almost entirely overspread with ashgray, smooth except for the longitudinal, conspicuous, raised lenticels.

Leaves five inches long, two and one-fourth inches wide, folded upward, elliptical to obovate, thin; upper surface medium green, somewhat glossy, smooth; lower surface light green, thinly pubescent; apex acute, base abrupt; margin doubly serrate, with small, dark glands; petiole one and three-fourths inches long, slender, tinged with red, lightly pubescent along the upper side, with two or three reniform, reddish glands on the stalk.

Buds pointed, plump, free, arranged singly as lateral buds or on numerous, very short spurs in clusters variable in size; leaf-scars prominent; blooming in mid-season; flowers white, one and one-fourth inches across; borne in dense clusters; pedicels one inch long, pubescent, reddish-green; calyx-tube tinged with red, light green within, campanulate, glabrous; calyx-lobes reddish, obtuse, glabrous within and without, reflexed; petals roundish-oval, entire, with short, broad claws and a notched apex; filaments in four series, the longest one-half inch; pistil glabrous, shorter than the stamens.

Fruit matures in mid-season; three-fourths of an inch in diameter, cordate, compressed; cavity wide, flaring; suture a more or less distinct line; apex roundish or pointed, with a small depression at the center; color amber overspread with bright red; dots numerous, small, grayish, conspicuous; stem one and three-fourths inches long, adhering to the fruit; skin tough; flesh whitish, with colorless juice, tender, meaty, with a pleasant and refreshing flavor; very good to best in quality; stone free, small, roundish-ovate, with smooth surfaces; ridged along the ventral suture.

\section{KNIGHT}

\section{Prunus avium}

I. Am. Pom. Soc, Cat. 26. 1909.

Knight's Early Black. 2. Lond. Hort. Soc. Cat. 52. 1831. 3. Prince Pom. Man. 2:120. 1832. 4. Proc. Nat. Con. Fr. Gr. 52. I848. 5. Dochnahl Führ. Obstkunde 3:19. 1858. 6. Mortillet Le Cerisier 2:83. I866. 7. Mas Pom. Gen. 11:85, 86, fig. 43. I 882 .

Knights Frühe Herzkirsche. 8. Ill. Handb. 3 fig., 4. 1867. 
This old English variety has long been popular in America, where it is generally known as Knight's Early Black, this name having been shortened by the American Pomological Society to Knight. Possibly Knight is to be found in dooryards and home gardens in Eastern United States as often as any other Sweet Cherry with the exception of Black Tartarian. The characters which give it popularity are excellent quality, handsome appearance because of its glossy, dark purple color and uniformity in color, shape and size, and its earliness, it being the earliest good Sweet Cherry. Unfortunately, even in the best soil and under the most painstaking treatment, the cherries run small, a defect for American markets. The small size also leads to comparatively low yields even though the fruits are often borne in prodigious numbers. Knight, in size, color and flavor, is much like Black Tartarian but the cherries are smaller and ripen earlier. As the trees grow on the grounds of this Station they are about all that could be desired in a Sweet Cherry. The trees are characteristically marked by smooth bark which is dotted with large lenticels. There are now better sweet varieties than Knight for most purposes but still this old variety has too many merits, especially for home grounds, to be wholly forgotten.

Knight comes from a seed of May Duke crossed with Yellow Spanish by T. A. Knight, Downton Castle, Wiltshire, England, about i 8 ro. The new variety sprang into prominence almost immediately, being mentioned by French, German and English writers. Knight is still one of the wellrecognized sorts in Europe and America and has appeared continuously on the fruit list of the American Pomological Society since $18+8$. Mathieu has included several synonyms under this head which we question as we believe they belong to the Guigne Noir Hâtive, a distinct variety though very similar.

Tree of medium size, upright-spreading, open-topped, very productive; trunk stocky, variable in smoothness; branches smooth, light reddish-brown nearly overspread with ash-gray, with small lenticels; branchlets thick, brown lightly covered with ash-gray, variable in smoothness, with small, raised, inconspicuous lenticels.

Leaves numerous, five and one-half inches long, two and one-half inches wide, folded upward, obovate to long-oval, thin; upper surface dark green, rugose; lower surface light green, thinly pubescent; apex and base variable in shape; margin doubly serrate, with small, dark glands; petiole two inches long, slender, tinged with red, with a shallow groove and with few hairs, with two or three large, reniform, reddish glands, usually on the stalk.

Buds long, conical or pointed, plump, free, arranged singly as lateral buds and in 


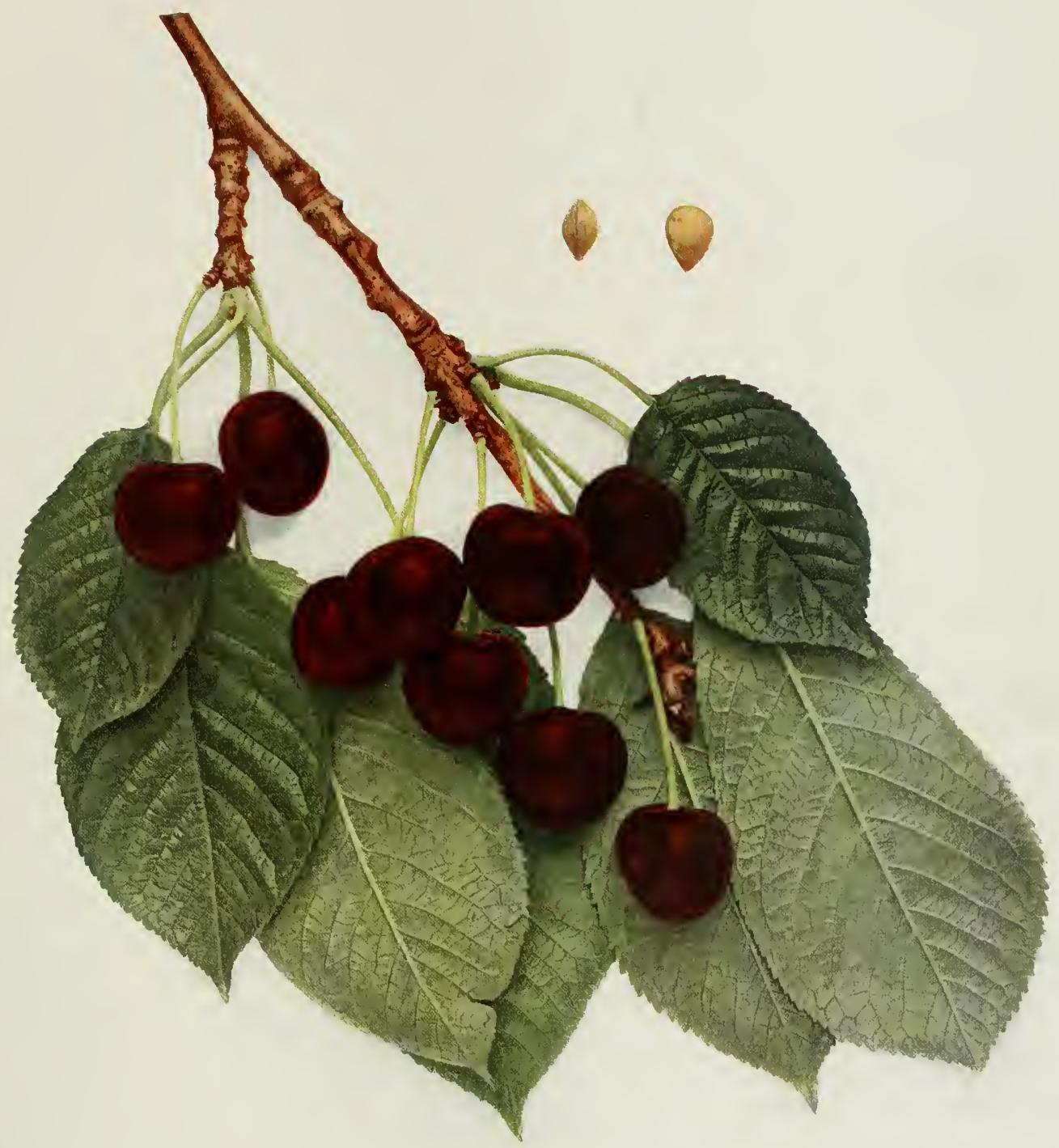



small clusters on spurs variable in length; leaf-scars prominent; season of bloom intermediate; flowers white, one and one-fourth inches across; borne in dense clusters, usually in twos; pedicels one inch long, slender, glabrous; calyx-tube green, campanulate, glabrous; calyx-lobes lightly tinged with red, long, acute, glabrous within and without, reflexed; petals oval, entire, deeply notched at the apex; filaments nearly one-half inch long; pistil glabrous, equal to the stamens in length.

Fruit matures early; three-fourths of an inch in diameter, cordate to conical; cavity wide, rather abrupt; suture indistinct; apex flattened, with a small depression at the center; color dark reddish-black, obscurely mottled; dots numerous, small, russet, obscure; stem slender, one and one-half inches long, adhering well to the fruit; skin thin, tender, separating from the pulp; flesh dark red, with dark colored juice, tender, meaty, mild, sweet; of good quality; stone free except along the ventral suture, small, roundish-ovate, with smooth surfaces.

\section{LAMBERT}

\section{Prunus avium}

I. U. S. D. A. Pom. Rpl. 24. 1894. 2. Am. Pom. Soc. Cat. 24. 1899. 3. U. S. D. A. Yearbook 307-309, P1. 3r. 1907.

Nowhere else in America, possibly nowhere else in the world, can the Sweet Cherry be grown as well as in Oregon and Washington. From these States, more particularly Oregon, several meritorious cherries have been added to pomology. One of the best of these is Lambert, now a standard sort in its native State but still on probation in Eastern America. Lambert is a Bigarreau, a seedling of Napoleon by Black Heart, and a worthy rival of its parents in most respects and superior in some. In appearance, Lambert is more like its male than its female parent, having much the same shape and color, but it is larger, more rotund, smoother, clearer and brighter - one of the handsomest of the dark-colored Sweets. The flesh and flavor leave little to be desired; the flesh is purplish-red marbled with lighter red, firm, meaty and juicy, with a sweet, rich flavor that at the first taste one marks very good. The tree is strong, vigorous, healthy and usually fruitful and regular in bearing. The fruit sets in great, loose clusters - often a dozen or more cherries to the fruit-spur. The leaves are remarkably large and dark green, the foliage betokening the vigor of the variety. Lambert is well worthy thorough testing for either home or market wherever the Sweet Cherry can be grown.

Lambert originated as a seedling under a Napoleon tree which was planted by the late Henderson Lewelling ${ }^{1}$ about 1848 in the orchard of

\footnotetext{
${ }^{1}$ Little is known of the early life of Seth and Henderson Lewelling. They were of Welsh ancestry and both were born in Salem, North Carolina, Henderson on the $25^{\text {th }}$ of April, 1809 , and Seth on the 6 th day of March, 1819. Henderson died in California December 28th, 1878, while Seth died in Milwaukee,
} 
J. H. Lambert, Milwaukee, Oregon. This seedling, supposed to have been a cross between Napoleon and Black Heart, was grafted to May Duke and later transplanted. About 1880 , the top died and a sprout from the seedling stock formed a new top. Mr. Lambert gave the new variety his name and in I 895 turned over his stock to the Oregon Horticultural Society with the exclusive right to propagate. The variety was placed on the fruit list of the American Pomological Society in I 899 where it still remains.

Tree medium to large in size and vigor, upright-spreading, very productive; branches smooth, dull reddish-brown, with numerous small lenticels; branchlets thick, long, dark reddish-brown nearly covered with ash-gray, smooth, glabrous, with a few inconspicuous lenticels.

Leaves four and one-fourth inches long, two and one-half inches wide, folded upward, oval to obovate, thin; upper surface medium green, smooth; lower surface light green, lightly pubescent; apex acute, base abrupt; margin doubly serrate, glandular; petiole one and one-half inches long, dull red, glandless, or with from one to three rather small, globose, reddish glands on the stalk.

Buds large, pointed or conical, free, arranged singly as lateral buds or in small clusters on short spurs; leaf-scars prominent; season of bloom intermediate, short; flowers

Oregon, February 2Ist, 1897. When the boys were still very young their parents moved from North Carolina to Ohio and founded the town of Salem in Ross County; later they moved to Indiana where their father established a nursery and became one of the pioneer fruit-growers of what was then the West and here again they founded a town of Salem. We next hear of Henderson Lewelling in Salem, Henry County, lowa, the town of his naming, with the statement that in 1837 he planted a small nursery of 35 varieties of apples and some peach, plum and cherry trees.

The history of the Lewellings now becomes more definite for we have it from Seth Lewelling ${ }^{1}$ (we spell the name as does he and not "Luelling" as do many in writing of him) that in March, 1847. Henderson Lewelling planted an assortment of apples, pears, peaches, plums and cherries and loaded them into two wagons and started to Oregon. This traveling nursery was on the road from March to November and one can imagine the labor of watering and caring for the trees in this trip across mountains and plains. Henderson Lewelling formed a partnership with William Meek under the firm name of Meek \& Lewelling, Milwaukee, Oregon. Seth joined his brother in the fall of $185^{\circ}$ bringing with him from the East a considerable quantity of fruit seed. For the next few years their nursery operations were on a large scale, over 100,000 grafts being planted in 1853 . From time to time they made new importations of plants and fruit seeds from the East. Seth says that his brother quit the business and moved to California in 1853 and we hear no more of him until his death in 1878 . In 1857 , the partnership between Meek and Seth Lewelling was dissolved leaving the latter the owner of the Milwaukee nurseries. It was in 1860 that Seth Lewelling raised his first seedling cherry, the Republican, called by him Black Republican, which was sold to George Walling of Oswego and Mr. Hanson of East Portland, the proceeds bringing Lewelling $\$ 500$. Mr. Lewelling counts the Republican and Bing cherries and the Golden Prune as his most notable contributions to pomology.

The Lewellings are types of fruit-breeders who have done noble work for pomology in the settlement of all our states - men of indominable courage and will who have bred and grown fruits throughout their lives in spite of every adversity. Few other men labored longer and more devotedly to improve the cherry than Seth Lewelling.

1 Oregon St. Bd. Hort. An. Rpt. 2:242. 1893. 


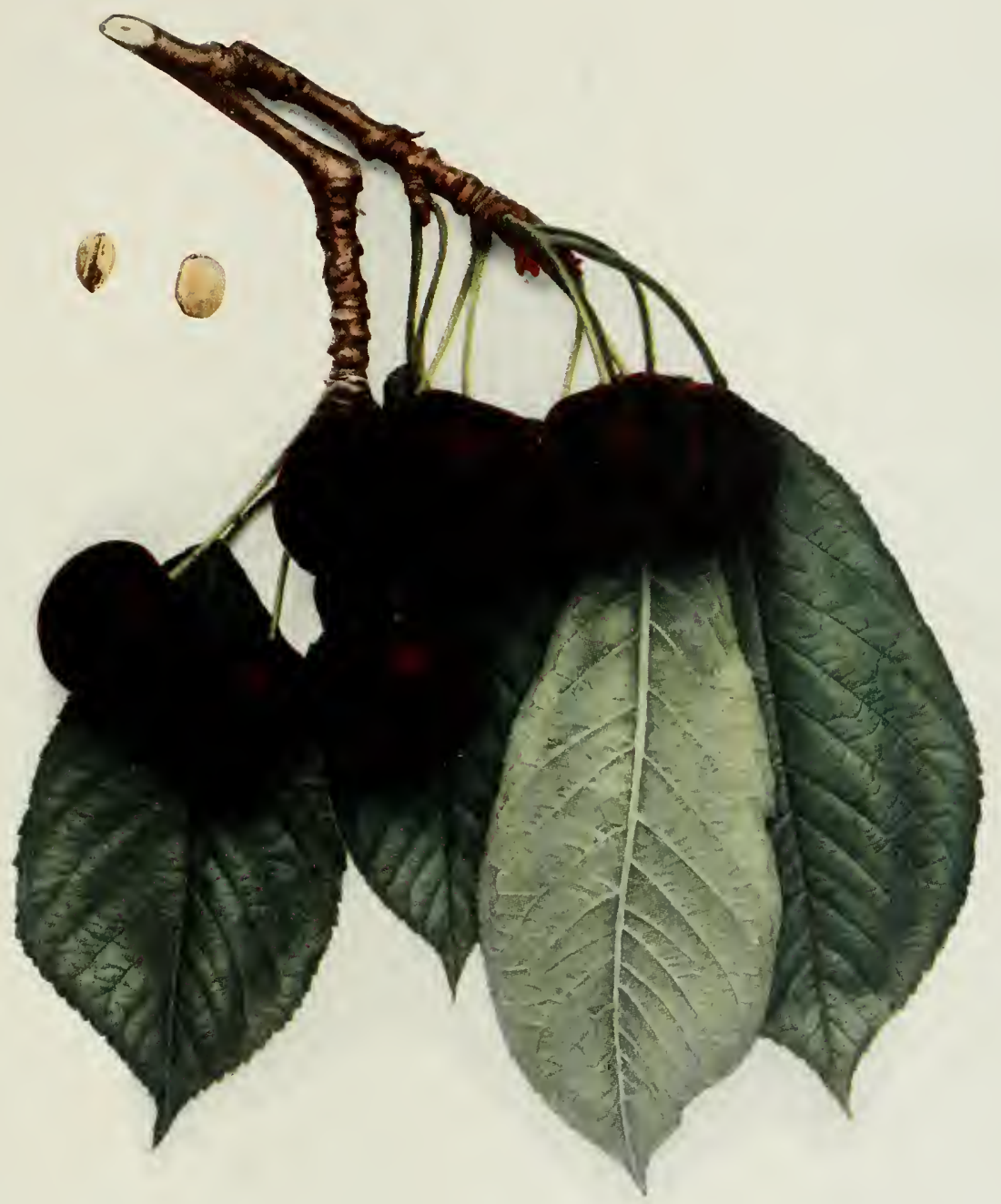

LAMBERT 


\section{ง}


one and one-fourth inches across, white; borne usually in twos; pedicels three-fourths of an inch long, glabrous, greenish; calyx-tube green, campanulate, glabrous; calyx-lobes long, broad, obtuse, finely serrate; petals roundish, entire, with short claws and with dentate apex; filaments one-half inch long; pistil glabrous, equal to the stamens in length.

Fruit matures in mid-season; one inch in diameter, roundish-cordate, compressed; cavity rather deep, slightly flaring; suture shallow, often a mere line; apex roundish, depressed at the center; color very dark red changing to reddish-black; dots numerous, small, russet, obscure; stem tinged with red, slender, one and one-fourth inches long, adherent to the fruit; skin thin, adhering to the pulp; flesh dark red, with scant dark red juice, meaty, firm, pleasant flavored, sweet; of very good quality; stone clinging, large, wide, ovate, flattened, blunt, oblique, with smooth surfaces; prominently ridged along the ventral suture.

\section{LARGE MONTMORENCY}

\section{Prunus cerasus}

1. Am. Pom. Soc. Cat. 22. 1885. 2. Ibid. 25. 1899. 3. Del. Sta. An. Rpt. 12:110, 114. 1900. 4. Am. Gard. 22:266, 267. 190I.

Flemish. 5. Bradley Gard. 211. 1739. 6. Lond. Hort. Soc. Cal. 49. 1831. 7. Thompson Gard. Ass't 530. I 859 .

Grosse Glaskirsche von Montmorency. 8. Truchsess-Heim Kirschensort. 465-470. I819. 8. Dochnahl Führ. Obstkunde 3:54, 55. 1858. 10. Ill. Handb. 165 fig., 166. I860.

Short Stem Montmorency. 11. Prince Pom. Man. 2:139, 140. 1832. 12. Ia. Sta. Bul. 73:75. 1903.

Grosser Gobet. 13. Ill. Handb. $5+3$ fig., 544. 186 I.

Montmorency. 14. Mortiliet Le Cerisier 2:195 fig. 54, 196, 197. 1866.

As its synonyms show, Large Montmorency has been grown under various names in Europe and America - a testimony to its merits. Were it not that the true Montmorency is so much more fruitful than this largerfruited offshoot of the same race of Amarelle cherries, Large Montmorency would be a leading commercial Sour Cherry, for it is equal to the smallerfruited strain in all other characters with the advantage of size. The relationship between this and the other Montmorencies is apparent but Large Montmorency is easily distinguished by several marked characters from the common Montmorency, known by all, with which it is most often confused. Its fruits are more often borne singly, are larger, have a shorter, thicker stem, are more oblate and ripen a little earlier. The trees are more upright, with stouter branches and are far less fruitful. The flesh-characters of the two kinds are much the same - excellent in both, the flavor being particularly refreshing to those who like the acidity of the Sour Cherry. Large Montmorency has been tried and found so wanting in productiveness that it can rarely be recommended as a commercial variety but it is much too good a fruit to be wholly lost and should be grown by connoisseurs who want a large, finely flavored Sour Cherry. 
This variety has been much confused with other cherries, particularly Montmorency, Early Richmond and Short Stem Montmorency. Bradley, in 1739 , mentioned a Flemish cherry which undoubtedly was the Large Montmorency of today, for the name Flemish has rather commonly been applied to this sort since Bradley's time. There is no doubt but that Large Montmorency sprang up about the same time as the true Montmorency, in the Montmorency Valley in France. It may have been a seedling of the Cerise Hâtive, afterwards known as Early Richmond, though some writers are of the opinion that the Montmorencies and Cerise Hâtive were all seedlings of the old Cerise Commune. At any rate, there have come to be at least three distinct types of Montmorency: the true Montmorency with long stems and moderate-sized fruit, called Montmorency à Longue Queue or, in America, Montmorency Ordinaire; the Large Montmorency with its large fruit and shorter, thicker stems, commonly known by the French and German writers as Montmorency à Gros Fruit, Gros Gobet, Grosse Glaskirsche von Montmorency and sometimes as Montmorency à Courte Queue; and the Short-Stem Montmorency, often called Montmorency à Courte Queue and sometimes Gros Gobet. Large Montmorency has often been sold for Montmorency, or for Early Richmond, hence the three varieties are more or less confused. Large Montmorency probably came to America about the same time as Montmorency and Early Richmond, early in the Nineteenth Century. In I875. Ellwanger \& Barry, Rochester, New York, disseminated this sort quite extensively but later it proved too unproductive for commercial use. It was soon replaced by the true Montmorency but often the names were interchanged and large forms of the Montmorency were thought to be this variety. The unproductiveness of this cherry has been consistently mentioned by nearly every writer from Duhamel's time to the present. Large Montmorency was added to the American Pomological Society's catalog list of fruits in 1885 as Montmorency Large but in 1899 this name was changed to Large Montmorency.

Tree rather large, vigorous, upright, vasiform, unproductive; trunk thick, roughened; branches stocky, nearly smooth, reddish-brown overspread with dark ash-gray, with numerous large, raised, conspicuous lenticels; branchlets thick, short, brown tinged with bronze, smooth except for the large, numerous yellowish, conspicuous, raised lenticels.

Leaves numerous, three and one-half inches long, one and three-fourths inches rride, folded upward, broad-oval to obovate, thick, stiff; upper surface dark green, slightly rugose; 


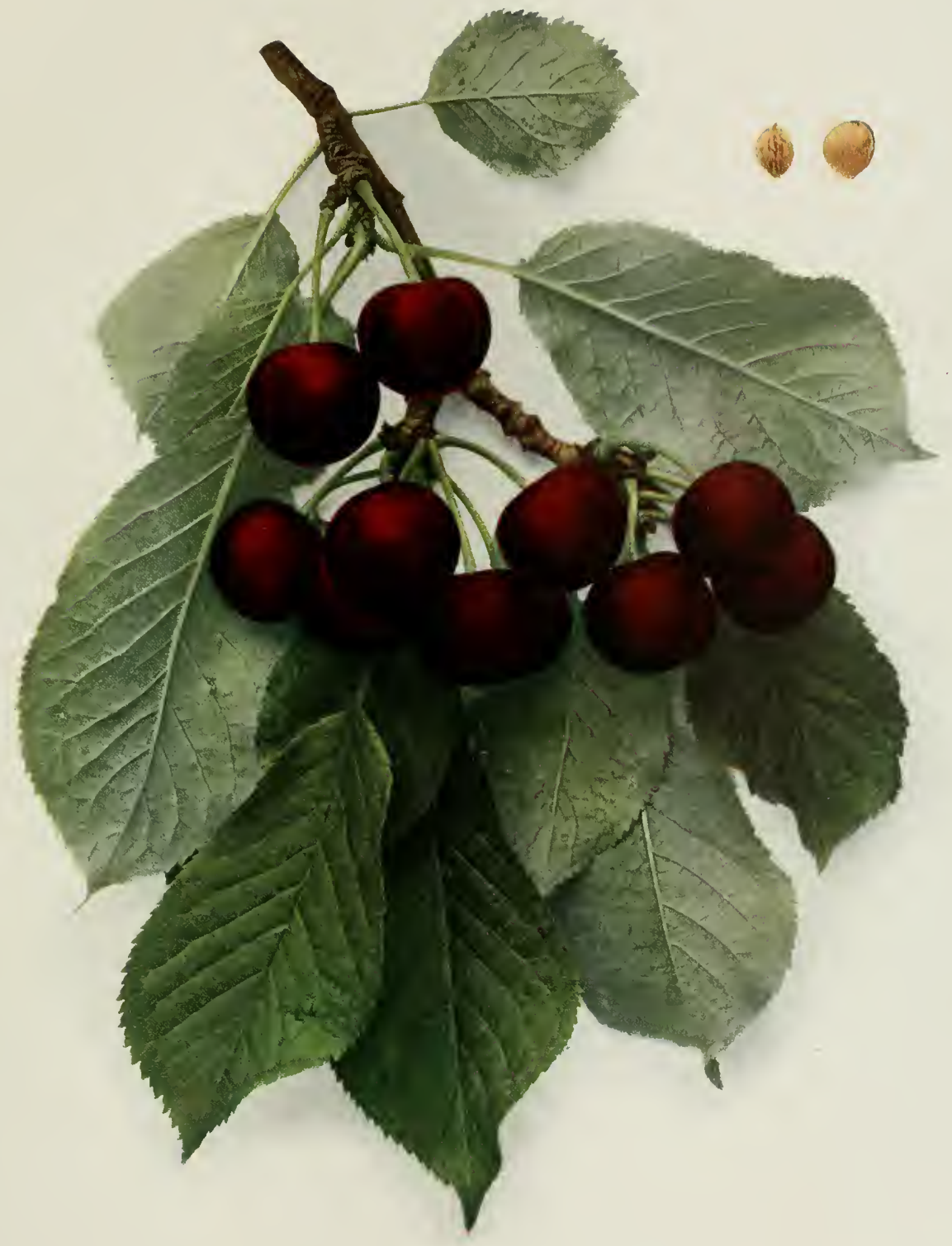



apex acute, base variable in shape; margin serrate, glandular; petiole one inch long, tinged with dull red, glandless or with from one to three globose, yellow or brownish glands, usually at the base of the blade.

Buds usually pointed, plump, free, arranged singly as lateral buds and in small clusters on short spurs; leaf-scars prominent; season of bloom intermediate; flowers white, one inch across; borne in scattering clusters, usually in threes; pedicels five-eighths inch long, glabrous, green; calyx-tube tinged with red, obconic, glabrous; calyx-lobes with a trace of red, long, broad, acute, serrate, glabrous within and without, reflexed; petals obovate, entire or slightly crenate, sessile, with a crenate apex; filaments one-fourth inch long; pistil glabrous, equal to or longer than the stamens, often defective.

Fruit matures in mid-season; three-fourths of an inch in diameter, oblate, compressed; cavity wide, flaring; suture shallow; apex flattened or depressed; color dark red; dots numerous, small, russet, somewhat conspicuous; stem thick, one inch long, adhering fairly well to the fruit; skin thick, separating from the pulp; flesh whitish, showing distinctly the fibers in the pulp, with abundant colorless or slightly tinged juice, tender and melting, sprightly, pleasant flavored, tart; of very good quality; stone free, roundish, plump, with smooth surfaces, tinged with red.

\section{LATE DUKE}

\section{Prumus avium $\times$ Prumus cerasus}

I. Pom. Mag. 1:45, Pl. 1828. 2. Lond. Hort. Soc. Cat. 48, 49, 55, 56. 1831. 3. Prince Pom. Man. 2:134, I35. 1832. 4. Hort. Reg. (Eng.) I:257, fig. I833. 5. Downing Fr. Trees Am. I91 fig. 80. 1845. 6. Mag. Hort. 13:397 fig. 33, 398. 1847. 7. Gard. Chron. 556. 1848. 8. Hovey Fr. Am. I:37, 38, P1. 1851. 9. Am. Pom. Soc. Cat. 74. I 862.

Wahre Englische Kirsche. 10. Christ Handb. 682, 1797. I1. Christ Wörterb. 284. 1802. 12. Truchsess-Heim Kirschensort. 405-410. 1819. 13. Dochnahl Führ. Obstkunde 3:50. 1858. 14. Ill. Handb. 499 fig., 500. 1861.

Späte Herzogenkirsche. 15. Truchsess-Heim Kirschensort. 434-437. 1819.

Anglaise Tardive. 16. Mortillet Le Cerisier 2:179-181, fig. 48. 1866. 17. Mas Le Verger 8:67, 68, fig. 32. 1866-73.

Late Duke is a variant of the well-known May Duke, ripening from two weeks to a month later. The size, color, flavor and season of the fruit all commend it, as do the vigor, health and fruitfulness of the trees. The cherries are not quite as sweet as those of May Duke, a little more marbled in color of skin and ripen through a longer season. The trees are readily told from those of the earlier Duke, being more open and spreading, scanter of foliage, with slender branches and with fruit more thickly clustered along the branchlets. Ripening in a season when hybrid varieties are gone or rapidly going, Late Duke is a valuable acquisition in the home orchard and for nearby markets to which tender-fleshed varieties can be shipped. If those who want late cherries will plant this variety on a northern slope, against a northern wall or where in any way shaded or in a cool soil, these delicious cherries can be had until well toward August. The 
tree is hardy and its blossoming-time is late so that the variety is well adapted to northern latitudes.

The origin of this variety is unknown. In 1797, Christ mentions " a true English cherry" which is probably Late Duke. At least Oberdieck, in I 861 , states that the true English cherry is identical with the Late Duke, or Anglaise Tardive. In 1823, Late Duke was introduced into England by the London Horticultural Society from M. Vilmorin, of Paris, under the name Anglaise Tardive. Though the French name of this variety seems to indicate an English origin, the old English writers were not aware of any cherry of this kind being in existence in England previous to its introduction by the Horticultural Society. Because of the close resemblance of Late Duke to May Duke it has often been confused with that sort and by some writers was supposed to be a late strain of May Duke. The American Pomological Society listed Late Duke in its fruit catalog in $\mathrm{I} 862$.

Tree vigorous, upright-spreading, becoming spreading at maturity, open-topped, productive; trunk and branches slender; branches brown overlaid with dark ash-gray, with numerous small lenticels; branchlets slender, short, reddish-brown, with ash-gray scarf-skin, with numerous conspicuous, small, raised lenticels.

Leaves numerous, three inches long, one and three-fourths inches wide, folded upward, obovate, thick; upper surface very dark green, smooth; lower surface light green, with a few scattering hairs; apex abruptly pointed; margin doubly crenate, with small, dark glands; petiole one inch long, lightly tinged with red, grooved and somewhat hairy on the upper surface, glandless or with one or two small, reniform, greenish glands, usually at the base of the blade.

Buds small, short, obtuse or conical, plump, free, arranged singly and in clusters; leaf-scars prominent; season of bloom late; flowers white, one inch across; borne in numerous, dense clusters, in twos, threes and fours; pedicels one inch long, slender, glabrous, green; calyx-tube reddish, campanulate; calyx-lobes broad, obtuse, serrate, reflexed; petals roundish, entire, almost sessile; filaments one-fourth inch long; pistil glabrous, equal to the stamens in length.

Fruit matures very late; one inch in diameter, blunt-cordate, somewhat compressed; cavity wide; suture shallow; color dark red; stem slender, one and one-half inches to two inches long, deeply inserted; flesh amber-colored, with abundant juice, tender, rich, sprightly subacid; stone semi-clinging, medium to large, roundish-ovate, compressed. 


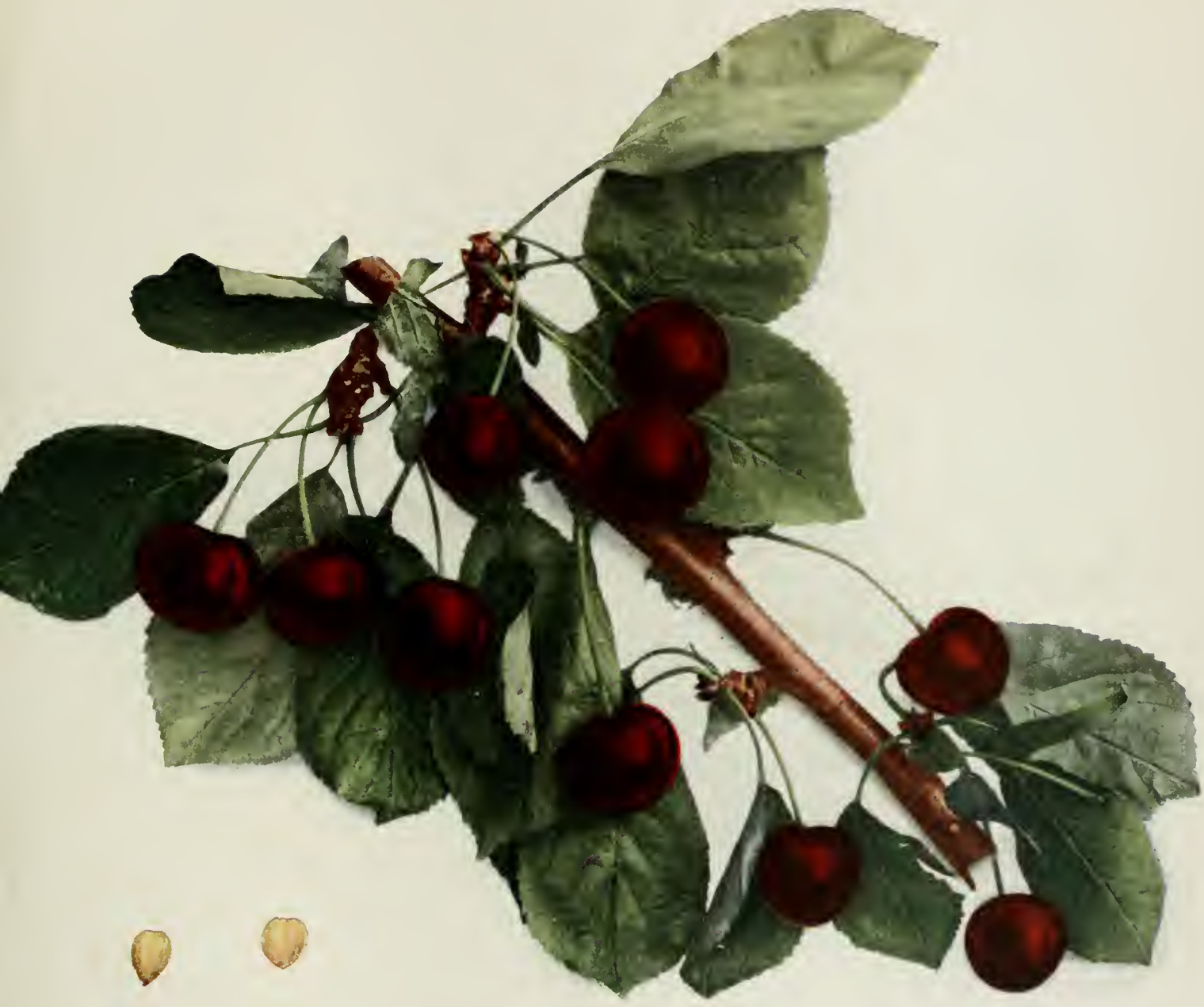





\section{LATE KENTISH}

Prunus cerasus

I. Downing Fr. Trees. Am. 197. 1845. 2. Am. Pom. Soc. Cat. 27. 1909.

Kentish Red. 3. Coxe Cult. Fr. Trees 249. I817.

Pie Cherry. 4. Thomas Am. Fruit Cult. 37r. 1849.

Red Pie Cherry. 5. Am. Pom. Soc. Rpl. 103. 1852.

Kentish. 6. Elliott Fr. Book 217. 1854.

This old cherry served well the needs of Americans in colonial times when all cherries were grown from pits or suckers. Though but little improvement on the wild Prunus cerasus, the trees were so hardy, vigorous, healthy and productive that any who had a bit of spare land could have cherries. This, therefore, became preeminently the "pie cherry" of New England and the North Atlantic States. The trees are long-lived and even so late as a generation ago Downing says that this variety is " better known among us than any other acid cherry, especially abundant on the Hudson and near New York." The variety is never planted now, having long since been superseded by better sorts, Early Richmond and Montmorency in particular, but it is still to be found as old trees or self-sown near where a tree of the variety formerly stood.

Late Kentish and Early Richmond, the latter the Kentish of some authors, are much confused. Late Kentish is the old Pie Cherry of Colonial times. It is a seedling sort belonging to America, having been planted along fences and roadsides in the earliest times. This cherry is mentioned by the Pilgrims in 1620 and this and the May Duke were listed as market varieties in Massachusetts. Many believe it to be a seedling of Early Richmond, sometimes, as we have seen, called Kentish, but this variety being two weeks later, received the name Late Kentish. The name was put on the fruit list of the American Pomological Society in I873. The following description is a compilation:

Tree small, bears annually, very productive, hardy.

Fruit matures about two weeks after Early Richmond; medium or below in size, roundish, flattened; stem one inch to one and one-half inches in length, stout, straight; color deep, lively red; flesh light colored, with abundant colorless juice, very tender, sour, remaining quite acid even when fully ripe; stone does not adhere to the stalk. 


\section{LITHAUER}

\section{Prunus cerasus}

I. Mich. Hort. Soc. Rpt. 328. 1888. 2. Can. Exp. Farm Bul. 17:9. 1892. 3. Mich. Hort. Soc. Rpt. 245. 1894. 4. Del. Sta. An. Rpt. 12:128. 1900. 5. Am. Pom. Soc. Sp. Rpt. 33. 1904-05. 6. Am. Pom. Soc. Cat. 27. 1909 .

It is barely possible that Lithauer, if the trees can be obtained, may have some value in the coldest and bleakest parts of New York where less hardy sorts cannot be grown. The variety is too poor in quality to be worth planting where the better but less hardy cherries will grow. We greatly doubt whether it is worthy a place in the recommended list of fruits of the American Pomological Society. It is included here only because of the prominence given it by a place in the fruit list named.

This is one of the varieties imported from Russia by Professor J. L. Budd of Iowa, who reported that it was much grown in southwest Russia for drying and in making cherry wine. As tested in various parts of this country Lithauer has proved of little value except in the extreme north. The American Pomological Society, in 1909, listed this sort in its catalog of recommended fruits for northern fruit regions. The following description is compiled:

Tree large, vigorous, tall, weeping, hardy.

Fruit matures from the middle to the last of July; small, roundish, slightly oblate; stem long, averaging one and one-half inches, slender; color dark purplish-red becoming almost black at maturity; skin thick, tough; flesh dark red, with reddish juice, firm, meaty, quite acid or bitter even when fully ripe; poor in quality; stone variable in size, roundish.

\section{LOUIS PHILIPPE}

\section{Prumus avium $\times$ Prunus cerasus}

I. Elliott Fr. Book 218. 1854. 2. Am. Pom. Soc. Cat. 74. 1862. 3. Horticulturist 22:289, 290 fig. 1867. 4. Thomas Guide Prat. 26, 195. 1876. 5. Cult. \& Count. Gent. 42:378. 1877. 6. Am. Pom. Soc. Cat. 27. 1909.

Here again we have a very evident hybrid between some Sweet Cherry and a Sour Cherry of the Morello type in which Morello characters are most prominent. If the description and color-plates of this variety and Olivet be compared it will be found that the two cherries are nearly identical. They differ only in season of ripening and in minor tree-characters which may be best summarized by the statement that this cherry has in the tree more of the aspect of a Morello than has Olivet. It may be suspected that one or the other of the two varieties on our grounds is mis- 


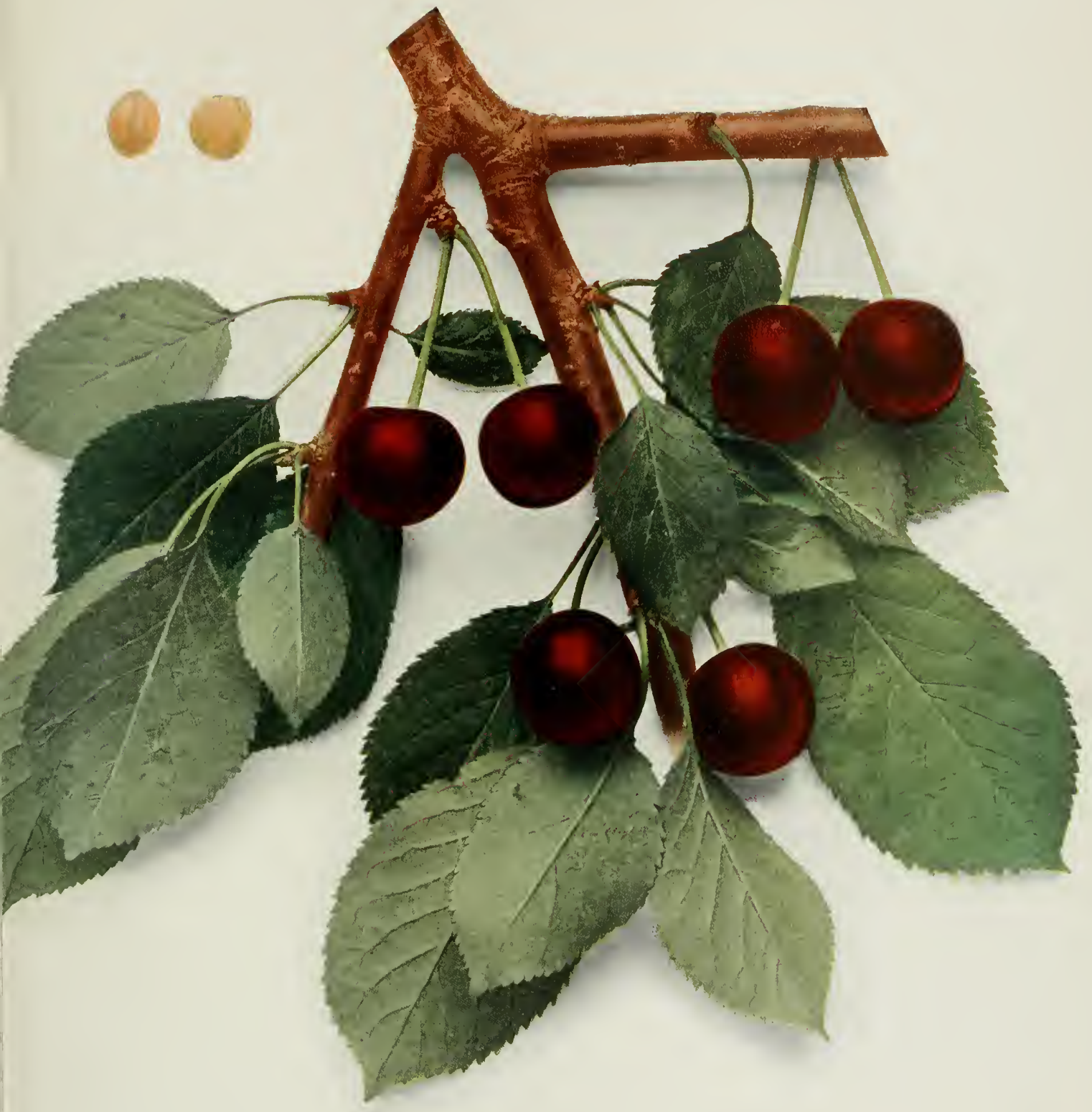

LOUIS PHILIPPE 

named but the descriptions of all who have described the two show that they are very similar, if not identical. The history of Louis Philippe, long known in America but little or not at all known in Europe, throws some light on the question of its distinctness from Olivet, the origin of which is known, inasmuch as Louis Philippe seems to be the older of the two. The value of the two varieties to cherry-growers is the same and is indicated in the discussion of Olivet.

Elliott, ${ }^{1}$ the American pomologist, imported Louis Philippe from France in 1846 but the cherry does not seem to have been known at that time in Europe and it is possible that Elliott gave it its name. For the first few years the variety was not given the recognition it deserved but, in 1862 , it was recognized by the American Pomological Society by a place on its list of recommended fruits which it still holds under the name, Philippe.

Tree vigorous, upright-spreading, open-topped; trunk and branches intermediate in thickness; branches with numerous very large, elongated, raised lenticels.

Leaves numerous, four and one-half inches long, two and one-eighth inches wide, oval to obovate, thick, leathery; upper surface dark, shiny green, smooth; lower surface olive-green, with a large, prominent midrib; apex taper-pointed; margin finely serrate, with reddish-brown glands; petiole one inch long, usually with one or two large, globose, yellowish-red, glands, variable in position.

${ }^{1}$ Elliott's American Fruit Growers Guide, published in $185^{8}$ and dedicated to Professor Jared P. Kirtland, was one of the notable pomological books of its day. Cherry growers, in particular, owe Elliott a debt of gratitude for the publicity that he gave to Kirtland's cherries, having described in his book 20 of the sorts originated by Professor Kirtland. Beside his fruit book he published Popular Deciduous and Evergreen Trees (1868), Handbook for Fruit-growers (1876) and Handbook of Practical Laudscape Gardening (1877). He also served pomologists well for many years, at various times, from 1850 to 1873 , as the secretary of the American Pomological Society. Franklin Reuben Elliott was born in Guilford, Connecticut, April 27, 1817. We know, from complimentary speeches, accepted by Elliott, that he was a descendant of John Eliot, "The Apostle of the Indians." As a young man he engaged with a brother in New York as an importer of dry goods, the firm being rated at half a million dollars. Financial ruin came through a disastrous fire and, in 1836 , Elliott went to Newburgh and was employed by A. J. Downing from whom he imbibed his knowledge and much of his love for pomology and horticulture. A roving disposition and dissipated habits led him to leave Downing for a position with a relative near Cincinnati who was a market-gardener. A ready pen seems from this time on to have been his chief means of livelihood for we find him successively in Cleveland, Ohio, and St. Louis, Missouri, in newspaper work; after a few years in each place he wandered to Washington where he was employed in the Agricultural Department of the Patent Office illustrating American fruits. From his hand in the Patent Office reports and from his fruit book, came some of the most accurate and beautiful representations of the fruits of this continent. It is probable that while in Washington he began work on his Fruit Growers Guide, the time for which, he tells us in his preface, took ten years. Social infirmities seem to have cost him his position in Washington and his last employment was with the Cleveland Herald, after which comes the record of his death and burial in a pauper's grave January 10, 1878. One of the most brilliant pomologists of his time, his career seems again and again to have been checked by the weaknesses of his life; even so, he rendered horticulture valuable services for which we must give him gratitude and honor. 
Flowers one and one-fourth inches across, white, well distributed, mostly in threes; pedicels one inch long, thick, glabrous, greenish; calyx-tube green, obconic, glabrous; calyx-lobes broad, obtuse, glabrous within and without, reflexed; petals slightly obovate, entire, broad, slightly notched at the apex; stamens one-fourth inch long; pistil glabrous, equal in length to the stamens.

Fruit matures in mid-season or later; nearly one inch in diameter, roundish-ovate; cavity abrupt; suture very shallow to a mere line; apex flattened, depressed; color very dark red; dots numerous, unusually small, obscure; stem one and one-fourth inches to one and one-half inches long, adhering well to the fruit; flesh light red, with much winecolored juice, fine-grained, tender and melting, sour at first, becoming pleasantly tart at full maturity; good in quality; stone separates readily from the flesh, small, roundishovate, plump; ventral suture grooved; dorsal suture with a small ridge.

\section{LUTOVKA}

Prunus cerasus

1. Ia. Hort. Soc. Rpt. 328, 1885. 2. Am. Pom. Soc. Cat. 17. 1897. 3. Am. Pom. Soc. Sp. Rpt. 32, 33. 1904-05. 4. Am. Pom. Soc. Cat. 27. 1909.

Galopin. 5. Thomas Guide Prat. 21. 1876. 6. Kan. Sta. Bul. 73:189. 1897.

For a time Lutovka and Galopin were listed as two distinct varieties. Unquestionably they are the same despite the seeming difference in origin. All we know of Galopin is that it was said to have been originated by a nurseryman in Belgium whose name it bears. The Lutovka was introduced into this country by J. L. Budd of Iowa, in $\mathbf{1} 883$, and, according to the introducer, was well known in Poland and Silesia as a roadside tree. Nothing is said of it in foreign literature. As was the case with many of Budd's importations, this variety did not stand the test of culture. It is a shy bearer and is now seldom recommended, although it was placed on the list of desirable fruits of the American Pomological Society in 1897 where it still remains. The variety has no value in New York. In I895, this Station sent out buds which they had been led to believe were the Lutovka and which they later found to be Brusseler Braune. The following description is compiled:

Tree large, upright, slightly spreading; leaves large, ovate, leathery, produced from short spurs along the main branches.

Fruit ripens the forepart of July; medium to above in size, roundish-oblate; suture often a line, sometimes lacking; stem short, stout, set in a large, deep cavity; skin dark, clear red, thin, tough, translucent; flesh colorless, meaty, juicy, slightly acid; quality good; pit large, roundish, free. 


\section{LYONS}

\section{Prunus avium}

Bigarreau de Lyon. I. Mag. Hort. 16:358. 1850. 2. Am. Pom. Soc. Rpt. 61, 62 fig. 1854.

Bigarreau Jaboulay. 3. Hogg Fruit Man. 74. 1866. 4. Mortillet Le Cerisier 2:100 fig. 20, 101. 1866. 5. Mas Le Verger 8:17, I8, fig. 7. 1866-73. 6. Pom. France 7: No. 16, Pl. I6. 1871. 7. Leroy Dict. Pom. 5:213 fig., 214. 1877. 8. Flor. \& Pom. 117. 1878 .

Early Lyons. 9. Flor. \&' Pom. 193, fig. I. 1875. 10. Hogg Fruit Man. 294, 295. 1884.

Early Jaboulay. I1. Hogg Fruit Man. 294. 1884.

Of the one hundred and twenty-five cherries tested on the grounds of this Station during the past ten years, Lyons is one of the best. Though grown for nearly a century in Europe it seems never to have been well tried in America probably because it has not been considered particularly valuable in the Old World. From its behavior at this Station it appears to deserve extensive trial as an extra early market cherry for dessert purposes, as it is one of the few tender-fleshed cherries that give promise of standing handling for distant markets. Though commonly classed as a hard-fleshed Bigarreau it is really an intermediate between the firm-offlesh cherries and the soft-fleshed Hearts. In the tree it is a typical Bigarreau. Besides being one of the earliest of the Heart-like cherries it is one of the largest, handsomest and best flavored. Unfortunately, because of an accident, we cannot show a color-plate of this splendid cherry. On these grounds the tree-characters are about all that could be desired, though we are making allowance for a slight lack of productiveness in the young tree which is one of the faults commonly attributed to Lyons by European writers; however, all agree that the trees become fruitful with age. The blossoms of this variety are conspicuously large and showy, with pistils unusual in being longer than the stamens. The merits of Lyons have been so pronounced in the several years we have watched it that we feel quite warranted in recommending it for both home and commercial orchards.

About I 822, M. Jaboulay, a nurseryman at Oullins, near Lyons, France, grafted over a number of seedling cherries which had sprung up on his grounds. Five years later, having decided to dig out the trees, he was attracted by the superb growth made by one of them upon which the graft had not started and ordered the tree to be saved. This tree produced a full crop of exceedingly large and attractive fruit which matured far in advance of other varieties. Jaboulay decided to save all the grafts for propagation the succeeding year but found upon going to the tree the fol- 
lowing spring that the wood had been stolen. About five years later M. Riviére, also a nurseryman at Oullins, placed upon the market at Lyons a very early cherry which he called Bigarreau Anglaise but which was recognized as the same as the one found by Jaboulay. Thus have come the several names given in the synonyms. Lyons has never been much grown in this country. Lewis B. Eaton of Buffalo, New York, in importing cherry trees from France in $184 \mathrm{I}$ and 1842 , found among them one without a label which turned out to be Bigarreau de Lyon, later the Lyons. Trees of this variety were received for testing at this Station from the United States Department of Agriculture under the name Hâtive de Lyons. These, as grown here, have proved identical in both tree and fruit characters with the many descriptions of Bigarreau Jaboulay, or Bigarreau de Lyon.

Tree vigorous, a rapid grower, upright-spreading; branches straggling, reddish-brown; branchlets thick, long, with long internodes, grayish-brown, with numerous rather large, conspicuous, raised lenticels.

Leaves numerous, variable in size, averaging five and one-half inches long, two and one-half inches wide, folded upward, long-elliptical to obovate, thin; upper surface dark green, smooth; lower surface light green, with few hairs; apex distinctly elongated, base abrupt; margin coarsely serrate, with small, dark glands; petiole often two inches long, thickish, pubescent on the upper surface, glandless or with from one to six large, reniform, reddish glands usually on the stalk.

Buds large, long, conical, free, arranged singly as lateral buds and in small, scattering clusters; leaf-scars obscure; season of bloom intermediate; flowers large, often one and one-half inches across, white; borne in dense clusters, in twos and threes; pedicels one inch long, glabrous, green with a trace of red; calyx-tube distinctly reddish, somewhat obconic, glabrous; calyx-lobes strongly tinged with red, broad, acute, glabrous within and without, reflexed; petals obovate, entire, tapering to distinct but short claws; apex entire or with a shallow, wide notch; filaments five-sixteenths of an inch long; pistil glabrous, equal to or longer than the stamens.

Fruit matures early; one inch in diameter, cordate, compressed; cavity flaring; suture shallow, or a mere line, often extending around the fruit; apex roundish or pointed; color very dark red; dots numerous, small, russet; stem thick, one and one-half inches long; skin thin, rather tender, separating from the pulp; flesh reddish, with dark colored juice, meaty, sprightly, sweet; of very good quality; stone semi-clinging, large, ovate, plump, with smooth surfaces; ridged along the ventral suture. 


\section{MAGNIFIQUE}

\section{Prunus avium $\times$ Prunus cerasus}

I. Am. Pom. Soc. Cat. 27. 1909 .

Belle et Magnifique. 2. Kenrick Am. Orch. 279, 280. I832. 3. Ibid. 239. 1841.

Belle Magnifique. 4. Downing Fr. Trees Am. 193. 1845. 5. Am. Pom. Soc. Cat. 54. 1852. 6. Elliott Fr. Book 191. 1854. 7. Downing Fr. Trees Am. 272, 1857. 8. Soc. Nat. Hort. France Pom. 82 fig., 83 . 1904.

Belle de Magnifique. 9. Ann. Pom. Belge 1:6r, fig. I. 1853. 10. Pom. France 7: No, 19, Pl. 19. $187 \mathrm{I}$.

Belle de Chatenay. 11. Ill. Handb. 179 fig., 180. 1860. 12. Mortillet Le Cerisier 2:175-178, fig. 48. 1866. 12. Mas Le Verger 8:57, 58, fig. 27. 1866-73. 13. Mathieu Nom. Pom. 334, 343. I889. 14. Guide Prat. 9, 181. 1895 .

This good, old cherry has never been considered a commercial fruit in the United States; yet it is, and has been, surprisingly popular with nurserymen, most of whom for nearly a century have offered it for sale. A generation ago, when American fruit-growing was in the hands of connoisseurs, Magnifique was more popular than now. It has failed as a commercial cherry because the crop ripens very unevenly, there being sometimes green and fully ripe cherries on the tree at the same time, though the season is usually given as very late. This is one of the lightest in color of the hybrid Dukes, the Sour Cherry parent very evidently having been an Amarelle - a conclusion to which both fruit and tree point. The quality is usually counted as very good though it is too acid to be a firstrate dessert cherry for some. The trees are very vigorous and usually are fruitful. Magnifique has been grown so long that its place in the orchard would seem to have been fixed by experience; yet it might be made more than a cherry for the home orchard if some commercial grower would plant it in a shaded place and a cool soil and thereby retard ripening time until other cherries were gone.

This valuable cherry was brought to notice in 1795 by Chatenay, surnamed Magnifique, a nurseryman near Paris. It seems, at first, to have been quite commonly called Belle de Chatenay but Belle de Magnifique became the commoner appellation ending in America at least with the universal name "Belle Magnifique." The variety was introduced into America from France sometime before 1830 , by General H. A. S. Dearborn, Boston, Massachusetts, President of the Massachusetts Horticultural Society. The cherry is typically a Duke sort and is so listed by most writers, though Downing in $18+5$ placed it with the Morello cherries. Magnifique was placed upon the fruit list of the American Pomological Society in 1852 where it has since remained. 
Tree large, vigorous, upright-spreading, dense, productive; trunk and branches stocky, brown overlaid with dark gray; branchlets with many, small conspicuous lenticels.

Leaves numerous, three and one-half inches long, two inches wide, obovate to oval, thickish; upper surface dark green, slightly rugose; lower surface finely pubescent; apex abruptly pointed, base variable in shape; margin finely serrate, with small, dark glands; petiole one inch long, tinged with dull red, grooved on the upper surface and with a few hairs, glandless or with one or two small, reniform, greenish glands usually at the base of the leaf.

Buds obtuse or conical, plump, free, arranged as lateral buds or in rather dense clusters on short spurs; leaf-scars obscure; season of bloom late; flowers white, one inch across, wide open; borne in dense clusters on short spurs, usually in threes or fours; pedicels one inch long, slender, glabrous, light green; calyx-tube greenish, campanulate, glabrous; calyx-lobes, broadly and shallowly dentate, glabrous within and without, reflexed; petals obovate, entire, with very short claws, indented at the apex; filaments one-fourth inch long; pistil glabrous, equal to the stamens in length.

Fruit matures late; nearly one inch in diameter, cordate; cavity rather deep; suture very shallow; color pale red changing to bright red; dots numerous, small, russet, conspicuous; stem one and one-fourth inches long; skin thick, tough, adherent to the pulp; flesh whitish, with abundant colorless juice, fine-grained, meaty but tender, pleasantly tart, sprightly; very good in quality; stone free, small, oval, plump, slightly pointed, with smooth surfaces; slightly notched near the base of the ventral suture.

\section{MAY DUKE}

\section{Prunus avium $\times$ Prunus cerasus}

1. Bradley Gard.21 I. 1739. 2. Duhamel Trait. Arb. Fr. I:194. 1768. 3. Prince Pom. Man. 2:133, 134. 1832. 4. Gard. Chron. 57. 1843. 5. Cultivator N. S. 2:319 fig. 93. 1845. 6. Downing Fr. Trees Am. 191, 192 fig. 8r. 1845. 7. Bridgeman Gard. Ass't Pt. 3: 53, 54. 1847. 8. Proc. Nat. Con. Fr. Gr. 52. 1848. 9. Elliott Fr. Book 2II. 1854. Io. McIntosh Bk. Gard. 2:542, 543. I855. II. Mas Le Verger 8: 133, 134, fig. 65. 1866-73. 12. Hogg Fruit Man. 305, 306. I884. 13. Guide Prat. 8, 195, 196. 1895 .

Duke Cherry. 14. Ray Hist. Plant. 2:1540. 1688.

May Cherry. 15. Miller Gard. Dict. 1:1754. 16. Mortiliet Le Cerisier 2:138-140, fig. 33. 1866.

Rothe Maikirsche. 17. Christ Handb. 669. 1797. 18. Christ Wörterb. 282. 1802. 19. TruchsessHeim Kirschensort. 377-389. 1819. 20. Ill. Handb. 151 fig., 152. 1860. 21. Mas Le Verger 8:135, 136, fig. 66. 1866-73. 22. Lauche Deut. Pom. III: No. 16, Pl. 1882, 23. Mathieu Nom. Pom. 374. 1889 .

Royale Hâtive. 24. Poiteau Pom. Franc. 2: Nos. 23, 24, Pl. 1846. 25. Pom. France 7: No. 4, P1. 4. 1871. 26. Leroy Dict. Pom. 5:389 fig., 390, 391. 1877.

Royale Cherry Duke. 27. Mas Pom. Gen. 11:127, 128, fig. 64. 1882.

Esel Kirsche. 28. Ohio Hort. Soc. Rpt. 22. 1892-93.

Anglaise Hâtive. 29. Soc. Nat. Hort. France Pom. 78 fig., 79. 1904.

May Duke is one of the oldest and, the world over, one of the most popular cherries. There are several reasons why it has attained and holds its popularity. It is finely flavored, especially when prepared for the table, 


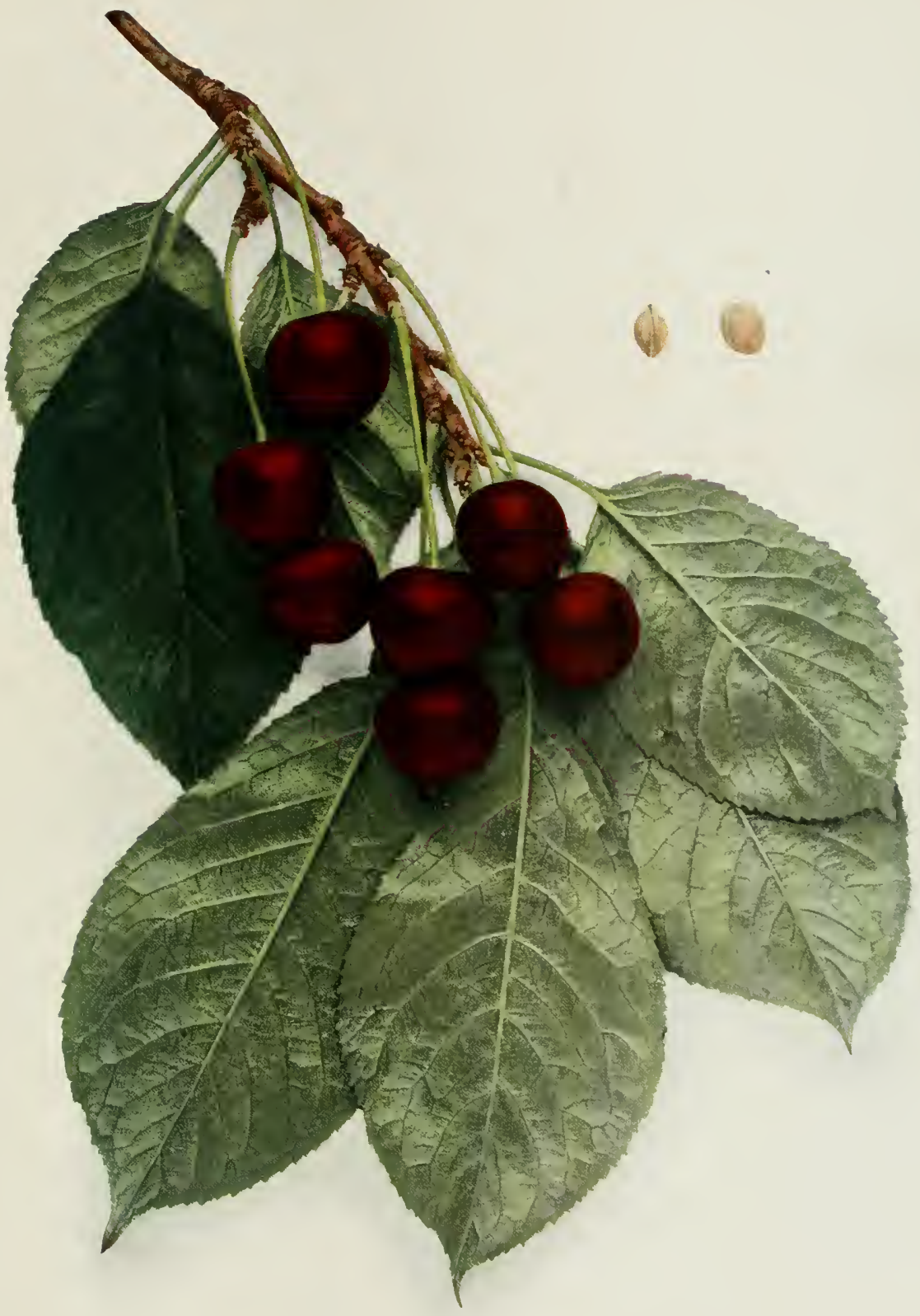



and even before ripe; it is also delicious to eat out of hand if the cherries are dead ripe, when it is one of the best of the subacid cherries; while one of the earliest of its class, it may be left to hang for a month or six weeks, becoming daily sweeter and more aromatic; few or no cherries thrive in greater variations of soil and climates, this fact accounting in greatest measure for its world-wide distribution in temperate regions; despite its tender flesh, it ships well though it is grown only for local markets since its long period of ripening makes necessary several pickings - a fatal defect for a canning cherry or one for the general trade; lastly, the trees are as fruitful as any, and are hardy, vigorous and healthy. The fruit is remarkably well distributed in dense clusters on trees characteristically upright and vasiform and bearing a heavy canopy of dark green, luxuriant foliage. May Duke fills a particular place in the cherry orchard as a fruit for the local market and hundreds of new-comers have not been able to supplant it. The fact that it has lost none of its pristine vigor, health and productiveness in the two hundred and more years it has been known contradicts the idea that varieties of fruit degenerate or wear out with age. When we pass in review all of the varieties of cherries, all characters and purposes considered, May Duke remains one of the best.

This variety seems to have been first mentioned by Ray in I688. May Duke is supposed by some English writers to have originated in a district in France known as Médoc and the name to have been derived from the place. When this cherry first received attention, the old style of reckoning time was in vogue and the IIth of June was the last day of May. It may, therefore, be presumed that the variety derived its name from its season of ripening rather than from a corruption of Médoc. A few years ago Professor J. L. Budd of Iowa imported from Russia several cherries among which was one called Esel Kirsche. Later this cherry was distributed by the United States Department of Agriculture. As grown on the grounds of this Station, Esel Kirsche has proved to be May Duke. In Ohio the two could not be distinguished and with this evidence we have listed Esel Kirsche as a synonym of May Duke. In I 832, William Prince mentioned May Duke as being among the first of the cherries introduced to America from Europe. From the references to this variety in the horticultural literature and in the nursery catalogs throughout the United States we may say that it is one of the most widely distributed and bestknown cherries in the country. The American Pomological Society placed May Duke on its fruit catalog list in $\mathbf{I} 848$. 
Tree large, upright becoming somewhat vasiform and spreading with age, opentopped, very productive; trunk of medium thickness, somewhat shaggy; branches smooth or roughish, reddish-brown partly covered with ash-gray, with numerous lenticels variable in size; branchlets short, brown partly covered with light gray, smooth, with small, inconspicuous, raised lenticels.

Leaves numerous, three and one-half inches long, two inches wide, folded upward, obovate; upper surface very dark green, rugose; lower surface thinly pubescent; apex abruptly pointed, base acute; margin finely serrate, with small, dark glands; petiole one inch long, slender, tinged with red, grooved, glandless or with one or two small, globose, brownish glands, usually at the base of the blade.

Buds obtuse, plump, free, in large clusters on short spurs; leaf-scars prominent; season of bloom intermediate; flowers white, one and one-fourth inches across; borne in dense clusters, in twos and threes; pedicels one inch long, slender, glabrous, greenish; calyxtube with a tinge of red, obconic, glabrous; calyx-lobes with a trace of red, rather long, narrow, acuminate, glabrous within and without, reflexed; petals broad-oval, entire, nearly sessile; apex crenate; filaments one-fourth inch long; pistil glabrous, equal to the stamens in length.

Fruit matures early, although variable in habit; three-fourths of an inch in diameter, cordate to conical, compressed; cavity abrupt, regular; suture indistinct; apex roundish, with a small depression at the center; color light changing to dark red at full maturity; dots numerous, russet, obscure; stem slender, one and one-half inches long, adhering strongly to the fruit; skin thin, tender, separating from the pulp; flesh medium to dark red, with pinkish juice, tender and melting, sprightly subacid, pleasant flavored; of very good quality; stone nearly free, small, roundish to elliptical, with smooth surfaces; slightly ridged along the ventral suture.

\section{MERCER}

\section{Prunus avium}

1. U. S. D. A. Rpt. 262, Pl. 5. 1892. 2. Am. Gard. 14:39 fig. 1893. 3. Can. Hort. 17:322 fig. 693. 1894. 4. Black \& Son Cat. 22 fig. 1909.

This comparatively new Bigarreau is on probation in many parts of the State and country, otherwise we should not give it prominence in The Cherries of New York, as the variety is all but worthless as it grows on the grounds of this Station. The trees are not sufficiently fruitful, the cherries are too small, the flavor in none too good and the fruit is not at all resistant to brown-rot - four fatal defects for a commercial cherry.

This variety is reported to have sprung from a pit of a Mazzard tree and was introduced several years ago by Black \& Son of Hightstown, New Jersey. The name, Mercer, after the county in New Jersey from which it was introduced, was given the cherry by H. E. Van Deman, then United States Pomologist. 
Tree vigorous, healthy, not always productive; branches long, grayish-brown, srnooth, with a few small, inconspicuous lenticels.

Leaves numerous, four and one-half inches long, two and one-fourth inches wide, folded upward, long-oval, leathery; upper surface dark green, smooth; lower surface light green, pubescent, grooved along the midrib; apex taper-pointed, base abrupt; margin coarsely and doubly serrate, glandular; petiole one and one-half inches long, tinged with dull red, thick, with from two to five very large, reniform, reddish glands, variable in position.

Buds of medium size and length, conical, plump, free; leaf-scars rather prominent; season of bloom early; flowers one and one-fourth inches across, in scattering clusters in twos and threes; pedicels three-fourths inch long, glabrous; calyx-tube green or faintly tinged red, campanulate, glabrous; calyx-lobes greenish streaked with red along the edges, long, obtuse, glabrous within and without, reflexed; petals broad-oval, entire, slightly indented at the apex, tapering to short, blunt claws; filaments one-half inch long, shorter than the petals; pistil glabrous, shorter than the stamens.

Fruit matures in mid-season; small, cordate to blunt-conic, compressed; cavity shallow, narrow, abrupt; suture an indistinct line; apex flattened or depressed; color black; dots small, numerous, obscure; stem slender, one and one-fourth inches long, adherent to the fruit; skin thin. rather tender; flesh reddish, with dark colored juice, tender, meaty, crisp, aromatic, mild flavored, sweet; fair to good in quality; stone free or semi-clinging, variable in size, ovate, flattened, blunt-pointed, with smooth surfaces, tinged with red.

\section{MEZEL}

Prunus avium

I. Am. Pom. Soc. Cat. 26. 1909.

Bigarreau Monstrueux, 2. Lond. Hort. Soc. Cat, 46. 1831.

Bigarreau of Mezel. 3. Horticulturist $\mathrm{I}: 475$ fig., 476. 18+6-47. 4. Mortillet Le Cerisier 2:107 fig., 108. 1866. 5. Downing Fr. Trees Am. 454. 1869. 6. Leroy Dict. Pom. 5:218 fig., 219. 1877.

Great Bigarreau. 7. Horticulturist 6:20 fig., 21. 1851. 8. Downing Fr. Trees Am. 253. 1857.

Monstreuse de Mezel. 9. Am. Pom. Soc. Cat. 74. 1862.

Schwarze Knorpel von Mezel. Io. Mathieu Nom. Pom. 377. 1889.

Mezel seems to have made a stir in pomological circles in the middle of the Nineteenth Century by reason of the great size and beautiful appearance of the cherries. Though on the recommended list of the American Pomological Society and frequently spoken of in the pomological works of the day and offered by some nurserymen, we have not been able to find many trees of this variety now growing in New York. We glean from the literature that Mezel pleased the eye more than the palate and that the trees, while vigorous and healthy, were not productive. At any rate after a decade or two of much advertising and what would seem to have been a very thorough trial, Mezel failed to receive very general approbation from cherry-growers and has now almost passed from cultivation. Contrary to the general 
behavior of the variety in New York, the tree and fruit from which the accompanying description was made have so many merits that one can well wish that the variety will not wholly pass out of cultivation.

This variety was found at Mezel, Puy-de-Dôme, France, by M. Ligier sometime prior to 1846 when it was brought to notice. Even so, it had grown in a vineyard at that place for thirty years and was only made public after an excursion of several members of a horticultural society to the vineyard. It was immediately heralded as a coming variety and grafts were distributed. Great Bigarreau, which made its appearance a few years later, is here included as a synonym though many writers list it as a distinct sort. Bigarreau Monstrueux, first listed in the London Horticultural Society catalog for 1831 , is held by many pomologists to be identical with Mezel which, if true, casts some doubt on the generally accepted history of the variety. Mezel appeared on the fruit list of the American Pomological Society in 1862 but was discarded in 1869 ; it was replaced in 1883 and is still on the list though it is scarcely known in any part of the United States.

Tree large, vigorous, upright-spreading, hardy, variable in productiveness; trunk stocky, nearly smooth; branches thick, smooth, reddish-brown partly overspread with dark ash-gray, with lenticels medium in number and size; branchlets of average thickness, variable in length, with internodes of medium length, brown partly covered with ash-gray, smooth, glabrous, with small, inconspicuous, raised lenticels medium in number.

Leaves numerous, five inches long, often two and one-half inches wide, long-oval, thin; upper surface dark green, strongly rugose giving a crumpled appearance; lower surface dull, light green, with slight pubescence; apex varies from abrupt to taper-pointed, base abrupt; margin glandular, coarsely serrate; petiole long, averaging one and one-half inches, slender, tinged with red, with from one to four reniform glands of medium size on the petiole.

Buds intermediate in size and length, plump, pointed, arranged singly as lateral buds or in clusters of various sizes on both long and short spurs; leaf-scars prominent; season of bloom intermediate; flowers one and seven-sixteenths inches across, well distributed in scattering clusters in twos and threes; pedicels one and one-eighth inches long, medium in thickness, glabrous, greenish; calyx-tube with a slight tinge of red, campanulate, glabrous; calyx-lobes long, medium in width, acute, slightly serrate, glabrous within and without; petals somewhat obovate, crenate, nearly sessile, with a very shallow notch at the apex; anthers yellow; filaments shorter than the petals; pistil glabrous, shorter than the stamens, often defective.

Fruit matures in mid-season; large, seven-eighths inch long, thirteen-sixteenths inch wide, cordate, compressed, the surface markedly irregular and broken into ridges; cavity very deep, wide, irregular, abrupt; suture variable, shallow to very deep and wide and 


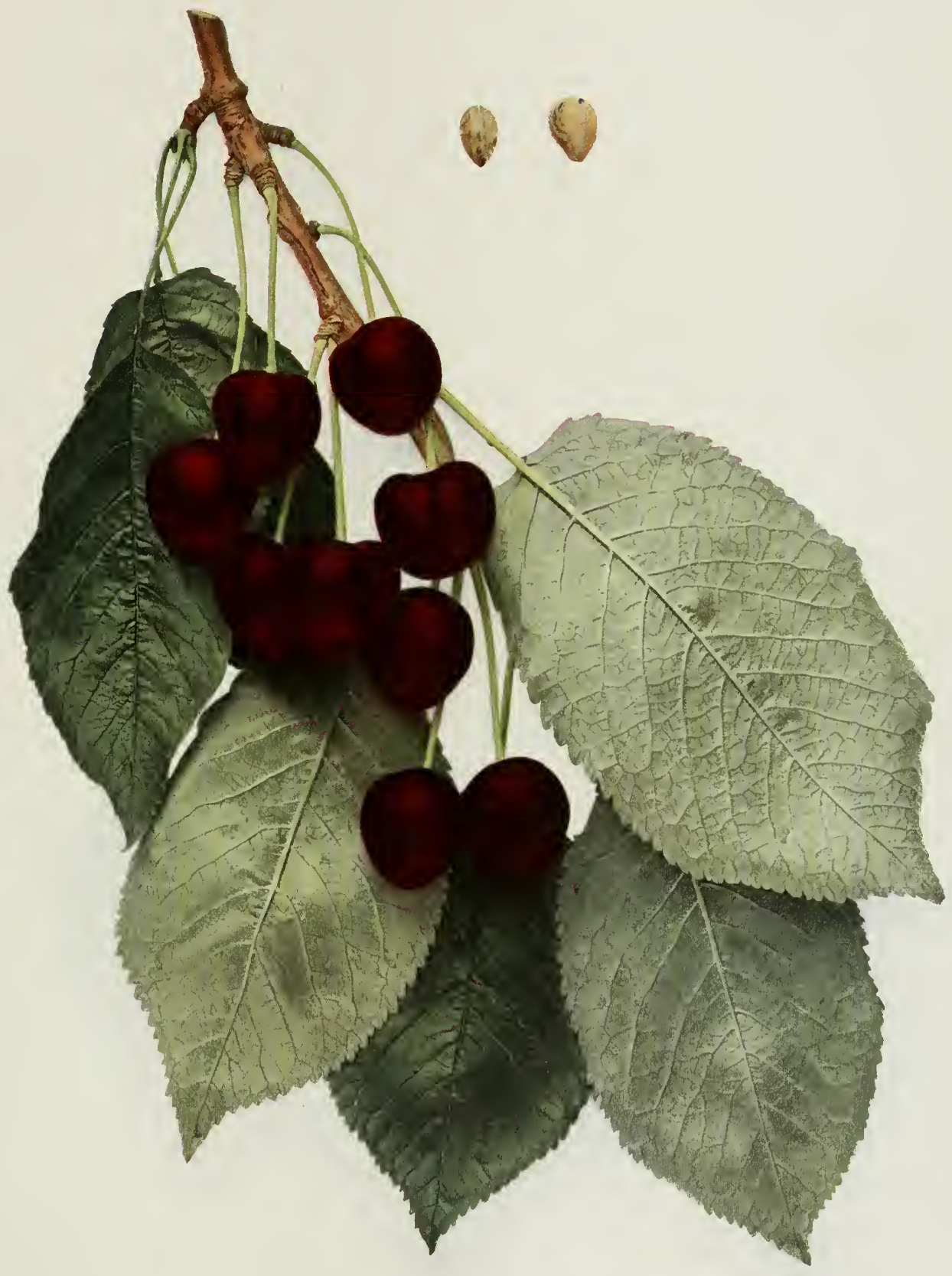



at times double; apex blunt-pointed, usually not depressed; color attractive purplishblack; dots numerous, very small, somewhat russet, obscure; stem medium in thickness, long, averaging two and one-eighth inches, adheres well to the fruit; skin medium in thickness, rather tender but not inclined to crack, adheres slightly to the pulp; flesh purplish-red, with abundant dark red juice, tender, meaty, mild, very pleasant, sweet; very good to best in quality; stone clinging, large, strongly ovate, with slightly roughish surface.

\section{MONTMORENCY}

\section{Prunus cerasus}

1. Duthamel Trait. Arb. Fr. I:181, 182. 1768. 2. Kraft Pom. Aust. 1:6, Tab. 15 fig. I. 1792. 3. Christ Wörterb. 292. 1802. 4. Truchsess-Heim Kirschensort. 656, 657, 691. 1819. 5. Kenrick Am. Orch. 281. 1832. 6. Poiteau Pom. Franc. 2: No. 14, Pl. 1846. 7. Mas Le Verger 8:53, 54, fig. 25. 1866-73. 8. Pom. France 7: No. 3, Pl. 3. 1871. 9. Leroy Dict. Pom. 5:361, 362 fig., 363, $364 . \quad 1877$. г. Mathieu Nom. Pom. 369. I889. I1. Guide Prat. 9, 196. 1895. I2. Del. Sta. An. Rpt. I2:112 fig. 4, I13, I14. 1900. 13. Am. Gard. 22:266, 267. I901. 14. Am. Pom. Soc. Cat. 27. 1909.

Kleine Glaskirsche von Montmorency. I5. Truchsess-Heim Kirschensort. 463, $464,465 . \quad 1819$.

Long Stem Montmorency. 16. Prince Pom. Man. 2:139. 1832.

Amarelle Royale. 17. Mortillet Le Cerisier 2:19I-I95, fig. 53. I 866.

Montmorency Ordinaire. 18. Am. Pom. Soc. Cat. 17. 1897. 19. Ia. Sta. Bul. 73:75, fig. 15. 1903. 20. Am. Pom. Soc. Sp. Rpt. 33, 34, PI. 2. 1904-05.

Montmorency is the most popular Sour Cherry grown in America. No one questions its supremacy. Probably half of the cherry trees in New York, Sweet or Sour, are Montmorencies and at least three-fourths of all the trees of the Sour Cherry are of this variety. It leads in the demands for this fruit in the markets, for the cannery and for home use as a culinary cherry. Several characters give it first place. It is surpassed by no other Sour Cherry, in New York at least, in vigor, health and productiveness of tree. In the last character, in particular, it is supreme. Year in and year out, Montmorency trees are fruitful. Possibly, too, no other Sour Cherry is adapted to a greater diversity of soils than Montmorency, which, with capacity to stand heat and cold, makes the variety suitable to wide variations in environment. The cherries are in no way remarkable - not much above the average for an Amarelle in size, appearance or quality, in all of these characters being much inferior to Large Montmorency. The fruit has the advantage of being presentable in appearance and fit for culinary purposes several days before it is fully ripe and this adds to the value of the variety for the market. Brown-rot takes less toll from this cherry than of others of its kind probably because of relatively firm flesh and thick skin. These characters, also, make the fruit stand handling well in harvesting, shipping and on the markets. The preserved product, whether canned at home or commercially, is attractive 
in appearance and very good. Montmorency is not a dessert cherry but for those who like Sour Cherries it may be eaten out of hand with relish when it is fully matured. Some maintain that the variety falls short in the size of the tree, which is seldom more than medium, but the head is spreading and much-branched and the fruit is borne in clusters thickly scattered throughout the whole head so that the total yield from a tree is greater than would be thought from its size. For any and all purposes to which Sour Cherries are put Montmorency may be recommended as the best in its season.

Unfortunately several quite distinct cherries bear the name Montmorency and it has been most difficult to separate them in pomological literature. To make matters worse, all of them have been much confused with other varieties, Early Richmond in particular. The different Montmorencies and Early Richmond originated in the Montmorency Valley, France, several centuries ago, at least before the Seventeenth Century, probably as seedlings of Cerise Hâtive or of Cerise Commune. These Montmorency cherries differ from each other principally in their stems and fruit, one having long stems and moderate-sized, regular fruit; one shorter stems and larger fruit; and the third, very short, thick stems and oblate, irregular fruit showing a distinct suture. The first cherry has been generally known, particularly among the French, as Montmorency à Longue Queue or sometimes Cerise de Montmorency. This is the Montmorency of this sketch. Duhamel, in 1768 , was the first writer to mention this cherry directly and according to his statement it was then esteemed around Paris, being superior in productiveness to the Large Montmorency.

Montmorency early found its way into England, where it soon became confused with its probable parent, the French Cerise Hâtive or the English Kentish. In a short time it had replaced Kentish in many nurseries and came to be called Kentish in much of the literature of the time. Just when Montmorency was introduced to this country is not known but it has been cultivated here under various names for many years. William Prince spoke of it in 1832 as the Long Stem Montmorency and it has long and commonly been known here as Montmorency Ordinaire. Montmorency is to be found in nearly every nursery in the United States under various names, some nurserymen using the French name, others the English, while still others are selling the variety as Large Montmorency. Many supposed strains have been given new names but it is doubtful if any distinct strains of this cherry exist. The American Pomological Society added 


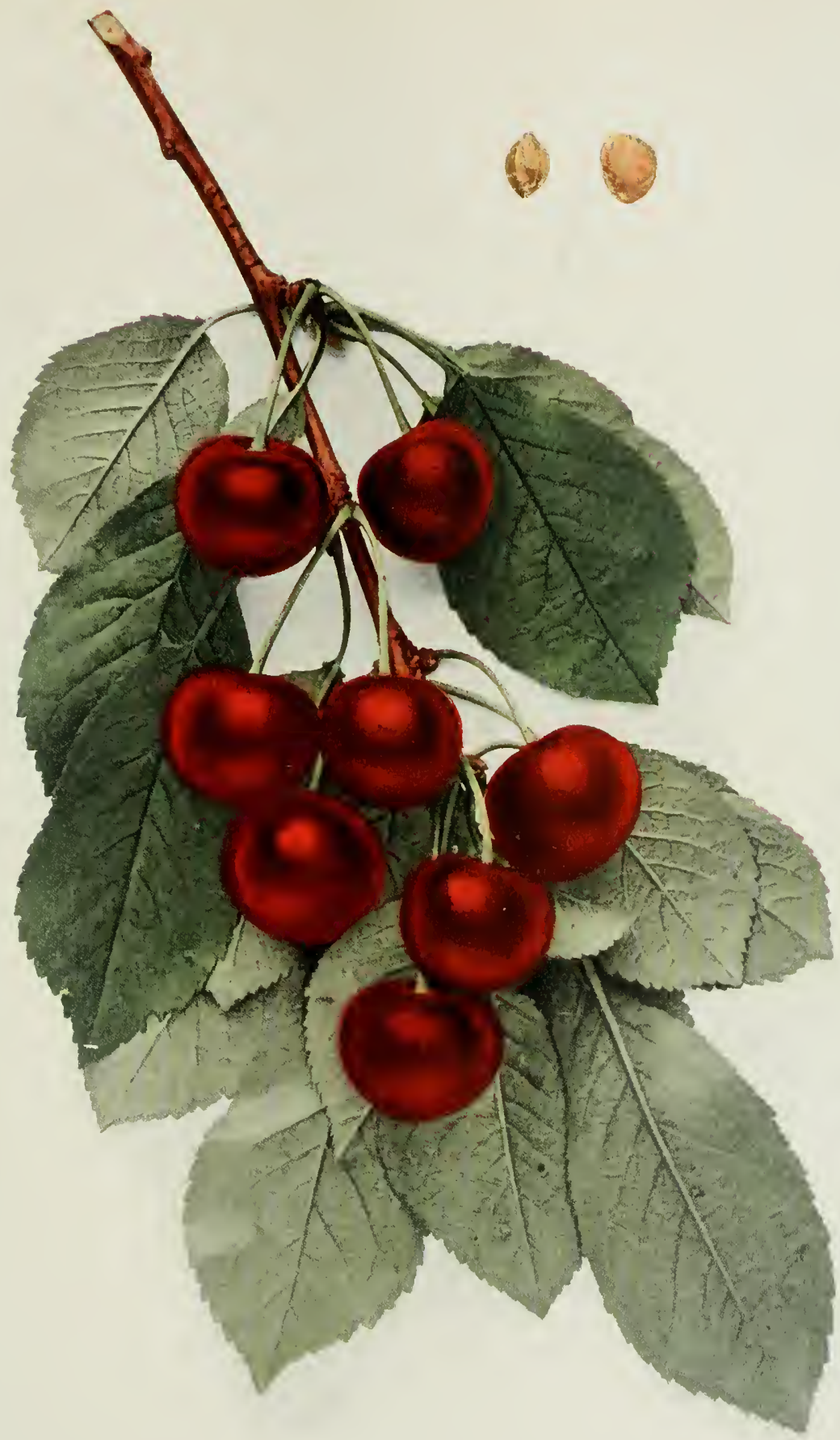



Montmorency to its fruit catalog list in I 897 using the qualifying term Ordinaire which was dropped in 1909.

Tree large, vigorous, upright-spreading, with the lower branches inclined to droop, round-topped, productive; trunk and branches smooth; branches reddish-brown tinged with light ash-gray, with a few lenticels of medium size; branchlets slender, reddish-brown partly overspread with ash-gray, smooth, with a few small, inconspicuous lenticels.

Leaves three inches long, one and one-half inches wide, folded upwards or flattened, oval to obovate, leathery; upper surface dark green, smooth; lower surface pale green, with a few scattering hairs; apex and base variable in shape; margin doubly crenate, glandular; petiole one inch long, tinged with dull red, glandless or with from one to three small, globose, brownish or yellowish glands, usually at the base of the blade.

Buds obtuse, plump, free, arranged singly or in clusters on short spurs; leaf-scars obscure; season of bloom intermediate; flowers white, one and one-fourth inches across; borne in scattered clusters in twos and threes; pedicels one inch long, glabrous, greenish; calyx-tube green, obconic, glabrous; calyx-lobes tinged with red, broad, serrate, glabrous within and without, reflexed; petals roundish to obovate, crenate, with short, blunt claws and shallow, crenate apex; filaments one-fourth inch long; pistil glabrous, equal to or slightly longer than the stamens.

Fruit matures in mid-season; three-fourths of an inch in diameter, roundish-oblate, slightly compressed; cavity abrupt; suture very shallow; apex roundish; color light to rather dark red; dots numerous, small, russet, inconspicuous; stem thick, usually with a faint tinge of red, one inch long, adhering well to the fruit; skin thin, tender, separating from the pulp; flesh pale yellow, with a reddish tinge, with abundant light pink juice, tender and melting, sprightly, tart; of very good quality; stone free, small, roundishovate, flattened, pointed, with smooth surfaces which are tinged with red.

\section{NAPOLEON}

Prunus avium

I. Prince Treat. Hort. 30. 1828. 2. Kenrick Anr. Orch. 273, 274. 1832. 3. Downing Fr. Trees Am. 183. 1845. 4. Thomas Am. Fruit Cult. 365. 1849. 5. Ann. Pom. Belge 1:27, 28, fig. 2. 1853. 6. Elliott Fr. Book 215. 1859. 7. Thompson Gard. Ass't 527. 1859. 8. Am. Pom. Soc. Cat. 74. 1862. 9. Mortillet Le Cerisier 2:132. 1866. Io. Downing Fr. Trees Am. 470. 1869. I1. Pom. France 7: No. 9, Pl. 9. 1871. 12. Leroy Dict. Pom. 5:219, 220 fig., 221. 1877. I3. Flor. \& Pom. 57, P1. 465. 1878. 14. Mas Pom. Gen. 11:109, 110, fig. 55. 1882. 15. Cornell Sta. Bul. 98:493, fig. 87. 1895. 16. Ont. Fr. Gr. Assoc. Rpt. 5:38 fig. 1898.

Gros Bigarreau Blanc. 17. Duhamel Trait. Arb. Fr. 1:165. 1768. 18. Truchsess-Heim Kirschensort. 308-310. 1819. 19. Mortillet Le Cerisier 2:123-126, fig. 29. 1866. 20. Leroy Dict. Pom. 5:179, I 80 fig., 181. I877. 21. Mathieu Nom. Pom. 354. 1889.

Lauermannskirsche. 22. Christ Handb.664. 1797. 23. Christ Wörterb. 280. I802. 24. TruchsessHeim Kirschensort. 292-295, 323-328. 1819. 25. Mathieu Nom. Pom. 367. 1889.

Jange Marmorkirsche. 26. Christ Handb. 655. 1797. 27. Truchsess-Heim Kirschensort. 330-333. I8I 9 .

Holländische Grosse Prinzessinkirsche. 28. Christ Wörterb. 281. 1802. 29. Truchsess-Heim Kirschensort. 295-299. 1819. 30. Ill. Handb. 125 fig., 126. 1860. 31. Mas Pom. Gen. I1:117, I18, fig. 59. 1882. 32. Mathieu Nom. Pom. 357. I889. 
Harrison's Heart. 33. Forsyth Treat. Fr. Trees 42. 1803. 34. Brookshaw Hort. Reposit. x:69, 70, Pl. 34 fig. 2. 1823. 35. Mas Le Verger 8:145, 146, fig. 71. 1866-73. 36. Mathieu Nom. Pom. 362. 1889 .

Grosse Weisse Marmorkirsche. 37. Truchsess-Heim Kirschensort. 316, 317, 682. I819.

Holland Bigarreau. 38. Downing Fr. Trees Am. 181 fig., 182. 1845.

Bigarreau d'Esperen. 39. Mortillet Le Cerisier 2:119, 120 fig., 121. 1866. 40. Downing Fr. Trees Am. 463. 1869. 41. Mas Le Verger 8:11, 12, fig. 4. 1866-73. 42. Leroy Dict. Pom. 5:198 fig., I99. 1877. 43. Nathieu Nom. Pom. 347. 1889. 44. Rev. Hort. 321, 322. 1912.

Bigarreau Gros Coeuret. 45. Mortillet Le Cerisier 2:126-129, fig. 30. 1866. 46. Pom. France 7: No. 23, Pl. 23. 1871. 47. Leroy Dict. Pom. 5:208, 209 fig., 210.1877.

Royal Ann. 48. Cal. Bd. Hort. Rpt. 59, Pl. 18. 1893-94. 49. Am. Pom. Soc. Rpt. I92. 1907. 50. Wash. Sta. Bul. 92:31, fig. 8. 1910.

Napoleon is the leading firm-fleshed Sweet Cherry. It takes its place by virtue of the large size, handsome appearance and high quality of the fruit and the phenomenal productiveness of the trees. The accompanying plate shows well the large size and beautiful color of the cherries - unsurpassed in either character by any other Bigarreau and possibly by any other cherry. The flavor is rich and sweet which, with the abundant juice and firm, crackling flesh, makes this a most delicious and refreshing cherry for dessert and, with the great size and attractive color, gives it preference over all other Sweet Cherries for culinary purposes. In particular, cherry-canners find that Napoleon makes a finely finished product. The cherries carry well and keep long and are, therefore, well thought of by fruit-dealers. Besides being very productive, the trees come in bearing early and are as vigorous, hardy and healthy as those of any other Sweet Cherry. They may usually be known by their upright growth and large, sturdy limbs. Napoleon, however, is not without its faults. The cherries crack badly in wet weather and the variety can be grown with certainty only in the dry summer climate of the Pacific Coast, where, especially in Oregon and Washington, it reaches truly wonderful perfection. In the East, too, Napoleon is more susceptible to brown-rot than several of its rivals. Possibly the greatest fault, however, is in the tree, which is very fastidious as to soils, thriving only in choice cherry land and in a congenial cherry climate. Despite these rather serious faults, cherry-growers agree that Napoleon takes first place among Sweet Cherries for both home and commercial plantings.

Napoleon is of unknown origin. Early in the Eighteenth Century it was grown by the Germans, French, Dutch and English, proof that it is a very old variety. Leroy believes that it was described by Merlet in I 667 but under another name. The great number of synonyms in several languages gives some idea of the countries in which the variety has been 


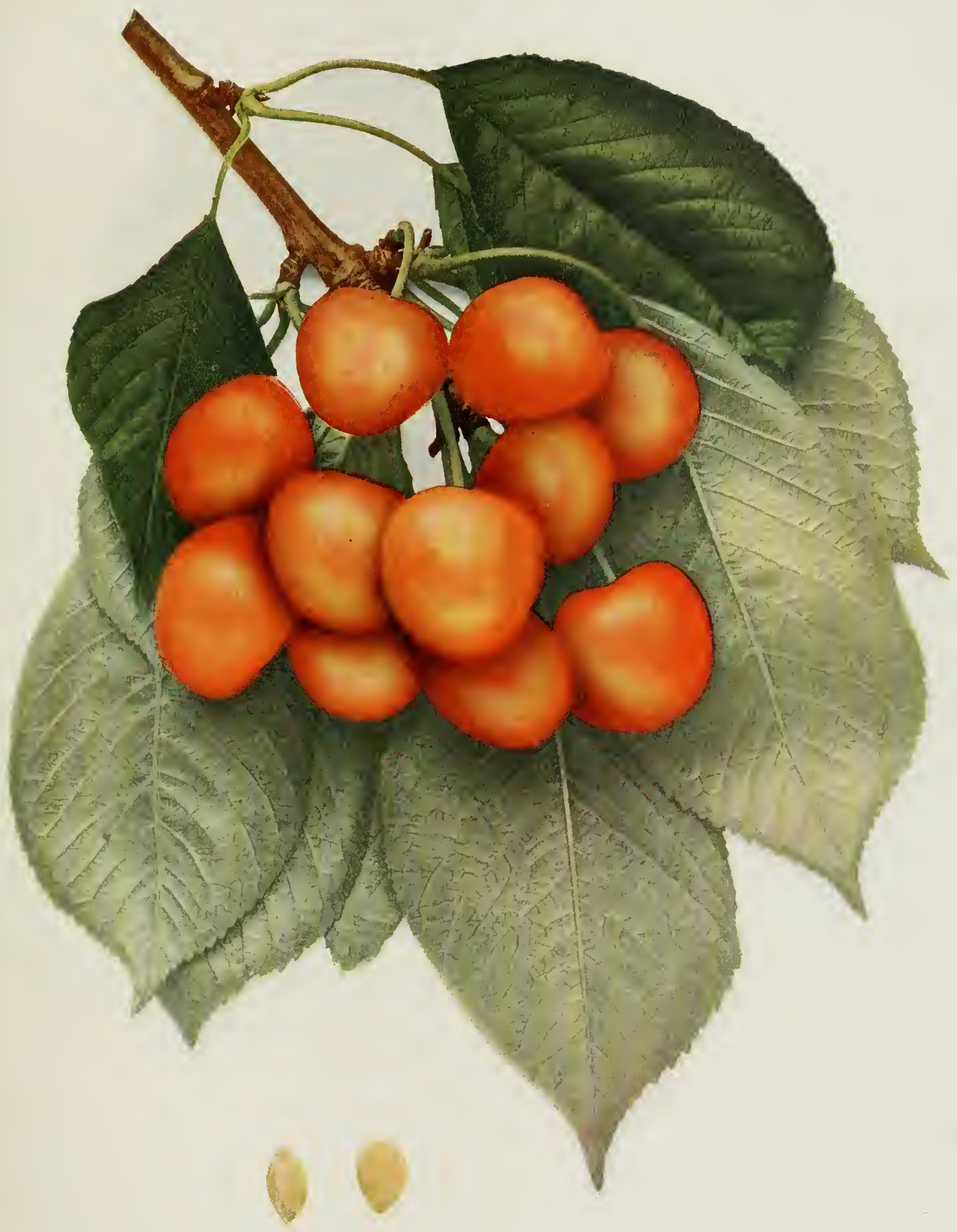



grown as well as the esteem in which it has been held. There are several accounts as to when the cherry was given the name Napoleon. Probably the best authenticated is that in which it is held that Parmentier, a Belgian, gave the cherry the name of the famous emperor in 1820 . When the variety was taken to England, where at that time Napoleon was not in good repute, the name of his conqueror, Wellington, was substituted but seems to have been little used. As if not content with the score or more of European names, cherry-growers in America have added at least two more. In many parts of the country it is locally called the Ox Heart. On the Pacific Coast it is grown and sold by nurserymen and fruit-growers alike as Royal Ann, a name given it by its introducer, Seth Lewelling, of Milwaukee, Oregon, who lost the label bearing the old name in taking it across the Continent in early days and gave it a new name. With incomprehensible persistency Western horticulturists maintain this synonym to the confusion of horticultural nomenclature. The American Pomological Society placed Napoleon on its fruit list in $\mathbf{1 8 6 2}$, it having been grown in America for at least 40 years before receiving this honor.

Tree large, vigorous, upright-spreading, open-topped, very productive; trunk thick, shaggy; branches thick, roughened by the lenticels, dull brown overlaid with ash-gray, with numerous large, raised lenticels; branchlets thick, long, light brown overspread with gray, smooth, with a few inconspicuous, small lenticels.

Leaves numerous, five and three-fourths inches long, two and one-half inches wide, folded upward, elliptical to obovate; upper surface dark green, rugose; lower surface light green, somewhat pubescent; apex acute, base variable in shape; margin doubly serrate, with small, dark glands; petiole one and one-fourth inches long, thick, tinged with dull red, hairy along the upper surface, with from one to three large, reniform, reddish-orange glands, usually on the stalk.

Buds variable in size, conical, free, arranged singly or in thin clusters from lateral buds and from spurs; leaf-scars prominent; season of bloom intermediate; flowers white, one and one-half inches across; borne in scattering clusters in ones or in twos; pedicels variable in length, averaging one inch long, glabrous, greenish; calyx-tube green, campanulate, glabrous; calyx-lobes tinged with red, long, rather narrow, acuminate, serrate, refexed; petals oval, entire, dentate at the apex, with short, narrow claws; filaments onehalf inch long; pistil glabrous, shorter than the stamens, often defective.

Fruit matures in mid-season; over one inch in diameter, conical to long-cordate, compressed; cavity deep, wide, flaring; suture a distinct line; apex much pointed; color, varying shades of bright red over a yellowish background, distinctly mottled; dots obscure; stem slender, more than one inch long, adherent to the fruit; skin thin, rather adherent; flesh whitish, with a faint yellow tinge, with colorless juice, tender, meaty, crisp, mild, the flavor improving as the season advances, sweet; good to very good in quality; stone semi-clinging, small, ovate, flattened, pointed, with smooth surfaces. 


\section{NOUVELLE ROYALE}

\section{Prunus avium $\times$ Prunus cerasus}

x. Flor. \&o Pom. 72, P1. 1862. 2. Gard. Mon. 7:248. 1865. 3. Hogg Fruit Man. 70, 88. 1866. 4. Mas Le Verger 8:147, 148, fig. 72. 1866-73. 5. Downing Fr. Trees Am. 484. 1869. 6. Am. Pom. Soc. Rpt. 31. 1875. 7. Gaucher Pom. Prak. Obst. No. 80, Tab. 33. 1894. 8. Guide Prat. 9. 1895.

If this cherry were to be judged by its behavior on the grounds of this Station, it would be called one of the best of the hybrid Dukes. In particular, it would be commended by its product, the trees not making as good a showing as the fruit. The cherries are distinguished by their large size, dark red color, glossy surface, good quality, lateness in maturity and, even more particularly, sweetness, keeping in mind that the variety is a hybrid and not a true Sweet Cherry. The shape, too, offers a distinguishing character, the fruits being more oblate than ir any other Duke. The long, stout stem is still another characteristic. Unfortunately the tree, while satisfactory in all other respects, is unproductive - a fatal fault in these days of commercial fruit-growing. Nouvelle Royale is not widely known in America and may well be given trial by those who want a late Duke.

This variety is supposed from its fruit- and tree-characters to be a hybrid between Early Richmond and May Duke but where, how and when it came to light is not known. Downing, in 1869 , mentions the Nouvelle Royale as having recently been introduced into this country and it was noted in the Report of the American Pomological Society for 1875 but has never received a place upon the Society's fruit catalog list.

Tree large, vigorous, upright, compact, moderately productive; trunk of medium size; branches upright, thickish; branchlets slender, long, brown partly covered with ashgray, with very numerous conspicuous, raised lenticels.

Leaves numerous, three and one-half inches long, two inches wide, folded upward, obovate; upper surface dark green, glossy, rugose; lower surface light green, lightly pubescent; apex abruptly pointed, base acute; margin finely and doubly serrate, glandular; petiole one and one-fourth inches long, slender, tinged with dull red, grooved and with few hairs along the upper surface, glandless or with from one to four globose, greenishyellow or reddish glands variable in size usually at the base of the blade.

Buds small, short, obtuse, plump, free, arranged singly as lateral buds and on short spurs in clusters variable in size; leaf-scars obscure; season of bloom intermediate; flowers white, one inch across; borne in dense clusters in threes and fours; pedicels three-fourths of an inch long, slender, glabrous, greenish; calyx-tube with a tinge of red, obconic, glabrous; calyx-lobes somewhat reddish, broad, acute, serrate, glabrous within and without, reflexed; petals roundish, entire, nearly sessile, apex entire; filaments one-fourth inch long; pistil glabrous, longer than the stamens. 


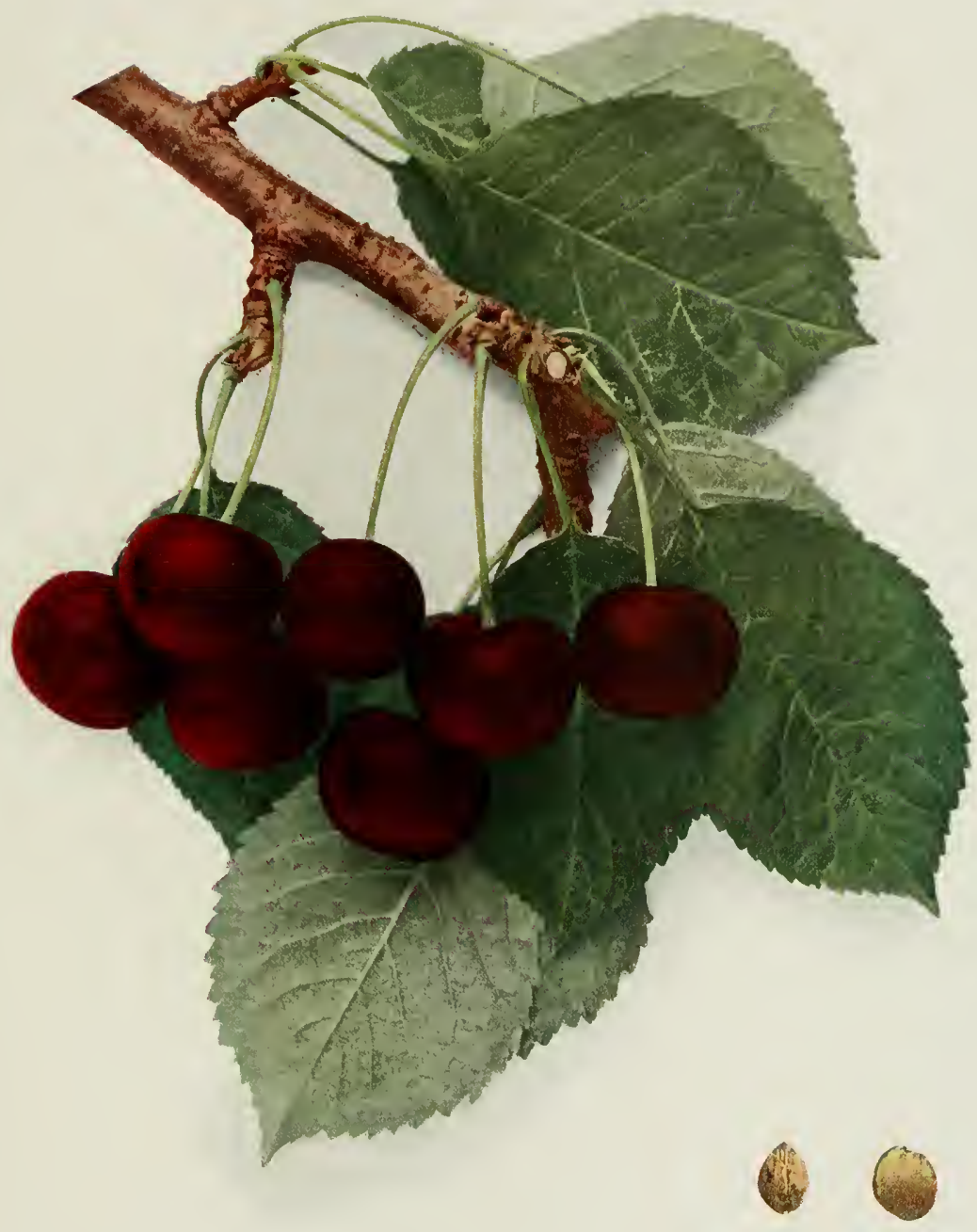

NOUVELLE ROYALE 

Fruit matures in mid-season; nearly one inch in diameter, oblate, strongly compressed; cavity deep, narrow, abrupt; suture shallow; apex flattened or slightly depressed; color dark red; dots numerous, small, russet, inconspicuous; stem one and three-fourths inches long, adherent to the fruit; skin thin, tender, separating from the pulp; flesh pale yellowish or with a tinge of red, with light pink juice, slightly stringy, tender and melting, pleasantly flavored, mildly tart; of very good quality; stone free, roundish-oval, plump, blunt, oblique, with smooth surfaces often tinged with red, with small ridges radiating from the base.

\section{OLIVET}

\section{Prunns avium $\times$ Prunus cerasus}

I. Gard. Mon. 19:19. 1877. 2. Am. Pom. Soc. Cat. 20. 1881. 3. Downing Fr. Trees Am. $3^{\text {rd }}$ App. 164. 1881. 4. Can. Exp. Farm Bul. 17:11. 1892. 5. Cal. Sta. An. Rpt. 316. 1895-97. 6. Va. Sta. Bul. 133:27. 1902. 7. Ia. Sta. Bul. 73:76, 77. 1903. 8. Am. Pom. Soc. Sp. Rpt. 24. 1904-05. 9. Wash. Sta. Bul. 92:21. 1910.

Olivet is a large, globular, deep red, glossy cherry with a rich, vinous, subacid flavor. Some writers call Olivet a Duke while others place it with the Morellos. The fruit, on the grounds of this Station, shows many characteristics of the Morellos while the tree appears to be a Duke, suggesting that it is a hybrid between trees of the two groups. The fruit, eaten out of hand, would be rated as a very good Morello or a subacid and somewhat mediocre Duke, a fruit hardly good enough for dessert and not as good as some of the sourer cherries for culinary purposes. It is one of the earliest of the Morello-like cherries and this may give it a place in the cherry flora of the country. The trees are large and vigorous and their much-branched, round tops would seem to give the maximum amount of bearing surface, but, unfortunately, the cherries do not set abundantly. On the grounds of this Station the variety is not fruitful, this being its chief defect. In other parts of the country, however, it is reported to be either very productive or moderately so. The descriptions of this cherry as given by American experiment stations and nurserymen show plainly that there are several distinct sorts passing under the name Olivet in this country.

Olivet, of comparatively recent origin, was found at Olivet, Loire, France. American nurserymen introduced this variety sometime previous to 1877 , for in that year the Gardener's Monthly mentioned the cherry as being "a valuable Duke sort filling an unoccupied place among the list of early cherries in central New York." Olivet was entered on the American Pomological Society's catalog list of fruits in $\mathbf{I} 88 \mathrm{I}$ where it is still retained.

Tree large, vigorous, upright-spreading, round-topped, unproductive; trunk thickish, rather rough; branches thick, smooth, reddish-brown partly overspread with ash-gray, 
with numerous small lenticels; branchlets short, brown partly overspread with ash-gray, smooth, with numerous raised lenticels.

Leaves numerous, three and one-half inches long, one and three-fourths inches wide, folded upward, obovate to oval, thin; upper surface dark green, smooth; lower surface light green, glossy, with a few scattering hairs; apex acute; margin doubly serrate, glandular; petiole one and one-fourth inches long, greenish, glandless or with one or two globose, brownish glands variable in position.

Buds usually pointed, plump, free, arranged singly as lateral buds and in small clusters on short spurs; leaf-scars prominent; season of bloom intermediate; flowers white, one inch across; borne in dense clusters, usually in threes; pedicels one-half inch long, glabrous, greenish; calyx-tube with a tinge of red, obconic, glabrous; calyx-lobes with a trace of red, long, of medium width, acute, serrate, glabrous within and without, reflexed; petals oval to slightly obovate, entire, nearly sessile; apex entire; filaments one-fourth inch long; pistil glabrous, equal to the stamens in length.

Fruit matures in mid-season; nearly one inch in diameter, roundish to slightly oblate, somewhat compressed; cavity abrupt, regular; suture a line; apex roundish, with a small depression at the center; color bright red; dots russet, obscure; stem thickish, one and one-fourth inches long, adhering well to the fruit; skin tough, separating from the pulp; flesh light red, with abundant light red or wine-colored juice, tender and melting, sprightly, astringent, tart; of fairly good quality; stone free, small, roundish, slightly flattened, somewhat pointed at the apex, with smooth surfaces; somewhat ridged along the ventral suture.

\section{OSTHEIM}

\section{Prunus cerasus}

I. Christ Obstbäume 159. 179I. 2. Christ Handb. 676. 1797. 3. Truchsess-Heim Kirschensort. 512-517. 1819. 4. Prince Pom. Man. 2:145. 1832. 5. Dochnahl Führ. Obstkunde 3:60. 1858. 6. Ill. Handb. 187 fig., 188. 1860. 7. Leroy Dict. Pom. 5:295, 296 fig. 1877. 8. Mathieu Nom. Pom. 371. 1889. 9. Am. Pom. Soc. Cat. 25. 1899. 10. Del. Sta. An. Rpt. 12:121, 122, 1900. 11. Ia. Sta. Bul. 73:78 fig. 18, 79. 1903. 12. Wash. Sta. Bul. 92:14, 21, 22. 1910.

Ostheim finds considerable favor in the prairie states of the Middle West but is all but worthless as grown in New York and other eastern states. It is one of the Morellos and falls far short of the best of its group, the cherries being too small and of but mediocre quality. The trees are typical Morellos, round-headed, with slender, drooping branches and branchlets and very dark green foliage. The fruit is borne toward the ends of short branches which are not well distributed over the main branches, leaving much bare wood. Like all Morellos the fruit hangs long after maturity and since the ripening season is late the variety may be worth growing because of its lateness; as it may, also, in cold climates because of great hardiness. The trees on their own roots throw up many suckers which are often used in propagation. The variety has the reputation, too, of coming true to name from seeds. 


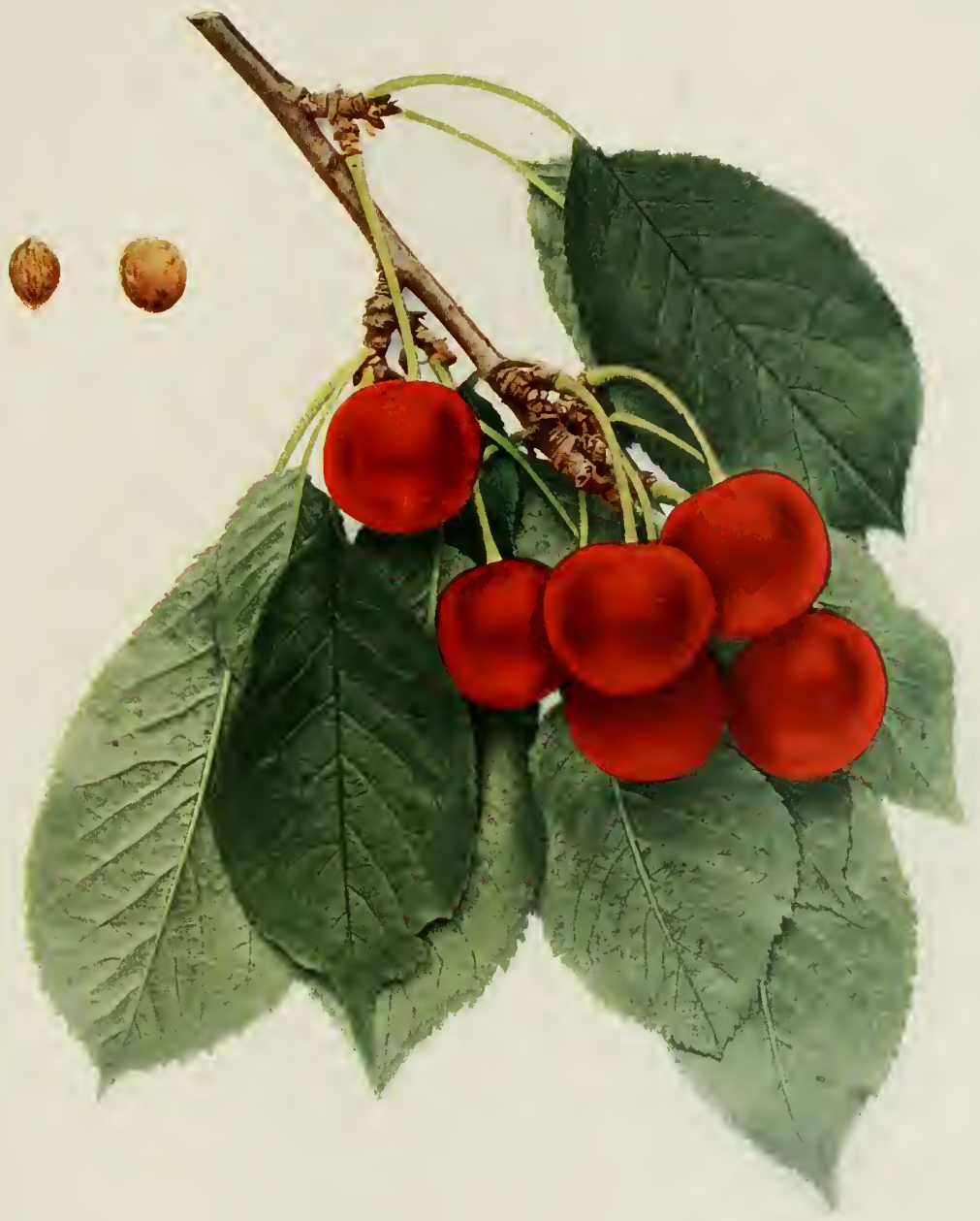

OLIVET 

. 
Ostheim is a native of Spain and not of Germany as many have supposed. The trees were found in the region of the Sierra Morena Mountains, Spain, and were taken to Germany by a Dr. Klinghammer after the Wars of the Succession, I 7OI-17 I 3. The cherry took the name Ostheim from the German town of that name where it was widely grown. The variety, being easily propagated, spread throughout Germany and soon became one of the best-known cherries. Later, the name seems to have come to be a class term for all cherries similar to the original Ostheim. The names Ostheim, Ostheimer, Griotte Ostheim and Ostheimer Weichsel are used interchangeably by foreign writers for this variety. American writers, however, have given these names to two very similar but distinct varieties. Ostheim was brought to the United States by William Robert Prince of the Linnean Botanical Gardens early in the Nineteenth Century. It has proved very satisfactory in some sections of the West and Canada, while in the East it is but a mediocre variety at best. At different times either buds or trees of so-called Ostheims have been imported to this country which have turned out not to be the true variety. What these sorts really are will remain uncertain until the several forms can be brought together and compared. Professor Budd imported a variety in $\mathbf{I} 88_{3}$, which since has become known as Ostheim, carrying Griotte d'Ostheim as a synonym. Whether or not this is the old variety or a distinct strain of the Ostheim class we are unable to say. The Cerise d'Ostheim received by this Station has proved identical with this variety. Ostheim was first listed by the American Pomological Society in I899. A cherry known as Minnesota Ostheim, introduced into Minnesota from Germany, is now recognized as a distinct sort. The variety as it is known in Kansas and Missouri is often called the German Ostheimer though some believe this to be different from the true sort.

Tree below medium in size, vigorous, upright-spreading, with drooping branchlets, dense, very productive; trunk smooth; branches rather slender, smooth, dark ash-gray partly overspreading reddish-brown, with small, raised lenticels; branchlets slender, willowy, long, brown partly overspread with ash-gray, smooth, glabrous, with small, inconspicuous lenticels.

Leaves very numerous, three and one-fourth inches long, one and one-haif inches wide, folded upward, obovate to oval; upper surface very dark green, smooth; lower surface pale green, with a few scattering hairs; apex taper-pointed, base variable in shape; margin finely serrate, with small, dark glands; petiole slender, one-half inch long, short, tinged with dull red, grooved, with a few scattering hairs, with from one to three small, globose, greenish-yellow glands at the base of the blade. 
Buds small, short, usually obtuse, plump, free, arranged as lateral buds and in small clusters on short spurs; leaf-scars prominent; season of bloom medium; flowers one inch across, white; borne in scattering clusters, in twos and threes; pedicels five-eighths of an inch long, rather slender, glabrous, greenish; calyx-tube green with a faint tinge of red, obconic, glabrous; calyx-lobes with a trace of red, rather long, serrate, glabrous within and without, reflexed; petals obovate, entire, nearly sessile, apex entire; filaments onefourth inch long; pistil glabrous, nearly equal in length to the stamens.

Fruit matures very late; nearly three-fourths of an inch in diameter, roundish to slightly oblate, compressed; cavity very shallow and narrow, flaring; suture indistinct; apex roundish with a small depression at the center; color very dark red approaching black; dots numerous, small, dark russet, inconspicuous; stem slender, one and one-fourth inches long, but slightly adherent to the fruit; skin thin, tender, separating readily from the pulp; flesh dark red, with much very dark colored juice, tender and melting, sprightly, tart, losing its astringency when fully ripe; of fair quality; stone free, nearly one-half inch in diameter, roundish-oblate, somewhat pointed, with smooth surfaces slightly stained with red.

\section{OX HEART}

\section{Prunus avium}

1. Miller Gard. Kal. 154. 1734. 2. Christ Handb. 663. 1797. 3. Brookshaw Hort. Reposit. 1:36, P1. 18 fig. 2. 1817. 4. Coxe Cult. Fr. Trees 249. 1817. 5. Truchsess-Heim Kirschensort. 132-135. 1819. 6. Downing Fr. Trees $A m$. 176. 1845. 7. Am. Pom. Soc. Rpt. 244. 1858. 8. Mas Pom. Gen. 11:57, 58, fig. 29. 1882. 9. Oberdieck Obst-Sort. 365, 366. 1882. 10. Mathieu Nom. Pom. 339, 371. 1889.

Bigarreau Gros Commun. I1. Mag. Hort. 9:203. $18+3$.

$\mathrm{Ox}$ Heart is very commonly used as a class name for the large, meaty varieties of cherries which are cordate in shape. In America the name is most often given to the light-fleshed cherries, such as Yellow Spanish, Napoleon or White Bigarreau. At one time, however, the name was applied to a distinct variety known throughout England, Germany and America, being first mentioned by Miller, an Englishman, in 1734. Coxe, in 1817 , was the first American writer to list the variety but it never became popular in the New World. Ox Heart appeared among the fruits rejected by the American Pomological Society in 1858 and from then on it gradually gave way to better varieties. The synonyms of the true $\mathrm{Ox}$ Heart are badly confused not only with other dark-fleshed varieties but with those of the Yellow Spanish type. As some of these varieties are merely listed while others have but a meager description, it is impossible to separate or group them with any degree of certainty. In the I909 catalog of the American Pomological Society there appears an Ox Heart of American origin and of recent introduction, known in the West as Major Francis. There are also in several nursery catalogs a "white-fleshed $\mathrm{Ox}$ 


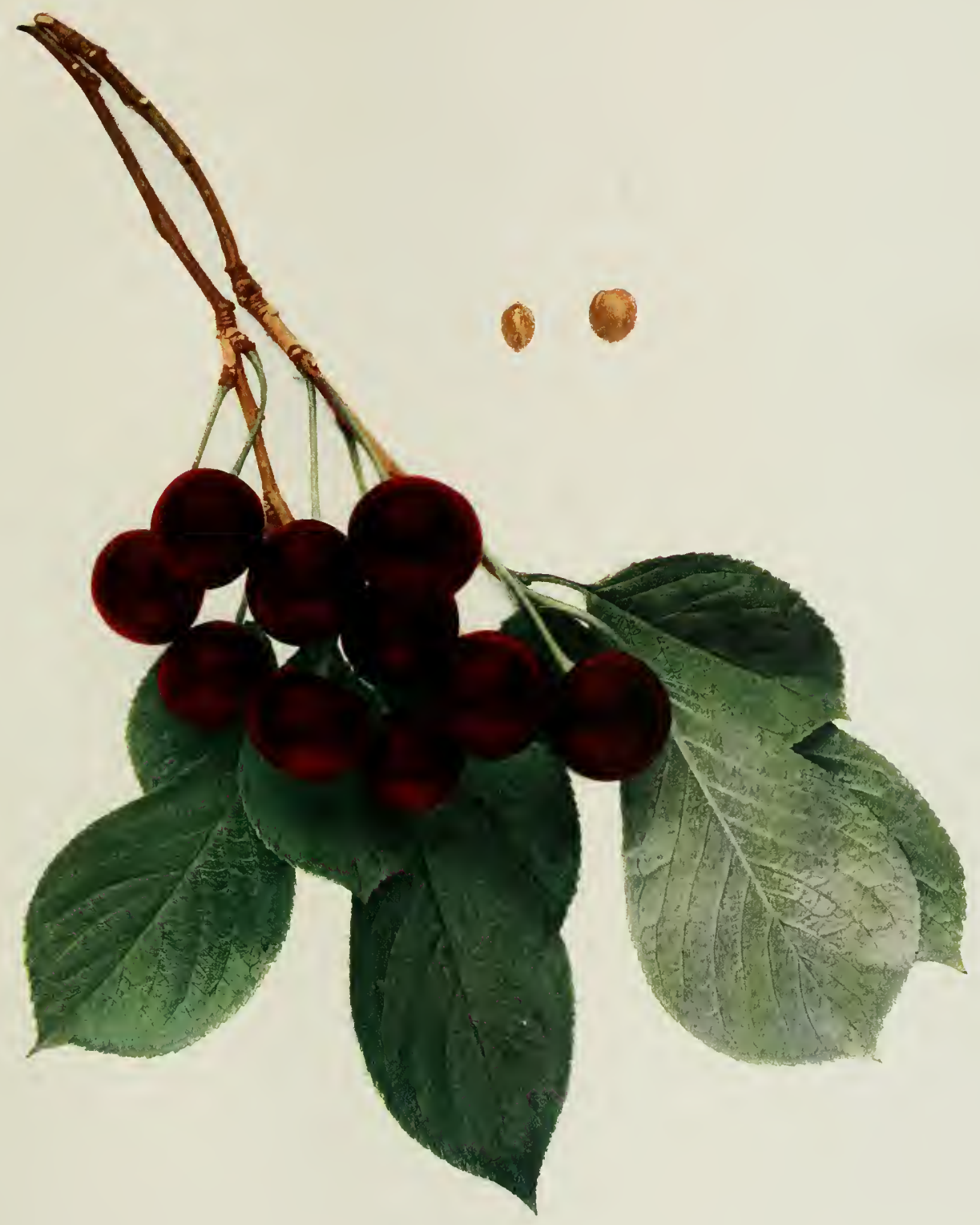



Heart." What this variety is we are unable to say. The following is a description of Ox Heart compiled from European fruit books:

Tree medium in vigor, round-topped, spherical, productive; branches somewhat curved; internodes of medium length; leaves obovate, obtusely pointed, margin finely serrate; petiole short, rather slender, flexible, tinged red, with two reniform glands; flowers small; petals irregularly elliptical.

Fruit matures the last of June or early in July; medium to large, cordate, pointed, sides uneveniy compressed; color lively red changing to intense purple or nearly black; stem of medium length and thickness, usually tinged red, inserted in a broad, deep cavity; skin tough; flesh dark red, with abundant colored juice, half-tcnder but firmer than most Hearts, sweet though slightly bitter before complete maturity; quality good; stone medium in size, broadly cordate, adhering to the flesh along the ventral suture.

\section{REINE HORTENSE}

\section{Prunus avium $\times$ Prunus cerasus}

I. Gen. Farmer 11:191 fig. 1850. 2. Am. Pom. Soc. Rpt. 55. 1856. 3. Am. Pom. Soc. Cat. 211. 1856. 3. Dochnahl Führ. Obstkunde 3:5. 1858. 4. Ill. Handb. 167 fig., 168. 1860. 5. Thomas Guide Prat. 17, 204. 1876. 6. Leroy Dict. Pom. 5:379-382, fig 1877 .

D'A remberg. 7. Lond. Hort. Soc. Cat. 45. 1831. 8. Kenrick Am. Orch. 215.1835.

Hortense. 9. Elliott Fr. Book 196, 197 fig. 1854. Io. A m. Pom. Soc. Cat. 27. 1909.

Were there not so many good Duke varieties of its season Reine Hortense would take high rank among hybrid cherries. Several qualities fit it admirably for home and somewhat for commercial plantations. To begin with, it is most excellent in quality, its flavor being a commingling of the refreshing acidity of the Sour Cherry and the richness of the Sweet Cherry, though to some there may be a little too much acidity for a firstclass dessert fruit. The cherries are also handsome - large, round, bright, glossy red with a shade of amber and very uniform in size, color and shape. The fruit is especially attractive on the tree as it hangs on long stems in twos and threes thickly scattered and never much clustered. Unfortunately the fruit does not stand handling in harvesting and marketing quite as well as that of some other Dukes and is a little too susceptible to brown-rot for a good commercial cherry. The chief faults of the variety, however, are in the trees rather than in the fruit. The trees are but of medium size, are not as productive as some others of the hybrid sorts, are at their best only in choice cherry soils and demand good care. In Europe, Reine Hortense is much used as a dwarf and for training on walls. It would seem that its merits and faults, as it grows in America, are such as fit it preeminently well only for the amateur.

Of the several accounts of the origin of Reine Hortense the one giving 
France as its home and Larose as its originator is here accepted as authentic. M. Larose of Neuilly-sur-Seine, Seine, a gardener of the imperial court, grew the original tree early in the Nineteenth Century from a seed of the Cerise Larose, a seedling of his introduction. Soon after the first mention of this variety, about I84I, there appeared the Louis XVIII, Morestin, Guigne de Petit-Brie and several others. The variety was seemingly rechristened by every nurseryman who got hold of it. At one time the name Monstreuse de Bavay was acceptable to many, it having been given to the variety by a Mr. Bavay of Vilvorde, Brabant, Belgium, about 1826 . The theory that Reine Hortense comes true to seed and therefore has several strains has been discredited. The American Pomological Society recognized Reine Hortense in $\mathbf{1} 856$, only a few years after being introduced into this country, by placing it on the recommended fruit list. In I909, the Society shortened the name from Reine Hortense to Hortense but in this text we prefer to use the full name, thereby indicating clearly the person for whom the cherry was christened.

Tree of medium size, upright-spreading, productive; trunk shaggy; branches smooth, dark reddish-brown covered with ash-gray, with a few large lenticels; branchlets rather slender, with short internodes, brown partly overspread with ash-gray, smooth, with inconspicuous, raised lenticels.

Leaves numerous, four and one-half inches long, two and one-half inches wide, folded upward, oval to obovate, thin; upper surface dark green, rugose; lower surface light green, pubescent along the midrib; apex taper-pointed, base abrupt; margin coarsely serrate, with dark glands; petiole one inch long, tinged with red, pubescent along the grooved upper surface, with none or with from one to four small, globose, greenish-yellow or brownish glands, usually at the base of the blade.

Buds large, long-pointed, plump, free, arranged singly as lateral buds and in small clusters on few long spurs; blooms appearing in mid-season; flowers white, one and onefourth inches across; borne in dense clusters usually in threes; pedicels one inch long, slender, glabrous; calyx-tube with a tinge of red, campanulate, glabrous; calyx-lobes long, acuminate, glabrous within and without, reflexed; petals roundish, entire, sessile, with entire apex; filaments one-fourth of an inch long; pistil glabrous, shorter than the stamens.

Fruit matures in mid-season; nearly one inch in diameter, oblong-conic to obtuseconic, compressed; cavity somewhat shallow, narrow, abrupt, often lipped; suture indistinct; apex roundish with a small depression at the center; color amber-red; dots numerous, light russet, conspicuous; stem tortuous, slender, one and one-half inches long, adherent to the fruit; skin tender, separating from the pulp; flesh pale yellow, with colorless juice, tender and melting, sprightly subacid; of very good quality; stone free, rather large, oblong to oval, flattened, blunt, with smooth surfaces. 


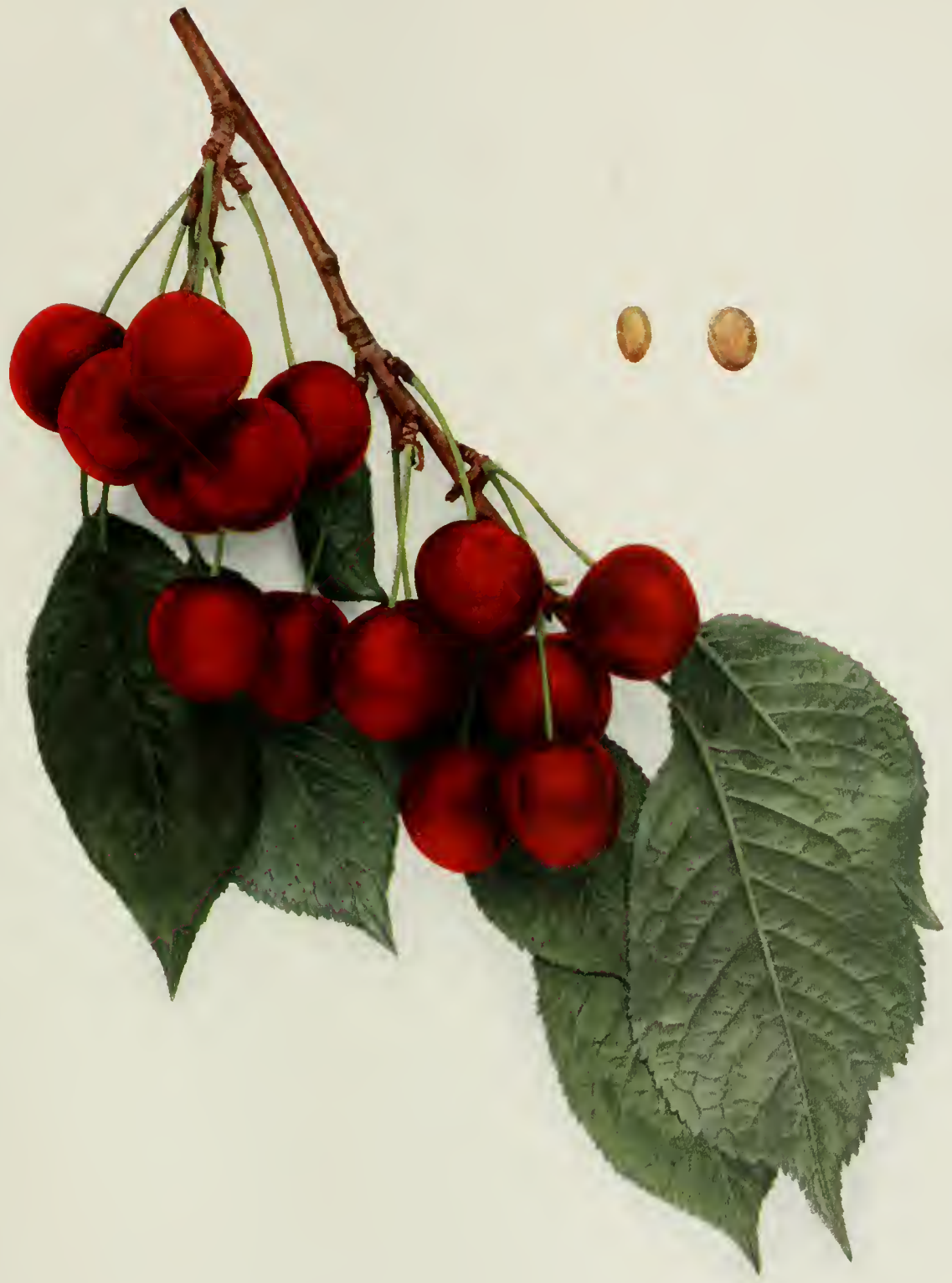

REINE HORTENSE 



\section{REPUBLICAN}

Prunus avium

I. Am. Pom. Soc. Cat. 26. I909.

Black Republican. 2. Cult. \& Count. Gent. 35:534. 1870. 3. Am. Pom. Soc. Cat. 20.1875. 4. Am. Gard. 9:357 fig. 1888. 5. Wickson Cal. Fruits 289. 1889. 6. Wash. Sta. Bul. 92:23, 25. 1910.

Leweilling. 7. Am. Pom. Soc. Rpt. 127. 1875. 8. Gard. Mon. 17:336. 1875. 9. Am. Pom. Soc. Cat. 26. 1909. то. Wash. Sta. Bul. $92: 28,29$, fig. 7. 1910.

For some reason Republican does not make headway in the favor of cherry-growers though all who have described it speak well of it. Judged by the palate, Republican is one of the best of the Bigarreaus. The cherries are rich and sweet in flavor, firm of flesh and with an abundance of refreshing juice. Judged by the eye, too, it holds its own with the best of its class, the fruit having a pleasing rotundness of shape and a beautiful dark red, almost black, glossy color. In size the variety very often falls short; for, though often given as one of the largest, it turns out to be, in many orchards, but of medium size and sometimes is small. Here seems to be its fatal defect. It is exceedingly capricious as to soils, failing wholly or in part in all but the very choicest cherry environments. The trees are large, spreading and vigorous but on the grounds of this Station are more susceptible to the shot-hole fungus than any other Sweet Cherry. It has been reported to be very subject to this disease at the Washington Station also. The failure of this cherry to meet the demands of commercial cherry-growers during a probationary period of nearly a half a century means that it is, at most, of but local value.

This variety, known under two other names, Black Republican and Lewelling, originated about the middle of the Nineteenth Century in the orchard of Seth Lewelling, Milwaukee, Oregon. In traveling across the continent in 1849, Mr. Lewelling took with him to Oregon, Bigarreau, Morello and Mahaleb cherries and from seeds of one of the Bigarreaus sprang several seedlings, among them one which was named Black Republican. The parentage of the sort is not known though it was thought to be a cross between Napoleon and Black Tartarian, having sprung up near these two trees. Some cherry-growers and nurserymen describe a cherry which they call Lewelling but in every case the descriptions agree very closely with Republican. Many list the two names separately as designating two distinct varieties of diverse origin. Of these, some have supposed Republican to be a seedling of Eagle originating in I860. The American Pomological Society for many years listed Black Republican 
alone beginning in its catalog of 1875 but in 1909 the catalog contained the two names, Republican and Lewelling. Inasmuch as the consensus of opinion is that both names apply to a single cherry this Station has decided to list Republican only.

Tree large, vigorous, upright-spreading, open-topped, very productive; trunk thick, somewhat shaggy; branches stout, roughened, brown covered with ash-gray, with large, raised lenticels; branchlets stout, with long internodes, brown nearly overspread with ashgray, smooth except near the base, with a few small, raised, inconspicuous lenticels.

Leaves numerous, five inches long, two and five-eighths inches wide, folded upward, obovate to oval, thin; upper surface dark green, smooth; lower surface slightly hairy; apex acute, base abrupt; margin coarsely and doubly serrate, glandular; petiole one and one-fourth inches long, thick, tinged with dull red, with two or three large, reniform, light green or reddish glands on the stalk.

Buds pointed or obtuse, plump, free, arranged singly on the branchlets, or in small clusters on spurs of medium length; season of bloom intermediate; flowers white, one and one-half inches across; borne in scattering clusters in ones and twos; pedicels variable in length, averaging one inch long, characteristically thick, glabrous; calyx-tube tinged with red, campanulate, glabrous; calyx-lobes variable in width, tinged with red, longobovate to acute, finely serrate, glabrous within and without, reflexed; petals obovate, entire, with short, blunt claws, with shallow, notched apex; filaments five-sixteenths of an inch long; pistil glabrous, equal to the stamens in length, often defective.

Fruit matures late; about one inch in diameter, wide, variable in shape, cordate or roundish-cordate, compressed, with angular and uneven surfaces; cavity deep, wide, flaring; suture a shallow groove, often extending around the fruit; apex with a small depression at the center; color purplish-black; dots numerous, small, dark russet, inconspicuous; stem thick, one and one-eighth inches long, adherent to the fruit; skin thin; flesh purplishred, with dark colored juice, tender, meaty, crisp, mild, sweet or with slight astringency before fully mature; of good quality; stone semi-free, small, ovate, flattened, rather blunt, with smooth surfaces.

\section{ROCKPORT}

Prumus avium

I. Horticulturist 2:59 fig., 60. 1847-48. 2. Elliott Fr. Book 201, 202 fig. 1854. 3. Hooper W. Fr. Book 270, 271. 1857. 4. A m. Pom. Soc. Cat. 74. 1862. 5. Nortillet Le Cerisier 2:131. 1866. 6. Oberdieck Obst-Sort. 372. 1881 .

Rockport is of very doubtful commercial value and has too many faults to be included with the best sweet sorts for a home orchard. It is more easily characterized by its faults than its merits. Compared with the well-known Yellow Spanish, of which it is a seedling and to which it is similar, the cherries are smaller and the pits are larger than those of the parent variety,- - quite too large for the amount of pulp. Worst of the faults of the variety is, however, that the cherries are not sufficiently 


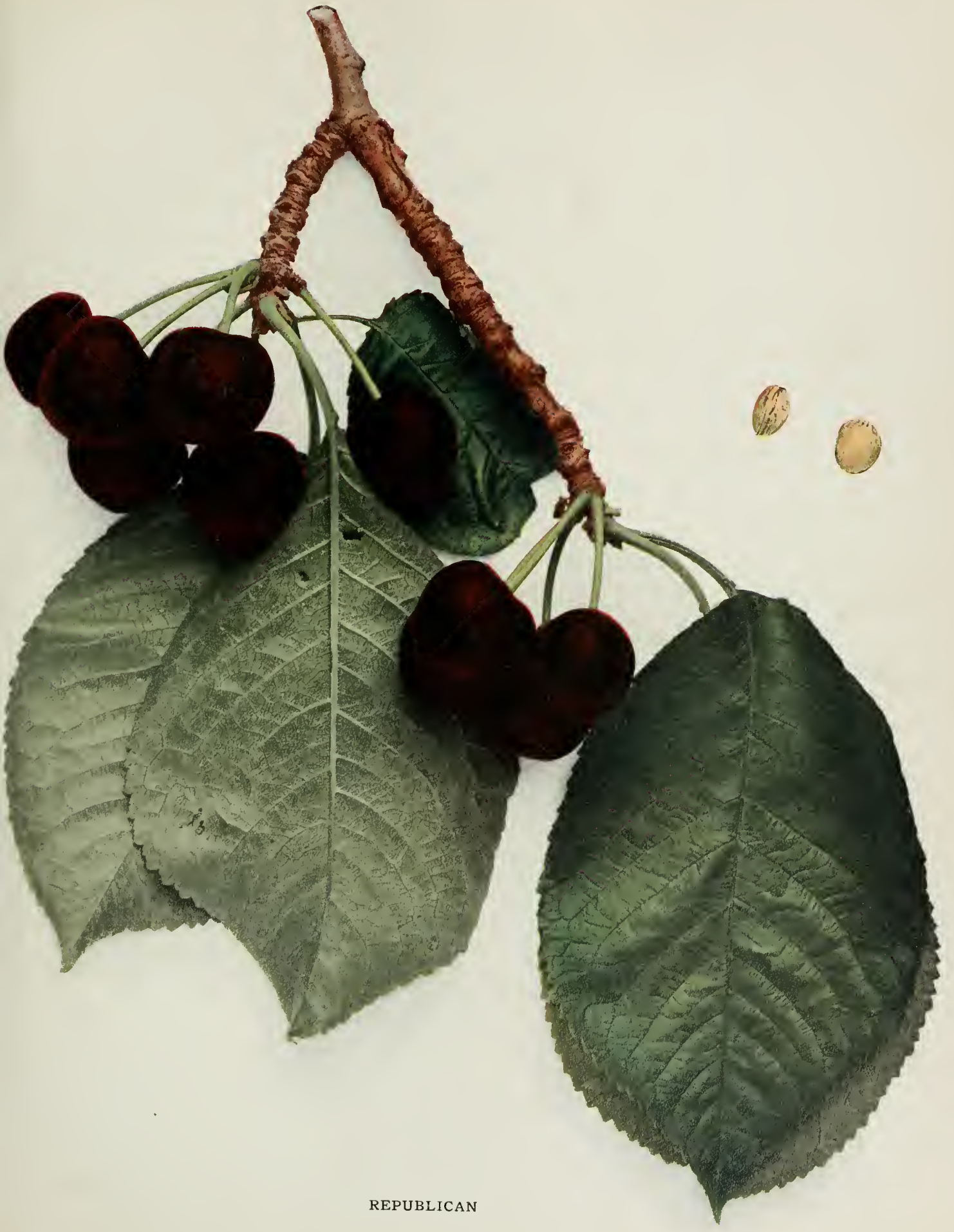





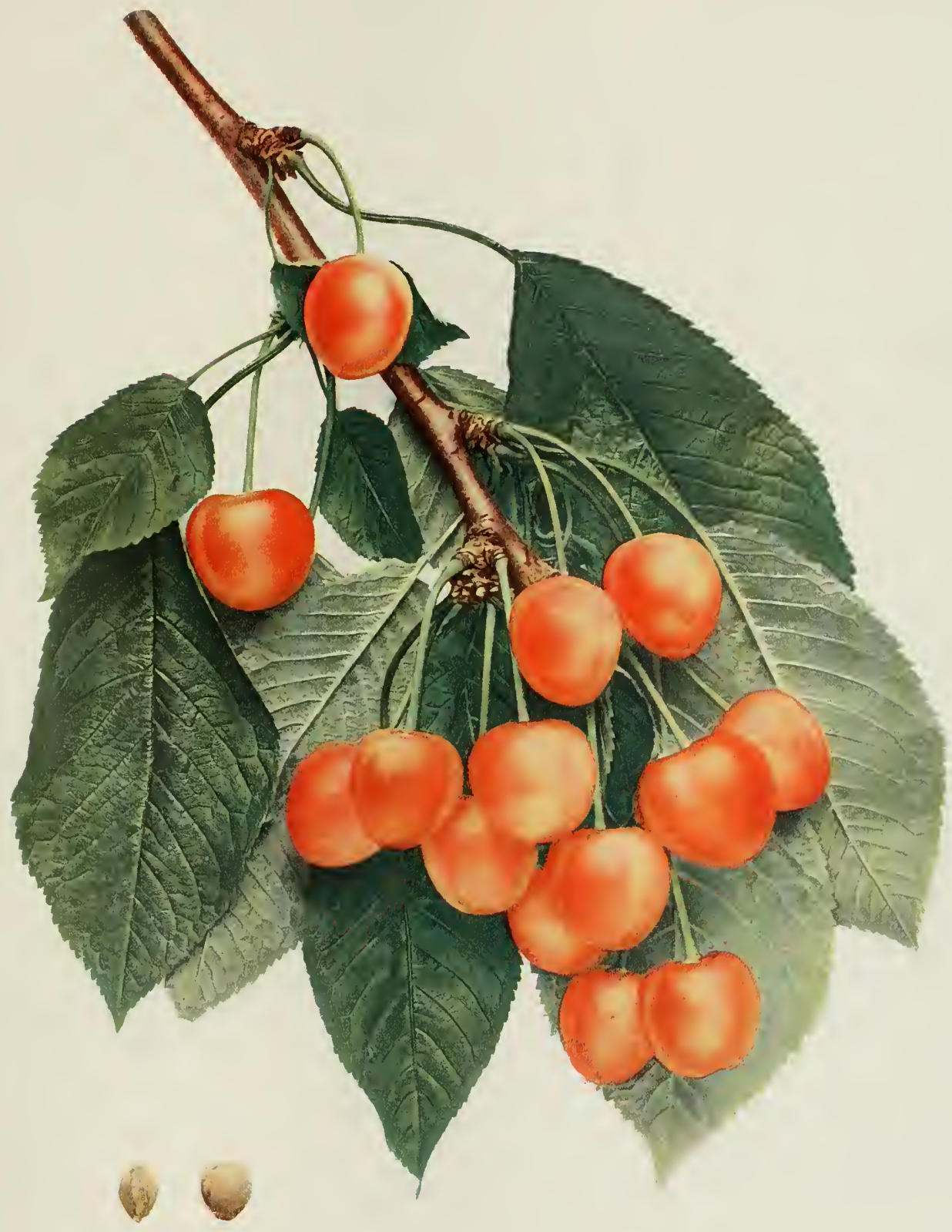

ROCKPORT 

firm of flesh to withstand harvesting, shipping and the attacks of the brown-rot fungus. To offset the defects of the fruit the flesh is rich, sweet ard tender, making it, all in all, as good as any other Sweet Cherry for dessert. The trees, too, are very satisfactory, being large, vigorous and very fruitful, though with the reputation of requiring good soil and the best of care, of lacking a little in hardiness to cold, and of having the period of maturing the crop more or less changed by soil and culture. Rockport has been, and is, more or less popular in New York but it can be recommended only for a home orchard.

Rockport is another of Professor Kirtland's introductions, having been raised by him at Cleveland, Ohio, about $\mathbf{1} 842$, from a seed of Yellow Spanish. It soon won a place, in I862, on the fruit list of the American Pomological Society where it still remains. It is mentioned by several foreign authors and many American nurserymen offer it for sale. Swedish is given as a synonym of Rockport by Hooper.

Tree large, vigorous, upright, very productive; trunk somewhat slender, roughish; branches smooth, reddish-brown, with numerous small lenticels; branchlets stout, variable in length, with long internodes, brown almost entirely overspread with ash-gray, smooth, with conspicuous, raised lenticels.

Leaves numerous, three and one-half inches long, one and three-fourths inches wide, folded upward, long-oval to obovate; upper surface dark green, somewhat rugose; lower surface dull, light green, pubescent along the veins; apex acute to taper-pointed, base abrupt; margin coarsely serrate, glandular; petiole two inches long, tinged with red, with a few hairs on the upper surface, glandless or with from one to four large, reniform, reddish glands variable in position.

Buds large, long, pointed, plump, free, arranged singly and in clusters from lateral buds and short spurs; leaf-scars prominent; season of bloom intermediate; flowers white, one and one-fourth inches across; borne in clusters usually in twos; pedicels one inch long, glabrous, greenish; calyx-tube green, campanulate, glabrous; calyx-lobes acute, glabrous within and without, reflexed; petals roundish, entire, dentate at the apex, nearly sessile; filaments nearly one-half inch long; pistil glabrous, shorter than the stamens, often defective.

Fruit matures early; one inch in diameter, cordate to conical, compressed; cavity shallow, wide, flaring, regular; suture a distinct line; apex roundish, with a small depression at the center; color bright red over an amber-yellow background, mottled; dots very numerous, small, light yellowish, somewhat conspicuous; stem one and one-half inches long, adhering well to the fruit; skin thin, tender; flesh pale yellowish-white, with colorless juice, tender, somewhat melting, aromatic, mild, sweet; good to very good in quality; stone free, ovate, plump, with smooth surfaces. 


\section{ROYAL DUKE}

\section{Prunus avium $\times$ Prunus cerasus}

1. Mag. Hort. 9:204, 205. 1843. 2. Downing Fr. Trees Am. 192. 1845. 3. Thomas Am. Fruit Cult. 369. 1849. 4. McIntosh Bk. Gard. 2:543. 1855. 5. Thompson Gard. Ass't 530. 1859. 6. Am. Pom. Soc. Cat. 12. 1871, 7. Mas Pom. Gen. 11:125, 126, fig. 63. 1882. 8. Hogg Fruit Man. 311. 1884 .

Royale d'Angleterre. 9. Christ Obstbäume I59. I79I.

Cerise Royale. 10. Christ Worterb. 284. 1802. 11. Cat. Cong. Pom. France to fig. 1906.

Königskirsche. 12 Truchsess-Heim Kirschensort. 422, 423, 424. 1819.

Ungarische Süssweichsel. 13. Dochnahl Führ. Obstkunde 3:51. 1858.

Anglaise Hative 14. Mortillet Le Cerisier 2:16I-163, fig. 42. 1866. 15. Mas Le Verger 8:83, 84, fig. 40. 1866-73. 16. Pom. France 7: No. 24, P1. 24. 1871. 17. Guide Prat. 17, 180. 1895.

Belle de Worsery. 18. Mortillet Le Cerisier 2:181. 1866. I9. Mas Poin. Gen. 11:39, 40, fig. 20. 1882.

Royal Duke has a place in the cherry flora to follow in season the well-known May Duke and to precede another standard sort, Late Duke. It is so nearly like these two sorts, except in season, and so similar to Arch Duke, as well, that there is much difficulty in getting the variety true to name. It is more often taken for May Duke than for the other kinds named but it differs from this well-known sort in being a little later in season, and the cherries are larger, a little lighter in color, do not hang as thickly, being scattered along the branches, often singly, and are more oblate. The trees are markedly upright and the foliage is very dense. None of the Dukes are popular in America for market fruits and this is no exception though, among all, Royal Duke is as good as any - pleasantly flavored, juicy, refreshing and very good. The trees, too, are very satisfactory. The variety has a place in home orchards and for local markets. The French say that the tree makes a very weak growth budded on the Mahaleb and that it should be worked on the Mazzard, which is generally true of all Dukes. The buyer will have difficulty in getting the true Royal Duke in America.

The origin of this variety is unknown but the Royale d'Angleterre, mentioned by Christ in $179 \mathrm{I}$, was probably the variety now known as Royal Duke, although the description is too meager to be certain. According to Thompson, Royal Duke was one of the varieties formerly cultivated in England under the names Late Duke, Arch Duke, or Late Arch Duke and was probably introduced by the London Horticultural Society from France under the name of Anglaise Tardive. When or by whom this variety was introduced into America is not known but according to Downing it was very rarely found here in the first half of the Nineteenth 


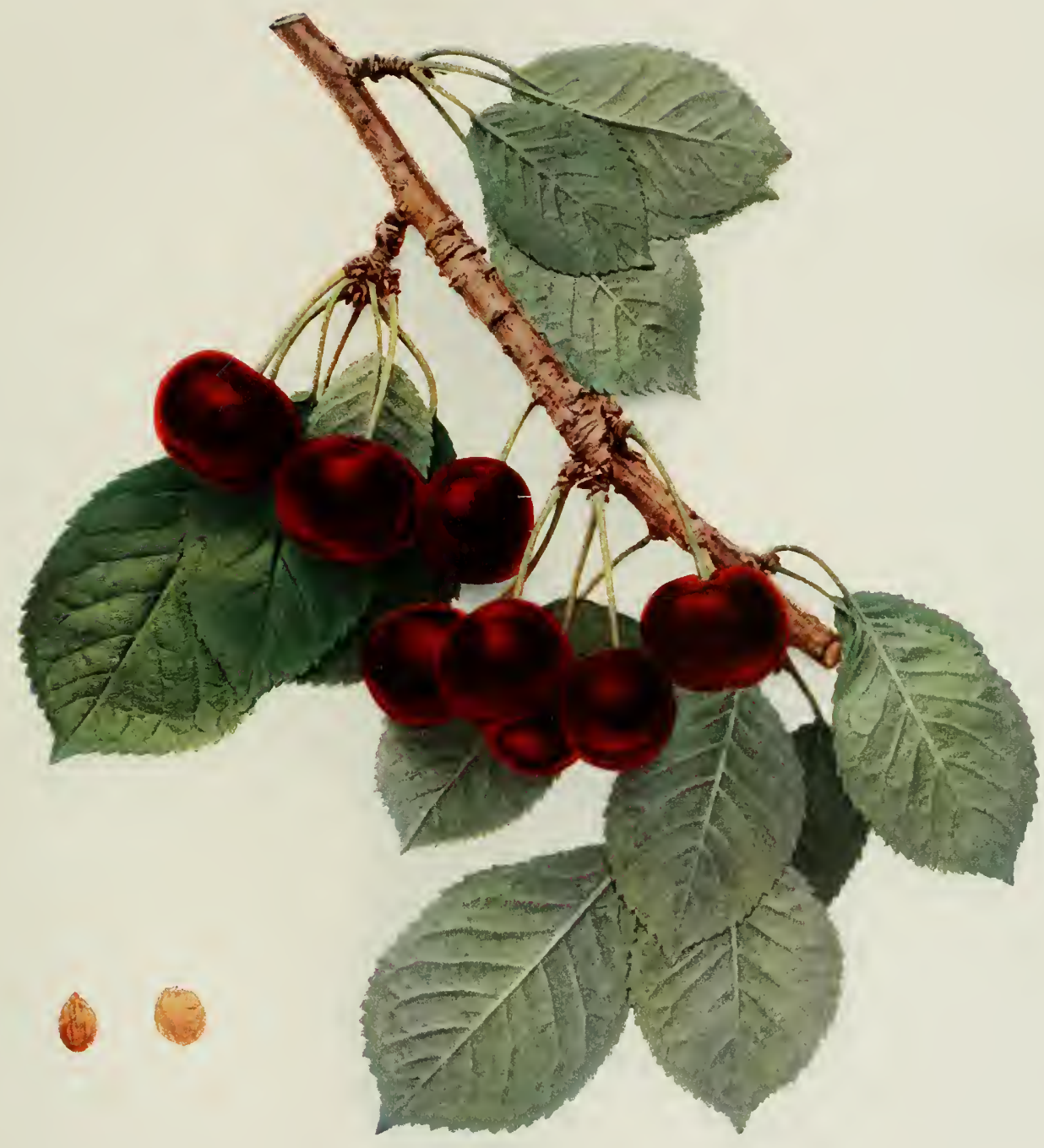



Century. The American Pomological Society placed Royal Duke upon its catalog list of recommended fruits in $187 \mathrm{I}$.

Tree of medium size, vigorous, upright, vasiform, unproductive at this Station; trunk slender, roughish; branches stocky, with roughened surface, dark reddish-brown covered with ash-gray, with lenticels of medium number and size; branchlets stout, long, brown partly overspread with ash-gray, smooth except for the lenticels which are inconspicuous.

Leaves numerous, variable in size, averaging four and one-half inches long, two inches wide, folded upward, oval to obovate; upper surface dark green, slightly rugose; lower surface medium green, pubescent along the midrib; apex abruptly pointed, base acute; margin serrate or crenate; petiole variable in length, often one and one-half inches long, not uniform in thickness, tinged with red, glandless or with one or two small, reniform. greenish-yellow or reddish glands, usually at the base of the blade.

Buds rather smail, pointed, plump, free, arranged singly as lateral buds and in very dense clusters on numerous short spurs; leaf-scars obscure; time of bloom mid-season; flowers white, one inch across; borne in very dense clusters, closely grouped in fours and fives; pedicels over one-half inch long, glabrous, green; calyx-tube green or with a tinge of red, obconic, glabrous; calyx-lobes with a trace of red, acute, serrate, glabrous within and without, reflexed; petals roundish, entire, sessile, apex entire: filaments nearly onefourth inch long; pistil glabrous, longer than the stamens.

Fruit matures early; three-fourths inch in diameter, oblate, compressed; cavity rather narrow, abrupt, regular; suture a mere line; apex flattened or depressed; color bright red becoming darker at maturity; dots few, small, obscure; stem one and one-half inches long, adhering to the fruit; skin thin, rather tough, separating from the pulp; flesh pale yellowish-white with tinge of red, pinkish juice, tender, sprightly, pleasantly acid; good to very good in quality; stone semi-free, small, ovate, slightly flattened, with smooth surfaces.

\section{SCHMIDT}

\section{Prunus avium}

1. Dochnahl Führ. Obstkunde 3:38, 1858, 2. Ill. Handb. 37 fig., 38. 1867. 3. Jour. Hort. N. S. 23:169 fig. 1872. 4. Flor. \& Pom. 12I, fig. 2. 1874. 5. Am. Pom. Soc. Cat. 17. 1897. 6. BuddHansen Am. Hort. Man. 2:290. 1903.

Smith. 7. Am. Pom. Soc. Cat. 26. 1909.

Schmidt, shortened in accordance with the rules of the American Pomological Society from Schmidt's Bigarreau, is not new nor can it be said to be little known, since it has been rather widely planted in America for a score of years. Yet in New York, at least, it is not receiving the attention that it deserves from commercial cherry-growers, being relegated to the rear of ten or a dozen kinds when it should be in the front rank. Indeed, about Geneva, where many Sweet Cherries are grown, while not the leading market variety, it is one of the best. The characters which entitle it to a high place as a money-maker are: large size, being unsurpassed 
in this respect by any other black cherry in this region; its round, plump form and glossy, black color which tempt the eye; crisp, firm, juicy flesh and sweet, rich flavor, delicious to the taste; dark ruby-red color under the skin which makes it as pleasing inwardly as outwardly; freedom from brown-rot, in this respect excelling any other market sort; and a vigorous, healthy, productive tree. The tree is further characterized by its abundant, large leaves of dark, luxuriant green. The fruit is often picked before it is ripe, at which time it is dark red and not black. There is a good deal of enthusiasm in New York over several new Sweet Cherries from the Pacific Coast but in this vicinity none of these is equal to Schmidt.

Schmidt is a seedling of Festfleischige Schwarze Knorpelkirsche and was raised by Herr Schmidt, Forester at Casekow, Prussia, Germany, about I84I. It was introduced into England by Thomas Rivers of Sawbridgeworth and eventually found its way to America but how and when is not known. Schmidt appeared on the fruit list of the American Pomological Society in 1897 but only for two years when for some reason it was dropped. In I909, a Smith was listed, with Smith's Bigarreau as a synonym. Budd-Hansen in the publication of 1903 also mentioned a Smith which is probably Schmidt. We are inclined to hold to the German spelling, Schmidt.

Tree large, vigorous, upright-spreading, open-topped, productive; trunk and branches stocky, smooth; branches dull reddish-brown covered with ash-gray, with numerous lenticels; branchlets thick, short, smooth, with rather conspicuous, raised lenticels.

Leaves numerous, six inches long, three inches wide, folded upward, obovate; upper surface light green, smooth; lower surface pale green, pubescent along the midrib and larger veins; apex acute, base abrupt; margin serrate, glandular; petiole one and onehalf inches long, thick, dull red, with a narrow, deep groove along the upper surface, glandless or with one or two large, reniform, reddish glands on the stalk.

Buds large, long, obtuse to conical, plump, free, arranged singly as lateral buds and in numerous small clusters; leaf-scars prominent; time of blooming mid-season; flowers white, one and one-half inches across; borne in scattering clusters in twos and threes; pedicels one inch long, thick, glabrous; calyx-tube green or with a tinge of red, campanulate, glabrous; calyx-lobes long, broad, acute, serrate, glabrous within and without, reflexed; petals oval, crenate, with short, narrow claws; filaments three-eighths inch long; pistil glabrous, shorter than the stamens.

Fruit matures in mid-season; one inch in diameter, cordate, compressed, often slightly oblique; cavity deep, wide, flaring; suture indistinct; apex bluntly pointed; color purplishblack; dots numerous, small, dark russet, obscure; stem slender, one and one-half inches long, strongly adherent to the fruit; skin tough, separating from the pulp; flesh purplishred, with dark colored juice, very meaty, crisp, firm, mild, sweet; of good quality; stone semi-clinging, ovate, slightly oblique, with smooth surfaces; ventral suture prominent. 


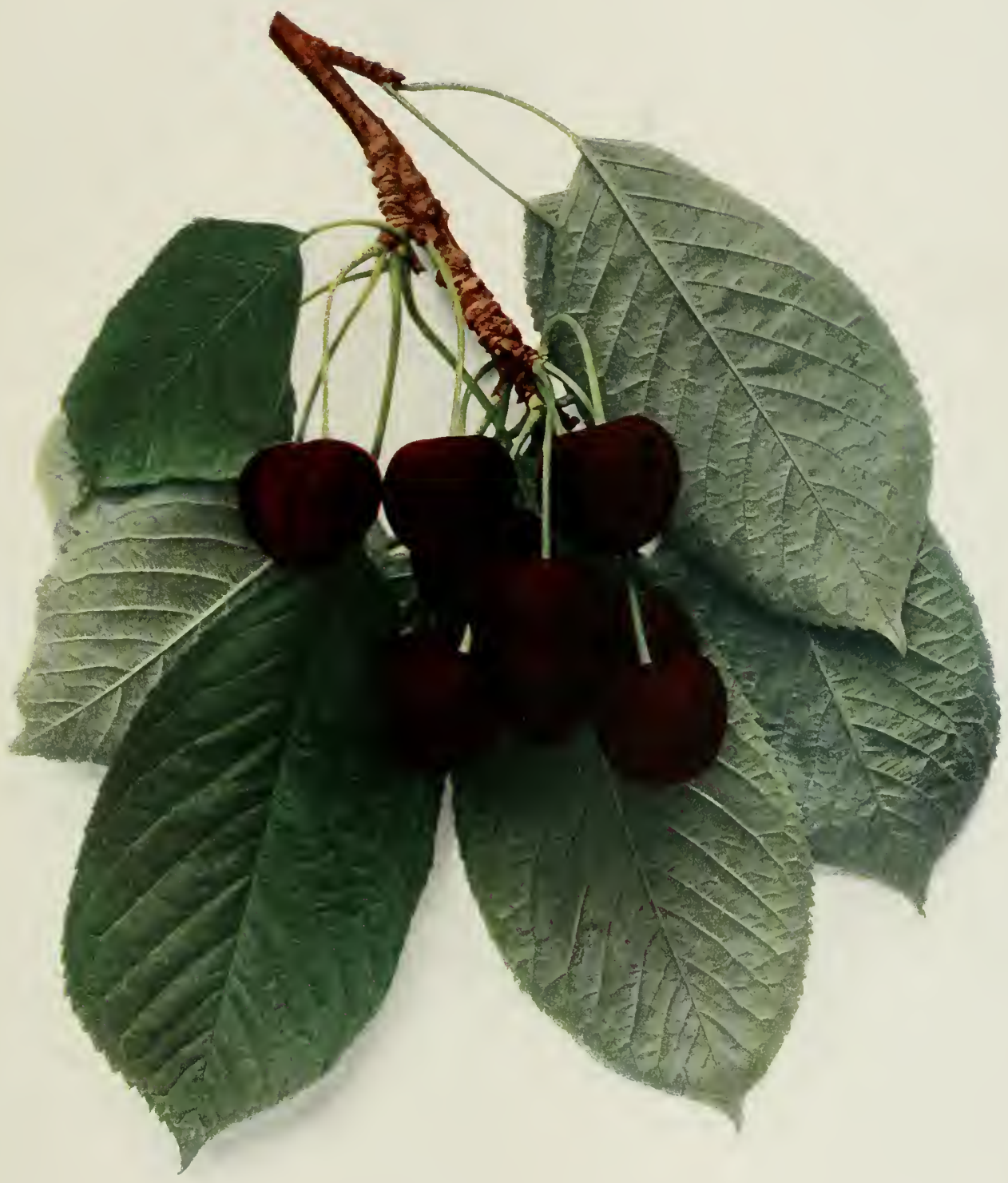





\title{
SHORT-STEM MONTMORENCY
}

Prumus cerasus

\begin{abstract}
1. Christ. Handb. 679. 1797. 2. Prince Pom. Man. 2:141, 142. 1832. 3. Leroy Dict. Pom. $5: 365,366$ fig., $367 . \quad 1877$.

Gobet à Courte Queue. 4. Duhamel Trait, Arb. Fr. I:180, 181, P1. VIII. 1768. 5. Kraft Pom. Aust. 1:7, Tab. 18 fig. 1. 1792.

Gros Gobet. 6. Truchsess-Heim Kirschensort. 634-638. 1819. 7. Dochnahl Führ. Obstkunde 3:71, 72. 1858. 8. Mortillet Le Cerisier 2:204, 308. 1866. 9. Mas Le Verger 8:51, 52, fig. 24. 1866-73. 10. Hogg Fruit Man. 299, 300. 1884. I1. Mathieu Nom. Pom. 358. 1889. I2. Guide Prat. 9, 190. 1895 .
\end{abstract}

Flemish. 13. Downing Fr. Trees Am. I95 fig. 85, I96. 1845 .

Cerise à Courte Queue. 14. Poiteau Pom. Franc. 2: No. 15, Pl. 1846.

Cerise Gros Fruit. 15. Pom. France 7: No. 11, Pl, I1, 1871.

In tracing the history of the Montmorency cherries from Duhamel's time to the present we have been led to conclude that three distinct types are now being cultivated. Of these closely related strains, all of which probably originated about the same time in Montmorency Valley, France, Montmorency is by far the most important and the one now grown commercially in all parts of the country. Large Montmorency, while quite similar to Montmorency, is much less grown because of its unproductiveness, although in quality it is quite equal or perhaps superior to Montmorency. Short-Stem Montmorency, under discussion here, varies considerably both in tree and fruit from either of the other two, although it is frequently taken for Large Montmorency. The tree is smaller and more drooping but usually very productive. The fruit, similar in size to Large Montmorency, differs from it by being more oblate and irregular, and in having a very deep, wide suture which becomes an indistinct line towards the apex. The skin seldom becomes as dark red even at perfect maturity. The flavor is more sprightly but its quality is not as high. All three varieties have long lists of synonyms, many of which have been used for each of the three sorts. Many writers believe that only two distinct strains of Montmorency exist and that Short-Stem Montmorency is identical with Large Montmorency. The variety is little grown in North America and is not as worthy for any purpose as either of the other two better-known sorts.

Tree upright-spreading, round-topped, productive; trunk shaggy; branches roughish, reddish-brown covered with ash-gray, with numerous lenticels; branchlets slender, long, brown partly overspread with ash-gray, smooth, with conspicuous, numerous, small, raised lenticels.

Leaves numerous, variable in size, averaging four inches long, one and three-fourths 
inches wide, long-oval to obovate, thick; upper surface dark green, smooth; lower surface medium green, with a prominent midrib; apex taper-pointed, base acute; margin doubly crenate, glandular; petiole one inch long, tinged with dull red, variable in thickness, lightly pubescent, glandless or with from one to three large, raised, reniform glands on the stalk.

Buds small, short, variable in shape, free, arranged as lateral buds and on few, if any, spurs; leaf-scars obscure; season of bloom late; flowers white, one inch across; borne in a few scattering clusters, variable in number of flowers per cluster; pedicels one-half inch long, thick, greenish; calyx-tube green or with a tinge of red, campanulate, glabrous; calyxlobes with a trace of red, obtuse, serrate, glabrous within and without, reflexed; petals roundish-oval, crenate, sessile, with a distinctly notched apex; filaments one-fourth inch long; pistil glabrous, equal to the stamens in length, often defective.

Fruit matures in mid-season; over three-fourths of an inch in diameter, decidedly oblate, irregular in outline, slightly compressed; cavity deep, wide, irregular, flaring; suture very deep near the stem but shallow at the apex which is flattened or depressed; color light to dark red; dots numerous, small, russet, inconspicuous; stem very thick, less than three-fourths of an inch long, adhering strongly to the fruit; skin rather tender, separating from the pulp; flesh pale yellow, with colorless juice, tender and melting, sprightly, sour; of fair quality; stone clinging along the ventral suture, small, roundish, plump, blunt, with smooth surfaces, faintly tinged with red; ventral suture very prominent.

\section{SKLANKA}

\section{Prunus cerasus}

1. Ia. Hort. Soc. Rpt. 330. 1885. 2. Mich. Hort. Soc. Rpt. 327. 1888. 3. U. S. D. A. Pom. Rpt. 40, 4r. I895. 4. Del. Sta. An. Rpt. 12:116 fig. 6, 117. 1900. 5. Ia. Sta. Bul. 73:83 fig. 21, 84. 1903.

Sklanka is evidently a cross between a cherry of the Amarelle group and one of the Morellos - another indication of the frequency of hybridization in this fruit. The cherries of Sklanka have the light-colored skin and juice of the Amarelles while the dwarfish, round-topped trees with pendant branches and abundant, small leaves are typical of the Morellos. The variety is in no way remarkable unless it be in hardiness, the pomolo. gists of the colder parts of the Mississippi Valley holding that it is one of the hardiest of cherries. The fruit is not on a par with that of a score of other Amarelles and the trees, in New York at least, are too small and unproductive to be worth planting. The cherry has value, then, only where hardiness is a prime requisite.

Sklanka was imported to this country from Russia in 1883 by Professor J. L. Budd of Ames, Iowa. Its parentage and origin are uncertain. It does not seem to have been grown in continental Europe outside of Russia but in certain sections of that country it is reported as being one of the hardiest and most productive of the Sour Cherries. As grown in 


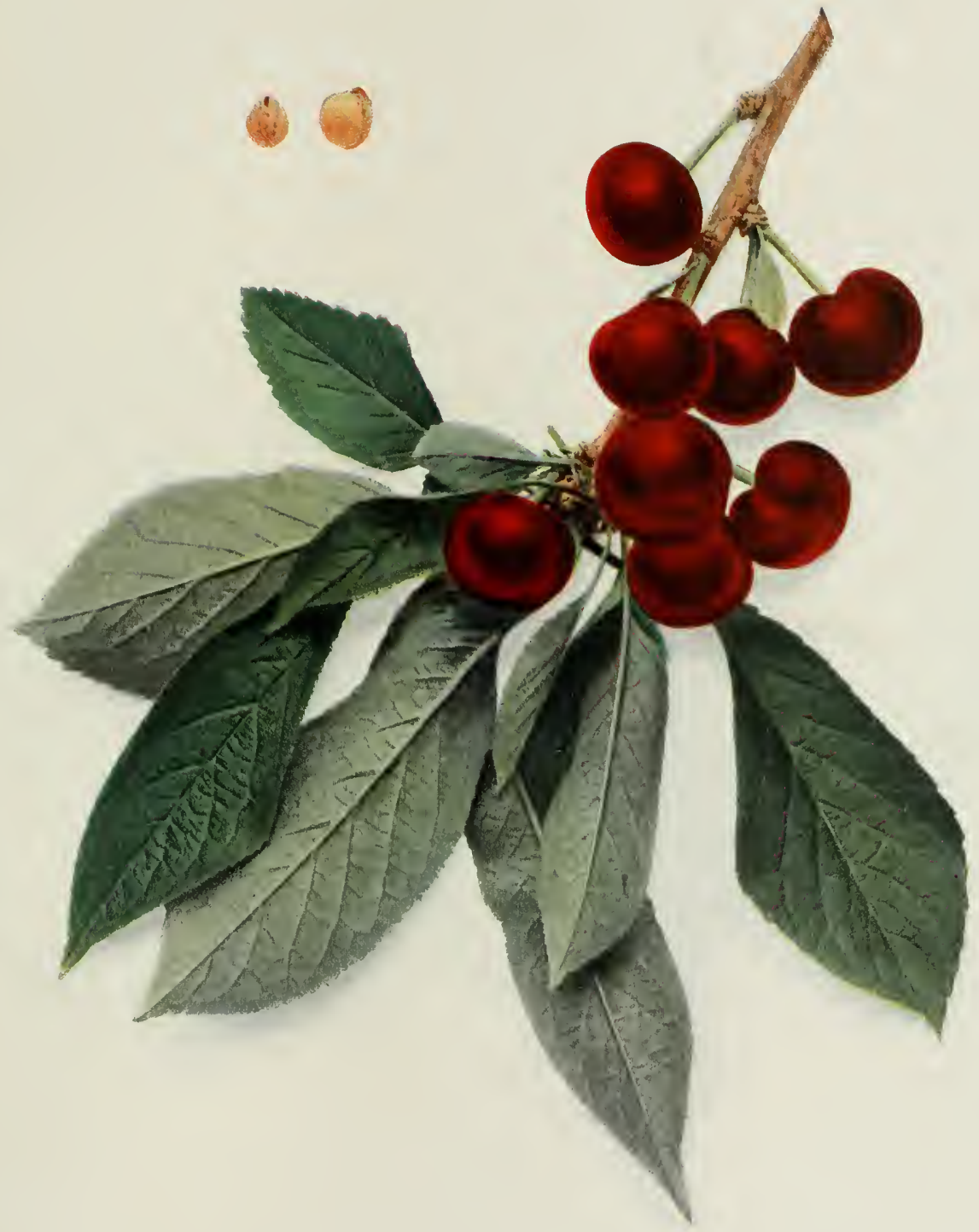





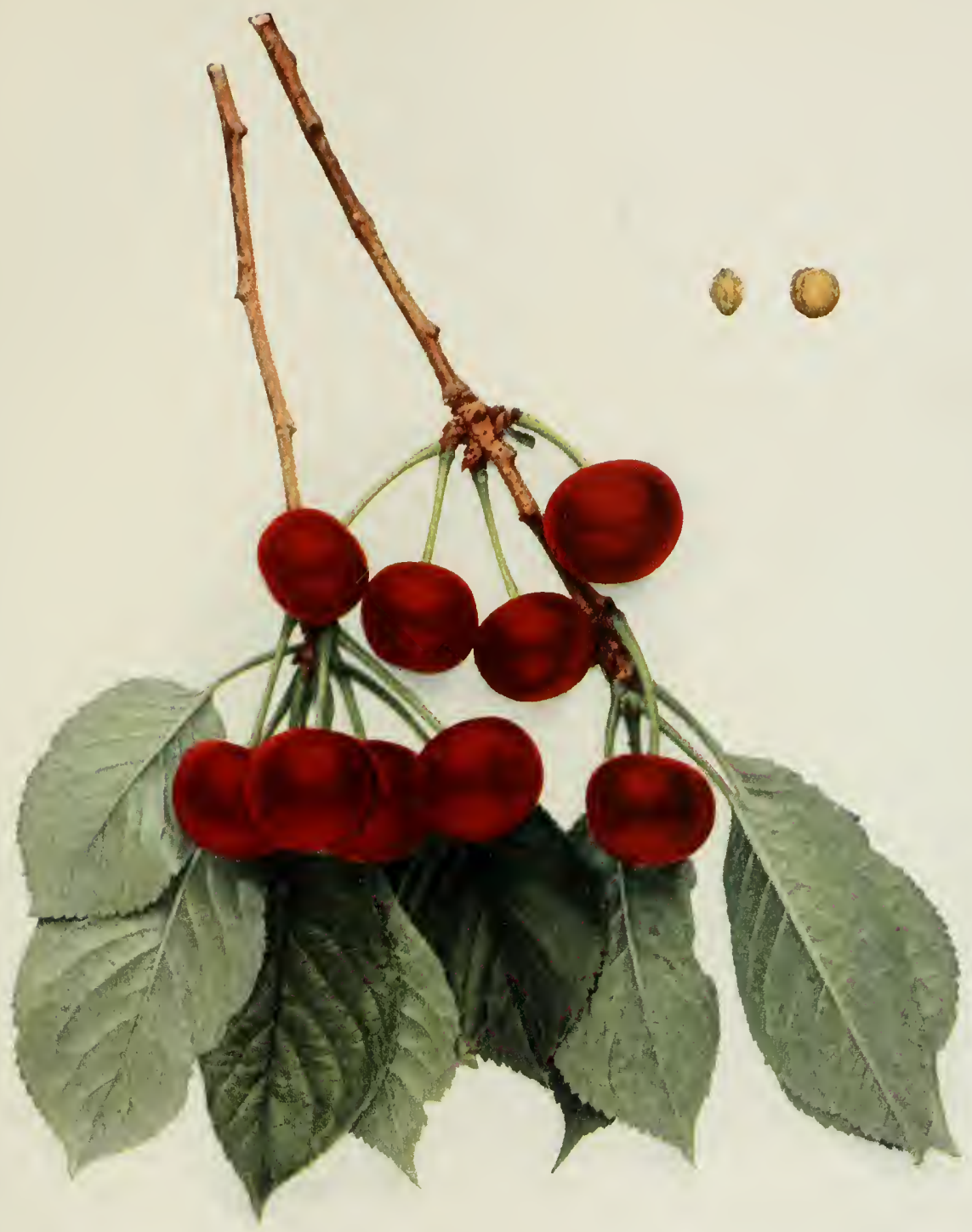



our Northern Central States it has proved one of the hardiest of all varieties but has not, as yet, gained much reputation commercially even in these coid regions. It is mentioned but seldom in the literature and is listed by but few nurserymen.

Tree of medium size, vigorous, spreading, with drooping branchlets, open-topped, unproductive; trunk thick and smooth; branches rather slender, long, slightly roughened, reddish-brown partly overspread with ash-gray, with numerous rather small lenticels; branchlets slender and willowy, with short internodes, brown nearly covered with ashgray, smooth except for the lenticels, which are small, numerous, raised, conspicuous.

Leaves of medium number, three and one-fourth inches long, one and three-fourths inches wide, folded upward, obovate to elliptical, thick, stiff; upper surface very dark green, glossy, smooth; lower surface medium green, finely pubescent along the midrib and larger veins; apex and base acute; margin finely and doubly serrate, with small, dark glands; petiole three-fourths of an inch long, thick, tinged with dull red, grooved, with a few hairs along the upper surface, with from one to four small, globose, orange-colored glands usually at the base of the blade.

Buds small, short, variable in shape, plump, free, arranged singly as lateral buds and in few, very small clusters; time of blooming mid-season; flowers one and three-sixteenths inches across, white; borne in dense clusters usually at the ends of branches or spurs, well distributed, usually in threes; pedicels over one-half inch long, glabrous, greenish; calyxtube green, obconic, glabrous; calyx-lobes broad, obtuse, serrate, glabrous within and without, reflexed; petals roundish, entire, nearly sessile, with almost entire apex; filaments one-fourth inch long; pistil glabrous, equal to the stamens in length.

Fruit matures early; about three-fourths of an inch in diameter, oblate, not compressed; cavity of medium depth, narrow, abrupt; suture lacking; apex flattened or strongly depressed; color bright currant-red; dots numerous, light colored, slightly conspicuous; stem thick, less than one inch long, adherent to the fruit; skin rather tough, separating from the pulp; flesh pale yellow, with colorless juice, tender and melting, sour; of good quality; stone semi-free, clinging only along the ventral suture, about one-third inch in diameter, roundish, slightly flattened, blunt, with smooth surfaces.

\section{SPARHAWK}

Prunus avium

I. Kenrick $A m$. Orch. 219, 220. 1835 .

Sparhark's Honey. 2. Downing Fr. Trees Am. 177. 1845. 3. Am. Pom. Soc. Cat. 74. 1862. 4. Mas Le Verger 8: 143,144 , fig. 70, 1866-73.

Honey Heart. 5. Cole A m. Fr. Book 234 fig. 37, 235. 1849.

Sparhawk has little to recommend it for either a home or commercial orchard; but the rich and honeyed sweetness of the cherries, scarcely surpassed in flavor, might make it worth planting by plant-breeders and connoisseurs of choicely good fruits. The name "honey" which appears in several of the synonyms is indicative of the flavor of the fruit. The 
cherries are quite too small and the pits altogether too large for a commercial product. The tree is upright-spreading, with numerous thick branches over which the cherries are rather thickly scattered in ones, twos and threes and never in clusters. The fruit-stems are characteristically long and slender. Though of the Bigarreau group the flesh is too tender to well withstand harvesting, shipping and the brown-rot.

This cherry was introduced by Edward Sparhawk, for whom it was named, of Brighton, Massachusetts. The variety has been known under a number of different names, the number being no measure of its merit, however, for it has never been extensively cultivated. The American Pomological Society placed it in its fruit catalog list of recommended varieties in 1862 but dropped it in $187 \mathrm{I}$ and for many years but little attention has been given it. It is now for sale in but few of the nurseries of the country.

Tree large, vigorous, upright, rather open-topped, hardy, unproductive; trunk stocky, slightly shaggy; branches thick; branchlets medium in thickness and length; leaves numerous, five inches long, two and one-fourth inches wide, long-oval to obovate, thin, medium green; margin coarsely and doubly serrate, glandular; petiole two inches long, thick, overlaid with red, with one or two large, reniform, reddish glands on the stalk; buds intermediate in size and length; season of bloom intermediate, average length five days; flowers one and one-fourth inches across; pistil shorter than the stamens.

Fruit matures in mid-season, average length about nineteen days; nearly seven-eighths inch in diameter. somewhat conical, compressed; color dark red over a yellowish background, finely mottled; stem of medium thickness, one and three-eighths inches long, adherent to the fruit; skin thin, tough, separates from the pulp; flesh pale yellowish-white, with colorless juice, tender, crisp, highly flavored, mild, aromatic, sweet; very good in quality; stone nearly free, large for the size of the fruit, ovate, flattened, slightly oblique, with smooth surfaces.

\section{SPÄTE AMARELLE}

\section{Prunus cerasus}

1. Christ Handb. 679. 1797. 2. Christ Iïörterb. 294. 1802. 3. Truchsess-Heim Kirschensort. 629632. 1819. 4. Dochnahl Führ. Obstkunde 3:67, 68. 1858. 5. Ill. Handb. 54I fig., 542. 1861. 6. Mas Le Verger 8:149, I50, fig. 73. 1866-73. 7. Lauche Detut. Pom. III: No. 24, Pl. 1882. 8. Am. Gard. 9:264. 1888. 9. Ia. Sta. Bul. 2:36. 1888. 10. Del. Sta. An. Rpt. 12:126, 127. 1900.

Späte Morello. II. Ia. Hort. Soc. Rpt. 78. I890. I2. Budd-Hansen Am. Hort. Man. 2:282, 283. 1903.

This is another variety with Amarelle fruit and a Morello-like tree and is unquestionably a hybrid between varieties of the two groups. Several references from the Middle West mention Späte Amarelle as very promising but in New York, where such sorts as Early Richmond and the Montmorencies thrive, it is unpromising for any purpose. The cherries 
are quite too poor in quality, being very sour, and the trees too unproductive to make the variety even a poor rival of a score or more of Amarelles and Dukes with which it would have to compete in this State.

The origin of this cherry is unknown but according to Truchsess it was sent out from Hanover as Späte Morelle in 1785. In 1797, Christ mentions a cherry under this name the description of which agrees with that of Späte Amarelle. Lauche states that Truchsess received the variety from Hanover under the name Späte Morelle and later changed the name to Späte Amarelle. This cherry was grown in the Paris National Nursery under the name Cerise Amarelle Tardive and at one time was commonly grown in gardens in France. In the spring of 1883 , Professor J. L. Budd of Iowa brought to America a large number of cherries from central and eastern Europe. Somehow there was confusion in the description of these imported cherries and two kinds were described under the name Späte Amarelle, one a light-fleshed sort, the other with red flesh and colored juice. The true variety has light flesh and juice and a pleasant, acid flavor and is probably identical with the old French sort, Cerise Amarelle Tardive. The cherry sometimes called Späte Morello can be no other than the Späte Amarelle.

Tree of medium size, vigorous, upright-spreading, round-topped, rather unproductive; trunk stocky, somewhat shaggy; branches smooth, dark brown overspread by ash-gray, with numerous lenticels variable in size; branchlets slender, rather short, brown nearly covered with ash-gray, smooth, with slightly raised, inconspicuous lenticels.

Leaves numerous, small, folded upward, oval to somewhat obovate, rather stiff; upper surface dark green, smooth; lower surface medium green, pubescent only on the midrib and larger veins; apex acute, base variable in shape; margin finely serrate, glandular; petiole greenish or with a slight bronze tinge, glandless or with from one to four small, globose, brown or yellowish glands usually at the base of the blade.

Buds small, pointed, plump, free, arranged singly as lateral buds and in clusters on long or short spurs; leaf-scars prominent; season of bloom late; flowers one inch across, white; borne in scattered clusters, usually in threes; pedicels three-fourths of an inch long, slender, glabrous, greenish; calyx-tube green with a tinge of red, obconic, glabrous; calyxlobes with a trace of red, rather narrow, acute, serrate, glabrous within and without, reflexed; petals broad-oval, entire, slightly crenate at the apex; filaments one-fourth inch long; pistil glabrous, equal to or longer than the stamens.

Fruit matures in mid-season; one-half inch long, oblate, slightly compressed; cavity shallow, narrow; suture indistinct; apex roundish or depressed; color dark red; dots numerous, very small, obscure; stem slender, one and one-half inches long; skin thin, tender; flesh light red, with light colored juice, tender, tart; of good quality; stone free, roundish, flattened, with smooth surfaces; distinctly ridged along the ventral suture. 


\section{SUDA}

\section{Prunus cerasus}

1. Am. Pom. Soc. Cat. 27. 1909.

Suda Hardy. 2. Ohio Hort. Soc. Rpt. 21. 1892-93. 3. Am. Pom. Soc. Cat. 25. 1899. 4. Stark Brothers Cat. 1899. 5. Ia. Sta. Bul. 73:84 fig., 85. i903. 6. Am. Pom. Soc. Sp. Rpt. 36. 1904-05.

Suda has been widely advertised as an improved English Morello but, while there seem to be some slight differences between the two, the new variety is not an improvement on the old so far as can be discovered at this Station. The trees of Suda in general aspect are more upright and the stems of the cherries longer and more slender than those of English Morello, being but an inch in length in the one variety and an inch and threefourths in the other. The trees on the grounds of this Station are not as productive as those of English Morello. The cherries, if anything, are not as high in quality as those of the older and probably the parent variety. It is doubtful if there is a place for Suda in the cherry industry of New York.

This cherry originated in the garden of a Captain Suda, Louisiana, Missouri, about I880. The American Pomological Society listed Suda in its fruit catalog of 1899 as Suda Hardy but in 1909 shortened the name to Suda, a change which has generally been accepted.

Tree vigorous, rather unproductive; branches slender, with numerous small lenticels; branchlets slender, long; leaves numerous, four inches long, two and one-fourth inches wide, obovate to oval, dull, dark green; margin doubly serrate, with dark glands; petiole one inch long, of medium thickness, tinged with dull red, glandless or with one or two reniform, yellowish-brown glands usually at the base of the blade; buds small, short, obtuse, arranged singly as lateral buds and on but very few, if any, spurs; season of bloom late; flowers white, one inch across; filaments one-fourth inch long; pistil shorter than the stamens.

Fruit matures very late; three-fourths inch in diameter, roundish-cordate, slightly compressed; cavity flaring; suture indistinct; color dark purplish-red; stem slender, one and three-fourths inches long, adherent to the fruit; skin separating from the pulp; flesh dark red, with dark colored juice, tender, somewhat meaty, sprightly, astringent, very sour; poor in quality; stone free or nearly so, ovate, slightly pointed, with smooth surfaces.

\section{TIMME}

\section{Prunus cerasus}

I. Ia. Sta. Bul. 73:85, 86. 1903. 2. Am. Pom. Soc. Cat. 27. 1909.

Timme can hardly be distinguished from Early Richmond, differing only in smaller fruits, and probably is a seed variation of that variety. On the grounds of this Station the trees of Timme are even more productive 


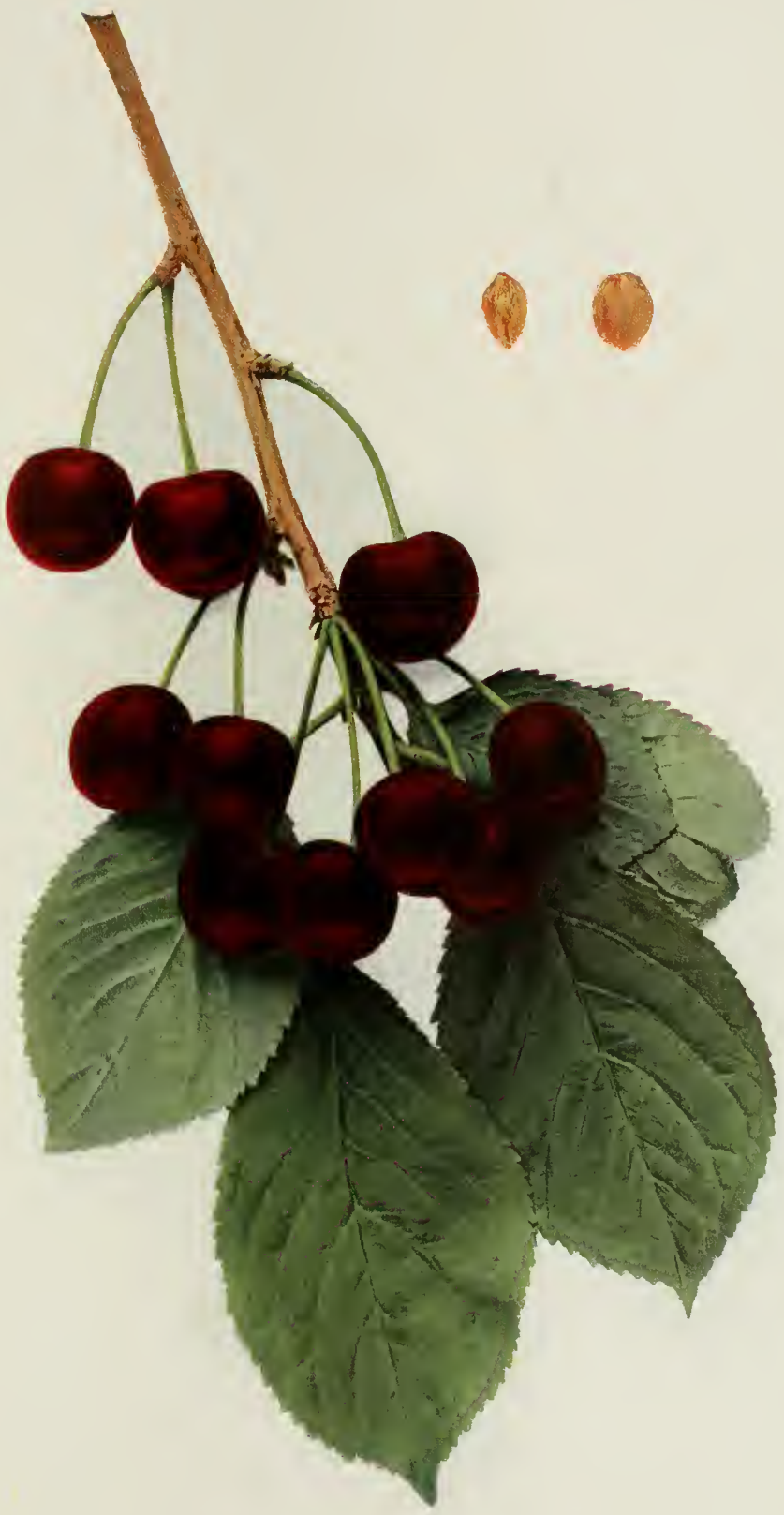

SUDA 



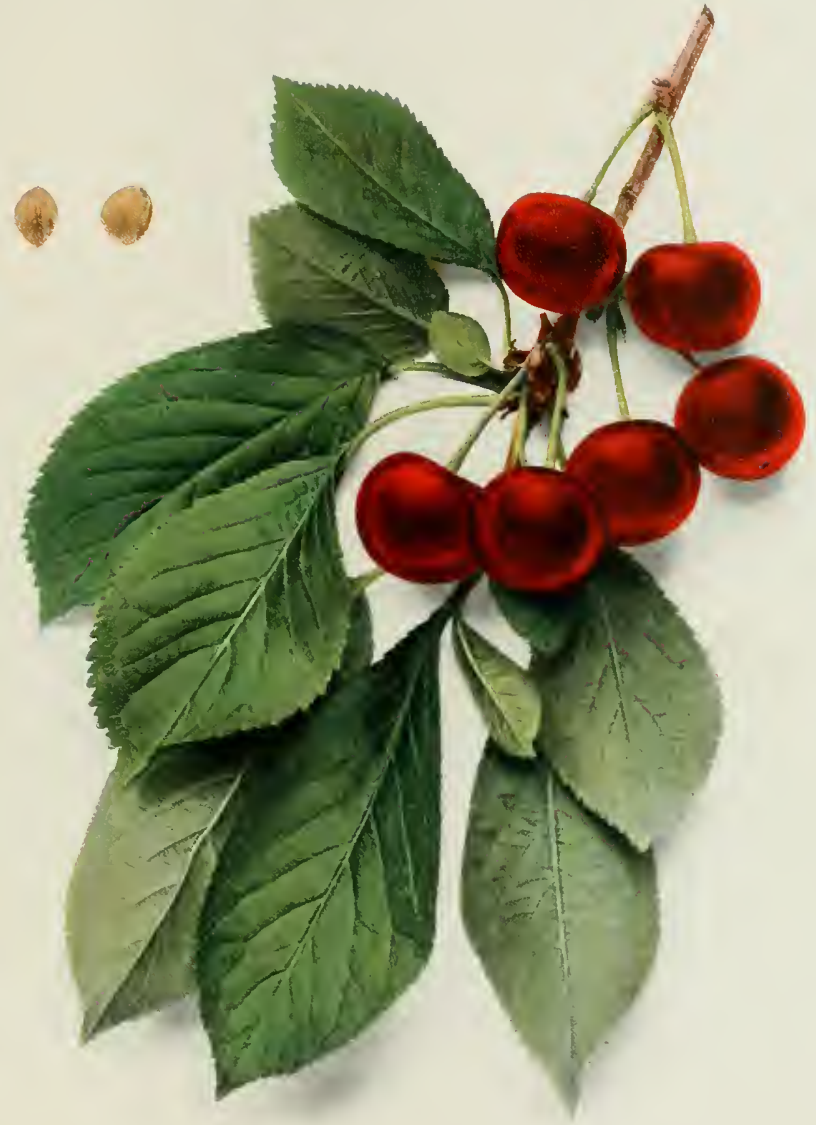



than those of Early Richmond, one of the most fruitful of all cherries, but the greater fruitfulness of the tree hardly offsets the smaller size of the cherries. It is doubtful if this new strain can displace the older Early Richmond, which is well established in the favor of cherry-growers everywhere.

This variety is supposed to have been brought to America from Germany by a Mr. Timme of Omaha, Nebraska. It is of some local importance in Iowa and Nebraska but as yet has not been widely distributed in America. Possibly it will be found in time that it is some old German variety renamed. It was placed on the fruit list of the American Pomological Society in 1909 .

Tree medium in size, rather vigorous, upright-spreading, open-topped, healthy; trunk and branches thick, with numerous large lenticels; branchlets slender, long, willowy; leaves three and one-half inches long, one and five-eighths inches wide, ovate to obovate, thick, stiff, leathery, dark green; margin finely serrate, tipped with reddish-brown glands; petiole three-fourths of an inch in length, with one or two large, globose glands variable in position; flowers one inch across, in dense clusters.

Fruit matures medium early; over one-half inch in diamter, roundish-oblate; color light red becoming dark red at full maturity; stem one inch long; flesh yellowish-white, with abundant pinkish juice, tender and melting, pleasant flavored, sprightly; good in quality; stone semi-clinging, roundish-ovate, plump; prominently ridged along the ventral suture.

\section{TOUSSAINT}

\section{Prumus cerasus}

1. Duhamel Trait. Arb. Fr. r: 178-180, Pl. VII. 1768. 2. Kraft Pom. Aust. 1:7, Tab. I8 fig. 2 1792. 3. Poiteau Pom. Franc. 2: No. 21, Pl. 1846. 4. Ann. Pom. Belge 1:103, 104, P1. 1853. 5. Mortillet Le Cerisier 2:205, 308. I866. 6. Leroy Dict. Pom. 5:305, 306 fig., 307, 308. I877. 7. Rev. Hort. 250. 1906.

Siäts Blühender Kirschbaum. 8. Krünitz Enc. 42, 43. 1790.

All Soints. 9. Truchsess-Heim Kirschensort. 661-668. 1819. 10. Prince Pom. Man. 2:152, I53. 1832. I1. Dochnahl Führ. Obstkunde 3:72. 1858. 12. Hogg Fruit Man. 277. 1884. 13. Mathieu Nom. Pom. 332. I889.

Toussaint is a marked deviation from its species. Instead of bearing blossoms normally this variety sends out small branches from the buds. In the axis of the first four leaves are borne the buds destined to produce similar branches the following spring. As the branches elongate these buds remain dormant but others are borne which produce flowers in umbellike clusters of two or three. The trees begin blooming three or four weeks later than other cherries and new buds and flowers appear continually until August or thereabouts. The tree, too, is most striking in appearance, 
being dwarfish in stature, thickly set with pendant branchlets and, all in all, attractive enough to make it a rather handsome ornamental. The cherries are of little or no value, being quite too acid to eat out of hand but furnishing very late fruit which may be used for culinary purposes. The description given is compiled.

The history of the variety is uncertain. Leroy says that it was mentioned by Daléchamp, a French writer, as early as 1586 . Duhamel seems to have been the first pomologist to describe it which he did in 1768 under the name Cerisier de la Toussaint. The variety is well known in Europe, being widely distributed in Austria, Germany, Belgium, France and England, pomologists and nurserymen in all these countries seeming to be well acquainted with it. There are no records of its culture in America, although Prince and Elliott describe it from European fruit books.

Tree small, hardy, moderately productive; branches slender, numerous, pendant.

Fruit small, flattened on the ends and sides; stem long; color clear red, darker on maturing, rather transparent; flesh white somewhat red at the center, with reddish juice; flavor, if mature, sour, though not excellent; stone large, long, clings to the flesh more than to the stem. The fruit borne in October never reaches maturity.

\section{VLADIMIR}

\section{Prunus cerasus}

I. Ia. Hort. Soc. Rpt. 84, 85. 1882. 2. Am. Pom. Soc. Rpt. 75. 1883. 3. Ia. Hort. Soc. Rpt. 327, 328. 1885. 4. Ia. Sta. Bul. 19:550. 1892. 5. Ia. Hort. Soc. Rpt. 454. I895. 6. Del. Sta. An. Rpt. 12:128, 129. 1900. 7. Ia. Sta. Bul. 73:87. 1903. 8. Am. Pom. Soc. Cat. 27. 1909.

Vladimir is a Morello-like cherry not more promising in New York, at least in the orchard of this Station, than any other of the many competitors of English Morello. The cherries are large, very similar in size and appearance to those of English Morello; the pit is small, the skin very thin and separating readily from the pulp. The variety is further characterized by the very dark red flesh and dark colored juice which is too astringent and sour to eat out of hand but does very well for culinary purposes. The tree is much like that of English Morello but is far more dwarfish and not as productive, these being fatal faults for commercial planting in New York. It falls short of English Morello in another respect - the fruit ripens very unevenly. Vladimir has the reputation of being one of the hardiest of all cherries. It is said to come true from seed and does better on its own roots than on either Mazzard or Mahaleb. The Russians, according to Budd, succeed best with it when it is propagated from sprouts and allowed to form a bushy plant with several stems, the 


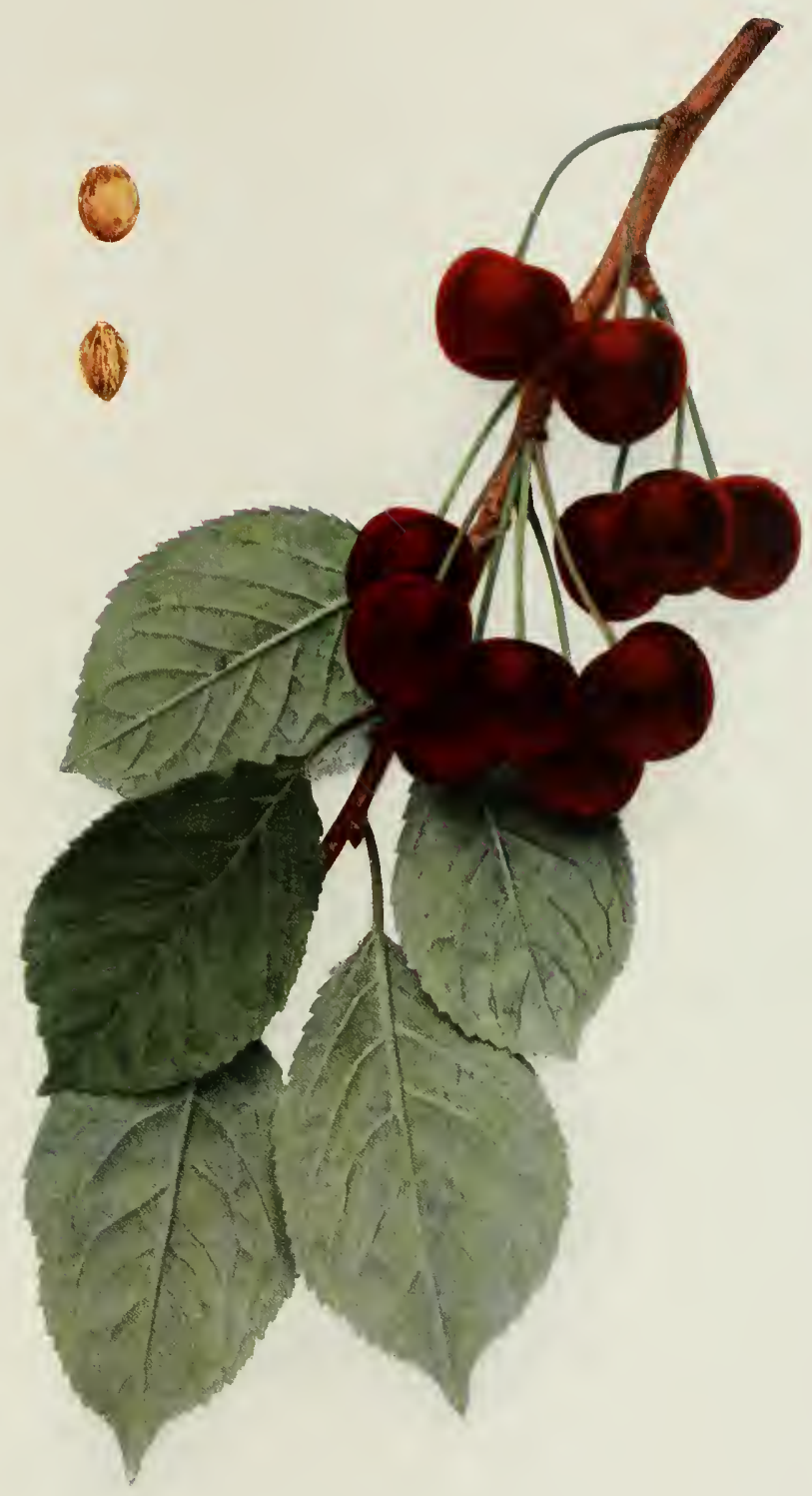

VLADIMIR 


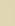


oldest of which are cut from time to time. There seems to be little in the variety to commend it for either home or commercial plantings in New York.

Vladimir is a generic name for a group of varieties grown in Russia, principally in the province of Vladimir east of Moscow. Most of these cherries are large, black fruits with highly colored juice and good quality, much valued for market use in their native country. Professor J. L. Budd imported a number of these Vladimir cherries from Orel in Central Russia and grew them at the Experiment Station grounds in Iowa, giving to each a seedling number as a distinguishing characteristic. One, Orel No. 25, was selected as being superior in many respects to the others and was finally named Vladimir. This variety, typical of these Russian cherries, has been considerably propagated and is generally distributed throughout this country. The American Pomological Society added Vladimir to its list of recommended fruits in 1909 .

Tree dwarfish, round-topped, very hardy, productive; trunk medium or below in size; branches willowy, drooping, reddish-brown slightly overspread with ash-gray; branchlets slender, long, smooth, with a few small, raised lenticels.

Leaves numerous, three inches long, one and three-fourths inches wide, folded upward, oval, thick; upper surface dull, dark green, smooth; lower surface light green, with a few scattering hairs; apex acute, base slightly abrupt; margin finely serrate, with dark colored glands; petiole one-half inch long, tinged with red, with a few scattering hairs along the stalk, glandless or with from one to four small, reniform, greenish-yellow glands at the base of the blade.

Buds small, short, very obtuse, plump, free, arranged singly as lateral buds and in small clusters on small spurs; leaf-scars obscure; season of bloom intermediate; flowers white, one and one-fourth inches across; borne in scattering clusters in twos, threes and fours; pedicels three-fourths of an inch long, rather slender, glabrous, greenish; calyx-tube with a tinge of red, somewhat obconic, glabrous; calyx-lobes reddish, broad, obtuse, serrate, glabrous within and without, reflexed; petals roundish or slightly obovate, irregularly crenate, with short, blunt claws, apex entire; filaments over one-fourth inch long; pistil glabrous, shorter than the stamens.

Fruit matures very late; three-eighths of an inch long, seven-eighths of an inch wide, roundish-cordate, slightly compressed; cavity rather shallow; suture a line; apex roundish; color dark red almost black at full maturity; dots numerous, small, russet, inconspicuous; stem slender, one and one-half inches or more in length, adherent to the fruit; skin thin, separating from the pulp; flesh dark red, with very dark colored juice, slightly stringy, melting, sprightly, astringent, sour; of fair quality; stone semi-clinging, rather large, longovate to oval, with smooth surfaces, tinged with red. 


\section{WATERLOO}

Prunus avium $\times$ (Prunus avium $\times$ Prunus cerasus)

I. Prince Treat. Hort. 29. 1828. 2. Lond. Hort. Soc. Cat. 56. 1831. 3. Prince Pom. Man. $2: 118$. 1832. 4. Downing Fr. Trees Am. 178. 1845. 5. Floy-Lindley Guide Orch. Gard. IOI, 102. 1846. 6. Elliott Fr. Book 213, 214. 1854. 7. Hogg Fruit Man. 314. I884.

This old sort, seemingly well thought of in Europe, has not been popular in America and has only historical value to cherry-growers of this country. It is an interesting cherry resembling the Bigarreaus in tree and leaf-characters while the flowers are more like those of the Dukes, the fruit, too, taking on more the aspect of the Dukes than of the Sweet Cherry. The variety has long since passed from general cultivation in the United States and can now be found only in collections or as an occasional dooryard tree.

This cherry was raised early in the Nineteenth Century by T. A. Knight, Downton Castle, Wiltshire, England, and first fruited in I815, shortly after the Battle of Waterloo, hence its name. It was supposed to be a cross between Yellow Spanish and May Duke. The variety was brought to this country by Honorable John Lowell of Newton, Massachusetts, though it was described by Prince in 1828 from European fruit books. The following description is compiled:

Tree vigorous, thrifty, rather irregular and spreading, productive; branchlets thick, stocky, grayish; leaves large, drooping, wavy; margin slightly serrate; flowers large; stamens shorter than the pistil.

Fruit matures the last of June or early in July; large, obtuse-cordate, broad at the base, convex on one side, flattened on the other; stem one and one-half to two inches in length, slender; color dark purplish-red becoming nearly black at maturity; skin thin; flesh purplish-red becoming darker next to the stone, firm but tender, juicy, fine flavored, sweet; good in quality; stone separating readily from the pulp, small, roundish-ovate, compressed.

\section{WHITE BIGARREAU}

\section{Prunus avium}

I. Thacher Am. Orch. 217 . 1822. 2. Prince Pom. Man. 2:125. 1832. 3. Mag. Hort.8:283. 1842. 4. Downing Fr. Trees Am. I80 fig., 181. 1845. 5. Thomas Am. Fruit Cull. 366. 1849. 6. McIntosh Bk. Gard. 2:54r. 1855 .

Tradescant. 7. Coxe Cult. Fr. Trees 250. 1817.

White Oxheart. 8. Kenrick Am. Orch. 278. 1832.

White Bigarreau is a cherry of the past, having been considered one of the good sorts of a century ago. Rivers, the English pomologist, believed it to have come originally from Russia. It is reputed to have been 
brought to America from France by Chancellor Livingston of Revolutionary fame. Thacher, in 1822 , described the variety first under its present name. The variety, as the synonymy shows, has been grown under many names both in America and Europe. In 1845, according to Downing, this cherry was common in the neighborhood of New York and Philadelphia but since Downing's time no one seems to have mentioned it. The variety is usually spoken of in the United States as neither hardy nor productive. The fruit books describe it as follows:

Tree medium in size, spreading, very tender, unproductive; leaves narrow, waved.

Fruit matures the last of June or early in July; large to very large, heart-shaped, somewhat pointed; color yellowish-white with a bright red cheek, mottled; flesh very firm, breaking, pleasantly flavored, sweet; very good in quality; stone separating readily from the flesh.

\section{WHITE HEART}

\section{Prunus avium}

I. Bradley Gard. 2II. 1739. 2. Downing Fr. Trees Am. 173, I74 fig. 1845. 3. Elliott Fr. Book 216. 1854. 4. Horticulturist 15:327, Pl. fig. 1. 1860. 5. Hogg Fruit Man. 315. 1884.

Amber Heart. 6. Miller Gard. Kal. 154. 1734. 7. Jour. Roy Hort. Soc. $21: 355.1898$.

Frühe Bernsteinkirsche. 8. Truchsess-Heim Kirschensort. 304, 305. 1819. 9. Dochnahl Führ. Obstkunde 3:39. 1858. 10. Mas Pom. Gen. 11:45, 46, fig. 23. 1882. 11. Mathieu Nom. Pom. 348. 1889.

Kentish Bigarreau. I2. Bunyard-Thomas Fr. Gard. 43. 1904.

White Heart is mentioned in The Cherries of New York only because of its reputation in Europe and the frequent references, therefore, that American cherry-growers see to it in European publications. Bunyard and Thomas, in the reference given, speak of it as one of the best and most profitable cherries grown in the famous Kent cherry orchards. Early American horticulturists describe it but it seems not to have been widely grown in America and has probably long since passed from cultivation. It failed, according to Elliott, because it was a "variable and uncertain bearer" and while an early cherry " not early enough to compete with many new varieties."

White Heart seems to have been mentioned first by Miller in 1734 . A little later it is found to be described in both Germany and France, indicating that it must have been known and widely distributed before the time given. It seems to have been brought to America before the War of the Revolution and to have been grown in this country under the several different names which are given in the list of synonyms. The following description is compiled: 
Tree large, vigorous, somewhat erect, very healthy, rather productive; branches stocky, somewhat angular, with large, roundish, light colored lenticels; internodes of unequal length; leaves medium in size, oval or obovate, sharply pointed; margin finely serrate; petiole short, slender, tipped with two reniform, orange-red glands; flowers medium in size; petals obovate.

Fruit matures early in June; rather small, roundish-cordate, often one-sided, with a distinct suture; color whitish-yellow, tinged and speckled with pale red in the sun; stem long, slender, inserted in a wide, shallow cavity; skin firm; flesh light colored, firm, halftender, breaking, juicy, sugary, pleasant; first quality; stone rather large, roundish-oval, with a pointed apex.

\section{WINDSOR}

\section{Prunus avium}

I. Gard. Mon. 24:208. 1882. 2. Cult. \& Count. Gent. 49:636. 1884. 3. Am. Pom. Soc. Cat. 22. 1885. 4. Del. Sta. Bul. $35: 16$ fig. 7. 1897. 5. Ont. Fr. Exp. Sta. Rpt. 5:4I fig. 1898. 6. Am. Gard. 21:76. 1900. 7. Can. Hort. 25:3, 262 fig., 263. 1902. 8. Am. Pom. Soc. Rpt. 56, 57. 1907.

Windsor is the standard late Bigarreau and one of the most profitable of the hard-fleshed cherries grown in New York. Both fruit and trees deserve the approbation of cherry-growers. In color the cherries meet the market demand, buyers preferring a dark-colored Sweet Cherry. None would find fault with the appearance of Windsor. The flesh is firm and the product stands harvesting and shipping well and at a season of the year when brown-rot is usually rife this variety is fairly free from this scourge of the Sweet Cherry. The quality is from good to very good, equaled but not surpassed by others of its class. But it is in its tree-characters that the superiority of Windsor is best shown. The trees have the reputation of being the hardiest of the Bigarreaus and of thriving in many soils. They are usually fruitful. To offset these merits, the trees have two or three rather serious faults. Thus, they do not come in bearing early; they are tall and upright in growth, being almost fastigiate, making it difficult to harvest the crop; and the load of fruit is too much clustered. Cherry-growers agree that the worst of all pests of this fruit is the robin and that the Windsor, for some reason or other, is the freest of its kind from this and other thieving birds. From the behavior of the variety in New York, we can heartily join with practically all who are growing this variety in recommending it as a late, market Sweet Cherry

Windsor originated in the latter half of the Nineteenth Century on the farm of James Dougall, Windsor, Ontario, Canada, and was introduced to fruit-growers in 188I by Ellwanger \& Barry, Rochester, New York. It has been planted extensively in many sections of this country for both 


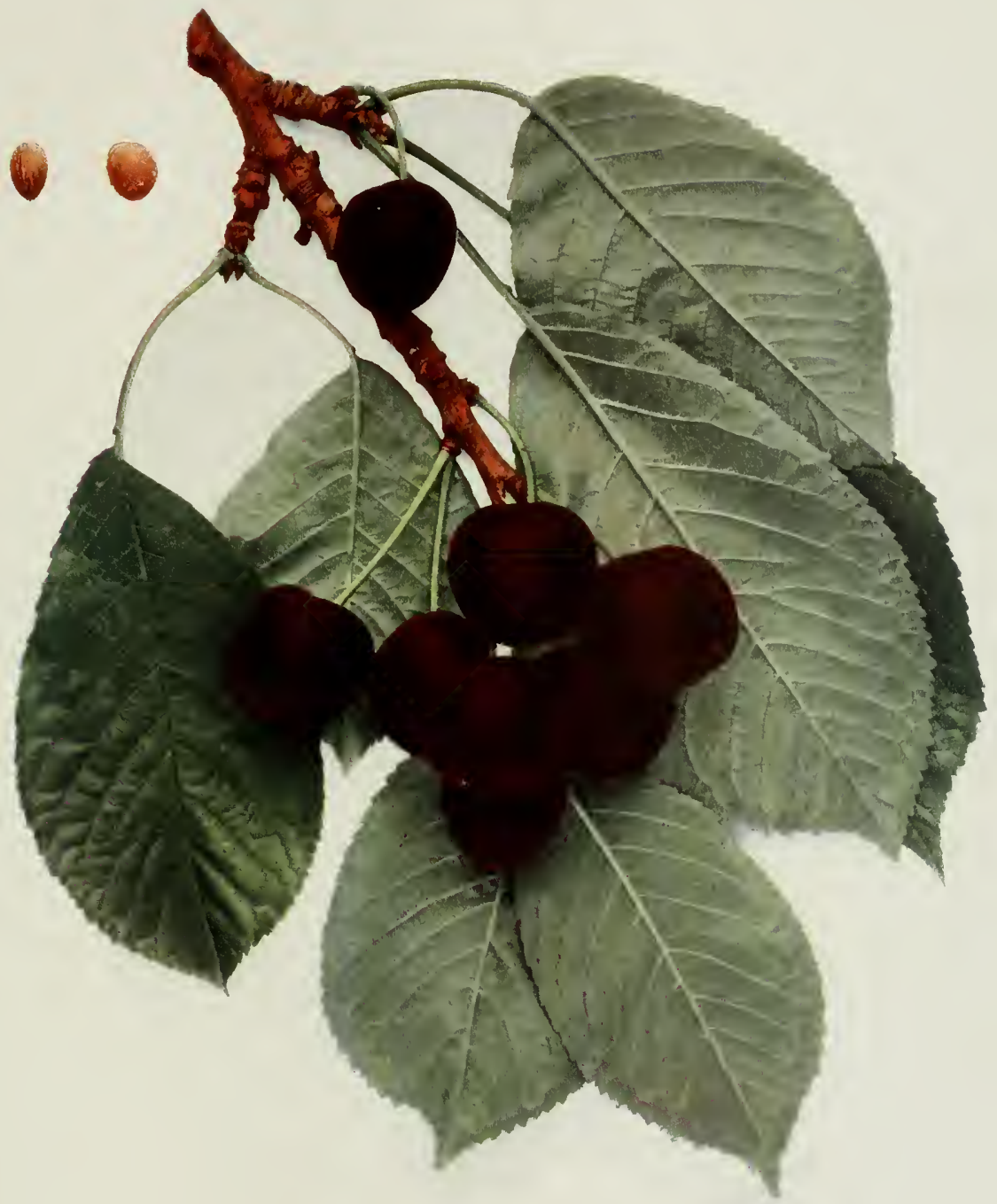



home and market use and is now offered for sale by a large number of nurserymen. The American Pomological Society added Windsor to its fruit catalog list in 1885 and the variety still holds a place there. Though rather widely known in the United States the commercial culture of this variety is almost wholly confined to New York. It seems as yet not to have found its way to Europe, a fact to be regretted, for its many good qualities would soon make it known in the Old World where the Sweet Cherry is better grown and more appreciated than in America.

Tree large, vigorous, upright-spreading, open-topped, very productive; trunk thick, shaggy; branches stocky, very smooth, brown nearly overspread with ash-gray, with large lenticels; branchlets thick, rather short, brown overspread with light ash-gray, smooth, with few small, inconspicuous lenticels.

Leaves four inches long, two inches wide, folded upward, obovate to oval, thin; upper surface dark green, slightly rugose; lower surface light green, pubescent; margin doubly crenate, glandular; petiole one and one-fourth inches long, tinged with dull red, with from one to three globose, reddish glands of medium size on the stalk.

Buds conical or pointed, plump, free, arranged singly as lateral buds and in very numerous clusters variable in size, on short spurs; leaf-scars somewhat prominent; season of bloom intermediate; flowers white, one and one-fourth inches across; borne in scattering clusters, in ones and twos; pedicels one inch long, slender, glabrous, greenish; calyx-tube green, campanulate, glabrous; calyx-lobes greenish or with a tinge of red, acute, glabrous within and without, reflexed; petals broad-oval, slightly crenate, with short, blunt claws; filaments five-sixteenths of an inch long; pistil glabrous, shorter than the stamens.

Fruit matures in late mid-season; three-fourths of an inch in diameter, slightly oblong to conical, compressed; cavity deep, wide, flaring; suture a line; apex roundish, with a depression at the center; color very dark red becoming almost black; dots numerous, small, russet, obscure; stem slender, one and one-fourth inches long, adherent to the fruit; skin thin, adhering to the pulp; flesh light red, with reddish juice, tender, meaty, crisp, mild, sweet; good to very good in quality; stone semi-free, ovate, flattened, blunt-pointed, with smooth surfaces; ventral suture rather prominent near the apex.

\section{WOOD}

\section{Prunus avium}

I. Am. Pom. Soc. Cat. 26.1909.

Governor Wood. 2. Elliott Fr. Book 196 fig. 185t. 3. Am. Pom. Soc. Cat. 108. 1856. 4. Leroy Dict. Pom. 5:324 fig. 1877 .

Wood is preeminently a Sweet Cherry for the amateur, having many qualities that fit it for the home orchard and but few to commend it to commercial growers. The trees are a little tender to cold, are not quite productive enough to make the variety profitable and are, too, somewhat fastidious as to soils. To offset these defects, they are vigorous and 
healthy and bear early. But the chief fault of the cherry from the cherrygrower's standpoint is to be found in the fruit. The flesh is soft and the cherries will not stand handling in harvesting and shipping and are very susceptible to brown-rot and crack badly in wet weather. Wood has special merit in the home collection, however, because of its earliness, its beautiful appearance and delicious flavor. It is one of the first of the Sweet Cherries, is large and, as the color-plate shows, is a beautiful yellowish-white tinted with shades of crimson, with conspicuous russet dots - a beautiful fruit. The flesh separates readily from the skin, is tender, juicy, with an abundance of colorless juice and a flavor that has given it the reputation, wherever grown in America, of being one of the best in quality. It would be hard to name another cherry better suited for small plantations and it is to be hoped that it will long be kept in the gardens of connoisseurs of good fruit.

Wood is one of the best of Professor J. P. Kirtland's ${ }^{1}$ seedlings. It was raised by him in 1842 at Cleveland, Ohio, and named in honor of Reuben Wood, at one time Governor of Ohio. In 1856 , it was added to the fruit list of the American Pomological Society where it still remains, being changed in 1909 to Wood with Governor Wood as a synonym. Its popularity is shown in the United States by the fact that practically every nurseryman in this country lists this variety.

${ }^{1}$ Jared P. Kirtland, M. D., though now less well known than some of his contemporaries, was one of the great pomologists of his time and a man of notable achievements in other branches of natural history as well. Professor Kirtland was born at Wallingford, Connecticut, November 10, 1793, and died at East Rockport, near Cleveland, Ohio, December 11 , 5877 . For sixty years of a long life his avocation was the production of new varieties of fruits and flowers and, though a half century has passed since he ceased active work, the results of his labors are yet to be found in the gardens and orchards of the whole country. In pomology he gave special attention to breeding grapes, raspberries, pears and cherries. He achieved success, too, as a hybridizer of peonies and in the introduction of rare foreign magnolias. Professor Kirtland is given credit as being the first horticulturist successfully to bud and graft magnolias, an achievement which has made possible their cultivation under many conditions and to a degree of excellence that otherwise could not be obtained. He was the founder of the Cleveland Society of Natural History and was for many years its president. He was a member of the American Philosophical Society, the highest recognition for scientific work to be obtained in his time in this country. He served as professor in several medical schools and filled other places of honor and trust. From his boyhood we are told that he was interested in natural history and was intimately acquainted with the plants and animals of Ohio, having special knowledge of birds and fishes, the propagation of the latter being one of his hobbies. In pomology we owe him most for the many new cherries he has given us, thirty varieties described in The Cherries of New York having come from his breeding grounds. Among these are Wood, Pontiac, Powhatan, Tecumseh, Osceola, Kirtland and Red Jacket, sorts scarcely surpassed for high quality and grown commonly in America and to some extent wherever Sweet Cherries will thrive. His 84 years seem to have been well ordered, given almost wholly for the good of the public, and his name should be cherished by pomologists among those who have done most for fruits and fruit-growing on this continent. 


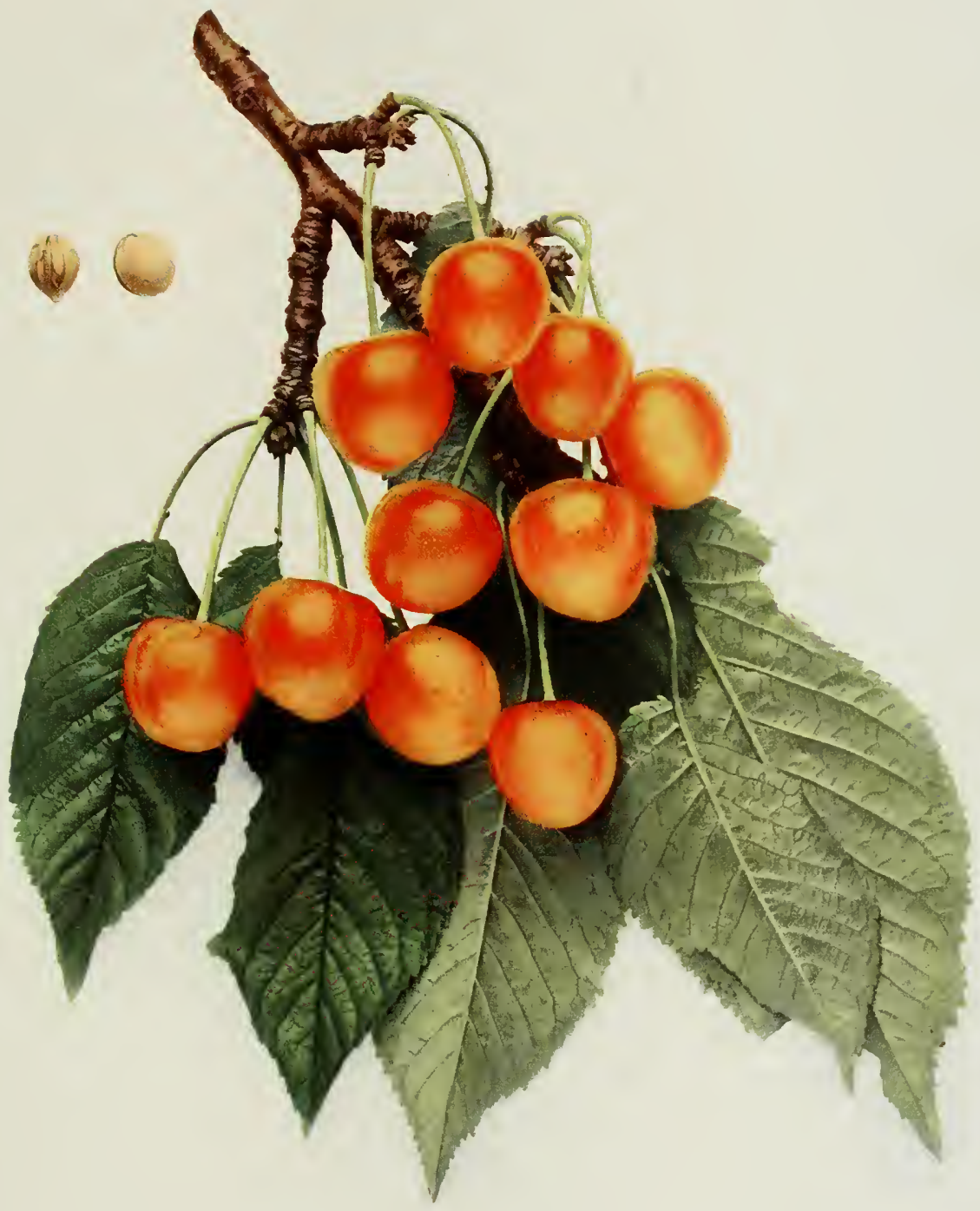

WOOD 

Tree vigorous, upright-spreading, open, productive; trunk stout; branches thick, smooth, dull reddish-brown covered with ash-gray, with a few small lenticels; branchlets thick, reddish-brown slightly overspread with ash-gray, smooth, glabrous, with a few inconspicuous, raised lenticels.

Leaves numerous, four and one-half inches long, two and one-half inches wide, folded upward, obovate, thin; upper surface light green, smooth; lower surface dull green, lightly pubescent; apex acute, base abrupt; margin coarsely and doubly serrate, glandular; petiole one and one-half inches long, slender, tinged with dull red, with from one to three reniform, reddish glands on the stalk.

Buds large, long, pointed, very plump, free, arranged singly as lateral buds or in small clusters on short spurs; leaf-scars prominent; season of bloom intermediate; flowers one inch across, arranged in twos and threes; pedicels one inch long, slender, glabrous, greenish; calyx-tube tinged with red, obconic, glabrous; calyx-lobes reddish, long, acute, glabrous on both surfaces, reflexed; petals roundish, crenate, with short, blunt claws; anthers yellowish; filaments one-eighth inch long; pistil glabrous, equal to the stamens in length, sometimes defective.

Fruit matures in early mid-season; nearly one inch in diameter, roundish-cordate, compressed; cavity of medium depth, wide, flaring; suture variable in depth, distinct, wide; apex roundish; color shades of crimson on a yellowish-white background; dots numerous, small, light russet, somewhat conspicuous, especially just before maturity; stem slender, one and one-half inches long, adhering well to the fruit; skin thin, tender, separating from the pulp; flesh whitish, with colorless juice, tender, meaty, mild, sweet; very good in quality; stone clinging, rather large, roundish, blunt, with smooth surfaces; with a broad, ventral suture.

\section{WRAGG}

Prunus cerasus

1. Ia. Hort. Soc. Rpt. 171. 1884. 2. Am. Pom. Soc. Rpt. 95. 1887. 3. Can. Exp. Farm Bul. 17:15 fig. 8. 1892. 4. Neb. Hort. Soc. Rpt. 39. 1892. 5. Am. Gard. 20:178. 1899. 6. Del. Sta. An. Rpt. 12: I 19, I 20. 1900. 7. Ia. Sta. Bul. 73:89, fig. 26. 1903. 8. Am. Pom. Soc. Sp. Rpt. 38. 1904-05. 9. Wash. Sta. Bul. 92:22, 23. 19 ro.

Wragg is either English Morello or a strain of that variety. Trees on the grounds of this Station are identical with English Morello but it may be that here, and occasionally elsewhere, the older sort has been substituted for Wragg. In Iowa, where the new variety is most largely grown, pomologists claim that it is distinct and that it is an improvement on English Morello. Professor J. L. Budd, an authority on Russian cherries, believed that this sort is distinct and of Russian origin having, according to him, been brought to America by Ellwanger \& Barry of Rochester, New York, in an importation of Russian trees. Captain C. L. Watrous of Des Moines, Iowa, another prominent pomologist of that State, was of the opinion that Wragg came to light on the grounds of J. Wragg, Waukee, Iowa, as a sprout 
from another tree. Colonel G. B. Brackett, pomologist of the United States Department of Agriculture, who visited Mr. Wragg's place some years ago and compared the new cherry with the English Morello, could find no distinguishing characters between the two. On the other hand, Mr. Wragg insisted that they were distinct. The American Pomological Society calls Wragg and English Morello the same. Those who believe that the two are distinct say that the fruit of Wragg is larger, the trees hardier and that the cherries ripen a little later than those of English Morello. With the information now at hand it is impossible to say here whether or not Wragg is distinct. A compiled description taken from the text describing this cherry is so unsatisfactory that we offer none and refer the reader to that of English Morello from which it differs but little, if at all.

\section{YELLOW SPANISH}

\section{Prunus avium}

I. Miller Gard. Dict. I: 1754. 2. Forsyth Treat. Fr. Trees 42. 1803. 3. Prince Treat. Hort. 28. 1828. 4. Prince Pom. Man. 2: 125. 1832. 5. Thomas Am. Fruit Cult. 372. 1867. 6. Am. Pom. Soc. Cat. 17. 1897. 7. Budd-Hansen Am. Hort. Man. 2:291. 1903.

Biguarre Cherrie. 8. Parkinson Par. Ter. 572. 1629. 9. Rea Flora 205. 1676.

Spanish. 10. Gerarde Herball 1503, fig. 3. 1636.

Bigarreau Commun. II. Duhamel Trait. Arb. Fr. I:167, I68. 1768. 12. Prince Pom. Man. 2:128. 1832. 13. Poiteau Pom. Franc. 2: No. 5, P1. 18+6. 14. Mortillet Le Cerisier 2:115-119, fig. 26.1866. 15. Pom. France 7: No. 2, Pl. 2. 1871. I6. Leroy Dict. Pom. 5: 188-191, fig. 1877. 17. Cat. Cong. Pom. France 20, fig. I906.

Gemeine Marmorkirsche. 18. Truchsess-Heim Kirschensort. 301-303. 1819. 19. Ill. Handb. 123 fig., 124. 1860 .

Graffion. 20. Truchsess-Heim Kirschensort. 338-340. I8I9. 21. Brookshaw Hort. Reposit. I:69, Pl. 34 fig. I. 1823. 22. Prince Pom. Man, 2:137, 138. 1832. 23. Cultivator N. S. 6:21, fig. 6.1849. 24. Elliott $\mathrm{Fr}$. Book 208. 1854 .

Bigarreau. 25. Mag. Ilort. 9:202. 1843. 26. Downing Fr. Trees Am. 179 fig., 180.1845. 27. Floy-Lindley Guide Orch. Gard. 102. 1846. 28. Proc. Nat. Con. Fr. Gr. 52. 1848. 29. Cole Am. Fr. Book 233 fig. 31. 1849. 30. Hogg Fruit Man. 281, 282. $\quad$ I 884.

For centuries Yellow Spanish must have been the best of all the Bigarreaus and it is only in comparatively late years that it has had rivals. Even yet in tree-characters it is hardly equaled, surpassing Windsor, which has a notable tree, in several respects and falling short of it only in hardiness. The trees are large,- - perhaps the largest of all the varieties of Prumus avium, - having an upright-spreading top which gives a large bearing surface and forms a canopy of splendid foliage. The trees are vigorous, bear abundantly and regularly and come in bearing young, with the crop well distributed and not in clusters as is the case and the fault of Windsor. Unfortunately, the cherries, though very good in most characters, 


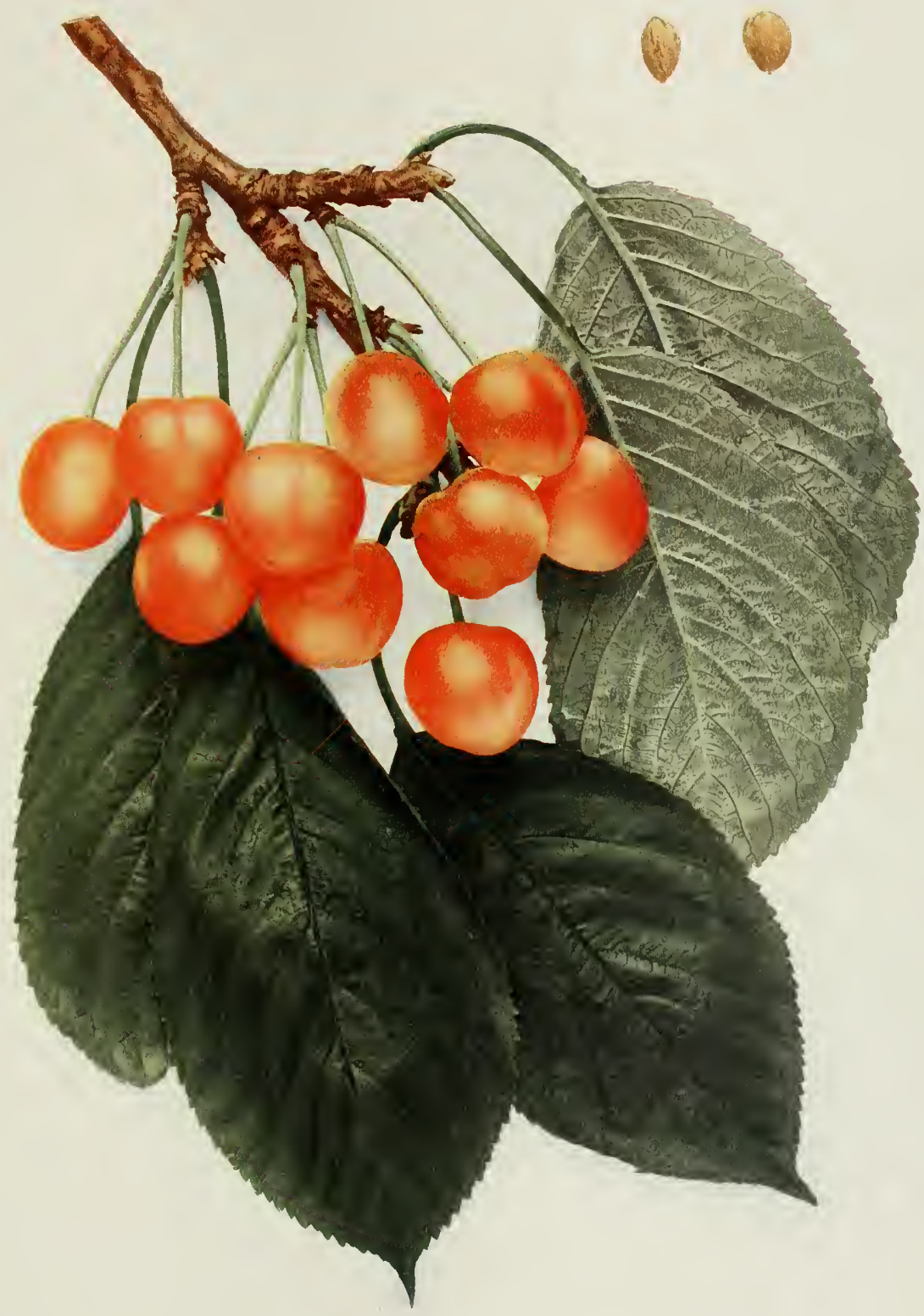

YELLOW SPANISH 

do not come up to the trees in points of superiority. They are rather smaller than those of Napoleon, the greatest competitor of Yellow Spanish, and are more subject to attacks of brown-rot than several others of the Bigarreaus. As may be seen by comparing the color-plates, however, Yellow Spanish is rather the handsomer of the two cherries, the crimson color being more evenly distributed and the skin not having the mottled appearance of Napoleon. In quality Yellow Spanish is the better of the two, having tenderer flesh and a sweeter and richer flavor. Yellow Spanish is notable in the nursery for its strong, upright growth and its large leaves, the leaves of no other cherry attaining so great a size. In blossoming time the variety may be distinguished by the whiteness of the blossoms as they open and a reddish tint as they drop. It is a mid-season cherry, ripening after Wood and a few days before Napoleon. Despite the great age of the variety it still remains one of the best, furnishing proof, by the way, that varieties of cherries do not degenerate with age. In New York Yellow Spanish cannot be spared from either home or commercial plantings.

Yellow Spanish is so old and so widely disseminated that its origin can only be conjectured. From the name we naturally infer a Spanish nativity and yet it is almost equally well known as Bigarreau, a word of French derivation. Under the last name French pomologists believe that they trace its history to the First Century of the Christian Era as the variety described by Pliny under the name Cerasum Duracinum. The Germans and Austrians certainly knew this variety in the Eighteenth Century and probably much earlier, an inference to be drawn from the references given. Parkinson, the English herbalist, described a cherry in I629 which he called the Biguarre Cherrie which later came to be known as the Bigarreau or Graffion by English writers and which we now know to be Yellow Spanish. Seven years later Gerarde described a Spanish cherry the description of which is not unlike our Yellow Spanish. Miller and Forsyth, English writers, also at an early date described a Spanish cherry which may be the fruit of this discussion.

Fortunately we are well informed as to the history of Yellow Spanish in America. Prince, one of the most accurate of American pomologists, in 1832 , gave the following historical account of the Graffion, or Yellow Spanish: "This tree was imported from London by the father of the author, in the year 1802, under the name Yellow Spanish, and one of the original trees is now growing in his garden, where it produces abundantly, and there is little doubt that from his stock have originated most of the 
trees of this kind now in our country, as he has taken much pains to recommend it." Why Prince and other Americans came to call the variety introduced by the elder Prince of Europe as Yellow Spanish, as Bigarreau and Graffion, does not appear unless the younger Prince wanted to make the name in this country conform to that in most common usage in England at the time. Besides the names already given, Yellow Spanish has been rather widely grown in America as Ox Heart and White Caroon. This variety was placed on the recommended list of the National Congress of Fruit Growers, which afterwards became the American Pomological Society, in 1848 , under the name Bigarreau. The name was changed in 1897 to Yellow Spanish and it now appears on the list of that organization as Spanish.

Tree very large and vigorous, upright-spreading, rather open-topped, productive; trunk thick, of medium smoothness; branches stocky, reddish-brown covered with ashgray, smooth except for the numerous large lenticels; branchlets short, brown nearly overspread with ash-gray, smooth, with small, slightly raised, inconspicuous lenticels.

Leaves numerous five and one-half inches long, two and one-half inches wide, folded upward, obovate to elliptical; upper surface dark green, nearly smooth, grooved along the midrib; lower surface light green, lightly pubescent; apex acute, base variable in shape; margin coarsely and doubly serrate, with small, dark glands; petiole one and three-fourths inches long, thick, heavily tinged with dull red, grooved along the upper surface, with from one to four large, reniform, reddish-yellow glands variable in position.

Buds conical, plump, free, arranged singly or in small clusters as lateral buds and from short spurs; leaf-scars prominent; season of bloom intermediate; flowers white, one and one-fourth inches across; borne in well-distributed clusters, in twos and in threes; pedicels about one inch long, glabrous, green; calyx-tube greenish, obconic, glabrous; calyxlobes acute, reflexed; petals oval, entire, strongly dentate at the apex, tapering to short, blunt claws; filaments three-eighths inch long; pistil glabrous, equal to the stamens in length.

Fruit matures in mid-season; one inch or over in diameter, cordate, compressed; cavity deep, wide, flaring; suture a mere line; apex roundish, not depressed; color bright amber-yellow with a reddish blush, slightly mottled; dots numerous, small, light russet, obscure; stem one and one-half inches long, adherent to the fruit; skin thin, tough, separating from the pulp; flesh whitish, with colorless juice, tender, meaty, crisp, aromatic, sprightly, sweet; very good to best in quality; stone free, ovate, slightly flattened, oblique, with smooth surfaces; with two small, blunt ridges along the ventral suture near the apex. 


\title{
CHAPTER V
}

\section{THE MINOR VARIETIES OF CHERRIES}

\author{
A Coeur Hâtive. P. avium. I. Mas Pom. Gen. Ix:I59. I882.
}

Listed in this reference.

A Feuilles de Pêcher Grosse. P. cerasus? I. Lond. Hort. Soc. Cat. 49. I83 I.

Merely mentioned; probably similar to Willow Leaved.

Abels Schwarze Knorpelkirsche. P. avium. x. Proskauer Obstsort. 55.1907.

Mentioned in this reference as a black, hard-fleshed, Sweet Cherry.

Abundance. $P$. avium. I. Burbank Cat. 7 . I9II-I2.

Abundance is one of Burbank's seedlings from Napoleon. The tree is a heavy, almost annual bearer. The fruit is large, never cracks, and exceeds the parent in productiveness and beauty; it ripens a week later.

Abbesse. $P$. avium $\times P$. cerasus. I. Ia. Hort. Soc. Rpt. 8o. I8go. 2. Budd-Hansen Am. Hort. Man. 2:284. 1903.

Abbesse was found in North Silesia and is supposed to be a Red Duke cross. Fruit medium to large, cordate; stem long, thick at the base; cavity shallow; suture distinct; skin dark red; flesh meaty, with colored juice, mildly acid; quality good.

Act Gillos. P. avium. 1. Ohio Hort. Soc. Rpt. 22. I892-93.

Act Gillos was imported by Leo Weltz of Ohio, in a collection of sweet varieties said to have come from Bokhara, Turkestan. Tree vigorous; leaves large; fruit yellow, resembling Cleveland.

Adams Crown. P. avium. I. Brookshaw Hort. Reposit. I:45, Pl. 23 fig. I. I823. 2. Hogg Fruit Man. 275, 277 . I884. 3. Mawe-Abercrombie Comp. Gard. 632. 1829. 4. Leroy Dict. Pom. 5:312 fig., 313. I877.

Adams Herzkirsche. 5. Ill. Handb. 99 fig., roo. I860. 6. Mathieu Nom. Pom. 332. I889.

Adam. 7. Mas Le Verger 8:69, 70, fig. 33. I866-73.

Adams Crown is supposed to have been raised by a man named Adams in the vicinity of Sittingbourne, Kent, England. It was formerly grown in the orchards near London for market trade. Tree large, vigorous, usually productive, bears early; fruit medium in size, roundish-cordate, flattened at the base, slightly compressed; cavity wide, deep; suture shallow, indistinct; stem slender, long; skin thin, transparent, attractive pale red speckled with darker red deepening to carmine, showing distinctly the fibers underneath; flesh whitish, juicy, tender, somewhat stringy, sweet, sprightly, pleasant; very good in quality; stone small, roundish-ovate, flattened at the base, plump; season early. Adlington. Species? 1. Lond. Hort. Soc. Cat. 45. 183 I.

Mentioned in the reference given.

Affane. Species? I. Lond. Hort. Soc. Cat. 45. 183 I.

Mentioned in this reference.

Afghanistan. P. avium. I. Thomas Am. Fruit Cult. 315. I897. 2. Van Lindley Cat. 37 I. 1899. 
This variety is said by Van Lindley to have been introduced into North Carolina by a missionary from South Africa. The fruit closely resembles Windsor. Tree tall, spreading, vigorous; fruit large, cordate, often swollen along the suture giving it an angular appearance; skin dark red to reddish-black; flesh firm, tender, sweet; ships well; season the last of May.

Alaternblättrige Süssweichsel. $P$. avium. I. Dochnahl Führ. Obstkunde 3:48. I $\delta 58$.

Fruit medium large, roundish, flattened, with a faint suture; skin glossy, brownishred; stem mostly covered with leaves, greenish-yellow; flesh soft, acidulated; stone heartshaped.

Albertine Millet. Species? I. Thomas Guide Prat. 22. 1876. 2. Guide Prat. 17. I895.

Received from Belgium without description; its value is questioned in Guide Pratique.

Alexandrine Béon. Species? 1. Mathieu Nom. Pom. 332. I889.

Listed in this reference.

Alfred Wesmael. P. cerasus. 1. Thomas Guide Prat. 25. 1876. 2. Guide Prat. 17. 1895 .

This variety is similar to Montmorency according to Guide Pratique.

Allen. P. avium. I. Storrs \& Harrison Cat. 137. I899. 2. Brown Cat. 23. 1900.

A seedling cherry found in Lake County, Ohio. It is darker, later and smaller than Windsor. The tree is healthy, very productive; fruit somewhat heart-shaped, nearly black, glossy, smooth; flesh meaty, firm, sweet; of small size.

Allen Late Favourite. $P$. avium. 1. Prince Pom. Man. 2:123. 1832.

Sent to the Prince nursery by Zachariah Allen of Providence, Rhode Island. The tree is vigorous; fruit of fine quality, juicy, well flavored; ripens in Rhode Island with Black Mazzard.

Allerfruiheste Bunte Maiherzkirsche. P. avium. I. Dochnahl Führ. Obstkunde 3:19. 1858 .

Tree productive; fruit of medium size, obtuse-cordate; stem long, deeply set; skin clear red, spotted with dark brown; flesh whitish, sweet; stone oval; ripens in mid-June. Alte Königskirsche. P. cerasus. I. Christ Obstbäume 158. I791. 2. Christ Handb. 671 . I797. 3. Truchsess-Heim Kirschensort. 422. I819.

Tree large, very productive; fruit large, round, slightly heart-shaped; stem long; skin reddish-black; flesh very delicate, tender, juicy, sweet, with an aromatic, very pleasing sourness; stone small.

Altenlander Frühkirsche. P. avium. I. Ill. Handb. 465 fig., 466. I861.

Cerise précoce d'Altenlaud. 2. Mortillet Le Cerisier 2:301. I 866.

This variety is distinguished from Frühe Maiherzkirsche by its fruits which are larger, deeper in color, sourer and more angular and a few days later. Tree productive; fruit of medium size, obtuse-cordate, sometimes angular; cavity wide, shallow; apex often widely depressed; stem stout, of medium length; suture shallow; skin glossy, charcoal black in some spots when fully ripe, rather tough; flesh reddish-black, tender, very juicy, sweet with a pleasing sourness; stone short, oval; season early.

Amaranthkirsche. P. avium. I. Christ Wörterb. 277. I802. 2. Truchsess-Heim Kirschensort. 215-219. I8I9. 3. Dochnahl Führ. Obstkunde 3:28. I858.

In 1790 , this variety was reported to have been brought to Hanover, Prussia, Germany, 
from England. Truchsess describes this cherry as being of medium size, roundish-cordate, with a pronounced suture; stem short; cavity shallow; apex abruptly rounded; skin red on the sunny side, yellowish, flesh-colored on the shady side; flesh tender, light yellowishwhite, juicy, sweet yet without excellence; stone round, rather broad, not long, nearly free; unproductive.

Amarelle Hâtive. P. cerasus. 1. Can. Exp. Farm Bul. 17:6 fig. 1892, 2. Am. Pom. Soc. Cat. 24. 1899. 3. Del. Sta. An. Rpt. 12:110. 1900. 4. Am. Pom. Soc. Cat. 27. 1909.

This variety was imported by Professor J. L. Budd of Iowa, in 1885. It resembles Early Richmond but ripens ten days later. It appeared on the fruit list of the American Pomological Society in 1899 and in 1909 Morello Hâtive was given as a synonym. This variety, however, is of the Amarelle type while Morello Hâtive is a true Morello.

Amarelle mit Weissem Stempelpunct. P. cerasus. I. Truchsess-Heim Kirschensort. 655 ,

656. 1819. 2. Dochnahl Führ. Obstkunde 3:70. I8 58.

Amarelle à point pistillaire blanc. 3. Mas Pom. Gen. II:159. I882.

According to Truchsess, this variety was first mentioned by Christ as early as 1795 , under the name, Roque Cherydere. Fruit of medium size, roundish, flattened; stem short; skin dark red; flesh white, with colorless juice, although a glistening red when pressed out, subacid; season early; medium productive; resembles Bunte Amarelle.

Amber. $P$. avium. I. Kenrick Am. Orch. 272. 1832.

This variety was found in an old garden in Providence, Rhode Island. Fruit below medium in size, perfectly round; amber, delicate red towards the sun; flesh melting, lively, very sweet; early.

Amber Gean. P. avium. I. Downing Fr. Trees Am. 168. 1845. 2. Gard. Chron. 1068.

1861. 3. Hogg Fruit Man. 277. 1884.

Amber? 4. Rea Flora 206. 1676.

Late Amber Gean. 5. Fish Hardy-Fr. Bk. 2:105. I 882.

This is probably the Amber of the old English writers - an attractive, small Gean or Mazzard. Tree bears abundantly; fruit small, obtuse-cordate, usually regular; stem long, slender, shallowly inserted; skin very thin, pellucid, exhibiting the texture of the flesh, pale yellow or amber, tinged with delicate red; flesh white, tender, juicy, melting, with a rich, sweet, pleasant flavor; ripens the last of July.

Ambrée de Guben. P. avium. I. Mortillet Le Cerisier 2:118, 119, 303. 1866. 2. Mas Le Verger 8:99, 100, fig. 48. 1866-73.

Gubener Bernsteinkirsche. 3. Truchsess-Heim Kirschensort. 342, 685. 1819. 4.

Dochnahl Fiihr. Obstkunde 3:42. $185^{8}$.

This variety resembles Yellow Spanish; in fact the name is listed as a synonym of Yellow Spanish by Mortillet. We feel sure, however, that it is a distinct variety. Fruit large, roundish-cordate, truncate at the base; suture shallow; stem long; cavity wide, shallow; skin glossy, pale yellow washed with carmine in the sun; flesh firm, fibrous, sweet, with a sourness that disappears if allowed to remain on the tree; quality good; stone oval, slightly flattened at the base; ripens the first of July in France. 
American Amber. P. avium. I. Kenrick Am. Orch. 272. 1832. 2. Downing Fr. Trees Am. 167. 1845. 3. Bridgeman Gard. Ass't Pt. 3:54. 1847. 4. Thomas Am. Fruit Cult. 359. 1849. 5. Elliott Fr. Book 214. 1854. 6. Am. Pom. Soc. Cat. 74. 1862 .

This variety was introduced some time previous to $1_{32}$ by the originator, Daniel Bloodgood, Flushing, New York. It held a place on the American Pomological Society's list of fruits from 1862 until 1869 . It resembles American Heart but differs in being a tender-fleshed fruit of regular outline. Tree productive; fruit hanging in bunches for a long time without rotting. Fruit borne in threes or fours, hangs well, of medium size, roundish-cordate often nearly round; stem long, slender, inserted in a slight, narrow cavity; skin very thin, smooth, glossy, clear, light amber becoming mottled and overspread with clear bright red; flesh amber, tender, sprightly, juicy, usually of only fair quality; pit large; season the last of June to the middle of July.

American Heart. P. avium. I. Mag. Hort. 9:202. 1843. 2. Downing Fr. Trees Am. I78, 179 fig. 70. I845. 3. Bridgeman Gard. Ass't Pt. 3:54. I847.

According to Downing, this variety came from Long Island but its exact origin is unknown. Tree vigorous, spreading, variable in productiveness; fruit medium to large, cordate, often nearly angular and irregular in outline; cavity small, shallow; stem long, slender; skin tough, adhering to the pulp, pale yellow or amber-red; flesh very juicy, yellowish, half-tender, sweet, pleasant; very good in quality; stone medium in size.

Amos Owen. P. avium. I. N. C. Sta. Bul. 184: I2 I. I903.

Amos Owen is a black Mazzard used by nurserymen as a stock for grafting. The fruit is small and black; of poor quality.

Andrews. Species? I. Wickson Cal. Fruits I87. I908.

Andrews is a seedling named after C. N. Andrews, Redlands, California, who fruited it in 1896 . It is grown in the mountain valley near Redlands and is apparently a fine shipping variety.

Anne. P. avium. I. Elliott Fr. Book 204. 1854. 2. Downing Fr. Trees Am. $254 . \quad$ I857.

This cherry is reported by Charles Downing to have originated at Lexington, Kentucky; distributed by A. V. Bedford, Paris, Kentucky. Tree moderate in growth; fruit of medium size, bright red; flesh tender, juicy, very sweet; quality excellent; early.

Annonay. P. avium. I. Flor. \& Pom. 28. I882, 2. Rivers Cat. I8. I898-99. 3. Bunyard-Thomas Fr. Gard. 43. 1904.

Annonayer Herzkirsche. 4. Proskauer Obstsort. 55. I907.

A Heart cherry mentioned in ${ } 88_{2}$ as a promising new fruit because of its extreme earliness and excellent quality. This variety, introduced by Thomas Rivers \& Son, Sawbridgeworth, England, should not be confused with an older French sort often known by the same name but of a reddish-brown color. Tree moderate in growth; fruit glossy, black, round, of medium size, produced in clusters; flesh charcoal-black, very rich in flavor. Anstad. P. avium. 1. Ont. Fr. Gr. Assoc. Rpt. I7. 1908.

A seedling from seeds planted in 1898 by A. P. Anstad, Trail, British Columbia. The fruit is large, heart-shaped; cavity of medium depth and width; stem long, slender; apex depressed; suture indistinct; skin moderately thick, tender, dark red or blackish; dots 
obscure; flesh dull red, meaty, juicy, sweet, pleasant; quality good; stone of medium size, clinging; season in Ontario, the end of July.

Argental Late. P. avizm. I. Barry Fr. Garden 325. IS51. 2. Downing Fr. Trees Am. 45I. 1869 .

Downing says this variety is of French origin and that the fruit is unlike any other cherry in form. Tree spreading; branches slender, irregular; fruit of medium size, elongated-oval, sides compressed; suture narrow; stem medium in length, slender; cavity small; skin deep purplish-black; flesh half-tender, juicy, sweet, of peculiar flavor; quality very good; stone small, narrow, elongated-oval; ripens about July roth.

Auburn Duke. $P$. avium $\times P$. cerasus.

A stray variety not mentioned in cherry literature, occasionally grown in western New York The fruit, on the Station grounds, is above medium size, roundish; skin glossy, amber-yellow with a dark red cheek, often wholly suffused with red, sometimes mottled with translucent spots underneath the skin; suture a distinct line; stem slender, one and one-half inches long, inserted in a broad cavity; flesh white, very tender, juicy, nearly sweet; quality good but not rich; stone small, adhering to the stem; season late June. The fruit cracks in wet weather.

August Duke. P. avium $\times P$. cerasus. I. Cultivator 3 rd Ser. I:248 fig., 249. I853.

Vail's August Duke. 2. Horticulturist 4:264 fig., 265. 1849-50. 3. Elliott Fr. Book 213. I 854 .

This variety originated with Henry Vail of Troy, New York. It is valued for its lateness, maturing three weeks after Downer, generally about the tenth of August. Tree hardy, healthy, moderate in growth; fruit borne in pairs, hanging in thick clusters along the branches, of medium size, obtuse-cordate; stem of medium length, thickening where it joins the fruit, set in a deep, narrow cavity; skin bright red; flesh tender, subacid, much like May Duke in flavor; pit oval.

Augustine de Vigny. Species? I. Mathieu Nom. Pom. 333. 1889. 2. Am. Pom. Soc. Rpt. 54. I 856.

Mentioned in the references given.

Aurischotte. P. cerasus. I. Truchsess-Heim Kirschensort. 589-59 I. I8I9. 2. Dochnahl Fülir. Obstkunde 3:65. 1858 .

According to Truchsess, this cherry was described in 1802 by Christ who states that it originated in Wanfred, Prussia, Germany. Truchsess believed, however, that the name was a corruption of Sauriotte, a sour or Weichsel cherry. Fruit round, somewhat flattened, above medium in size; suture indistinct; apex slightly depressed, gray; stem strong; skin dark red; flesh and juice of a slight reddish cast, sour, rather repulsive; stone large.

Badacsony. $P$. avium. I. Mich. Sta. Bul. 177:31. 1899. 2. Ibid. 187:62. 1901. Géante de Badacson. 3. Thomas Guide Prat. 27, 194. 1876.

Badacsoner Ricsenkirsche. 4. Mathieu Nom. Pom. 333. I889.

Badacconyi. 5. Mich. Sta. Bul. I69: 198. 1899.

Badacsoner Schwarze Riesenkirsche. 6. Reut. Pom. Inst. Festschrift 122. 1910.

Badacsonyer Knorpelkirsche. 7. Obstzüchter 8:74. I910. 
A strong-growing variety of the Bigarreau group which originated in the volcanic regions near Balaton Lake, Hungary. Tree spreading, productive, subject to shot-hole fungus; fruit very large, heart-shaped, compressed; stem long, slender; cavity deep, wide; skin dark red, mottled with purple; flesh crisp, breaking, pinkish, juicy, sweet; quality good; ripens in July.

Baender. P. cerasus. I. Mich. Sta. Bul. 88:20. 1892. 2. Wash. Sta. Bul. 92:12. I 910 .

An unproductive Morello. Tree medium in size, upright, round-topped; fruit medium to large, round, flattened; stem stout, long; skin dark red, thin, tender; flesh firm, meaty, slightly stained, rich acid; stone long, smooth; ripens the last of July in Washington.

Baltavar. P. avium. I. U. S. D. A. Pom. Rpt. 39. 1895. 2. Budd-Hansen Am. Hort. Man. 2:284. 1903 .

Bigarreau monstrenx de Baltava. 3. Thomas Guide Prat. 27. 1876.

Baltavari. 4. Mich. Sta. Bul. 169:199. I899.

Baltavacr Knorpclkirsche. 5. Proskauer Obstsort. 55. 1907.

Baltavar was introduced from Hungary by the United States Department of Agriculture. Tree upright, somewhat spreading; fruit resembles Napoleon in size and shape; cavity medium in depth, irregular, flaring; stem variable, slender; suture shallow; skin thick, glossy, light red changing to dark crimson on a yellow ground; dots numerous, minute, golden; flesh melting, yellowish, meaty, translucent, juicy, sprightly, mild subacid; quality good to very good; stone large, long, clinging; ripens the forepart of July. Baluder Morello. P. cerasus. I. Kan. Sta. Bul. 73:189. 1897.

Tree upright, unproductive; fruit medium to large; stem slender; skin dull red, tough; flesh red, tender, juicy, acid, lacking in richness; ripens unevenly about June I8th; not a commercial variety.

Barnhart. P. avium. I. Gard. Mon. 18:242. 1876. 2. Downing Fr. Trees Am. 3rd App. I6r. I88I.

This variety originated with Louis Shepler, Belle Vernon, Pennsylvania. Tree healthy, vigorous, bears abundantly; fruit of the Bigarreau type, large, obtuse-cordate, slightly compressed; cavity large, deep; stem rather long, slender; suture shallow; skin whitishyellow, shaded and mottled with light and dark, rich red; flesh firm, juicy, sweet, with a rich, rather sprightly flavor; ripens the last of June.

Baseler Herzkirsche. P. avium. I. Thomas Guide Prat. 22. 1876.

A medium-sized cherry of little value.

Bates. P. cerasus. I. Green Cat. 28 fig. 1906.

Said to have originated with S. J. Bates, Shelby, Michigan; introduced by C. A. Green, Rochester, New York; not propagated at present. As grown on our grounds it is identical. with Olivet but our trees may not be correctly named.

Bay State. P. cerasus. I. Adams Cat. II. I894. 2. Sweet Cat. I8. I907.

Bay State on the Station grounds resembles Reine Hortense and may be identical. (See description of Reine Hortense.) In I 894 it was listed by J. W. Adams of Springfield, Massachusetts, under the name Bay State and in 1907 was offered for sale by The George A. Sweet Nursery Company of Dansville, New York. 
Baylor. Species? I. Mas Pom. Gen. II: 159. I882.

Mentioned in this reference.

Bedford Prolific. P. avium. 1. Thomas Guide Prat. 22. I876. 2. Flor. \& Pom. 41, Pl. fig. I. 1882.

Bedford Prolific is similar to its parent, Black Tartarian, but has the advantage of being much hardier and more productive. It is inferior in quality to its parent. Many writers confuse it with Black Tartarian.

Belle Audigeoise. P. avium $\times$ P. cerasus. I. Ann. Pom. Belge 5:65, P1. 1857.

Schöne Audigeoise. 2. Mathieu Nom. Pom. 376. I889.

Very similar to Choisy. Tree vigorous, but moderately productive; fruit large, roundish, flattened at the ends; stem of medium length; cavity large, round; skin glossy, transparent, almost entirely washed with red at complete maturity; flesh yellowish, juicy, sweet, acidulated; ripens in France late in July.

Belle Bosc. Species? I. Lond. Hort. Soc. Cat. 45. I831.

Listed in the reference given.

Belle de Boskoop. Species? I. Mas Pom. Gen. I1:159. I882.

Listed in this reference without description.

Belle de Caux. P. avium. I. Guide Prat. 17. 1895.

Listed as similar to Duchess de Palluau.

Belle de Couchey. P. avium. I. Rev. Hort. 412. 1866. 2. Mas Pom. Gen. II:137, 138, fig. 69. 1882 .

Schöne von Couchey. 3. Proskauer Obstsort. 57. 1907.

Raton, a laborer, found this variety in 1715 , growing in a garden in Cote d'Or, France. Here and in the surrounding country it was commonly known as Cerise Raton. Tree vigorous, abundantly productive; fruit large, heart-shaped, irregular, often flattened; stem long, slender, inserted in a large, deep cavity; apex conical; skin tender, at first clear purple changing to blackish-purple; flesh tender, rather succulent, intense purple, juicy, sweet, sugary, very pleasing; stone small for the size of the fruit, ovate, short, broad, turgid; ripens the last of June. In France, one of the best fruits of the season standing shipment well notwithstanding its tender flesh.

Belle Defay. Species? I. Mathieu Nom. Pom. 334. I 889 .

Listed without a description in this reference.

Belle de Franconville. P. avium. I. Rev. Hort. 463 . I 891 . 2. Ibid. I4, I5 fig. I892.

This variety is a chance seedling found in the forests of Seine-et-Oise, France, and propagated by M. Arthur Nienard, a nurseryman of the same place. The variety is valued for its lateness and its good shipping qualities. Fruit elongated-cordate, slightly depressed; suture rather deep; cavity rather large, regular; stem slender, long; skin glossy, brilliant purplish-red, firm; flesh clear yellow, rather transparent, juicy, sprightly yet sugary, agreeable but slightly strong; pit oblong, tapering at the top, truncate, partly adherent; season late September in France.

Belle 1'Herissier. P. avium. I. Rev. Hort. 470, Pl. $\quad$ I 875 .

This cherry was raised from seed in 1865 by M. Doublet, horticulturist at Montrichard, Loir-et-Cher, France. Tree vigorous, productive; fruit large, usually borne in clusters, 
depressed on the side, with a faint suture; stem very long, slender, adhering strongly to the pit; skin a brilliant red but never black; flesh pale red, juicy, sweet, slightly sprightly; quality very good; pit irregular, very small, elongated; ripens the middle of June in France. Belle de Kis-Oers. P. avium. I. Thomas Guide Prat. 27. 1876. 2. Guide Prat. 13. I895.

This is a Hungarian cherry. Fruit of medium size, elongated, marbled with red; flesh white, sugary; in France it ripens the middle of July.

Belle de Loche. P. avium $\times P$. cerasus. I. Thomas Guide Prat. 25, I8 7. I876.

This name is wrongly used as a synonym of Magnifique. Distributed by Jacquement-Bonnefont, nurseryman at Annonay, Ardèche, France, who described it as a very good, large, productive fruit, ripening in June.

Belle d'Orleans. P. avium. 1. Mag. Hort. 16:358, 540 fig. I850. 2. Am. Pom. Soc. Cat. 2I I. I856. 3. Mortillet Le Cerisier 2:84, 85 fig., 86. I866. 4. Leroy Dict. Pom. 5:314 fig., 315. I877.

Beauty of Orleans. 5. Ill. Handb. I5 fig., if. I867. 6. Can. Exp. Farms Rpt. 4I 5. 1899 .

Belle de Bruxelles. 7. Guide Prat. 10, 17, I8r. 1895.

Some writers state that Thomas Rivers, Sawbridgeworth, England, originated this variety about 1852 ; others hold that it is of French origin. Tree large, very vigorous, productive; fruit usually attached in pairs, medium to above in size, roundish-oval or often cordate; stem medium in length, rather slender; skin transparent, clear pale yellow with a light red cheek, occasionally slightly mottled; flesh pale amber, juicy, tender, sweet; good in quality; stone large, roundish-obovate; season early.

Belle de Ribeaucourt. P. avitm. I. Mag. Hort. 20:269. I854. 2. Mortillet Le Cerisier 2:181, 210. I866. 3. Leroy Dict. Pom. 5:170 fig., 171. I877.

Schöne von Ribeaucourt. 4. Mathieu Nom. Pom. 335, 377. I889.

This variety probably originated in Northern France. Fruit globular, flattened at the ends, large, usually borne in twos; stem long; cavity large, deep; skin transparent, red, more intense in the sun; flesh yellow, rose-colored under the skin, sweet, juicy, acidulated; pit small, oval, round; ripens about the middle of June.

Belle de Rochelle. Species? I. Gard. Chron. I068. I861.

Mentioned as remarkable for its size, its abundant juice and rich flavor which are said to make it one of the best fruits of its season. Its long stems facilitate picking.

Belle de Rocmont. P. avium 1. Duhamel Trait Arb. Fr. 1: I67, I68. I768.

Glanzende goldgelb und roth marmorirte Kramelkirsche. 2. Kraft Pom. Aust. I:3, Tab. 5 fig. 2. 1792.

Schöne von Rocmont. 3. Truchsess-Heim Kirschensort. 3II-3I6. I8Ig.

Pigeon's Heart. 4. Prince Treat. Hort. 30. 1828.

Bigarreau belle de Rocmond. 5. Lond. Hort. Soc. Cat. $46 .{ }_{18}$ I.

Coeur de Pigeon Gros. 6. Ibid. 48. I831.

Pigeon Heart Bigarreau. 7. Prince Pom. Man. 2:127. I832.

Bigarreau de Rocmont. 8. Poiteau Pom. Franc. 2 :No. 6, Pl. I846.

Rocmonter Marmorkirsche. 9. Dochnahl Führ. Obstkunde 3:39. I858.

Rothe Spanische Marmorkirsche. Io. Ibid. $39,40 . \quad{ }_{1} 858$. 
Belle de Rocmont is so similar to Yellow Spanish that some writers consider them the same. If not the same they are so nearly so that a description of this variety is unnecessary.

Belle de Saint Tronc. P. avium. 1. Thomas Guide Prat. 27. 1876. 2. Flor. Gै Pom. 117. 1878. 3. Mathieu Nom. Pom. 334, 359. I889.

This Heart cherry was introduced in ${ }_{1} 873$ by M. Antonie, Marseilles, Bouches-duRhône, France. It is described by the French as a brownish-black cherry but Rivers lists it as a light red sort. Fruit cordate; stem short; brownish-black; flesh deep red, juicy; first quality; early; productive.

Belle Vezzouris. Species? I. Downing Fr. Trees Am. 278. I857. 2. Thomas Am. Fruit Cult. 664. I 897 .

A medium to large, light red, somewhat transparent cherry with a subacid flavor; quality good; ripens with Downer.

Belle de Voisery. P. avium. 1. Mathieu Nom. Pom. 334. 1889. 2. Guide Prat. 17. I895.

Similar to Duchesse de Palluau according to Guide Pratique.

Bender (of Michigan). P. cerasus. I. Wood Cat. 32. I912.

This is a seedling found by a man named Bender near Shelby, Michigan. It ripens between Early Richmond and Montmorency, surpassing the latter in size, color and quality; sour.

Bender (of New York). P. avium $\times P$. cerasus.

Marguerite. I. McKay Cat. 7. 1912.

This variety is an accidental seedling found by J. O. Bender, Fayetteville, New York, about 1875 . It is a late cherry of the Duke group. The fruit is attractive both in size and color, making a valuable market sort. Fruit roundish-cordate to oblate, compressed; cavity medium, flaring; suture very shallow; stem slender, above medium in length; skin of medium thickness and toughness, separating from the pulp, light red, yellowish on the shaded side; flesh pale yellow, somewhat coarse and stringy, tender, melting, subacid, juicy; good in quality; stone large, slightly clinging along the ventral suture. Very similar to Late Duke.

Berlin Amarelle. P.cerasus. I. Can. Exp. Farms Rpt. 549. I901.

A vigorous variety received from L. Spath, Berlin, Germany. Fruit medium to large, oval; skin glossy red; flesh tender, juicy, pleasingly acid; season from the middle to the last of July in Canada.

Bernard. P. cerasus. I. Am. Hort. An. 88. 1869.

Described by D. B. Wier, Lacon, Illinois, as a seedling of the Morello group. Tree vigorous, pyramidal in growth; fruit the size, shape, color and flavor of English Morello but with a smaller pit.

Bettenburger Glaskirsche. $P$. avium $\times P$. cerasus. I. Truchsess-Heim Kirschensort. 445, 446, 689. I819. 2. Ill. Handb. I 7 I fig., 172. I860.

Transparent de Bettenburg. 3. Mas Le Verger 8:77, 78, fig. 37. 1866-73.

Belle Allemande. 4. Thomas Guide Prat. 25 . 1876.

Truchsess, a German, grew this variety from a stone of the Prager Muscateller, in 
1794. The tree has a close growth and with its large, wide leaves is easily recognized from other light Duke cherries. The fruit is often confused with Double Glass but the color is darker, the stem longer and thicker, the flavor sweeter, and the season from eight to ten days later. Tree moderately vigorous; fruit large, cordate, rather obtuse, with a pronounced suture extending into the cavity; stem long, set in a smooth, shallow cavity; skin tough, clear purple changing to dark red; flesh yellowish-white, transparent, juicy, not colored unless well ripened, sweetish-sour, slightly aromatic; stone of medium size, globular, plump, truncate at the base; season late.

Bettenburger Herzkirsche. P. avium. I. Ill. Handb. 65 fig., 66 . 1860.

Bettenburger Schwarze Herzkirsche. 2. Truchsess-Heim Kirschensort. I 15, I 6. I8I9. Guigne de Bettenbourg. 3. Mortillet Le Cerisier 2:301. 1866.

This variety is a seedling of a worthless black Heart cherry, raised by Truchsess in 1794. Fruit very large, flattened, heart-shaped, sides compressed; stem short, set in a shallow cavity; apex slightly depressed; skin tough, deep dark-brown with light spots. turning black when ripe; flesh tender, juicy, very sweet; stone almost small, plump, roundish; season the last of June in Germany.

Bettenburger Kirsche von der Natte. P. cerasus. I. Truchsess-Heim Kirschensort. 507-5Ir. I8I9. 2. Dochnahl Fuhr. Obstkunde 3:6r. 1858.

A variety received by Truchsess as Kirsche von der Natte and disseminated by him as such. After a few years he found that it was not true to name and to avoid further confusion added the word Bettenburger. Fruit large, roundish, flattened at the base; suture indistinct; stem short, slender, shallowiy inserted; skin tough, dull, dark brown, inclined to black; flesh dark red, juicy, aromatic, subacid; stone not large, plump; ripens the middle of July in Germany.

Bettenburger Weichsel. P. cerasus. I. Dochnahl Fïhr. Obstkunde 3:62,63. $185_{5} 8$.

Bettenburger Weichsel Grosser Gobet. 2. Truchsess-Heim Kirschensort. 52 I, 522, 523. 1819 .

Bettenburger Weichsel von der Natte. 3. Liegel Syst. Anleit. I7 1. I825.

Griotte de Bettenbourg. 4. Thomas Giide Prat. 22, I94. 1876.

This German variety came from seeds of Grosse Gobet planted by Truchsess in 1794 . Fruit very large, sides compressed; skin tough, dark brownish-red; flesh and juice dark, pleasingly sour, improves if left on the tree; stone large, cordate, pointed.

Bicolor Van Mons. Species? I. Mortillet Le Cerisier 2:99, 208. I866.

Fruit medium in size, slightly elongated; attractively variegated with red; of mediocre quality; matures the last fortnight of June.

Bigarreau Abbesse de Mouland. P. avium. I. Mathieu Nom. Pom. 334. I889.

Listed in the reference given.

Bigarreau Antoine Nomblot. P. avium. 1. Rev. Hort. 569, 570, Pl. I91 2.

In 1903 , Alfred Nomblot pianted what he believed to be a seed of Bigarreau Dönnissen but the resulting tree in many of its characters resembled Bigarreau Noir de Kruger which stood near the supposed parent. A cross between these varieties might result in a dark fruit similar to this. Tree vigorous, upright, very productive; fruit above medium in size, cordate, attached in ones, twos and threes; stem long; skin marbled with purple 
changing to black; flesh firm, sugary, juicy, high flavored; pit small, ovoid; early. Recommended by the Société Pomologique de France as a good, early cherry.

Bigarreau Blanc Précoce. P. avium. I. Mas Pom. Gen. II:I44. ISS2.

A short description of the tree-characters is given in this reference.

Bigarreau Blanc-Rosé de Piémont. P. avium. I. Thomas Guide Prat. 22. IS76. 2. Givide Prat. 17. rS95.

Matures late; according to Guide Pratique, I895, it is very similar to Napoleon.

Bigarreau Bordan. P. avium. I. Leroy Dict. Pom. 5: 183 , I84 fig. 1877 .

Bordans frihe weisse Herzkirsche. 2. Dochnahl Fïhr. Obstkunde 3:27. I 858 .

Bordans Herzkirsche. 3. Ill. Handb. 97 fig., 98. I860. 4. Thomas Guide Prat. I8. I97. 1876 .

Guigne Blanche de Bordan. 5. Mortillet Le Cerisier 2:97, 98, 208. I866.

This variety was raised by M. Bordan of Guben, Prussia, Germany, and was first described by Oberdieck. Leroy lists it as a Bigarreau as he believes the flesh is too firm for a Guigne as many Germans have described it. Tree hardy, productive; fruit usually borne in pairs, elongated-cordate, sides and base often compressed; suture shallow; stem long, slender, set in a wide, deep cavity; skin glossy, yellowish, spotted and streaked with red, becoming almost entirely washed with red in the sun; flesh tender, whitish, juicy, sugary, slightly acidulated, pleasing; stone medium, oval, turgid; season early.

Bigarreau de Bourget. P. avium. I. Mathieu Nom. Pom. 335. I889.

Listed without a description by Mathieu.

Bigarreau Brun. P. avium. I. Knoop Fructologie $2: 35$. $177 \mathrm{I}$.

Not described.

Bigarreau de Capucins. P. avium. r. Gard. Chron. N. S. 19:255. I883.

Kapuziner Knorpel. 2. Mathieu Nom. Pom. 364. 1889 .

This variety is little known out of Belgium. Tree vigorous, productive; fruit large, obtuse-oblong, regular, depressed at the ends; skin amber-yellow, blushed with red; flesh white, crisp, juicy.

Bigarreau de la Caserne. P. avium. I. Gard. Chron. 663. 1866.

According to the reference this variety is spoken of in La Belgique Horticole as a variety with prodigious leaves, yellow fruit dashed with red and of good quality.

Bigarreau Cayenne. P. avium. I. Thomas Guide Prat. 22. I876. 2. Leroy Dict. Pom. 5: I 86 fig. 1877 .

Cayenner Knorpelkirsche. 3. Proskaner Obstsort. 55. 1907.

This variety was received by Leroy in ${ }_{1} \delta_{57}$ from Angouleme, Charente, France. Fruit generally borne in pairs; of medium size, oval, somewhat cylindrical, compressed at the cxtremities, with a large, rather deep suture; apex generally prominent; stem long; cavity broad and regular; skin thick, yellow, washed with pale red changing to lively red in the sun; flesh yellowish, firm, brittle, juicy, sweet, slightly sugary and aromatic; pit large, oval, slightly convex; ripens the last of June to the first of July.

Bigarreau de Châlons. P. avium. I. Mortillet Le Cerisier 2: 13 I, I32, 209. I866.

A local variety, widely known in the departments of Jura and Saône-et-Loire, 
France, as Châlonnaise. Fruit large, roundish-cordate, depressed at the base, one face flattened, the other bulged; suture slight; stem short; skin a deep purple tint in the sun, spotted with clear red in the shade; flesh white or of a slight rose color, with uncolored juice, sugary, aromatic; pit small; season the middle of June.

Bigarreau de Champvans. P. avium. I. Thomas Guide Prat. 27. I876. 2. Guide Prat. I7. I895.

This is an excellent cherry of the Bigarreau type with colored juice and transparent skin, which originated in the department of Saône-et-Loire, France; said in the second reference to be similar to Napoleon.

Bigarreau Corniola. P. avizm. I. Leroy Dict. Pom. 5:191, I92 fig. I877.

The name Corniola is derived from cornaline, the French for cornelian. Tree medium in size and productiveness; fruit attached in twos or threes, large, roundish, slightly compressed at the ends and faces; suture deep; stem short, set in a rather deep cavity; skin whitish-yellow, largely washed with rose color and spotted with deep carmine; flesh yellowish, firm, not fibrous, juicy, sugary, slightly acidulated; first quality; season early June.

Bigarreau Court Picout Hâtif. P. avium. I. Mas Pom. Gen. I I: I59. I882.

Listed in this reference.

Bigarreau Court Picout Tardif. P. avium. r. Mas Pom. Gen. II: I59. I882.

Mentioned in the reference given.

Bigarreau Dönnissen. P. avium. 1. Thomas Guide Prat. I6, I89. 1876.

Dönnissens gelbe Knorpelkirsche. 2. Liegel Syst. Anleit. I62. 1825. 3. Dochnahl Führ. Obstkunde 3:44. 1858. 4. Ill. Handb. I45 fig., I46. I86o.

Bigarreau jaune de Dönissen. 5. Mortillet Le Cerisier 2:304. I 866.

This variety is a seedling from Guben, Prussia, Germany, named for the originator; it fruited first about 1824 . Tree vigorous, productive; fruit attached in twos, sometimes threes, large, roundish-cordate; suture slight; stem long, rather stout; cavity broad, shallow; skin glossy, transparent, yellowish-orange when ripe; flesh whitish, firm, slightly fibrous, moderately juicy, sugary, pleasingly acidulated; first quality; pit large, ovoid, plump; ripens the last of June to the first of July.

Bigarreau Doré. P. avium. I. Thomas Guide Prat. 22. 1876. 2. Guide Prat. I5. 1895. Fruit yellow, round.

Bigarreau Double Royale. P. avium. r. Leroy Dict. Pom. 5:195 fig., 196. 1877.

Königliche Fleischkirsche. 2. Dochnahl Führ. Obstkunde 3:34. $\quad$ 1858.

Königliche Hergkirsche. 3. Ill. Handb. 467 fig., 468. I86I.

Guigne Royale. 4. Mortillet Le Cerisier 2:301. 1866.

The fact that Oberdieck received this variety from the Sociéte Horticole de Prague under the French name Double Royale leads us to believe, as does Leroy, that it is of French rather than of Austrian origin as many German writers hold. Tree vigorous; fruit usually borne in pairs, large, cordate, rather abrupt at the ends; stem long, slender; cavity shallow; suture almost indistinct; skin glossy, reddish-brown to nearly black; flesh moderately tender, red, juicy, vinous, sweet; quality very good; pit small, ovoid, turgid; ripens about the middle of June.

Bigarreau Dur. P. avinm. I. Lond. Hort. Soc. Cat. $46 . \quad$ I831.

Listed in this reference without description. 
Bigarreau Duranno. P. avium. I. Leroy Dict. Pom. 5:191. I877.

This variety is first mentioned by Leroy in IS68, appearing in his catalog of 1875 incorrectly as Bigarreau Duracino. The trees are used for stocks. Fruit large, roundishcordate, uneven; suture narrow; stem long, slender; skin deep red in the sun; flesh firm, dry, acidulated, sugary; matures early in July.

Bigarreau Galopin. P. avium. I. Mas Pom. Gen. II: $159 . \quad$ I882.

Mentioned in this reference.

Bigarreau Glady. P. avium. I. Leroy Dict. Pom. 5: 206 fig. I 877 .

This variety was sent from the Jumard nursery about 1850 to Eugène Glady, Bordeaux, France. Fruit above medium in size, cordate, elongated; stem of medium length, set in a straight, deep cavity; skin brownish-red, striped with carmine; flesh a light rose color, firm, crisp, juicy, sugary, slightly acidulated; first quality; pit of medium size; ripens the first of June.

Bigarreau Grand. P. avium. 1. Pom. France 7:No. 13, Pl. 13. I8; I, 2. Guide Prat 15. 1895 .

This cherry was introduced into the vicinity of Lyons, France, in I 849 by M. Grand who probably brought it from his nurseries in Italy. It has many characters in common with Lyons. Tree moderately vigorous, productive; fruit large, roundish-cordate, truncate at the base; suture wide, deep; stem medium, straight, set in a wide, deep cavity; skin thin, smooth, changing from a whitish-green to a rose-red and later to a deep crimson; flesh fine, half-tender, rose-colored, lighter near pit, with pale juice, sugary, aromatic; good; pit large, oval; season very early.

Bigarreau Groll. P. avium. I. Ill. Handb. 135 fig., I36. I860. 2. Leroy Dict. Pom. 5:207 fig., 208. 1877 .

Grolls bunte Knorpelkirsche. 3. Truchsess-Heim Kirschensort. 328, 329. I8I9.

Bigarreau blanc de Groll. 4. Guide Prat. 17, I82. 1895.

This seedling from Guben, Prussia, Germany, bearing the name of its originator, has been known and rather widely written about since early in the Nineteenth Century. Tree of moderate vigor; fruit generally borne in pairs, large, cordate, truncate at the base; sides compressed and marked by a suture; stem long, set in a wide, shallow cavity; skin red, becoming darker, spotted and streaked; flesh yellowish, somewhat firm, juicy, aromatic; first quality; stone large, oval; ripens in June and hangs for a long time.

Bigarreau Gros Noir de Luther. P. avium. I. Thomas Guide Prat. 22. 1876.

Listed in the reference given.

Bigarreau Hâtif de Champagne. P. avium. I. Thomas Guide Prat. 27. 1876. 2. Guide Prat. 17. 1895 .

Found at Champagne, Ain, France, and introduced in 1873 by M. Fandon. The tree is an erect, vigorous grower; fruit large, brownish-black, ripening two weeks before Lyons; of little value.

Bigarreau Hâtif de Saint-Laud. P. avium. I. Mas Pom.Gen. II: 107, 108, fig. 54. I882.

2. Mathieu Nom. Pom. 337. I889.

Fruit large, cordate, slightly irregular in outline; stem rather short, set in a wide, round cavity; skin clear red, striped with deeper red changing to purple; flesh rather 
tender, tinged red, with abundant colored juice, sugary, vinous; good; pit small, ovoid, slightly compressed; matures the middle of June.

Bigarreau d'Italie. $P$. avium. I. Mortillet Le Cerisier 2:102-104, 219, fig. 21.1866. 2. Leroy Dict. Pom. 5:211, 212 fig. I877.

Bohemian Black Bigarreau. 3. Hogg Fruit Man. 69, 76, 94. I866.

Black Bohcmian. 4. Fish Hardy-Fr. Bk. 2: 104. I882.

This old variety was much esteemed by the Italians and later by the Belgians who grew it as early as 1815 ; it is of more recent introduction into France and England. It is sometimes confused with the Florence of Hogg and Downing. Fruit roundish, slightly heart-shaped, flattened at both ends; suture distinct; stem thick, short, inserted in an acute, deep cavity; skin firm, thick, glossy, very deep purple changing to black; flesh firm, dark, juicy, sugary, aromatic; pit medium, roundish-oval, convex, suture and grooves prominent; season the last two weeks of June.

Bigarreau Jacquet. P. avium. I. Mathieu Nom. Pom. 337. I889.

Listed in this reference.

Bigarreau Jumard. P. avium. x. Leroy Dict. Pom. 5: 206. I877.

Mentioned as having been received by Eugène Glady, Bordeaux, Gironde, France, in a shipment of trees received about $185^{\circ}$ from the Jumard nursery.

Bigarreau Krüger. $P$. avium. x. Leroy Dict. Pom. 5:215, 216 fig. I877.

Bigarrcau noir de Kriuger. 2. Thomas Guide Prat. 22, 190. 1876.

Krüger's Schwarze Knorpelkirsche. 3. Mathieu Nom. Pom. 366. 1889.

This variety was introduced into France by M. Eugène Glady, 1858 , from Guben, Prussia, Germany, and is thought to have been originated by one of the Krüger family. Tree vigorous, bears early; fruit large to above, cordate, more or less roundish, faces compressed; suture wide; stem long, slender, set in a large cavity; skin yellowish-white, mingled with red, changing to brownish; flesh pale yellow, rather firm, slightly fibrous, juicy, sweet though sprightly; pit large, elongated-oval, flat; ripens toward the middle of June.

Bigarreau Legrey. P. avium. I. Hogg Fruit Man. 69, 74. I866.

A small, cordate-shaped Bigarreau, more curious than useful.

Bigarreau de Lory. P. avium. 1. Truchsess-Heim Kirschensort. 205. I819.

Bigarreau de Loire. 2. Mas Pom. Gen. II I I59. I882.

Mentioned as a medium-sized, dark brownish-red, firm-fleshed fruit

Bigarreau Marjolet. P. avium. x. Guide Prat. 7. 1895.

Guigne Marjolet. 2. Mas Pom. Gen. II:I35, 136, fig. 68. I882. 3. Mathieu Nom. Pom 360. I889.

Bigarrean Marjeollais. 4. Ibid. 337. $\quad$ I889.

Marjolets Knorpelkirschc. 5. Proskaner Obstsort. 57. 1907.

The descriptions of the Guigne Marjolet and the Bigarreau Marjolet are identical and we have combined the two. The variety was named after its originator, M. Marjolet; tree vigorous, productive; fruit large, roundish-cordate, dark red; flesh tender, red, vinous, pleasing; ripens the middle of June.

Bigarreau Mongin. P. avium. I. Can. Exp. Farms Rpt. $482 . \quad 1904$.

Tree of medium growth; fruit medium in size, cordate; stem long, inserted in a deep 
cavity; skin clear yellow blushed with red; flesh yellowish-white, tender, juicy, sweet, pleasant; ripens in July in Canada.

Bigarreau Monstreuse de Bavay. P. avium. I. Am. Pom. Soc. Rpt. 235. I 854.

Spoken of, in $18_{54}$, as promising but evidently it has been discarded as no reference has been made to it since that date. It may be Reine Hortense.

Bigarreau Moreau. P. avium. I. Rev. Hort. 552, 553, Pl. I913.

This cherry recently originated as a chance seedling near Lyons, France, several persons claiming the honor of its discovery. Its value was discussed at the meetings of the Société Pomologique de France in 1909 and $19 \mathrm{II}$ when it was adjudged by leading French pomologists to be one of the earliest of all varieties, earlier than Lyons, and showing high commercial possibilities. Tree handsome in type of growth, with open, somewhat erect branches; leaves large, deeply serrate; fruit very large; color beautiful clear red becoming darker at maturity; flesh white, breaking, very firm, with uncolored juice, sweet, very refreshing; stone medium to small; season in France very early.

Bigarreau Napoléon Noir. P. avium. I. Thomas Guide Prat. 22. I876.

Bigarrean Noir Napoléon III. 2. Leroy Dict. Pom. 5:227 fig., 228. I877.

Napoléon Noir. 3. Hogg Fruit Man. 307. 1884.

Herzkirsche Napoléon III. 4. Mathieu Nom. Pom. 362. 1889.

The origin of this cherry is uncertain. Leroy first noted it in the Simon-Louis catalog in 1867 . To avoid confusion with the well-known Napoleon, he added the number III. Fruit usually attached in pairs, large, varying from elongated-oval to cylindrical; stem long, set in a large cavity; color dull red changing to deep maroon; flesh rose-colored, moderately firm, very juicy, sweet; ripens the last of June.

Bigarreau Noir d'Ecully. P. avium. I. Mathieu Nom. Pom. 338. I889. 2. Cat. Cong.

Pom. France 522. 1906.

Ecullyer Knorpelkirsche. 3. Proskaner Obstsort. 55. 1907.

Tree vigorous, productive; fruit medium in size, black at maturity; flesh firm, crisp, dark, vinous, sugary, juicy, good; late.

Bigarreau Noir à Gros Fruits. P. avium. I. Le Bon Jard. 345. I882.

Fruit large, flattened; flesh firm, sweet; first quality; ripens early in June.

Bigarreau Noir de Heintzen. P. avium. I. Thomas Guide Prat. 22, 190. I876.

Heintzen's (Heintze's) Schwarze Knorpelkirsche. 2. Mathieu Nom. Pom. 362. I889.

This is said to be a very good and productive cherry ripening in the fifth week of the cherry season.

Bigarreau Noir de Tabor. P. avium. I. Thomas Guide Prat. 19, 190. I876.

Tabors schwarze Knorpelkirsche. 2. Ill. Handb. 79 fig., 80. I860.

Tree vigorous, upright; fruit of medium size, cordate, often obtuse; sides compressed; suture but a line; stem medium long; cavity variable; skin glossy, dark reddish-brown; flesh firm, dark red, sweet, rich; stone small, roundish; ripens the last of June.

Bigarreau d'Octobre. P. avium. I. Am. Pom. Soc. Rpt. 243. I 858 .

Oktobor-Knorpelkirsche. 2. Dochnahl Führ. Obstkunde 3:38. $\quad{ }^{8} 85^{8}$.

This variety was refused a place on the American Pomological Society's fruit list in I858. Fruit small, oval to roundish-cordate, flattened at the cavity; stem short; skin black, glossy; stone large, oval; good. 
Bigarreau de l'Once. P. avium. 1. Thomas Guide Prat. 20, 190. 1876. 2. Mas Pom. Gen. II: 5 , 6, fig. 3. I882.

It is thought that this variety originated in the vicinity of Nice, Alpes-Maritimes, France. Fruit very large, elongated-cordate; suture distinct on one side, a colored line on the other side; stem very long, slender; cavity deep, large; skin a clear cherry-red on a yellow ground; flesh yellowish, crisp, firm, sweet, refreshing, with abundant, uncolored juice; quality good; pit large; season the first of July.

Bigarreau Pourpré. P. avium. 1. Thomas Guide Prat. 20, 190. 1876.

Gros Bigarreau pourpré. 2. Mortillet Le Cerisier 2:212, 21 5, 2 I8. 1866.

Tree vigorous; fruit large, roundish-cordate; skin deep reddish-brown; flesh firm, good; ripens early in July.

Bigarreau Printanier d'Oullins. P. avium. I. Mas Pom. Gcn. II: I59. I882.

Mentioned in this reference.

Bigarreau Reverchon. $P$. avium. I. Mortillet Le Cerisier 2: I33. I866. 2. Leroy Dict. Pom. 5:235 fig., 382. I877. 3. Hogg Fruit Man. 285. 1884.

M. Paul Reverchon introduced this variety about 1855 , into France from Italy, where it had long been known about Florence as Bigarreau Papal. Tree vigorous, moderately productive; fruit attached in ones or twos, large, obtuse-cordate, marked distinctly on one side by the suture; stem thick, short, set in a prominent cavity; skin smooth, glossy, tough, rose-yellow streaked with purple in the sun and with red in the shade; flesh light red, crisp, fibrous, moderately juicy, rather sweet; pit small, ovoid, plump; season the last of June to the first of July.

Bigarreau Richelieu. P. avium. 1. Leroy Dict. Pom. 5:235, 236 fig. 1877.

This variety, says Leroy, was introduced into France from Nikita, Crimea, Russia, about $185^{8}$. Fruit borne in pairs, large, elongated-cordate, with one side flattened; stem long, inserted in a small mamelonated cavity; skin glossy, yellowish-amber, with a rosecolored blush in the sun; flesh firm, breaking, filamentose, juicy, sweet, aromatic; first quality; stone of medium size, elongated-cordate; ripens the last of June.

Bigarteau Rosa. P. avium I. Leroy Dict. Pom. 5:239 fig. 1877 .

Tree moderately productive; fruit usually borne in pairs, large, elongated-cordate, faces flattened; suture wide, deep; stem long, rather stout, set in a wide cavity; skin yellowish on rose-colored ground, amply washed with brilliant red on which are scattered small, white dots; flesh yellowish-white, firm, compact, filamentose, juicy, uncolored, rather sugary, acidulated, aromatic; second quality; pit large, turgid; ripens the last of June.

Bigarreau Rose Dragon. P. avium. I. Am. Pom. Soc. Rpt. 96. IS77.

Reported by the Committee on Foreign Fruits in 1877 as worthy of trial but not grown at present. Fruit large, pale yellow, with a red cheek; flesh firm, juicy, sweet, good; season the middle of July.

Bigarreau de Schrecken. P. avium. I. Thomas Guide Prat. 20, 190. I876.

Schreckens Kirsche. 2. Mathieu Nom. Pom. 377. I889.

Tree vigorous, productive; fruit large, obtuse-cordate; brownish-black, glossy; flesh moderately firm; first quality; matures in mid-June. 
Bigarreau Strié. P. avium. I. Nortillet Le Cerisier 2: I14, 115, 208. 1866.

Fruit large, elongated-cordate, faces compressed; suture wide; stem short, rather stout; skin many shades of red and purple on a rose-colored ground with flesh-colored spots; flesh reddish, firm, crisp, sweet; juice slightly colored; quality fair; stone small; season early; deteriorates rapidly.

Bigarreau de Trie. P. avium. I. Cat. Cong. Pom. France 13. r887.

Origin unknown, but rather widely cultivated around Trie, Hautes-Pryénées, France. Tree vigorous; fruit of medium size, roundish, compressed, slightly cordate; stem long, slender; skin tough, deep red, transparent, with a slight blush of amber; flesh whitishyellow, very firm, juicy, uncolored, sugary, aromatic; good; season early July.

Bigarreau à Trochets. P. avium. 1. Thomas Guide Prat. 22. ${ }_{1} 876$.

An extremely productive variety distributed in some parts of France; fruit large, red; flesh brittle; ripens in late June.

Bigarreau Turca. P. avium. 1. Leroy Dict. Pom. 5:247, 248 fig. 1877.

This old cherry was described in 1785 as Heaume Rouge but was found in 1862 by Leroy in Florence, Italy, as Bigarreau Turca by which name it was well known. It is probably not of Turkish origin as the name would indicate. Fruit often borne in pairs, large, obtuse-cordate; suture noticeable but not deep; stem short; cavity spacious; color deep red, lightly spotted with gray; flesh rather firm, fibrous, mottled with light red becoming darker near the pit, juicy, sweet, sprightly; pit large, ovoid, plump; ripens late in June.

Bigarreau de Walpurgis. P. avium. I. Leroy Dict. Pom. 5:250 fig. 1877 .

St. Walpurgiskirsche. 2. Dochnahl Fuihr. Obstkunde 3:35. 1858.

Walpurgiskirsche. 3. Ill. Handb. 4I fig., 42. 1867.

Cerise Walpurgis. 4. Mas Le Verger $8: 1_{57}, 1_{5} 8$, fig. 77. ${ }_{1} 866-73$.

This variety is a seedling from the village of Walpurgisburg, near Cologne, Germany, originating about 1845 . Tree vigorous, productive; fruit attached in pairs, very large, roundish-cordate, compressed; suture shallow, extending entirely around the fruit; stem slender, rather long; cavity wide, shallow, sides only slightly raised; skin firm, adherent, glossy, dark cherry-red changing to almost black; flesh firm, dark red, juicy, aromatic, vinous; pit of medium size, oval, dark red; ripens late in July.

Bigarreau de Zeisberg. P. avium. I. Thomas Guide Prat. 20, 190. 1876.

Zeisbergische Kirsche. 2. Ill. Handb. 3 I fig., 32. I867.

Cerise de Zeisberg. 3. Mas Pom. Gen. 11:35, 36, fig. I8. I88 z.

Oberdieck received this variety, which bears the name of its originator, from Hanover, Prussia, Germany, in 1857 . Fruit very large, obtuse-cordate; suture wide, flat on the dorsal side, extending slightly beyond the apex; stem long, rather slender, set in a flaring cavity; skin glossy, brownish-black, later becoming black, adhering to the pulp; flesh firm, dark red, juicy, pleasant, with an aromatic sweetness when mature; season the last of June.

Bigarreau Zschedowitzer Schwarze. P. avium. I. Thomas Guide Prat. ${ }^{23}$. ${ }_{1876} 6$

Listed in the reference given.

Bigarreautier à Petit Fruit Noir. P. avium. I. Noisette Man. Comp. Jard. 2:503. I 860.

A mediocre but productive cherry ripening in August. 
Bigarreautier à Petit Fruit Rose. P. avium. I. Noisette Man. Comp. Jard. 2:503. I860.

A variety raised from seed in 1824 ; tree vigorous; stem long; flesh tender, white, sugary; quality fair; July.

Bill and Coo. $P$. avium. I. Downing Fr. Trees Am. 454. 1869.

Two lovers made the original tree their haunt, hence, the name "Bill and Coo." This variety originated on the grounds of Professor J. P. Kirtland, Cleveland, Ohio. Fruit of medium size, regular heart-shaped, flattened at the apex; stem long, slender; cavity deep; suture broad on one side, the opposite side knobby; color amber-yellow, marbled with clear red; flesh rich, delicate, sweet; ripens early in June.

Bismarck. P. avium. I. Hoopes, Bro. \& Thomas Cat. 20. 1907.

This variety is a Sweet Cherry from near Baltimore, Maryland. Fruit very large, dark red, firm, sweet, juicy and rich; vigorous and productive; ripens the first of July. Black American. Species? I. Lond. Hort. Soc. Cat. 47. 1831.

Listed without description in this reference.

Black Bigarreau. P. avium. I. Knoop Fructologie $2: 35,37,38$. 1771. 2. Prince Pom. Man. 2:130. 1832 .

Bigarreau hâtif. 3. Le Bond Jard. 345. I882.

Bigarreau noir Hâtif. 4. Hogg Fruit Man. ${ }_{28}$. 1884.

Black Bigarreau is an old variety of unknown origin quite distinct from any others of its class. Tree productive; fruit medium to large, heart-shaped, obscurely flattened; stem long; skin at first dotted with red, later becoming black, glossy; flesh firm, rather dry, with dark colored juice, breaking, sweet; not high in quality; ripens the last of June and the first of July.

Black Bigarreau of Savoy. P. avium. I. Downing Fr. Trees Am. 185. 1845. 2. Ibid. 256. 1857.

New Large Black Bigarreau. 3. Kenrick Am. Orch. 234, 235. 1841. 4. Downing Fr. Trees Am. 185. I845. 5. Mag. Hort. 16: 538 fig., 539. 1850.

Large Black Bigarreau of Savoy. 6. Mag. Hort. 8:25I. I 842.

II'alsh Seedling. 7. Am. Pom. Soc. Rpt. 196, 197. 1854.

Bigarreau noir de Savoie. 8. Mas Le Verger 8:33, 34, fig. I 5. 1866-73.

The original tree of this variety was brought from the south of France by the father of George Walsh, Charlestown, Massachusetts. The tree came into bearing about IS40. In $\mathrm{I}_{4} \mathrm{I}$, fruits were exhibited from trees introduced into American collections from Italy as New Large Black Bigarreau, and were thought by several people to be the Black Bigarreau of Savoy. Until ${ }_{1} 857$, all writers held these two varieties to be distinct but Downing then declared them to be the same and on his authority we combine the two. Tree vigorous, handsome; fruit large, regular, cordate, slightly obtuse; stem long, rather stout, set in a narrow, even cavity; skin smooth, not very glossy, nearly black when mature; flesh dark purplish-red, firm, juicy, sweet, rich, slightly adherent to the stone; pit rather large; ripens the middle of July.

Black Hungarian Gean. P. avium. I. Lond. Hort. Soc. Cat. 50. I831.

A round, black Guigne of second quality with tender, transparent flesh; used for dessert. 
Black Margaret. Species? I. Watkins Cat. 32. 1892 .

Described as a fine, black, very late, English cherry.

Black Prolific. Species? I. Lond. Hort. Soc. Cat. 55. I 83 I.

Listed in the reference given.

Black Spanish. P. avium. I. Rea Flora 205. 1676. 2. Truchsess-Heim Kirschensort. I 77 -I80 I8I9.

Schwarze oder Späte Herzkirsche. 3. Krünitz Enc. 60, 61. I790.

Spanish. 4. Kenrick Am. Orch. $217 . \quad$ I835.

Schwarze Spanische Knorpelkirsche. 5. Dochnahl Führ. Obstkunde 3:37. 1858.

Bigarreau noir d'Espagne. 6. Thomas Guide Prat. 23, I89. 1876

This is an old variety first mentioned by the English and in all probability is of English origin. It has been greatly confused by some German writers with other black cherries but Truchsess maintains that if placed beside the Grosse Schwarze Knorpelkirsche and the Grosse Schwarze Knorpelkirsche mit Festem Fleische, the two with which it is most often confused, differences could be noted especially as to firmness of flesh and smallness of pit. Fruit large, obtuse-cordate, compressed; suture distinct; stem slender, short; cavity small, smooth, shallow; skin dark reddish-brown changing to black, lighter along the suture; flesh more tender than in most hard-fleshed sorts, dark red, sweet; stone small, adhering before fully mature, colored; ripens early in July or earlier.

Black Turkey Heart. P. avium. I. Watkins Cat. 32. I892.

Fruit large, black, late; suitable for market and home use.

Blasse Johanni Kirsche. Species? I. Thomas Guide Prat. 23. 1876.

Received by Thomas with a recommendation from Baron Emanuel Trauttenberg of Prague.

Bocage. Species? I. Thomas Guide Prat. 25. 1876. 2. Guide Prat. I7. I895.

This variety is said, in Guide Pratique, 1895 , to be similar to Carnation, a Sour Cherry, while Thomas says it is similar to Reine Hortense, a hybrid sort.

Bohemian Queen. P. cerasus. I. Can. Hort. 13:104. 1890.

This variety is said to come true to seed; to be similar in fruit-characters to Ostheim, though larger and more fleshy; to be productive and a cherry of good flavor; and to succeed well in moist land.

Bon Bon. Species? I. Childs Cat. I53 fig. I893.

A very early, large, dark red, juicy cherry; ships well and bears regularly.

Book. Species? I. Pa. Dept. Agr. Rpt. Pt. I:427. 1902.

This is a local variety recommended by John Weitzel, Bethesda, Lancaster County, Pennsylvania. Fruit medium to large, dark red; ripens the middle of June.

Boppard. P. avium. I. Can. Exp. Farms Rpt. 4I5. I 899.

Boppard's Early. 2. Can. Exp. Farm Bul. 2nd Ser. 3:58. 1900.

Bopparder Frühkirsche. 3. Proskauer Obstsort. 55. 1907.

Tree vigorous; fruit large, obtuse-cordate; skin glossy, dark red; flesh red, firm, juicy, sweet.

Boquet Morello. P. cerasus. I. Ia. Hort. Soc. Rpt. 78 . I89o.

Amarelle Boquet. 2. Ibid. 331. I885. 3. Del. Sta. An. Rpt. I2:I10. 1900. 
This is one of Budd's importations of $188_{3}$, according to the third reference. It is often confused with the Boquet Amarelle of the French. The fruit resembles Early Richmond in size, shape, season and color, differing only in its flesh being more firm, its pit smaller, and the tree less productive; of no value commercially.

Boreatton. P. avium. r. Lond. Hort. Soc. Cat. 47. 1831. 2. Elliott Fr. Book 2 I5. I 854 .

A small, roundish-cordate, nearly black Sweet Cherry, with half-tender flesh; poor quality; ripens in mid-July.

Boughton Early Black Duke. $P$. avium $\times P$. cerasus. I. Lond. Hort. Soc. Cat. 47. I83 I. Mentioned in the reference given.

Boulebonner Kirsche. $P$. avium I. Ill. Handb. 47 fig., 48 . I867.

Bigarreau Hâtif Boulbon. 2. Mas Pom. Gen. II: 103, I04, fig. 52. 1882.

This cherry was introduced into Belgium from France some years previous to 1867 . Tree not vigorous, but productive; fruit large, broadly cordate, variable in size and form, sides compressed; suture distinct, deepest near the cavity; apex slightly depressed; stem slender, usually long, set in a wide, shallow cavity; skin a glossy, rose-red color with a yellowish tinge, dotted and streaked with clear blood-red and washed with dark purplish-red; flesh yellowish-white, reddish-white under the skin, firm, juicy, rich, pleasing; stone large, oval, somewhat flattened, with a short point; partially clinging; ripens the last of June and, according to Oberdieck, hangs during wet seasons without cracking.

Bount Dantzic. Species? I. Lond. Hort. Soc. Cat. 47. 183 I.

Mentioned in the reference given.

Bouquet-Herzkirsche. P. avium. I. Dochnahl Führ. Obstkunde 3:23. 1858. 2. Ill. Handb. 7 fig., 8. 1867.

The tree of this variety has the growth of a Sweet Cherry with small, black, Heart fruits borne like the cluster cherries, one, two, three and four on the stem. The single fruits are roundish-cordate, with flattened ends while the double and triple fruits are more narrow and elongated; the fruit matures unevenly, having green, red and black fruits at the same time; pit roundish-oval, slightly pointed at the base, somewhat larger in the double fruits.

Bouquetweichsel. P. cerasus. I. Christ Wörterb. 29I. 1802, 2. Truchsess-Heim Kirschensort. 519, 520,521. 1819 .

This cherry was received by Truchsess in 1796 from Mayer under the name Bouquetkirsche. Many of the flowers have six, seven, eight, and occasionally as high as twelve petals, with two or three pistils. Fruit usually very small, attached to a long, stiff, woody stem shallowly inserted; round, flattened beneath; suture shallow; flesh and juice reddish-black, with a bitterish-sour flavor, which it loses if allowed to remain on the tree; pit of medium size.

Boussieuer Knorpelkirsche. P. avium. I. Proskaner Obstsort. 55. 1907.

A variegated Sweet Cherry.

Bowers' Seedlings. P. cerasus. I. Ia. Sta. Bul. 73:64. I903.

Three seedlings originated with John Bowers, Sigourney, Iowa. No. 1.- Fruit medium, dark red; juice colorless; quality fair. No. 2.- Tree hardy; bears regularly; 
fruit large, oblate, roundish; stem long, slender; skin dark red; juice colorless; fair in quality; late. No. 3.- Fruit large, red to dark red; juice slightly colored, mild subacid; of very good quality.

Bowyer Early Heart. P. avium. I. Lond. Hort. Soc. Cat. 47. I83 т. 2. Kenrick Am. Orch. 234. I84I. 3. Mas Pom. Gcn. I1:I5, I6, fig. 8. I $\$ 82$.

Boyer's Early. 4. Hooper IV. Fr. Book 269. 1857. 5. Thomas Am. Fruit Cult. 665. I 897 .

Roberts' Red. 6. Hooper W. Fr. Book 269. $\quad 1857$.

This variety probably originated in England nearly a century ago. Some writers confuse it with Early White Heart but the two are undoubtedly distinct. Tree vigorous, round-topped, hardy, productive; fruit medium in size, obtuse-cordate, slightly compressed; cavity shallow, wide; suture distinct; stem variable in length; skin of medium thickness, pale amber-yellow overspread with light red; flesh whitish, tender, juicy, sweet, sprightly, refreshing; very good in quality; stone of medium size, short-ovate, plump, blunt at the apex; season early.

Boyd Early Black. Species? I. Am. Pom. Soc. Rpt. I38. I881.

Mentioned in a report from Ohio as a variety of great superiority and value.

Brandon. P. pumila. I. Can. Exp. Farms Rpt. 353. 1896.

A prolific seedling of Prumus pumila; introduced by the Manitoba Station.

Brandywine. P. avium $\times$ P. cerasus. 1. Horticulturist N. S. 5:492, P1. 1855. Downing Fr. Trees Am. 258 . ${ }_{18} 87$.

John R. Brinckle, Wilmington, Delaware, produced this variety from a seed of White Bigarreau grown near May Duke. It fruited for the first time in $185 \mathrm{I}$. Tree vigorous, spreading, productive; fruit above medium in size, roundish, obtuse-cordate; suture indistinct; stem long, slender; cavity shallow, small; skin yellowish, mottled and marbled with light crimson, glossy; flesh semi-transparent, tender, very juicy, sprightly, acidulous; stone rather large: season the last of June; recommended for culinary uses.

Brant. P. avium. 1. Mag. Hort. 19:167, 168. I853. 2. Elliott Fr. Book I9I fig. I $8_{54}$. 3. Downing Fr. Trees Am. 258 . 1857.

Brant was grown by Professor J. P. Kirtland, Cleveland, Ohio, about the middle of the Nineteenth Century, from a pit of Yellow Spanish. Tree vigorous, spreading; fruit large, roundish-cordate, uneven, sides slightly compressed; stem medium, set in an angular cavity; skin thin, lively purplish-red changing to dark purplish; flesh dark purplish-red with indistinct white lines radiating from the center, tender, with abundant, colored juice, sweet and richly flavored; pit medium in size, roundish-oval, nearly smooth; season from the middle of June to the first of July.

Brassington. P. cerasus. I. Call Cat. 5, fig. I9 13.

A chance seedling found in Oceana County, Michigan. Fruit large, dark red, sprightly subacid; ripens with Early Richmond; productive.

Braunauer Glaskirsche. P. cerasus. I. Liegel Syst. Anleit. I68. 1825.

Braunauer Amarelle. 2. Dochnahl Führ. Obstkunde 3:72. I 858.

This variety originated about 1825 . Tree large, moderately productive, with large, Sour Cherry leaves. Often classed as an Amarelle because of the resemblance in the 
branches. Fruit very large, round, compressed; suture distinct; stem very long, shallowly inserted; color dark red, rather cloudy; flesh yellowish, tender, juicy, pleasing subacid when fully ripe; stone of medium size; ripens in August.

Braune Soodkirsche. P. ccrasus. I. Christ Wörterb. 287. I802. 2. Truchsess-Heim Kirschensort. $58_{3}, 58_{4}, 58_{5}$. I 8 I9.

Tree of medium growth; branches drooping; fruit large to very large, flattened, slightly depressed; stem long, set in a rather deep cavity; skin brownish-red; flesh dark red at the stone becoming clear red beneath the skin, tender, with abundant, red juice, pleasing subacid; stone roundish-elongated, one-half an inch long; season the last of July.

Braune Spanische Kirsche. P. avizm. I. Christ Wörterb. 275. ISO2.

Spate braune Spanische Herzkirsche. 2. Christ Handb. 66o. 1797.

Braune Spanische Herzkirsche. 3. Dochnahl Führ. Obstkunde 3:22. $185^{8}$.

This cherry differs from the black Hearts in being smaller, more compressed and sweeter, the flesh softer and more melting. Tree small, productive; fruit small, roundish, compressed on both sides; black, somewhat red on one side; ripens at the end of June. Braunrote Weichsel. P. cerasus. I. Truchsess-Heim Kirschensort. 544, 545. I8I9.

Braune rothe Sauerkirsche. 2. Christ Wörterb. 289 . I 802.

Griotte rouge foncé. 3. Mortillet Le Cerisier 2:306. IS66.

This variety was found in Bernburg, Prussia, Germany. It is distinguished from the other Sour Cherries ripening with it by its lingering brownish-red color, its pleasing, mild sourness, its tender flesh, and by its wood. Tree not large, making a close growth, productive; branches erect; fruit bunch-like, large, almost round, flattened at the ends, sides slightly compressed; stem long, stout, inserted in a rather wide, deep cavity; color remains brownish-red for quite a period, later becoming almost black; flesh tender, with abundant, colored juice, pleasingly sour; stone egg-shaped, almost oval; season the last of July.

Briggs Sweet. P. avium. I. Green-River Nur. Cat. 22. 1899 .

Briggs Sweet was raised from seed in the garden of Dr. J. A. Briggs, South Union, Kentucky, where it has fruited for twenty years. The tree is thrifty, a regular bearer and resembles Wood in appearance of both tree and fruit but is much hardier.

Brindilles. P. corasus. I. Can. Exp. Farms Rpt. 424. I903.

This is a vigorous cherry with a low, slender habit of growth, blooming the middle of June and ripening late in August. Fruit of medium size, round, depressed or oblate; stem long, set in a narrow cavity; skin light, clear red; flesh tender, juicy, sprightly.

Brown Best. P. cerasus. I. Brown Bros. Cat 24. I900.

Brown Best was introduced some twenty-five years ago by Brown Brothers, Rochester, New York, having been budded from an old tree. Fruit large, dark red, tender, sour, rich; quality good; very late; productive.

Brown Seedling. P. avium. I. Elliott Fr. Book 214. I854. 2. Downing Fr. Trees An. 457. I 869 .

Originated in Connecticut. Tree vigorous, upright; fruit medium in size, obtusecordate, compressed with a line and a light suture; cavity broad; skin whitish, shaded and mottled with red; flesh half-tender, juicy, sweet; quality fair; season early July. 
Buckatzsch Weisse Herzkirsche. P. avium. I. Truchsess-Heim Kirschensort. 277, 278, 677,678 . ISI9.

A medium-sized cherry of fair quality from Guben, Prussia, Germany, where it first fruited in $x \mathrm{~S}$. 6 .

Buckatzsch Weisse Knorpelkirsche. P. avium. I. Truchsess-Heim Kirschensort. 34I, 685. I8I9.

This is another seedling from Prussia, Germany; stem of medium length; flesh somewhat tender and light.

Budd No. 533. P. cerasus. I. Wash. Sta. Bul. 92:I4. I910.

This is probably a Russian seedling sent out by Professor J. L. Budd, Ames, Iowa. Tree small, round-topped, with slender, recumbent branches; foliage scant, mostly on the tips of the branches; fruit very large, roundish heart-shaped; stem short, thick; skin tough, thin, dark, mottled red; flesh firm, yellow, slightly stained with red, astringent, subacid; quality fair; stone large, round; season the last of July.

Buffalo. P. avium. I. Gard. Mon. 13:150. I871.

This cherry was received from Buffalo, New York, by Smiley Shepard of Hennepen, Illinois, in the "fifties." The fruit with him proved very hardy and productive and promised to become a valuable sweet variety for prairie orchards. Mr. Shepard sent cions to different localities for testing but nothing has been heard further about the variety.

Bunte Morello. P. cerasus. 1. Ia. Sta. Bul. 19:551. 1892. 2. Budd-Hansen Am. Hort. Man. 2:273. 1903 .

This is not a Morello, though grown in North Silesia under this name. Tree vigorous and hardy, but a late bloomer; fruit large, cordate, reddish; flesh light-colored, juicy.

Burbank. P. avium. I. Burbank Cat. 4, I9. 19 II.

Burbank Early. 2. Leonard Coates Cat. I9II.

This is another of Burbank's cherries, trees of which have not yet fruited at the Station. Trees described as vigorous, sure croppers; foliage very large; fruit very large, attractive deep crimson; season very early. Its large leaves, it is claimed, protect the fruit from the birds and from cracking during late spring rains.

Burchardts Schwarze Rosenobel. P. avium. I. Truchsess-Heim Kirschensort. I66, I67, I8I9. 2. Mas Pom. Gen. II:91, 92, fig. 46. I882.

This cherry was raised by the German pomologist Burchardt from a seed of Rosenobel. Fruit of medium size, obtuse-cordate; stem medium in length, set in a deep, straight cavity; skin purple, changing to almost black; flesh purple, rather tender, juice slightly colored, sweet; first quality; season the first of June.

Burghley Park. P. avium $\times$ P. cerasus. I. Flor. \& Pom. 229, 230. 1870. 2. Gard.

Chron. I057. I 870 .

Burghley Park is a seedling, raised by R. Gilbert, Burghley Park, Stanford, England; it was placed on the list of new fruits of the Royal Horticultural Society in July, I87I. There is a question as to whether it is distinct, some believing it to be Reine Hortense. Fruit very large, usually oval, often flattened, with an obscure suture; stem long, rather slender; skin very thin, transparent, a brilliant dark red if left hanging; flesh dull yellowish-red, veined or netted, very juicy, melting, with a pleasing astringency; ripens in mid-season. 
Burr. $P$. avizun. $\quad$ r. Cole Am. Fr. Book 233. I 849 . 2. Mathieu Nom. Pom. 342. I889. Semis de Burr. 3. Nas Le Verger 8:163, 164, fig. So. I866-73.

Burr originated about 1844 , with Zera Burr, of Perrinton, New York. Tree vigorous, erect, round-topped, very productive, not always hardy; fruit medium to large, obtuse-cordate with a pointed apex; stem long, slender; skin thin, mottled with light and dark red; flesh whitish, rather tender, juicy, sprightly, agreeably sweet; very good in quality; stone small, irregularly ovate, short, thick; ripens in early mid-season.

Büttner Gelbe Knorpelkirsche. P. avium. I. Truchsess-Hcim Kirschensort. 361, 362, 363. 1819. 2. Mortillet Le Cerisier 2:129, 130 fig. 31. 1866. 3. Leroy Dict. Pom. 5:214 fig., 215. 1877 .

Büttncr's Yellow'. 4. Downing Fr. Trees Am. 185. 1845. 5. Am. Pom. Soc. Cat. $20 \quad{ }^{2} 875$.

Wachsknorpelkirsche. 6. Dochnahl Führ. Obstkunde 3:44, 45. $185^{8}$.

Büttner, at Halle, Prussia, Germany, raised this cherry as a seedling and it is probably superior to any of the varieties originated by this horticulturist. It fruited for the first time about 1800 and was introduced shortly after. It was grown in America as Büttner's Yellow in the first half of the Nineteenth Century and was listed in the American Pomological Society's fruit catalog in 1875 but was dropped in 1899 . Tree strong, vigorous, hardy, productive; fruit of medium size, roundish-cordate, flattened at the base; suture indistinct; stem thick, inserted in a broad, shallow cavity; skin firm, thick, pale yellow, slightly spotted with brownish-red; flesh pale yellow, firm, breaking, juicy, sweet, aromatic, with a rich, lively flavor; quality good; stone small, roundish-ovate, free; ripens early in July. Büttner Rothe Herzkirsche. P. avium. I. Truchsess-Heim Kirschensort. 236, 237. I 8 I9.

Buttncr's rothe Molkenkirsche. 2. Dochnahl Führ. Obstkunde 3:29. 1858.

Another seedling raised by Büttner about 1797 and later tested by Truchsess. Tree vigorous, very productive; fruit of medium size, heart-shaped, with sides somewhat compressed; stem long; skin yellowish-white mingled with clear red, sometimes dark red; flesh yellowish-white, very soft, juicy, sweet; quality fair; stone small, heart-shaped; matures the first half of July.

Büttner Rothe Knorpelkirsche. P. avium. I. Truchsess-Heim Kirschensort. 299, 300, 301. 1810 .

Bittner's rothe Marmorkirsche. 2. Dochnahl Fithr. Obstkunde 3:43. I8 58 .

Bigarrcau rouge de Buitner. 3. Mortillet Le Cerisier 2:132. I866. 4. Leroy Dict. Pom. 5:240 fig., 241. I877.

Grown from seed about I795, by Büttner. Büttner Spăte Rote, one of Büttner's seedlings is similar to this one. Tree vigorous, productive; fruit large, obtuse-cordate, with a shallow suture; skin thick, lively red on one side and shaded with carmine on the other; flesh yellowish, firm, breaking, strongly adhering to the pit, sweet, aromatic; quality good; stone of medium size, round; matures the last of June or the first of July.

Büttner Schwarze Herzkirsche. P. avium. I. Truchsess-Heim Kirschensort. 122, 123, 124. I819. 2. Elliott Fr. Book 204, 205. I854. 3. Mortillet Le Cerisier 2:64 fig., $65,66 . \quad 1866$. 
Büttner's schwarze neue Herakirsche. 4. Christ WÖrterb. 275. I $\mathrm{SO}_{2}$.

Bigarreau Noir Bütner. 5. Leroy Dict. Pom. 5:222 fig. 1877.

Still another variety obtained from seed by Bütner in $\mathbf{1 7 9 5}$. With several others it was sent to Truchsess, about 1801 , for testing. Tree strong, vigorous, erect, hardy, productive; fruit large, obtuse-cordate, compressed; suture prominent; stem of medium length, set in a deep cavity; skin firm, glossy, deep reddish-black; flesh dark red, moderately firm, juicy, sweet and pleasant; quality good; stone of medium size, roundish-oval; ripens early in July.

Büttner Schwarze Sauerkirsche. P. cerasus. I. Truchsess-Heim Kirschensort. 601, 602, 603. 1819 .

Buittner's schwarze nene Sauerkirsche. 2. Christ IVörterb. 289 . ISO2.

Raised from seed by Büttner and sent to Truchsess for testing about 1797. Fruit round, of medium size, glossy, black; flesh firm, red, moderately juicy, agreeably acid; quality fair; ripens in August.

Büttner Späte Rothe Knorpelkirsche. P. avium. I. Truchsess-Heim Kirschensort. 329 , $330,682,683.1819$.

Büttner's harte Marmorkirsche. 2. Dochnahl Führ. Obstkunde 3:43. I858.

Bigarreau Ronge Tardif de Buttner. 3. Mas Pom. Gen. II:I1, I2, fig. 6. 1882.

Buittner's Late Red. 4. Can. Exp. Farm. Bul. 2nd Ser. 3:59. 1900.

Another seedling raised by Büttner early in the Ninetecnth Century and quite similar to Büttner Rote, except in its time of ripening, which is later. Tree of medium vigor, crect; fruit large, heart-shaped, flattened at the base, compressed at the apex; suture medium in depth; skin thick and firm, yellowish-white mingled with red, changing to dark red; flesh yellowish, firm, breaking, sweet, aromatic, with abundant, uncolored juice; quality good; stone large, oval, slightly clinging to the flesh; matures the last of July.

Buittner Späte Weichsel. P. cerasus. I. Ill. Handb. 53 I fig., 532. I861.

Bütner's September und Octoberweichsel. 2. Truchsess-Heim Kirschensort. 609. I819.

Buitner's October Zucker Weichsel. 3. Lond. Hort. Soc. Cat. 47. 1831.

Buittner's Sehrspäte. 4. Ibid. 47. 1831.

Büttner's October Morello. 5. Downing Fr. Trees Am. 193, 194. 1845. 6. Am. Pon. Soc. Cat. 74. 1862.

Griotte Tardive de Büttner. 7. Mas Le Verger 8:95, 96, fig. 46. 1866-73.

Bigarreaut Tardif Büttner. 8. Leroy Dict. Pom. 5:245 fig., 246. I 877 .

Bittner's October. 9. Hogg Fruit Man. 288. 1884.

Produced from seed about ISoo, by Büttner. As one of the latest of all cherries, it was at one time considered of value for culinary purposes and for a time was grown to a limited extent in this country. The American Pomological Society placed it on its fruit catalog list in 1862 but dropped it in 1869 . Tree hardy, productive; fruit often hangs to the tree till October, large, round, somewhat oblate; suture indistinct; apex depressed; stem long, slender; cavity shallow; skin thin but firm, reddish-brown, separating easily from the pulp; flesh light red, reticulated with whitish fibers, firm, breaking, juicy, sweet, rich, mingled with pleasant subacid; quality good; stone large, oval, semi-clinging; ripens the last of August and early September. 
Byrnville. Species? I. Mas Pom. Gen. II: I60. 1882.

Listed in this reference.

Cameleon. Species? I. Parkinson Par. Ter. 574. 1629.

A strange cherry, changeable in color, spoken of by Parkinson because of its peculiarities. The fruit is very red in color and of good taste, but varies greatly in color, shape and arrangement. It also bears blossoms, green and ripe fruit at the same time.

Cardinalskirsche. P. avium. I. Christ Obstbäume 159. 179r. 2. Christ Wörterb. 284. I 802 .

A cherry similar to the Doctorkirsche in both tree- and fruit-characters; fruit dark brown, with a subacid flavor.

Carmine Stripe. P. avium. I. Elliott Fr. Book 206. I854. 2. Downing Fr. Trees Am. 258 . 1857.

Cerise Carminée. 3. Mas Pom. Gen. II:23, 24, fig. I2. I882.

Carmine Stripe is a seedling from Professor J. P. Kirtland, Cleveland, Ohio. Tree vigorous, spreading, very productive; fruit above medium in size, heart-shaped, compressed on the sides, surface often uneven, with a suture on one side, followed by a line of carmine; stem variable; skin amber-yellow, shaded and mottled with bright, lively carmine; fiesh tender, juicy, sweet, with agreeable sprightliness; pit small; season the last of June.

Caroline. P. avium. I. Elliott Fr. Book 206. 1854.

Originated by Professor J. P. Kirtland, Cleveland, Ohio. Tree upright-spreading, vigorous; fruit above medium in size, roundish-oblong, one side slightly compressed; color pale amber, mottled with clear, light red, becoming rich red in the sun; flesh tinged with pale red, translucent, tender, juicy, sweet; pit of medium size, oblong, oval; season the last of June. Delicious for dessert.

Catskill. Species? I. Chase Cat. I888.

This variety, sent out by R. G. Chase, Geneva, New York, in I888, is probably now extinct. Fruit of medium size, heart-shaped; skin light yellow, nearly covered with light carmine; stem slender, long; flesh light yellow, juicy, sprightly, mild subacid; good.

Cerise Albanes. Species? 1. Rev. Hort. 284. I86r.

Introduced from Revel, Haute-Garonne, France. It is a fruit of first size, excellent quality, with dark green leaves, productive; fruit white with more or less yellow.

Cerise d'Angleterre Précoce. Species? I. Poiteau Pom. Franc. 2:No. 25, Pl. I 846.

According to Poiteau, this cherry, sometimes called Cerise Nouvelle d'Angleterre, was confused by Duhamel with his Cerise Guigne. Fruit small in the first stages of ripening, later becoming larger, flattened at the base and apex; color clear red changing to almost black at complete maturity.

Cerise de l'Ardèche. Species? I. Thomas Guide Prat. 25. I876.

Belle grosse d'Ardèche. 2. Mas Pom. Gen. Ir: I59. I 882.

Schöne von Ardêche. 3. Mathieu Nom. Pom. 376. I889.

Distinct from other varieties in its manner of growth, according to Thomas.

Cerise Bellon. Species? I. Mas Pom. Gen. Ir: r60. I882.

Mentioned in this reference. 
Cerise de la Besnardière. P. cerasus. 1. Mortillet Le Cerisier 2:181. I866. 2. Leroy Dict. Pom. 5: 172 fig. 1877 .

Kirsche von Bénardière. 3. Nathieu Nom. Pom. 334. I889.

In $184 \mathrm{I}$, Leroy mentioned this variety in his catalog stating that it was found in the gardens of the Baron of Besnardière. Mortillet believed it to be Carnation not being convinced of the contrary until after he had published his description of the Carnation. Tree strong, moderately productive; fruit attached singly, large, globular, compressed at the ends; suture apparent; stem of medium length, inserted in a rather wide, deep cavity; skin clear red, brilliant; flesh reddish at the surface, whitish near the center, tender, with abundant, slightly colored juice, pleasantly acidulated and sweet; first quality; stone small, round, plump; season the end of June in France.

Cerise du Bicentenaire. $P$. avium $\times$ P. cerasus. I. Rev. Hort. $284,285, \mathrm{Pl}$. 1903.

Bicentenaireweichsel. 2. Proskaner Obstsort. 58. 1907.

This variety is supposed to be a bud variation of Royal Duke found in a garden at Lieusaint, France. The trees resemble those of Royal Duke but the fruit is superior in size and ripens from three weeks to a month later. Said to be valuable on northern exposures which increase the advantages of late maturity.

Cerise Blanche à Petit Fruit. P. avium. I. Noisette Man. Comp. Jard. 2:507. I860. Similar to the Cerisier à Gros Fruit Blanc but smaller.

Cerise Commune. P. cerasus. I. Poiteau Pom. Franc. 2: No. I r, Pl. I846. 2. Le Bon Jard. 346 . I $88_{2}$.

One of the French varieties of cherries grown in the neighborhood of Paris to supply the early market trade. Sometimes called La Grosse Cerise Commune.

Cerise à Côtes. P. cerasus. I. Leroy Dict. Pom. 5:258, 259 fig. I 877 .

This cherry is similar in tree and fruit to Large Montmorency but the fruit is traversed on both sides by a prominent suture. Fruit attached in threes, of medium size, globular, compressed at the ends; suture deep, completely encircling the fruit; stem variable in length, inserted in a large, deep cavity; apex slightly depressed; skin clear red; flesh yellowish, transparent, tender, juicy, sugary, acidulated; pit of medium size, round; second quality; season the end of June; moderately productive.

Cerise d'Espagne. P. cerasus. $\quad$ x. Thomas Guide Prat. 25. $\quad 1876$.

Fruit large, deep red, delicious, acidulated, ripening from June to July.

Cerise à la Feuille. P. cerasus. I. Duhamel Trait. Arb. Fr. I: 174, I75. I 768.

The fruit is of medium size, roundish-cordate, faces flattened; stem long; cavity deep and straight; skin deep reddish-brown; flesh red, with an acid flavor which it loses somewhat at complete maturity; stone large, lightly tinted; ripens the middle of July.

Cerise de Gembloux. P. avium. I. Ann. Pom. Belge 8:91, Pl. I860.

M. Staquet Berger of Gembloux, Belgium, grew this cherry from seed. Tree productive, vigorous; fruit large, roundish, slightly cordate; suture pronounced; stem long, slender; skin thin, glossy, nearly black; flesh red, fine, melting, juicy, sugary, acidulated; stone small, oval; ripens the last of July.

Cerise Guigne. P. avium. I. Duhamel Trait. Arb. Fr. I: 195, 196, P1. I6 fig. I. I768. 2. Mortillet Le Cerisier 2:140, I4I fig. 34, I42. 1866. 3. Mas Le Verger 8:159, I60, fig. 78. I866-73. 4. Leroy Dict. Pom. 5:254, 255 fig., $256 . \quad 1877$. 
Griotte Guigne. 5. Prince Pom. Man. 2 : 149. 1832.

Cerise Anglaise. 6. Poiteau Pom. Franc. 2:No. 26, Pl. 1846.

Rothe Muskateller. 7. Ill. Handb. I59 fig., I60. I860.

This cherry is now of historical interest only. It has been called Cerise Guigne since Duhamel described it in 1768 , and may be the variety known long ago by the Romans as Cecilienne. There is no record to show that Cerise Guigne was ever brought to America. Tree large, vigorous, productive; fruit of medium size, roundish-cordate, flattened at the base; suture distinet; stem of medium thickness and length; skin thin; color clear red becoming reddish-brown; flesh clear red, with abundant, colored juice, tender, slightly stringy, sweet, sprightly, agreeable; quality good; ripens early.

Cerise de Mai Double. Species? I. Knoop Fructologie 2:36, 40. 1771.

Briefly discussed by Knoop.

Cerise de Mai Simple. Species? I. Knoop Fructologie 2:36, 40, 41. I771.

Resembles Cerise de Mai Double but smaller.

Cerise de Martigné. Species? I. Mas Pom. Gen. II:147. I882.

The tree-characters are briefly described in this reference.

Cerise de Ostheim. P. cerasus. I. Ia. Hort. Soc. Rpt. $78 . \quad$ I89o.

Ostheim. 2. Ia. Sta. Bul. 73:79, fig. 18. 1903.

In $188_{3}$, Professor J. L. Budd of Ames, Iowa, brought this variety to Iowa. It is very similar to the Minnesota Ostheim but a few days later. Fruit of medium size, round, occasionally cordate; stem of medium length, slender, set in a shallow cavity; skin firm, deep red, with highly colored juice, mildly subacid; quality very good.

Cerise du Prince Maurice. Species? I. Knoop Fructologie 2:36, 41. 177 I.

Tree vigorous, erect, productive; fruit scarlet, with whitish dots.

Cerise de Prusse. P. cerasus. I. Mortillet Le Cerisier 2:151 fig., 152, 153, $221,304$. I 866 .

Guindoux de Provence. 2. Truchsess-Heim Kirschensort. 429, 430. 1819.

Prussian Cherry. 3. Prince Pom. Man. 2:150. 1832.

Provencer Sussweichsel 4. Dochnahl Führ. Obstkunde 3:50. 1858.

Cerise de l'Esvière. 5. Mas Pom. Gen. II: I60. I882.

Cerise de Prusse noire? 6. Ibid. 11:160. 1882.

This old variety is supposed to be of French origin. It is distinguished from other sorts by its cordate form, its more or less distinct suture, its thick skin, and its heartshaped pit. Tree vigorous, moderately productive; fruit rather large, partially cordate, marked by a suture on both sides, more pronounced towards the base; stem of medium length, inserted in a rather deep cavity; skin thick, tough, separating from the pulp, deep reddish, almost black; flesh rather firm, deep red, juicy, sprightly, vinous, with a pronounced acidity; stone rather large, oval-pointed, turgid; ripens early in July.

Cerise de Rouën Double. P. avium. I. Knoop Fructologie 2:36, 42. 177 I.

Tree vigorous and productive; fruit cordate, marked with a suture of moderate depth; color streaked with clear red on a yellow ground; flesh brittle, sweet, very agreeable.

Cerise de Rouën Simple. P. avium. I. Knoop Fructologie 2:42. 1771 .

Resembles the preceding variety in form, color and quality but is somewhat smaller. 
Cerise Rouge Pale. P. cerasus. I. Mas Le Verger 8:89, 90, fig. 43. 1866-73. 2. Leroy Dict. Pom. 5:383, $38_{4}$ fig., 385. I 877 .

Cerisier à Gros Fruit Ronge-pâle. 3. Duhamel Trait. Arb. Fr. I:182, 183, I84, P1. 9. 1768. 4. Kraft Pom. Aust. I:5, Tab. I4 fig. I. 1792.

Villennes. 5. Prince Pon. Man. 2: $140 . \quad$ I 832.

Bleichrothe Glaskirsche. 6. Ill. Handb. 75 fig., 76. 1867 .

This cherry is of interest only because of its past. Of its origin no record can be found. It is first mentioned by Duhamel, in 1768 , under a somewhat longer name, "Cerisier à Gros Fruit Rouge-pâle," which many later writers have confused with Carnation. Tree large, vigorous, productive; fruit large, roundish, flattened; stem long, thick; cavity deep, broad; skin thin; color a clear, brilliant red growing darker as maturity advances; flesh transparent, juicy, firm, tender, sweet, yet sprightly; of very good quality; season late.

Cerise Rouge Sanguine. Species? I. Mas Pom. Gen. II:160. I 882.

Listed in this reference.

Cerise Royale Ordinaire. Species? 1. Poiteau Ponn. Franc. 2:No. 22, P1. I846.

This variety is known in Normandy as Cerise Musquée because of its slight musky taste. Fruit small, sides compressed; skin red; flesh yellowish, juicy, sugary; quality fair.

Cerise de Soissons. P. cerasus. I. Lond. Hort. Soc. Cat. 55. I $8_{3}$ I.

Französiche Süssweichsel. 2. Dochnahl Führ. Obstkunde 3:51. 1858 .

Admirable de Soissons. 3. Downing Fr. Trees Am. 476. I869.

Cerise de Soissons is described as a Morello, medium to above in size, broadly cordate, slightly compressed, with a slight suture; stem short; skin dark red; flesh red, tender, juicy, brisk subacid; ripens the middle of July.

Cerise de Tiercé. Species? I. Mas Pom. Gen. II: I60. I 882.

Listed without a description.

Cerise de Xavier. P. cerasus. 1. Mag. Hort. I7:363. I851. 2. Elliott Fr. Book 2 I 5 . I854.

A Morello cherry, first shown in $1_{5} \delta_{5}$, by M. P. Wilder, Dorchester, Massachusetis. Fruit medium in size, round, dark red, acid.

Cerisier Commun à Fruit Rond. P. cerasus. I. Duhamel Trait. Arb. Fr. 1: 172, I 73 . I768. 2. Truchsess-Heim Kirschensort. 658,659. ISI9.

Under this heading are grouped many wild cherries in France, grown from seeds, whose trees, leaves and flowers vary as well as the size, taste and time of ripening of the fruits. One of the best of these is grown around Paris, the fruit being small; stem long; pit large; quality and flavor variable.

Ceriser Commun Pleureur. P. cerasus. I. Rev. Hort. 397. I888.

This cherry was found in a Sour Cherry plantation. It resembles Montmorency in habit of growth and the Heart cherries in texture of flesh. The tree is used for ornamental planting and its fruit for culinary purposes. Tree very productive, bushy, branches inclined to droop; fruit large, oblong; stem long, inserted in a large cavity; skin glossy, dark red; flesh rose-colored, transparent, sugary, juicy; pit of medium size, elongated-oval; ripens early in June. 
Cerisier à Feuilles Laciniées. P. avium. I. Leroy Dict. Pom. 5:267, 268 fig. 1877 .

This is a chance seedling first mentioned by Leroy in his catalog in $\mathbf{r} 860$. Because of its foliage it is often used as an ornamental. Tree strong, moderately productive; fruit generally attached singly, small, oval; suture apparent; stem long; cavity moderately large; skin clear red, marbled with reddish-brown; flesh firm, yellowish-white, with abundant, uncolored juice, sugary, slightly acidulated; pit of medium size, elongated-oval, plump.

Cerisier à Gros Fruit Blanc. P. avium. I. Noisette Man. Comp. Jard. 2:507. I860.

A cherry ripening in July but described as very sugary and very good; flesh watery, aromatic; productive.

Cerisier Royal Tardif à Fruit Noir. Species? I. Noisette Man. Comp. Jard. 2:506. 1860.

The fruit ripens in July, becoming deep black.

Cerisier Très-fertile. P. cerasus. I. Duhamel Trait. Arb. Fr. I : 175, I76. ${ }_{7} 68$.

Weichselbaum mit bundelförmigen Früchten. 2. Kraft Pom. Aust. 1:5, Tab. I2 fig. I. 1792 .

Cerise à Trochet 3. Lond. Hort. Soc. Cat. 56. 1831. 4. Leroy Dict. Pom. 5:397, 398 fig. 1877 .

Prolific Cherry. 5. Prince Pom. Man. 2: I32. 1832.

Amarelle très-fertile. 6. Mortillet Le Cerisier 2:201 fig., 202, 203. 1866.

Leroy states that this variety was long ago well known in France. Because it was grown in the neighborhood of Angers and Saint-Laud, and was of the Montmorency type, Leroy says it was locally named Cerisier Montmorency Hâtif de Saint Laud. He is doubtful whether it existed before the Eighteenth Century; Duhamel was the first to describe it in 1768 . The tree resembles the Cluster cherry and is probably but a variation of the Cerise Commune type. Tree small; fruit generally attached in threes, of medium size, globular, compressed at the stem; cavity rather deep; apex small, somewhat prominent; stem of medium size, unequal in length; skin transparent, clear red, deeper when mature; flesh tender, white, juicy, sugary, strongly acidulated; stone medium in size, roundish, turgid; ripens the middle of June. Its graceful habit and productiveness make it a favorite for ornamental purposes.

Cerisier de Varenne. Species? I. Noisette Man. Comp. Jard. 2:507. I860.

Belle de Varennes. 2. Mas Pom. Gen. II: I59. 1882.

Tree erect, very vigorous; fruit large, compressed; stem long; color bright red.

Challenge. P. pumila. I. Can. Exp. Farms Rpt. 353. 1896.

Challenge is a Sand Cherry seedling grown in Canada; fair flavor and of medium size.

Champagne. Species? r. Horticulturist 5:76, 77 fig. 1850. 2. Elliott Fr. Book 205. I 854 .

Champagne is a seedling raised by Charles Downing, ${ }^{1}$ Newburgh, New York, and so

${ }^{1}$ Charles Downing, whose likeness we show in the frontispiece, was born at Newburgh, New York, July 9,1802 . He spent his life in the place of his birth, dying January 18,1885 . His parents were natives of Lexington, Massachusetts, who shortly before the birth of Charles Downing, the eldest son, came to Newburgh, the father establishing a shop for the manufacture of wagons, a business which he soon 
named because of the peculiar and lively mingling of sweet and acid in its flavor. Tree very hardy, vigorous, bearing regularly, and withstanding the attacks of rot and blight. Fruit of medium size, roundish-cordate, slightly angular; stem moderately long; cavity shallow, flat; skin lively brick-red, inclining to pink; flesh amber, juicy, sprightly, rich; ripens the middle of June.

Champion. P. pumila. I. Can. Exp. Farms Rpt. 307. 1898.

Champion is one of many seedlings of the Manitoba Sand, a native Canadian cherry named and described in 1898 , by Wm. Saunders of the Canadian Experimental Farms. Fruit large, very dark red, nearly black when ripe; flesh sweet, nearly free from astringency; quality good; ripens in Manitoba the last of August.

Chapman. P. avizm. I. Am. Pom. Soc. Rpt. Izo. I897. 2. Cal. Nur. Cat. I:I4. I898. 3. Ore. Nur. Cat. 2 I. 1903. 4. Am. Pom. Soc. Cat. 26.1909.

Chapman was grown by W. H. Chapman of Napa, California, and is supposed to be a seedling of Black Tartarian, surpassing that variety in size and earliness. By some horticulturists Chapman and California Advance are considered identical, but most growers, particularly in California, declare the two to be distinct. Fruit matures early; very large, roundish, purplish-black; stem long, slender; flesh slightly tender; very good in quality; stone small.

Cheresoto. P. pumila $\times$ P. americana. I. S. Dak. Sta. Bul. I30:I84, Pl. Io, P1. I I, I85. I9II.

Cheresoto is a cross between the Sand Cherry and the De Soto plum from the South Dakota Experiment Station. The tree resembles the plum in growth but the fruit, in looks and flavor, is like that of the Sand Cherry. Fruit rather long with a prickle at the apex; about one and three-eighths inches in diameter; skin black with a bluish bloom, thin, free from acerbity; flesh yellowish-green, sprightly; pit clinging.

abandoned to become a nurseryman. Here, in the first successful nursery established in the region, were trained Charles and Andrew Downing, receiving under the careful guidance of the father a knowledge of the business and of fruits which with later self instruction made them the most distinguished pomologists of their day. With the death of the father in 1822 , before Charles had obtained his majority, the responsibility of conducting the business and the support of the family devolved upon him. Andrew J., the younger brother, in 1834 , at the age of 19 , united with Charles in the management of the nursery business under the firm name of C. \& A. J. Downing, a partnership which lasted only until 1 839 . Charles continued in the nursery business for many years during which time he became the foremost pomologist in the United States and eventually, about 1850 , sold his holdings to devote himself to the study of varieties of fruits and the revision of the Fruits and Fruit Trees of America. This great pomological book was projected and published by Andrew but most of the work of the book as it is now known was done by Charles in revising the original and adding to its many editions. It is and has long been, as all know, the highest authority on American fruits. Naturally of an inquiring turn of mind Charles Downing studied closely the qualities of the varieties that came under his observation and seldom described without the fruit in hand. His variety orchard is said to have contained at one time 1,800 varieties of apples and $\mathrm{I}, 000$ pears with lesser numbers of the other fruits. A few trees of this wonderful collection still stand. Charles Downing was one of the most modest and retiring of men, in his younger days delighting in the things of which his brother wrote and seldom putting pen to paper until after his brother's death when he became a regular contributor to horticultural publications over the signature " C. D." He was never known to make a public speech. He earned his high distinction in American pomology by his accurate and conscientious descriptions and discussions of varieties of fruits. 
China Bigarreau. P. avitum. I. Prince Pont. Man. 2: $126 . \quad 1832$.

China Heart. 2. Prince Treat. Hort. 30. I8 28 . 3. Lond. Hort. Soc. Cat. $48.183 \mathrm{I}$. This variety was raised from the seed of an Ox Heart by William Prince, Flushing, New York, and at first was called China Heart. W. R. Prince in his Pomological Manual of $\mathrm{r}_{3} 3_{2}$, calls it China Bigarreau as it is more of the Bigarreau than of the Heart type of cherries. Tree vigorous, large; fruit medium in size, roundish or oval-cordate, with a distinct suture; stem long, slender, set in a shallow cavity; skin when fully ripe, glossy red mottled with lighter red; flesh firm, somewhat melting, with a sweet, rich, peculiar flavor; ripens just after Black Tartarian and forms a link between it and the later varieties; very productive.

Choque. P. avium. I. Thomas Guide Prat. I5, 191. 1876. 2. Mas Pom. Gen. II: I41, I42. I 882 .

Guigne Choque. 3. Can. Exp. Farms Rpt. 482. I904.

Originated near Metz, Lorraine, Germany. Tree vigorous, productive; fruit rather large; of a deep red color at maturity; flesh white, slightly tinted with a rose color, firm, very juicy, sweet; ripens the last of June.

Christbauer. P. cerasus. I. Mo. Hort. Soc. Rpt. 42. I892.

A sort reported to ripen before Early Richmond.

Christiana. P. avium $\times P$. cerasus. I. Elliott Fr. Book 206. $\quad$ I 854.

This variety was raised by B. B. Kirtland, Greenbush, New York, and resembles May Duke in character of tree and fruit. The fruit is borne in clusters, is of a bright, lively red color, and has a sprightly subacid flavor.

Churchill Heart. P. avinm. 1. Lond. Hort. Soc. Cat. 48. I8 31 . 2. Hogg Fruit Man. 290. I 884 .

Tree hardy, productive; fruit large, heart-shaped; stem long; cavity shallow; skin glossy, of a clear, waxen, pale yellow, bright red when exposed to the sun, mottled with dark red and orange; flesh pale yellow, firm, sweet, rich, moderately juicy; season the end of July.

Cistena. P. pumila $\times$ P. pissardi. I. S. Dak. Sta. Bul. 130:190, 19г. I9II.

Cistena is a cross between the Sand Cherry and Prunus pissardi, interesting only because of its beautiful purple foliage.

Clark September. P. avium. 1. Ont. Fr. Gr. Assoc. Rpt. 22:XVIII. I 890.

Clark September is a local sort from Lower Granville, Nova Scotia. The fruits are of medium size and when fully ripe are of a dark red color; flesh firm, of a sweet and agreeable flavor.

Cluster Black Heart. P. avium. I. Can. Exp. Farms Rpt. 48 I. 1904.

Tree vigorous; fruit small or of medium size, cordate; stem long; skin glossy, black; flesh very dark red, tender, juicy, agreeably mild acid; ripens in July.

Cocklin Favorite. P. avium. 1. Gard. Mon. 3:249 fig., I86 I 2. Downing Fr. Trees Am. $45^{8}$. 1869.

Late Amber. 3. Horticulturist 17:38 I. 1862.

This seedling was introduced by E. H. Cocklin, Shepherdstown, Pennsylvania, but its origin is unknown. Tree upright, conical, very productive; fruit large, roundish, 
regular, slightly compressed, somewhat flattened at the base, almost without a suture; apex depressed; stem long, slender; cavity deep; skin yellowish shaded and mottled in the sun with a light crimson; flesh tender, juicy, sweet, vinous; quality good; stone very small for the size of the fruit; season late.

Coe Late Carnation. P. cerasus $\quad$ r. Elliott Fr. Book $216 \quad$ I 854 . 2. Downing Fr. Trees Am. 275. $\quad 1857$.

Coe's Späte Rote Kirsche. 3. Mathieu Nom. Pom. 343, 344. I 889.

This is a late variety of unknown origin - possibly a seedling of Carnation. Fruit medium to large, cordate; suture shallow; color yellowish-amber mottled with clear red; flesh tender, juicy, subacid; quality fair; season the last of July.

Coeur de Pigeon Noir. Species? I. Mas Pom. Gen. II: I 48. I882.

Fruit of medium size, cordate, slightly elongated.

Coeur de Poule. P. avium. I. Prince Pom. Man. 2: I24. I $8_{32}$.

Gros Bigarreau coenr-de-Ponle 2. Rev. Hort. 65. I 88 I.

According to Prince, this variety was rather extensively cultivated in the south of France especially in the vicinity of Toulouse, where it was known as Cor dè Galino. The fruit ripens in July, has the form of the Hearts; its vivid red changes to nearly black as does also the juice.

Cole. P. cerasus.

Cole is a rather small-sized Morello of little value and no doubt now out of cultivation. Fruit cordate, compressed along the sutures; stem long, slender, set in a wide cavity; skin nearly black; flesh tender, rather meaty, dark red, lighter near the pit, having abundant, wine-colored juice, sour, sprightly; stone clings; season late.

Columbia. P. avium. I. Downing Fr. Trees Am. 459. I 869.

Tree vigorous, spreading, productive; fruit of medium size, heart-shaped, inclining to a point, surface angular and uneven, sides compressed; suture deep, narrow; stem long, slender; cavity large, deep; skin whitish-yellow, blushed and mottled with light red; flesh whitish, stained with pink, tender, juicy, pleasant; season the last of June.

Common Morello. P. cerasus. I. Prince Pom. Man. 2: I43, I44. I832. 2. Am. Pom. Soc. Rpt. 103. 1852.

Wild Morello. 3. Lond. Hort. Soc. Cat. 54. I $8_{3}$ I.

Common Red Morello. 4. Kant. Hort. Soc. Rpt. I+4. IS86

This variety must not be confused with the well-known English Morello. Through self-propagation, it is widely known, as are its many seedlings which oft-times surpass it in size and quality.

Como. Species? I. Mas Pom. Gen. I I: r6o. 1882.

Listed in the reference given.

Comtesse de Médicis Spada. Species? I. Mas Pom. Gen. II: I60. I882.

Listed without a description.

Condé. Species? I. Knoop Fructologie 2:35. $\quad$ I 77 I.

Mentioned in the reference given.

Conestoga. P. avium. I. Mag. Hort. 19:423. 1853. 2. Horticulturist 17:381. I862. Conestoga was introduced by Casper Hiller, Conestoga, Lancaster County, Pennsyl- 
vania. Tree a rampant, spreading grower, very productive; fruit very large, obtusecordate, slightly compressed and indented at the apex; suture shallow; stem very long, inserted in an open cavity; skin deep red, purplish, somewhat mottled; flesh firm, rather tender, juicy, sugary, brisk; quality good; season early July.

Constance Maisin. P. cerasus. 1. Thomas Guide Prat. 25. 1876. 2. Guide Prat. I7. 1895.

This is a Belgian variety, which, according to Guide Pratique, I895, is very similar to Montmorency.

Cook Imperial. P. avium. I. Am. Pom. Soc. Sp. Rpt. $25 . \quad$ 1904-05.

This variety, a seedling of Napoleon, originated with Steven Cook, Benton Harbor, Michigan. It is mentioned as a promising new sort, resembling Black Tartarian in shape, flavor, color, and length of stem but earlier and larger.

Cornelia. P. avium. I. Downing Fr. Trees Am. 459. 1869.

Cornelia originated with Charles Pease, near Cleveland, Ohio. Tree vigorous, uprightspreading, very productive; fruit medium to above in size, compressed, heart-shaped; suture slight; stem long; cavity narrow, deep; skin whitish-yellow, shaded with bright crimson on the sunny side; flesh light yellow, tender, juicy, sweet, rather lively; quality good; stone small; season the last of June.

Corning. P. cerasus. I. Ia. Hort. Soc. Rpt. 72. 1899. 2. Ia. Sta. Bul. 73:66 fig. 1903.

Corning is a cross between the Wragg and Lutovka and originated with A. F. Collman, Corning, Iowa. Fruit oblate-cordate, above medium in size; suture lacking; stem of medium length, stout, inserted in a medium deep, narrow cavity; skin rather thick, tender, red; flesh firm, breaking; juice slightly colored, briskly subacid; quality good; stone medium large, ovate; ripens in August.

Corone. P. avium. 1. Parkinson Par. Ter. 572. 1629. 2. Rea Flora 205. 1676. 3. Hogg Fruit Man. 29I. I884.

Englische Schwarze Kronherzkirsche. 4. Truchsess-Hein Kirschensort. 149-152. 1819. 5. Mathieu Nom. Pom. 347. I889.

Corone, as the references show, is one of the oldest-named varieties, though strictly speaking, since it was largely grown from seed, according to the old writers, it is a type and not a variety. In character of fruit it seems to be midway between Black Mazzard and Black Tartarian. Tree vigorous, productive; fruit below medium in size, roundish-cordate, compressed and often roughened; suture deep; stem slender, long; cavity deep, round, narrow; color a deep, shining black; flesh dark purple, very firm, sweet; ripens late.

Corwin. P. cerasus. I. Elliott Fr. Book 216 . 1854 .

This is a medium-sized, roundish, red Morello with tender, acid flesh and a large stone; season July.

Coularde. P. avium. I. Truchsess-Heim Kirschensort. 424-427. I8I9.

Cerisier de Hollande. 2. Duhamel Trait. Arb.Fr. 1:184, 185, Pl. 10. 1768. 3. Leroy Dict. Pom. 5:298, 346. 1877. 4. Mathieu Nom. Pom. 363. 1889.

Holländische Weichselbaum mit sehr grosser Frucht [or] Coulard. 5. Kraft Pom. Aust. I: 5 , Tab. I2 fig. 2. 1792. 
Holländische grosse Kirsche Coulard. 6. Christ Handb. 670. 1797.

Hollandische grosse Weichsel [or] Coulard. 7. Christ Wörterb. 284. 1802.

Holland Griotte. 8. Prince Pom. Man. 2:141. 1832. 9. Kenrick Am. Orch. 280. 1832 .

Holländische Süssweichsel. 10. Dochnahl Fïhr. Obstkunde 3:51. 1858.

Cerisier conlard de Holland. II. Noisette Man. Comp. Jard. 2:505. I860.

Leroy states that Coularde has been known since 1740 but is often confused with other cherries. According to Leroy, this variety was reintroduced as a novelty about I 864 , under the name Belle d'Orleans. American writers, however, list a Belle d'Orleans as early as $185^{\circ}$, which is of the Guigne type rather than the Griotte. Tree the largest of its class; branches strong and straight; blooms profusely; fruit large, round; skin red; flesh firm, reddish-white, sweet, agreeable; ripens the end of June. The pistils being much longer than the stamens, many flowers are never fertilized which gives the blossoms a blighted appearance.

Courte-queue de Gaiberg. Species? I. Thomas Guide Prat. 23, I92. I876.

Courte-pendu de Gaiberg. 2. Mas Pom. Gen. II: I60. I882.

Listed as having been received from Germany on the recommendation of Oberdieck.

Crawford. Species? I. Mas Pom.Gen. II:160. I882.

Listed, not described.

Crown Prince. Species? I. Can. Exp. Farms Rpt. 465. 1900.

Tree vigorous; fruit above medium in size, cordate; skin yellow with a light red blush; flesh whitish, juicy, tender, refreshing; quality good; ripens the last of May.

Cserszeger Honigkirsche. P. avium. I. Proskaner Obstsort. 55. 1907.

A yellow Heart cherry.

Cullen Cherrie. P. cerasus. I. Parkinson Par. Ter. 574. 1629.

"The Cullen Cherrie is a darke red cherrie like the Agriot, which they of those parts neere Cullen and Vtrecht \&c. vse to put into their drinke, to give it the deeper colour."

Cumberland. P. avium. I. Elliott Fr. Book 205. 1854.

Triumph of Cumberland. 2. Horticulturist 7:100. 1852. 3. Downing Fr. Trees Am. 267, 268. 1857. 4. Mas Pom. Gen. I1:87, 88, fig. 44. I882.

Cumberland Heart. 5. Gard. Mon. 2:118. 1860.

Cumberland Spice. 6. Horticulturist 17:498. I862.

Cumberland is a chance seedling found in Cumberland County, Pennsylvania; introduced by David Miller of Carlisle. Tree strong in growth, erect, vigorous, productive; fruit obtuse-cordate, sides compressed; stem rather long, slender, set in a broad, open cavity; apex slightly depressed; suture entirely around the fruit, but a line on one side; skin medium thick, tough, clear purple changing to a purplish-black; flesh deep purple, crisp, aromatic, with abundant, colored juice; quality good; pit roundish-oval, compressed, slightly clinging; ripens the middle of June.

Cyclone. P. avium. I. Nova Scotia Fr. Gr. Assoc. Rpt. 23. 1894.

This variety is said in Nova Scotia to be somewhat similar to Wood and Rockport but to be superior to either in size and quality. 
Dacotah. P. avium. I. Mag. Hort. 26:402, 403. I860. 2. Downing Fr. Trees Am. 459 . I 869 .

Dacotah is a seedling of one of Professor J. P. Kirtland's sorts, originated by his son-in-law, Charles Pcase, Cleveland, Ohio. In growth it resembles Rockport; in fruit, Black Tartarian although it is later. The fruit is borne on spurs on the body as well as on the limbs, thus being protected from birds by the foliagc. Fruit medium to large, heart-shaped, compressed; suture shallow; stem long, slender; cavity deep, narrow; skin rich dark red, almost black, slightly roughened; flesh rather tender, purplish, juicy, sweet; of high quality; stone of medium size; productive.

Daiber Schwarze Knorpelkirsche. P. avium. I. Mathieu Nom. Pom. 344. 1889 .

Listed by Mathieu.

Dankelmannskirsche. P. avium. I. Truchsess-Heim Kirschensort. 242-246,677. I8I9.

Schwefelkirsche. 2. Krünitz Enc. 72, 73. 1790.

Agatkirsche. 3. Christ Handb. 666. 1797.

Dankelmann's Weisse Herzkirsche. 4. Ibid. 666. 1797.

Kleine weisse Perlkirsche. 5. Ibid. 683. 1797.

Dankelmann's Molkenkirsche. 6. Dochnahl Fuhr. Obstkunde 3:28. 1858.

Bigarreautier à fruit jaune? 7. Noisette Man. Comp. Jard. 2:504. I860.

Bigarreau jaune. 8. Mortillet Le Cerisier 2: 133.1866.

In I79I, Truchsess received grafts of what he thought were several distinct varieties and disseminated them as such. Later, they were found to be identical with the Dankelmann. The fruit is recognized from others of its class by its small size, its honey sweetness, its peculiar color and its transparent skin. Fruit more round than cordate, with a shallow suture; stem slender, inserted in a narrow, shallow eavity; skin yellow washed with red, transparent allowing the pit to be visible; flesh yellowish-white, tender, very juicy, very sweet if ripened thoroughly; stone small, round, almost free when ripe; season the last of June to July.

Datge. Species? I. Can. Exp. Farm Bul. 2nd Ser. 3:59. 1900.

Mentioned in this reference as being moderate in growth.

Davenport. P. avium. 1. Prince Pom. Man. 2: $154 . \quad 1832$.

Davenport's Early Red. 2. Kenrick Am. Orch. 2 I $8 . \quad$ I835.

Davenport's Early Black. 3. Ibid. 233. I8 4 I

Davenport's Early. 4. Downing Fr. Trees Am. I72, I73. 1845 .

This early cherry, resembling somewhat Black Heart, was originated nearly a century ago by Edward Davenport, Dorchester, Massachusetts. Tree medium in size, productive; fruit above medium to large, roundish-cordate; stem long, rather thick; skin bright red becoming purplish-black; flesh firm but tender, sprightly, pleasant, juicy, sweet; very good in quality; season early.

De Belleu. Species? I. Can. Exp. Farm Bul. and Ser. 3:59. I 900.

Mentioned in this reference as being a variety of moderate growth.

De Jacap. Species? I. Lond. Hort. Soc. Cat. 52. 1831.

Mentioned in the referenee given.

De Ravaene. Species? I. Mas Pom. Gen. II:160. I882.

Listed without a description. 
De Sibérie à gros fruit et à rameaux pendans. Species? I. Noisette Man. Comp. Jard. 2:508. 1860 .

This is a dwarf ornamental tree bearing small, oval, mediocre fruits ripening in August and September.

De Spa. P. cerasus. 1. Mag. Hort. 17:363. 1851. 2. Downing Fr. Trees Am. 278 . 1857 .

De Spa is a medium-sized, dark red, acid Morello forming a prolific bush, ripening soon after May Duke.

De Vaux. Species? I. Can. Exp. Farm. Bul. 2nd Ser. 3:59. 1900.

Listed in the reference given.

Dearborn Red French. $P$. avium $\times P$. cerasus. I. Kenrick Am. Orch. $280 . \quad 1832$.

This is a Duke cherry imported from France by H. A. S. Dearborn, Roxbury, Massachusetts. The name having been lost, the importer renamed it.

Dechenaut. $P$. avium $\times$ P. cerasus. I. Hogg Fruit Man. 78. I866.

Fruit large, roundish-cordate, broad at the base, rather flattened; suture faint; skin bright cornelian-red, becoming darker red when ripe, glossy; stem long, set in a wide, deep cavity; flesh tender, succulent; resembling May Duke in flavor and season.

Delaware Bleeding Heart. P. avium. 1. Mo. Hort. Soc. Rpt. 6r. I 898 .

This is a medium-sized, dark red, nearly black fruit with solid flesh and good flavor. Delicate. P. avium. 1. Mag. Hort. 19:167, 168. 1853. 2. Elliott Fr. Book 193 fig. I 854 .

Delicate was raised by Professor J. P. Kirtland, Cleveland, Ohio, in $184^{2}$, from a pit of Yellow Spanish, probably crossed with Black Tartarian, Black Mazzard, or May Duke. Tree moderately vigorous, upright-spreading, productive; fruit medium to large, roundishoblate; suture rather pronounced; stem medium in length; skin thin, translucent, amberyellow overspread and mottled with light carmine; flesh pale yellow, juicy, pleasant, sweet; very good in quality; stone small, roundish-oval; season the last of June and the first of July.

Délicieuse. Species? I. Mas Pom. Gen. II:I60. I882.

Listed by Mas.

Denner Black. Species? I. Lond. Hort. Soc. Cat. 48. I $\delta_{31}$.

Listed but not described.

Des Cheneaux. Species? I. Mas Pom. Gen. II: I60. I882.

Mentioned in the reference given.

Deutsche Belzweichsel. P. cerasus. I. Christ Wörterb. 290. 1802. 2. Truchsess-Heim Kirschensort. $60_{3}, 604,605$. I8 8 ig.

Probably this is but a wild seedling used in grafting. Fruit of medium size, round; suture indistinct; stem long, slender, set in a shallow cavity; skin glossy, dark brown; flesh firm, dark, reddish directly under the skin, juicy, with a sourish wine-flavor; stone small, oval; ripens the middle of July.

Disnoder Gewürzkirsche. P. avium. I. Proskauer Obstsort. 55. 1907.

Listed as a black Bigarreau.

Ditst. Species? I. Mas Pom. Gen. I I : 160. I882.

Listed in the reference given. 
Dobbeete Moreller. Species? I. Lond. Hort. Soc. Cat. 54. I831.

Listed in this reference.

Doctay. Species? 1. Horticulturist $17: 498.1862$.

Reported in the reference as a good, late cherry of second size as grown by E. Manning, Harrisburg, Ohio.

Doctor. P. avium. I. Horticulturist $2: 123$ fig. I847-48. 2. Mag. Hort. I9: 167, I68. 1853. 3. Mas Le Verger 8:37, 38, fig. I7. 1866-73.

American Doctor. 4. Hogg Fruit Man. 7 I. 1866.

Doctor was originated by Professor J. P. Kirtland, Cleveland, Ohio, in I842, from a pit of Yellow Spanish, probably crossed with Black Tartarian, Black Mazzard, or May Duke. Hogg called it American Doctor to distinguish it from the German Doctorkirsche. Tree of medium vigor, upright-spreading, healthy, very productive; fruit medium to large, roundish-cordate; stem long, rather slender; skin light yellow, mottled, blushed and at times almost entirely overspread with red; flesh pale yellow, juicy, tender, aromatic, sweet; good in quality; stone small.

Dr. Flynn. P. avium. I. Coates Cat. I911-12.

Dr. Flynn is a chance seedling which originated in Portland, Oregon, with a Dr. Flynn. Fruit large, dark red; similar to Lambert in shape; preceding Napoleon.

Dr. Wiseman. P. avium. I. Van Lindley Cat. 23. 1892. 2. Thomas Am. Fruit Cult. 321 . I897.

This cherry was named after Dr. Wiseman, Davie County, North Carolina, who claimed it to be the earliest Sweet Cherry. Van Lindley believes it to be the Doctor which originated with Professor Kirtland. Fruit of medium size, light yellow, shaded with bright red, resembling Wood.

Doctorkirsche. P. avium. 1. Christ Obstbäume I61. I791. 2. Christ Handb. 674.

1797. 3. Truchsess-Heim Kirschensort. 402-405. I8I9. 4. Ill. Handb. 497 fig., 498. I $86 \mathrm{I}$.

This variety was first mentioned in I79I. It should not be confused with another sort mentioned by Büttner and Truchsess as Doctorknorpelkirsche. Fruit large, roundish, somewhat compressed; stem long; cavity rather deep; skin tough, brownish-red changing to reddish-black; flesh dark red, melting, juicy, sweet yet with a sprightly flavor; pit round, slightly pointed; ripens the middle of July.

Doctorknorpelkirsche. P. avium. 1. Truchsess-Heim Kirschensort. 201, 202, 203. I8I9.

2. Dochnahl Führ. Obstkunde 3:37. I 858 .

According to Truchsess, this sort was received by him in 1797 , from Büttner at Leipzig under the name of Doctorkirsche. Because one or two other sorts were growing at that time under this name, Christ changed this one, following Büttner's description, to Doctorkirsche mit Hartem Fleisch, which has since been shortened to Doctorknorpelkirsche. Fruit large, slightly compressed; stem long and slender; color black; flesh firm, clear red, juicy, agreeably sweet; ripens the middle of August.

Dollaner Schwarze. P. avium. I. Ill. Handb. 9 fig., Io. 1867.

According to Oberdieck, this variety originated at Dollan, Bohemia, Austria, the home of the Dollaner prune. Fruit above medium in size, truncate-cordate, traversed 
entirely by a suture; stem slender, long, set in a narrow, shallow cavity; skin tough, brownish-black with light spots, wholly black when ripe; flesh and juice dark red, flesh firm, but tender enough to be classed among the Hearts, sweet, aromatic, with a slight sourness before fully ripe; stone elongated-oval; season late.

Donna Maria. P. cerasus. 1. Barry Fr. Garden 326. 1851. 2. Am. Pom. Soc. Cat. 74. 1862. 3. Am. Hort. An. 84 fig. 41, 85. 1869.

This is a Morello cherry, probably of French origin. It is distinct from the Early May grown in the West with which it has been confused. Donna Maria held a place on the American Pomological Society's catalog of fruits from i 862 until 1899. Tree small, productive; fruit medium in size, roundish, dark red; flesh tender, juicy, sprightly; good in quality; season late.

Doppelte Weichsel. P. cerasus. I. Christ Handb. 673. 1797. 2. Truchsess-Heim Kirschensort. 505, 506, 507. 1819 .

Doppelte Amarelle. 3. Christ Obstbäume 158.1791.

Christ first described this variety as Doppelte Amarelle but in his later writings changed it to Doppelte Weichsel. It is distinguished from the Spanische Frühweichsel in being larger, longer in stem, and sourer. Fruit above medium in size, globular; suture shallow; stem long, rather stout, set in a shallow cavity; skin dark brownish-red, thin, not glossy in wet years; flesh dark, firm for a Weichsel, juicy, light colored. pleasing subacid; pit small, more round than broad, free; season the end of June.

Dorotheenkirsche. Species? I. Mathieu Nom. Pom. 347. 1889.

Mentioned in this reference.

Dörrells Neue Himbeerkirsche. P. avium. I. Dochnahl Führ. Obstkunde 3:27. 1858 .

Tree productive; fruit large, cordate, flattened; stem stout; skin dark red; flesh firm, whitish, sweet, aromatic; stone small; ripens at the end of June.

Doty. Species? 1. Am. Inst. An. Rpt. 212. 1867.

This is a small but pleasantly flavored seedling exhibited by William M Doty, Star Landing, New Jersey.

Double Yellow Spanish. P. avium. I. Ia. Hort. Soc. Rpt. 331.1885.

This variety was imported to America by Professor J. L. Budd of Ames, Iowa. The tree has a drooping habit, large foliage and sweet fruit of best quality.

Douce de Bardowick. P. avium. I. Mas Pom. Gen. II:160. I882.

Listed in the reference given.

Dougall. Species? I. Cult. \& Count. Gent. 39:454. 1874.

Dougall is a large, black, seedling fruit introduced by James Dougall, Amherstburgh, Canada. Ripens before Early Purple.

Doulin Bigarreau. P. avium. I. Downing Fr. Trees Am. 460. 1869 .

This is a foreign variety which may not be distinct. Tree a rapid, spreading grower, bears early; fruit large, heart-shaped, compressed on one side; stem slender, curved, set in a deep cavity; suture slight: skin dark purplish-red; flesh pinkish, rather tender, juicy, sweet, pleasant; quality good; season early June.

Dove Bank. Species? I. Mas Pon. Gen. II: 160.1882.

Listed in the reference given. 
Downing Red Cheek. P. avium. 1. Downing Fr. Trees Am. I86 fig. 76 . I845. 2. Elliott Fr. Book 205. I854.

Rouge de Downing. 3. Mas Le Verger 8:85, 86, fig. 41. 1866-73.

Downing's Sämling. 4. Mathieu Nom. Pom. 346. I889.

This attractive cherry, resembling Yellow Spanish, was raised by A. J. Downing, ${ }^{1}$ Newburgh, New York, about I840; its exact parentage is unknown. Tree vigorous, upright-spreading, productive; fruit medium to large, obtuse-cordate, slightly compressed; stem long, siender, inserted in a shallow cavity; skin thin, yellowish-white blushed and mottled with attractive dark crimson; flesh yellowish but often very nearly white, halftender, juicy, delicate, sweet; good in quality; stone medium in size; ripens from the middle to the last of June.

Downton. P. avium. I. Pom. Mag. 3:138 Pl. 1830. 2. Prince Pom. Man. 2:124. 1832. 3. Am. Pom. Soc. Cat. 74. I862. 4. Ill. Handb. 485 fig., 486. I86r.

Downtoner Molkenkirsche. 5. Dochnahl Führ. Obstkunde 3:30. 1858.

Guigne Downton. 6. Mortillet Le Cerisier 2:98, 303. I866. 7. Leroy Dict. Pom. 5:321 fig. 1877 .

Impératrice Downton? 8. Mas Pom.Gen. II:I61. I882.

${ }^{1}$ Andrew Jackson Downing was born in Newburgh on the Hudson, the town in which he always lived and which he loved, October 30,1815 . He perished while trying to save other passengers in the burning of the steamer Henry Clay on the Hudson River, July 28, 1852, at the age of 37. Andrew Downing's education was largely acquired from self instruction although he attended the schools of his native town and the academy in the adjoining village of Montgomery. His father, a nurseryman, whose work was mentioned in the sketch of Charles Downing, elder brother of Andrew, gave the younger son every opportunity to cultivate an early developed taste for horticuiture, botany and the natural sciences. When but a youth he joined his brother Charles as partner in a nursery firm, a relationship maintained for but a few years and which he severed to begin a career as a writer on landscape gardening and pomological subjects. His first publication was a Treatise on the Theory and Practice of Landscape Gardening adapted to North America, with a view to the Improvement of Country Residences, with Remarks on Rural Architecture, a book published in 1841 , the author being but 26 years of age. The work passed into instant popularity and is the word of authority which has told thousands of Americans what to do to make their grounds beautiful. Within a few months so great was the success of the first venture that in response to the demand he published his Coltage Residences, a companion book which was received with equal favor, thus giving Andrew Downing first rank as an authority on rural art. In $18+5$ the Fruits and Fruit Trees of America, then and now the chief pomological authority of this continent, was printed simultaneously in London and New York, a second edition coming out in 1850 . In 1846 Andrew Downing became the founder and editor of the Horticulturist, which he continued to publish until his death. In $18+9$ he wrote Additional Notes and Hints about Bullding in the Country, published in Wightwick's Hints to Young Architects. The summer of 1850 was spent in England in the study of landscape gardening and rural architecture from the result of which came his Architecture of Country Houses. His last work was the editing of Mrs. Loudon's Landscape Gardening for Ladies though Rural Essays appeared after his death as a collection of his writings with a memoir by George IVilliam Curtis and a Letter to his Friends by Frederika Bremer. He was employed in planting the public grounds of the Capitol, the White House and the Smithsonian Institution at Washington when he met his untimely death. Downing is the creator of American landscape gardening and shares with his brother Charles the honor of being the most distinguished pomologist of the country. In the epoch-making Fruits and Fruit Trees of America Andrew Downing was the real genius, Charles Downing the conscientious and painstaking student who worked out the details. 
Downton was raised early in the Nineteenth Century by T. A. Knight, Downton Castle, England, from a seed of Eiton. Tree strong in growth, spreading; fruit attached in pairs, large, obtuse-cordate, roundish; stem rather long, slender; skin pale yellowish, heavily specked with red, which oftens merges into a blush on the sunny side; flesh light yellow, very tender, juicy; high in quality; stone slightly adherent; ripens after May Duke. Dresdener Mai Herzkirsche. P. avizm. 1. Thomas Guide Prat. 23. 1876.

A very early Heart cherry received by Thomas from Germany.

Drogan White Bigarreau. P. avium. I. Hogg Fruit Man. 79. 1866. 2. Thomas Guide Prat. 20, 188. 1876.

Drogan's Weisse Knorpelkirsche. 3. Truchsess-Heim Kirschensort. 341, 684. I8I9. 4. Ill. Handb. 55 fig., 56 . I867.

This is one of Drogan's seedlings from Guben, Prussia, Germany, I809. Leroy includes Drogan's White and Yellow Bigarreaus with his Guigne Blanche (Grosse) but the three are distinct varieties. Tree vigorous, productive; fruit large, roundish-cordate, flattened on one side; suture distinct; stem rather short, stout; cavity wide, deep; apex pointed; skin tough, pale yellow, mottled and blushed with red where much exposed; flesh firm, pale yellow, juicy, sweet; stone plump, ovate to oval; desirable for table and kitchen use; late.

Drogan Yellow Bigarreau. P. avium. I. Ill. Handb. 147 fig., 148. I860. 2. Hogg

Fruit Man. 79, 80. 1866. 3. Mas Le Verger 8:111, 112, fig. 54. 1866-73.

Bigarreau (Golden)? 4. Fell Cat. 41. 1893-94.

Tree vigorous, productive; fruit large to very large, oblate-cordate, resembling May Duke, compressed on the faces, truncate at the base, traversed by a shallow suture; stem long, stout, inserted in a wide, deep cavity; skin rather glossy, clear yellow, golden in the sun; flesh firm, yellowish, having abundant, uncolored juice, with a sweetness which increases as the season advances; quality high; pit small, turgid, roundish-oval, truncate at the base; ripens late.

Drogans Schwarze Knorpelkirsche. P. avium. 1. Truchsess-Heim Kirschensort. 206, 207, 677. 1819 .

A Prussian seedling from Guben, Germany, which in favorable years is of good size and pleasant flavor; skin black; flesh firm, juicy, colored; ripens the middle of July.

Drooping Guigne. P. avium. I. Prince Pom. Man. 2:119. 1832.

Guignier d̀ rameaux pendans. 2. Noisette Man. Comp. Jard. 2:503. 1860.

Noisette lists this variety under the Merisiers while others take it to be Toussaint which it resembles in habit of growth. Fruit large, roundish or heart-shaped, glossy black, with a long stem; flesh reddish-black, watery, sweet; season July; very productive. Du Comte Egger. Species? 1. Mas Pom. Gen. 11: 160. I882.

Listed, not described.

Du Nord Nouvelle. P. cerasus. I. Barry Fr. Garden 326. 1851.

Mentioned as a Morello from France ripening in August. Fruit of medium size, bright red, tender, acid; useful because of its lateness.

Duchesse d'Angoulême. P. cerasus. 1. Mas Le Verger 8:155, 156, fig. 76. 1866-73.

2. Leroy Dict. Pom. 5:261. 1877. 3. Ia. Sta. Bul. 73:67, fig. 12. I903.

Herzogin von Angouleme. 4. Ill. Handb. 535 fig., 536. 1861. 
Duchesse d'Angouleme is supposed to have come from the vicinity of Vienna, Austria, although some writers give France as its place of origin. It is often confused with other sorts. Tree large, vigorous, upright, slightly spreading, productive; fruit medium to above in size, roundish-oblate; stem rather long and thick, set in a large, deep cavity; skin firm, bright red; flesh yellowish white, tender, juicy, sprightly, agreeably aromatic at extreme maturity; quality fair to good; stone nearly round, slightly compressed; ripens from the middle to the end of June.

Duchesse de Palluau. $P$. avium $\times$ P. cerastus. I. Mag. Hort. 19:407 fig. 28 . 1853 . 2. Leroy Dict. Pom. 5:261, 262 fig. 1877. 3. Rev. Hort. 236, 237, Pl. 1901.

Herzogin von Paluau. 4. Ill. Handb. I69 fig., 170. 1860.

Précoce Lemercier incor. 5. Mortillet Le Cerisier 2: 142-146, fig. 1866.

Duchesse de Palluau was raised about 18,0 by M. Pierre Bretonneau near Tours, Indre-et-Loire, France. In 1844 he gave cions of this variety, under the name Duchesse de Palluau, to Leroy who propagated and probably disseminated the sort. Tree large, productive; fruit medium to large, heart-shaped, compressed; stem long, slender; skin thin, dark purple becoming almost black; flesh tinged with red, juicy, brisk subacid becoming sweet; good in quality; stone nearly free, oblong-ovate, small; ripens in early mid-season.

Duke of Edinburgh. P. avium. I. Agr. Gaz. N. S. Wales 19:998. 1908.

Tree stunted, upright; fruit too small and soft for market; similar to Belle d'Orleans; ripens in November in Australia.

Dumas. Species? I. Mas Pom. Gen. II:160. 1882.

Mentioned in the reference given.

Dunkelrothe Knorpelkirsche. $P$. avium. I. Truchsess-Heim Kirschensort. 680-682. 1819.

Bigarrcau à Longue Quene. 2. Nortillet Le Cerisier 2:121, I22 fig., 123, 219. 1866. Bigarreau Rouge Foncé. 3. Ibid. 2:302. 1866.

Bigarrcau Violet. 4. Leroy Dict. Pom. 5:249 fig. 1877 .

This variety probably originated with Van Mons in Belgium about 1790. It was received by Truchsess a little later as a French sort under the name Bigarreau Violet. Fruit large, elongated-cordate, sides compressed; suture very distinct dividing the fruit into halves; stem very long, more deeply inserted in unripe fruits; skin firm but not tough, yellowish, overspread with dark red, verging to violet; flesh yellowish, firm, juicy; quality excellent; stone free, small, roundish-oval; apex acutely pointed; ripens the middle of June. Duraccia. P. avium. I. U. S. D. A. Rpt. 292. 1893. 2. Am. Pom. Soc. Rpt. 175. I 895 .

E. E. Goodrich, Santa Clara, California, received cions of this variety from Lucca, Italy, thinking it to be the famous "Pistojese " used extensively in Italy for brandying. Fruit above medium in size, cordate; stem long, slender, set in a large, deep, regular cavity; suture deep, extending beyond the apex; skin thin, tough, smooth, glossy, finely pitted, dark purple to almost black; flesh red with lighter veinings, firm, meaty, rich, sweet; quality very good; pit of medium size, plump, partially adherent; season at Santa Clara the last of July to August; ships well; has not been reported from the eastern states. 
Dure Noir Grosse. Species? I. Mas Pom. Gen. Ir: 160. I882.

Not described.

Dwarf Siberian. P. fruticosa. I. Prince Pom. Man. 2: I53. I $8_{32}$.

Dutch ITeeping. 2. Lond. Hort. Soc. Cat. 48 . I 83 I.

De Sibérie. 3. Ibid. 55. 183 I. 4. Poiteau Pom. Franc. 2:No. 20, Pl. I 846.

ITeeping. 5. Kenrick Am. Orch. $28_{3}$. I $8_{32}$.

De Sibéric à fruit rond? 6. Noisette Man. Comp. Jard. 2:508. I860.

Dwarf Siberian belongs to Prunus fruticosa, the dwarf cherry of the Old World, of which Cerasus chamaecerasus is a synonym This cherry was introduced into America by Prince of Flushing, New York, and was thought by him to be the most suitable species to furnish stocks for dwarf trees. At best the variety reaches a height of from three to four feet with branches very numerous, forming a dense shrub. The flowers have long peduncles, often solitary but are usually united in umbels of from three to five each, which are sessile and axillary; fruit globular, red, small; flesh red, very acid, tender.

Early Amarella. P. cerasus. I. Albertson \& Hobbs Cat. 26. I904. 2. Vincennes Nur. Cat. 26. I906.

Tree upright, hardy, very productive; fruit large, brilliant red becoming darker as it gets riper; stem very long.

Early Amber. P. avium. I. Hogg Fruit Man. 69. So. 1866, 2. Lond. Hort. Soc. Cat. 45. I83 I.

River's Early Amber Heart. 3. Kenrick Am. Orch. 234. 1841. 4. Downing Fr. Trees Am. 177. I 845 .

Guigne panachée précoce. 5. Mortillet Le Cerisier 2:97, 208. I866.

Bigarreau Ambré Précoce. 6. Mas Le Verger 8:49, 50, fig. 23. 1866-73. 7. Leroy Dict. Pom. 5:174, 175 fig. 1877 .

Thomas Rivers of Sawbridgeworth, England, is given credit for this variety as a strain of the old Early White Heart. Leroy, however, states that his grandfather propagated this cherry under the name Cerise Panache or Suisse, as early as 1790 but without knowing its origin. He dropped the précoce because other varieties ripened long before this one. Tree vigorous, erect, productive; fruit borne in threes, medium in size, obtusecordate, slightly compressed; suture wide; stem long, slender, set in a straight, deep cavity; skin firm, medium thick, changing from lively red to reddish-brown; flesh yellowish, tender, cracking, with uncolored juice, sweet, aromatic; pit large for the fruit; season early.

Early Black Bigarreau. P. avium. I. Hogg Fruit Man. 69, So. I866. 2. Mortillet Le Cerisier 2:302. 1866 .

Fruit large, distinctly heart-shaped; stem long; color jet black; flesh dark purple, firm, rich, sweet; excellent; season the last of June and the first of July.

Early Eugene. Species? I. Ill. Hort. Soc. Rpt. 437. 1898.

Reported by H. L. McGee, Villa Ridge, Illinois, as being a hardy and productive variety.

Early May. P. cerasus. I. Rural N. Y. 12:375. IS61. 2. Trans. Ill. Agr. Soc. 5:199. 186I-64. 3. Am. Jour. Hort. I:123. 1867. 4. Ibid. 3:18-22. I868. 5. Am. Hort. An. 84. 1869. 6. Country Gent. 39:1 18. 1874 . 
This variety originated a generation or more ago in Virginia and was known there and in neighboring states as Early May. Later, it became widely disseminated in the Middle West where it was often confused with Early Richmond, Late Kentish and Montmorency. Early May should not be confused with a European cherry of the same name formerly grown upon the continent but now seldom seen. The fruit of the American sort is much like Early Richmond though of inferior quality and is now probably wholly replaced by the latter variety.

Early Prolific. P. avium. I. Elliott Fr. Book I93, I94. 1854.

Early Prolific was raised by Professor J. P. Kirtland, Cleveland, Ohio, in 1842 . Tree healthy, vigorous, upright, slightly spreading; fruit large, round, obtuse-cordate; suture distinct; stem variable; skin bright carmine-red mottled on a light amber-yellow ground; flesh rather tender, firm, juicy, rich, sweet; very productive; season early June.

Early Red Bigarreau. P. avium. 1. Prince Pom. Man. 2:130. 1832. 2. Hogg Fruit Man. 69, 81, 94. 1866. 3. Thomas Guide Prat. 23. 1876.

Bigarreau Rouge de Guben. 4. Leroy Dict. Pom. 5:242 fig., 243. I877.

This varicty originated about $\mathrm{I} 845$, from seed in the garden of the Pomological Society, at Guben, Prussia, Germany. The Russians, who were growing it in $\mathrm{i} 858$, sent the variety from Crimea to M. Eugène Glady, who in turn gave cions of it to Leroy. Tree moderately vigorous, productive; fruit usually attached in pairs; above medium to large, obtuse-cordate, more or less irregular, compressed; suture indistinct; stem long, slender, inserted in a deep cavity; skin thick, dark red changing to reddish-brown; flesh dark colored, firm, breaking, juicy, sweet, pleasant; quality excellent; stone rather large, ovate; ripens the last of June.

Early Red Guigne. P. avium. I. Thomas Guide Prat. 23. I876. 2. Guide Prat. I7. I895. 3. Rivers Cat. I8. I898-99.

This cherry, of unknown origin, was propagated by Thomas Rivers of Sawbridgeworth, England. It is thought by some to be Elton. Fruit large, pale red; flesh very tender, rich and good; ripens in early June.

Early Red and Yellow. P. avium. I. Mag. Hort. 8:282. I842.

This variety was raised by Robert Manning, Salem, Massachusetts, from the seed of a white Bigarreau. Fruit of medium size, obtuse-cordate; light red on a yellow ground; sweet, juicy; good; ripe the last of June.

Early Rivers. P. avium. I. Flor. \& Pom. 5 fig., 6. 1872. 2. Thomas Guide Prat. 28, 204. I876. 3. Flor. \& Pont. II7. 1878, 4. Downing Fr. Trees Am. 3rd App. 162. I88 I. 5. Hogg Fruit Man. $296 . \quad$ I 884.

Guigne Early Rivers. 6. Soc. Nat. Hort. France Pom. I04 fig., 105. 1904.

Early Rivers is a seedling of Early Purple raised by Thomas Rivers, Sawbridgeworth, England; first fruited in 1869 . Tree large, vigorous, upright-spreading, hardy, productive; fruit large, roundish-cordate, somewhat uneven and indented on the surface; stem long, rather slender; skin thin, deep red changing to glossy black; flesh reddish, juicy, very tender, rich, sweet; very good in quality; stone very small, elongated; season early.

Early York. P. cerasus. I. Thomas Am. Fruit Cult. 666. I897.

Fruit medium in size; flesh greenish-white, tender, juicy, subacid. 
Ebenter Cherry. Species? I. Flor. \& Pom. II I. I879. 2. Mathieu Nom. Pom. 347. I889.

This cherry is said to be cultivated on the shores of Lake Constance, Germany, notably at Lindau and Tettnang, and is distinguished for its firm flesh, large size and small stone. Ripens after all other table cherries.

Edouard Seneclause. Species? I. Mas Pom. Gen. 11:160. I882.

Not described.

Elfner Kirsche. Species? I. Mathieu Nom. Pom. 347. I889.

Listed by Mathieu.

Elizabeth. P. avium. 1. Elliott Fr. Book 207. I854. 2. Mas Pom. Gen. II: 160. 1882 .

Elizabeth is a seedling from Caleb Atwater, Portage County, Ohio, 1823. Tree vigorous, upright, prolific; fruit medium to large, heart-shaped, flattened on the sides; stem of medium length, set in a regular cavity; skin rich, dark red; flesh yellowish, slightly tinged with red, rather tender, juicy, pleasantly sweet; pit roundish-ovate; season the middle of June.

Emperor Francis. $P$. avium. I. Mas Pom. Gen. II:III, II2, fig. 56. I882. 2. Bunyard-Thomas Fr. Gard. 42. 1904. 3. Jour. Roy. Hort. Soc. 30:133. 1906.

Bigarreau Empereur-Francois. 4. Thomas Guide Prat. I6. I876.

Kaiser Franz Josef. 5. Proskauer Obstsort. 56. 1907. 6. Reut. Pom. Inst. Festschrift I22. I910.

The origin of Emperor Francis is not given in any of the references though the variety seems to be quite well known in both France and England. Tree vigorous, productive; fruit large, obtuse-cordate; stem rather short; cavity medium in size; skin marbled with red on a yellowish-white ground; flesh firm, crisp, sweet, high flavored; stone small, bluntly pointed; ripens rather late.

English Amber. P. avium. 1. Elliott Fr. Book 207, 208. I854.

Probably this is an old variety known under some other name. Tree vigorous, strong in growth, very productive; fruit of medium size, roundish-cordate, regular; stem long; skin delicate amber, mottled with pale red; flesh whitish-yellow, half-tender, delicate, juicy, very sweet; pit of medium size; ripens the last of June.

English Bearer. P. cerasus. 1. Brookshaw Pom. Brit. PI. 9. I8I7. 2. Brookshaw Hort. Reposit. 2:131, Pl. 7 I fig. 3. $\quad$ I823.

English Preserve. 3. Lond. Hort. Soc. Cat. 49. 1831.

This variety is grown in Kent, England, where it is known as English Preserver. It is distinguished from the Kentish only by its larger size and the dark, irregular spots under the skin. Ripens early in July.

English Gaskin. Species? I. U.S. Pat. Off. Rpt. 309. 1854.

An almost worthless sort mentioned in the reference given.

Englische Weinkirsche. P. cerasus. I. Truchsess-Heim Kirschensort. 284 . I8Ig.

Fruit large, roundish; stem long; skin tender, ground-color milky-white, crimson where exposed, on maturity the white changes to yellowish; juicy, vinous, aromatic; ripens in July. 
Englische Weisse Herzkirsche. P. avium. I. Dochnahl Führ. Obstkunde 3:27. 1858.

Englische weisse ganz frihe Herzkirsche. 2. Christ Handb. 683. 1797. 3. Christ

Wortcrb. 2So. I802, 4. Truchsess-Heim Kirschensort. 251, 252, 253. I819.

Possibly this is the same as the White Heart of England. It is without a doubt a separate variety from the Guignier à gros fruit blanc of Duhamel. Fruit above medium in size, elongated-cordate; stem very long, slender, set in a deep cavity; suture a line skin yellowish-white, tinged with red in the sun, uneven, glossy, transparent; flesh white, not very tender, juicy, sweet; quality good; stone of medium size, cordate, acute; ripens at the end of June.

Enopa. P. pumila $\times$ P. triflora. I. S. Dak. Sta. Bul. 108:1908. 2. Ibid. 130:178 P1. 8. I9I I.

Enopa, a cross between the Sand Cherry and the Occident plum, was sent out in 1908 by the South Dakota Station. Fruit one and one-sixteenths inches in diameter, round, with a minute prickle at the apex; skin thin, free from acerbity, dark red, with blue bloorn; flesh green.

Episcopale. P. ccrasus. I. Thomas Guide Prat. 25, 193. 1876. 2. Leroy Dict. Pom. 5:265 fig. 1877 .

This variety, according to Leroy, was found in the vicinity of Paris and was introduced by M. Jamin-Durand, Bourg-la-Reine, in 1846. The tree is distinguished from that of Montmorency in being more erect, less dense, less productive; the fruit is more acid and later in ripening.

Eppers Weichsel. P. cerasus. I. Dochnahl Führ. Obstkunde 3:67. $\quad$ I858.

Tree vigorous, productive; fruit large, oval, flattened at the base, brownish-red, with a deep suture; flesh clear red, juicy, strongly subacid; pit elongated; ripens in September.

Erfurter Augustkirsche. P. cerasus. 1. Christ Obstbäume 159. 1791. 2. TruchsessHeim Kirschensort. 550-554. I II9.

D'Aout Erfurt. 3. Mas Pom. Gen. II:89, 90, fig. 45. I882.

Délices d'Erfurt. 4. Guide Prat. 17. I 895.

Erfurt Delicious. 5. Gard. Chron. 19:429. 1896.

Hochgenuss Von Erfurt. 6. Proskauer Obstsort. 59. 1907.

This cherry is well known in and about Thuringia forest, Germany, where it is propagated by suckers and is valued for its lateness. Tree vigorous; fruit above medium in size, roundish-cordate, flattened; stem of medium length, set in a noticeable cavity; suture indistinct; skin tender, glossy, brownish-red changing to purplish-black; flesh tender, reddish, juicy, sugary, acidulated; stone free, small, pea-shaped; ripens the last of July. Etopa. P. pumila $\times$ P. triflora. I. S. Dak. Sta. Bul. 108:1908. 2. Ibid. 130:179. I9I I.

Etopa is a cross between the Sand Cherry and the Occident plum. Said to be excellent in quality and remarkable for its intense black, purplish color of skin, flesh and juice; skin thin, free from acerbity; ripens there about September twelfth.

Eugène Furst. P. avium $\times$ P. cerasus. I. Guide Prat. 18. I 895 .

Fürst's Hcrzkirsche. 2. Dochnahl Führ. Obstkunde 3:23. I 858.

Fruit above medium in size, elongated-cordate; stem of medium length, slender; skin 
black; flesh red, sugary, acidulated; matures the last of June to July. Said to be similar to May Duke.

Everbearing. P. cerasus. I. Okla. Sta. Bul. 2:13. I892. 2. Budd-Hansen Am. Hort. Man. 2:276. I903.

Fruit large, roundish-oblate, somewhat compressed; stem long, inserted in a broad, shallow cavity; skin dull red to dark red when ripe; flesh quite tender, juicy, mildly acid; quality good.

Excellente Douce Tardive. P. avium. I. Ann. Pom. Belge 2:101, I02, P1. 1854.

This cherry was produced from seed, in France in I839. Tree vigorous, productive; fruit above medium in size, roundish, flattened at the ends; stem long, stout, inserted in a deep, wide cavity; skin thin, glossy, deep red mottled with clear red changing to reddishblack, often yellowish-amber in the shade; flesh yellowish, melting, sugary, slightly acidulated; quality very good; pit small, yellowish, roundish, apex pointed; ripens in August. Eyami. P. pumila $\times$ P. triflora. 1. S. Dak. Sta. Bul. 108:1908. 2. Ibid. 130:179. I 9 I I.

Eyami is a cross between the Sand Cherry and the Occident plum and was sent out by the South Dakota Station in 1908. Fruit one and three-sixteenths by one and fivesixteenths inches in size, round; skin thin, dark red, semi-transparent; flesh green, pleasant; pit large.

Ezaptan. P. pumila $\times$ P. triflora. I. S. Dak. Sta. Bul. I30:I80 Pl. 9, ISI. I9II.

Ezaptan, a cross between the Sand Cherry and the Occident plum, was introduced in I9I I by the South Dakota Station. It is remarkable for its early and heavy bearing; skin thin, free from acerbity, dark purple; flesh black purplish-red to the pit.

Faversham Heart. P. avium. I. Lond. Hort. Soc. Cat. 49. I 831 .

Mentioned in the reference given.

Favorite. P. avium. I. Elliott Fr. Book 207 fig. I 854.

Elliott's Favorite. 2. Horticulturist 2:124. I $8_{47-48}$. 3. Thomas Am. Fruit Cult. 361. I849. 4. Mag. Hort. I9: 167, I68. I853.

Favorite is one of Professor J. P. Kirtland's cherries originating in Cleveland, Ohio, in $\mathrm{I}_{42}$, from a pit of Yellow Spanish, probably crossed with Black Tartarian, Black Mazzard, or May Duke. The tree resembles American Heart while the fruit is similar to Choisy in flavor and texture but larger. Tree vigorous, half-spreading, productive: fruit medium in size, round, regular, slightly compressed; stem long, set in an even and regular cavity; skin pale amber-yellow, with a bright, marbled, carmine-red cheek; flesh pale amber, translucent, tender, delicate, juicy, with a sweet, fine flavor; pit small, angular, smooth.

Festfleischige Schwarze Knorpelkirsche. P. avium. I. Ill. Handb. 35 fig., $36 .{ }_{1} 86_{7}$.

Grosse dunkel brannrothe Kramelkirsche. 2. Kraft Pom. Aust. I:3, Tab. 7 fig. I. I 792 .

Grosse schwarze Knorpelkirsche mit festem Fleisch. 3. Truchsess-Heim Kirschensort. 193-195. I819.

Bigarreau-noir à chair très-ferme. 4. Thomas Guide Prat. 20, I89. 1876.

This cherry has the hardest flesh of all the black, hard-fleshed cherries, differing from 
the Grosse Schwarze Knorpelkirsche in its firmer flesh. Tree vigorous, productive; fruit rather large, plump, truncate at the apex, sides compressed; suture not prominent; stem stout, long, set in a variable cavity; skin tough, almost black at maturity; flesh very firm, juicy, colored, very sweet, although with a mixture of sourness; stone small, turgid, cordate, sides compressed, clinging; ripens late.

Flagg. P. cerasus. 1. Cult. \& Count. Gent. 41:502. 1876. 2. Downing Fr. Trees Am. 3rd App. I64. I88 r.

Flagg was introduced by its originator, D. B. Wier, Lacon, Illinois, as Wier's Early Kentish, a selected seedling of Early Richmond, hardier and ten days earlier. Tree slender, short-jointed, regularly conical, moderate in growth; at its best in high, dry, airy situations, with light soil; fruit medium in size, heart-shaped; skin black, firm; flesh tender, purplishred, juicy, changing from a rich subacid to a very sweet, rich flavor; pit small; adapted to kitchen and table use.

Flamentine. $P$. avium. 1. Truchsess-Heim Kirschensort. 211-215. 1819. 2. Mas Le Vorger 8:137, 138, fig. 67. 1866-73.

Bigarreautier à petit fruit hâtif. 3. Duhamel Trait. Arb. Fr. I:165, I66. 1768.

Bigarreau à petit fruit blanc. 4. Lond. Hort. Soc. Cat. 46. I831.

Early Guigne. 5. Prince Pom. Man. 2: I I I, II2. 1832.

Early White Bigarreau. 6. Ibid. 2:129. 1832.

Petite Bigarreau hâtif. 7. Mortillet Le Cerisier 2: 130, г3 I. 1866.

Bigarreau Blanc (Petit). 8. Leroy Dict. Pom. 5: 182 fig., 183. 1877 .

Türkine? 9. Reut. Pom. Inst. Festschrift 121. 1910.

This cherry probably originated more than a century ago in the vicinity of Angers, France. Names of wholly distinct varieties have sometimes been attached to it causing much confusion in the nomenclature. Tree strong, vigorous, productive; fruit usually in threes, above medium in size, obtuse-cordate, flattened at the base, compressed; suture often a line; stem long, almost stout, inserted in a deep, narrow cavity; skin thin, glossy, whitish-yellow, mottled with dark red; flesh yellowish-white, transparent, rather firm, juicy, aromatic, sugary; first quality; stone small, oval; ripens the middle of June.

Flemish Gean. P. avium. I. Lond. Hort. Soc. Cat. 50. 1831.

A small, red, obtuse-cordate fruit of fair quality and tender flesh, ripening early in July.

Fleurs Doubles. P. cerasus. I. Duhamel Trait. Arb. Fr. I:174. I768. 2. Lond. Hort. Soc. Cat. 49. I 83 I.

Great rose. 3. Parkinson Par. Ter. 402, 574. 1629.

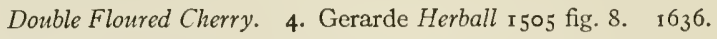

Bloem-kers double. 5. Knoop Fructologie 2:35, 38. 177 I.

Weichselbaum mit sehr gross gefüllter Blüthe. 6. Kraft Pom. Aust. I:5, Tab. I I fig. I. 1792 .

Glaskirsche mit dickgefüllter Blithe. 7. Christ Handb. 680. 1797.

Amarellenbaum mit ganz gefüllter Blüte. 8. Truchsess-Heim Kirschensort. 640-644. I 8 I9.

Small Double Flowering. 9. Prince Treat. Hort. 31. 1828. 
Dwarf Double Flowering. 10. Prince Pom. Man. 2:151, 152. 1832.

Gefültblïhende Amarelle. II. Dochnahl Führ. Obstkunde 3:68. I858.

The tree of this variety, unlike many other double-flowering sorts, attains but moderate size, in many cases is but a bush or shrub. The blossoms are exceedingly double, very showy, with a slight tinge of pink on opening, the blooming season extending over three or four weeks. Frequently the blossoms have small leaflets intermingled with the petals, while often a smaller flower appears to rise out of the center of another. The trees very seldom, if ever, bear. Truchsess reports having fruited it twice in ten years. The early English writers make brief mention of several double-flowering sorts which have been included under this variety.

Fleurs Semi-doubles. P. cerasus. 1. Duhamel Trait. Arb. Fr. I:173, P1. V. 1768. 2. Lond. Hort. Soc. Cat. 49. I83 I.

Lesser rose. 3. Parkinson Par. Ter. 402, 574. 1629.

Red-flowered. 4. Ray Hist. Plant. I538. I688.

Bloem-kers double. 5. Knoop Fructologie 2:35, 38. I77 I.

Gefüllter Kirschbaume. 6. Krünitz Enc. 43, 44. I790.

Weichsel mit halbgefullter Blüthe. 7. Kraft Pom. Aust. I:9, Tab. 2 r fig. 1. 1792.

Glaskirsche mit halbgefüllter Blüthe. 8. Christ Handb. 680. 1797.

Gedoppelte Amarelle mit halbgefüllter Blüte. 9. Truchsess-Heim Kirschensort. 646-649. 1819.

Halbgefülltblühende Amarelle. Io. Dochnahl Führ. Obstkunde 3:68. I858.

Amarelle mit halbgefullter Bluthe. II. Ill. Handb. 93 fig., 94. I867.

The home of this cherry is not known, it having been greatly confused with other double-flowering sorts. The flowers have a double row of from fifteen to twenty petals and of ten have two pistils, especially on the older trees. These generally bear twin-fruits though often the pistils are changed into small, green leaves, in which case the flowers are neither large nor attractive. The tree is of the Amarelle type, small, blooming profusely; fruit moderately round, compressed on one side with a shallow suture; stem long, stout; cavity wide; skin clear red, becoming darker and flecked with brown; flesh whitish, tender, juicy, sweet, pleasing, subacid at first; stone oval, bluntly pointed, often small and round, free when fully ripe; ripens the middle of July.

Florianer Kirsche. P. avium. I. Dochnahl Fïhr. Obstkunde 3:34. I858.

A productive seedling Bigarreau of medium size, elongated, angular; stem short, stout; skin black; flesh sweet, aromatic; second quality; ripens at the end of June.

Folgerkirsche. P. avium. I. Christ Wörterb. 283. ISO2. 2. Truchsess-Heim Kirschensort. 4I5-4I9. I8I9.

Holländische Folgerkirsche incor. 3. Christ Handb. 673. 1797.

Cerise de Folger. 4. Mortillet Le Cerisier 2: 158,209 . 1866.

A few authors describe this cherry as Volgers; the Volger described by Knoop in 1771 , however, is a distinct variety. Duhamel's variety, Cerise-Guigne, is possibly the same. Fruit large, roundish, truncate at the base, in unfavorable seasons the apex and sides are strongly compressed, with a noticeable suture; stem stout, long, set in a wide cavity; skin deep reddish-purple, glossy, tender; flesh delicate, sweet with a piquant taste; stone small, turgid, roundish-oval. 
Folgers Swolfe. P. cerasus. I. Christ W'örterb. 292. 1802.

According to Christ, Salzman says that in Holland several Sour Cherries were known as Folgers. This is a large, black, pleasant subacid fruit with a very characteristic growth. Fouche Morello. P. cerasus. I. Am. Gard.9:264. I888. 2. Ia. Sta. Bul. 73:75. I903.

This variety is said to have been imported by Professor J. L. Budd, Ames, Iowa, from Riga, Russia, where it was found planted along walks and drives. Tree rather small; fruit small, roundish-oblate; cavity shallow, broad; stem slender, rather long; suture a line; skin thin, rather tough, dark red changing to crimson; flesh firm, breaking, juicy, colored, sprightly subacid; quality fair; stone nearly round, of medium size; ripens early in July.

Frauendorfer. P. cerasus. x. Del. Sta. An. Rpt. 12:125. 1900.

Frauendorfer Weichsel. 2. Ill. Handb. 5I 3 fig., 5I4. I86I. 3. Montreal Hort. Soc. Rpt. 103. 1886-87.

Griotte de Franendorf. 4. Thomas Guide Prat. 22, 194. 1876.

This variety was imported into this country by Professor J. L. Budd in $188_{3}$ from North Silesia. The Montreal Horticultural Society believes two forms exist, one from North Silesia being perfectly hardy while another from Metz, Germany, is far less so. Tree productive; branches drooping; fruit above medium in size, roundish-oblate; suture shallow; stem long; cavity small; skin thin, glossy, dark red at maturity; flesh tender, tinted with abundant, uncolored juice, acidulated; stone large; matures the last of June and the first of July.

French Amarelle. P. cerasus. I. Rural N. Y. 49:453. I89o.

Trees thrifty and tall but set fruit sparingly; fruit large, yellow with a blush, two weeks later than Early Richmond.

French Weichsel. P. cerasus. 1. Tex. Sta. Bul. 16:99. I891.

In the reference this cherry is listed as a Russian variety introduced by Professor J. L. Budd. If so, it was probably under some other name, as it seems not to be mentioned by Budd.

Frogmore Early Bigarreau. P. avium. 1. Gard. Chron. 606. 1865. 2. Hogg Fruit Man. 298. I884. 3. Flor. \& Pom. 148 fig. I867. 4. Bunyard-Thomas Fr. Gard. 43. 1904.

Frogmore Early Prolific. 5. Daniels Bros. Cat. 51. 1895.

Frogmore Bigarreau. 6. Agr. Gaz. N. S. Wales. 998. I908.

Unlike the rest of its class, this cherry has tender flesh but is a Bigarreau in tree-habit, leaf and in appearance of fruit, and is therefore classified as such. The variety is a seedling raised by Thomas Ingram of the Frogmore Royal Gardens at Windsor, Berkshire, England. Tree bears freely in clusters; fruit large, obtuse-cordate, slightly compressed, with a faint suture; stem long, set in a small cavity; skin waxen, orange-yellow, with a network of red and a blush of deeper red on the sunny side; flesh of a primrose color, very tender, translucent, rich, sweet; stone spoon-shaped, indented on one side; season early but short.

Frogmore Early Crown. Species? I. Gard. Chron. 364. I 866.

Also a seedling from Mr. Ingram. It is a small, red fruit about ten days earlier than May Duke, of a rich flavor when fully ripe. 
Frogmore Late Bigarreau. P. avium. I. Flor. of Pom. 229, Pl. fig. I. 1874. 2. Guide Prat. I5. I 895.

Still another seedling raised by Ingram of the Frogmore Royal Gardens. Fruit large, bluntly heart-shaped, hanging long without cracking; suture slight; stem very long; skin pale, waxy-yellow, bright red on the sunny side; flesh tender, juicy; season very late.

Frogmore Morrelo. P. cerasus. I. Thomas Guide Prat. 25. 1876.

New Frogmore Morello. 2. McIntosh Bk. Gard. 2:543. 1885.

This variety attracted notice on account of the perfection to which it had been brought in the Royal Gardens at Frogmore, Berkshire, England, where it is believed to have originated. For productiveness and size it is said to far surpass the old Morello.

Fromm Heart. P. avium. 1. Ill. Handb. $6_{3}$ fig., 64. I860. 2. Mortillet Le Cerisier 2:68, 69 fig., 70. 1866. 3. Leroy Dict. Pom. 5:322, 323 fig. 1877. 4. Can. Exp. Farms Rpt. 549. I901.

Fromms Schwarze Herzkirsche. 5. Truchsess-Heim Firschensort. 164, 674. IS I9. 6. Liegel Syst. Anleit. I 50, 15 I. 1825.

Fromm Heart was obtained from seed in I 806 by Fromm, at Guben, Prussia, Germany. In sandy soils and favorable years the trees are very productive; fruit usually borne in pairs, above medium in size, truncate-cordate, sides compressed; suture shallow; stem of single fruits long, stout, inserted in a wide, deep cavity; skin dark reddish-brown to glossy black; flesh tender, dark red, juicy, sugary, pleasingly acidulated, aromatic; second quality; pit medium in size, turgid, roundish; ripens the third week of the cherry season.

Frihe bunte Herzkirsche. P. avium. I. Truchsess-Heim Kirschensort. 222, $223,224$. I 8 I 9 .

Fruhe Lange IVeisse Herzkirsche. 2. Christ I'örterb. 278 . 1802.

Guigne panachée longue précoce. 3. Thomas Guide Prat. I8, 199. 1876.

This cherry is easily recognized by its elongated, cylindrical form and should not be confused with several others of similar type. It was found near Weinberge, Germany, by Buttner who sent it to Truchsess in 1797 . Fruit medium in size, cylindrical, flattened on both sides, slightly drawn in at the apex and base; suture distinct on one side; stem long, inserted in a shallow cavity; skin yellow, blushed and faintly splashed with red where exposed; flesh pale yellow with a slight red tinge underneath the skin, moderately firm, juicy, without much sweetness; stone small, elongated, pointed at the apex; ripens early. Frihe Kurzstielige Knorpelkirsche. P. avium. I. Proskauer Obstsort. 55. 1907.

Mentioned as a black, hard-fleshed cherry.

Fruihe Maikirsche. P. avium $\times P$. cerasus. 1. Truchsess-Heim Kirschensort. 39I-394. I 8 I 9 .

Frühe Maikirsche differs from May Duke in being darker of skin and juice, smaller in size, sweeter, and less distinct in suture.

Frühe Morello. P. cerasus. I. Ill. Handb. 185 fig., 186. I860. 2. Mortillet Le Cerisier 2:306. I866. 3. Mas Pom. Gen. II:47, 48, fig. 24. I882. 4. Nathieu Nom. Pom. 349. 1889 .

An old variety of uncertain origin. Tree large, spreading; fruit often large, roundish, flattened; suture indistinct; stem slender, shallowly inserted; skin tender, nearly black 
when mature; flesh tender, juicy, dark red, acidulated; stone round, plump; ripens the first of June in France.

Frühe Säuerkirsche. P. cerasus. I. Truchsess-Heim Kirschensort. 554, 555. I8I9.

This cherry is thought to be a sub-variety of Kirsche von der Natte. Tree medium in growth; branches slender; fruit medium in size, round, sides compressed; stem long; cavity shallow; skin tough, black; flesh tender, dark red, juicy, sour, without a trace of sweetness; ripens the middle of July.

Frühe Schwarze Knorpelkirsche. P. avium. I. Christ Wörterb. 277. 1802. 2. Truchsess-Heim Kirschensort. 197, 198, 674, 675. I819.

Obtained by Büttner in 1797 who later sent it to Truchsess. Tree productive; fruit small, roundish-cordate, compressed; suture distinct; stem of medium length; skin glossy, reddish-black deepening to black; flesh hard, reddish-black, juicy, sweet, with a slight bitterness; stone ovate, rather large; ripens the first half of July.

Frühe von der Natte. $P$. avium $\times P$. cerasus. I. Ill. Handb. I53 fig., I54. I86o.

Frühe Natte aus Samen. 2. Christ Handb.67 I. 1797. 3. Truchsess-Heim Kirschensort. 4I3, 4I4, 4I5. I8I9.

Fruhe Süssweichsel von der Natt. 4. Dochnahl Führ. Obstkunde 3:49. $185^{8}$.

Hâtive de Nattes. 5. Mortillet Le Cerisier 2: $158,304 . \quad 1866$.

Natte hâtive de semis. 6. Mas Pom. Gen. Ir:161. 1882.

Christ received this cherry in 1793 , as Frühe von der Natte aus Saamen. Fruit above medium in size, cordate, flattened on one side; suture distinct; stem long, often dividing about an inch down into two, three, or four stems; apex depressed; skin glossy, dark brown when ripe; flesh dark red, soft, tender, juicy, refreshing, subacid; stone medium, oval; ripens early.

Früher Gobet. $P$. cerasus. I. Truchsess-Heim Kirschensort. 619-62 I. I8I9.

Gobet Hâtif. 2. Mas Le Verger 8: 125, I26, fig. 61. 1866-73.

Truchsess received this variety from Mayer as Gros Gobet which it resembles very closely in size, form, and flavor but is much earlier and not as flattened. Fruit of medium size, flattened; suture but a line; stem one inch long, often shorter, straight; cavity shallow; color clear red, becoming darker; flesh whitish with a reddish cast, tender, juicy, pleasingly acid; stone small, round, free but hanging to the stem.

Früheste Bunte Herzkirsche. P. avium. I. Truchsess-Heim Kirschensort. 207-2IO. I8I 9 .

Weiss und rothe grosse Herzkirsche. 2. Kraft Pom. Aust. I:2, Tab. 3 fig. I. 1792.

3. Christ Wörterb. 277 . I802.

Frühirsche? 4. Christ Handb. 672. I797.

Friheste bunte Molkenkirsche. 5. Dochnahl Fuihr. Obstkunde 3: $26 . \quad$ I 858.

Guigne panachée très-précoce. 6. Mortillet Le Cerisier 2:302. 1866. 7. Mas Pom.

Gen. II: 13, I4, fig. 7. I882.

The origin of this variety is unknown although it probably originated in Austria, as the celebrated Austrian pomologist, Kraft, was the first to mention it. Tree vigorous and in favorable seasons productive; fruit of medium size, obtuse-cordate, compressed, with a suture; stem medium, set in a deep, narrow cavity; skin tender, yellowish-white, 
striped with red around the base, spotted about the apex; flesh yellowish-white, with clear juice, sweet, pleasing, deteriorates on hanging; stone small, oval-cordate, clinging; ripens the last of May.

Frïheste der Mark. Species? I. Mathieu Nom. Pom. 350. 1889. 2. Lucas Handb. Obst. 121. 1893. 3. Lange Allgem. Garten. 440. 1897.

Fruit medium to above, truncate-cordate; stem very long, slender, set in a wide, deep cavity; skin purplish, glossy; flesh reddish, firm, pleasing; ripens early.

Fürst Schwarze Septemberkirsche. P. avium. I. Liegel Syst. Anleit. I53. I825.

Discovered by Liegel in Braunau, Bohemia, Austria, and named for his friend I. E. Fürst. Tree vigorous, productive; fruit small, oblate; stem very long; skin black; flesh firm, sweet, aromatic; stone large; one of the last to ripen, September to October.

Galusha. P. cerasus. I. Downing Fr. Trees Am. 3rd App. 165. I 88 r.

This cherry is seedling No. 1 f from D. B. Wier, Lacon, Illinois. Tree hardy, vigorous, an abundant bearer; fruit above medium in size, light red changing to a very dark, bright red; subacid becoming a rich sweet; ripens three days before Early Richmond.

Gamdale. Species? I. Horticulturist I7:498. I862.

A cherry described by E. Manning, Harrisburg, Ohio, as of second rank in size and quality.

Garcine. $P$. avium. I. Mortillet Le Cerisier 2:75 fig., 76, 77. 1866. 2. Thomas Guide Prat. 24, I98. 1876.

Garcine was obtained from seed about 1808 by M. Garcine, near Grenoble, Isère, France. It is propagated in that locality by suckers, hence it was called by some, Aventurière. Tree pyramidal, productive; fruit large, oblate, ends drawn in and flattened, sides convex; stem long, inserted in a large, deep cavity; skin glossy black; flesh dark, firm, sugary, aromatic, juicy; stone large, turgid; ripens the middle of June.

Gardiner. P. avium. I. Me. Sta. An. Rpt. 22:175. 1906.

Gardiner is a seedling of Black Tartarian. It is frequently killed back by severe winters in Maine.

Gaskins. Species? 1. Hogg Fruit Man. 298. I884.

Gaskins is a corruption of Gascoignes. About Rye, Sussex, England, the name is still in general use, the people believing the variety was brought from Gascony, France.

Gauchers Knorpelkirsche. P. avium. I. Proskauer Obstsort. 56. 1907.

Listed in this reference.

Geer. P. avium. I. Am. Pom. Soc. Rpt. I56. 1897.

Geer is a new cherry from eastern Oregon said to be later than Napoleon and to surpass it in size and quality.

Gelbe Herzkirsche. P. avium. I. Christ Obstbäume r6r. г791. 2. Truchsess-Heim Kirschensort. 342-349. I8 I9.

Grosser weisser glänzender Herzkirschbaum. 3. Kraft Pom. Aust. I:2, Tab. 4 fig. 1. 1792 .

Guigne Jaune. 4. Mortillet Le Cerisier 2:99, 303. I866.

Guigne Grosse ambrée. 5. Le Bon Jard. 345. 1882.

First mentioned in 1786 as Gelbe or Weisse Herzkirsche. It is distinguished from 
Goldgelbe Herzkirsche through its cordate form, lighter color and earlier ripening. Fruit above medium in size, borne in twos and threes, cordate, sides compressed; suture shallow; stem long, slender, slightly inserted; skin pale yellow, glossy, tough, adherent, blushed with red on the sides; flesh clear, not tender, juicy, acidulated; stone free, small, elongatedcordate; ripens in July.

Gelbe Wachskirsche. P. avium. I. Truchsess-Heim Kirschensort. 355, 685, 686. I8 I9.

2. Dochnahl Führ. Obstkunde 3:33. I858.

An unproductive seedling from the North Sea, ripening later than Gelbe Herzkirsche which it resembles. Fruit medium in size, round, flattened; stem long; skin glossy, clear waxy-yellow, transparent; flesh yellowish, firm, moderately sweet, without aroma; ripens from the middle to the end of July.

Gemeine Glaskirsche. $P$. avium $\times$ P. cerasus. 1. Christ ITörterb. 292. 1802.

This is a well-known Duke cherry in Germany. Tree large; fruit large, almost round; skin clear, light red on a yellow ground; flesh melting, with uncolored juice, pleasant sourness; ripens early in July and lasts a long while.

Genesee. $P$. avium.

A chance seedling of the Bigarreau type originating about twenty-five years ago and recently introduced by J. A. Morgan of Scottsville, New York. The fruit is above medium in size, cordate, compressed; cavity shallow, wide, flaring; suture a line; apex roundish; stem slender, long; skin medium thick, tender, adherent, dark red mottled with amber; dots numerous, small, obscure; flesh yellowish-white, juicy, meaty, crisp, mild, sweet; quality good; stone clinging, medium, ovate, flattened, smooth, slightly tinged red; use late market.

German. P. avium. I. Mich. Sta. Bul. 169: 199. 1899.

German (Kraus). 2. Ibid. 143:181. 1897.

German is said to have been introduced into Michigan from New York. Tree vigorous, though not productive; fruit large, roundish-cordate; stem long, slender, set in a broad, moderately deep cavity; color very dark red, nearly black; flesh firm, red, sweet, slightly bitter, with dark juice; ripens early in July.

German Morello. P. cerasus. r. Prince Pom. Man. 2:147. 1832.

Griotte d'Allenagne. 2. Duhamel Trait. Arb. Fr. I:192, 193, Pl. XIV. 1768.

3. Christ Obstbäume 159. 1791. 4. Leroy Dict. Pom. 5:276, 277 fig. 1877.

Deutscher Griottier ITcichselbaun. 5. Kraft Pom. Aust. 1:6, Tab. I6 fig. 2. 1792.

Deutsche Griotte. 6. Christ Handb. 675. 1797. 7. Truchsess-Heim Kirschensort. $569,570,57$ I. I8I.

Grosse Deutsche Belzkirsche. 8. Ibid. 421. I8rg.

Griotte de Chaux. 9. Lond. Hort. Soc. Cat. 50. 1831.

German Duke. Io. Kenrick Am. Orch. 280. 1832.

Deutsche II'eichsel. Ir. Dochnahl Fiiltr. Obstkunde 3:62. 1858.

Süssucichsel von Chanx. 12. Ill. Handb. 7 I fig., 72. ${ }_{1867 .}$

De Chaux. 13. Downing Fr. Trees Am. 478. I869.

Cerise d'Allemagne. I4. Le Bon Jard. 346. I882.

This old variety is badly confused with other cherries and its origin is uncertain. 
Fruit large, roundish-oblate; stem long, slender; cavity deep, wide; skin glossy, tough, brownish, almost black; flesh firm, dark red, juicy, with pleasing acidity, sweet if in a dry, warm soil; stone large, oval-pointed; ripens the middle of July; productive.

Germersdorf. P. avium. I. Can. Exp. Farm Bul. and Ser. 3:60. 1900.

Bigarreau noir de Germersdorf. 2. Thomas Guide Prat. 22, I89. 1876.

Germersdorfer Grosse Kirsche. 3. Lauche Deut. Pom. III: No. 7, Pl. I882.

A seedling of German origin. Tree large, vigorous, productive; fruit very large, roundish-cordate; suture distinct; stem medium, set in a deep, wide cavity; skin dark brown with dark spots and streaks; flesh rather firm, light red, juice tinted, sweet, pleasingly acidulated; stone of medium size, oval; ripens the fifth week of the season.

Geschiltztblättrige Süssweichsel. P. avium. I. Dochnahl Führ. Obstkunde 3:47. I858.

An ornamental cherry distinguished from May Duke through its smaller fruit and laciniated leaves.

Gestriefte Herzkirsche. P. avium. I. Truchsess-Heim Kirschensort. 259, 260. I8I9.

2. Dochnahl Fuihr. Obstkunde 3:30. I 858 .

Fruit cordate; stem long, slender, set in a shallow carity; skin thin, tender, white, streaked with red, which, if allowed to remain on the tree, becomes nearly solid red; flesh tender, soft, fibrous under the skin, juicy, colorless, honey-sweet, refreshing; ripens in July lasting about three weeks.

Gewöhnliche Muskatellerkirsche. P. cerasus. I. Christ Handb. 672. 1797.

Fruit smaller than that of the Black or Red Muskateller, roundish, very dark brown, almost black; flesh red, pleasant subacid; ripens at the end of June.

Giant. P. avium. I. Burbank Cat. 8. I9I4.

Giant was grown in 1900 by Luther Burbank and introduced by The Luther Burbank Company in I9I4. It is claimed by its introducer that it is the largest cherry grown. Tree rapid in growth, with large and heavy foliage; fruit glossy black, rich, sweet, delicious; ripens in California about June 20 th.

Gibb. P. cerasus. I. Ia. Sta. Bul. 2:39. I888. 2. Ia. Hort. Soc. Rpt. 79. I89o. 3. Wash. Sta. Bul. 92:17. 1910.

Gibb was imported from Orel, Central Russia, without a name. It is much like Brusseler Braune in tree, fruit, and in habit of bearing a double crop of blossoms and fruit, but is hardier. Fruit large, roundish-cordate; stem stout; skin thick, tender, dark crimson changing to purplish-red; flesh dark red, meaty; quality good; stone large, oblong; ripens the last of July to early August.

Gifford. P. avium. I. Downing Fr. Trees Am. 270. 1857 .

Fruit small, light red, roundish-cordate, very sweet; productive; season the last of June.

Glasherzkirsche. $P$. avium. I. Truchsess-Heim Kirschensort. 246-248. I8Ig.

Grosse Glas-Herzkirsche. 2. Christ Wörterb. 281. I 802.

Glas-Molkenkirsche. 3. Dochnahl Führ. Obstkunde 3:30, $31 . \quad$ I858.

This cherry differs from others of its class in being rounder, darker, and later. Fruit of medium size, roundish-cordate, convex on one side, compressed on the other, with a shallow suture; stem long, slender, shallowly inserted; skin mingled with dull red and 
clear white, often streaked; flesh yellowish-white, tender, juicy, sweet, but not high; stone large, acutely pointed; ripens the middle of July.

Glaskirsche von der Natte. P. cerasus. I. Truchsess-Heim Kirschensort. 470-473, 689. I8I9.

According to Truchsess this variety is very similar to, and often taken for Double Natte, Frühe von der Natte, and Double Glass.

Glasskirsche Kurzstielige. P. avium. I. Ia. Hort. Soc. Rpt. 33 1. $\quad$ I885.

This Sweet Cherry is supposed to have come from Vilna, Russia.

Gloire de France. P. cerasus. I. Thomas Guide Prat. 26, 194. 1876. 2. Leroy Dict. y Pom. 5:271, 272 fig. I877. 3. Downing Fr. Trees Am. 3rd App. 162. 1881.

Bonnemain. 4. Guide Prat. 9, I84. I895.

Originated from seed by Auguste Bonnemain, Etamps, Seine-et-Oise, France, fruiting in ${ } S_{45}$ for the first time. On Mazzard stock the tree never reaches full size but on Mahaleb it grows large and regular and is more globular in form. At best it is only moderately productive. Fruit borne in threes, medium in size, roundish-oblate, somewhat depressed; suture broad, shallow, often indistinct; apex rather large, slightly depressed; stem short, thick, inserted in a wide cavity; skin a reddish-brick color, occasionally mottled with greenish-brown in the shade and red on the sunny side; flesh pale red, grayish, transparent, rather tender and fibrous, with abundant juice, sprightly acidulated, agreeable; pit of medium size, roundish-oval, convex; season the first of July.

Golden Knob. Species? I. Lond. Hort. Soc. Cat. 50. 1831.

Golden Knob is a worthless, medium-sized, oval cherry ripening the middle of July; skin yellow and flesh firm.

Goldgelbe Herzkirsche. P. avium. I. Truchsess-Heim Kirschensort. 350-354. I8I9.

Kleine Ambra, [or] Goldgelber Herzkirschbaum. 2. Kraft Pom. Aust. I:2, Tab. 4 fig. 2. 1792 .

Kleine Ambra. 3. Christ Handb. 665. I797.

Distinguished from other yellow Heart cherries by its round form, dark yellow color, and rather firm flesh. Fruit of medium size, roundish; suture a line; stem very long, slender, deeply inserted; skin thin, tough, readily removed, transparent, glossy, goldenyellow; flesh moderately tender, yellowish, with darker spots showing through the skin, very juicy, with a pleasing sweetness when ripe; stone of medium size, oval, slightly adherent; ripens the last of June.

Goldsmith Black Heart. P. avium. I. Lond. Hort. Soc. Cat. 47. 183 I.

Mentioned but not described in this reference.

Goodspeed. P. cerasus. I. Ia. Sta. Bul. 73:70. 1903.

Goodspeed is of the Montmorency type ripening just after Early Richmond. The trees are long-lived and regular bearers. Fruit of medium size, oblate, slightly cordate; cavity deep, broad; suture shallow; stem short, stout; skin thin, tender, dark red; flesh moderately firm, tender, with uncolored juice, slightly subacid; quality good; stone free, of medium size, roundish-ovate.

Gormley. Species? I. Can. Hort. 20:317. 1897. 2. Ibid. 21:297. I897.

This hardy seedling, now about twenty-five years old, was found by John Gormley 
of Pickering, Canada. It resembles Montmorency in color, English Morello in shape, and a Bigarreau in texture. Its firm, yellowish flesh parts readily from the pit.

Gottorper. P. avium. 1. Truchsess-Heim Kirschensort. 289, 290, 29I, 1819. 2. Liegel Syst. Anleit. I59. 1825 .

Gottorper Marmorkirsche. 3. Dochnahl Führ. Obstkunde 3:41. ${ }_{1} 858$.

Cerise de Gottorpe. 4. Mortillet Le Cerisier 2: II 7-I I9. I866.

Originated in the vicinity of Coburg, Germany, toward the latter part of the Eighteenth Century. It resembles Yellow Spanish. Tree above medium in size, very productive; fruit abruptly cordate to roundish; stem short, slender; cavity shallow; skin tough, red, mottled with yellow; fiesh yellowish-white, not very firm, juicy, usually very sweet, slightly aromatic; stone small, oblate, free; ripens the fourth week of the cherry season; cracks in the rain when nearly mature; excellent for home use.

Gould No. X. Species? I. Ill. Hort. Soc. Rpt. 21 I. $1 \$ 96$.

Reported by the Illinois Horticultural Society in 1896 .

Governor Luce. Species? I. Mich. Sta. Bul. I43: 181. I897.

Listed as growing at the Michigan Station.

Grafenburger Frühkirsche. Species? I. Reut. Pom. Inst. Festschrift I2I. 1910.

A very productive, strong-growing cherry recommended for table and market use; fruit large, truncate-cordate, red, early.

Graham. P. avium. I. W'ash. Sta. Bul. 92:28. 1910.

The Washington Experiment Station lists this variety as: Tree of medium size, upright, with abundant foliage; fruit small, round; skin thin, tender, dark red; flesh light red, juicy, rich, sweet; good; season the last of July; productive.

Grande Ronde. Species? r. Am. Pom. Soc. Rpt. I $56 .{ }_{1} S_{97}$.

A new, early, large, black cherry recommended in eastern Oregon; ships well.

Great Bearing. P. cerasus. I. Rea Flora 205. 1676 .

Fruit large, blackish-red on the outer side when ripe, blood-red within. Ripens late, with a sharp taste; bears well.

Great Leafed. Species? I. Parkinson Par. Ter. 57 I. 1629.

This is a variety with very large leaves; relatively unproductive, bearing pale red fruit of only medium size.

Gridley. P. cerasus. I. Prince Pom. Man. 2:123, 124. I832. 2. Downing Fr. Trees Am. I87. I845. 3. Gard. Mon. II:2 I9. I869. 4. Am. Pom. Soc. Cat. I2. I871. Apple. 5. Cole Am. Fr. Book 234. I849.

This variety was discovered by William Maccarty about the beginning of the Nineteenth Century, growing in the garden of Deacon Samuel Gridley, Roxbury, Massachusetts. For a good many years it was considered a valuable cherry but later was supplanted by better sorts. Tree upright, vigorous, very productive; fruit medium in size, roundish; stem short; color black; flesh firm, purplish-red, medium juicy, sprightly, rather acid at first becoming milder when fully ripe; stone small; matures in mid-season.

Grenner Glas. P. cerasus. I. Ont. Dept. Agr. Fr. Ont. 94. I914.

Tree upright, vigorous, moderately productive; fruit borne in clusters, large, oblate, one-sided; suture distinct on one side; stem long; cavity broad, shallow; apex a small 
depression; skin bright red; flesh yellowish, tender, very juicy, tart; quality good; season the middle of July.

Griotte Acher. P. cerasus. I. Leroy Dict. Pom. 5:275 fig., 276. 1877. 2. Mas Pom. Gen. I1:67, 68, fig. 34. 1882. 3. Can. Exp. Farms Rpt. 482. I904.

Griotte Double. 4. Knoop Fructologie 2:35, 38, 39. 177 I.

Acher's W'eichsel. 5. Mathieu Nom. Pom. 332. I889.

The origin of Griotte Acher is not known but it may have sprung up by chance in Holland a century and a half ago. Tree medium in growth, productive; fruit usually borne in pairs, medium to large, flattened heart-shaped with truncate sides; cavity narrow; suture distinct; stem variable, usually long, medium thick; skin rather firm, vivid purple shading to almost purplish-black; flesh tender, slightly stringy, reddish-purple, medium sweet, somewhat pleasing because of a slight tart, acid flavor, with abundant, violet juice; stone medium in size, ovoid, truncate at the base, turgid; ripens the last of July and the first of August.

Griotte de Büttner. P. cerasus. I. Am. Gard. 9:264. I 888 .

A dwarf sort that blossoms and ripens late; much like Imperial Morello.

Griotte Commune. P. cerasus. I. Noisette Man. Comp. Jard. 2:508. I860. 2. Thomas Guide Prat. 26, 194. 1876. 3. Leroy Dict. Pom. 5:282 fig., 283. I 877 .

Griotte. 4. Duhamel Trait Arb. Fr. I:187-189, Pl. XII. I768. 5. Truchsess-Heim Kirschensort. 431, 432 . I819.

Griotte simple. 6. Knoop Fructologie 2:36, 39. 1771 .

Griottier Weichselbaum. 7. Kraft Pom. Aust. 1:6, Tab. ${ }_{5}$ fig. 2. 1792.

Common French Griotte. 8. Prince Pom. Man. 2:148. 1832.

Gemeine Süssweichsel. 9. Dochnahl Führ. Obstkunde 3:49. I858.

Cerise Commune. Io. Mortillet Lo Cerisier 2:146 fig., I47, I48, 220. I866.

The origin of this variety is unknown but according to French writers it was brought from Syria by the Crusaders about $\mathrm{I}_{4} \delta_{5}$. Tree large, productive; fruit medium in size, usually borne in pairs, distinguished from others of its class by its firm flesh, its black skin, and its colored juice, oblate, flattened at the base; suture slight; stem long, rather stout, set in a broad, shallow cavity; skin thin, glossy, dark red, changing to black; flesh colored, firm, vinous, aromatic, juicy; first quality; pit small, turgid, round; ripens the first of July.

Griotte Douce Précoce. P. cerasus. I. Knoop Fructologie 2:35, 39. 1771. 2. Thomas Guide Prat. 21, 194. 1876. 3. Del. Sta. An. Rpt. 12: I18. I900.

Süsse Frühweichsel. 4. Liegel Syst. Anleit. 170. 1825. 5. Ill. Handb. I83 fig., I84. I 860.

\section{Liegel's Süsse Frühweichsel. 6. Dochnahl Führ. Obstkunde 3:58. $185^{8}$.}

This variety is often confused with Süsse Frühweichsel. The two are distinct, however, in that the latter has light colored flesh while the former is a dark fleshed sort. Tree vigorous, drooping, productive; fruit often borne in twos or threes, of medium size, roundish, compressed; suture shallow; stem rather slender, variable, medium to above in length, inserted in a narrow, shallow cavity; skin dark brownish-red changing to reddish-black: flesh tender, dark red, juicy, subacid, becoming milder at maturity; stone small, roundish; ripens the forepart of June. 
Griotte de Kleparow. P. cerasus. x. Lond. Hort. Soc. Cat. 50. 1831. 2. Mortillet Le Cerisier 2: 186 fig., 187, 221. I866.

Polnische grosse Weichsel. 3. Kraft Pom. Aust. 1:8, Tab. 20 fig. 2. 1792.

Pohlnische Kirsche. 4. Christ Handb. 682. I797.

Polnische Weichsel. 5. Dochnahl Führ. Obstkunde 3:60. 1858.

Kleparower Süssweichsel. 6. Ill. Handb. 69 fig., 70. 1867.

Kleparavoska. 7. Am. Pom. Soc. Rpt. 75. 1883.

Griotte Kleparite. 8. Budd-Hansen Am. Hort. Man. 2:277. I903. 9. Ia. Sta. Bul. $73: 7$ I fig. 1903 .

Budd found this variety very hardy about Galicia, Austria, and Warsaw, Russia, and imported it for central and southern Iowa. It is grown from seed in the forests of Poland. The Griotte Kleparite of Budd-Hansen is probably the same variety. Tree strong in growth, large, productive; fruit of medium size, generally attached in pairs, roundish-cordate, sides often compressed; suture shallow, often a line; stem long, slender. set in a wide, deep cavity; skin tough, clinging to the flesh, glossy, dark brownish-red, deep black when ripe; flesh tender, fibrous, lightly colored, juicy, acid, although sugary, aromatic; quality fair; pit small, turgid, almost spherical; ripens the last of July.

Griotte Lodigiana. P. cerasus. I. Leroy Dict. Pom. 5:290, 29 I fig. I877.

Introduced into France from Florence, Italy, by Leroy about $186_{4}$. Fruit of medium size, globular, compressed at the ends; stem of medium length, inserted in a wide cavity; apex depressed; skin deep red; flesh pale yellow, tender, slightly fibrous, juicy, very sugary, slightly acidulated; second quality; stone of medium size, round, turgid; ripens the last of June.

Griotte Noire. P. cerasus. I. Thomas Guide Prat. $26 . \quad$ i 876.

Listed as a large, blackish-red, acidulated fruit, ripening in July.

Griotte Noire de Piémont. P. cerasus. r. Leroy Dict. Pom. 5:294, 295 fig. 1877.

Griotte à gros fruit noir de Piémont. 2. Thomas Guide Prat. $26 . \quad$ 1876.

This variety, probably from Piedmont, Italy, was received by Leroy in $\mathbf{1} 864$. Fruit generally borne in pairs, above medium in size, globular, compressed at the ends; suture indistinct; stem long, set in a deep cavity; skin uniformly blackish-red; flesh tender, reddish, very juicy, acidulated, slightly sweet; quality fair; stone of medium size, roundishoval, swollen; ripens the middle of June.

Griotte du Nord Améliorée. P. cerasus. x. Thomas Guide Prat. 27. I876.

Mentioned as possibly larger and better than Griotte du Nord.

Griotte à Petit Fruit. P. cerasus. I. Lond. Hort. Soc. Cat. 50. I831.

Listed in the reference given.

Griotte Précoce. P. cerasus. I. Ia. Hort. Soc. Rpt. 329. I885. 2. Budd-Hansen Am. Hort. Man. 2:277. 1903 .

According to the first reference, this variety was brought into Spain from Central Asia and was known in parts of Europe as "Early Spanish." It was imported to America from Russia. Tree hardy; fruit large, flattened; suture distinct; stem medium in size, curved, set in a deep cavity; skin bright, glossy red; flesh soft, breaking, uncolored; quality very good; ripens the middle of June. 
Griotte Rouge de Piémont. P. ccrasus. I. Leroy Dict. Pom. 5:303 fig., 304, 385 . 1877. Griotte à gros fruit rouge de Piémont. 2. Thomas Guide Prat. $26 . \quad$ i 876.

According to Leroy, it is not at all improbable that this cherry is the one spoken of by Pliny under the name, "Apronian." Fruit attached in pairs, above medium in size, globular, compressed at the ends; suture indistinct; stem short, stout, set in a small cavity; skin lively red; flesh whitish, tender, juicy, acidulated, somewhat bitter yet sugary; second quality; stone of medium size, roundish-oval, swollen; ripens the last of June.

Griotte de Schaarbeck. Species? I. Mathieu Nom. Pom. 353. I889.

Mentioned in this reference.

Griotte Tardive d'Annecy. Species? I. Mas Pom. Gcn. II: 160. I882.

Listed in this reference.

Griotte Tardive de Plombiéres. P. avium. I. Rev. Hort. 503. 1888.

This variety is recommended because of its lateness but it remains a local variety, little known outside of Plombières, Vosges, France, where it was found. Fruit ovalcordate, elongated at the apex; skin glossy, brownish at complete maturity; flesh firm, adherent to the stone, whitish-gray, very sweet, agreeable; pit cordate; ripens the last of August, remaining on the tree during Septembcr.

Griotte de Toscane. P. cerasus. 1. Leroy Dict. Pom. 5:304, 305 fig., 396. 1877.

Leroy brought this cherry from Florence, Italy, to France about i864. Fruit globular, more or less compressed at the ends; suture very shallow; stem long, set in a pronounced cavity; skin intense red changing to blackish; flesh of a garnet color, tender, juicy, sugary, slightly bitter; second quality; stone of medium size, round, turgid; ripens in early July.

Griotte de Turquie. $P$. avium $\times P$. cerasus. I. Lond. Hort. Soc. Cat. 5 I. 1831 .

Fruit large, round, red; flesh tender, ripens early in July. Similar to Choisy.

Griottier à Feuilles Cucullées. P. cerasus. 1. Leroy Dict. Pom. 5:267, 286 fig., 287. 1877 .

Cerisicr cuculle? 2. Mas Pom. Gen. I1: 160. 1882.

Originated at Tours, Inde-et-Loire, France. Its only point of merit is in its cucullated foliage. Fruit small, globular, compressed at the ends; suture imperceptile; stem short; cavity variable; skin almost clear red; flesh tender, light rose-colored, juicy, acidulated, mildly sweet; quality hardly fair; pit very small, round, more or less swollen; ripens at the end of June.

Griottier à Fruit Aigre. P. cerasus. I. Noisette Man. Comp. Jard. 2:508. 1860.

Tree of medium size, rather vigorous; fruit small, oval-roundish, blackish; flesh tender, juicy; mediocre quality; ripens in September and October in France.

Griottier à Longues Feuilles. P. cerasus. I. Leroy Dict. Pom. 5:291, 292 fig. 1877 .

Leroy grew this cherry as early as 1845 but did not know its origin. Fruit above medium in size, globular, slightly compressed at the ends; stem very short, inserted in a pronounced cavity; skin deep red, with gray dots; flesh tender, fibrous, yellowish-white, juicy, acidulated, slightly sweet, agreeable; second quality; stone of medium size, roundish-oval, turgid; ripens the first of July.

Groll Schwarze Knorpelkirsche. P. avium. 1. Mathieu Nom. Pom. 354. 1889.

Listed in the reference given. 
Gros Bigarreau Rond. P. avium. I. Mortillet Le Cerisier 2:114, 208. 1866.

Fruit large, even, roundish, though often larger and less flattened than Bigarreau d'Italie; stem medium in length; color becoming black; flesh red, firm, sweet, pleasing; pit small and slightly elongated; ripens the last of May.

Gros Guindoul Hâtif. P. cerasus. I. Rev. Hort. 335, I870-7 I.

Tree large; fruit of first size, superior quality, large, dark red, juicy, sprightly; ripens in June-July.

Grosse Blanche Carrée. P. avium. x. Mag. Hort. 9:204. I843.

A firm, red, heart-shaped cherry of second size and quality, used principally for the table, ripening in July.

Grosse Bunte Herzkirsche. P. avium. I. Truchsess-Heim Kirschensort. 226, 227, 228. I 8 I 9 .

Weiss Herzkirsche. 2. Christ Obstbäume 161. I 79 г.

Grosse bunte Molkenkirsche. 3. Dochnahl Führ. Obstkunde 3:28. $185^{8}$.

This cherry is distinguished from others of its class by its peculiar coloring. At one time it was recommended because of its size, flavor, and length of season. Fruit large, thick at the base, both sides compressed and marked by a suture; stem long, slender, set in a shallow opening; ground color a dingy pale yellow more or less covered with red; flesh tender, melting, pleasing; ripens at the end of June.

Grosse Friedrichskirsche. Species? I. Dochnahl Führ. Obstkunde 3:39. I858.

Fruit large, compressed, roundish-cordate, pale yellow, washed with crimson; flesh slightly aromatic; ripens the end of June; productive.

Grosse Glaskirsche. $\quad$. avium $\times$ P. cerasus. I. Krünitz Enc. 57, 58. 1790. 2. Christ

Wörterb. 292. 1802. 3. Truchsess-Heim Kirschensort. 473-475. 1819.

Grosse Cerise Transparente. 4. Mortillet Le Cerisier 2:172-175, fig. 1866. 5. Guide

Prat. I8, I90. 1895 .

Through an error which he later rectified, Truchsess described the Double Glass as this variety. This cherry differs in having a shorter stem, larger size and in ripening later. Fruit very large, almost round, flattened at the ends, depressed at the apex; stem stout, short, inserted in a large cavity; skin glossy, becoming dark red; flesh pale yellowish, melting, juicy, mild yet with a piquant, pleasing sourness; stone roundish, turgid, clinging to the flesh more than to the stem; ripens in August.

Grosse Gomballoise. P. avium. I. Mas Pom. Gen. II: 150, I51. I882.

Bigarreau Grossc Gomballoise. 2. Guide Prat. 17. 1895.

Fruit large to very large, thickly cordate, often elongated, truncate at the ends; suture deep, but a colored line on one side; stem long, stout, set in a large, deep cavity; skin thick, firm, intense purple changing to almost black; flesh purple, firm, juicy, sugary, vinous, aromatic; pit of medium size; ripens at the end of June.

Grosse Guigne Blanche. P. avium. I. Truchsess-Heim Kirschctsort. $25^{8}$. I8I9. 2.

Leroy Dict. Pom. 5:315, 316 fig. 1877 .

Guigne à gros fruit blanc. 3. Duhamel Trait. Arb. Fr. I:I6I, P1. I fig. 3. 1768.

4. Mortillet Le Cerisier 2:98, 99. I 866.

Kleine weisse Frühkirsche. 5. Christ Wörterb. 278 . I802. 
Guigne Blanche. 6. Lond. Hort. Soc. Cat. 5I. I83I. 7. Pom. France 7:No. 20, P1. 20. $187 \mathrm{I}$.

Early White Guigne. 8. Prince Pom. Man. 2:112. 1832.

IThite Heart. 9. Floy-Lindley Guide Orch. Gard. 107. 1846.

An old variety, probably of French origin, which, according to Leroy, was described by Nerlet in 1667 . Fruit large, attached in pairs, cordate, slightly elongated; stem medium in length, set in a wide cavity; skin dull yellow, tinged and mottled with dull red; flesh whitish, tender, juicy, slightly acidulated; quality fair, insipid in wet seasons; stone large, ovoid, clinging; ripens the last of June.

Grosse Guigne Noire à Court Pédicelle. P. avium. I. Noisette Man. Comp. Jard. 2:503. I 860 .

Guignier à Gros Fruit Noir et Court Pédoncule. 2. Pom. France 7:No. 28, Pl. 28. $187 \mathrm{I}$.

An old variety of uncertain origin. Fruit large, roundish-cordate; suture broad; stem short, set in a narrow, shallow cavity; skin tender but firm, beautiful black at maturity; flesh soft, juicy, agreeable; quality good; stone of medium size, oval, reddish; ripens the last of June.

Grosse Höckerige Marmorkirsche. P. avium. r. Dochnahl Führ. Obstkunde 3:42. I858.

Fruit very large, uneven, roughened, dark red; flesh hard, rather sweet; ripens at the end of July; not very productive.

Grosse Mogulkirsche. P. avium. I. Christ Obstbäume 160. I791.

Fruit large, cordate, red, dotted here and there with white; flesh mild; excellent; pit small.

Grosse Morelle. P. cerasus. I. Christ Wörterb. 284. 1802. 2. Truchsess-Heim

Kirschentsort. 545-548. I8I9.

Grosse Morelle double? 3. Mas Pom. Gen. II: I6I. IS82.

Fruit large, globular; stem medium in length, slender, set in a smooth cavity; skin glossy, smooth, inky-black; flesh blood-red, veined, juicy, wine-sour, not unpleasant; stone of medium size, blood-red; ripens from the end of June to July; often dried.

Grosse Nonnenkirsche. P. cerasus. I. Christ Wörterb. 287. I802. 2. Truchsess-Heim Kirschensort. $5^{17}, 5_{18}^{18}, 519 . \quad 1819$.

Varrenne, De. 3. Lond. Hort. Soc. Cat. 56. I83 I.

Grosse Cerise des Religieuses. 4. Mas Pom. Gen. II:97, 98, fig. 49. I882.

Probably of French origin. Tree moderately productive; fruit of medium size, round, sides unevenly compressed, with a shallow suture; stem long, set in a wide cavity; skin brownish-black, glossy; flesh tender, colored, juicy, subacid; stone small, very broad, clinging to the stem; ripens the middle of July.

Grosse Picarde. P. cerasus.

The United States Department of Agriculture received this variety from F. Jamin, Bourg-la-Reine, France, in 1905, after which trees were sent to this Station for testing. Tree vigorous, rapid in growth; fruit of the Montmorency type, above medium in size, roundish-cordate, slightly compressed; cavity intermediate in depth and width, abrupt; suture a line; apex roundish; stem slender, long; skin moderately thick, tough, separating 
readily from the pulp, very dark red; dots numerous, small, obscure; flesh dark red, stringy, tender, melting, astringent, sour, juicy; poor to fair in quality; stone of medium size, ovate, slightly pointed, smooth, tinged with purple; season very late.

Grosse Schwarze Friihe Herzkirsche. P. avium. 1. Kraft Ponn. Aust. r:2, Tab. 2 fig. 2.

1792. 2. Christ Wörterb. 274. I802. 3. Truchsess-Heim Kirschensort. 158. I8I9.

Guigne à Gros Fruit Noir Hâtif. 4. Pom. France 7:No. 25, Pl. 25. 187 r.

This cherry differs from Frühe Maiherzkirsche in having a firmer flesh. Fruit above medium in size, cordate, pointed, black; suture distinct on one side; stem long, slender, deeply set; ripens in June.

Grosse Schwarze Herzkirsche. P. avium. x. Christ Wörterb. 275. I802.

Gemeine Schwarze Herzkirsche. 2. Truchsess-Heim Kirschensort. I42-I 45, I 56, I 57 . I 8 I 9.

Guignier à gros fruit noir? 5. Noisette Man. Comp. Jard. 2:502. I I86o.

Fruit large, cordate, flattened on one side; stem long, set in a deep cavity; skin thick, dark red changing to black, pitted; flesh rather firm, tender, fibrous, dark red, juicy, exceedingly sweet and refreshing, with a slightly bitterish after-taste; stone clinging; ripens in July.

Grosse Späte Schwarze Knorpelkirsche. P. avium. I. Christ Wörterb. 277 . 1802.

2. Truchsess-Heim Kirschensort. 200, 201. 1819.

Found in a German garden in $\mathbf{1 7 9 7}$; distinguished from Elkhorn in ripening later. Fruit large, round, flattened on the sides and apex; skin black, glossy; stem thick; flesh firm, juicy; ripens early in August.

Grosse Siisse Maiherzkirsche. P. avium. I. Truchsess-Heim Kirschensort. I26-I30. I8I9. 2. Dochnahl Führ. Obstkunde 3:20. I8 88.

Grosse Sïsse Maikirsche. 3. Christ Handb. 662. I797.

Fruit above medium in size, roundish-cordate, sides compressed; stem of medium length, stout, set in a narrow, shallow cavity; skin tough, almost black; flesh tender, reddish-black, juicy, sprightly, rich; stone of medium size, broadly cordate, with a faint point; ripens at the end of June; used for table and kitchen.

Grosse Tardive. P. avium. I. Thomas Guide Prat. I $7 . \quad{ }_{1} 876$.

Grosse späte Amarelle. 2. Proskauer Obstsort. $5^{8} .1907$.

Grosse Tardive is thought to have originated near Paris, France. It ripens the first of August when all other sweet, black cherries are gone. The tree resembles Montmorency. Grosse Transparente. Species? 1. Can. Exp. Farm Bul. 2nd Ser. 3:60. I900.

Mentioned in the reference given.

Grosse Ungarische Kirsche. P. avium. I. Krünitz Enc. 66-68. I790.

Ungarische Herzkirsche. 2. Christ Handb. 661. 1797.

Grosse schwarze ungarische Herzkirsche. 3. Dochnahl Führ. Obstkunde 3:20. $\quad 1858$.

Fruit large, oval, rather angular; stem medium in length; cavity deep, irregular; suture distinct; skin glossy, black; flesh dark red, fine-grained, aromatic, sweet; stone large, oval; ripens early in July; productive.

Grosse de Verrirèes. P. avium. I. Rev. Hort. 7I, 72, P1. I870-7I.

This cherry is extensively grown at Verrières, France, where it is often called, "La Grosse." The fruit, however, is but a trifle larger than Cerise Commune from which it 
differs only in its slightly elongated-cordate form; stem medium in length; skin deep red; flesh red, juicy, sweet; season the middle of July.

Grosse de Wagnellee. $P$. avium. I. Downing Fr. Trees Am. 465. 1869 .

A vigorous, productive cherry of Belgian origin; fruit large, oval; skin yellow, washed and spotted with red; flesh tender, juicy, sweet; ripens in July.

Grosse Weinkirsche. P. cerasus. I. Oberdieck Obst-Sort. ${ }_{3} 85$. I88I.

Grosse-Griotte à vin. 2. Thomas Guide Prat. 2 1, 196. 1876.

Fruit flattened, roundish, rather large; stem rather long; suture indistinct; skin very dark, glossy red; flesh tender, dark red, juicy, sprightly, acid; pit egg-oval; ripens in July; used for conserves and coloring wines.

Grosse Weisse Frühkirsche. P. avium. I. Truchsess-Heim Kirschensort. 285, 679, 680. I819.

Fruit large, truncate-cordate, one side compressed, with a shallow suture; stem long, stout, set in a wide, shallow cavity; skin firm, tough, pale yellow, washed with deep red; flesh firm, juicy, sweet, pleasing; stone small, round, plump, partly clinging; ripens the middle of July.

Groth Braune Knorpelkirsche. P. avium. I. Mathieu Nom. Pom. $35^{8} . \quad 1889$.

Listed without description in this reference.

Groth Gelbe Knorpelkirsche. P. avium. I. Proskaner Obstsort. ${ }_{5}^{6 .} 1907$.

Bigarrean jaune de Groth. 2. Thomas Guide Prat. 27, 189. 1876.

Groth's Wachskirsche. 3. Mathieu Nom. Pom. 337, 358. I889.

Tree vigorous and very productive; fruit rather large, truncate-cordate; skin transparent, brilliant yellow; flesh rather firm, very sweet, agreeable; first quality; matures early in July.

Grïnstiel-Kirsche. P. cerasus. I. Dochnahl Führ. Obstkunde 3:22. 1858.

Fruit black, of medium size, obtuse-cordate, noticeably furrowed; stem long, shallowly inserted; flesh firm, colored, subacid; pit of medium size, round, somewhat clinging; ripens the middle of July.

Guben. P. avium. 1. Can. Exp. Farms Rpt. 549. 1901.

Bigarreau noir de Guben. 2. Thomas Guide Prat. 20, 190. 1876.

Gubener Schwarze Knorpel. 3. Oberdieck Obst-Sort. 369. 1881.

Late Black Bigarreau? 4. Guide Prat. 18.1895.

Guben originated near the town of the same name in Prussia, Germany. Fruit large, obtuse-cordate, sides slightly compressed; suture indistinct; stem rather long; cavity shallow; skin firm, glossy, nearly black; flesh firm, dark red, sweet, with a pleasing sourness; pit roundish; ripens the last of June.

Gubens Ehre. Species? I. Mathieu Nom. Pom. 358. 1889. 2. Lange Allgem. Garten. 423. 1897 .

Fruit large, dark red, with a slightly aromatic flavor.

Guigne Anglaise Blanche Précoce. P. avium. I. Mas Pom. Gen. II:161. 1882.

Listed in the reference given.

Guigne d'Argovie. P. avium. 1. Lond. Hort. Soc. Cat. $5^{1} .1831$.

Mentioned in the reference given. 
Guigne Blanche Précoce. P. avium. I. Leroy Dict. Pom. 5:316. 1877.

Received by Leroy from Germany in 1860 and said by him to lack size and quality.

Guigne Bonne Alostoise. P. avium. I. Mathieu Nom. Pom. 359. 1889.

Mentioned in the reference given.

Guigne de Buxeuil. P. avium. I. Mas Pom. Gen. II:161. I882.

Listed without a description.

Guigne Carnée Winkler. P. avium. I. Leroy Dict. Pom. 5:317, 318 fig., 319. 1877.

Winkler weisse Herzkirsche. 2. Truchsess-Heim Kirschensort. 278, 279. I819.

Guigne Blanche de Winkler. 3. Mas Le Verger 8:161, 162, fig. 79. 1866-73.

Guigne de Winkler. 4. Thomas Guide Prat. 15, 199. 1876.

This variety is said to be a seedling raised by a Herr Winkler at Guben, Prussia, Germany, about i8 8 . Fruit attached in pairs, large, roundish-cordate, compressed; suture not prominent; stem long, inserted in a deep, narrow cavity; skin flesh-colored; flesh tender, slightly fibrous, light yellow, juicy, sweet, pleasingly aromatic; pit of medium size, plump, oval; ripens the second week of the cherry season.

Guigne de Chamblondes. P. avium. 1. Mathieu Nom. Pom. 359. 1889.

Mentioned in the reference given.

Guigne Chamonale. P. avium. I. Mas Pom. Gen. II: I5I. 1882.

Flowers and foliage only described.

Guigne Chavanne. P. avium. I. Mas Pom. Gen. II: 161. 1882. 2. Mathieu Nom. Pom. 359. I889.

Mentioned in the reference given.

Guigne Courte-queue d'Oullins. $P$. avium. I. Mortillet Le Cerisier 2:62 fig., 63, 218 . I 866 .

Guigne à courte queue? 2. Cat. Cong. Ponn. France 20. I 887.

This variety is said to have originated at Oullins, near Lyons, France. Tree vigorous, upright, productive; fruit rather large, obtuse-cordate, truncate; stem short to very short, inserted in a shallow, narrow cavity; suture a well-marked line; skin rather thick, glossy, shaded with red changing to deep black; flesh red, tender but not soft, sweet with some acidity, agreeable; quality excellent; pit large for the size of the fruit, ovoid; ripens early in June.

Guigne Ecarlate. P. avium. I. Lond. Hort. Soc. Cat. 5 I. I 83 I.

A worthless, medium-sized, red, oval fruit, with firm flesh, ripening in July.

Guigne de l'Escalier. P. avium. I. Thomas Guide Prat. 24. I876. 2. Guide Prat. II. I 895 .

This is a large, brownish-black, French cherry of the Heart class. Fruit with an uneven surface; flesh red, sugary, sweet; first quality; ripens the first of July.

Guigne de Gland. P. avium. I. Rev. Hort. 213 . 1880.

Guigne de Gland received its name from the small community of Gland, Aisne, France, where it appears to have been first cultivated. It is one of the first to be found on the markets; is very productive, and of good quality; fruit large, clear red, very sweet.

Guigne Grosse Rouge Hâtive. P. avium. I. Lond. Hort. Soc. Cat. 5 I. I 83 I.

A firm, red, cordate cherry of second quality for table use; ripens in July. 
Guigne Grosse Rouge Tardive. P. avium. I. Lond. Hort. Soc. Cat. 51. I 83 I.

Listed in this reference.

Guigne Guindole. $P$. avium. I. Thomas Guide Prat. I8, I98. I876.

Many writers, including Leroy, believe this cherry to be identical with the Flamentine. Tree vigorous, productive; grown for market; fruit large, elongated-cordate; skin deep red with carmine mottling on a yellowish ground; flesh tender, soft, juicy, sugary; matures the last part of June.

Guigne Hâtive d'Elsdorf. P. avium. I. Thomas Guide Prat. 27, I98. 1876.

A German variety " much recommended."

Guigne Marbrée. P. avium. I. Pom. France 7:No. I8. Pl. I8. I871. 2. Wickson Cal. Fruits. 286. 1889. 3. Cat. Cong. Pom. France 523. 1906.

The origin of this variety is uncertain. Fruit large, obtuse-cordate: suture wide, shallow; stem of medium length, set in a shallow, wide cavity; skin glossy, white, washed with a rose color changing to carmine, adherent to the pulp; flesh yellowish, firm, sweet, faintly aromatic; pit small, roundish; ripens early in July.

Guigne Marie Besnard. P. avium. I. Thomas Guide Prat. I5. I876.

A large, oblong, Heart cherry of good quality; skin light yellow overspread with red; flesh tender, juicy; late.

Guigne de Nice. P. avium. I. Thomas Guide Prat. 24. 1876. 2. Guide Prat. I1. I895.

Fruit very large, oblong, light red; season early in warm years; trees rather tender.

Guigne Noir Luisante. P. avium. I. Elliott Fr. Book 208. I854. 2. Am. Pom. Soc.

Cat. 74. I862.

Guignier à gros fruit noir luisant. 3. Duhamel Trait Arb. Fr. I:162, 163. I768.

Grosse glänzende schwarze Herkirsche. 4. Kraft Pom. Aust. I:2, Tab. 3 fig. 2. 1792.

5. Truchsess-Heim Kirschensort. I46, I47. I819.

Grosse Guigne noire luisante. 6. Mortillet Le Cerisier 2:72 fig. 73, 74, 2 I 8 . I 866.

Guigne Reinette noire. 7. Thomas Guide Prat. $24 . \quad$ I876.

Guigne noire hâtive à gros fruits. 8. Soc. Nat. Hort. France Pom. Io8 fig., Iog. I904.

This variety should not be mistaken for the Black Spanish of the Germans although Elliott speaks of it as such with the statement that it was grown in New Jersey about $\mathrm{I}_{23}$, from whence it was introduced into Ohio. It was known as Guigne Reinette Noire about the provinces of Main and Anjou, France, where it is said to have originated. Some authors have confused it with Hogg's Black Heart from which it differs in being more firm. Tree large, vigorous, productive; fruit large, usually attached in threes, obtusecordate, plump; suture wide; stem medium in length, inserted in a rather wide, deep cavity; skin thick, glossy, brownish-red changing to black; flesh colored, tender, fibrous, juicy, sweet, vinous; quality good; pit small, roundish-oval, turgid; ripens the last of June.

Guigne Noire Hâtive. P. avium. I. Lond. Hort. Soc. Cat. 51. 1831.

Guignier à Gros Fruit noir hâtif. 2. Leroy Dict. Pom. 5:330 fig., 331. 1877.

This old variety originated in France early in the Sixteenth Century. Tree moderately productive; fruit attached in threes, large, obtuse-cordate, irregular; stem long, stout; cavity large; skin becomes reddish-black; flesh deep red, fibrous, juicy, acidulated, sweet; quality fair; pit above medium, ovoid, plump; ripens the last of May. 
Guigne Noire de Monstreux. P. avium. I. Thomas Guide Prat. 24. 1876.

Described by M. M. Vérilhac, nurseryman at Annonay, France, as a large, good, productive cherry ripening the first part of June.

Guigne Nouvelle Espéce. P. avium. I. Lond. Hort. Soc. Cat. 51. I831.

Mentioned in the reference given.

Guigne Olive. $P$. avium. I. Mortillet Le Cerisier 2:79, 80 fig., 8I, 220. I866.

Fruit large, elongated-oval, more pointed at the cavity; suture wide; stem long, slender, set in a slightly deep, abrupt cavity; skin at first rose-colored, marbled with red changing to almost black; flesh tender, colored, agreeably acid, with a slight bitterness; pit very large, oval, resembling the pit of an olive; ripens at the beginning of July.

Guigne Petite Blanche. P. avium. I. Lond. Hort. Soc. Cat. 5I. I83 I.

Mentioned in the reference given.

Guigne Petite Rouge. P. avium. I. Lond. Hort. Soc. Cat. $51 . \quad$ I 831 .

Listed in this reference.

Guigne la Plus Hâtive. P. avium. I. Mortillet Lc Cerisier 2:5 I-54, fig. 1866.

Guigne marbrée précoce. 2. Mas Le Verger 8: II5, II6, fig. 56. 1866-73.

Guigne d'Annonay. 3. Thomas Guide Prat. I5, 197. 1876.

Fruit of medium size, cordate, often slightly elongated; skin thin, mottled with red changing to almost black; stem moderately slender, set in a rather deep, wide cavity; flesh purplish, tender, juicy, agreeably acidulated; pit small, ovoid; ripens the last of May.

Guigne Précoce Leo d'Ounons. P. avium. I. Rev. Hort. 65. I88 I.

This variety was found in an orchard near Vigne, France. The fruit is large and sweet with an agreeably aromatic juice; ripens the first half of June.

Guigne Précoce de Mathère. P. avium. I. Thomas Guide Prat. $27 . \quad$ i876.

Early Mathere. 2. Can. Exp. Farms Rpt. 416. I899.

Tree vigorous; fruit of medium size, roundish-oval; stem short; skin red; flesh yellowish-red, juicy, sweet; stone small, clinging; early.

Guigne Précoce Ponctuée. P. avizun. I. Mortillet Le Cerisier 2:208. 1866.

A variegated cherry with uncolored juice, mentioned by Mortillet.

Guigne de Provence. P. avium. I. Thomas Guide Prat. I8. 1876. 2. Mas Pom. Gen.

II : I52. I882. 3. Guide Prat. 18. I895.

Although very similar to Transparente de Coë, according to Guide Pratique, I895, Guigne de Provence is a distinct variety. Tree vigorous, productive; fruit of medium size, obtuse-cordate; skin reddish-carmine; flesh rather firm, sweet; first quality; matures the last half of June.

Guigne Ramon Oliva. P. avium. I. Rev. Hort. 355. I888. 2. Soc. Nat. Hort. France Pom. II 2 fig., II3. I 904 .

A chance seedling noticed first by M. Charozé, horticulturist, at Pyramide-Trelazé, near Angers, France. Tree vigorous, productive; fruit large, usually borne in twos or threes, roundish-cordate; suture indistinct; stem long; color brownish-black, glossy; flesh fine, juicy, sweet; pit large, oval; ripens early in June.

Guigne Rose Hâtive. P. avium. I. Thomas Guide Prat. 24, I99. 1876.

Kleine frithe rothe Herzkirsche. 2. Truchsess-Heim Kirschensort. I64. I8I9. 
Rosenrothe Maikirsche. 3. Dochnahl Fïhr. Obstkunde 3:18. 1858. 4. Ill. Handb. 55 fig., 56.1860 .

Guignier à fruit rose hâtif. 5. Noisette Man. Comp. Jard. 2:503. I860.

Guigne Rose Hâtive was received by Jahn from Dochnahl who believed Rheinpfalz, a former palatinate in Germany, to be its home. Tree productive, drooping; fruit of medium size, uneven particularly about the stem, roundish-cordate, sides flattened; suture indistinct; stem medium in length; cavity shallow; skin rose-colored in the middle of May, later changing to a reddish-purple or black; flesh tender, with colored juice, sweet if ripe; stone rather large, ovate to oval; ripens at the end of May or the beginning of June.

Guigne Rouge Commune. P. avium. I. Mas Pone. Gen. II: I52. I882.

The flowers and foliage only are described.

Guigne Rouge Ponctuée. P. avium. I. Mortillet Le Cerisier 2:89 fig., 90, 9 I, 2 I8. 1866.

This cherry is similar to Rothe Molkenkirsche but is different in pit. It was found in the province of l'Isere, France. Fruit large to above, depressed at both extremities, flattened on both sides, one of which is traversed by a wide, shallow suture; stem above medium in length, set in a shallow, rather narrow cavity;.skin firm, thick, brilliant, changing to deep red, mottled; flesh white, faintly rose-colored especially about the pit, moderately firm, at maturity it loses its sourness becoming sugary and aromatic; pit large, oblongoval; ripens at the beginning of June.

Guigne de Russie à Fruit Blanc. P. avium. I. Lond. Hort. Soc. Cat. $52.583 \mathrm{I}$.

Mentioned in the reference given.

Guigne Très Précoce. P. avium. I. Hogg Fruit Man. 275, 301. I884.

A very early, black cherry, a week earlier than the Early Purple. Fruit rather small, obtuse-cordate, irregular in outline; stem long, slender, deeply inserted in a wide cavity; skin quite black; flesh very tender; juice colored; good.

Guigne van der Broek. P. avium. I. Knoop Fructologie 2:39, 40. 177 I.

A very small, juicy cherry similar to the Black Guigne in form, color and taste; somewhat oblong; dark, brownish-black; of a very sweet, agreeable taste.

Guigne Villeneuve. P. avium $\quad$ r. Thomas Guide Prat. 15. 1876.

Villeneuver Herzkirsche. 2. Proskauer Obstsort. 57. 1907.

This variety is believed to be native to the region around the Auvergne mountains, France. Fruit very large, quadrangular; skin a vivid rose color overspreading a whitish ground; ripens late in June.

Guignier à Fruit Noir et Très-long Pédoncule. P. avium. I. Noisette Man. Comp. Jard. 2:503. I $\$ 60$.

Obtained from seed and fruited first in $\mathbf{1} 824$. Tree erect, vigorous; fruit small, conical, black; stem nearly four inches long; flesh watery, colored, sweet, agreeably acidulated.

Guignier à Petit Fruit Noir. P. avium. I. Noisette Man. Comp. Jard. 2:502. I860. This variety differs from the Grosse Schwarze Herzkirsche only in size of fruit.

Guindoux Noir de Faix. Species? I. Thomas Guide Prat. $26 . \quad$ 1876.

Mentioned by Thomas without description. 
Gunsleber Späte Knorpelkirsche. P. avium. I. Truchsess-Heim Kirschensort. $320,32 \mathrm{I}$. I8 i 9 .

A seedling of White Spanish ripening early in August. Fruit small, blushed with light and dark red on a white ground; flesh firm, sweet; unproductive.

Halbgefülltblühende Weichsel. P. cerasus. I. Dochnahl Fuhr. Obstkunde 3:66, 67. $185^{8}$.

Schwarze Weichsel mit halb gefüllter Blute. 2. Truchsess-Heim Kirschensort. 606, 607, 608. I8I9.

Truchsess says that only the semi-doubles have perfect pistils and the other flowers do not produce fruit. Fruit oblate; stem long, inserted in a shallow cavity; skin thin, tough, glossy, black; flesh tender, fibrous near the stem, with dark juice, pleasing.

Halifax. Species? I. Am. Pom. Soc. Rpt. 94. 1854.

Halifax is an old variety reported from Maryland.

Hallock. $P$. avium.

Hallock is a supposed seedling of Downer found by Nicholas Hallock, Milton, New York; not disseminated. It resembles Downer in color but is slightly smaller and about two weeks later.

Hallowell. P. avium. I. Me. Sta. An. Rpt. 22:175. 1906.

Hallowell is a seedling of Black Tartarian.

Hamell Kirsche. Species? I. Mas Pom. Gen. II: 161. I882.

Mentioned in the reference given.

Hamels Arissen. Species? I. Mas Pom. Gen. II: I6 I. I882.

Mentioned in this reference.

Hartlib. Species? I. Lond. Hort. Soc. Cat. 52. $183 \mathrm{I}$.

Listed without a description.

Hartlippe. Species? I. Parkinson Par. Ter. 572. 1629.

"The Hartlippe Cherrie is so called of the place where the best of this kinde is noursed up, being betweene Sittingbourne and Chattam in Kent, and is the biggest of our English kindes."

Hartz Mountain. Species? I. Minn. Hort. Soc. Rpt. 48. IS 74.

This variety was brought from Germany by a Mr. Meyer of St. Peter, Minnesota, with whom it has proved hardy and productive.

Hâtive de Balis. Species? I. Mathieu Nom. Pom. 362. I889.

Mentioned in the reference given.

Hâtive ou Précoce. Species? I. Lond. Hort. Soc. Cat. 52. I $S_{3}$ I.

Listed without a description.

Hâtive de Prin. P. cerasus. I. Rev. Hort. 280,28 r, Pl. I893. 2. Guide Prat. I7. 1895. Priner Frühweichsel. 3. Proskaner Obstsort. 59. 1907.

This variety was introduced by M. Maquerlot of Fismes, Marne, France. It resembles Montmorency in shape, with a longer stem. Fruit often borne in fours; cavity deep; skin thin, deep red; flesh of a rose color, transparent, sugary, acidulated, juicy; pit of medium size, orbiculated.

Hâtive de St. Jean. Species? I. Lond. Hort. Soc. Cat. 52. I 83 I.

Listed without a description. 
Headley. Species? I. Mas Pom. Gen. II:I61. I882.

Mentioned in this reference.

Healy. P. avium. I. Sweet Cat. II. 1897.

Healy is an old, sweet variety thought to have come from Pennsylvania; introduced by George A. Sweet, Dansville, New York.

Hedelfingen. P. avium. I. Can. Exp. Farms Rpt. 549. 1901.

Hedelfingen Risenkirsche. 2. Ill. Handb. 77 fig., 78. I860.

Colassale d'Hedelfingen. 3. Mortillet Le Cerisier 2:301. 1866.

Géante d'Hedelfingen. 4. Thomas Guide Prat. 20, I94. 1876.

Monstrueuse d'Hedelfingen. 5. Mas Pom. Gen. II:59, 60, fig. 30. I882.

Bigarreau de Hedelfingen. 6. Gard. Chron. 20: 160 . I896.

This variety probably originated in the village of Hedelfingen, Germany. Tree strong, vigorous, productive; fruit very large, obtuse-cordate; suture noticeable on both sides; stem very long; cavity deep, narrow; skin glossy, tough, dark brown changing to black, with light red dots; flesh fibrous, dark red, more tender than many Bigarreaus, yet firm, juicy, pleasing, aromatic; stone of medium size, long, truncate at the base; ripens in July; good for table, kitchen and market.

Hedwigs Kirsche. Species? I. Mas Pom.Gen. II:161. I882. 2. Mathieu Nom. Pom. 362. 1889 .

Listed but not described.

Heidelberger Kirsche. P. cerasus. I. Christ Wörterb. 290.1802.

A very dark, black, small, short-stemmed Sour Cherry ripening at the beginning of September.

Heiges. P. avium. I. U.S. D. A. Pom. Rpt. 40. I895.

Heiges is a seedling of the Bigarreau type, from C. E. Hoskins, Springbrook, Oregon, ripening there the last of June. Fruit large, heart-shaped, very smooth; cavity medium in size and depth, regular, flaring; stem short, slender; suture shallow, narrow; skin thin, tenacious, dark purplish-black, with minute golden, indented dots; flesh very dark, purplish-black, with a few light veins, meaty, tender, juicy, sweet, aromatic; quality best; pit large, oval, semi-clinging.

Heintzen (Heintze's) Fruhe Kirsche. Species? I. Mathieu Nom. Pom. 362. I889.

Listed in the reference given.

Henneberger Grafenkirsche. P. cerasus. I. Christ Handb. 675. 1797. 2. TruchsessHeim Kirschensort. 548, 549, 550. 1819. 3. Dochnahl Führ. Obstkunde 3:64. 1858. 4. Christ Obstbäume I59. I791.

Cerise du Comte de Henneberg. 5. Mortillet Le Cerisier 2:307. I866.

Fruit of medium size, flattened, without a suture; black when ripe; stem long, slender, shallowly inserted; flesh tender, with a pleasant sourness; ripens in July.

Hensel Early. Species? I. Horticulturist 22:233 fig. 1867.

Hensel is an accidental seedling found on the grounds of G. W. Zahm, Lancaster, Pennsylvania, and named after the former owner of the property. Tree moderate in growth, hardy, productive; fruit roundish, obtuse at the base; stem slender; flesh halftender, juicy; good; ripens the first part of June; not disposed to rot. 
Herzkirsche Léona Quesnel. Species? 1. Mathieu Nom. Pom. 362. 1889.

Mentioned but not described by Mathieu.

Herzkirsche Trauben. Species? I. Mas Pom. Gen. II:I53. I882.

The flowers and foliage only are described.

Herzkirsche Wils Frühe. Species? I. Lange Allgem. Garten. 439. I897.

Listed without a description.

Herzkirschweichsel. P. cerasus. 1. Christ Handb. 673. I797.

According to Christ, this cherry is a Morello; fruit large, with an indistinct suture; stem rather long, deeply set; color reddish-black; flesh tender, subacid; stone cordate; ripens the middle of July.

Herzog May. P. avium $\times$ P. cerasus. 1. Ia. Hort. Soc. Rpt. 330. 1885. 2. Ohio Hort. Soc. Rpt. 22. $1892-93$.

Imported by Professor J. L. Budd from Southwestern Russia where it does well on wet, unfavorable soil. Tree open and upright, a true Duke of the best quality.

Hoadley. P. avium. I. Elliott $F r$. Book 209 fig. 1854.

Hoadley was raised by Professor J. P. Kirtland, Cleveland, Ohio, in 1842, and was named by Elliott in honor of George Hoadley of Cleveland. Tree healthy, vigorous, with a round, spreading head; fruit above medium in size, roundish-cordate; stem of medium length; cavity shallow; skin pale yellow, mottled and striped with clear carmine; flesh yellowish, tender, juicy, sweet, sprightly, almost translucent; pit of medium size; season the last of June; valuable for table use but will not stand shipment.

Hockenberg. P. cerasus.

Mentioned in a letter from H. Back \& Sons, New Trenton, Indiana, as resembling an Amarelle; of no particular value.

Hogg Black Gean. P. avium. I. Hogg Fruit Man. 69, 84. I866. 2. Mas Ponn. Gen. II: 161. I 882 .

Fruit of medium size, obtuse-cordate; stem long; skin black, glossy; flesh and juice dark, rich, sweet, tender; season at the beginning of July.

Hogg Red Gean. P. avinm. I. Hogg Fruit Man. 69, 84. 1866.

Fruit medium large, roundish, inclined to heart-shape; stem long; skin red, mottled with amber-yellow; flesh yellowish, tender, sweet, rich, with uncolored juice; ripens the first of July.

Hoke. P. avium $\times$ P. cerasus. I. U.S. D. A. Pon. Rpt. 24. 1894.

Hoke is a Duke, long known in York County, Pennsylvania, and regarded as worthy of wider dissemination. It originated at Hanover, Pennsylvania, with Henry Wirt, and was known as Wirt until the farm changed hands in 1848 , when it became known as Hoke. The fruit, as grown at this Station, is large, obtuse-cordate; cavity large, deep; skin thick, tough, resisting rot in rainy weather, dark, mottled with red; stem long, moderately thick, swollen at either end; flesh firm, meaty, dark pink, subacid, sprightly; quality very good; stone medium; season the last of June.

Höllandische Späte Weichsel. P. cerasus. I. Christ Handb. 677. 1797. 2. Christ

Wörterb. 288 . 1802 .

Hollandische Kirsche. 3. Truchsess-Heim Kirschensort. 597-599. 1819.

Höllandische Weichsel. 4. Dochnahl Führ. Obstkunde 3:65. I858. 
This variety is distinguished from others of its class by its smaller stone, tender flesh, longer stem and later ripening. Tree never large, productive; fruit large, nearly round, sides slightly compressed; suture distinct; stem long; color brownish-red; flesh tender, colored, juicy, very sour; ripens in August but hangs until September.

Holman Duke. P. avium $\times$ P. cerasus. I. Langley Pomona 86, Pl. I7 fig. I. 1729 . 2. Prince Pom. Man. 2:135, 136. I832. 3. Floy-Lindley Guide Orch. Gard. 99. I846. 4. Leroy Dict. Pom. 5:346, 347 fig. I 877 .

Cerise Rojale Tardive D'Angleterre. 5. Ann. Pom. Belge I: 107, 108, P1. I853.

Cherry-Duck. 6. Noisette Man. Comp. Jard. 2:507. I860.

Royale Tardive. 7. Mortillet Le Cerisier 2:I55, I56 fig., I57, I58, 305. 1866. 8. Pom. France 7:No. I, P1. I. I87 I. 9. Mas Pom. Gen. II:I62. IS82.

Holman Duke is thought to be of English origin and a seedling of May Duke. The name, Royale Tardive, a synonym of Holman Duke, has been used interchangeably for several Duke cherries. Fruit large to above, roundish-cordate; suture moderate; stem above medium in size, set in a rather deep, narrow, irregular cavity; skin thin, brownislred changing to nearly black when fully mature; flesh red, fibrous, juicy, vinous, acidulated; pit of medium size, ovoid; dorsal suture not very apparent; ripens the middle of July.

Holme Late Duke. $P$. avium $\times P$. cerasus. I. Thomas Guide Prat. $27 . \quad$ i 876.

Mentioned by Thomas without a description.

Holstein. Species? I. Mag. Hort. 17:363. I 85 I.

A medium-sized, round, red, seedling cherry.

Homer. P. cerasus. I. Ia. Sta. Bul. 73:71, 72. 1903. 2. Jewell Cat. 35. 1906. 3. Am. Pom. Soc. Cat. 27. I909.

Homer is a seedling of the Morello type from New Haven, Connecticut, introduced from Homer, Minnesota; said to be valuable in the Northwest. Fruit medium to large, roundish-oblate; stem short, stout; cavity shallow, moderately broad; skin red, becoming darker, thin, rather tough; flesh tender, uncolored, juicy, mildly subacid; pit round, semiclinging; ripens the last of June.

Honey. P. avium. I. Coxe Cult. Fr. Trees 25I. 18I7. 2. Elliott Fr. Book 217. I854. 3. Am. Pom. Soc. Rpt. 243. ${ }_{1} 858$.

Large Honey. 4. Lond. Hort. Soc. Cat. $5^{2}$. I $8_{3}$ r.

Yellow Honey. 5. Prince Pom. Man. 2 : 1 10. $18_{32}$.

Cream. 6. Horticulturist I: 148 . I846-47.

Summer's Honey? 7. Cole Am. Fr. Book 228. I 549.

Late Honey? 8. Ibid. 235,236 . I 849 .

Honey, though grown only in America, is probably of foreign origin - an old sort renamed. Tree similar to Black Mazzard but more spreading. Fruit small, roundishoval, yellowish, mottled with red, becoming deep amber-red; stem long, slender; flesh tender, melting, juicy, sweet; pit large; season the middle of July.

Honey Dew. P. avium. I. Conn. Bd. Agr. Rpt. II:340. I877.

Spoken of as a valuable variety originating in Connecticut.

Honeywood. P. avium. I. Lond. Hort.Soc.Cat.52. I831. 2. Mag. Hort. 9:205. I843. Mentioned as unworthy of cultivation. 
Hoppock Yellow. P. avium. I. Mich. Sta. Bul. 12:164. 1886.

This variety originated in Bucks County, Pennsylvania, from seed sown by Cornelius Hoppock. Fruit of medium size, cordate, sweet; very productive.

Hoskins. P. avium. I. U. S. D. A. Rpt. 262 . 1892. 2. Ibid. 292, Pl. VI. I893. 3. Am. Pom. Soc. Rpt. 150. 1895. 4. Am. Pom. Soc. Cat. $24 . \quad$ I 899.

Hoskins originated with C. E. Hoskins, ${ }^{1}$ Newberg, Oregon, about I880, as a seedling of Napoleon. Tree vigorous, upright, somewhat spreading; fruit large, roundish-cordate suture a line; stem short, set in a roundish cavity; color dull purplish-red; fiesh purple, fibrous, firm, sprightly, sweet; quality good; ripens in mid-season.

Hovey. P. avium. 1. Hovey Fr. Am. 2:25, 26, Pl. 1851. 2. Mag. Hort. 19:405, 406

fig. 27. 1853. 3. Am. Pom. Soc. Cat. 74. 1862.

Hovey originated with C. M. Hovey, Boston, Massachusetts, being selected from a bed of seedlings in 1839 ; first fruited in 1848 . For a time it was considered a cherry of considerable value but at present it is but little known. Tree very vigorous, upright. spreading, productive; fruit large, obtuse-cordate; stem short, rather stout; skin rich amber mottled with brilliant red; flesh pale amber, rather firm but tender, sprightly becoming sweet; very good in quality; stone slightly adherent to the pulp, small, oval. Hoy. P. avium. 1. Chase Cat. 12. 1909. 2. Ibid. P1. 1910.

A new cherry recently found in one of the suburbs of Philadelphia and introduced in 1909 by the Chase Nursery Company, Geneva, New York, as a very valuable Sweet Cherry. As grown at the Geneva Station it is smaller and no better than Napoleon. Tree vigorous, hardy, healthy, unproductive on the Station grounds. Fruit large, roundishcordate, slightly flattened, with irregular surfaces; cavity deep; suture a line; stem of medium thickness and length, adhering to the fruit; skin rather thin, of medium toughness, adhering to the pulp, amber covered with light red, sometimes spotted; flesh whitish, juicy, stringy, tender, somewhat meaty, crisp, sprightly, sweet; quality good; stone clinging, roundish, plump; ripens in mid-season.

${ }^{1}$ Oregon has given to pomology two notable breeders of cherries, Seth Lewelling and C. E. Hoskins, the subject of this sketch. Cyrus Edwin Hoskins was born on a farm in Clinton County, Ohio, July 3 , 1842, and there he grew to manhood. Almost at the first call for men to defend the Union in the Civil War, Mr. Hoskins responded and joined the I3th Ohio regiment, serving until the close of the war. Returning to Ohio, he gave attention to fruit culture, testing many varieties of several fruits and producing some new grapes and berries. In I 877 Mr. Hoskins moved to Newberg, Yamhill County, Oregon, settling on new land and thus becoming a pioneer in the Northwest. His first pomological venture in Oregon was in growing prunes, his orchard of this fruit being one of the first, and he is credited with having built one of the first evaporators for the curing of prunes in America. For some years he maintained his prune ranch and evaporator, developing a product that gave him the highest reputation in prune markets and made him one of the leading authorities on this fruit in the United States. Early in his orchard work in Oregon Mr. Hoskins began to produce new varieties of cherries and soon offered for sale a number of promising seedlings of which Vesta, Lake, Occident, Stryker and Hoskins were most worthy. Unfortunately, ill health in the family compelled Mr. Hoskins to move from Yamhill County, to which place, after having spent several years in Jackson County, Oregon, and in the Hawaiian Islands, he returned with the expectation of taking up his work in breeding cherries and prunes, but his death, August 18 , I908, occurred before his work had been again well begun. The Pacific Northwest owes a debt of gratitude to Mr. Hoskins for the spendid part he played in developing the fruit industry of that region and pomologists the country over owe him much for his labors in breeding cherries. 
Hubbard. P. cerasus. I. Ill. Hort. Soc. Rpt. 437. 1898.

Hubbard is a variety of the Morello class grown about Villa Ridge, Illinois. Tree dwarfish, drooping, bears early, productive; fruit large, cordate, nearly black; precedes Early Richmond.

Hungarian Gean. P. avium. 1. Lond. Hort. Soc. Cat. 50. 18 3 1. 2. Hogg Fruit Man. 302. 1884 .

Hungarian Cherry of Zworts. 3. Parkinson Par. Ter. 574. 1629. 4. Rea Flora

1 206. I676.

Although there seems to be a discrepancy in the size of the cherry mentioned by Parkinson and Rea and the one described by Hogg, all three writers undoubtedly referred to the same sort. While the first two references describe the variety as exceptionally large no definite statements are made, thus giving strength to the following description made by Hogg many years later. Tree productive; fruit rather below medium in size, obtuse-cordate; skin amber, mottled with red on the sunny side; flesh white, half-tender, mildly sweet; quality fair; stone large, ovate; ripens in July.

Hyde Late Black. P. avium. I. Cole Am. Fr. Book 237. I849. 2. Downing Fr. Trees Am. 262. $\quad$ I857.

This variety originated with T. \& G. Hyde, Newton, Massachusetts. Tree strong in growth, productive; fruit medium in size, obtuse-cordate, purplish-black; flesh halffirm, melting, juicy; resembles Eagle but is later.

Hyde Red Heart. P. avium. I. Mag. Hort. 8:284. I 842 . 2. Downing Fr. Trees Am.

175. 1845 .

Hyde's Seedling. 3. Cole Am. Fr. Book 232. 1849.

Another seedling from T. \& G. Hyde, Newton, Massachusetts. Tree vigorous, hardy, spreading, productive; fruit of medium size, cordate; stem short; skin pale yellow, becoming lively red; flesh tender, with a pleasant sprightliness, juicy; season early July.

Imperial Morello. P. cerasus. 1. Downing Fr. Trees Am. 279. $\quad 1857$.

Poiton griotte. 2. Prince Pom. Man. 2: 148.1832.

Imperial. 3. Elliott Fr. Book 209. 1854.

Griotte Impériale. 4. Thomas Guide Prat. 17, 195. 1876. 5. Can. Exp. Farm Bul. I7:9. 1892.

Griotte à Courte Quene. 6. Leroy Dict. Ponn. 5:284 fig., 285. $\quad$ I877.

Guindoux du Poitou. 7. Mas Pom. Gen. II: II3, I14, fig. 57. I882.

Kaiserliche Weichsel. 8. Mathieu Nom. Pom. 364. I889.

An old variety recently introduced into the Northwest where it has proved very hardy. Tree small, low-headed, productive, bears early; fruit medium to large, roundish-oval; stem very short, shallowly inserted; skin very dark red; flesh tender, juicy, pleasantly acid when ripe; pit small, long, pointed; ripens the middle of July.

Incomparable en Beauté. Species? I. Mas Pom. Gen. II: I6I. I882.

Listed in the reference given.

Intorka. P. cerasus. I. Thomas Am. Fruit Cult. 667. 1897.

Intorka is an importation from Russia. Fruit of medium size, round, yellow and red; flesh firm, yellowish, subacid. 
Jaune de Prusse. P. avium. I. McIntosh Bk. Gard. 2:544. 1855. 2. Downing Fr. Trees Am. 466. I 669 . 3. Mas Pom. Gen. II:93, 94, fig. 47. I882.

Tree vigorous, productive; fruit small, obtuse-cordate; stem long, slender, inserted in a narrow cavity; skin firm, light yellow, translucent; flesh yellowish-white, tender, juicy, sweet but slightly bitter before it is fully ripe; pit large for the size of the fruit; ripens after Downer.

Jean Arendsen. Species? I. Knoop Fructologie 2:37. 177 I.

According to Knoop, it closely resembles the round Pragische Muskateller in both form and color but is not as good in quality.

Jenkin Black Heart. P. avium. I. Lond. Hort. Soc. Cat. 47. I 831 .

Mentioned without description.

Jerusalem Kirsche von der Natte. Species? I. Mas Pom. Gen. II:153, I54. I882.

Flowers and leaves only are described.

Jerusalemskirsche. P. cerasus. I. Truchsess-Heim Kirschensort. 557-56 I. I\$I9.

Späte Konigliche Weichsel. 2. Kraft Pom. Aust. I:S, Tab. I9 fig. 2. I792.

3. Truchsess-Heim Kirschensort. 561-563. I 8 I 9 .

Späte grosse königliche IWeichsel. 4. Christ Handb. 683. 1797.

Pyramidenkirsche. 5. Christ Wörterb. 291. I802.

Pyramidenweichsel. 6. Truchsess-Heim Kirschensort. 529-53I. I8I9.

The origin of this old variety is unknown but it was chiefly grown in Germany. Tree unproductive; fruit large, oval, with a shallow suture; stem long, set in a shallow cavity; skin dark red, changing to black, glossy; flesh moderately firm, juicy, pleasing subacid; pit large, walnut-shaped, clinging; ripens the last of July in Germany.

Jocosot. P. avium. I. Mag. Hort. 19:167, 168, 404. 1853. 2. Elliott Fr. Book I97 fig. I 854 .

Jockotos. 3. Hooper II. Fr. Book 2;0. I8 57.

Jocosot was raised by Professor J. P. Kirtland, Cleveland, Ohio, in 1842 , from a pit of the Yellow Spanish and named after an Indian chief. Tree thrifty, round-topped, productive; fruit large, regular, obtuse-cordate, indented at the apex, sides compressed; suture broad; stem long, set in a cavity of medium size; skin glossy, of a dark-liver color, almost black; flesh tender, with indistinct radiating lines, juicy, sweet; pit below medium in size, smooth; ripens the last of June.

Joel Keil Kleine Schwarze Herzkirsche. P. avium. I. Dochnahl Führ. Obstkunde 3:22. I 858 .

Fruit small, roundish-cordate; suture indistinct; stem long, slender, shallowly inserted; skin black; flesh rather firm, sweet, juicy, colored; pit oval, clinging; ripens the middle of July to the middle of August.

June Amarelle. P. cerasus. I. Ia. Hort. Soc. Rpt. 330. 1885. 2. Ia. Sta. Bul. 73:72. 1903.

Cerisier juniat. 3. Truchsess-Heim Kirschensort. 649, 650, 691. I8г9.

Junius Amarelle. 4. Dochnahl Fuhr. Obstkunde 3:70. 1858.

Juniat Amarelle. 5. Mas Pom. Gen. II:159. I882, 6. Mich. Hort. Soc. Rpt. 328. 1888. 7. Vt. Sta. An. Rpt. 12:243. IS98-99.

June Morello. 8. Ia. Sta. Bul. 19:548. I892. 
Truchsess refers to this cherry as having been described by Sickler in I805. Budd, in his importations of $188_{3}$, from Russia, included this variety. Tree of medium size, vigorous, rather unproductive; fruit above medium in size, roundish-oblate; stem stout, of medium length; suture indistinct; skin thin, rather tough, separating readily from the pulp, light red; flesh firm, meaty, yellowish, juicy; flavor subacid; quality fair; stone of medium size, somewhat round; season that of Early Richmond which it resembles in size, flavor and color.

June Duke. P. avium $\times$ P. cerasus. I. Hooper W. Fr. Book 269. 1857.

Shippen. 2. Coxe Cult. Fr. Trees 248, I 8 I7.

A tart variety similar to May Duke, known about Philadelphia as Shippen and Wetherill. Tree vigorous; fruit large and pleasing; ripens late in June.

Justinische Morello. P. cerasus. I. Christ Wörterb. 291. 1802. 2. Truchsess-Heim Kirschensort. 523,524 . 1819 .

Justinische Amarelle. 3. Christ Handb. 683. 1797.

This variety is separated from other Sour Cherries ripening with it, through its firm flesh, its straight, shallowly set stem and its astringent, sour flavor. Fruit of medium size, roundish, sides broadly compressed; stem of medium length, rather stout; suture shallow; skin tough, brownish-red; flesh dark red, with clear red juice.

Kamdesa. P. pumila $\times P$. persica. I. S. Dak. Sta. Bul. 108:19o8.

Noted in the reference as a cross between the Sand Cherry and the Opulent peach. "The blossoms show a tendency to double."

Kappenblättrige Süssweichsel. $P$. avium $\times P$. cerasus. 1. Dochnahl Führ. Obstkunde 3: $47 . \quad 1858$.

Distinguished from May Duke through its smaller fruit and rolled leaves.

Kassin Frïhe Herzkirsche. P. avium. I. Lauche Ergänzungsband 601. 1883. 2. Can. Exp. Farm Bul. and Ser. 3:60. 1900.

Kassin, a vineyardist, in Potsdam, Prussia, Germany, raised this sort from seed. Fruit large, obtuse-cordate, sides compressed; suture indistinct; stem of medium length, thick, set in a small cavity; skin dark brown changing to reddish-black, dotted; flesh dark, juicy, sweet; excellent; stone roundish-oval; ripens the first weck of the season.

Katie. (P. avium $\times P$. cerasus $) \times P$. avium. 1. Am. Hort. An. 86 fig. 1869.

Katie is a seedling of Louis Philippe crossed with a Mazzard. The tree has the Mazzard habit of growth, yet produces fruit resembling May Duke in form and size but deeper in color; flesh tender; matures with Downer.

Kaufmann. P. cerasus. I. Ia. Hort. Soc. Rpt. 345. 1906.

Kaufmann is a stray seedling of English Morello from Minnesota. It is larger and a little longer in stem than the supposed parent and ripens with the last of the Early Richmond.

Kazan Seedling. Species? I. Vt. Sta. An. Rpt. 12:240. 1898-99.

Listed in the reference given.

Kelly. P. avium. 1. Am. Pom. Soc. Rpt. 253. 1903.

A Sweet Cherry from Berrien County, Michigan. 
Kennicott. $P$. avium. I. Elliott Fr. Book 2 ro fig. 1854 .

Kennicott was raised by Professor J. P. Kirtland and named by Elliott after Dr. J. A. Kennicott of Northfield, Illinois. Tree vigorous, hardy, spreading, productive; fruit large, oval-cordate, compressed; suture shallow; stem short, inserted in an irregular cavity; skin amber-yellow, mottled with bright, clear, glossy red; flesh yellowish-white, firm, juicy, sweet; pit below medium in size, smooth; ripens about the middle of July. Kentish Drier. P. cerasus. 1. Lond. Hort. Soc. Cat. 52 . $183 \mathrm{I}$.

A medium-sized, red cherry of first quality used for culinary purposes; ripening in July. Confused by some with Early Richmond.

Kentish Preserve. Species? I. Lond. Hort. Soc. Cat. 52. I831.

Listed without a description.

Keokuk. P. avium. I. Mag. Hort. 19:167, 168. 1853. 2. Elliott Fr. Book 210 fig. I8 54 .

Keokuk is another seedling raised by Professor J. P. Kirtland, Cleveland, Ohio, from a pit of Yellow Spanish, probably crossed with Black Tartarian, Black Mazzard, or May Duke. Tree vigorous, strong; fruit large, cordate; stem stout; skin dark purplish-black; flesh half-tender, purple, rather coarse; deficient in flavor; pit of medium size; season early in July.

Kesterter Fruih Kirsche. Species? I. Mathieu Nom. Pom. 364. I889.

Listed in the reference given.

King George the Second. P. avium. I. Brookshaw Pom. Brit. Pl. 6. I817. 2. Brookshaw Hort. Reposit. I:3, P1. II fig. I. I 823 .

This variety is distinguished from other black cherries by its uneven surface. Fruit large, with a rich, sweet flavor; ripens the first of June and hangs for six wceks.

King Morello. P. cerasus. 1. Ia. Hort. Soc. Rpt. 78 . 189o. 2. Can. Exp. Farm Bul. 2nd Ser. 3:60. 1900. 3. Budd-Hansen Am. Hort. Man. 2:277. I903.

King Morello is another of Budd's importations from Russia. Tree very hardy, moderate in growth; fruit large, oblate; stem variable; skin dark red; flesh yellowishwhite, firm, sprightly, juicy, good; pit very small; ripens with Early Richmond.

Kirsche von Basel. P. avium. I. Ill. Handb. ig fig., 20 . 1867.

$\mathrm{Jahn}$, in his Handbuch, calls attention to the error in calling this variety Bigarreau Hâtif de Bale as it is not a Bigarreau but a variegated Heart. Fruit compressed unevenly giving it a cordate appearance, small; suture shallow; apex slightly depressed; stem long, slender, set in a shallow cavity; skin thin, bright yellow washed with pale red, mottled and streaked; flesh pale yellow, soft, with abundant, uncolored juice, pleasing but not high in quality; stone large, roundish, slightly pointed; ripens the middle of July.

Kirchheimer. P. cerasus. I. Christ Wörterb. 290. 1802. 2. Can. Exp. Farms Rpt. 549. I90I.

Kirchheimer Weichsel. 3. Truchsess-Heim Kirschensort. 580-583. I819. 4. Ill. Handb. 85 fig., 86 . I867.

This old cherry is from Kirchheim, Erfurt, Prussia, Germany. It is propagated by root cuttings and is used for wine and for canning. It is mentioned as growing in British Columbia but is otherwise not spoken of by American writers. Tree large, vigorous, 
drooping; fruit of medium size, round; suture a line; stem long, slender, shallowly inserted; skin thin, glossy, almost black when ripe; flesh mild subacid, pleasing, juicy; stone small, oval, turgid; ripens at the end of July.

Kirtland Morello. P. cerasus. 1. Horticulturist 22:292, 293 fig. 1867.

Kirtland's Large Morello. 2. Horticulturist N. S. 3:123. 1853.

Large Morello. 3. Elliott Fr. Book 2 ro. ${ }_{1854}$.

A seedling originated by Professor J. P. Kirtland, Cleveland, Ohio; it thrives in sections of the south and west where Sweet Cherries are generally unsuccessful. Tree vigorous, spreading; fruit uniformly distributed, borne in pairs, large, uniform, roundish; stem short; cavity round, narrow; skin glossy, dark red; flesh tender, juicy, acid; high quality; pit small; ripens early in July.

Kleindienst Braune Knorpel. P. avium. I. Mathieu Nom. Pom. 365. 1889.

Bigarreau Brun Kleindienst. 2. Leroy Dict. Pom. 5: 184,185 fig. 1877 .

Leroy, in $\mathrm{I} 866$, stated that this variety was raised from seed by M. Kleindienst, a vineyardist at Guben, Prussia, Germany. Tree moderately productive; fruit usually borne in pairs, large, cordate, flattened; stem long, moderately stout; skin vivid red, changing from grayish-red to almost black; flesh of a whitish-rose color, firm, filamentose, juicy, sugary, acidulated, aromatic; first quality; pit large, ovoid; ripens the last of June.

Kleine'Amarelle. P. cerasus. I. Truchsess-Heim Kirschensort. 644-646. I8I9.

Truchsess states that this variety was described by Büttner in I797, as Kleine Glaskirsche but that it belongs to the Amarelles. Tree productive; fruit small, globular, pale reddish-yellow; flesh melting, watery; ripens the middle of July.

Kleine Bunte Frihkirsche. P. avium. I. Truchsess-Heim Kirschensort. 248-25I. I8I9.

Bigarreau à petit fruit rouge hâtif. 2. Duhamel Trait. Arb. Fr. I: 166, I67. ${ }_{7} 68$.

3. Lond. Hort. Soc. Cat. 47. I8 3 I.

Bigarreautier à petit fruit rouge. 4. Truchsess-Heim Kirschensort. 308-310. I8Ig.

Bigarreau rouge hâtif (petit). 5. Leroy Dict. Pom. 5:243 fig., 244. I877.

Petit Bigarreau Hâtif? 6. Mas Pom. Gen. I I:105, 106, fig. 53. 1882.

Fruit of medium size, usually attached in pairs, irregular, cordate, flattened on both faces; stem long, slender; skin almost wholly red, occasionally showing streaks of yellow; flesh yellowish, firm, juicy, aromatic; pit of medium size, ovoid; ripens about the middle of June.

Kleine Bunte Herzkirsche. P. avium. I. Truchsess-Heim Kirschensort. 219-222. I819.

Kleine bunte Molkenkirsche. 2. Dochnahl Fïhr. Obstkunde 3:28. I858.

Fruit small, nearly round, sides compressed; suture distinct; stem long, slender, deeply inserted; skin dull blood-red, with yellow spots; flesh tender, pale yellow, juicy, honey sweet; stone small; ripens at the end of June.

Kleine Friihe Amarelle. P. cerasus. I. Truchsess-Heim Kirschensort. 650-652. I8 I9.

Fruit small, round, flattened; stem short; suture a line; skin clear red, transparent, tender; flesh tender, pleasant subacid; stone small, adhering more to the stem than to the flesh; ripens the last half of July.

Kleine Natte. Species? I. Mathieu Nom. Pom. 365. ${ }_{1889 .}$

Listed in the reference given. 
Kleine Nonnenkirsche. $P$. cerasus. r. Truchsess-Heim Kirschensort. 585-588. I8I9. 2. Dochnahl Fïhr. Obstkunde 3:65, 66. I 858 .

This variety is a seedling of the common wild Sour Cherry. The fruit is the smallest of the Sour Cherries and resembles the black Bird cherries but has a shorter stem. Tree of medium size, drooping; fruit very small, oblate; stem short, shallowly inserted; skin glossy, black, thin but tough; flesh firm, tender, juicy, with a peculiar sourness; stone small, round, adhering to the flesh more than to the stem, stained violet; ripens early in August continuing for three weeks.

Kleine Schwarze Frühe Herzkirsche. P. avium. I. Truchsess-Heim Kirschensort. I55, I56. I8I9. 2. Dochnahl Führ. Obstkunde 3:20. I858.

No doubt this varicty, the Kleine Schwarze Herzkirsche, and the Black Heart greatly resemble each other and some writers combine them.

Kleine Schwarze Herzkirsche. P. avium. I. Christ W'örterb 275. I802. 2. Truchsess-

Heim Kirschensort. I48, 149. I8I9.

Mayer's kleine schwarze Herzkirsche. 3. Dochnahl Fuhr. Obstkunde 3:22. IS5S.

This variety is distinguished from the Grosse Schwarze Herzkirsche only through its size and later ripening; fruit regular, cordate, somewhat flattened; skin brownish-black; flesh soft, tender; ripens the latter part of July.

Kleine Schwarze Knorpelkirsche. P. avium. I. Christ Wörterb. 277. I802. 2. Truchsess-Heim Kirschensort. 195-197, 674. 1819.

Distinguished from others of its class through its smallness and firmness. Fruit small, variable, flattened at the ends; suture often lacking; skin very dark brown; flesh firm, dark red, juicy, not unpleasant but not excellent; stone small; ripens early in August; productive.

Kleine Weisse Frühkirsche. P. avium. I. Truchsess-Heim K̈irschensort. 256-258. ISI9. 2. Dochnahl Führ. Obstkunde 3:27. I 858 .

Described as one of the first to ripen. Fruit of medium size, oblate, compressed; stem long, inserted in a shallow basin; skin tough, yellowish-white, shaded with red; flesh tender, juicy, sweet; ripens early in June.

Kleiner Früher May Herzkirschbaum. P. avium. 1. Kraft Pom. Aust. I: I, Tab. 2 fig. I. I792.

Distinguished from the Grosser Früher Mai-Herzkirschbaum by its inferior size and lighter flesh and juice; ripens at the end of May.

Knapp. Species? I. Wickson Cal. Fruits 290. I 889.

This cherry is a seedling from George Knapp, Lafayette, Oregon; introduced by E. R. Poppleton, $\mathrm{I}_{8} 8_{5}$; fruit of medium size, round, black.

Knight Late Black. P. avium. I. Lond. Hort. Soc. Cat. 52. I831. 2. Mag. Hort. 9:204. I 843 .

Bigarreau-noir de Knight. 3. Thomas Guide Prat. 20, 190. ${ }_{1} 876$.

Fruit large, black, obtuse-cordate, firm; second quality; ripens at the end of July. Knudson. P. avium $\times P$. cerasus.

According to a letter from the Utah Experiment Station, this variety was discovered by William O. Knudson, Brigham City, Utah, in 1896 . Although similar to Late Duke, 
further testing may prove it distinct. Tree bears early, hardy; fruit medium to large, bright scarlet; ripens over a long period; used for pies and canning.

Knyasnaia Sjevera. P. ccrasus $\times$ P. avium. I. S. P. I. Bul. 72:519. I912. 2. Ibid. 73:536 P1. 1912 .

This is a large-fruited cherry, originated in 1888 by the Russian plant-breeder, I. V Mijurin, at Kozlov, Central Russia, and named " Knyasnaia Sjevera," meaning "Queen of the North." The United States Department of Agriculture introduced it into this country under the number 32674 . It is claimed to be a hybrid between an early Vladimir and a variety of Sweet Cherry called "White Winkler." It possesses excellent shipping and keeping qualities. This cherry has stood the severe winters of Central Russia very well and may be expected to thrive in parts of the Middle West and where the climate is more or less semi-arid. Tree vigorous, upright, with few side branches; trunk smooth and clean; fruit large, pale red, with a fresh sour-sweet flavor; ripening about the end of June.

Koch Späte Schwarze Knorpelkirsche. P. avium. I. Dochnahl Führ. Obstkunde 3:38. 1858. 2. Mathieu Nom. Pom. 365. I889.

Originated about 1851 . Fruit large, obtuse-cordate; suture shallow; stem medium long, shallowly inserted; skin glossy, black; flesh firm, piquant; quality high; stone small, roundish-oval; ripens at the end of August.

Kochs Ostheimer Weichsel. P. cerasus. I. Proskaner Obstsort. 59. 1907.

Kochs verbesserte Ostheimer Weichsel. 2. Reut. Pom. Inst. Festschrift 122. 1910.

A strong-growing, productive variety, said to exceed its parent, Ostheim, in size, color, and flavor.

Koeper. Species? 1. Can. Exp. Farms Rpt. 341. 1893.

Listed in the reference given.

Kolaki. P. avium. I. Mas Pom. Gen. I1:29, 30, fig. 15. I882.

According to Oberdieck, this variety is of Bohemian origin. Fruit of medium size, cordate, slightly elongated; apex obtuse; suture distinct; stem medium long, slender, set in a narrow, shallow cavity; skin moderately firm, transparent, yellow in the sun, purplish in the shade; flesh tinged yellow, tender, juicy, somewhat sugary; first quality; pit small, oval, flattened at the base, obtuse at the apex; ripens the first of June.

Korkovanyer Kirsche. Species? I. Proskauer Obstsort. $56 . \quad 1907$.

Listed but not described.

Koslov. P. cerasus. I. Budd-Hansen Am. Hort. Man. 2:278. I903.

Koslov bush Morello. 2. Can. Hort. 12:216, fig. 58, 218 . 1889.

Koslov-Morello. 3. Del. Sta. An. Rpt. 12:128. 1900.

The Koslov cherries are seedlings, not a single variety. A number of seedlings were imported by the Ontario Fruit Growers' Association in I889, from Koslov, Crimea, Russia, where they were grown by Russian peasants, being propagated from pits. The trees are low, bush-shaped, slow in coming into bearing and most of the fruit is worthless. The one most grown is moderately large, roundish, pointed at the apex; suture barely traceable; stem long, set in a slight depression; skin dark red, turning black; flesh dark red, tender, juicy, acid; ripens from the last of July to the last of August. 
KosteInice. P. cerasus. I. Mas Pom. Gen. II:19, 20, fig. Io. 1882.

Originated in Neustadt, Prussia, Germany. Tree moderately vigorous; fruit medium to below in size, obtuse-cordate; stem short, set in a straight, rather deep cavity; skin tough, vivid purple changing to almost black; flesh tender, juicy, vinous, agreeably acidulated; good; stone very small, ovoid, turgid; ripens early in June.

Kostelniti. Species? I. Mas Pom. Gen. II: I6I. I882.

Listed in the reference given.

Kriek van den Broek. Species? 1. Truchsess-Heim Kirschensort. 165, 166. 18 I9.

This variety, coming to Truchsess in 1808 , from Holland, was confused with several others received at the same time.

Kritzendorfer Einsiedekirsche. Species? 1. Obstzüchter 8:52. I910.

An intensely black, large, late cherry which is valued for market because of its color.

Kronberger Kirsche. P. avium. I. Christ Wörterb. 274. I802.

Kronkirsche. 2. Christ Handb. 663. 1797.

Kronberg Black Heart. 3. Truchsess-Heim Kirschensort. 124-126. 1819. 4. Mag.

Hort. 9:203. I 843 .

Kronberger Herzkirsche. 5. Lond. Hort. Soc. Cat. 48.4831.

Wildling von Kronberg. 6. Ill. Handb. 29 fig., 30. 1867.

Bigarreau de Kronberg. 7. Guide Prat. 15, I82. 1895.

According to German pomologists, this variety was raised from seed at Kronberg, Prussia, Germany. Tree productive; fruit of medium size, obtuse-cordate, sides unevenly compressed; suture indistinct; stem long, stout, set in a shallow cavity; skin tough, glossy, black when mature, lighter along the suture; flesh firmer than others of its class, dark red, aromatic, sweet; pit broadly cordate, somewhat adherent; ripens at the end of June.

Kronprinz von Hannover. P. avium. I. Ill. Handb. 479 fig., $480 . \quad$ I 86 I.

Prince Royal du Hanovre. 2. Mortillet Le Cerisier 2:302. I $\$ 66$.

Bigarrean Prince Royal de Hanovre. 3. Leroy Dict. Pom. 5:232 fig. I877.

Prince de Hanovre. 4. Mas Pom. Gen. II:43, 44, fig. 22. I882.

Grown by M. Lieke, a nurseryman at Hildesheim, Prussia, Germany, fruiting for the first time in ${ }^{8} 8_{54}$. Tree moderately vigorous, productive; fruit large, usually attached in pairs, roundish to pointed-cordate; suture shallow; stem long, slender, inserted in a rather deep cavity; skin rather tender, glossy, yellowish, streaked and mottled with red; flesh firm, yellowish, juicy, pleasingly acidulated; pit medium large, ovate, plump; ripens early in June.

Krüger Herzkirsche. P. aviım. $\quad$ r. Ill. Handb. 67 fig., 68. 1860.

Krïgers schwarze Herzkirsche. 2. Truchsess-Heim Kirschensort. I61, 162. I819.

Krügers Herzkirsche zu Frankfurt. 3. Lond. Hort. Soc. Cat. $5^{2} . \quad$ I8 31.

Guigne de Kruger. 4. Thomas Guide Prat. I8, I98. I876. 5. Mas Pom.Gen. II:77, 78 , fig. $39 . \quad 1882$.

This cherry was first heard of at Guben, Prussia, Germany, in 1810 . It is distinguished from Eagle in being larger, shorter stemmed, lighter in color, and less tender in flesh. Tree vigorous, productive, upright; fruit large, obtuse-cordate, oblate; suture shallow; stem medium long, rather deeply inserted; skin dark brown or black; flesh dark 
red, juicy, vinous, tender, yet often firm; stone small, roundish-oval, plump, adhering slightly to the flesh on one side; ripens about the middle of July.

La Nappe. Species? I. Proskauer Obstsort. 59. I907.

Listed in this reference.

Lacure (Large). P. avium. I. Parkinson Par. Ter. 572. 1629.

"The great Lacure or Hart Cherrie differeth not in forme, but in greatnesse, being usually twice as great as the former [Lacure (Small)], and of a reddish blacke colour also: both of them are of a firme substance, and reasonable sweete. Some doe call the white cherrie, the White hart cherrie."

Lacure (Small). P. avium. I. Parkinson Par. Ter. 572. 1629.

" The smaller Lacure or Hart Cherrie is a reasonable faire Cherrie, full above, and a little pointing downward, after the fashion of a heart, as it is usually pointed, blackish when it is full ripe, and lesser than the next " [Lacure (Large)].

Ladé Late. P. avium. I. Can. Exp. Farm Bul. 2nd Ser. 3:60. 1900.

Von Lade's Späte Knorpelkirsche. 2. Lauche Ergänzungsband 605. 1883 .

Bigarreau Tardif de Ladé. 3. Guide Prat. 15, I84. 1895.

A German variety probably raised from seed by M. Ladé. Fruit of medium size, long, cordate, compressed at the stem, roundish at the apex; suture indistinct; stem long, thin, slightly curved; cavity shallow; skin yellowish overspread with glossy light red, darker in the sun, faintly streaked; flesh firm, yellowish, sweet, vinous; excellent; stone long, oval; ripens in September lasting a month; productive.

Lady of the Lake. P. avium. I. Country Gent. 28:398. 1866-67. 2. Downing Fr. Trees Am. 467. I869.

Lady of the Lake is a seedling from Charles Pease, Cleveland, Ohio. Tree vigorous, upright-spreading, productive; fruit medium to large, roundish-obtuse-conic, compressed, with a shallow suture; stem medium, inserted in a deep cavity; skin light yellow, shaded and mottled with bright crimson; flesh half-tender, pale yellow, juicy, sweet, rich; season according to the climate, early May to late June.

Lady Southampton. P. arium. I. Hogg Fruit Man. 69, 85. 1866.

Lady' Southampton's Y'ellow. 2. Lond. Hort. Soc. Cat. 53. 1831. 3. Downing Fr. Trees $A m$. IS 7 . I $\$_{45}$.

According to the reference, this is an almost worthless yellow Bigarreau. Fruit of medium size, heart-shaped; skin yellow; flesh pale, firm, rather dry, with uncolored juice, season the middle of July.

Laeder Kirsebaer. Species? I. Lond. Hort. Soc. Cat. 53. 1831.

Mentioned but not described.

Lake. P. avium. 1. Am. Pom. Soc. Cat. 26. I909.

Lake was named in honor of Professor E. R. Lake, then of the Oregon Agricultural College, by the originator, C. E. Hoskins, Springbrook, Oregon. The tree came into bearing about $\mathrm{I}^{8} 9_{2}$ and is reported in the American Pomological Society's fruit list of 1909 as succeeding well in the northwest. Fruit large, sweet, and very good.

Laker or Loker Bunte Knorpelkirsche. P. avium. I. Mas Pom. Gen. II:I61. I882.

Listed in the reference given. 
Lamaurie. P. avium. 1. Mich. Sta. Bul. 177:31. 1899.

Early Lamaurie. 2. Downing Fr. Trees Am. 46I. 1869. 3. Wickson Cal. Fruits 286, 291 . 1889.

The chief asset of this variety is its earliness for which it is cultivated in England, France and America. The parentage and originator are unknown. Tree of medium vigor and productiveness; fruit large, roundish-cordate, compressed; stem slender; skin thin, moderately tough; color dark reddish-purple; flesh dark red, juicy, stringy, tender, mild, sweet; of very good quality; season very early.

Lampen Schwarze Knorpelkirsche. P. avium. I. Truchsess-Heim Kirschensort. 204, 205, 676. I819.

Lampers Knorpel-Kirsche. 2. Lond. Hort. Soc. Cat. 53. 1831.

Bigarreau noir de Lampé. 3. Mortillet Le Cerisier 2:302. I866. 4. Thomas Guide Prat. 20, 190. 1876. 5. Leroy Dict. Pom. 5:226 fig., 227, 352. I 877 .

A German cherry raised from seed at Guben, Prussia, Germany, in 1810 , and named for its originator. Fruit above medium in size, attached in twos and threes, obtuse-cordate; stem slender, set in a wide, shallow cavity; skin thin, rather dark reddish-brown; flesh dark red, rather firm, juicy, sugary, wine-like; second quality; pit large, oval; ripens early in June.

Lancaster. P. cerasus. I. Downing Fr. Trees Am. 3rd App. 163. I881. 2. Del. Sta. An. Rpt. I2:III. 1900.

Lancaster is an accidental seedling on the grounds of Daniel Smeych, Lancaster, Pennsylvania. Tree moderately vigorous, more open and spreading than Early Richmond; fruit medium large, heart-shaped to oblate, slightly roundish; cavity deep, broad; stem long, slender; suture very slight; apex small; skin light red, very thin, tender; flesh white, moderately soft, juicy, sweet with a sprightly flavor; stone roundish, slightly ovate, partially free; season June.

Langsurer Prachtweichsel. Species? I. Proskancr Obstsort. 59. I907.

Mentioned in this reference.

Large Black Gean. P. avium. I. Lond. Hort. Soc. Cat. 50. I 831 .

A medium-sized, firm, black Heart cherry of poor quality, ripening early in July.

Large Double Flowering. P. avium. I. Thacher Am. Orch. 217 . 1822. 2. Prince Pom. Man. 2: I11. I832. 3. Downing Fr. Trees Am. 199. 1845.

Merisziere. 4. Rea Flora 20. 1676.

Merise à Fleur Double. 5. Duhamel Trait. Arb. Fr. 1:157. 1768. 6. Lond. Hort. Soc. Cat. 53. $183 \mathrm{I}$.

Kramelkirschenbaum mit gross gefullter Blüthe. 7. Kraft Pont. Aust. I:4, Tab. 8. 1792.

Herzkirschenbaum mit grosse gefüllter Blithe. 8. Christ Handb. 668. 1797.

Süsskirschenbaum mit ganz gefüllter Blüte. 9. Truchsess-Heim Kirschensort. 363-370. I819.

Gefulltbluhende Süsskirsche. I0. Dochnahl Führ. Obstkunde 3:18. I858.

This variety in growth and foliage resembles the Mazzard and Black Heart and not the common double-flowering cherry with its small tree and small, pointed leaves. The 
flowers which appear at the usual season are produced in the most showy profusion being from one to one and one-half inches in diameter; they are composed of about forty whitc petals disposed in the form of a rose, with about thirty stamens and a large, abortive pistil. The numerous double flowers, resembling clusters of small, white roses, make the tree a very useful ornamental.

Large Griotte. P. cerasus. I. Prince Pom. Man. 2:148. 1832.

Large Griotte resembles Griotte Commune but is larger and earlier; skin glossy black; flesh dark red, firm, sweet, pleasing.

Large Guindolle. Species? I. Prince Pom. Man. 2:149, I50. I832.

Leaves are deeply indented, double-toothed; fruit large, flattened at the ends, pale red; flesh white, melting, juicy; ripens at the end of June or beginning of July.

Large Heart-shaped Bigarreau. P. avium. I. Prince Pom. Man. 2:129. 1832. 2. Elliott Fr. Book 199 fig. 1854.

Bigarreau Gros Monstrueux. 3. Lond. Hort. Soc. Cat. 46. $183 \mathrm{I}$.

Bigarrean Gros Coeuret. 4. Ibid. 46. 1831. 5. Downing Fr. Trees Am. 453. 1869.

Monstrous Heart. 6. Hogg Fruit Man. 78, 87. 1866.

A variety of French origin which was never extensively grown in America. Tree strong, vigorous, productive; fruit large, roundish-cordate; suture often raised; stem variable, set in a shallow cavity; skin dark, glossy red, nearly black, surface uneven; flesh firm but tender, reddish, pleasant, moderately juicy; good in quality; stone large, oval; ripens the first of July.

Large Late Red Bigarreau. P. avium. I. Prince Pom. Man. 2:128, 129. 1832.

Bigarreau à gros Fruit Rouge Tardif. 2. Lond. Hort. Soc. Cat. $46 . \quad$ I 83 I.

The fruit is somewhat smaller and much later in maturity than that of the Large Red Bigarreau. The color is dark red on the shaded side and on the other a brownish-red, almost black which has given it the name Black Bigarreau; flesh firm, juicy and of excellent flavor.

Large Spanish. Species? I. Miller Gard. Dict. I: 1754 .

Mentioned in the reference given.

Laroses Glaskirsche. P. cerasus. I. Ill. Handb. 177 fig., $178 . \quad 1860$.

Larose. 2. Leroy Dict. Pom. 5:352 fig., 353. 1877 .

This cherry was raised from seed in 1826 by M. Larose, of Neuilly-sur-Seine, France. Tree vigorous, productive; fruit usually borne in pairs, large, obtuse-cordate; sides compressed; suture shallow; stem medium in length, set in a large, deep cavity; skin glossy, tough, mottled with pale red becoming darker; flesh yellowish, tender, slightly fibrous, juicy, mildly acid; pit rather large, plump, oval, flattened at the base; ripens the last of July.

Late Bigarreau. P. avium. I. Horticulturist 2:124. 1847-48. 2. Cole Am. Fr. Book 235. 1849. 3. Elliott Fr. Book 199. 1854.

Late Bigarreau was raised in 1842 by Professor J. P. Kirtland, Cleveland, Ohio. Tree vigorous, round-topped, very productive; fruit large, obtuse-cordate, occasionally somewhat angular; stem long; skin attractive yellow, occasionally nearly overspread with crimson-red, delicately blotched or mottled; flesh yellowish, with distinct radiating lines, 
juicy, firm, crisp, sweet, pleasant; very good in quality; stone rather small, roundish; season late, the same as Downer.

Late Black Bigarreau. P. avium. 1. Prince Pom. Man. 2:130. 1832. 2. Mortillet Le Cerisier 2: II2 fig. 25, I I3, I14. I866. 3. Mathieu Nom. Pom. 338. I889.

This variety differs from Black Bigarreau in being smaller, less heart-shaped, and in ripening later. It was first known as Bigarreau Noir Tardif but Prince, in 1832 , at which time he possibly brought it to America, translated the name into English and called it Late Black Bigarreau under which name it is now known in English and American pomologics. Tree large, vigorous, upright, productive; fruit medium to large, cordate; suture indistinct; color dark brownish-red changing to glossy black; flesh purplish-red, with abundant, highly colored juice, very firm, crisp, sweet yet sprightly, aromatic; quality good; ripens in mid-season or later.

Late Gean. P. avium. I. Lond. Hort. Soc. Cat. 50. 1831 .

According to the reference, this is a small, black Heart of poor quality ripening early in July.

Late Large Black Griotte. P. cerasus. x. Prince Pom. Man. 2: I45, I46. I832.

Worthy of consideration because of its beauty and lateness, often remaining on the tree until October. Tree of medium size; branches numerous, slender; fruit large, roundish; stem very long; skin dark red, nearly black; flesh red, very acid and bitter, somewhat milder at maturity.

Late Purple Guigne. P. avium. I. Hogg Fruit Man. 69, 85. 1866. 2. Downing Fr. Trees Am. 468. 1869. 3. Thomas Guide Prat. 24. 1876.

A large, dark red, German variety ripening the latter part of July; flesh firm, juicy, agreeable.

Late Richmond. P. cerasus. I. Del. Sta. An. Rpt. I2:III. Igoo. 2. Ia. Sta. Butl. $73: 73$. I 903 .

The origin of this variety is uncertain but it seems to have been grown in the Middle West about forty years ago. It is supposed to be a seedling of Early Richmond differing from its parent in ripening later, being of better quality, and more upright in growth. Fruit round, conical; stem thick, moderately long; cavity shallow, broad; skin thin; flesh tender, with abundant, colorless juice, acid; quality good; ripens a week or ten days later than Early Richmond; unproductive.

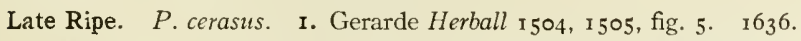

According to Gerarde, this cherry is similar to the wild English cherry in branches and foliage but the flowers are often doubled; fruit small, round, dark red, often dried with the stems on; used by physicians.

Late White Guigne. P. avium. I. Prince Pom. Man. 2: 11 $3 . \mathrm{I}_{32}$.

Fruit nearly round, with a deep suture; skin whitish or very pale amber, tinged with light red; flesh firm, agreeable; ripens in France in September.

Latham. Species? I. Ont. Sta. An. Rpt. 3:45. I 896.

Listed as having been grown at the Simcoe Station.

Laura. P. avium. I. Downing Fr. Trees Am. 468. I869.

Laura originated with Charles Pease, Cleveland, Ohio. Tree spreading, upright, 
productive; fruit medium to large, heart-shaped, globular, often one-sided; stem medium, inserted in a shallow depression; skin pale yellow, largely overspread with rich, bright red; flesh white, juicy, sweet, rich, half-tender; pit medium to small; ripens early in June and hangs well.

Leather Stocking. P. avium. 1. Mag. Hort. 19:167, 168. 1853. 2. Elliott Fr. Book $211,212 . \quad 1854$.

Leather Stocking was grown by Professor J. P. Kirtland, Cleveland, Ohio, in 1842, from a pit of Yellow Spanish. Tree vigorous, hardy, moderately productive; fruit large, heart-shaped, often obtuse; skin faint red becoming a rich reddish-black when fully ripe, with irregular stripes and blotches of black; cavity deep, open; flesh firm, tinged with red, sweet, fair; pit of medium size; season the last of July.

Leib. P. avium. 1. Gard. Mon. I4:28. 1872. 2. Horticulturist 29:256. 1874. 3. Downing Fr. Trees Am. 3 rd App. 163. 188 I.

This variety was brought from Germany about $185^{\circ}$ and planted in the garden of a Mr. Leib, Galena, Illinois. It resembles Early Richmond and was claimed to be very productive and hardy at the time of its introduction; it has not been widely disseminated. Tree hardy, healthy, upright in growth, bearing abundantly; fruit of a crimson color, sweet; quality good; season the end of June, following Early Richmond.

Leitzkauer. P. cerasus. I. Christ Wörterb. 287 . 1802.

Sauer Einmach and Backkirsche. 2. Krünitz Enc. 73, 74. 1790.

Leitzkauer Einmachweichsel. 3. Truchsess-Heim Kirschensort. 567-569. 1819.

No doubt the name of this cherry arises from the cloister, Leitzkau, in Magdeburg, Prussia, Germany, where it is widely planted. It is propagated by root cuttings and if not pruned, grows tall, weak and drooping. Fruit medium to small, roundish; stem long; skin dark brown to glossy black; flesh reddish, juicy, sour; stone small, red; ripens in August; of little value.

Lemercier. P. avium $\times$ P. cerasus. I. Hort. Reg. (Am.) I:343, 344. 1835. 2. Mag. Hort. 13:399 fig., 400. 1847. 3. Hogg Fruit Man. 85. 1866. 4. Thomas Guide

Prat. 25. 1876. 5. Leroy Dict. Pom. 5:353, 354 fig. 1877 .

Frühe Lemercier. 6. Ill. Handb. 157 fig., 158 . 1860.

Discovered by M. Lemercier in Brabant, Belgium, about 1830 ; introduced into Paris in 1835 and into America in 1842 . It resembles Late Duke with which it ripens. Fruit large, obtuse-cordate; suture shallow; stem long, inserted in a wide, deep cavity; skin glossy, transparent, mottled with red; flesh yellowish before ripe, becoming red, firm but melting, juicy, slightly acidulated, with a peculiar fragrance; stone rather large, roundish, truncate at the base, slightly clinging; ripens the last of July.

Léopold (II). Species? I. Mathieu Nonl. Pom. 367 . I889.

Mentioned but not described.

Leopoldskirsche. P. cerasus. I. Christ Handb. 674. I797. 2. Truchsess-Heim Kirschensort. 564-566. I8I9.

Griotte de Léopold. 3. Thomas Guide Prat. 26, 195. 1876.

This variety was received by Truchsess in 1796 from Pastor Winter as Brusseler Bruyn by which name it was called by a few German pomologists. It should not be con- 
fused with the present Brusseler Braune. Fruit large, almost round, compressed on one side; skin dark brown changing to nearly black; flesh dark red, juicy, melting, mild when mature; stone almost round; ripens toward the end of July. The drooping branches, the small, sour cherry leaves which turn yellow and drop and the sweetness in flavor separate it from the Grosse Morelle.

Leschken (Leschke's) Schwarze Knorpel Kirsche. P. avium. 1. Mathieu Nom. Pon. 367. I 889 .

Mentioned in the reference given.

Lethe. P. avium. I. U.S. D. A. Pom. Rpt. 40. 1895 .

Lethe was grown by C. E. Hoskins, Springbrook, Oregon. Fruit of the Bigarreau type, large, heart-shaped, surface smooth, glossy; cavity medium in size and depth, irregular, flaring, marked by irregular waves; suture shallow; stem very long, slender, curved; skin thin, tenacious, purplish-black; dots minute, indented; flesh very dark purplish-red, firm, meaty, juicy, mild subacid, almost sweet; quality good; pit large, oval, semi-clinging; ripens the last of June in Oregon.

Liefeld Braune. P. avium. I. Mathieu Nom. Pom. 367. I889.

Guigne brune de Liefeld. 2. Guide Prat. 6, 191. 1895.

Tree of medium size, very vigorous and productive; fruit large, cordate, brownish, mottled; flesh red, sweet; of first quality; matures early in June.

Lieke Bunte Knorpelkirsche. P. avium. I. Ill. Handb. 61 fig., 62. I867. 2. Mathieu Nom. Pom. 367 . r889.

Bigarreau Tardi de Lieke. 3. Thomas Guide Prat. 21, I90. I876.

Originated with Herr Lieke of Hildesheim, Prussia, Germany, fruiting for the first time in $185 \mathrm{I}$. The fruit is one of the latest to ripen; large, obtuse-cordate, compressed; stem long, slender, inserted in a rather wide, deep cavity; suture indistinct; skin glossy, tough, yellow, streaked and spotted with a mild red; flesh faintly yellow, firm, sweet with a pleasing sourness; stone small, oval; season late.

Lincoln (I). P. avium. I. Downing Fr. Trees Am. 468. $\quad$ 1869.

Lincoln is a vigorous, spreading variety, found near Cleveland, Ohio. Fruit large, oblong-cordate, pointed; suture broad, shallow; stem long; cavity deep; skin dark brown when ripe; flesh firm, veined and mottled with shades of red, juicy, sprightly, sweet, pleasant; pit above medium in size; season the first to the rniddle of July.

Lincoln (II). P. avium. I. Wickson Cal. Fruits 289. I889. 2. Wash. Sta. Bul. 92:29. I910.

Seth Lewelling of Milwatkee, Oregon, raised this variety in 1865 probably from a seed of Eagle. Tree large, spreading, with an open top, seriously affected with black aphis; fruit of medium size, roundish-cordate; skin very dark, thick, tough; stem short; flesh firm, deep red, juicy; good quality; pit small, round.

Lindley. P. avium. I. Elliott Fr. Book 2 II. 1854.

Lindley was raised by Professor J. P. Kirtland from seeds given him by M. Lindley, Euclid, Ohio. Tree vigorous, moderately prolific; fruit large, heart-shaped, surface uneven; skin dark purplish-red; flesh almost firm, tinged red, juicy, deficient in richness; season the first of July. 
Lipp. P. avium. I. Budd-Hansen Am. Hort. Man. 2:279. 1903.

Lipp Late Blood. 2. Green Cat. 29. I906.

Lipp originated in Lancaster, Pennsylvania. Fruit large, dark red or crimson; stem long; flesh and juice very dark, meaty; late.

Litham. P. cerasus. I. Stone \& Wellington Cat. 33. 1907.

This is a Russian chcrry introduced by Stone \& Vellington, Toronto, Ontario. Fruit of medium size; color red; flesh firm.

Little Phil. Species? I. Wyo. Sta. Bul. 34:129. 1897.

Mentioned as not hardy in Wyoming.

Logan. P. avium. I. Mag. Hort. 19:167, I68. 1853. 2. Elliott Fr. Book 200 fig. 1854.

- 3. Thomas Guide Prat. 24, 201. 1876.

Logan is another of Professor J. P. Kirtland's cherries originating in 1842 from a pit of Yellow Spanish. Tree hardly healthy, somewhat spreading; fruit large, obtuse-cordate, with a shallow depression at the apex; stem variable, set in a deep cavity; skin purplishblack when ripe; flesh firm, dark red, with white, radiating lines, juicy, sweet, rich; pit above medium in size, oval; mid-season.

Long Finger. Species? I. Parkinson Par. Ter. 574. ${ }_{1629 .}$

" The long finger Cherry is another small long red one, being long and round like a finger, whereof it took the name: . . ."

Look No Further. P. avium. I. U.S. Pat. Off. Rpt. 294. 1853.

This variety was introduced into this country in $18_{15}$, from the Royal Gardens of Luxembourg, Paris, by Samson V. S. Wilder of Bolton, Massachusetts. Said to be very productive, sweet, large and attractive.

Lord Belhaven White Heart. P. avium. I. Lond. Hort. Soc. Cat. 56. I8 3 I.

Mentioned but not described.

Lothaunner Erfurter. Species? I. Mas Pom. Gen. II: 161. I882.

Mentioned in this reference.

Lothkirsche. P. cerasus. I. Christ Wörterb. 288. I802. 2. Truchsess-Heim Kirschensort. 595-597. 1819. 3. Dochnahl Führ. Obstkunde 3:65. I858.

Fruit large, nearly round, flattened on one side; stem long; skin reddish-black; flesh very tender, red, sour; ripens the first of August.

Louise. P. cerasus. 1. Chase Bros. Cat. 20. 1907.

Louise was found about 1887 by the late Lewis Chase in the vicinity of Rochester. New York. Tree hardy, productive; fruit large, dark red, sour; ripens in June.

Louisiana Iron Clad. P. cerasus. I. La. Sta. Bul. 22:682. 1893. 2. Ibid. 112:11. 1908.

This cherry originated in Louisiana about 1900 with A. K. Clingman. It is said to be the only cherry which will produce fruit in Louisiana; of the Morello type.

Löwener Frühkirsche. P. cerasus. I. Oberdieck Obst-Sort. 359. $188 \mathrm{I}$.

Frühe Englische Kirsche aus Löwen. 2. Ill. Handb. 79 fig., So. 1867.

Hâtive de Louvain. 3. Thomas Guide Prat. 17, 200. 1876.

Lowener Frihweichsel. 4. Proskaner Obstsort. 59. 1907.

This variety probably originated in Belgium nearly half a century ago. Fruit variable in size, often large, sides and ends compressed giving it a square appearance; suture shallow; 
stem long, strongly inserted in a wide, regular, deep cavity; skin rather glossy, dark brownish-red; flesh dark red, tender, juicy, acidulated, refreshing; stone plump, almost round, base abrupt, with a slight depression; early.

Lucien. P. avium. 1. Truchsess-Heim Kirschensort. 228, 229. I819. 2. Liegel Syst. Anleit. 157. I825. 3. Mas Le Verger 8:79, 80, fig. 38. I866-73. 4. Mathieu Nom. Pom. 367. 1889. 5. Can. Exp. Farm Bul. and Ser. 3:61. 1900.

Guigne Lucien. 6. Thomas Guide Prat. 18, 198. 1876.

This forcign variety is planted in Canada but is not known in the United States. It was found by Uellner in Luneburg, Prussia, about 1806 . Leroy is of the opinion that this is the cherry he calls Guigne Carnée Winkler which came out a few years later as a seedling of Winkler from Guben, Prussia.

Ludwig Bigarreau. P. avium. I. Hogg Fruit Man. $86 . \quad$ I 866.

Guigne Ludwig. 2. Thomas Guide Prat. I8, 198. 1876. 3. Leroy Dict. Pom. 5:326 fig. 1877 .

Ludwig's Bunte Herzkirsche. 4. Mathieu Nom. Pom. 367, $368 . \quad$ i 889 .

Ludwig is a seedling obtained by Thomas Rivers of Sawbridgeworth, England, about I860. Fruit large, cordate, terminating in a sharp point; suture slightly indistinct; stem very long, slender, inserted in a wide cavity; skin glossy, bright red, paler on the shaded side; flesh pale yellow, tender, melting; pit small, roundish, plump; ripens the last of June. Lukeward. P. avium. 1. Parkinson Par. Ter. 572. 1629. 2. Phillips Comp. Gard. 79. I831. 3. Floy-Lindley Guide Orch. Gard. 106. 1846.

Lukeward's Heart. 4. Prince Pom. Man. 2:125. 1832.

A variety supposed to have come from Italy which has long since passed from cultivation. Fruit cordate, dark brown or nearly black; ripens early in August.

Lundie Guigne. P. avium. I. Forsyth Treat. Fr. Trees 43. 1803. 2. Prince Pom. Man. 2:118. 1832. 3. Elliott $F r$. Book 218. I854.

Lundie Guigne is an old English cherry first spoken of by Forsyth in 1803 . Tree vigorous, large; fruit medium in size, roundish-elongated, dark purplish-black; flesh tender, juicy, subacid, pleasant; season July.

McAdow. P. avium. I. An. Hort. An. 88 fig. 1869. 2. Ohio Hort. Soc. Rpt.32. I869.

McAdow is supposed to be a cross between Black Tartarian and Elton, grown from seed by Dr. McAdow, Chillicothe, Ohio. Tree vigorous, productive, bears early; fruit large, obtuse-cordate, compressed, without a suture; stem slender, deeply inserted; skin light, pale yellow, overspread and mottled indistinctly with light, elear red; flesh firm, yellowish, tender, juicy, pleasant but not rich; quality good; stone medium to large, oval.

MacRoach. P. avium $\times$ P. cerasus. I. Green-River Nur. Cal. 23. I899.

This cherry was found near Guthrie, Kentucky, on the farm of John MacRoach, where it has fruited for many years and is considered a very good cherry of the May Duke type.

Madame Courtois. P. avium. 1. Rev. Hort. 335. $1870-71$.

Found by Bonamy, a nurseryman, in I860, upon a farm belonging to the Chateau of Lamothe, near Puylaurens, Tarn, France. Tree productive; fruit large; skin clear red; flesh tinted with a rose color, sweet, very agreeable; ripens in June-July. 
Madame Grégoire. P. avizum. X P.cerasus. I. Thomas Guide Prat. 26. 1876. 2. Guide Prat. I8. I 895 .

This variety is said in Guide Pratique, I895, to be very similar to Reine Hortense.

Madeleine. P. cerasus. I. Thomas Guide Prat. 26, 201. 1876.

Cerise Commune (de la Madeleine). 2. Poiteau Pom. Franc. 2: No. 12, Pl. 1846.

Cerisier de la Madleine. 3. Noisette Man. Comp. Jard. 2:507. 1860.

Amarelle de la Madleine. 4. Mortillet Le Corisier 2:205. 1866.

Madeleine is probably a late strain of the old Cerise Commune formerly extensively grown about Paris. Fruit of medium size, roundish, flattened at the ends; suture a line: stem medium in length; skin clear red changing to brownish-red; flesh whitish, tender, acid; pit small; ripens the last of July; productive.

Madison. P. avium. I. Elliott Fr. Book 2 I I, I854.

Madison Bigarreau. 2. Kenrick Am. Orch. 235. I841. 3. Thomas Am. Fruit Cult. 367. 1849 .

Madison's Bunte Herzkirsche. 4. Mathieu Nom. Pom. 368. I889.

Madison is a seedling of the White Bigarreau, raised by Robert Manning, Salem, Massachusetts. Tree healthy, productive, moderate in growth, spreading; fruit of medium size, regular, heart-shaped; stem rather short, slender; skin heavily dotted and mottled with rich red on amber-yellow ground; flesh yellowish, rather tender, juicy, with agreeable sprightliness; pit small, oval; season the last of June.

Magann. P. avium. I. New Haven Nur. Cat. I2. I899-1900.

Magann is a hardy, Sweet Cherry originating in Franklin County, Missouri; fruit large, nearly black, borne in large clusters.

Magèse. P. cerasus. I. Thomas Guide Prat. 24. 1876. 2. Leroy Dict. Pom. 5:327 fig. 1877 .

Magèse was received by Leroy from Florence, Italy, about I864. Fruit large, attached in twos and threes, obtuse-cordate; stem stout, short, inserted in a wide, deep cavity; skin yellow, washed with carmine; flesh yellowish, moderately tender, juicy, sugary, acidulated; first quality; stone small, round, plump; ripens the first of June.

Magnifique de Daval. Species? I. Mas Pom. Gen. II:I54. 1882. 2. Mathieu Nont. Pom. 368.1889.

The flowers and foliage are described by Mas in his Pomologie Générale.

Magog. Species? I. Okla. Sta. Bul. 2: г3. I 892.

Listed in the reference given.

Mammoth. P. avium. I. Ohio Pom. Soc. Rpt. 10:44. 1862.

Kirtland's Manmoth. 2. Elliott Fr. Book I98 fig. I854. 3. Mas Pom. Gen. II:3 I, 32, fig. I6. 1882 .

Mammuthkirsche. 4. Proskauer Obstsort. 56. 1907.

Mammoth was raised, probably about $\mathrm{I} 84^{2}$, by Professor J. P. Kirtland of Cleveland, Ohio, from a pit of a Yellow Spanish tree grown apart from other cherries. Tree large, vigorous, round-topped, usually unproductive; fruit of the largest size, often averaging three and one-half inches in circumference, obtuse-cordate, with a large, prominent suture; stem of medium thickness, long; skin moderately thick, attractive clear yellow, blushed 
or mottled with light red; flesh whitish, with abundant, uncolored juice, fine-grained, with distinct radiating lines, nearly tender, sweet yet almost sprightly; very good in quality; stone roundish-oval, regular; season early.

Mammoth Oxheart. P. avium. I. Pioncer Nur. Cat. 16. 1905-06.

Listed, probably not propagated at present.

Manger. Species? I. Ill. Hort. Soc. Rpt. 2 I I. 1896.

Mentioned without a description.

Manning Early Black. P. avizm. I. Mag. Hort. 8:282. I842. 2. Elliott Fr. Book 2 I8. 1854.

This variety was grown from a pit of Black Heart by Robert Manning, Salem Massachusetts. It differs from the parent only in time of ripening, which is ten days earlier, and in form of tree, which is more spreading.

Manning Early White Heart. P. avium. I. Kenrick Am. Orch. 243. I84 I.

Still another seedling raised by Robert Manning, this one coming from a seed of White Turkey Bigarreau. Fruit of medium size, cordate, pale red, amber in the sun, sweet, fine; ripens in June.

Manning Late Black. P. arium. I. Mag. Hort. 8:284. 1842. 2. Cole Am. Fr. Book 234. I849.

Manning Black Bigarreau. 3. Kenrick Am. Orch. 235. I 84 I.

Black Bigarreau. 4. Bridgeman Gard. Ass't Pt. 3:54. $\quad$ I847.

This is another of Robert Manning's seedlings of the Black Heart. Tree vigorous, hardy, productive; fruit medium in size, roundish-cordate; skin deep purple, nearly black; stem long; flesh purplish-red, firm, rather juicy, sprightly, with a pleasant, luscious flavor; ripens the second week in July.

Manning Mottled. P. arium. I. Downing Fr. Trees Am. I76. I845. 2. Thomas Am.

Fruit Cult. 36r. 1849.

Mottled Bigarreaut. 3. Mag. Hort. 8:283. 1842 .

Robert Manning, Salem, Massachusetts, raised this cherry from a seed of White Bigarreau. Tree vigorous, productive; fruit rather large, roundish-cordate, flattened on one side, with a distinct suture; stem slender, inserted in a shallow cavity; skin amber, shaded and mottled with red, with a semi-transparent, glossy appearance; flesh yellow when fully ripe, tender, with a sweet, delicious juice; stone large; season at the end of June.

Maple Heart. P. avium. I. Brookshaw Pon. Brit. Pl. 8. I8I7. 2. Lond. Hort. Soc. Cat. 53. $\mathrm{I}_{3} \mathrm{I}$.

This a rather firm-fleshed, red Heart of second size and third quality, ripening in July.

Marells Royal. Species? I. Ariz. Sta. Bul. 15:65. 1895.

Mentioned as having been planted in Arizona.

Maria Gaucher. P. avizm. I. Proskaner Obstsort. 57. 1907.

Listed as a variegated, hard-fleshed cherry.

Marie de Châteauneuf. P. avium. I. Thomas Guide Prat. I8. 18;6.

Probably named after the wife of the Marquis de Chateauneuf; fruit very large, 
obtuse-cordate, purplish-black; flesh rose-colored, moderately firm, juicy, sugary, agreeable; ripens the middle of June.

Marie Thérèse. P. avium. I. Leroy Dict. Pom. 5:358 fig. I 877 .

This variety originated with $M$. de Luigné near Châteaugontier, Mayenne, France, and was named after his daughter Marie Thérèse. Tree strong, vigorous, moderately productive; fruit above medium in size, roundish, flattened at the ends; suture broad; stem long, slender; cavity small; skin transparent, firm, red, dotted with whitishgray; flesh yellow, compact, melting, juicy, aromatic; first quality; ripens the last of June.

Markirsche. P. avium. I. Wash. Sta. Bul. 92:29, 30. 1910.

Tree large, upright, open-topped, productive; foliage frequently attacked by aphis; fruit large, dark red, cordate, with a short stem; skin thick, tender, while the flesh is meaty and deeply stained; stone round, smooth; ripens the third week in July, often hanging on the trees until the middle of August.

Marsotte. P. arium. I. Guide Prat. I2. I895.

Tree vigorous, productive; fruit medium in size; stem of medium length; skin black; flesh juicy, sugary; used in making Kirschwasser.

Mary. P. cerasus. I. Elliott Fr. Book 2 II. I 854.

Mary was raised by B. B. Kirtland, Greenbush, New York. Fruit borne in clusters, having a bright, lively red color and a sprightly subacid flavor.

Master White Heart. P. avium. I. Lond. Hort. Soc. Cat. 56.183 I.

Listed in this reference.

Mastodon. P. avium. I. Mich. Hort. Soc. Rpt. I85. I894.

Black Mastodon. 2. Wickson Cal. Fruits 289. I889.

Mastodon is a seedling of Pontiac and originated with W. H. Chapman, Napa, California; introduced by Leonard Coates, then of the same place. Fruit very large, obtusecordate, base very broad; cavity large, deep; stem stout, long; skin entirely mottled with pinkish or heavy red; flesh firm, yellowish, tinged with red, meaty, moderately juicy, with a rich, lively sweet flavor.

Matilda. P. avium. I. U. S. D. A. Rpt. 262. $\quad$ 1 892.

Matilda originated with C. E. Hoskins, formerly of Newburg, Oregon. Fruit medium to large, broad-cordate, surface smooth; skin glossy, dark red, nearly black; dots very fine; flesh dark red, firm, sprightly, sweet; very good; ripens in Oregon about the middle of June.

Matts. P. avium.

J. G. Youngken, Richlandtown, Pennsylvania, writes that this cherry is a seedling of Black Tartarian. Tree vigorous, productive; fruit large.

Mayo. P. avium. I. Samuels \& Co. Cat. 22. 1892.

The original tree of Mayo is on the farm of a Mr. Mayo near Jackson, Tennessee. Tree vigorous, hardy, productive; fruit large, amber shaded with red, tender; resembles Wood.

Mazarine. Species? I. Thacher Am. Orch. 2 I6. I822.

Listed as one of the twenty principal varieties in the United States. 
Mednyansky. P. avium. 1. Mich. Sta. Bul. 177:31. 1899.

Moduyansky. 2. Mich. Hort. Soc. Rpt. 185 . 1894 .

This Hungarian variety was introduced to this country in 1894 . In the second reference the name is spelled Moduyansky but in the first it is given Mednyansky which form is deemed best to follow here. Tree upright, spreading, rather vigorous; fruit cordate; suture variable, indistinct on some specimens but a noticeable ridge from the cavity to the apex on others; stem stout, long, inserted in a narrow, deep, irregular cavity; skin very dark purple turning black; flesh firm, rich, sweet, sprightly; quality very good. Meininger Späte Knorpelkirsche. P. avium. I. Ill. Handb. 137 fig., I38. 1860; 2. Oberdieck Obst-Sort. 370 . $188 \mathrm{I}$.

Bigarreau-tardif de Meiningen. 3. Thomas Guide Prat. 21 , 190. I876.

Tree vigorous, productive, blooming late; fruit of medium size, cordate, sides compressed; suture shallow; stem slender, variable in length, set in a narrow, shallow cavity; color pale golden-yellow, spotted with pale red, which often conceals the ground color; flesh firm, whitish-yellow, reddish-yellow under the skin, juicy; stone large, oval, usually somewhat adherent; ripens in August lasting until September.

Meissener Weisse. Species? I. Mas Pom. Gen. II: I6 I. I882.

Mentioned in the reference given.

Merise Grosse Rose Oblongue. Species? I. Lond. Hort. Soc. Cat. 53. 1831.

Probably a small, wild variety.

Merise Petite Ronda. Species? I. Lond. Hort. Soc. Cat. 53. I83 I.

Listed without a description.

Merisier Fastigié. Species? I. Poiteau Pom. Franc. 2: No. 3, P1. 1846.

Poiteau was uncertain as to the name of this variety which he noticed in the gardens of M. Cels. Tree very pyramidal; fruit yellowish-amber.

Michigan. P. avium. 1. Am. Pom. Soc. Rpt. 17. 1885.

Michigan is a supposed cross between Black Tartarian and Yellow Spanish fruiting for the first time in 1877 . It was grown by Stephen Cook, Benton Harbor, Michigan. Fruit large, cordate, slightly compressed; stem long; suture lacking; skin deep red, nearly black; flesh firm, juicy, sweet; ripens early in July. Said to be nearly rot proof.

Miller. Species? 1. Am. Pom. Soc. Cat. 27. 1909.

Listed but not described.

Millet. P. avium $\times$ P. cerasus. 1. Brookshaw Pon. Brit. P1. 7. 1817. 2. Brookshaw Hort. Reposit. I:45, Pl. 23 fig. 2. I823.

Described as one of the best black, heart-shaped late Dukes, ripening the last of June and continuing until September; flesh moderately firm; stone small; excellent.

Minnesota. P. cerasus. I. Budd-Hansen Am. Hort. Man. 2:280. 1903. 2. Mich. Sta. Bul. 205:27. 1903.

Sprouts of this variety were brought from Sweden to Professor J. L. Budd, Ames, Iowa. Fruit medium in size, roundish-cordate, slightly compressed; stem long; skin dark red; flesh dark, tender, juicy, subacid; very good.

Minnesota Ostheim. P. cerasus. I. Del. Sta. An. Rpt. I2:120. 1900.

Ostheim. 2. Ia. Hort. Soc. Rpt. 37 I. I881. 
This variety was introduced into Minnesota from North Germany by E. Meyer, St. Petersburg, Minnesota. It is well adapted to cold regions where the Montmorency group does not flourish. Tree upright, dense; fruit large, roundish-oblate, dark red; flesh dark, tender, sweet subacid; good in quality; stone roundish, slightly flattened; ripens the middle of July.

Minnie. P. pumila. I. Can. Exp. Farms Rpt. 35.3. 1896.

Minnie is a vigorous seedling of Prunus pumila grown in Manitoba, Canada; fruit large and good.

Monkirsche Rote. Species? I. Mas Pom. Gen. II: I6 I. I882.

Mentioned in this reference.

Monstrous Duke. P. avium $\times$ P. cerasus. I. Leroy Dict. Pom. 5:360 fig., 36 I. I877.

Monstrous Duke is mentioned by MM. Simon-Louis in $x 866$ as a new sort of the Anglaise hâtive. It is probably of English origin, but the name is misleading as the fruit is only moderately large; attached in pairs, globular; stem stout, short, shallowly inserted; skin transparent, yellowish, partly covered with red; flesh yellowish, tender, slightly fibrous, very juicy, sugary, sprightly; pit small, roundish, plump, adhering to the stem; ripens the last of June.

Monstrueuse Hennequine. Species? I. Lond. Hort. Soc. Cat. 54. I 83 I.

Listed without description.

Montmorency Pleureur. P. cerasus. I. Guide Prat. I7, 196. 1895.

Described as a handsome tree with drooping branches. Its fruit is somewhat similar to that of the Montmorency.

Montmorency de Sauvigny. P.cerasus. I. Soc. Nat. Hort. France Pom. I20 fig., I 2 I. I904. Cerise de Sauvigny. 2. Thomas Guide Prat. 27. 1876.

Belle de Sauvigny. 3. Mathieu Nom. Pom. 334. I889.

Schöne aus Sanvigny. 4. Proskauer Obstsort. 59. 1907.

This cherry is a popular fruit about Paris where it is used for confitures and brandy. Fruit large, roundish, attached in twos or threes; stem short; cavity large, shallow; color dark red; flesh yellow, transparent, slightly fibrous, acidulated; stone small, round; ripens the second half of July.

Montmorency Stark. P. cerasus. I. Stark Bros. Cat. 4:46. I9I3.

Montmorency Stark is described as having been produced on the Stark Brothers Nursery grounds, Louisiana, Missouri, from a select tree which bore large fruit.

Montreuil. P. cerasus. I. Mich. Sta. Bul. 80:23. I892. 2. Ibid. 194:4I. I901.

3. Am. Pom. Soc. Cat. 27 . 1909.

Belle de Montreuil. 4. Rev. Hort. 451. 1875.

Schöne von Montreuil. 5. Reut. Pom. Inst. Festschrift I23. I9го.

This variety was mentioned by European writers as early as 1875 but was not known in America until recently. It is a valuable cherry and was placed on the fruit list of the American Pomological Society in I909. Tree upright, spreading, vigorous, more productive than Reine Hortense; fruit of medium size, roundish-cordate; stem long, stout; skin mottled red approaching black; flesh tender, light red, with abundant, colored juice, subacid, pleasing; quality good; season July; valuable for dessert and culinary purposes. 
Moorhouse. P. avium. I. Leonard Coates Cat. 10. I9Ir.

Moorhouse is no longer propagated, being inferior to its parent, Napoleon.

Morella Extra Noir. P. cerasus. I. Lond. Hort. Soc. Cat. 54. I831.

Listed without a description.

Morella Wye. P. cerasus. 1. Can. Exp. Farm Bul. and Ser. 3:6I. 1900.

Listed in this reference.

Morelle von Wilhelmshöhe. P. cerasus. I. Guide Prat. I6. I895.

A very good table cherry ripening the seventh week of the season.

Moreller Langstilkede Sode. P. cerasus. I. Lond. Hort. Soc. Cat. 54. 183 I.

Listed without a description.

Morisco. Species? I. Langley Pomona 86. 1729.

Mentioned without description.

Morocco. P. ccrasus. I. Parkinson Par. Ter. 572. 1629.

"The Morocco Cherrie hath a large white blossome, and an indifferent big berrie, long and round, with a long stalke of a darke reddish purple colour, a little tending to a blew when it is full ripe, of a firme substance; the juice is of a blackish red, discolouring the hands or lips, and of a pleasant taste: some doe thinke that this and the Morello be both one."

Morten Seedling. Species? I. Mas Pom. Gen. II:I6I. I882.

Listed but not described.

Mosler Schwarze Herzkirsche. P. avium. I. Dochnahl Führ. Obstkunde 3:23. $185^{8}$.

Fruit medium in size, obtuse-cordate, sides compressed; stem long, slender; skin black, tough; flesh dark, tender, very sweet; pit oblong-cordate; ripens the middle of July; productive.

Moyer Honey Heart. P. avium. I. Horticulturist N. S. 8:22. I858. 2. Downing Fr.

Trees Am. 469, 470 . I $\$ 69$.

This variety was grown by Josiah G. Youngken, Allentown, Pennsylvania. Tree healthy, vigorous, productive; fruit large, obtuse-cordate, slightly compressed; suture small; stem long, slender; skin whitish, shaded and mottled with rich red; flesh yellow, juicy, sweet, pleasant; often partially clinging; ripens the middle of June.

Mückelberger Grosse. P. avium. I. Thomas Guide Prat. 24. I876.

A Sweet Cherry originating in Guben, Prussia, Germany.

Murdock. P. avium. I. Budd-Hansen Am. Hort. Man. 2:289. 1903.

Murdock's Bigarreau. 2. Gard. Mon. 28:240, 24I. 1886. 3. Reid Cat. 35. 1892.

Murdock is thought to have originated in I887 with John R. and A. Murdock, then of Pittsburg, Pennsylvania. Tree large, vigorous, upright-spreading; fruit large, roundishcordate; cavity deep, wide, rather abrupt; stem long, slender; skin thin, moderately tough, amber overlaid and mottled with light red; flesh whitish, firm, crisp, somewhat sprightly, juicy, sweet; quality very good; stone clinging, large, ovate, flattened, smooth; ripens early in July, hanging long on the trees; not susceptible to rot.

Nancy. P. avium. I. Downing Fr. Trees Am. 470. 1869.

Nancy originated with Charles Pease, Sr., Cleveland, Ohio. Tree upright-spreading; fruit large, obtuse-cordate; stem long, stout, inserted in a large cavity; suture slight; skin 
pale yellow, shaded and mottled with crimson; flesh tender, juicy, rich, sweet; very good; stone small; ripens the last of June.

Naples. P. avium. I. Parkinson Par. Ter. 572. 1629.

Neapolitanische Knorpclkirsche. 2. Dochnahl Fïhr. Obstkunde 3:35. 1858. 3. Ill. Handb. 39 fig., 40. 1867 .

Bigarreau de Naples. 4. Thomas Guide Prat. 20, 189.1876.

This is an Italian cherry introduced into Germany, France and England from Florence, Italy. It is very productive and is distinguished by its color and its lateness. Tree vigorous, bears early; fruit large, obtuse-cordate, sides only faintly compressed; suture indistinct; stem of medium length, set in a wide, deep cavity; skin tough, firm, glossy, becoming dark brown or black; flesh firm, juicy, sweet, vinous; stone oval, plump; ripens the sixth week of the season.

Ne Plus Ultra. P. avium. I. Gard. Mon. 22:208. 188o.

Ne Plus Ultra was raised by John Mosely of Goodrich, Ontario. It resembles Napoleon but is inferior.

Neapolitanische Molkenkirsche. P. avium. I. Dochnahl Führ. Obstkunde 3:33. ${ }_{1858 .}$ Bigarrcautier de Naples. 2. Noisette Man. Comp. Jard. 2:504. 1860.

Napolitaine. 3. Mas Pom. Gen. II: I61. I8S2.

This is a large, lemon-colored, rather firm-fleshed variety that should not be confused with Naples. Tree small, vigorous; flesh sweet, pleasing; ripens late in July.

Nebraska Sweet. P. avium. I. Gage County Nur. Cat. S. 1906.

Listed in this reference as a dark, Sweet Cherry doing remarkably well in Nebraska.

Nelson Kentish. P. cerasus. I. Ohio Hort. Soc. Rpt. 23. I892-93.

Said to be more vigorous in growth and more hardy in bud than Early Richmond.

Neue Englische Weichsel. P. cerasus. I. Truchsess-Heim Kirschensort. 542, 543. I8I9.

2. Ill. Handb. $8_{3}$ fig., $8_{4}$. 1867 .

Nene Englische Kirsche. 3. Christ Wörterb. 286. ISO2.

According to Truchsess, Mayer grew this cherry about 5775 . Tree of medium height, moderately productive; fruit often large, roundish, more or less compressed; suture faint; stem straight, medium in length; cavity wide, deep; skin glossy, tender, black; flesh tender, dark red, juicy, pleasing subacid; pit plump, small, oval; ripens early in July.

Neue Ochsenherzkirsche. P. avinm. I. Ill. Handb. 73 fig., $74 . \quad$ I 860.

Hcrmhäuscr nene Ochsenherzkirsche. 2. Dochnahl Fuhr. Obstkunde 3:22. I858.

Nonvelle Guigne des Boeufs. 3. Mortillet Le Cerisier 2:301. I\$66.

Fruit very large, acute-cordate, irregular near the apex; stem long, slender; skin glossy, brownish-black; flesh dark red, tender, sweet, vinous; stone cordate-oblong; ripens the middle of July; not very productive.

Neumann Schwarze Knorpelkirsche. P. avium. I. Mathieu Nom. Pom. 370. I889.

Mentioned in the reference given.

New Century. $P$. cerasus $\times(P$. avium $\times P$. cerasus $)$. I. Texas Nur. Cat. Io. 1907.

New Century is thought to be a cross originating in Grayson County, Texas, between English Morello and some Duke; it was introduced by the Texas Nursery Company. 
Tree of the Duke type, upright; fruit medium to above in size; light red; good. The trees are free from mildew in Texas but do not hold their fruit well.

New Royal. Species? I. Lond. Hort. Soc. Cat. 54. $183 \mathrm{r}$.

Listed without a description.

Nienburger Frühe Bunte Herzkirsche. P. avium. 1. Dochnahl Führ. Obstkunde 3:27. 1858 .

Fruit large, obtuse-cordate, sides compressed; stem of medium length, stout, straight; skin yellowish, spotted and streaked; flesh aromatically sweet; pit oval; ripens the middle of June.

Noble. P. avium $\times P$. cerasus. I. Am. Gard. 20:576. 1899. 2. Bunyard-Thomas Fr. Gard. 44. 1904 .

This variety is said to resemble May Duke. Fruit large; color deep crimson to darker; flesh firm, colored, rich; late; productive.

Noire des Vosges. P. cerasus. 1. Mas Le Verger 8:105, 106, fig. 51. I866-73.

Griotte Noire des Vosges. 2. Soc. Nat. Hort. France Pom. 98 fig., 99. 1904.

This old variety is probably a native of eastern France. The fruit is used for confections and liquors. Fruit attached in pairs, medium in size, obtuse-cordate; suture indistinct; stem long, slender, set in a shallow cavity; color almost black at maturity; flesh dark, tender, vinous, acidulated; stone small, oval, obtuse at the apex; ripens late in July.

Nonpareil. Species? I. Wickson Cal. Fruits i 87 . 1908.

Nonpareil is a black cherry which originated at Vacaville, California.

Norfolk. Species? 1. Mass. Hort. Soc. Rpt. 87. 1872.

Mentioned as a seedling cherry grown by J. H. Fenno; not described.

Norma. P. avium. I. Fruit Grower 19:368. 1908 .

Norma is a black cherry grown by R. H. Weber, The Dalles, Oregon; it is earlier than Napoleon.

Northeast. P. cerasus. I. Mich. Sta. Sp. Bul. 27:11. 1904.

Northeast is a rather dwarf cherry of the Morello type; very productive. Said to be valuable as a late market variety but the trees are lacking in vigor and subject to leaf blight.

Northwest. P. cerasus. I. Downing Fr. Trees Am. 3rd App. i65. i881. 2. Am. Pom. Soc. Cat. 25. 1899. 3. Ia. Sta. Bul. $73: 76$ fig. 16, 88. 1903.

This is one of the varieties originated by D. B. Wier, Lacon, Illinois, and first distributed by Professor J. L. Budd as Wier's No. 29; the fruit resembles Baldwin. The American Pomological Society placed Northwest on its fruit catalog in I 899 but dropped it in 1909. Tree medium in size, resembling English Morello closely both in size and habit, very productive; fruit medium to large, roundish, obscurely heart-shaped; sten long, adhering quite firmly to the fruit; skin tough, medium in thickness, dark attractive red, becoming nearly black; flesh deeply colored, firm, brisk but pleasant acid, mingled with a slight astringency; good in quality; stone small, roundish; season early.

Occident. P. avium. I. U. S. D. A. Pom. Rpt. 4o. 1895.

Occident is a seedling of Napoleon which originated with C. E. Hoskins, Springbrook, 
Oregon. Fruit heart-shaped, above medium in size, smooth; stem long, slender; cavity large, regular, deep, flaring, shaded with pink; suture shallow; skin very dark purplishred, thick, tenacious; dots numerous, small, russet, indented; flesh dark reddish, translucent, with white veining, firm, meaty, juicy, mild subacid, rich; good to very good; season late in June; a good shipper.

Ohio Beauty. P. avium. I. Horticulturist 2:123 fig. 19. 1847-48. 2. Elliott Fr. Book 21 2. 1854. 3. Mortillet Le Cerisier 2:93 fig. 18, 94, 95. 1866. 4. Am. Pom. Soc. Cat. I2. I871.

Bigarreau Banté de l'Ohio. 5. Leroy Dict. Pom. 5:177, I78 fig. 1877 .

Ohio Beauty probably originated in 1842 with Professor J. P. Kirtland, Cleveland, Ohio; first disseminated in 1847 . The American Pomological Society listed it on its fruit catalog in $187 \mathrm{I}$ but dropped it in 1895 . Tree large, vigorous, hardy, very productive; fruit medium to large, cordate, compressed; cavity of medium depth, wide; stem slender, long; skin thin, of medium toughness, light yellow overspread with crimson; dots numerous, light russet, conspicuous; flesh whitish, with colorless juice, tender, meaty, mild, sweet; good in quality; stone clinging, irregular-ovate; season early.

Okiya. P. pumila $\times$ P. americana. 1. S. Dak. Sta. Bul. 108:1908. 2. Ibid. 130:176, P1. 6. I9II.

Okiya is a cross between the Sand Cherry and Gold plum. Fruit roundish, dark red; flesh green; excellent quality.

Oliver. Species? 1. Ariz. Sta. Bul. 15:65. 1895. 2. Neb. Hort. Soc. Rpt. 18. 1900.

Oliver is said to be a valuable cherry for home use in Nebraska; slow in coming into bearing.

Opata. P. pumila $\times$ P. americana. I. S. Dak. Sta. Bul. 108:1908. 2. Ibid. 130:173, I 74 Pl. $4,175,176$. I9II.

Opata, a cross between the Sand Cherry and Gold plum which was sent out in 1908 . It is a plum in habit of growth, vigorous; foliage large, glossy; fruit one and three-sixteenths inches in diameter, roundish; skin thin, tender, dark purplish-red with blue bloom; flesh green, firm; flavor very pleasant combining the sprightly acid of the Sand Cherry with the rich sweetness of the Gold plum; pit very small; season early, the middle of August.

Oregon. P. avium. I. Wickson Cal. Fruits 290. 1889. 2. Am. Pom. Soc. Rpt. I50. 1895 .

Oregon is a seedling of Napoleon originated by H. W. Prettyman, East Portland, Oregon, and named by the Oregon Horticultural Society in 1888 . W. S. Failing of Portland introduced it the same year. Tree vigorous, upright; fruit of medium size, roundishcordate, irregularly flattened along the suture; stem medium in length, stout, set in a deep, irregular cavity; skin black; flesh firm, very dark, juicy, sweet; later than Napoleon.

Orel. P. cerasus. I. Mich. Hort. Soc. Rpt. 327. 1888. 2. Maine Pom. Soc. Rpt. 145 . 1889 .

This name is given to a dwarf cherry similar to Vladimir from Orel, Russia. It has small leaves and a close habit of growth; comes into bearing when from three to four feet in height; fruit larger than Montmorency, nearly black when ripe, mildly subacid. 
Orel No. 24. P. cerasus. I. Mich. Hort. Soc. Rpt. 328. 1888. 2. Ia. Sta. Bul. 73:77, 78. 1903 .

This variety was imported by Budd but the name was lost. Some believe it to be Lutovka but as grown at the Iowa Station it is more like Early Morello in form and size of tree and fruit. Tree smaller and more open than Lutovka; fruit of medium size, roundish-oblate; cavity deep; stem medium in length, stout; suture a faint line; skin thin, translucent, cornelian-red; flesh firm, colored, juicy, pleasingly acid; good; pit round, angular; season the latter part of June.

Orel Sweet. P. ccrasus. I. Ia. Sta. Bul. 19:549. 1892. 2. Wash. Sta. Bul. $92: 2$ I. 1910.

Orel No. 26. 3. Mich. Hort. Soc. Rpt. 328. I 888.

Orel Sweet is known in Europe as Lianzkaja Black; it was introduced into America by Budd as Orel 26; one of the hardiest of Sweet Cherries. Tree large, with a spreading top; fruit of medium size, roundish-oblate; stem long, slender; skin thin, tender, dark red; flesh soft, subacid; pit small, round, stained; ripens the last of July in Washington.

Orleans. P. cerasus. I. Brown Bros. Cat. I9. 1906.

Orleans originated in Orleans County, New York. Probably not propagated at present, although known to many as an improved Montmorency.

Orléa Smith. Species? I. Mas Pom. Gen. I1:161. I882.

Mentioned but not described.

Osceola. P. avium. I. Mag. Hort. I9:167, 168. 1853. 2. Elliott Fr. Book 200 fig. I854. 3. Am. Pom. Soc. Cat. 74. 1862.

Professor J. P. Kirtland of Cleveland, Ohio, originated the Osceola in 1842, from a pit of the Yellow Spanish. It was placed on the fruit list of the American Pomological Society in 1862 but was taken from the list in 1891 . Tree round, spreading, hardy, healthy, productive; fruit medium to large, cordate; stem moderately stout inserted in a deep cavity; suture deep, broad; color dark purplish-red, inclining to black; flesh dark red, juicy, rich, sweet; pit medium or small, ovate, rounded; season the last of June and early July.

Ostheim (of Morris). P. ccrasus. I. Can. Exp. Farms Rpt. 75. I 890.

This is a small, dark colored cherry differing from the Minnesota Ostheim in being later and slightly inferior in quality. Fruit round, compressed; quality fair, lacking in juiciness; pit large; ripens about August 6th in Ottawa, Canada.

Othello. P. pumila. I. Can. Exp. Farms Rpt. 353. 1896.

One of the Canada Experiment Farm's seedlings of Prunus pumila, the Sand Cherry; fruit large, very black, fair.

Owanka. P. pumila $\times$ P. americana. 1. S. Dak. Sta. Bul. 108:1908. 2. Ibid. I30: I76. I9I I.

Owanka, a cross between the Sand Cherry and Gold plum, was discarded soon after it was sent out because of its bitter skin; tree hardy, productive; fruit one and three-eighths inches in diameter; apex terminated by a minute prickle; skin dark red, with blue bloom; flesh yellow.

Ox Heart (of America). P. avium. 1. Am. Pom. Soc. Cat. 24. I899.

Major Francis. 2. Am. Pom. Soc. Rpt. 127. 1875. 3. Wash. Sta. Bul. 92:29. 1910.

Coeur de Boeuf nouveau? 4. Mas Pom. Gen. 11: 160. I882. 
This cherry originated with G. W. Walling, Oswego, Oregon, about I865, and was renamed in honor of Major Francis of Portland. As yet it is known only in the Northwest. The fruit is of good quality, attractive color, ripening with Black Tartarian, but is readily sought by the birds. Tree very large, vigorous, upright, productive; fruit large, heartshaped, dark red; flesh deeply stained with red, juicy, sweet; quality good; too tender for long shipment; season early.

Pandys Glaskirsche. Species? I. Proskauer Obstsort. 59. 1907.

Listed but not described.

Paramdam. P. ccrasus. I. Hogg Fruit Man. 308 . I 884.

This variety was found nearly a century and a half ago in Paramdam, England. Tree small; fruit small, round; skin pale red; stem an inch long; flesh pale, tender, lively acid, agreeable; ripens the last of July.

Parent. Species? I. Can. Exp. Farms Rpt. 302. I890.

Listed in the reference given.

Paretzer Herzkirsche. P. avium. I. Mas Pom. Gen. II: 161. I882.

Listed in this reference.

Pariser Griotte. P.cerasus. I. Truchsess-Heim Kirschensort. 430. I8I9. 2. Mas Pom. Gen. II: 160. 1882. 3. Mathieu Nom. Pom. 371. I889.

This cherry is thought by some to be Duhamel's Griotte but it differs in its more tender flesh, sweeter taste, and smaller stone.

Parisian Guindoux. P. avium. I. Prince Pom. Man. 2:1 10. 1832.

Tree moderately large; fruit large, pale red; flesh sweet; excellent; ripens the middle of June.

Paul. P. avium. I. Wickson Cal. Fruits I85. 1908.

Paul was found by E. V. D. Paul of Ukiah, Oregon; it was propagated and introduced by the Leonard Coates Nursery Company, Morganhill, California, in I908. Fruit large, black, mottled with dark red; late; a good shipper.

Pauline de Vigny. Species? I. Mas. Pom. Gen. I I:I6r. I882.

Listed without a description.

Peach-Blossomed. Species? I. Prince Pom. Man. 2:151. I $_{32}$.

An ornamental cherry with rose-colored flowers.

Pease. P. avium. 1. Am. Hort. An. 86, 87. I869.

Pease is a black, swect seedling from Charles Pease, Sr., Cleveland, Ohio. Tree upright; fruit large, obtuse-cordate; flesh purplish, juicy, rich; follows Black Tartarian in ripening.

Perlkirsche. P. avium. I. Christ Handb. 667. I802. 2. Truchsess-Heim Kirschensort. 237-242. i8ig. 3. Ill. Handb. I I I fig., II2. I860. 4. Mas Pom. Gen. II:25, 26, fig. I3. I882. 5. Mathieu Nom. Pom. 37 I. I889.

This variety is often taken for the Yellow Spanish but is distinct. Tree strong, vigorous, productive; fruit usually large, roundish-cordate, sides compressed; suture distinct; stem short, shallowly but firmly inserted; skin tough, glossy, resembling Yellow Spanish; flesh moderately tender, juicy, pleasing, sweet; stone rather large, elongated-cordate, nearly free; ripens about the middle of July. 
Perlknorpelkirsche. P. avium. 1. Truchsess-Heim Kirschensort. 305-308. 1819. 2. Ill. Handb. 129 fig., 130 . 1860.

Espagne bigarrée. 3. Knoop Fructologic 2:35, 38. I77 I.

Perlmarmorkirsche. 4. Dochnahl Führ. Obstkunde 3:43. 1858.

This Bigarreau, though called a Heart by some, should not be confused with Perlkirsche. Fruit medium to above, roundish-cordate; suture indistinct; stem medium short, shallowly inserted; skin tough, glossy, resembling Yellow Spanish; flesh firm, fibrous, juicy, pleasing, sweet; stone medium in size, plump, oval; ripens the last of July to first part of August.

Petite Morelle. P. cerasus. I. Mortillet Le Cerisier 2: 182 fig., I83, I84, 2 I6. I866.

This is a small, acid cherry used in northern Germany for wine-making and in the kitchen. Tree vigorous, small, bushy; fruit small, round; suture indistinct; stem short, set in a straight, shallow cavity; color dark red changing to black; flesh red, tender, always acid; pit small, reddish, oval, plump; ripens the fourth week of the season.

Pfitzmann Schwarze Herzkirsche. P. avium. I. Mathieu Nom. Pom. 372. I889.

Listed in the reference given.

Pierce Late. P. avium. I. Mag. Hort. 20:89, I34. I854. 2. Am. Pom. Soc. Rpt. 45 . I854. 3. Downing Fr. Trees Am. 265. I857.

This variety originated with Amos Pierce but was introduced by James Hyde and Son, Newton, Massachusetts. Tree upright, free, round-topped; fruit of medium size, obtuse-cordate, dark red, mottled with light amber; stem slender, rather short; flesh soft, tender, very juicy, sweet, rich; stone small; ripens the last of July.

Pink Heart. P. avium. I. Elliott Fr. Book 2 I9. I $8_{54}$.

Pink Heart is a small, pinkish-red, oval Mazzard; stem short; ripens in July.

Planchoury. P. avium. 1. Gard. Mon. 7:248. I865. 2. Mas Le V crger.8:61, 62, fig. 29. I866-73. 3. Leroy Dict. Ponn. 5:374, 375 fig. I 877 .

Cerise de Planchouri. 4. Ann. Pom. Belge 6:71, P1. 1858.

Kirsch von Planchoury. 5. Mathieu Nom. Pom. 372. I889.

A Dr. Bretonneau grew this variety on his grounds near the River Loire, France. Fruit large, obtuse-cordate, flattened at the base, slightly compressed on the sides, completely transversed by a suture; stem long, set in a large, deep cavity; skin glossy, clear red changing to darker red, uniform; flesh tinged with red, semi-tender, sugary, juicy, agreeably acidulated; first quality; stone large, oval, free; ripens carly in July.

Plattgedriickte Schattenmorelle. P. ccrasus. I. Thomas Guide Prat. 26. I8;6.

Differs from the English Morello in being more compressed in form.

Plumstone. P. cerasus. x. Am. Pom. Soc. Cat. 27 . I909.

Plumstone Morello, 2. Prince Treat. Hort. 29. 1828. 3. Downing Fr. Trecs Am. IgS fig. IS45. 4. Am. Pom. Soc. Cat. 74. I862. 5. Del. Sta. An. Rpt. I2: I 20. I 900 .

The origin of this variety is unknown but it was found in Virginia early in the Nineteenth Century by William Prince who brought it to Flushing, New York. Its name seems to have arisen from the form of the stone. According to Prince, this variety surpasses all of the European Morellos for culinary purposes. Tree vigorous, medium in 
size, productive; fruit very large, roundish or inclined to obtuse-cordate; stem long, rather slender, straight; skin dark red becoming nearly black; flesh reddish, tender, juicy, highly flavored, sprightly, with pleasant acidity when fully mature; stone long, resembling a plum; season late July.

Plymouth Rock. P. avium. I. Lovett Cat. 25 fig. 1895. 2. Mich. Sta. Bul. I69:200. I899.

Plymouth. 3. Ont. Dept. Agr. Fr. Ont. 102. 1914.

Plymouth Rock is generally believed to have originated with J. H. Black, Hightstown, New Jersey. Tree vigorous, upright, round-topped; fruit above medium in size, heartshaped, roundish; skin tender, reddish-amber, with a bright red blush; stem long, slender; cavity narrow, shallow; flesh rather tender, light colored, juicy; pit round, plump, small; season early July.

Podiebrad. P. avium. I. Thomas Guide Prat. 27. 1876.

Podiebrad Bunte Herzkirsche. 2. Dochnahl Führ. Obstkunde 3:29. 1858. 3. Ill. Handb. 2 I fig., 22. I 867 .

Probably a seedling from Podiebrad, Hungary. Tree vigorous, productive, bears early; fruit above medium in size, obtuse-cordate; suture indistinct; stem long; cavity wide, moderately deep; skin tender, translucent, sulphur-yellow, nearly entirely washed and spotted with red; flesh tender, pale yellow, juicy, sweet, without sourness; stone medium egg-shaped; ripens early in July.

Pointed Guigne. P. avium. I. Prince Pom. Man. 2:119. 1832.

This cherry is so named because part of the style becomes hard and ligneous forming a sharp point at the apex of the fruit. Fruit cordate; color red on a yellow ground; flesh firm, crisp, rich, tinged with a slight bitterness; early.

Polsted. Species? I. Jour. Hort. N. S. 24:412, I 873.

Polsted received its name from a parish in Suffolk, England, where it was extensively grown.

Polton Gean. P. avium. I. Lond. Hort. Soc. Cat. 50. I83 I.

Listed without a description.

Pomeranzen. P. avium. I. Truchsess-Heim Kirschensort. 479-482. I819. 2. Dochnahl Fïhr. Obstkunde 3:53. 54. $\quad 1858$.

Cerise Orange. 3. Mortillet Le Cerisier 2:306. I 866.

The name was given this cherry because of the appearance of the tree which resembles that of the orange. Tree round with a globular head; fruit large, broadly oblate; stem of medium length, firmly set in a deep cavity; suture a line; skin clear, almost brick-red, becoming glossy, darker, and transparent with many white spots; flesh clear, tinged red, with yellowish-white veins, juicy, sweetly acidulated; first quality; stone medium in size, round, turgid, sharply pointed; ripens the middle of July.

Pontiac. P. avium. I. Mag. Hort. 19:167, r68. 1853. 2. Elliott Fr. Book 201 fig. I854. 3. Hogg Fruit Man. 69, 89. 1866.

Pontiac originated in 1842 , with Professor J. P. Kirtland, Cleveland, Ohio, from a pit of Yellow Spanish. Tree vigorous, upright, somewhat spreading, healthy, productive; fruit medium to large, obtuse-cordate, with sides compressed; stem long, slender, 
inserted in a broad, shallow cavity; skin moderately firm, dark purolish-red, becoming nearly black at maturity; flesh purplish-red, with dark colored juice, rather tender, juicy, pleasant, aromatic, sweet; good in quality; stone medium in size, smooth, separating readily from the flesh; ripens in mid-season.

Pope. P. cerasus. I. Prince Pom. Man. 2:150. 1832 .

Some of the fruits of this cherry are green in the middle of July whereas the majority are quite ripe; introduced into France from Italy. Fruit large, round, red; stem very long; flesh similar to but more firm than that of the Montmorency.

Portugal. Species? 1. Rea Flora 205. 1676. 2. Coxe Cult. Fr. Trees 247. 1817.

Tree productive; fruit cordate, red; flavor rich and pleasant; ripens early in June.

Powhattan. P. avium. 1. Mag. Hort. 19:167, 168. 1853. 2. Elliott Fr. Book 201. 1854. 3. Mich. Sta. Bul. 67:23. I890.

This is one of the numerous seedlings originated by Professor J. P. Kirtland, from a pit of Yellow Spanish. Fruit roundish-cordate, uneven in outline, compressed on the sides; stem medium to long; skin brownish-red, glossy; flesh purplish-red, half-tender, juicy, sweet; stone small.

Pragische Muskateller. P. avinım. I. Krünitz Enc. 51, 52, 53. 1790. 2. Truchsess-

Heim Kirschensort. 398-.702. I 819.

Cerise de Prague tardive. 3. Knoop Fructologie 2:36, 42. 1771 .

Muscat de Prague. 4. Lond. Hort. Soc. Cat. 54. ${ }_{1} \$_{3} \mathrm{I}$.

The cherry, introduced into Germany from Holland about i 785 under the name Prager Muskateller, was undoubtedly the variety mentioned by Knoop in 1771 , as Cerise de Prague Tardive. With this variety three other sorts were confused; the Cerise Blanche, Cerise Guigne, and the Grosse Ungarische Kirsche, but when fruit was obtained from all, separation was comparatively easy. Tree very productive; fruit large, globular; suture a line; stem rather thick, of medium length; cavity narrow, shallow; skin thin, brownish-red cnanging to black; flesh tender, melting, juicy, light red, sweet, wine-like; stone oval or roundish; ripens the middle of July.

Précoce de Marest. Species? I. Thomas Guide Prat. 28 . 1876.

Of doubtful value according to the reference.

Précoce de Sabaret. Species? I. Gard. Chron. 1068. 1861. 2. Rev. Hort. 335. 1870.

There seem to be several strains of this cherry; it is one of the earliest cultivated sorts in France, ripening at the beginning of June and lasting a nomth.

President. P. avizum. I. Elliott Fr. Book 21 2. 1854. 2. Downing Fr. Trees Am. 47 1. 1869.

President is another of Professor J. P. Kirtland's cherries raised in Cleveland, Ohio, in 1842 . Tree vigorous, spreading, productive: fruit mediun to large, regular, cordate, slightly compressed; stem stout, slender; suture indistinct; skin red, slightly mottled with yellow; flesh yellowish-white, half-tender, juicy, sweet; good; pit medium in size; ripens from the middle to the last of June.

Pride of Washington. P. avium $\times$ P. cerasus. I. Wash. Hort. Assoc. Rpt. 95. 1905.

This variety is a seedling of the Late Duke grown by J. F. Strong, Spokane, Washington. The tree is more productive and less disposed to seaming of limbs where connecting with the body than its parent and its fruit is also larger, earlier and of better quality. 


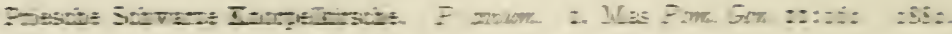

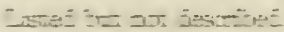

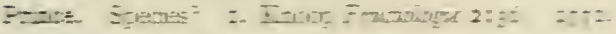

Isté

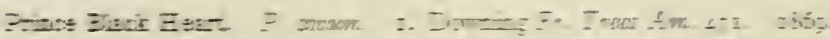

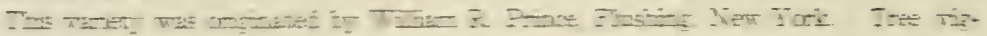

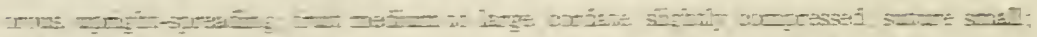

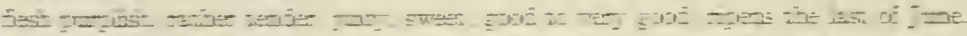

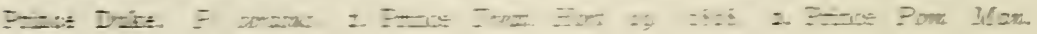

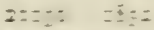

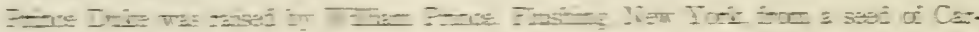
-

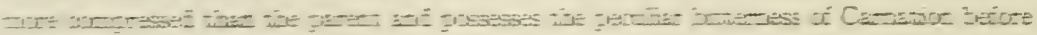
Ix $\div=1=$

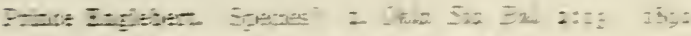

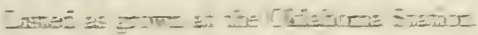

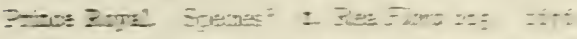

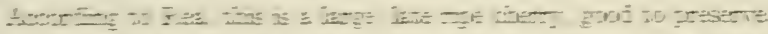

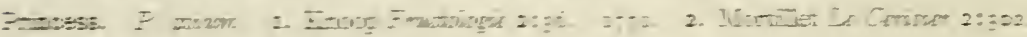

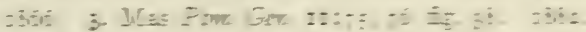

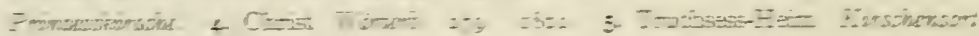
$\therefore=\therefore z=-i=$

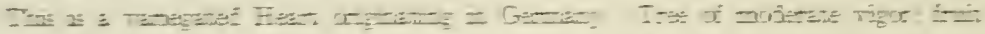

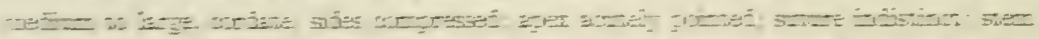

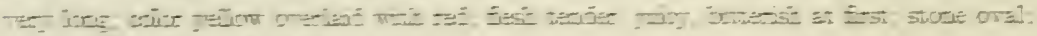
군:

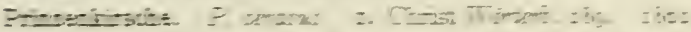

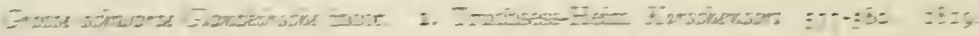

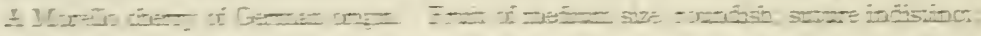

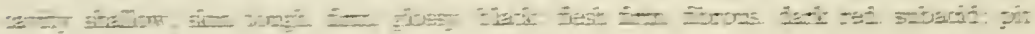
if

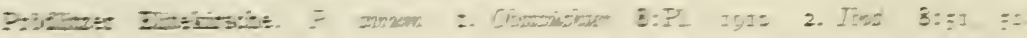
$::=$

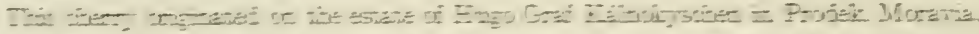

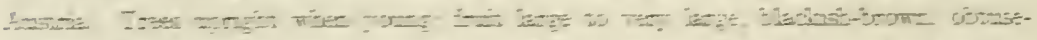

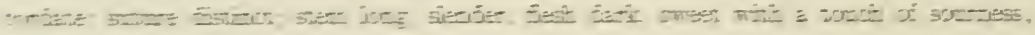
rex $=0$

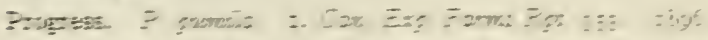

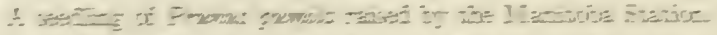

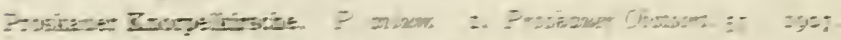

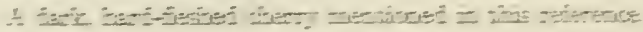

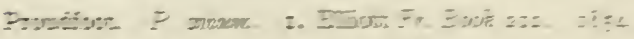

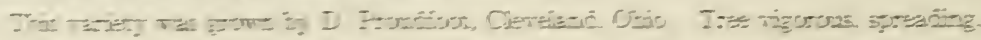


moderately productive; fruit large, cordate, flattened at the base; skin dark purplish-red; cavity open; flesh yellowish, firm, juicy, sweet; pit large; season the middle of July.

Puhlmann Frïhe. P. avium. I. Mathieu Nom. Pom. 373. 1889. 2. Proskaner Obstsort. 57.1907 .

Listed as an early black Heart.

Punktirte Marmorkirsche. P. avium. I. Dochnahl Führ. Obstkunde 3:42. 1858.

Punctirte Süsskirsche mit festem Fleische. 2. Christ Wörterb. 28 I. 1802. 3. Truchsess-Heim Kirschcnsort. 333-336. 1819.

Bigarreau Ponctué. 4. Mas Le Vorger 8:81, 82, fig. 39. I866-73.

Punktirtc Knorpclkirsche. 5. Ill. Handb. 57 fig., 58. 1867.

Tree vigorous, upright; fruit roundish-cordate, large; suture deep; stem long, adhering to the stone; cavity deep; color yellowish-white overspread with clear red; flesh rather tender but firm, fibrous, translucent, sweet; pit round, often rather large; ripens at the end of July.

Punktirte Molkenkirsche. P. avium. I. Dochnahl Führ. Obstkunde 3:29. 1858.

Tree very large, branches long; fruit large, obtuse-cordate; suture indistinct; color yellow more or less overspread with red; flesh sweet; stone small, cordate; ripens early in July.

Purity (I). P. avium. I. Wickson Cal. Fruits 289. 1889. 2. Mich. Sta. Bul. 177:3 I. I899.

Purity (I) is a seedling of Elton which originated with W. H. Chapman, Napa, California, and was propagated by Leonard Coates of that place. Tree upright-spreading, fairly vigorous; fruit heart-shaped, compressed; suture broad, rather indistinct; stem long, slender; cavity broad, shallow; skin amber, shaded and mottled with bright red, waxy, transparent, thin; flesh rich, sweet, tender, juicy, melting; very good; season early; rather too tender for market.

Purity (II). P. cerasus. I. Ont. Dept. Agr. Fr. Ont. IoI. I9I4.

This is a productive cherry of the Morello class which resembles Dyehouse and ripens a little earlier than Early Richmond. Tree moderately vigorous, healthy, bears early; fruit of medium size, roundish; stem long; cavity deep; apex noticeably depressed; skin very dark red; flesh yellowish, tender, very juicy, pleasant subacid; quality good; season late June to early July.

Quaker. P. avium. I. U.S. D. A.Rpt. 262. I $\delta_{92}$.

Quaker originated with C. E. Hoskins, Newberg, Oregon. Fruit of medium size, heartshaped, dark red, almost black; dots numerous; flesh firm, dark purple, sprightly, sweet; quality very good; season early July.

Rainier French. Species? I. Lond. Hort. Soc. Cat. 55. IS 3 I.

Listed without a description.

Red Bigarreau. P. avium. 1. Knoop Fructologie 2:35, 3S. 177 1. 2. Prince Pom. Man. 2:126. I832. 3. Elliott Fr. Book $219 . \quad$ I 854.

Bigarrean à Gros Fruit Rouge. 4. Duhamel Trait. Arb. Fr. I:163-165, Pl. II. 1768. 5. Truchsess-Heim Kirschensort. 308. ISI9. 6. Pom. France 7:No. 7, Pl. 7. I87 I. Purpurrothe Knorpelkirsche. 7. Truchsess-Heim Kirschensort. 340, 683, 684. I8Ig. 
Large Red Bigarreau. 8. Kenrick Am. Orch. 273. I832. 9. Prince Pom. Man. 2:127. 1832. I0. Mortillet Le Cerisicr 2:104, 105 fig., 106, 301. 1866.

Red Bigarreau is probably an old French variety. Fruit very large, roundish-cordate, irregular, swollen on one side; suture distinct; stem slender, long, set in a deep, wide cavity; color glossy, tough, dark red; flesh firm, sweet, rose-colored especially near the pit, juicy; pit small, oval, adherent along the suture; ripens in July.

Red Canada. Species? I. Ariz. Sta. Bul. 15:72. I895.

Listed without a description.

Red Guigne. P. avium. I. Knoop Fructologie 2:36. 1771. 2. Prince Pom. Man. 2: I1 2 . I832.

Fruit more oblong than the Early Guigne and somewhat larger; skin entirely red; flesh soft but not high in quality; ripens in June.

Red Jacket. P. avium. I. Elliott Fr. Book 202 fig. I854. 2. U. S. D. A. Rpt. I 48 , P1. I3 fig. I. I864. 3. Thomas Guide Prat. I9, 204. 1876.

Red Jacket was raised in 1842 by Professor J. P. Kirtland, Cleveland, Ohio, from a pit of Yellow Spanish, crossed with Black Tartarian, Black Mazzard, or May Duke. It was formerly grown commercially in this country and Europe because of its productiveness and quality. Tree very vigorous, upright-spreading, hardy, very productive; fruit large, inng, obtuse-cordate; stem rather long, slender; skin thin, pale red becoming rather bright red; flesh yellowish-white, half-tender, juicy, pleasant, somewhat astringent until fully ripe when it becomes sweet; good in quality; stone medium in size; ripens in late mid-season.

Red Muscatel. P. cerasus. I. Ia. Hort. Soc. Rpt. 330. 1885. 2. Mich. Hort. Soc. Rpt. 329. 1888.

A variety from North Silesia where it is said to be commonly grown; fruit large, of good quality.

Red Oranien. P. avium $\times$ P. cerasus. I. Mich. Hort. Soc. Rpt. 329. I888. 2. Ia. Sta. Bul. 19:551. 1892.

This name has been given by some writers as a synonym of Carnation but Red Oranien as introduced into America from Russia appears to be distinct and is probably another of the Duke hybrids. Tree productive; fruit large, dark red, mildly subacid.

Red Rock. P. cerasus. I. Can. Exp. Farms Rpt. 434. I905.

Fruit of the Morello type, round; stem long, inserted in a noticeable cavity; skin clear red; flesh reddish-yellow with colored juice, mild but pleasantly acid, refreshing; ripens late in July.

Red Russian. Species? I. Kenrick Am. Orch. 237. 1841.

The original name of this variety was lost in importing it from Russia to Brooklyn, New York, about I80o. Fruit large, dark red, good; productive; ripens in August.

Reichart. Species? 1. Pa.Fr.Gr. Soc. Rpt. I I. I881.

Recommended as valuable in Pennsylvania.

Reine-Hortense Hâtive. $\quad P$. avium $\times P$. cerasus. I. Thomas Guide Prat. $28 . \quad$ i876.

A seedling of Reine Hortense introduced in 1873 . It resembles the parent in many respects, differing, however, in earlier ripening and in having red flesh. 
Remington. P. avium. I. Downing Fr. Trees Am. I88. I $8+5$.

Remnington Heart. 2. Prince Treat. Hort. 30. 1828. 3. Lond. Hort. Soc. Cat. 55. 183x. 4. Prince Pom. Man. 2: 117, II 8.1832.

Remington originated in 1823 from a pit planted by Zachariah Allen, Providence, Rhode Island. Its only merit is lateness, not ripening until August; fruit small, cordate, yellow, tinged with red; flesh firm; bears abundantly.

Rentz Morello. P. cerasus. I. Mo. Bd. Agr. Rpt. 243. $\quad$ I8 88.

Mentioned as succeeding fairly well in Missouri.

Resacks Knorpelkirsche. P. avium. I. Mathicu Nom. Pom. 373. 1889.

Listed without a description.

Richardson. P. avium. I. Cole Am. Fr. Book 238. 1849. 2. Elliott Fr. Book 2 12. 1854 .

Originated in the garden of J. R. Richardson, Boston, Massachusetts. Tree upright, hardy, productive; fruit large, heart-shaped, rather short, tapering to a point; stem short, slender; skin dark red, inclining to black; flesh deep red, half-tender, rich, luscious, sweet; ripens the last of June to July.

Richardson Late Black. Species? I. Mag. Hort. 8:285. I 842 .

Originated in the garden of Dr. William P. Richardson, Salem, Massachusetts. A small, round, black cherry, ripening late in July; very juicy and productive.

Richter Sämling. Species? I. Mathieu Nom. Pom. 373. I889.

Listed but not described.

Riga No. 108. P. cerasus. I. Tex. Sta. Bul. 16:99. 1891.

Listed among the Russian fruits growing at the Texas Station.

Riga No. 109. P. cerasus. I. Kan. Sta. Bul. 73:189. I897.

Received from Professor J. L. Budd in 1890 . Tree upright, unproductive; fruit borne singly, large; stem short; color dark red; flesh and juice colored, pleasant, but lacking in quality; ripens the middle of June.

Rival. P. avium. I. Gard. Mon. 7:248. 1865. 2. Hogg Fruit Man. 69, 90. 1866.

3. Mathieu Nom. Pom. 373. I889.

Bigarrcan Rival. 4. Leroy Dict. Pom. 5:236, 237 fig. ${ }_{1} 877$.

This cherry probably came from M. Rival, Saint-Genis-Laval, Rhône, France. Fruit of medium size, borne in clusters, never less than four in a cluster, obtuse-cordate, flattened on one side; suture a colored line; apex shallow, eccentric; stem long. slender; cavity shallow; skin moderately firm, yellow, mottled with red becoming darker, nearly black when mature; ripens the last of July to August.

Rivers Early Heart. $P$. avium. I. Downing Fr. Trecs Am. 177. 1845. 2. Thomas Am. Fruit Cult. 204. $\mathrm{I}_{4} 6$.

A seedling raised by Thomas Rivers, Sawbridgeworth, England, which he says originated about the same time as his Early Amber. The fruit is of the Heart class, medium in size and season.

Roberts Red Heart. P. avium. I. Mag. Hort. 8:285. 1842. 2. Downing Fr. Trees Am. 176. 1845. 3. Horticulturist 5:76 fig. 1850. 4. Ibid. 6:21 fig. 1851. 5. Mas Le Verger 8:119, 120, fig. 58. 1866-73. 
This variety originated with David Roberts, Salem, Massachusetts, and was first brought to notice by Robert Manning. Fruit of medium size, roundish-cordate, slightly obtuse; suture distinct; stem long, slender, set in a moderate cavity; skin pale amber overspread with pale red, mottled with deeper red and pale amber specks; flesh white, tender, juicy, sweet, sprightly; season at the end of July.

Rochaline. $P$. avitum. I. Leonard Coates Cat. Iо. I9 II.

Rochaline, a scedling of Napoleon, is no longer propagated, being inferior to its parent.

Rock. Species? I. Ray Hist. Plant. 1539. I688. 2. Miller Gard. Dict. I:1754.

Mentioned as a perfumed cherry.

Rockland. Species? I. Mass. (Hatch) Sta. An. Rpt. I:33. I 889.

Mentioned as growing at the Massachusetts Station.

Rocky Hill Honey Heart. P. avium. I. Mag. Hort. I3:424. I847.

A variety originating near Wethersfield, Connecticut, late in the Eighteenth Century.

Rocky Mountain. P. besseyi. 1. Country Gent. 26:238. 1865. 2. Rural N. Y. 52:138, 330, fig. 46. 1893. 3. Cornell Sta. Bul. 70:261, Pl. I fig. 2. 1894. 4. Storrs \& Harrison Cat. 136 fig. ז806. 5. Wis. Sta. An. Rpt. 13:229, $230 . \quad$ I 896.

Rocky Mountain, a variety of Prunus besscyi, is a native of the mountains of Colorado having been discovered there many years ago. It is chiefly used as a dwarf ornamental, being adapted to a great variety of soils. Tree small, bushy, averaging about four feet high, very hardy and productive; fruit ripens after all other cherries are gone, small, variable in shape, from roundish to nearly oblong; color almost jet black; flavor sweet with some astringency but edible when fully mature.

Roe. P. avium. I. Better Frtit 5: No. I1:49. I9I I.

Roe is a seedling from Yamhill County, Oregon, being introduced by the Oregon Nursery Company, Salem, Oregon; it is said to resemble Napoleon but is much firmer and later. Romaine. Species? I. Thomas Guide Prat. 26. $\quad$ I876.

A variety of doubtful value; ripens in July.

Ronald. Species? I. Bunyard-Thomas Fr. Gard. 44. 1904.

According to the reference, this is a valuable late variety. Tree small, compact; fruit very large, bright red, transparent; flesh yellowish, tender, juicy.

Röschers Kirsche. P. cerasus. 1. Ill. Handb. I fig., 2. I867. 2. Mas Pom. Gen. I1:9, I0, fig. 5. 1882 .

A chance seedling found by a peasant, Rösclers, near Heidelberg, Baden, Germany. Fruit medium, oblate-cordate; sides compressed, angular; stem long; cavity wide, deep; skin tough, black; flesh dark red, juicy, vinous; pit small, oval; ripens very early.

Rose Charmeux. Species? I. Am. Pom. Soc. Rpt. 75. I883.

A Polish variety introduced by Professor J. L. Budd, Ames, Iowa; fruit large, red, delicate, watery and mild-flavored.

Rosenobel. $P$. avium. I. Truchsess-Heim Kirschensort. 280, 678. 1819. 2. Dochnahl Führ. Obstkunde 3:27. I858.

An old German variety fruiting for the first time in 18 $_{15}$. Fruit large, obtuse-cordate, yellow, streaked with red around the cavity; stem long; flesh white, tender, sweet; stone oval; ripens the last of June. 
Rostraver Bigarreau. P. avium. I. Gard. Mon. 28:240, 24 I. I 886.

This variety was introduced in 1887 , by the originators, John R. and A. Murdoch, Pittsburg, Pennsylvania. The trees, as grown on the Station grounds, are vigorous, moderately spreading; fruit large, blunt heart-shaped; suture indistinct; stem long, set in a large, deep cavity; skin thin, tough, rich yellow, mottled with red, similar to Napoleon; flesh meaty, firm, white, sweet, moderately juicy; season the middle of July.

Rothe Glanzkirsche. Species? I. Truchsess-Heim Kirschensort. 490-492, 689. I8I9.

Fruit of medium size, roundish-oblate; suture distinct; stem slender, of medium length, set in a shallow cavity; color clear red mixed with darker red, glossy; flesh tender, white, fibrous; excellent; stone large, oval, smooth; ripens from the end of June to the middle of July.

Rothe Herzkirsche. P. avium. I. Krünitz Enc. 58, 59. 1790. 2. Truchsess-Heim Kirschcnsort. $437,438,439$. ISI9.

Herzförmigc Sissweichsel. 3. Dochnahl Führ. Obstkunde 3:48. I858.

Fruit of medium size, obtuse-cordate; suture indistinct; skin clear red changing to darker red, thin, tough; stem medium in length, set in a deep, narrow cavity; flesh tender, red near the stone, fibrous, vinous; stone broadly oblong, clinging to the flesh; ripens at the beginning of July.

Rothe Maiknorpelkirsche. P. arium. 1. Truchsess-Heim Kirschensort. 286, 287. I8I9.

Fruit medium in size, roundish-cordate, compressed on both sides; suture distinct; stem rather long; cavity shallow; color wholly red on a yellow ground; flesh yellowish-white, rather tender, pleasing; excellent; stone large, cordate, plump; ripens at the beginning of June. Rothe Molkenkirsche. P. avium. I. Christ Handb. 667. I797. 2. Truchsess-Heim Kirschensort. 229-233. I 8 I9.

Cerise de petit-lait ronge. 3. Mortillet Le Cerisier 2:302. I866.

Christ grew this variety from seed at Kronberg, Prussia, Germany. Tree productive; fruit of medium size, flattened at the ends and sides; ventral suture distinct; stem rather long; cavity shallow; skin thin, glossy, overspread with light red, darker in the sun; flesh tender, light yellow, juicy, bitter before ripe, sweet when mature; stone roundish, free, tinged with red along the suture; ripens with Black Tartarian.

Rothe Soodkirsche. P. cerasus. I. Christ Wörtcrb. 294. 1802.

Soodamarclle. 2. Truchsess-Heim Kirschensort. 632-634. I8I9. 3. Thomas Guide Prat. $27,206 . \quad 18 ; 6$.

The fruit is borne in twos and threes, below medium in size, roundish, compressed on one side; apex shallow; stem long; color dull blood red, lighter near the suture; flesh melting, dull yellow; juice reddish, abundant, tart; stone small, broad, frce.

Rouaanse Kirsche. P. avium. I. Truchsess-Heim Kirschensort. 340. I819.

A Heart cherry, clear, light red spotted with red in color; flesh firm.

Rouge Pâle Tardive. Species? I. Lond. Hort. Soc. Cat. 55. I 83 I.

Listed without a description.

Rouge des Vosges. P. cerasus. 1. Mas Le Verger 8: 107, 108, fig. 52. I866-73. 2. Soc.

Nat. Hort. France Pom. I00 fig., I01. 1904.

Cultivated in the region of Fougerolle, Haute-Saône, France, as the Noire des Vosges 
and largely used in the manufacture of a liqueur. Fruit usually borne in pairs, large, elongated-cordate; suture distinct; stem long; cavity of medium size; skin glossy, dark red; flesh yellowish, tender, sprightly; stone small, roundish, with a small point at the apex; ripens the last half of July.

Round Sweet. P. avium. I. Can. Exp. Farm Bul. 2nd Ser. 3:6r. 1900.

Mentioned in this reference.

Royal American. Species? I. Can. Exp. Farm Bul. 2nd Ser. 3:62. 1900.

Tree strong in growth; fruit large; skin light red becoming darker in the sun; flesh yellowish-white, firm, juicy, agreeable; ripens in July.

Royal Hâtif. P. avium. I. Noisette Man. Comp. Jard. 2:505. I860.

Tree very productive, of medium size; fruit large, compressed at the apex and base; stem green, short, often with stipules; flavor sweet; very good; ripens at the end of May. Rumsey. P. cerasus. I. Del. Sta. An. Rpt. 12:122. 1900.

Rumsey's Late Morello. 2. Downing Fr. Trees Am. I99 fig. I 845 .

This very late cherry was grown by Dr. J. S. Rumsey, Fishkill Landing, New York, about $\mathrm{I}_{35}$. Fruit usually borne in pairs, large, roundish-cordate; suture distinet; stem long; cavity narrow, deep; skin glossy, a rich, lively red; flesh juicy, melting, acid; stone long; ripens from the first part of August until frosts.

Runde Marmorirte Süsskirsche. $P$. avizm. I. Christ Wörterb. 280. ISo2. 2. Truchsess-Heim Kirschensort. 336, 683. 1819. 3. Oberdieck Obst-Sort. 382. 188 I. 4. Mathieu Nom. Pom. 375. I889.

WVeiss und hellroth geflekte grosse Kramelkirsche. 5. Kraft Pom. Aust. I:3, Tab. 6 fig. I. 1792 .

Runde Marmorirte Süskirsche is one of the varieties which has been confused with Napoleon and Yellow Spanish, Tree vigorous, very productive; fruit large, roundishcordate, slightly compressed; suture shallow; stem long; cavity shallow, wide, depressed on the ventral side; skin yellow, streaked, dotted and overlaid with red - the amount depending on the exposure to the sun; flesh whitish-yellow, medium firm, juiey, very sweet, sprightly, excellent; stone ovate to oval; matures usually with Napoleon.

Rupert. P. pumila $\times$ P.? I. Can. Exp. Farms Rpt. 435. 1901.

Mentioned in this reference as being a cross between the Prunus pumila, the Sand Cherry, and a plum.

Rupp. P. avium $\times$ P. cerasus. I. U.S. D. A. Pom. Rpt. 40, Pl. 3. I895. 2. Mich. Sta. Bul. 187:62. 1901.

Rupp is supposed to have originated with Solomon Rupp, York County, Pennsylvania. It was sent to several Experiment Stations for testing by the United States Department of Agriculture. As grown at the Michigan and Geneva Stations it cannot be distinguished from Reine Hortense and we are inclined to believe that the old variety has been overshadowed by a new name.

Russian Morello. P. cerasus. 1. Ont. Dept. Agr. Fr. Ont. 103. I914.

Russian 207. 2. Can. Exp. Farms Rpt. 76. I890.

Tree upright, vigorous; fruit above medium in size, round, flattened at the base; stem long; skin bright red; juicy; fair quality; ripens the first of August. 
Russian Seedlings Nos. 8, 42, 49, 54, 109, 128, 169, 199. P. cerasus. I. Ia. Sta. Bul. $73: 80,81$. 1903 .

These seedlings were grown at the Iowa Experiment Station from selected seeds of Russian varieties. They show every variation from a low, compact, spreading tree to a tall, conical one, while the fruit varies in season from early June to late July.

Russie à Fruit Blanc. Species? I. Lond. Hort. Soc. Cat. 55. $183 \mathrm{I}$.

Listed without a description.

Ryley Black Tartarian. P. avium. I. Lond. Hort. Soc. Cat. 55. 1831.

Listed in the reference given.

Sächsische Frïhe Maikirsche. Species? x. Christ Handb. 683. I797.

Listed without a description.

Sacramento. Species? I. Grecn River Nur. Cat. 23. 1899.

This is a productive variety, resembling May Duke, found near Sacramento, Kentucky.

Saint-Laurent. Species? I. Mas Pom. Gen. x I: I62. I $\$ S_{2}$.

Listed without a description.

Sansoto. P. pumila $\times$ P. americana. I. S. Dak. Sta. Bul. 130:184, P1. 10, P1. 11, 185. I II I.

Sansoto is a cross from the South Dakota Experiment Station between the Sand Cherry and the De Soto plum. In growth the tree resembles that of the plum but the fruit in looks and flavor is more like the Sand Cherry. Fruit is round, about threeeighths inch in diameter; skin black with a bluish bloom, thin, free from acerbity; flesh yellowish-green, sprightly; pit clinging.

Sapa. P. pumila $\times$ P. triflora. I. S. Dak. Sta.Bul. ro8:Pl. 9. 1908. 2. Ibid. 130:176, 177 Pl. 7,178 . 1911 .

Sapa, a cross between the Sand Cherry and the Occident plum, was introduced in I 908 by the South Dakota Station. Tree plum-like in habit; fruit-buds numerous; fruit about one and three-eighths inches in diameter; skin glossy, dark purple; flesh rich, dark purple; season extremely early.

Sappington. P. avism. 1. Ohio Hort. Soc. Rpt. 22. 1S92-93. 2. Budd-Hansen Am. Hort. Man. 2:282. 1903 .

Grown about St. Louis, Missouri, where it originated. The tree resembles Mazzard in growth, vigor and productiveness; fruit sweet; early.

Sauerjotte. P. cerasus. I. Guide Prat. $17 . \quad 1895$.

Listed as a variety of doubtful value.

Saure Herzkirsche. P. cerasus. I. Christ Obstbäume I6 I. I 791.

Described as a black, Sour Cherry of the first rank, with tender flesh and excellent juice.

Sauvigny Knorpelkirsche. P. avium. I. Ill. Handb. 9 I fig., 92. I860.

Bigarrean de Sanvigny. 2. Nortillet Le Cerisier 2:302. 1866.

Dure de Sauvigny. 3. Mas Pom. Gen. II: 160. 1882.

Fruit large, elongated, obtuse-cordate, compressed more strongly upon the side showing a suture; stem variable, usually of medium length; cavity narrow, deep; skin glossy, dark brownish-red, mottled with lighter red; flesh very firm, dark red, juicy; quality very good; pit small, oval, acutely-pointed at the apex, free; ripens in late July. 
Scharlachkirsche. $P$. avium $\times P$. cerasus. I. Christ Handb. 669. 1797 .

This varicty is supposed by some to be May Duke. Usually borne in twos and threes; fruit medium in size; stem above medium in length, slender; suture indistinct; ripens the latter part of June.

Schleihahn Sweet. P. avium. I. Ia. Sta. Press Bul. 28: I9I I.

Bigarrean de Schleihahn. 2. Thomas Guide Prat. 20, 190. 1876.

A variety of German origin, introduced into Iowa about 1892 and described as a desirable variety for that State by the Iowa Agricultural College. It follows Early Richmond and has a long season. Tree productive, hardy for a sweet variety; fruit of medium size, cordate, sides flattened; stem long, slender, set in a rather deep, wide cavity; skin firm, glossy, surface often pitted; dots numerous, obscure; suture often lacking; color bright deep red, becoming dark red or black; flesh dark red, very firm, moderately juicy, sweet; good; pit above medium in size, pointed, oval, turgid, nearly free; season at Ames, Iowa, from June 2 oth to July ist.

Schlössers Schattenmorelle. P. cerasus. I. Reut. Pom. Inst. Festschrift I23. I910.

2. Pom. Inst. Reut. 3I. I9II-I2.

Tree vigorous; fruit large, round, dark brownish-red, similar to the Brusseler Braute but larger; sour.

Schmehls. P. avium. I. Can. Exp. Farms Rpt. 549. I901.

Tree vigorous; fruit large obtuse-cordate; skin mottled with yellow and pale red; flesh tender, juicy, sweet, pleasing; ripens the middle of July.

Schmidt Bigarreau No. 2. P. avium. 1. Can. Exp. Farm Bul. 2nd Ser. 3:62. I900.

Tree vigorous; fruit large, neariy round; skin dark red; flesh red, firm, juicy, sweet; season late June.

Schmidt Frïhe Herzkirsche. P. avium. I. Lauche Ergänzungsband 603. I 883.

F. Schmidt, Potsdam, Prussia, Germany, grew this variety. Tree fruitful and succeeds in all soils; fruit large, abruptly cordate; suture indistinct; stem medium in length; cavity wide, deep; color glossy dark brown changing to black; flesh firm, juicy, sweet; good; stone medium, roundish; early.

Schneeberger Kirsche. Species? I. Obstzüchter 8:52. 1910.

This is a market cherry grown about Vienna, Austria, ripening about the middle of July and lasting for a month. Some fruits are round, others cordate, depending on the altitude in which it is grown; stem slender; color black; flesh moderately firm, adhering to the pit.

Schneider Frühe Herzkirsche. P. avium. I. Mathieu Nom. Pom. 376. I889.

Guigne-hâtive de Sclmeider. 2. Thomas Guide Prat. I8, I98. I876.

Tree vigorous and productive; fruit large, cordate, truncate; skin a brilliant brownishblack; flesh firm; of first quality; matures early in June.

Schneider Späte Knorpelkirsche. P. avium. I. Oberdieck Obst-Sort. 370, 37 I. I88I.

2. Lauche Deut. Pom. III:No. 8, Pl. I 882.

Origin, Guben, Prussia, Germany. Tree vigorous, productive; fruit very large, oval, often cordate, sides compressed; suture indistinct; stem long, inserted in a wide, deep cavity; skin glossy, cherry-red changing to dark brown, with numerous flecks; flesh 
firm, yellowish, sweet, with slightly colored juice; stone elongated-ovate, large, plump; late.

Schöne von Brügge. Species? I. Mathieu Nom. Pom. 376. I889. Belle Brugeoise Saint-Pierre. 2. Mas Pom.Gen. I1: I59. 1882.

Listed but not described in the reference given.

Schöne von Marienhohe. P. avium. 1. Ill. Handb. 57 fig., 58. I860. 2. Proskauer Obstsort. 57. I907.

Belle glorie de Marie. 3. Mortillet Le Cerisier 2:300. 1866.

Belle de Maricnhöhe. 4. Thomas Guide Prat. 19, 187. 1876.

Beauty of Marienhohe. 5. Can. Exp. Farms Rpt. 549. 1901.

This old variety originated in $18{ }_{3} 6$ from pits planted in the Royal nursery of Marienhöhe near Weimar, Saxe-Weimar, Germany. Trees strong, healthy and productive; fruit medium in size, heart-shaped, often variable; sides plump; cavity noticeable; apex a small yellowish-brown point in a slight depression; stem slender, green; skin thin, glossy, reddish-black; flesh and juice dark red, tender, sweet; quality very good; pit egg-shaped, smooth without a point, turgid; ripens the first of July.

Schröcks Späte Bunte Knorpelkirsche. P. avium. 1. Dochnahl Fïhr. Obstkunde 3:43. I 858 .

Fruit large, elongated-cordate, compressed, often uneven; suture noticeable; stem long, slender; skin dark red, variegated; flesh firm, vinous, sweet; stone elongated-cordate, adherent; ripens at the end of July.

Schwarze Forellenkirsche. P. cerasus. I. Krünitz Enc. 70, 71. 1790. 2. TruchsessHeim Kirschensort. 593, 594. 18 I 9.

Tree productive, not large; fruit large, roundish, slightly flattened; stem very long, set in a cavity of medium size; skin glossy, dark brownish-black becoming almost black; flesh very red, melting, juicy, sour; stone reddish, one-half inch long; ripens early in August.

Schwarze Maiweichsel. P. cerasus. I. Christ Wörterb. 285. ISo2. 2. Dochnahl Führ. Obstkunde 3:58. $\quad$ I 858 .

Schwarze Maikirsche. 3. Truchsess-Heim Kirschensort. 498, 499, 500. I819.

This variety differs from other Morellos in its very short stem. Tree small, not productive; fruit usually small, roundish, flattened; suture indistinct; stem short; color black when ripe; flesh dark red, juice lighter, sour, becoming aromatic on hanging; stone very small, round; ripens the middle of June.

Schwarze Muskateller. P. avium. I. Christ Handb. 671. 1797. 2. Truchsess-Heim Kirschensort. 419, 420, 421. I8I9.

Fruit round, somewhat flattened on one side; stem short; skin and flesh dark red; flesh soft, juicy, mingled with a slight sourness; ripens the latter part of July.

Schwarze Oranienkirsche. Species? I. Krünitz Enc. 56. I790. 2. Truchsess-Heim Kirschensort. 432. I819.

Schwarze Malvasierkirsche. 3. Ibid. 433, 434. 18 I9.

Fruit large, pitch-black, aromatic; from Holland.

Schwarze Soodkirsche. P. cerasus. I. Christ Wörterb. 286. I802. 2. Truchsess-Heim Kirschensort. 556, 557. I8I9. 
Branches slender, drooping; fruit of medium size, oblate, sides flattened; stem slender; cavity shallow; suture a fine line; color almost black; flesh tender, slightly fibrous, dark red at the stone, juicy, pleasingly subacid; stone small, roundish; season the middle of July.

Schwarzbraune Knorpelkirsche. P. avium. I. Truchsess-Heim Kirschensort. 198, 199, 200, 675. Isig.

Of German origin and first mentioned in 1797 . Fruit moderately large, uneven, flattened at the base and sides; stem slender, rather long, deeply inserted; skin brownishred approaching black, tough, leather-like; flesh firm, sweet, with violet juice when ripc; ripens early in August.

Schwarzes Taubenherz. $P$. avium. I. Truchsess-Heim Kirschensort. 147, 148. 1819.

This variety is peculiar in that its stem is green and its fruit has a deep suture on the compressed side; skin very dark brown; flesh tender, soft, bitter, sweet when fully ripe but insipid; ripens early in July.

Sebril. P. avium. I. Mich. Sta. Bul. 152:192. I898.

Listed as a Sweet Cherry.

Seckbacher. $P$. cerasus. I. Truchsess-Heim Kirschensort. 167-174. I819. 2. Ill. Handb. 475 fig., 476 . I86 I.

Späte Maikirsche. 3. Christ Handb. 660. 1797.

Seckbacher Knorpelkirsche. 4. Dochnahl Führ. Obstkunde 3:34. i 858 .

Cerise de Seckbach. 5. Mas Pon. Gen. II:55, 56, fig. 28 . I882.

This variety probably originated in Prussia, Germany. Fruit small, round or cordate, compressed, with a faint suture; stem long, shallowly inserted; color glossy, black, lighter along the suture; flesh dark red, firm, juicy, aromatic, piquant; stone large; ripens the middle of June.

Seederberger. P. avium. I. Col. O. Hort. Soc. Rpt. 3 1. ${ }_{1} 892$.

Listed as a sweet variety from Virginia and said to resemble Yellow Spanish but the fruit is larger and the tree more vigorous.

Select Beauty. Species? I. Prince Treat. Hort. $30 . \quad$ I $\delta 28$.

A large, red, well-flavored cherry with a long stem; not very productive; ripens in July.

Shadow Amarelle. P. cerasus. I. Mich. Hort. Soc. Rpt. 326. i 888. 2. Ia. Sta. Bul. $73: S_{2}$ fig. 1903.

Frühe Schattenmorelle. 3. Dochnahl Fuhr. Obstkunde 3:64. 1858 .

Schatten Amarelle. 4. Am. Pom. Soc. Rpt. 75. 1883. 5. Ia. Hort. Soc. Rpt. 329. I885. 6. Del. Sta. An. Rpt. 12:126. 1900.

Shadow Morcllo. 7. Ia. Hort. Soc. Rpt. 78. i 890. 8. Lucas Handb. Obst. 3rd Ed. I22. 1893 .

Professor J. L. Budd of Ames, Iowa, in I 893 , imported this variety from south-central Asia. It is very similar to the Brusseler Braune and Lucas gives it as the same. Whether or not they are identical we cannot determine, as the variety is not grown on the Station grounds. The name Schatten is derived from the mirror-like reflection of the glossy skin when exposed to the sun. From the description it seems to differ from the Brusseler 
Braune in being smaller in size, not so globular, nor as dark in color, a few days earlier, and the tree is more spreading in growth.

Shailer. P. avium. I. Lond. Hort. Soc. Cat. 55. I83I.

A yellowish-red, hard-fleshed Heart cherry of inferior quality; ripens in July.

Shannon. P.cerasus. I. Elliott Fr. Book 202, 203. I854. 2. Mag. Hort. 19: I67, I68, I853.

Shannon Morello. 3. Hogg Fruit Man. 7о, 91. I866.

Gov. Shannon. 4. Ill. Hort. Soc. Rpt. 33. $\mathrm{I} 873$.

Shannon was raised by Professor J. P. Kirtland, Cleveland, Ohio, I829, and described in 18.49 , being named after Wilson Shannon, once Governor of Ohio. It sprung from a Morello tree standing near a Carnation cherry tree and bears fruit of the Morello type. Tree very hardy; fruit above medium in size, globular, flattened at the base; stem long, slender; cavity open; flesh tender, reddish-purple, juicy, acid; pit small.

Shelton. P. avium. I. Milton Cat. ro. I9II.

Shelton is a seedling of Napoleon grown by Judge William Shelton of Walla Walla, Washington. Tree hardy, vigorous, upright; fruit smaller than Napoleon; skin pale yellow with a red cheek; flesh sweet, tender, juicy; ripens two weeks before Napoleon.

Short-stem May. Species? r. Continental Plant Cat. 22. I9r4.

Merely listed as an old, well-known, productive cherry.

Shubianka. P. cerasus. I. Mich. Hort. Soc. Rpt. 327. I888. 2. Ia. Sta. Bul. $73: 83$. 1903 .

Shubianka is an inferior small-fruited cherry of the Vladimir family imported from Russia in $\mathrm{I} 88_{3}$ by Professor J. L. Budd, Ames, Iowa. Tree dwarf, round-topped; fruit small, round; stem long, slender; cavity broad, shallow; skin tough, thick, deep red; flesh firm, juicy, colored, sprightly, astringent with a bitter after-taste; stone round, rather large; season at the end of June; worthless.

Sibrel. P. cerasus. I. Greening Bros. Cat. 74 fig. I899.

Sibrel is of the Morello type and originated at Bettsville, Ohio; distinguished for its productiveness, lateness, size and quality.

Silver Thorne. P. cerasus. I. Ia. Sta. Bul. 73:83. I903.

Silver Thorne is supposed to have originated in Muscatine County, Iowa, about sixty years ago. It resembles Early Richmond in tree and fruit but the cherries have firmer flesh and are less acid.

Skublics Weichsel. P. cerasus. I. Proskaner Obstsort. 59. I907.

Mentioned in the reference given.

Sleinhaus. Species? I. Mas Pom. Gen. II:162. I882.

Listed without a description.

Small Black Guigne. P. avium. I. Prince Pom. Man. 2:I12. I832.

This cherry differs from Black Guigne in being shorter and inferior in quality.

Small Morello. P. cerasus. I. Thacher Am. Orch. $217 . \quad 1822$.

A cherry from Salem County, New Jersey; the fruit has a lively acid taste.

Smidt Yellow. Species? I. Thomas Am. Fruit Cult. 669. I897.

A good, early, prolific, southern variety. Fruit medium in size, yellow, mottled with red. 
Socsany. P. avium. I. U.S. D. A. Pom. Rpt. 4I. 1895.

Socsany was received from Hungary by the United States Department of Agriculture in I893 and was sent to C. E. Hoskins, Springbrook, Oregon, for testing. Fruit small, smooth, cordate; suture shallow; stem long, slender; cavity medium in size, irregular, flaring; skin thick, tenacious, yellow, well covered with red, with numerous, subcutaneous, oblong dots; flesh yellowish, translucent, meaty, with whitish veins, juicy, sweet, aromatic; stone large, oval, clinging; very good; season the first of July.

Soft-stone Cherry. Species? I. Prince Pom. Man. 2:145. 1832.

Soft Sheld. 2. Parkinson Par. Ter. 574. I629.

Cerise à Noyau tendre. 3. Duhamel Trait. Arb. Fr. 1:174, 175. 1768.

Many writers mention a seedless cherry but Duhamel doubts its existence. He does, however, describe one with a tender, ligneous pit that is easily broken by the fingers. The fruit is round, almost an inch in diameter and very good.

Souths Breite Herzkirsche. P. avium. I. Truchsess-Heim Kirschensort. 164. I8I9.

2. Thomas Guide Prat. 25. 1876 .

A large, black, glossy Heart cherry.

Souvenir d'Essonnes. P. avium. I. Mas Le Verger 8:109, I10, fig. 53. I866-73.

This cherry was obtained by M. Courtin, a nurseryman at Essonnes, Seine-et-Oise, France, about I86o. Fruit of medium size, oval, slightly compressed; suture indistinct; stem medium; cavity of medium size, regular; skin tender, mottled on a red ground; flesh whitish, tender, sweet though sprightly; pit small, oval; ripens the middle of June.

Spanische Frühkirsche. P. avium. I. Ill. Handb. 149 fig., I50. 1860.

Spanische Herzkirsche. 2. Christ Obstbäume i6o. 1791.

Schwarze Spanische Fruhkirsche. 3. Christ Handb. 662. 1797. 4. Christ Wörterb. 282. I802, 5. Truchsess-Heim Kirschensort. 410-413. I819.

Précoce d'Espagne. 6. Mas Le Verger 8:73, 74, fig. 35. 1866-73. 7. Thomas Guide Prat. 16, 204. 1876.

Fruit medium in size, roundish-cordate, sides compressed; suture wide, deep, often only a line on the dorsal side; stem long, slender, inserted in a shallow, narrow cavity; skin glossy, tough, deep red changing to black; flesh tender, juicy, sweet, with a pleasing sourness, brownish-red; pit elongated-oval, not plump, rather smooth; season the middle of Jurie. Spanische Frühweichsel. P. cerasus. I. Christ Handb. 674. I797. 2. Christ Wörterb. 289. I802. 3. Truchsess-Heim Kirschensort. 500, 501, 502. I819.

Griotte Précoce d'Espagne. 4. Mas Le Verger 8:41, 42, fig. 19. 1866-73.

Tree strong, vigorous, productive; fruit above medium in size, roundish, truncate at the base; suture marked on the side most compressed; stem long, moderately stout, inserted in a deep, narrow cavity; skin tender, purplish-brown, changing to black, somewhat lighter near the suture; flesh tender, juicy, dark red, with a pleasing acidity; first quality; stone small, roundish-oval, apex pointed; season the last of June

Spanische Glaskirsche. P. cerasus. I. Ill. Handb. 503 fig., 504. I861.

Grosse Spanische Weichsel? 2. Christ Handb. 683. I797.

Transparente d'Espagne. 3. Mas Le Verger 8:101, 102, fig. 49. 1860-73.

Fruit large, oblate, compressed on the dorsal side; suture lacking; stem rather long; 
cavity deep; color dark red; flesh yellowish, tender, juicy, acidulated; stone small, nearly round; ripens from the middle to the end of June.

Spanish Griotte. P. avium $\times$ P. cerasus. I. Prince Pom. Man. 2: 136.1832.

Prince believed this variety to be a sub-variety of Arch Duke which it resembles. The fruit is larger than the Arch Duke, oblong, somewhat flattened along the sides; stem very large, of medium length; skin brownish-red approaching black; flesh red, firm, slightly melting, sweet; ripens at the beginning of July.

Spätblühende Glaskirsche. P. cerasus. I. Christ Handb. 683. I 797 .

Weichselbaum mit gelb, weiss, und rothlich marmorirte Frucht. 2. Kraft Pom. Aust. 1:7, Tab 17 fig. 2. I792. 3. Truchsess-Heim Kirschensort. 477-479, 690. I819.

Fruit of medium size; stem long, slender; color red; flesh pleasingly subacid; ripens the middle of July; blooms very late.

Späte Maulbeerkirsche. P. avizm. I. Christ Wörterb. 276 . I802. 2. Ill. Handb. 75 fig., 76 . I 860 .

Späte Maulbeerherzkirsche. 3. Truchsess-Heim Kirschensort. 135-140. 1819.

Guigne mûre de Paris. 4. Mortillet Le Cerisier 2:83, 207. 1866.

Tree vigorous, with a broad crown, productive; fruit variable in size, flattened somewhat squarely; stem long, stout, straight; cavity wide, shallow; skin tough, black, rather dull; flesh tender, reddish-black, with abundant, colored juice, sweet with a piquant sourness; pit round; season the last of July.

Späte Rote Knorpelkirsche. P. avium. I. Mathieu Nom. Pom. 378 . I889.

Listed without a description.

Späte Schwarze Forellenkirsche. P. cerasus. I. Christ II orterb. 291. I802. 2. Truchsess-Heim Kirschensort. 605, 606. I8 19 .

This variety was found in Bernburg, Anhalt, Germany. Tree medium in height, with branches drooping; fruit large, dark brownish-red; very sour; stone very long; ripens in September with a few fruits remaining until October.

Späte Schwarze Knorpelkirsche. P. avium. I. Ill. Handb. 43 fig., 44. 1867.

Fruit very large, roundish, flattened, angular; suture but a line; stem rather long; cavity shallow; skin glossy, dark red, becoming black, streaked; flesh dark red, firm, sweet, aromatic, with a slight bitterness; stone oval; ripens in late August.

Späte Schwarze Spanische Herzkirsche. P. avium. I. Christ Handb. 66. I 797.

2. Truchsess-Heim Kirschensort. 152, I53. 18 I 9.

This variety is distinguished from all others of its class by its soft, tender stone; it differs from the Soft-stone Cherry in shape. Fruit elongated, tapering-cordate; skin glossy, dark brown, changing to black; flesh tender, dark red, juicy, aromatic; stone medium in size, flattened, often abortive, with a thin covering over the kernel easily broken by the hand; ripens in late August.

Speckkirsche. P. cerasus. I. Christ Handb. 665. 1797. 2. Truchsess-Heim Kirschensort. $287-289$. 1819 .

Cerise Graisseuse. 3. Mortillet Le Cerisier 2:303. 1866.

Cerise Lard. 4. Mas Pom. Gen. II:81, 82, fig. 41. 1882.

This cherry is sometimes mistaken for Corone. It differs from other Bigarreaus 
in its variable form. Tree productive; fruit medium to large; stem rather long, set in a shallow cavity; color dark red with lighter red flecks; flesh firm, pale yellow, subacid; stone rather large, nearly free; ripens the middle of July.

Spitzens Herzkirsche. P. aium. I. Truchsess-Hein Kirschensort. 160, 161, 673. I819.

2. Ill. Handb. 7 1 fig., 72. 1860. 3. Mortillet Le Cerisier 2:301. 1866. 4. Thomas Guide Prat. 18, 199. I876.

Guigne noire Spitz. 5. Leroy Dict. Pom. 5:333 fig. 1877.

Bigarreau noire de Spitz. 6. Mas Pom. Gen. Ir:159. 1882.

Spitzens Herzkirsche is a seedling found in Guben, Prussia, Germany, about 1790. Tree vigorous, productive; fruit usually borne in pairs, large, obtuse-cordate, compressed; suture shallow; stem short; cavity shallow; skin glossy, tender, dark reddish-brown changing to black, lighter along the suture; flesh dark red, tender, fibrous, sweet, aromatic when fully ripe; stone of medium size, plump, oval, slightly adherent; season late.

Srdcovka v Skalka. P. avium. 1. Obstzüchter 8:51. 1910.

A Heart cherry found in the markets of Brünn, Moravia, Austria.

Stanapa. P. pumila $\times P$. pissardi. I. S. Dak. Sta. Bul. I30:190, 191. 1911.

Stanapa is a cross between the Sand Cherry and Prunus pissardi, interesting only because of its beautiful purple foliage.

Standard. P. pumila. I. Can. Exp. Farms Rpt. 353. 1896.

Standard is a seedling of Prunus pumila, the Sand Cherry, grown by the Experiment Station at Manitoba, Canada; fruit large, astringent.

Starr Prolific. Species? I. Ont. Fr. Exp. Sta. Rpt. I:22. I894.

Mentioned as growing on the grounds of L. Woolverton, Grimsby, Ontario, Canada. Strass Early Black. $P$. avium $\times P$. cerasus. I. Downing Fr. Trees Am. 473. 1869 . 2. Agr. Gaz. N. S. Wales 19:996. 1908.

Many writers believe Strass Early Black to be Reine Hortense. Tree vigorous, productive; fruit small, partly cordate, flattened on one side; stem of medium length, set in a shallow cavity; skin dark red becoming almost black; flesh reddish-pink, rather soft, sweet, with pinkish juice; stone large.

Strauss. P. cerasus. 1. Del. Sta. An. Rpt. 12:127. 1900.

Strauss Weichsel. 2. Ia. Hort. Soc. Rpt. 328. 1885. 3. Can. Exp. Farm Bul. I7: 1 r. I892.

This is not the Strauss Weichsel of Europe but one of Budd's importations. Tree upright, hardy, round-topped, vigorous, unproductive; fruit medium to large, truncate, flattened at both ends; cavity medium; apex smooth; stem short, slender; flesh dark red almost black, firm, juicy, sprightly, acid, astringent; stone small, round; season the last of June.

Strauss Weichsel. P. cerasus. I. Christ Wörterb. 289. 1802. 2. Truchsess-Heim Kirschensort. 502-505. 1819. 3. Dochnahl Führ. Obstkunde 3:59. 1858. 4. Ill. Handb. 8 I fig., 82 . I867.

Tree dwarfish, unproductive; fruit on a single stem but several come out of one bud and the buds are closely set; fruit large, flattened at both ends; apex slightly rounded; stem long, thin, straight; color brownish-black; flesh tender, dark red, with abundant, colored juice; quality good; ripens the middle of June. 
Striker. P. avium. I. U. S. D. A. Pom. Rpt. 4 I. 1895.

Striker is a seedling of Napoleon grown by C. E. Hoskins, Springbrook, Oregon. Fruit large, cordate; cavity wide, deep, flaring, pink; stem of medium length, slender; suture shallow; skin thick, tender, glossy, yellow, washed and mottled with red; dots minute, russet, elongated; flesh yellowish, translucent, fibrous, firm, juicy, mild, sprightly; very good; pit of medium size, oval, semi-clinging; season the last of June to early July.

Striped-Leaved. P. cerasus. I. Prince Pom. Man. 2:151. 1832.

Cerasus hortensis foliis eleganter variegatis. 2. Miller Gard. Dict. I: 1754 .

Cultivated as an ornamental.

Stuart. P. avium.

Stuart originated from nursery-sown pits and was propagated by C. W. Stuart of Newark, New York, who sent trees to this Station for testing in 1900 . Tree of medium size, vigorous, productive; fruit large, cordate or inclined to conic, compressed; suture indistinct; stem long, slender; cavity deep, wide, obtuse; skin thin, tender: color light red over a yellowish background changing to dark, glossy red; flesh whitish, juicy, tender, meaty, crisp, mild, sweet; quality good; ripens in mid-season.

Sucrée Léon Leclerc. P. avium. I. Thomas Guide Prat. 19, 206. 1876

Guigne sucrée de Léon Leclerc. 2. Mortillet Le Cerisier 2:98. 1866. 3. Leroy Dict. Pom. 5:339, 340 fig. I 877 .

Léon Leclercs Herzkirsche. 4. Proskauer Obstsort. 56. 1907.

This variety originated with Léon Leclerc of Laval, Mayenne, France, about 1853. Tree small, productive; fruit of medium size, borne in twos or threes, cordate-ovoid; stem long, slender, inserted in a cavity of medium size; skin deep rose-carmine; flesh whitish, semi-tender, very sugary, aromatic; pit medium in size, elongated-oval; ripens about the end of June.

Summit. $P$. avium.

Summit is a seedling sent this Sitation by Isaiah Lower, Barberton, Ohio. According to $\mathrm{Mr}$. Lower, the tree is vigorous and bears large, dark red cherries, very rich in juice and of a pleasing taste.

Siisse Amarelle. P. cerasus. 1. Kraft Pom. Aust. 1:8, Tab. 20 fig. 1. 1792. 2. Truchsess-Heim Kirschensort. 618, 619. 1819. 3. Ill. Handb. 89 fig., 90. 1867. 4. Oberdieck Obst-Sort. 356, 357. I88 I.

Späte Amarelle incor. 5. Christ Wörterb. 294. 1802.

This variety is probably of French origin. Tree medium in height, bushy, productive; fruit large, flattened on both ends and on one side giving it a four-angled appearance; stem short, stout; cavity flat, shallow; apex slightly depressed; suture short, slightly prominent; skin dark red, thin, tough, separating readily from the pulp; flesh tender, juicy, white, sweet; stone large, thick, round, free; season the middle of June.

Süsse Frühherzkirsche. $P$. avium. I. Truchsess-Heim Kirschensort. I 54, ${ }_{555}, 672$. I8I9.

Fruit rather small, round, compressed and marked by a suture; stem long, slender; color dark brown, becoming black; flesh tender, sweet, piquant; stone large, adherent; season the end of June. 
Süsse Frühweichsel. P. cerasus. 1. Christ Wörterb. 288. 1802. 2. Truchsess-Heim Kirschensort. 536-538. I8I9. 3. Mathieu Nom. Pom. 379. I889.

Cerise Hâtive. 4. Mas Le Verger 8:23, 24, fig. 10. 1866-73.

This cherry should not be confused with the dark-fleshed variety, Griotte Douce Précoce. Branches long, flexible; fruit usually borne in twos or threes, of medium size, roundish, flattened; suture rather distinct; stem short, set in a large cavity; skin tender, clear red becoming darker; flesh whitish, mild; stone small, roundish; ripens early in June. Suisse Maiherzkirsche. P. avium. 1. Christ Handb. 662. 1797. 2. Truchsess-Heim

Kirschensort. III-1I5. I8I9. 3. Dochnahl Führ. Obstkunde 3:19. I858.

Fruit round, medium in size; suture indistinct; skin black; flesh dark red, piquant; stone small, plump, roundish, adherent along the suture; season the middle of June to July.

Süsse Spanische. $P$. avium. I. Truchsess-Heim Kirschensort. 233-235. 1819. 2. Thomas Guide Prat. 18, 206 . 1876.

Douce d'Espagne. 3. Mas Pom. Gen. II:21, 22, fig. II. I882.

This cherry was sent out by Pastor Winter of Germany in 1796 as a seedling of White Spanish. Fruit above medium to large, cordate; sides compressed and marked by a suture; stem rather long, slender, set in a narrow cavity; skin dull yellow, spotted with red, often dull; flesh whitish-yellow with a reddish tinge near the skin, tender, sweet; stone small, broadly cordate, adherent; season late.

Siisskirsche mit Gefurster Bluthe. P. avium. I. Mas Pom. Gen. II:162. I882.

Listed without a description.

Sweedish. P. avium. I. Cultivator N. S. 7:270. 1850.

Sweedish is one of Professor J. P. Kirtland's varieties, possibly identical with White Heart. Its strikingly rugose or wrinkled surface distinguishes it from other cherries.

Sweet Montmorency. P. avium. 1. Mag. Hort. 8:284. 1842. 2. Downing Fr. Trees Am. 193 fig. 1845 .

Allen's Sweet Montmorency. 3. Bridgeman Gard. Ass't Pt. 3:183. I847.

The fruit of this variety resembles Montmorency in external appearance but it is of a sweet, delicate flavor and the growth and habit of the tree is that of a Heart. Probably it is a hybrid between a Heart and a Morello or Montmorency. It was raised by J. F. Allen, Salem, Massachusetts. Tree vigorous, somewhat spreading; fruit rather small, nearly round; suture shallow; stem short; cavity shallow; skin pale amber in the shade, deep orange in the sun, becoming darker, and mottled with yellow; flesh yellowish, tender, juicy, sweet, high quality; stone small, round, slightly adherent; season the last of July to August.

Sweet Morello. Species? I. Lond. Hort. Soc. Cat. 54. 1831 .

Mentioned in the reference given.

Tarascon Kirsche. P. avium. 1. Ill. Handb. 5 fig., 6. I867.

Guigne de Tarascon. 2. Mortillet Le Cerisier 2:59-61, fig. 4, 219. 1866. 3. Thomas Guide Prat. 18, 199. 1876. 4. Leroy Dict. Pom. 5:336, 337 fig. I877.

Tarascon Kirsche originated in Bouches-du-Rhône, France. Tree of medium height, moderately vigorous; fruit rather large, usually attached by fours, obtuse-cordate, surface 
irregular; suture indistinct; stem rather slender, medium in length; cavity often shallow; skin glossy, changing to nearly black; flesh colored, juicy, tender, sweet; ripens late in June.

Tardive d'Avignon. P. avium. I. Mortillet Le Cerisier 2:153, I54 fig. 39, I55. 1866.

2. Leroy Dict. Pom. 5:395, 396 fig. 1877 .

This variety is grown at Avignon, Vaucluse, France. Tree vigorous, large; fruit usually attached in pairs, of medium size, compressed at the base, mamelon at the apex; suture indistinct; stem very long, slender, set in a broad, shallow cavity; apex prominent; skin thin but firm, dark glossy red, never becoming black, easily detached from the pulp; flesh clear blood-red netted with white, tender, juicy, sweet, with pronounced acidity; first quality; pit small, roundish, moderately grooved; matures at the beginning of July. Tardive de Brederode. Species? I. Mas Pom. Gcn. II: I56. I882.

Leaves and flowers described.

Tardive Noire d'Espagne. Species? I. Mas Pom. Gen. II:162. I882.

Mentioned in the reference given.

Tardive de Peine. Species? I. Mas Pom. Gen. II:162. I882.

Listed without a description.

Tecumseh. P. avium. 1. Elliott Fr. Book 203. I854. 2. Mag. Hort. I9:167, I68. I853. 3. Mas Pom. Gen. I1:65, 66, fig. 33. I882.

Tecumseh was raised in 1842 by Professor J. P. Kirtland, Cleveland, Ohio, from a pit of Yellow Spanish, probably fertilized by Black Tartarian, Black Mazzard, or May Duke. Tree moderately vigorous, spreading, hardy, productive; fruit medium to large, obtusecordate, compressed, with a broad, shallow suturē; stem long, moderately thick; skin thin, tender, deep reddish-purple changing to purplish-black, glossy, sometimes mottled with red; flesh reddish-purple, rather tender, very juicy, sweet yet sprightly but not high flavored; quality good; stone medium in size, smooth, round, slightly elongated; ripens from the middle to the end of July.

Temple. P. avium $\times$ P. cerasus. I. Col. O. Hort. Soc. Rpt. 31. I892.

Temple is a large Duke, subacid in flavor, ripening about June roth. Tree an upright grower.

Terry. P. cerasus. I. Ia. Hort. Soc. Rpt. I68. I897. 2. Del. Sta. An. Rpt. I2:122. 1900. 3. Budd-Hansen Am. Hort. Man. 2:283. 1903.

Terry Early. 4. Stark Bros. Cat. 21. I910.

Terry was probably imported by H. A. Terry, Crescent, Iowa, from Russia. Tree moderately upright, hardy; fruit of medium size, roundish, flattened laterally; suture indistinct; stem medium long; cavity shallow; skin tough, slightly astringent, deep red; flesh meaty, subacid, colored; stone small, roundish; ripens the middle of June.

Thirty Day. Species? I. Col. O. Hort. Soc. Rpt. 9. I 890.

Thirty Day is said to ripen thirty days from the time of blossoming. It was grown by a Mr. Irwin of Fairfield County, Ohio; fruit large and of excellent quality.

Thompson. $P$. avium. I. Wickson Cal. Fruits 290. I889.

Thompson is a seedling of Black Tartarian, which it closely resembles, from Napa County, California. Tree hardier and the fruit firmer than Black Tartarian. 
Thränen Muskatellerkirsche. P. avium. I. Christ Handb. 683. 1797. 2. TruchsessHeim Kirschensort. 174-177. I819. 3. Dochnahl Führ. Obstkunde 3:35. 1858. Bigarreautier à rameaux pendants. 4. Ann. Pom. Belge $4: 8_{5}, 86, \mathrm{Pl}$. 1856. 5. Leroy Dict. Pom. 5:233 fig., 234. 1877 .

Muscat des Larmes. 6. Mortillet Le Cerisier 2:301. 1866.

This old variety is said to have been introduced into Germany and France from the Island of Minorca in the Mediterranean. The branches very soon take on a drooping habit whence its name; leaves long and narrow, peach-like; fruit large, often borne in pairs, flattened at the stem as well as at the sides, marked by a suture; skin dark brownishred; flesh dark red, firm, juicy; excellent; stone plump, oval; ripens the middle of July. Tilgner Rothe Herzkirsche. P. avium. 1. Truchsess-Heim Kirschensort. 254, 255. 1819. 2. Dochnahl Führ. Obstkunde 3:27. I 858 . 3. Ill. Handb. 103 fig., 104. I860.

Guigne de Tilgener. 4. Mortillet Le Cerisier 2:302. 1866.

Bigarreau ronge de Tilgener? 5. Mas Pom. Gen. II: I59. I882.

This variety is a seedling from Guben, Prussia, Germany. Tree large, productive; fruit above medium in size, cordate; suture shallow; stem medium to above in length, rather deeply inserted; color yellowish, spotted and streaked with red often becoming wholly red; flesh pale white, juicy, tender, sweet, aromatic; quality very good; stone oval, acutely pointed, plump, grooved; ripens at the end of June.

Tilgner Schwarze Knorpelkirsche. P. avium. I. Ill. Handb. 33 fig., $34 . \quad 1867$. 2. Mathieu Nom. Pom. 380 . I889.

Bigarreau noir de Tilgner. 3. Leroy Dict. Pom. 5:230 fig. 1877 .

Another seedling from Guben, Prussia, Germany, originating about IS 52 . Tree vigorous, healthy, productive; fruit usually borne in threes, very large, obtuse-cordate, often pointed, compressed; suture indistinct; stem short, stout, set in a deep, rather wide cavity; skin moderately tender, glossy, black when ripe; flesh rather tender, dark red, aromatic, pleasing; stone of medium size, oval; season late.

Tobacco-Leaved. P. avium. I. Prince Pom. Man. 2:122, I23. I 832 .

Ounce. 2. Parkinson Par. Ter. 57 I. 1629.

Cerise à Feuilles bigarrées. 3. Knoop Fructologie 2:35. $177 \mathrm{I}$.

Four to the Pound. 4. Truchsess-Heim Kirschensort. 267-277. I8I9. 5. Lond. Hort. Soc. Cat. 49. I $8_{3}$ I.

Ächte (sein sollende) Kirsche Vier auf ein Pfund. 6. Truchsess-Heim Kirschensort. $283,284,679$. I8I9.

Bigarreautier à grandes fenilles. 7. Poiteau Pom. Franc. 2: No. 10, P1. I846.

Gross blättrige Molkenkirsche. 8. Dochnahl Führ. Obstkunde 3:3 1. I\$ 58 .

Bigarreau à Feuilles de Tabac. 9. Leroy Dict. Pom. 5:201 fig., 202, 203, 204. I877.

The foliage is an object of curiosity in this variety, the leaves often measuring a foot in length and from five to eight inches in width. The fruits are rather below medium in size. The young shoots present a much undulated appearance. The variety is evidently of English origin, being mentioned in 1629, by Parkinson. Fruit below medium in size, heart-shaped; stem long, slender; skin tender, glossy, yellow overspread 
with red; flesh firm, transparent, juicy, rich, sweet; stone of medium size, ovate; ripens early in August.

Toctonne Précoce. Species? I. Mas Pom. Gen. II: I56. I882.

The fruit is not described.

Tokeya. P. pumila $\times$ P. simonii. I. S. Dak. Sta. Bul. 108:Pl. 4. I908. 2. Ibid. I30:I88 Pl. I3, I89. I9I.

Tokeya is a cross between the Sand Cherry and the Simon plum and was introduced as South Dakota No. 7 by the South Dakota Station. The early fruiting and the dwarfing habit of the Sand Cherries are very evident; fruit one and three-eighths inches in diameter, flat, dark red; flesh green, sprightly subacid, intermediate between that of the two parents; of good quality; pit very small.

Tomato. $\quad P$. avium $\times P$. cerasus. I. Hogg Fruit Man. 92. 1866.

Pomme-d'Amour. 2. Thomas Guide Prat. 21, 203. 1876.

Love Apple. 3. Downing Fr. Trees Am. 3rd App. I63. I88 I.

Tomato is a Duke cherry of Spanish origin. Fruit large, roundish-oblate, often depressed or tomato-shaped; suture shallow; apex a dot; stem long, slender, set in a large, broad, moderately deep cavity; skin yellowish, shaded with red; flesh yellowish, tender, juicy, sprightly subacid; quality very good; ripens early in July.

Toronto. Species? I. Ohio Hort. Soc. Rpt. 22. I892-93. 2. Agr. Gaz. N. S. WVales I9:998. 1908 .

Tree upright, fairly vigorous, productive; fruit borne in twos and threes, small, cordate, flattened on the sides, dark red; flesh and juice dark red, soft.

Toupie. P. avium. I. Mag. Hort. 20:270. 1854. 2. Mas Pom. Gen. II:17, I8, fig. 9. I 882 .

Kreiselkirsche. 3. Ill. Handb. 25 fig., 26. 1867.

Bigarreau Toupie. 4. Leroy Dict. Pom. 5:246, 247 fig. 1877 .

A peculiar top-shaped fruit raised by M. Denis Henrard of the University of Liege, Belgium. Tree vigorous, moderately productive; fruit large, elongated, pointed-cordate, sides slightly compressed; suture indistinct; stem moderately long, slender, often curved, inserted in a narrow, shallow cavity; skin pale red becoming darker; flesh half-tender, juicy, dark red where exposed, sweet, acidulated; pit large, oval, tapering toward the apex, plump; ripens at the last of June.

Townsend. P. cerasus.

Townsend is a strong, vigorous, productive cherry grown by W. P. Townsend, Lockport, New York. Fruit large, obtuse-cordate, with a high shoulder, compressed; suture distinct; stem long, rather slender, set in a broad, somewhat deep cavity; skin light amber, mottled and shaded with carmine; flesh almost tender, juicy, sprightly, refreshing; pit small; ripens late in June.

Transparent. P. cerasus. I. Hogg Fruit Man. 92. 1866.

Transparent was grown by M. De Jonghe of Brussels, Belgium, from seed of Montmorency. Fruit above medium in size, oblate, with a faint suture which is distinctly marked at the apex; skin pale red, thin, transparent, showing the fibrous flesh beneath; flesh tender, melting, sweet, delicious. 
Transparent Guigne. P. avium. 1. Forsyth Treat. Fr. Trees 43. 1803. 2. Prince Pom. Man. 2:I19. 1832. 3. Downing Fr. Trecs Am. I77. 1845.

Jahns Durchsichtige. 4. Ill. Handb. 143 fig., I44. I860.

Transparent de Jahn. 5. Mas Le Verger 8:65, 66, fig. 31. 1866-73.

This is a European cherry formerly grown to some extent in America. Tree moderately vigorous, erect at first; fruit small, borne in pairs, regular, oval-cordate; stem rather long, inserted in a narrow cavity; suture a wide, dark line; skin thin, glossy, pellucid, showing the stone, yellowish-white, blotched with fine red; flesh yellowish-white, with a reddish cast, tender, juicy, aromatic; stone medium in size, oval, free; ripens late in June.

Transparente de Meylan. P. cerasus. I. Thomas Guide Prat. $28 . \quad$ i876.

Fruit large, round, transparent; flesh delicate, fine, acid at first becoming sugary; ripens at the end of May.

Transparente de Rivers. P. avium. I. Thomas Guide Prat. 17, 207. 1876.

This is an English variety introduced into France about 1865 . Fruit large, spherical, depressed, with a spotted rose-carmine color; flesh firm, juicy, sugary, slightly acidulated; first quality; ripens early in July.

Transparente de Siebenfreund. Species? I. Thomas Guide Prat. 28. 1876. 2. Guide Prat. I I. I 895 .

A large, beautiful cherry ripening the last of June from M. Siebenfreund, a druggist at Tyrnau, northwestern Hungary.

Triomphe de Fausin. Species? I. Mas Pom. Gen. II:Í́z. I88z.

Listed in the reference given.

Troprichters Schwarze Knorpelkirsche. P. avium. 1. Truchsess-Heim Kirschensort. 206, 676,677 . I8I9.

Guigne Troprichtz. 2. Leroy Dict. Pom. 5:340, 34 I fig. 1877.

An old German variety. Fruit large, roundish-oval; skin clear red becoming more intense; flesh juicy, sweet, aromatic; of good quality; ripens early in June.

Truchsess Schwarze Herzkirsche. P. avium. I. Mathieu Nom. Pom. 380. I889.

Listed but not described.

Tubbs. P. cerasus. I. Ia. Sta. Bul. 73:86. I903.

Tubbs originated in Iowa City, Iowa. Fruit of medium size, oblate, slightly cordate; stem long, rather stout, inserted in a deep, narrow opening; suture very indistinct; apex convex; skin thick, dark red; flesh colored, crisp, meaty, slightly acid, juicy; quality very good; stone small, round; ripens late in June.

Türkine. P. avium. I. Christ Handb. 667. 1797. 2. Truchsess-Heim Kirschensort. 265-267. I8 г9. 3. Ill. Handb. Iо9 fig., гіо. I860.

Christ once labeled the Flamentiner, Türkine, which has given rise to some confusion. The true Türkine was sent out by Sello as Runde Weisse Späte Kirsche. Tree not very vigorous or productive; fruit of medium size, very broad, cordate; suture indistinct; stem long, slender; cavity variable; skin spotted with red and yellow; flesh softer than most Hearts, white, juicy; quality very good; stone plump, roundish; ripens late in July. 
Turkirsche Grosse. P. avium. I. Guide Prat. II. $\quad$ I 895.

A German variety which resembles Elton; fruit large, pointed; flesh white, sweet; first quality; ripens throughout July.

Turner Late. Species? I. Van Lindley Cat. 37. 1899.

A productive black cherry of medium size ripening the middle of June.

Twyford. Species? 1. Agr. Gaz. N. S. W'ales 19:997. 1908.

Tree vigorous, upright-spreading, productive; fruit borne singly and in pairs, above medium in size, roundish-cordate, flattened; stem slender, long; skin yellow, mottled with bright, light red; flesh rather firm, whitish, tinged red near the skin, with clear juice; good; ripens in New South Wales in November.

Uhlhorns Trauerkirsche. P. cerasus. 1. Thomas Guide Prat. $28 . \quad 1876$.

Thomas states that this is a weeping cherry from Germany; fruit large and very good.

Ungarische Weichsel. P. cerasus. r. Dochnahl Führ. Obstkunde 3:6r. I858.

Schwarze Ungarische Kirsche. 2. Christ Wörterb. 284. I802. 3. Truchsess-Heim Kirschensort. 588, 589. I8I9.

This cherry should not be confused with the Grosse Ungarische Kirsche which is a Heart while this is a Morello. Fruit large, round, compressed; suture indistinct; stem slender, long, shallowly inserted; color black; flesh firm, tender, subacid, with dark red juice; pit small, elongated-oval; ripens the middle of July.

Urinall. P. avium. I. Parkinson Par. Ter. 572. I629.

"The Urinall Cherrie in a most fruitfull yeare is a small bearer, having many yeares none, and the best but a few; yet doth blossome plentifully every yeare for the most part: the cherrie is long and round, like unto an Urinall, from whence it tooke his name; reddish when it is full ripe, and of an indifferent sweete rellish."

Utha. P. cerasus. I. Minn. Hort. Soc. Rpt. 57. I894.

Spoken of by Joseph Wood, Windom, Minnesota, as a hardy but almost worthless fruit; unproductive.

Van Gaasbeck. P. avium. 1. Am. Pom. Soc. Rpt. 67. I875.

A seedling cherry of extrordinary keeping quality exhibited by W. Van Gaasbeck, Hudson, New York. The fruit is of medium size with firm, sweet flesh.

Vanskike. Species? I. Trans. Cal. Agr. Soc. 472 . 1873.

A flesh-colored cherry listed as being cultivated successfully in California.

Vaughn. Species? I. Can. Exp. Farm. Bul. 2nd Ser. 3:62. I900.

Listed as medium in growth; fruit not described.

Velser. $P$. avium $\times P$. cerasus. 1. Krünitz Enc. 54, 55. I790. 2. Truchsess-Heim Kirschensort. 394-398. I\$I9.

Prague Tardif (Muscadét de). 3. Knoop Fructologie 2:36, 42. 1771 .

Wanfrieder Weichsel. 4. Christ Handb. 672. 1797.

Douce de Palatinat. 5. Mag. Hort. 20:270. 1854.

Pfälzer Süssweichsel. 6. Dochnahl Führ. Obstkunde 3:49. I 858.

Cerise du Palatinat. 7. Mas Le Verger 8: 153 , I 54, fig. 75. I866-73.

Tree of medium growth; branches long, straight; fruit above medium in size, obtusecordate, distinguishing it from other dark Dukes, compressed; suture distinct; stem long; 
color dark red; flesh colored, fibrous, juicy, sweet with a pleasing subacid flavor; stone small, broad, cordate, adhering to both stem and flesh.

Very Large Heart. P. avium. I. Lond. Hort. Soc. Cat. 53. 1831.

Mentioned in this reference.

Vesta. P. avium. ז. U.S. D. A. Rpt. 262. r892. 2. Am. Pom. Soc. Rpt. $150 . \quad$ r895.

Vesta is a seedling of Napoleon which originated with C. E. Hoskins, Newberg, Oregon; fruit of medium size, obtuse-cordate, very dark; flesh firm, sweet; quality good; ripens the middle of June.

Vilna Sweet. P. avium. 1. Ia. Hort. Soc. Rpt. 330. 1885. 2. Wash. Sta. Bul. 92:31. 1910.

Vilna Sweet was imported by Professor J. L. Budd from Vilna, Russia. This variety shows much promise in the West as a local sort but is too tender to ship. Tree of medium size, upright, very hardy, free from diseases; fruit large, roundish to oblong, compressed; stem long, slender; cavity rather deep, narrow, often lipped on the side showing a suture; color red, often entirely covering the yellow ground; flesh whitish, tinged with pink, tender but meaty, sprightly, subacid becoming sweet; pit free, large, ovate, plump, smooth; ripens the middle of July hanging to the tree until the last of August.

Violet. $P$. cerasus.

According to a letter from H. Back \& Sons, New Trenton, Indiana, Violet resembles English Morello but is more round and not as acid.

Virginia May Duke. P. avium. I. Elliott Fr. Book 220. 1854. 2. Hooper W. Fr. Book 269. 1857 .

A small, cordate, bright red, second rate Mazzard cherry.

Vistula. Species? I. Can. Exp. Farms Rpt. 149. 1896.

Mentioned as planted and as having been killed by the winter.

Voronezh No. 27. P. cerasus. 1. Can. Exp. Farms Rpt. 76. ISgo.

A promising, vigorous variety imported under this number from Voronezh, Russia; Fruit very large, bright red, round, somewhat flattened; flesh juicy, subacid; pit small. season very late.

Wabash. P. cerasus. I. U. S. D. A. Pom. Rpt. 41. 1895.

Wabash was introduced by Samuel Kinsey, Kinsey, Ohio, the original tree having stood since $\mathrm{I} 848$ on the grounds of Mrs. Ellen Pawlings, Wabash, Indiana. Fruit borne singly, of the Morello type, roundish-oblate, above medium in size, surface smooth; cavity large, wide, deep, flaring; stem long, slender, curved; suture a shallow line; skin thin, tough, glossy, bright crimson turning to dark red; dots very small, indented; flesh yellowish, veined, translucent, tender, melting, subacid, rich; quality very good; season a week later than Early Richmond.

Wachampa. P. pumila $\times$ P. triflora. I. S. Dak. Sta. Bul. 130:181. 1911.

Wachampa is a cross between the Sand Cherry and the Occident plum. Fruit an inch to an inch and one quarter in diameter; skin bitter, dark purple; flesh and juice dark purple.

Wagner. P. avium. I. Wash. Sta. Bul. 92:31. 1910.

Tree upright, round-topped, with long branches; fruit medium to large, roundish- 
oblate; stem short, stout; skin thin, tender, dark red; flesh yellow, meaty, melting, sweet, with a slight acidity; quality good; ripens the middle of July.

Warner. P. avium. I. Rural N. Y. I0:247. I 859 .

Warner is a supposed seedling of American Amber grown by Mathew G. Warner, Rochester, New York; fruit amber to very dark red where exposed; stem long, slender; flesh firm, juicy, sweet; ripens late in July.

Warren Transparent. Species? I. Cole Am. Fr. Book 237. 1849.

Originated with a Mr. Warren, Brighton, Massachusetts. Fruit roundish-cordate; skin pale yellow and red; flesh very tender, transparent; ripens early in July.

Washington Purple. Species? I. Mas Pom. Gen. II: I62. 1882.

Listed without a description.

Waterhouse. P. avitum. I. U. S. D. A. Pom. Rpt. 25. I894.

This variety was originated by $\mathrm{Dr}$. Warren Waterhouse, 1873 , of Monmouth, Oregon. Fruit of the Bigarreau class, large, compressed, heart-shaped; cavity large, round; stem long, slender; suture a line; skin firm, smooth, glistening, yellowish-white with a bright red cheek, often nearly solid red; dots numerous, very small; flesh whitish, tinged yellow, firm, juicy, vinous, sprightly; quality very good.

Weeping. P. cerasus. I. Prince Pom. Man. 2:153. 1832.

IVeeping or Pendulous Morello. 2. Fish Hardy-Fr. Bk. 2: 106. I882.

Under the name Weeping are included many varieties with a drooping or pendulant habit and mostly of ornamental value only. This variety, listed by Prince, although much like Toussaint, has branches more pendant than those of other weeping cherries. The Weeping or Pendulous Morello of Fish is included here. The head in this variety seldom exceeds four or five feet in diameter, and the slender branches droop on all sides until they trail on the ground; the fruit is of medium size and when fully ripe is of a pleasant acid flavor.

Weeping Black Bigarreau. P. avium. I. Flor. \& Pom. I6. I 879.

Trauerknorpelkirsche. 2. Dochnahl Führ. Obstkunde 3:40. 1858.

Bigarreau pleureur. 3. Thomas Guide Prat. 23. $\quad 1876$.

One of the earliest black Bigarreaus. It differs from other sorts of its class in the weeping habit of the tree; very ornamental.

Weeping Napoleon. P. avium. I. Am. Pom. Soc. Rpt. 53. I87 I.

A seedling of Napoleon introduced by a Mr. Dougall, Windsor, Ontario. If budded high the branches are pendulous, which, with the large, dark fruit, makes a handsome ornamental.

Weis, Roth und Rosenfarbig Marmorirte Kramelkirsche. Species? I. Kraft Pom. Aust. I:3, Tab. 6 fig. 2. 1792 .

Flesh white, breaking, firm, with colorless juice, pleasing; ripens the middle of July. Weisse Rosenroth Marmorirte Herzkirsche. P. avium. I. Christ Wörterb. $28 \mathrm{SO}$. ISO2.

Weiss und hellroth gefleckte grosse Kramelkirsche. 2. Kraft Pom. Aust. I:3, Tab. 6 fig. I. I 792 .

Flesh white, less firm than others of this class; juice colorless; stone yellowish; ripens the middle of July. 
Weisse Mandelkirsche. Species? I. Proskauer Obstsort. 58. 1907.

Listed, not described.

Wellington. P. cerasus. 1. Lond. Hort. Soc. Cat. 56. 1831. 2. Elliott Fr. Book 220. I 854 .

W'ellington's IVeichsel. 3. Dochnahl Führ. Obstkunde 3:60. I858.

Griotte de Wellington. 4. Mortillet Le Cerisier 2:307. I866.

Mentioned by Elliott in 5854 as unworthy of further culture. Bigarreau Wellington, often used as a synonym of Napoleon, should not be mistaken for this Morello of supposedly English origin. Fruit of medium size, cordate; stem long; skin thin, glossy, black; flesh firm, dark red, moderately juicy, pleasant subacid; stone elongated, cordate, free; ripens the middle of July.

Wendell Mottled. P. avium. I. Mag. Hort. 13:494 fig. I847. 2. Elliott Fr. Book 213. r854. 3. Hoffy N. Am. Pom. P1. I860.

Wendell Mottled was raised from a seed of Yellow Spanish planted in r840, by Dr. Herman Wendell, Albany, New York. Tree upright, thrifty, bears early and abundantly; fruit large, obtuse-cordate, with a distinet suture; stem long, rather stout, set in a moderately deep cavity; skin dark purplish-red, mottled and streaked, nearly black; flesh deep crimson, firm, crisp, juicy; stone small; ripens the middle of July.

Wenzlecks Bunte Knorpelkirsche. P. avium. I. Mas Pom. Gen. II:162. I882.

Mentioned in the reference given.

Werder Early Black. P. avium. I. Downing Fr. Trees Am. I69. 1845. 2. Ill. Handb. 53 fig., 54. I860. 3. Hogg Fruit Man. 93. I866.

Werdersche Schwarze Allerfrüheste Herzkirsche. 4. Christ Handb. 683. 1797.

5. Truchsess-Heim Kirschensort. 109-1 i . I819.

Guigne Hâtive de IVerder. 6. Mortillet Le Cerisier 2:82, 300. 1866. 7. Mas Le Verger 8:27, 28, fig. 12. 1866-73.

Bigarreau Vierder. 8. Leroy Dict. Pom. 5:25 I fig. 1877.

This cherry was received by Truchsess in 1794 , from Christ; of unknown origin, Tree strong and upright in growth, very productive; fruit valuable for its earliness, rather large, flattened-cordate, with a deep suture on one side; stem of medium length and thickness, inserted in a rather small cavity; skin thin, rather deep purple changing to purplishblack; flesh deep purple, with abundant colored juice, firm, tender, sweet, yet moderately sprightly and aromatic; quality good; stone large, ovate, flattened at the base; ripens from the last of May to the first of June.

Werder'sche Bunte Herzkirsche. P. avium. I. Mathieu Nom. Pon. 382 . I889.

Listed without a description.

Wheeler. P. cerasus. I. Ia. Sta. Bul. 73:87. 1903.

A hardy seedling of English Morello originating with H. J. Wheeler, Carnforth, Iowa. White Bigarreau. P. avium. I. Mich. Sta. Bul. 205:28. I 903 .

This variety was received by the Michigan Station from the United States Department of Agriculture in IS95; it is between the Duke and the Morello in type. Tree low, slow in growth; fruit large, light red, slightly darker on one side; flesh tender, juicy, sprightly subacid. 
White French. Species? I. Pa. Fr. Gr. Soc. Rpt. I1. I88 I.

Spoken of as doing well in Pennsylvania.

White French Guigne. P. avium. 1. Barry Fr. Garden 323. I851. 2. Am. Pom. Soc. Cat. 74. 1862. 3. Garvin \& Son Cat. 18. 1892.

A distinct, rather large cherry listed in the fruit catalog of the American Pomological Society for I862. Tree vigorous, productive; fruit creamy-white; flesh tender, melting, juicy, sweet; ripens the middle of July.

White Gean. P. avium. 1. Lond. Hort. Soc. Cat. 50. 183 ז.

Listed, not described.

White Hungarian Gean. P. avium. 1. Lond. Hort. Soc. Cat. 50. $183 \mathrm{I}$.

A tender-fleshed, obtuse-cordate cherry, amber in color, ripening in July; second quality.

White Mazzard. P. avium. I. Manning Book of Fruits III. I838. 2. Mag. Hort.

8:285. I 842 . 3. Downing Fr. Trees Am. I 7 I. $\quad 1845$.

White Mazzard originated with Robert Manning at Salem, Massachusetts, from a seed of White Bigarreau. Downing considered it similar to Black Mazzard, except in color. Tree handsome, upright in growth, productive; fruit of medium size, cordate, of a cream color, with a bright red cheek; not of the finest flavor; ripens late.

White Spanish. P. avium. I. Parkinson Par. Ter. 572. I629. 2. Krünitz Enc. 6I, 62, 63. I790. 3. Truchsess-Heim Kirschensort. 317-320. I819. 4. Ill. Handb. I 27 fig., I28. I 860 .

This variety and Yellow Spanish are much alike in appearance yet the best European authorities consider them distinct. Tree healthy, not large, productive; fruit large, roundish-cordate, somewhat compressed; stem long; cavity depressed on the ventral side; color waxy yellow, streaked and dotted with red; flesh yellowish, firm, juicy, sweet, pleasant; ripens late.

White Tartarian. P. avium. I. Prince Pom. Man. 2:II4. 1832. 2. Downing Fr. Trees Am. 178. 1845. 3. Hogg Fruit Man. 315. I884.

Fraser's White Tartarian. 4. Forsyth Treat. Fr. Trees 43. 1803.

A variety with this name was grown for many years in America which was finally proved by William Prince to be a sub-variety of the White Heart. Tree vigorous, erect, usually productive; fruit rather small, roundish, inclined to obtuse-cordate; stem long, slender; skin transparent, pale yellow, approaching amber on the exposed cheek; flesh whitish-yellow, nearly tender, juicy, pleasant, brisk subacid becoming sweet; very good in quality; stone large, oval; season early.

White Transparent. Species? I. Lond. Hort. Soc. Cat. $5^{6 .}{ }_{1} 831$.

Mentioned in the reference given.

\section{Wier's Seedlings.}

D. B. Wier, Lacon, Illinois, disseminated several seedlings which he selected from a large number originated by him.

Wier No. 2. P. cerasus. 1. Rural N. Y. 49:453. I89o. 2. Am. Pom. Soc. Sp. Rpt. 37. 1904-05.

This cherry is said to be a seedling of Early Richmond but of the Morello type. Tree 
medium to large, upright-spreading, fruiting regularly; fruit of medium size, oblate-conic; cavity shallow, broad: stem short; suture slight; color dark red; flesh firm, meaty, dark red, mildly subacid; quality fair; stone oval; precedes Early Richmond.

Wier No. II. P. cerasus. I. Am. Pom. Soc. Sp. Rpt. 37. 1904-05.

Tree upright, productive, hardy; fruit cordate, black; juice dark, sweeter than many of the sour sorts; ripens earlier than Northwest and Early Richmond.

Wier No. I2. P. cerasus. I. Ia. Sta. Bul. 73:88. 1903.

Sometimes listed as Wier, being one of the best of Mr. Wier's seedlings but only moderately productive. Tree of medium size, slightly spreading; fruit of medium size, elongated-cordate; cavity rather deep and broad; stem stout, rather long; suture obscure; skin thick, tender, dark red; flesh firm, crisp, with slightly colored juice, sprightly subacid; quality fair; stone large, oval; season from July 12 th to 20 th; the latest of the Wier seedlings.

Wier No. 13. P. cerasus. 1. Kan. Sta. Bul. 73:190. 1897.

Tree upright, with scant foliage; fruit of medium size; skin dark red, tough; flesh slightly colored, mild; precedes Early Richmond; of no value.

Wier No. 19. P. cerasus. I. Kan. Sta. Bul. 73:190. 1897.

Fruit of medium size, oval, dark red; worthless.

Wier No. 24. P. cerasus. I. Ia. Sta. Bul. 73:88, 1903.

Tree medium in growth, upright-spreading; fruit conical, cordate, of medium size; cavity shallow; stem of medium length; suture indistinct; skin smooth, dark red; flesh firm, light yellow, juicy, sprightly subacid; quality fair; stone almost spherical, smooth; ripens the middle of June; not worthy of further trial.

Wier No. 44. P. cerasus. I. Ia. Sta. Bul. 73:88. 1903. 2. Am. Pom. Soc. Sp. Rpt. 38. $1904-05$.

Tree medium in growth, upright-spreading; fruit small to medium, oblate; cavity shallow; stem short; skin thin, tender, light red; flesh tender, juicy, acid; good; season late June; less productive than No. 2.

Wild Ross-shire. P. cerasus. I. Lond. Hort. Soc. Cat. 57. 1831 .

A small, wild, round, red fruit with juicy flesh, ripening in July; allied to the Kentish.

Wilde Bunte Marmorkirsche. P. cerasus. I. Dochnahl Führ. Obstkunde 3:38. 1858.

Distinguished from the Wild Red Bird cherry by its firmer flesh and later ripening. It grows wild and is sometimes cultivated along the highways; ripens the middle of August.

Wilhelmine Kleindienst. P. avium. I. Thomas Guide Prat. 20. I 876.

Of German origin; vigorous and productive; fruit large, brilliant reddish-brown; flesh firm, agreeably sweet; ripens the middle of July.

Wilkinson. P. avium. 1. Mag. Hort. 8:284. 1842. 2. Barry Fr. Garden 323. 1851 .

3. Downing Fr. Trees Am. 476. 1869 .

Wilkinson is thought by Hovey to be a native of Rhode Island. Tree vigorous, productive; fruit of medium size, resembling Black Heart but is more sprightly; ripens the middle of July. 
Willamette. P. avium. I. Am. Pom. Soc. Rpt. 127. 1875. 2. Wickson Cal. Fruits 290. 1889. 3. Can. Exp. Farm Bul. and Ser. 3:62. 1900. 4. Am. Pom. Soc. Rpt. 192. 1907 .

Willamette originated with Seth Lewelling, Milwaukee, Oregon, from a seed of Napoleon. Tree strong in growth; fruit large, light red; flesh whitish, firm, juicy, sweet, with a pleasant flavor; ripens in the Northwest in late June.

Willis Early. P. avium. I. Can. Exp. Farms Rpt. 465. 1900. 2. Can. Exp. Farm Bul. and Ser. $3: 62$. 1900 .

Tree vigorous in growth; fruit of medium size, obtuse-cordate; skin yellow, mottled with red; flesh yellowish-white, juicy, tender, sweet; ripens early in May.

Willow-Leaved. P. avium $\times$ P. cerasus. I. Prince Pom. Man. 2:141. 1832.

May Duke, Willow-leaved. 2. Lond. Hort. Soc. Cat. 53. 1831.

Griotticr à fcuilles de Pêcher. 3. Kenrick Am. Orch. 280. 1832.

ITeidenblätrige Süssweichsel. 4. Dochnahl Führ. Obstkunde 3:47. 1858.

Cerisier de Hollande à feuilles de saule ou de balsamine. 5. Noisette Man. Comp. Jard. 2: 505. 1860.

Griottier à fesilles de Saule. 6. Leroy Dict. Pom. 5:287 fig., 288. 1877.

Cerisier à Feuilles de Saule. 7. Mas Pom. Gen. Ir:160. I882.

The Willow-Leaved cherry seems to have originated in Holland and has been known since the middle of the Eighteenth Century. It differs from May Duke in the size and the shape of the foliage. It is not only cultivated for its singular foliage but also for its fine fruit. If the tree grows rapidly the leaves are said to assume normal shape.

Winkler Black. P. avium. I. Can. Exp. Farm Bul. and Ser. 3:62. I900.

Wincklers schwarze Knorpelkirsche. 2. Truchsess-Heim Kirschensort. 206, 676. I8I9.

Winkler's schwarze Herzkirsche. 3. Dochnahl Führ. Obstkunde 3:35. 1858.

Bigarreau noir Winkler. 4. Leroy Dict. Pom. 5:23I fig. 1877.

This is a seedling from Guben, Prussia, Germany. Fruit borne in pairs of medium size, broad, obtuse-cordate, compressed; suture indistinct; skin dark red; flesh pale red, firm, aromatic, subacid, pleasing; pit rather large, oval; ripens early in July; not very productive.

Winter Schwarze. Species? 1. Lond. Hort. Soc. Cat. 57. 1831 .

Listed without a description.

Wohltragende Holländische Kirsche. P. cerasus. 1. Truchsess-Heim Kirschensort. 59 1593. 1819. 2. Mathieu Nom. Pom. 382. 1889.

Grosse wohltragende holländische Morellè. 3. Christ Wörterb. 288. 1802.

Fruit large, sides unequally compressed; suture indistinct; stem medium in length, set in a large cavity; skin tough, dark brown when ripe; flesh fibrous, clear red, darker near the stone, with colored juice, pleasingly sour; stone long, colored; ripens late in July. Yan. P. avium. I. Rural N. Y. 6r:577 fig. 235. 1902. 2. Wash. Sta. Bul. 92:32. I910.

Yan is a seedling grown by Seth Lewelling of Milwaukee, Oregon; named for a faithful Chinese workman. Fruit large, roundish-cordate, with a distinct suture on one side; 
stem long, stout; skin tough, dark purplish-red; flesh streaked and flecked with light red, firm, juicy, mild subacid; very late; productive.

Yellow Glass. P. avium. I. Ia. Sta. Bul. I9:551. 1892. 2. Ibid. 73:89. 1903. 3. W'ash. Sta. Bul. 92:32. г 9 го.

Yellow Glass was introduced from North Silesia by Professor J. L. Budd, Ames, Iowa. Tree large, upright, with abundant foliage; fruit medium to above in size, roundish-cordate; cavity deep; stem long; suture a line; skin thin, tough, light lemon in color; flesh firm, yellow, meaty, sweet, with colorless juice; quality good; stone large, round, clinging.

Young Large Black Heart. P. avium. I. Pioneer Nur. Cat. I6. I905-06.

Merely listed in the reference given.

Yuksa. P. pumila $\times$ P. armeniaca. I. S. Dak. Sta. Bul. 108: I908.

Yuksa is noted in the reference as a cross between the Sand Cherry and the New Large Apricot.

Zimmtkirsche. P. cerasus. I. Dochnahl Fïhr. Obstkunde $3: 64 . \quad$ I 858 .

Fruit medium in size, round, flattened at the stem, without a suture; cavity deep; stem long; skin thin, dark red almost black; flesh aromatic, subacid; stone oval-pointed.

Zweifarbige Kirsche. Species? I. Mathieu Nom Pom. 382. I889.

Bicolor. 2. Mas Pom. Gen. II: I59. I882.

Listed without a description.

Zwitterkirsche. Species? I. Mas Pom.Gen. II:I62. I882.

Mentioned in this reference.

Zzuckser Schwarze Knorpelkirsche. P. avium. I. Dochnahl Führ. Obstkunde 3:35. I 858 .

Fruit large, elongated, sides strongly compressed; suture shallow; apex depressed; skin reddish-black; flesh very dark red, pleasing, slightly sweet; ripens in late July. 


\section{BIBLIOGRAPHY AND REFERENCES, WITH ABBREVLATIONS USED}

The list of books which follows contains all American pomological works in which the cherry is discussed at any length. Only such European books are listed, however, as were found useful in writing The Cherries of Yew York. Only periodicals are listed to which references are made in the text of the book. The reports and bulletins of experiment stations and horticultural societies are not included since the abbreviations used for such publications will be recognized by all.

Am. Gard............. American Gardening. An Illustrated Journal of Horticulture and Gardener's Chronicle. New York: 1892-1904. Copyright, 1903. (Before its union with Popular Gardening in 1892 , the publication was known as The American Garden. Both Popular Gardening and The American Garden resulted from the union or absorption of several other horticultural periodicals.)

Am. Gard. Mag......... The American Gardener's Magazine, and Register of Useful

Discoveries and Improvements in Horticulture and Rural Affairs. See Mag. Hort.

Am. Hort. An. ........ American Horticultural Annual. A Year-book of Horticultural Progress for the Professional and Amateur Gardener, Fruit-grower, and Florist. (Illustrated.) New York: 1867. Copyright, 1867. New edition. New York: 1870. Copyright, 1869 .

Am. Jour. Hort........ The American Journal of Horticulture and Florist's Companion. (Illustrated.) Volumes $1-5$. Boston: $1867-1896$. Copyrights, $1867-1869$. Continued as Tilton's Journal of Horticulture and Floral Magazine. (Illustrated.) Volumes 6-9. Boston: 1869-71. Copyrights, 1869-1 $8 ;$ I.

Am. Pom. Soc. Rpt..... . Proceedings of the American Pomological Society. Issued usually biennially from 1850 to date. First published as the Proceedings of the National Convention of Fruit Growers in 1848 .

Ann. Hort............ Annals of Horticulture and yearbook of information on practical gardening. 5 Volumes. London: $1846-1850$.

Ann. Pom. Belge......... Annales de Pomologie Belge et Étrangère; publiées par la Commission royale de Pomologie Instituée par S. M. le Roi des Belges. (Illustré.) 8 Tomes. Bruxelles: 18531860. 
Bailey, Ann. Hort.

Annals of Horticulture in North America for the Years I889-I893. A Witness of Passing Events and a Record of Progress. By L. H. Bailey. New York: 1890-1894. Copyrights, r889, r 89 r-I894.

Bailey, Cyc. Hort........ Cyclopedia of American Horticulture Comprising Suggestions for Cultivation of Horticultural Plants, Descriptions of the Species of Fruits, Vegetables, Flowers and Ornamental Plants Sold in the United States and Canada, Together with Geographical and Biographical Sketches. By L. H. Bailey, assisted by Wilhelm Miller. (Illustrated.) In Four Volumes. New York: 1900-1902. Copyrights, 19001902 .

Bailey, Ev. Nat. Fruits.... Sketch of the Evolution of our Native Fruits. By L. H. Bailey. (Illustrated.) New York: i 898 . Copyright, I 898 .

Bailey, Sur. Unlike...... The Survival of the Unlike. A Collection of Evolution Essays Suggested by the Study of Domestic Plants. By L. H. Bailey. (Illustrated.) Fifth Edition. New York: 1906. Copyright, is96.

Baltet, Cuit. Fr......... Traité de la Culture Fruitière Commerciale et Bourgeoise. Par Charles Baltet. (Illustré.) Quatrième Édition. Paris: 1908.

Bary, Fr. Garden........ The Fruit Garden. By P. Barry. (Illustrated.) New York: 1852. Copyright, I851. Revised Edition, I896. Copyright, $188_{3}$.

Bradley, Gard.......... New Improvements of Planting and Gardening, both Philosophical and Practical. In three parts. By Richard Bradley. (Illıstrated.) Seventh Edition with Appendix. London: 1739 .

Bridgeman, Gard. Ass't... The Young Gardener's Assistant, in three parts. By Thomas

Bridgeman. New Edition, with an Appendix. New York: 1857 . Copyright, 1847 .

Brookshaw, Hort. Reposit.. The Horticultural Repository, containing Delineations of the best Varieties of the Different Species of English Fruits. By George Brookshaw. (Illustrated.) In Two Volumes. London: 1823 .

Budd-Hansen, Am. Hort.

Man............... American Horticultural Manual. By J. L. Budd, assisted by N.E. Hansen. (Illustrated.) In Two Volumes, Volume 2, New York and London: 1903. Copyright, 1903.

Bunyard-Thomas, Fr. Gard. The Fruit Garden. By George Bunyard and Owen Thomas. (Illustrated.) London and New York: 1904. 
Can. Hort............ The Canadjan Horticulturist. (Illustrated.) Toronto and Peterboro: 1878 to date.

Cat. Cong. Pom. France... Société Pomologique de France Catalogue Descriptif des Fruits Adoptés par le Congrès Pomologique. Lyon: 1887. Ibid. : 1906.

Christ, Handb.......... Handbuch über dic Obstbaumzucht und Obstlehre. Von J. L. Christ. Zweite vermehrte. Frankfurt: 1797.

Christ, Obstbäume....... Von Pflanzung und Wartung der nüzlichsten Obstbäume. Von J. L. Christ. Zweiter Theil. Frankfurt: 1791.

Christ, Wörterb.......... Pomologisches theoretisch-praktisches Handwörterbuch, oder Alphabetisches Verzeichniss. Von J. L. Christ. Leipzig: I 802 .

Cole, Am. Fr. Book...... The American Fruit Book; containing directions for Raising, Propagating, and Managing Fruit Trees, Shrubs, and Plants; with a description of the Best Varieties of Fruit, including New and Valuable Kinds. By S. W. Cole. (Illustrated.) Boston: 1849. Copyright, I849.

Country Gent......... The Country Gentleman. Albany: $1853-1865$. The Cultivator \& Country Gentleman. Albany: 1866-1897. The Country Gentleman. Albany and Philadelphia: 1898 to date.

Coxe, Cult. Fr. Trees..... A View of the Cultivation of Fruit Trees, and the Management of Orchards and Cider; with accurate descriptions of the most estimable varieties of Native and Foreign Apples, Pears, Peaches, Plums, and Cherries, cultivated in the middle states of America. By William Coxe. (Illustrated.) Philadelphia: i8 17 . Copyright, 1817.

Cultivator............ The Cultivator. Albany: $1834^{-1865}$. In 1866 united with The Country Gentleman.

Cult. \& Count. Gent..... The Cultivator \& Country Gentleman. See Country Gent. Decaisne \& Naudin, Man.

Amat. Jard........... Manuel de L'Amateur Des Jardins Traité Général D'Horticulture. Par Jh. Decaisne et $\mathrm{CH}$. Naudin. (Illustré.) Tome Quatrième. Paris.

De Candolle, Or. Cult.

Plants

Origin of Cultivated Plants. By Alphonse de Candolle. Geneva [Switzerland]: 1882 . New York: 1885 .

Dochnah1, Führ. Obstkunde Der sichere Führer in der Obstkunde auf botanisch-pomologischen Wege oder Systematische Breschreibung aller Obstsorten. Von F. J. Dochnahl. Vier Bände. Nürnberg: 1855-60. Volume 3, 1858 . Cherries. 
Downing, Fr. Trees Am... The Fruits and Fruit Trees of America: or the culture, propagation, and management, in the garden and orchard, of fruit trees generally; with Descriptions Of All The Finest Varieties of Fruit, Native and Foreign, Cultivated In This Country. By A. J. Downing. (Illustrated.) New York \& London: 1845. Copyright, I845. Second edition, same text, with colored plates, 1847 . First revision, by Charles Downing. New York: I857. Copyright, I857. Second revision, by Charles Downing. New York: I869. First appendix, 1872 . Second appendix, 1876 . Third appendix, I88I.

Duhamel, Trait. Arb. Fr... Traité Des Arbres Fruitiers; Contenant Leur Figure, Leur Description, Leur Culture, \&c. Par M. Duhamel Du Monceau. (Illustré.) Tomes I et 2. Paris: I768. Édition publié en 1872 , en trois tomes. Nouvelle Édition en six tomes, $1807-1835$.

Elliott, Fr. Book........ Elliott's Fruit Book; or, the American Fruit-Grower's Guide in Orchard and Garden. By F. R. Elliott. (Illustrated.) New York: 1858. Copyright, 1854. Revised edition. 1859.

Fish, Hardy-Fr. Bk. . . . . . The Hardy-Fruit Book. By D. T. Fish. (Illustrated.) Two Volumes. London: probably i 882 .

Flor. \& Pom.......... The Florist And Pomologist: A Pictorial Monthly Magazine of Flowers, Fruits, and General Horticulture. Conducted at first by Robert Hogg and John Spencer, later by Thomas Moore and William Paul. (Illustrated.) London: is62-1884.

Floy-Lindley, Guide Orch.

Gard.

A Guide to the Orchard And Fruit Garden or an account of the Most Valuable Fruits cultivated in Great Britain. By George Lindley; edited by John Lindley. American edition by Michael Floy. New York: 1833 . New edition; with an Appendix. New York: i8 46 . Copyright, I846.

Forsyth, Treat. Fr. Trees... A Treatise on the Culture and Management of Fruit Trees. By William Forsyth. London: I802. Same with an Introduction and Notes, by William Corbett. Albany: 1803 . Seventh edition [English] London: i 824.

Gard. Chron............ The Gardener's Chronicle. (Illustrated.) London: ${ }_{4}{ }_{4}$ to date.

Garden............. The Garden. (Illustrated.) London: 1872 to date.

Gard. Mon............ The Gardener's Monthly and Horticultural Advertiser. Edited by Thomas Meehan. (Illustrated.) Philadelphia: I $859^{-1} 887$.

Gaucher, Pom. Prak. Obst.. Pomologie des Praktischen Obstbaumzüchters. Von N. Gaucher. (Illustrirt.) Stuttgart: I894. 
Gen. Farmer. ......... The Genesee Farmer. Edited by Luther Tucker, Rochester: I $8_{3}$ I-I 839 . Then consolidated with the Cultivator. Another periodical of the same name was published in Rochester from I 845 to I 865 . Also New Genesee Farmer and Monthly Genesee Farmer.

Gerarde, Herball........ The Herball or Generall Historie of Plantes. By John Gerarde. Enlarged and amended by Thomas Johnson. London: 1636.

Guide Prat........... Guide Pratique de L'Amateur De Fruits. Description Et Culture des Variétiés De Fruits Classées Par Séries De Mérite composant les collections pomologiques De L'Établissement Horticole Simon-Louis Frères. A PlantièresLes-Metz (Lorraine Annexée) Suivi D'Une Table Générale Alphabétique de tous les Synonymes connus, Francais et Étrangers appartenent à chaque variété. Deuxième Édition. Paris et Nancy: I895.

Hoffy, N. Am. Pom....... Hoffy's North American Pomologist, containing numerous Finely Colored Drawings, accompanied by letter press descriptions, \&c., of Fruits of American Origin. Edited by William D. Brincklé. Book No. I. Philadelphia: I860. Copyright, is60.

Hoffy, Orch. Com....... The Orchardist's Companion. Alfred Hoffy, Editor and Publisher. A quarterly journal. Vol. I, I8 $4_{1-2}$; Vol. II, I842-3. Philadelphia.

Hogg, Fruit Man....... The Fruit Manual: A Guide to the Fruits and Fruit Trees of Great Britain. By Robert Hogg. First edition, London: I860. Second edition, I86r. Third edition, I866. Fourth edition, 1873 . Fifth edition, 1884.

Hooper, W. Fr. Book..... Hooper's Western Fruit Book: a compendious Collection of Facts from the Notes and Experience of Successful Fruit Culturists, arranged for practical use in The Orchard and Garden. By E. J. Hooper. Cincinnati: 1857. Copyright, 1857 .

Hort. Reg. (Am.) . . . . . Horticultural Register and Gardener's Magazine. Edited by T. G. Fessenden and J. E. Teschemacher. Volume I. Boston: 1835 .

Hort. Reg. (Eng.)....... The Horticultural Register and General Magazine. By Joseph Paxton and Joseph Harrison. Vol. I. London: I 833 .

Horticulturist......... The Horticulturist and Journal of Rural Art and Rural Taste. Founded and first edited by A. J. Downing. (Illustrated.) Volumes I to 30 . Albany, Philadelphia and New York: $1846-1875$. 
Hovey, Fr. Am........ The Fruits of America, containing Richly Colored Figures, and full Descriptions of all the choicest Varieties cultivated in the United States. By C. M. Hovey. Volume I. Boston and New York: i 852 . Volume II. Boston: 1856 . Copyright, i 85 I.

I1I. Handb............ Illustrirtes Handbuch der Obstkunde, unter Mitwirkung mehrerer herausgegeben von .. F. Jahn ... Ed. Lucas und .. J. G. C. Oberdieck. Siebente Leiferung. Dritten Bandes. Stuttgart: I860; Neunte Lieferung. Dritten Bandes. Stuttgart: I86r; Sechszehnte Lieferung. Sechsten Bandes. Ravensburg: 1867 .

Jour. Hort. . . . . . . . . The Journal of Horticulture began as: The Cottage Gardener; or Amateur's and Cottager's Guide to out-door gardening and spade cultivation. 25 Volumes. London: $1849-\mathbf{r} 86 \mathrm{r}$. Continued as The Journal of Horticulture, Cottage Gardener, and Country Gentleman. A Journal of Horticulture, Rural and Domestic Economy, Botany and Natural History. New Series. 38 Volumes. London: I86I-1880. Continued as The Journal of Horticulture, Cottage Gardener, and Home Farmer. A Chronicle of Country Pursuits and Country Life, including Poultry, Pigeon, and Bee-keeping. Third Series. 59 Volumes. London: r 880-rgog.

Jour. Roy. Hort. Soc..... The Journal of the Royal Horticultural Society. London: I $8+6$ to date. Vols. $I-9, I S_{4} 6-55$, bear the title of The Journal of the Horticultural Society of London.

Kenrick, Am. Orch....... The New American Orchardist. By William Kenrick. Boston: 1833. Copyright, 1832 . Second edition. Boston: 1835. Copyright, 1835 . Seventh edition, enlarged and improved, with a supplement. Boston: i 845 . Copyright, I $8+\mathrm{x}$.

Knoop, Fructologie....... Part I. Pomologie, ou Description des meilleures sortes de Pommes et de Poires. Part II. Fructologie, ou Description des Arbres Fruitiers. Par Jean Herman Knoop. (Illustré.) Amsterdam: 177 r.

Koch, Deut. Obst....... Die Deutschen Obstgehölze. Vorlesungen gehalten zu Berlin im Winterhalbjahr $x_{875^{-7}}$. Von Karl Koch. Stuttgart: I 876 .

Kraft, Pom. Aust........ Pomona austriaca, Abhandlung von den Obstbäumen. Von Johann Kraft. 2 Theile. Vienna: 1792.

Krrünitz, Enc........... Ausschnitt aus Krünitz' Encyklopädie. I79o. Cherries.

Lange, Allgem. Garten.... Allgemeines Gartenbuch. Von Theodore Lange. 2 Bände.

Zweite vermehrte. Leipsic: I897. 
Langley, Pomona. . . . . . . Pomona, or the Fruit Garden Illustrated. By Batty Langley.

London: 1729 .

Lauche, Deut. Pom. . . . . . Deutsche Pomologie. Von W. Lauche. (Illustrirt.) Berlin: I $S_{2}$.

Lauche, Ergänzungsband... Erster Ergänzungsband zu Lucas' und Oberdieck's Illustrirtes Handbuch der Obstkunde. Von Wr. Lauche. Berlin: 1883 .

Le Bon Jard........... Le Bon Jardinier. I $26^{e}$ Édition Almanach Horticole, i 882 et $\mathrm{I} 29^{\circ}$ Édition, I 884 . Paris.

Leroy, Dict. Pom........ Dictionnaire de Pomologie. Par André Leroy. (Illustré.) 6 Tomes. Paris: $1867-1879$. Tome 5, IS77. Cherries.

Liegel, Syst. Anleit....... Systematische Anleitung zur Kenntniss der vorzüglichsten Sorten des Kern-, Stein-, Schalen- und Beerenobster. Von Georg Liegel. Passau: i 825 .

Lond. Hort. Soc. Cat.... . A Catalogue of the Fruits Cultivated in the Garden of the Horticultural Society of London. London: i 826 . Second edition, 183 I. Third edition, $18+2$. A supplement was published in 1853 .

Loudon, Arb. Frut. Brit... . Arboretum et Fruticetum Britannicum. Par J. C. Loudon. Deuxième Édition. Tome 2. London: I $8_{44}$.

Loudon's, Enc. Gard.... A. An Encyclopedia Of Gardening. By J. C. Loudon. (Illustrated.) New edition. London: i $8_{34}$.

Lucas, Handb. Obst...... Vollständiges Handbuch der Obstkultur. Von Ed. Lucas. (Illustrirt.) Stuttgart: First edition, I 880 ; second edition, I886; third edition, IS93. Third edition edited by Fr. Lucas, I894.

Mag. Hort. . . . . . . The Magazine of Horticulture. Boston: IS $37^{-1} 868$. First published as The American Gardener's Magazine, I835-6. Edited by C. M. Hovey with P. B. Hovey, Jr., associate editor during $\mathrm{I}_{35}-6$.

Manning, Book of Fruits... Book of Fruits. By Robert Manning. (Illustrated.) Salem: $\mathrm{I} 8_{3} 8$. Copyright, $\mathrm{I} \delta_{3} 8$.

Mas, Le Verger. . . . . . . . . Le Verger ou Histoire, Culture Et Description avec planches coloriées Des Variétés De Fruits Les Plus Généralement Connues. Par M. Mas. 8 Tomes. Paris: i866-73. Tome S. Cherries.

Mas, Pom. Gen.......... Pomologie Générale. Par. M. Mas. (Illustré.) I2 Tomes. Paris: ${ }_{1872-83}$. Tome II, I882. Cherries.

Mathieu, Nom. Pom...... Nomenclator Pomologicus. Von Carl Mathieu. Berlin: ISS9.

Mawe-Abercrombie, Com.

Gard............. The Complete Gardener. By Thomas Mare and John Abercrombie. London: IS29. 
Mawe-Abercrombie, Univ.

Gard. Bot.......... The Universal Gardener and Botanist. By Thomas Mawe and John Abercrombie. London: 1778.

Miller, Gard. Dict........ The Gardener's Dictionary. By Philip Miller. 2 Volumes. London: 1754. Revised edition. By Thomas Martyn London: I 807 .

Miller, Gard. Kal........ The Gardener's Kalendar. By Philip Miller. London: i734. McIntosh, Bk. Gard...... The Book of the Garden. By Charles McIntosh. (Illustrated.) Two Volumes. London: 1855 .

McMahon, Am. Gard. Cal. The American Gardener's Calendar. By Bernard McMahon. Philadelphia: Iso6.

Mortillet, Le Cerisier...... Arboriculture Fruitière. Les Meilleurs Fruits. Par M. P. De Mortillet. (Illustré.) Tome II. Le Cerisier. Grenoble: I $\$ 66$.

Nat. Nur.......... The National Nurseryman. Published by The National Nurseryman Publishing Co. (Illustrated.) Rochester: 1893 to date.

Nicholson, Dict. Gard.... The Illustrated Dictionary of Gardening, a practical and scientific Encyclopedia of Horticulture for Gardeners and Botanists. By George Nicholson, assisted by J. W. H. Trail and J. Garrett. 4 Volumes. London. Supplement to same. By George Nicholson et al. London: I900.

Noisette, Man. Comp.

Jard.............. Manuel Complet du Jardinier. Par M. Louis Noisette. Tome Deuxième. Paris: is6o.

Oberdieck, Obst-Sort. ..... Deutschlands beste Obst-Sorten. Von F. G. C. Oberdieck. Leipzig: I88 I.

Obstzüchter........... Der Obstzüchter Zeitschrift für die Gesamtinteressen des Obstbanes. References in Volume VIII, Numbers I, 2, 3, 4 and ro. Vienna: igro.

Parkinson, Par. Ter...... Paradisi in Sole. Paradisus Terrestris. By John Parkinson. (Illustrated.) London: 1629.

Phillips, Com. Orch. . . . . The Companion for the Orchard. An Historical And Botanical Account of Fruits Known In Great Britain. By Henry Phillips. New Edition. London: i83 I.

Poiteau, Pom. Franc. .... Pomologie Francaise. Recueil des Plus Beaux Fruits Cultivés En France. Par Antoine Poiteau. Tomes I-4. Paris: I 846 .

Pom. France........... Pomologie De La France ou Histoire Et Description de tous Les Fruits Cultivés En France Et Admis Par Le Congrès Pomologique. (Illustré.) Tomes I-VIII. Lyon: IS63I873. Tome VII, i871. Cherries.

Pom. Inst. Reut....... Pomologisches Institut Reutlingen. Reutlingen: I9I I-19I2. 
Pom. Mag.

The Pomological Magazine; or, Figures And Descriptions of the Most Important Varieties Of Fruit cultivated in Great Britain. Three Volumes. London: 1828-30. This work has also been published under the title Pomona Brittanica.

Popular Gard

Popular Gardening. An Illustrated periodical devoted to Horticulture in all its branches. Volume I. Buffalo: 1886. Continued as Popular Gardening and Fruit Growing. Volumes II-VI. Buffalo: I88 7 -I89r. Consolidated with The American Garden and continued as American Gardening. New York: $1892-1904$.

Prince, Pom. Man....... The Pomological Manual; or, A Treatise on Fruits. By

William Robert Prince, aided by William Prince. Second Edition. Part I. New York: 1832. Copyright, 1831 . Part II. New York: 1832 . Copyright, 1832.

Prince, Treat. Hort. . . . . A Short Treatise on Horticulture. By William Prince. New York: 1828 . Copyright, $1 \&_{2} 8$.

Prince, Treat. Trees \&

Plants........... A Treatise on Fruit and Ornamental Trees And Plants, cultivated at the Linnæan Botanic Garden, Flushing, Long-Island, near New-York. By William Prince. New York: 1820 .

Proskauer Obstsort....... Proskauer Obstsorten. Von Professor Dr. Stoll. Proskau bei Oppeln: 1907 .

Quintinye, Com. Gard.... The Compleat Gard'ner; or, Directions for Cultivating and Right Ordering of Fruit-Gardens, and Kitchen-Gardens. By Monsieur De la Quintinye. Seocnd Edition. London: I699.

Ray, Hist. Plant......... Historia Plantarum. By John Ray. Second volume. London: 1688 .

Rea, Flora............. Flora: Seu, De Florum Cultura; or A Complete Florilege. By John Rea. 3 Books. London: 1676. Book 3. Cherries.

Reut. Pom. Inst. Festschrift. Festschrift zum Fünfzigjährigen Bestehen des Pomologischen Instituts In Reutlingen. Reutlingen: 19 ro.

Rev. Hort............ Revue Horticole. Journal D'Horticulture Pratique. (Illustré.) Paris: I 829 to date.

Rural N. Y........... The Rural New-Yorker. A Journal for the Suburban and Country Home. (Illustrated.) Rochester and New York: I 850 to date.

Soc. Nat. Hort. France Pom. Société Nationale D'Horticulture De France. Section Pomologique. Les Meilleurs Fruits au début du $\mathrm{XX}^{\mathrm{e}}$ siècle. (Illustré.) Paris: I 904. 
Sou. Cult

The Southern Cultivator. A Monthly Journal, devoted to the improvement of Southern Agriculture. (Illustrated.) Augusta, Ga.: 1843-1 848 .

Thacher, Am. Orch

The American Orchardist. By James Thacher. Boston: I822. Copyright, I822.

Thomas, Am. Fruit Cult... The American Fruit Culturist. By John J. Thomas. (Illustrated.) First Edition. Geneva and Auburn, N. Y.: 1846. Copyright, 1846. Revised Edition. Auburn, N. Y.: i 85 I. Copyright, I849. Revised Edition. New York: I869. Copyright, 1867. Revised Edition. New York: 1885. Copyright, 1875-1885. Twentieth Edition, Revised and Enlarged. New York: 1897. Copyright, I897. Twentyfirst Edition, Revised and Enlarged. New York: 1911. Copyright, 1903 .

Thomas, Guide Prat...... Guide Pratique de L'Amateur de Fruits. Par O. Thomas. I876. Deuxième Édition. I895. See Guide Pratique.

Thompson, Gard. Ass't... The Gardener's Assistant; Practical and Scientific. By Robert Thompson. (Illustrated.) Two Volumes. London. 1859. Same, revised by William Watson. Six Volumes. London: 1901 .

Truchsess-Heim, Kirschensort............. Systematische Classification und Beschreibung der Kirschensorten. Von Christian Freiherrn Truchsess. Edited by Friedrich Timotheus Heim. Stuttgart: 1819.

U. S. D. A. Rpt........ Reports of the United States Department of Agriculture: I $862-1894$.

U. S. D. A. Yearbook...... Reports of the United States Department of Agriculture: I 894 to date.

U. S. Pat. Off. Rpt....... Reports of the Agricultural section of the United States Patent Office: 1837 to 186 I.

Wickson, Cal. Fruits..... The California Fruits and How To Grow Them. By Edward J. Wickson. (Illustrated.) Second Edition. San Francisco: r891. Copyright, r889. Fourth Edition. Los Angeles: 1909. Copyright, 1908. Seventh Edition. San Francisco: 1914. Copyright, 1914.

Willich, Dom. Enc....... Domestic Encyclopedia or a Dictionary of Facts. By A. F. M. Willich. First American edition with additions by James Mease. In five volumes. Volume 4. Philadelphia: $18 \circ 3$. 


\section{N D E X}

(Names of varieties in this index, if accepted names, appear in Roman type; synonyms in italics.)

À Coeur Hâtive, 205

À Feuilles de Pềcher Grosse, 205

Abbesse, 205

Abbesse d'Oignies, 97

Abels Schwarze Knorpelkirsche, 205

Abundance, 205

Acher's Weichsel (syn. of Griotte Acher), 262

Achte (sein sollende) Kirsche Vier auf ein Pfund (syn. of Tobacco-Leaved), 326

Act Gillos, 205

Adam (syn. of Adams Crown), 205

Adams, var, orig. with, 205

Adams Crown, 205

Adams Ilerzkirsche (syn. of Adams Crown), 205

Adlington, 205

Admirable de Soissons (syn. of Cerise de Soissons), 233

Advance (syn. of Califormia Advance), I I3

Affane, 205

Afghanistan, 205

Agathe (syn. of Hildesheim), $1+3$

Agatkirsche (syn. of Dankelmannskirsche), 240

Alaternblättrige Süssweichsel, 206

Albertine Millet, 206

Alexandrine Béon, 206

Alfred Wesmael, 205

All Saints (syn. of Toussaint), 193

Allen, 206

Allen, J. F., var. orig. by, 324

Allen, Zachariah, var. orig. with, 206, 3 I I

Allen Late Favourite, 206

Allen's Sroet Montmorency (syn. of Sweet Montmorency), 324

Allerfrüheste Bunte Maiherzkirsche, 206

Alte Königskirsche, 206

Altenlander Frühkirsche, 206

Amaranthkirsche, 206

Amarell-Weichsel (syn. of Early May), i 28

Amarelle à point pistillaire blanc (syn. of Amarelle mit

Weissem Stempelpunct), 207

Amarelle Boquet (syn. of Boquet Morello), 223

Amarelle de la Madleine (syn. of Madeleine), 294

Amarelle Double de Verre (syn. of Double Glass), 122

Amarelle Hâtive, 207

Amarelle mit halbgefüller Blüthe (syn. of Fleurs Semidoubles), 253

Amarelle mit Weissem Stempelpunct, 207

Amarelle Royale (syn. of Montmorency), 169

Amarelle très-fertile (syn. of Cerisier Très-fertile), 234

Amarellenbaum mit ganz gefüllter Blüte (syn. of Fleurs

Doubles), 252

Amber, 207

Amber (syn. of Amber Gean), 207
Amber Gean, 207

Amber Heart (syn. of White Heart), 197

Ambrée de Guben, 207

American Amber, 208

Anterican Doctor (syn. of Doctor), 242

American Heart, 208

Amos Owen, 208

Amygdalus, sub-genus of Prunus, I5

Amygdalus indica nana (syn. of $P$. glandulosa trichostyla sinensis), 2 I

Amygdalus pumila (syn. of P. glandulosa), 21; (syn. of P. japonica kerii), 22

Andrews, 208

Andrews, C. N., var. orig, with, 208

Anglaise Hâtive (syn. of May Duke), 164; (syn. of Royal Duke), 184

Anglaise Tardive (syn. of Late Duke), 155

Anne, 208

Annonay, 208

Annonayer Herakirsche (syn. of Annonay), 208

Anstad, 208

Anstad, A. P., var. orig. by, 208

Antonie, var. introduced by, 213

Appalachian cherry, botanical name of, 35

Arch Duke, 98

Argental Late, 209

Atwater, Caleb, var, orig. with, 249

Auburn Duke, 209

August Duke, 209

Augustine de Vigny, 209

Aurischotte, 209

Austen, R. A., quoted, 68

Badacconyi (syn. of Badacsony), 209

Badacsoner Ricsenkirsche (syn. of Badacsony), 209

Badacsoner Schroarze Riesenkirsche (syn. of Badacsony), 209

Badacsony, 209

Badacsonyer Knorpelkirsche (syn. of Badacsony), 209

Baender, 210

Baldwin, I00

Baldwin, S. J., var. orig. by, Ioo

Baltavaer Knorpelkirsche (syn. of Baltavar), 210

Baltavar, 210

Baltavari (syn. of Baltavar), 210

Baluder Morello, 2 ro

Barnhart, 2 ro

Barry, quoted, 70-71

Baseler Herzkirsche, 2 Io

Bates, 210

Bates, S. J., var, orig. with, 210

Baumann May, ioo

Bay State, 210 
Baylor, 2 I $\mathbf{I}$

Beauty of Marienhohe (syn. of Schöne von Marienhohe), 317

Beauty of Orleans (syn, of Belle d'Orleans), 212

Bedford, A. V., var. introduced by, 208

Bedford Prolific, 2 is

Belle Agathe (syn. of Hildesheim), itt

Belle Agathe de Novembre (syn. of Hildesheim), I 43

Belle Allemande (syn. of Bettenburger Glaskirsche), 213

Belle Audigeoise, 2 I I

Belle Bosc, 2 II

Belle de Boskoop, $21 \mathrm{I}$

Belle Brugeoise Saint-Pierre (syn. of Schöne von

Brügge), 317

Belle de Bruxelles (syn. of Belle d'Orleans), 212

Belle de Caux, 211

Belle de Chatenay (syn. of Magnifique), 163

Belle de Choisy (syn. of Choisy), i 6

Belle de Couchey, 2I I

Belle Defay, 211

Belle de Franconville, $2 \mathrm{I} I$

Belle glorie de Marie (syn. of Schöne von Marienhohe), 317

Belle grosse d'Ardèche (syn. of Cerise de l'Ardèche), 230

Belle l'Herissier, 2 I I

Belle de Kis-Oers, 2 I 2

Belle de Loche, 212

Belle Magnifique (syn. of Magnifique), I63

Belle de Magnifique (syn. of Magnifique), I 63

Belle at Magnifique (sy'n. of Magnifique), $\mathrm{I}_{3}$

Belle de Mariznhöhe (syn. of Schöne von Marienhohe),

317

Belle de Montreuil (sy'n. of Montreuil), 298

Belle d'Orleans, 212

Belle de Ribeaucourt, 212

Belle de Rochelle, 212

Belle de Rocmont, 2 I 2

Belle de Saint Tronc, 213

Belle de Sauvigny (syn. of Montmorency de Sauvigny), 298

Belle de Varennes (syn. of Cerisier de Varenne), 234

Belle Vezzouris, 213

Belle de Voisery, 213

Belle de VIorsery (syn. of Royal Duke), $\mathbf{1} 84$

Bender, var. orig. with 213

Bender, J. O., var. orig. with, 213

Bender (of Michigan), 213

Bender (of New York), 213

Berger, Staquet, var. orig. by, 23 I

Berlin Amarelle, 213

Bernard, 2 I 3

Bessarabian, Ior

Bessey's Cherry, botanical name of, 37

Bettenburger Glaskirsche, 213

Bettenburger Herzkirsche, 214

Bettenburger Kirsche von der Natte, 2 I4

Bettenburger Schwarze Herzkirsche (syn. of Bettenburger

Herzkirsche), 214

Bettenburger Weichsel, 2 It

Bettenburger Weichsel Grosser Gobet (syn. of Betten-

burger (Weichsel), 214
Bettenburger Weichsel von der Natte (syn. of Bettenburger (Weichsel), 214

Bicentenaircweichsel (syn. of Cerise du Bicentenaire), 231

Bicolor (syn. of Zweifarbige Kirsche), 336

Bicolor Van Mons, 214

Bigarreau (syn. of Y'ellow Spanish), 202

Bigarreaut Abbesse de Mouland, 214

Bigarreau Ambré Précoce (syn. of Early Amber), 247

Bigarreau Antoine Nomblot, 214

Bigarreau Baumann (syn. of Baumann May), I00

Bigarreau Baute de lOhio (syn. of Ohio Beanty), 302

Bigarreau belle de Rocmond (syn. of Belle de Rocmont), 212

Bigarreau blanc de Groll (syn. of Bigarrean Groll), 217

Bigarreau Blanc (Petit) (syn. of Flamentine), 252

Bigarreau Blanc Précoce, 215

Bigarreau Blanc-Rosé de Piémont, 215

Bigarreau Bordan, 215

Bigarreau de Bourget, 215

Bigarreau Brun, 215

Bigarreau Brun Kleindienst (syn. of Kleindienst Braune Knorpel), 282

Bigarreau de Capucins, 215

Bigarreau de la Caserne, 215

Bigarreau Cayenne, 215

Bigarreau de Châlons, 215

Bigarreau de Champvans, 216

Bigarreau Commun (syn. of Yellow Spanish), 202

Bigatreau Corniola, 216

Bigarreau Court Picout Hâtif, 216

Bigarreau Court Picout Tardif, 216

Bigarreau Dönnissen, 216

Bigarreau Doré, 2 I6

Bigarreau Double Royale, 216

Bigarreau Dur, 216

Bigarreau Duranno, 217

Bigarreau Empireur-Francois (syn. of Emperor Francis), 249

Bigarreau d'Esperen (syn. of Napoleon), 172

Bigarreau de Fer (syn. of Hildesheim), It4

Bigarreau à Feuilles de Tabac (syn. of Tobacco-Leaved), 326

Bigarrcau de Florence (syn. of Florence), I 40

Bigarreau Galopin, 217

Bigarreau Glady, 217

Bigarreau (Golden) (syn. of Drogan Yellow Bigarreau), 245

Bigarreau Grand, 217

Bigarreau Groll, 217

Bigarreau Gros Coeuret (syn. of Large Heart-shaped Bigarreau), 288; (syn. of Napoleon), 172

Bigarreau Gros Commun (syn. of Ox Heart), 178

Bigarreau à Gros Fruit Rouge (syn. of Red Bigarreau), 309

Bigarreau à gros Fruit Rouge Tardif (syn. of Large Late Red Bigarreau), 288

Bigarreau Gros Monstrueux (syn. of Large Heartshaped Bigarreau), 288

Bigarreau Gros Noir de Luther, 217 
Bigarreau Grosse Gomballoise (syn. of Grosse Gomballoise), 265

Bigarreau Hâtif (syn. of Black Bigarreau), 222

Bigarreau Hâtif Boulbon (syn. of Boulebonner Kirsche), 224

Bigarreau Hâtif de Champagne, 217

Bigarreau Hâtif de Saint-Laud, 217

Bigarreau de Hedelfingen (syn. of Hedelfingen), 274

Bigarreau de Hildesheim (syn. of Hildesheim), 144

Bigarreau d'Italie, 218

Bigarreau Jaboulay (syn, of Lyons), $\mathbf{1 6 \mathbf { t }}$

Bigarreau Jacquet, 2 I 8

Bigarreau jaune (syn. of Dankelmannskirsche), 240

Bigarteau jaune de Dönissen (sỵn. of Bigarreau Dönnissen), 2 เ6

Bigarreau jaune de Groth (syn. of Groth Gelbe Knorpelkirsche), 268

Bigarreau Jumard, 218

Bigarreau de Kronberg (sy'n. of Kronberger Kirsche), $2 S_{5}$

Bigarreau Krüger, 218

Bigarreau Legrey, $2 \mathrm{t} 8$

Bigarreau de Loire (syn. of Bigarreau de Lory), 218

Bigarreau à Longue Qucue (syn. of Dunkelrothe Knorpelkirsche), 246

Bigarreau de Lory, 2 is

Bigarreau de Lyon (syn. of Lyons), I6I

Bigarreau Marjeollais (syn. of Bigarreau Marjolet), 2 I 8

Bigarreau Marjolet, 218

Bigarreau of Mezel (sy.n. of Mezel), 167

Bigarreau Mongin, 2 I 8

Bigarreau Monstreuse de Bavay, 219

Bigarreau monstreux de Baltava (sy ti. of Baltavar), 2 to

Bigarreau Monstrueux (syn. of Mezel), 167

Bigarreau Moreau, 219

Bigarreau de Naples (syn. of Naples), 300

Bigarreau Napoléon Noir, 219

Bigarreau Noir Büttner (syn. of Büttner Schwarze Herzkirsche), 299

Bigarreau-noir à chair très-ferme (syn. of Festfleischige Schwarze Knorpelkirsche), 25 I

Bigarreau Noir d'Ecully, 2 I 9

Bigarreau Noir d'Espagne (syn. of Black Heart), 106

Bigarreau noir d'Espagne (syn. of Black Spanish), 223

Bigarreau noir de Germersdorf (syn. of Germersdorf), 259

Bigarreau Noir à Gros Fruits, 219

Bigarreau noir de Guben (syn. of Guben), $26 \mathrm{~S}$

Bigarreau noir Hâtif (syn. of Black Bigarreau), 222

Bigarreau Noir de Heintzen, 219

Bigarreau-noir de Knight (syn. of Knight Late Black), 283

Bigarreau noir de Krüger (syn. of Bigarreau Krüger), 218

Bigarreau noir de Lampé (syn. of Lampen Schwarze Knorpelkirsche), 287

Bigarreau Noir Napoléon III (syn. of Bigarreau Napoléon Noir), 2 I 9

Bigarreau noir de Savoie (syn. of Black Bigarreau of Savoy), 222

Bigarreau Noir de Tabor, 219
Bigarreau noir de Tilgner (syn. of Tilgner Schwarze Knorpelkirsche), 326

Bigarreau noir Winkler (syn. of Winkler Black), 335

Bigarreau noire de Spitz (syn. of Spitzens Herzkirsche), 322

Bigarreau d'Octobre, 219

Bigarreau de l'Once, 220

Bigarreau Pélissier, 102

Bigarreau a petit fruit blanc (syn. of Flamentine), 252

Bigarreau à petit fruit rouge hatif (syn. of Kleine Bunte Frühkirsche), 282

Bigarreau pleureur (syn, of Weeping Black Bigarreau), $33 \mathrm{I}$

Bigarreau Ponctué (syn. of Punktirte Marmorkirsche), 309

Bigarreau Pourpré, 220

Bigarreau Prince Royal de IIanoure (syn. of Kronprinz von Hannover), 28 ;

Bigarreau Printanier d'Oullins, 220

Bigarreau Reverchon, 220

Bigarreau Richelieu, 220

Bigarreau Rival (syn. of Rival), 311

Bigarreau de Rocmont (syn. of Belle de Rocmont), 212

Bigarreau Rosa, 220

Bigarreau Rose Dragon, 220

Bigarreau rouge de Büttner (syn. of Büttner Rothe Knorpelkirsche), 228

Bigarreau Rouge Foncé (syn. of Dunkelrothe Knorpelkirsche), 246

Bigarreau Rouge de Guben (sy'n. of Early Red Bigarreau), $24^{8}$

Bigarreau rouge hâtif (petit) (syn. of Kleine Bunte Friihkirsche), 282

Bigarreau Rouge Tardif de Bütiner (sy'n. of Büttner Späte Rothe Knorpelkirsche), 229

Bigarreau rouge de Tilgener (syn. of Tilgner Rothe Herzkirsche), 326

Bigarreau de Sauvigny (s:n. of Sauvigny Knorpelkirsche), 315

Bigarreau de Schleihahn (syn. of Schleihahn Sweet), 3 I6

Bigarreau de Schrecken, 220

Bigarreau Strié, 221

Bigarreau Tardif Büttner (syn. of Büttner Späte Weichsel), 229

Bigarreau Tardif de Hildesheim (syn. of Hildesheim), 143

Bigarreau Tardif de Ladé (syn. of Ladé Late), $2 S 6$

Bigarreau Tardif de Lieke (syn. of Lieke Bunte Knorpelkirsche), 291

Bigarreau-tardif de Meiningen (syn. of Mleininger Späte Knorpelkirsche), 297

Bigarreau Toupie (syn. of Toupie), 327

Bigarreau de Trie, 22 I

Bigarreau à Trochets, 221

Bigarreau Turca, 221

Bigarreau Violet (syn. of Dunkelrothe Knorpelkirsche), 246

Bigarreau de Walpurgis, 221

Bigarreau Werder (syn, of Werder Early Black), 332

Biagarreau de Zeisberg, 221

Bigarreau Zschedowitzer Schwarze, 221 
Bigarreautier à fruit jaune (syn. of Dankelmannskirsche), $24^{\circ}$

Bigarreautier à grandes feuilles (syn. of TobaccoLeaved), 326

Bigarreautier de Vaples (syn, of Neapolitanische Molkenkirsche), 300

Bigarreautier $\dot{a}$ petit fruit hâtif (syn. of Flamentine), 252

Bigarreautier à Petit Fruit Noir, 221

Bigarreautier à Petit Fruit Rose, 222

Bigarreautier à petit frutt rouge (syn. of Kleine Bunte Frühkirsche), 282

Bigarreautier $\dot{a}$ rameaux pendants (syn. of Thränen Muskatellerkirsche), 326

Biguarre Cherrie (syn. of Yellow Spanish), 202

Bill and $\mathrm{CoO}, 222$

Bing, 103

Bismarck, 222

Black, J. H., var. orig. with, 306

Black American, 222

Black Bigarreau, 222

Black Bigarreau (syn. of Manning Late Black), 295

Black Bigarreau of Savoy, 222

Black Bohemian (syn. of Bigarreau d'Italie), 2 I 8

Black Eagle (sy'n. of Eagle), 126

Black Guigne, 104

Black Hawk, 105

Black Heart, 105

Black Hungarian Gean, 222

Black Margaret, 223

Black Mastodon (syn. of Mastodon), 296

Black Prolific, 223

Black Republican (syn. of Republican), I8I

Black Spanish, 223

Black Tartarian, 107

Black Turkey Heart, 223

Blasse Johanni Kirsche, 223

Bleeding Heart, ros

Bleichrothe Glaskirsche (svn. of Cerise Rouge Pale), 233

Bloem-kers double (syn. of Fleurs Doubles), 252; (syn. of Fleurs Semi-doubles), 253

Bloodgood, Daniel, var. orig. by, 208

Blutherzkirsche (syn. of Bleeding Heart), 109

Blutrothe Molkenkirsche (syn. of Bleeding Heart), 109

Bocage, 223

Bohemian Black Bigarreau (syn. of Bigarreau d'Italie), 218

Bohemian Queen, 223

Bon Bon, 223

Bonamy, var, orig, with, 293

Bonnemain, Auguste, var, orig. by, 25o

Bonnemain (syn. of Gloire de France), 260

Book, 223

Boppard, 223

Bopparder Frühkirsche (syn. of Boppard), 223

Boppard's Early (syn, of Boppard), 223

Boquet Morello, 223

Boreatton, 224

Bordan, var. orig. by, 215

Bordans frühe weisse Herzkirsche (syn. of Bigarreau Bordan), 215

Bordans Herzkirsche (syn. of Bigarreau Bordan), 215
Bostock, quoted, 45

Boughton Early Black Duke, 224

Boulebonner Kirsche, 224

Bount Dantzic, 224

Bouquet-Herzkirsche, 224

Bouquetweichsel, 224

Bourgueil, Io9

Boussieuer Knorpelkirsche, 224

Bowers, John, var. orig. by, 224

Bowers' Seedlings, 224

Boyd Early Black, 225

Boyer's Early (syn. of Bowyer Early Heart), 225

Bowyer Early Heart, 225

Brandon, 225

Brandywine, 225

Brant, 225

Brassington, 225

Braunauer A marelle (syn. of Braunauer Glaskirsche), 225

Braunauer Glaskirsche, 225

Braune rothe Sauerkirsche (sy'n. of Braunrote weichsel), 226

Braune Soodkirsche, 226

Braune Spanische Herzkirsche (syn. of Braune Spanische Kirsche), 226

Braune Spanische Kirsche, 226

Braunrote Weichsel, 226

Bretonneau, Pierre, var. orig. with, I10, 246, 305

Briggs, J. A., var. orig. by, 226

Briggs Sweet, 226

Brinckle, John R., var. orig. by, 225

Brindilles, 226

Brown Best, 226

Brown Seedlings, 226

Bruce, quoted, $61-62$

Brusseler Braune, I10

Brüsselsche Bruyn (syn. of Brusseler Braune), I Io

Buckatzsch Weisse Herzkirsche, 227

Buckatzsch Weisse Knorpelkirsche, 227

Budd, J. L., quored, 74; var. introduced by, 97, 102, III, I 23, I 29, I 43. I47, 158, 160, 188, 195, 207, 224, $227,232,243,254,263,275,280,281,297,303,312$, $318,319,322,330,336$

Budd. No. 533, 227

Buffalo, 227

Bunte Amarelle, 112

Bunte Morello, 227

Burhank, 227

Burbank, Luther, var. orig. by, 205, 227, 259

Burbank Early (syn. of Burbank), 227

Burchardt, var, orig, by, 227

Burchardts Schwarze Rosenobel, 227

Burgnley Park, 227

Burr, 228

Burr, Zera, var, orig. with, 228

Büttner, var. orig. by, 228, 229

Bütrner Gelbe Knorpelkirsche, 228

Büttner Rothe Herzkirsche, 228

Büttner Rothe Knorpelkirsche, $2 \mathbf{2 8}$

Büttner Schwarze Herzkirsche, 228

Büttner Schwarze Sauerkirsche, 229

Bürtner Späte Rothe Knorpelkirsche, 229 
Büttner Späte Weichsel, 229

Büttner's harte Marmorkirsche (syn. of Büttner Späte Rothe Knorpelkirsche), 229

Büttner's Late Red (syn. of Büttner Späte Rothe Knorpelkirsche), 229

Büttner's October (syn. of Büttner Späte Weichsel), 229

Büttner's October Morello (syn. of Büttner Späte

Weichsel), 229

Büttner's October Zucker W'ichsel (syn. of Büttner Späte

Weichsel), 229

Büttner's rothe Marmorkirsche (syn. of Bïttner Rothe

Knorpelkirsche), 228

Büttner's rothe Molkenkirsche (syn. of Bürtner Rothe

Herzkirsche), 228

Büttner's schwarze neue Herakirsche (syn. of Büttner

Schwarze Herzkirsche), 229

Büttner's schoarze neue Sauerkirsche (syn. of Büttner

Schwarze Sauerkirsche), 229

Bütner's Sehrspäte (syn. of Büttner Späte Weichsel), 229

Büttner's September und Octoberweichsel (syn. of Büttner

Späte Weichsel), 22)

Bütner's Yellow (syn. of Büttner Gelbe Knorpejkirsche), 228

Byruville, 230

California Advance, 113

Cameleon, 230

Cardinalskirsche, 230

Carmine Stripe, 230

Carnation, I I4

Caroline, 230

Catskill, 230

Cayenner Knorpelkirsche (syn. of Bigarreau Cayenne), 215

Centennial, 115

Ceraseidos apetala (syn. of $P$. apetala), 21 ; (syn. of $P$. incisa), 20

Cerasus, group name of, 2; sub-genus of Prunus, 15

Cerasus acida (syn. of P. Cerasus), 24

Cerasus asplenifolia (syn. of $P$. avium) , 28

Cerasus austera (syn. of $P$. cerasus), 24

Cerasus Avium (syn. of $P$. avium), 28

Cerasus bigarella, 30 ; (syn. of $P$. cerasus), 25

Cerasus bigarella regalis, $3 \mathrm{I}$

Cerasus Bungei (syn. of P. cerasus), 25

Cerasus californica (syn. of P. emarginata), I6

Cerasus Caproniana (syn. of $P$. cerasus), 24

Cerasus caproniana flore roseo pleno (syn. of $P$. serrulata hisakura), 18

Cerasus cucullata (syn. of $P$. cerasus), 25

Cerasus decumana (syn. of $P$. asium), 28

Cerasus depressa (syn. of P. pumila), 34

Cerasus donarium (syn. of P. serrulata grandiflora), 18

Cerasus dulcis (syn. of $P$. avium), 28

Cerasus duracina (syn. of $P$. avium), 28

Cerasus cffusa (syn. of $P$. cerasus), 25

Cerasus glandulosa (syn. of $P$. glandulosa), 2 I

Cerasus glauca (syn. of $P$. pumila), 34

Cerasus Heaumiana (syn. of $P$. cerasus), 25

Cerasus herincquiana (syn. of $P$. pendula), 20

Cerasus heterophylla (syn. of $P$. avium), 28

Cerasus hortenses (syn. of P. cerasus), 24
Cerasus hortensis foliis eleganter variegatis (syn. of Striped-Leaved), 323

Cerasus incisa (syn. of $P$. incisa), 20

Cerasus intermedia (syn. of P. avium), 28

Cerasus itosakura (syn. of $P$. pendula), 20

Cerasus japonica (syn. of $P$. glandulosa trichostyla sinensis), 21

Cerasus japonica multiplex (syn. of $P$. glandulosa glabra albiplena), 21

Cerasus Juliana (syn. of $P$. acium), 28

Cerasus lannesiana (syn. of $P$. serrulata lannesiana), 18

Cerasus mactophylla (syn. of $P$. avium), 28

Cerasus mahaleb (syn. of P. mahaleb), 3 I

Cerasus Marasca (sy'n. of P. cerasus), 25

Cerasus nicotianaefolia (syn. of $P$. cerasus), 24

Cerasus nigra (syn. of $P$. avium), 28

Cerasus pallida (syn. of $P$. avium), 28

Cerasus paniculala (syn. of $P$. pseudocerasus sieboldii), 17

Cerasus pendula (syn. of $P$. pendula), 20

Cerasus pendula flore roseo (syn. of $P$. pendula), 20

Cerasus pendula kriegeri (syn. of $P$. serrulata kriegeri), is

Cerasus pendula rosea (syn. of $P$. pendula), 20

Cerasus phoshia (syn. of $P$. cerasoides), 19

Cerasus pseudocerasus (syn. of P. pseudocerasus), 17; (syn. of P. serrulata), 18

Cerasus pseudocerasus "James Veitch" (syn. of $P$. serrulata veitchiana), 18

Cerasus puddum (syn. of $P$. cerasoides), 19

Cerasus pumila (syn. of $P$. pumila), 34

Cerasus regalis, 31

Cerasus Rhexii (syn. of P. cerasus), 25

Cerasus rubicunda (syn. of $P$. avium), 28

Cerasus ruja (syn. of $P$. rufa), I9

Cerasus salicifolia (sinn. of $P$. avium), 28

Cerasus serratifolia rosea (syn. of $P$. serrulata hisakura), 18

Cerasus serrulata (syn. of $P$. serrulata), I8

Cerasus sieboldtii (syn. of $P$. pseudocerasus sieboldii), 17

Cerasus tomentosa (syn. of P. tomentosa), 33

Cerasus tridentina (syn. of P. cerasus), 25

Cerasus varia (syn. of $P$. avium), 28

Cerasus vulgaris (syn. of P. cerasus), 24

Cerasus watereri (syn. of $P$. pseudocerasus watereri), 17

Cerasus wattererii (syn. of $P$. pseudocerasus watcreri), 17

Cerise Albanes, 230

Cerise d'Allemagne (syn. of German Morello), 258

Cerise Anglaise (syn. of Cerise Guigne), 232

Cerise d'Angleterte Précoce, 230

Cerise de l'Ardèche, 230

Cerise Bellon, 230

Cerise de la Besnardière, 231

Cerise du Bicentenaire, $23 \mathrm{I}$

Cerise Blanche à Petit Fruit, 23 I

Cerise de Bourgueil (syn. of Bourgueil), 109

Cerise Carminée (syn. of Carmine Stripe), 230

Cerise Commune, 231

Cerise Commune (syn. of Griotte Commune), 262

Cerise Commune (de la Madeleine) (syn. of Madeleine), 294

Cerise du Comte de Henneberg (syn. of Henneberger

Grafenkirsche), 274 
Cerise à Côtes, 231

Cirise à Courte Queue (syn. of Short-Stem Montmorency), 187

Cerise d'Espagne, $23 \mathbf{I}$

Cerise de l' Esvière (syn. of Cerise de Prusse), 232

Cerise à la Feuille, 23 I

Cerise à Feuilles bigarrées' (syn. of Tobacco-Leaved), 326

Cerise de Folger (syn. of Folgerkirsche), 253

Cerise de Gcmbloux, 23 I

Cerise de Gottorpe (syn. of Gottorper), 26I

Cerise Graisseuse (syn. of Speckkirsche), 32 I

Cerise Gros Fruit (syn. of Short-Stem Montmorency), I 87

Cerise Guigne, $23 \mathbf{I}$

Cerise Hâtive (syn. of Süsse Frühweichsel), 324

Cerise Lard (syn. of Speckkirsche), $32 \mathrm{I}$

Cerise de Mai Double, 232

Cerise de Mai Simple, 232

Cerise de Martigné, 232

Crrise à Noyau tendre (syn. of Soft-stone Cherry), 320

Crise Orange (syn. of Pomeranzen), 306

Cerise d'Orange (sy'n. of Carnation), 114

Cerise de Ostheim, 232

Cerise du Palatinat (syn. of Velser), 329

Cerise de petit-lait rouge (syn. of Rothe Molkenkirsche), $3 \mathbf{I} 3$

Cerise de Planchouri (syn. of Planchoury), 305

Crise de Portugal (syn. of Arch Duke), 98

Cerise de Prague tardive (syn. of Pragische Muskateller), 307

Cerise précoce d'Altenlaud (syn. of Altenlander Frühkirsche), 206

Cerise du Prince Maurice, 232

Cerise de Prusse, 232

Cerise de Prusse noire (syn. of Cerise de Prusse), 232

Cerise de Rouën Double, 232

Cerise de Rouën Simple, 232

Cerise Rouge Pale, 233

Cerise Rouge Sanguine, 233

Cerise Royale (syn. of Royal Duke), 184

Cerise Royale de IIollande (syn. of Arch Duke), 98

Cerise Royale Ordinaire, 233

Cerise Royale Tardive D'.1ngleterre (syn. of Holman Duke), 276

Cerise de Sauvigny (syn. of Montmorency de Sauvigny), 298

Cerise de Seckbach (syn. of Seckbacher), 318

Cerise de Soissons, 233

Cerise de Tiercé, 233

Cerise à Trochet (syn. of Cerisier Très-fertile), 234

Cerise van der Nat (syn. of Double Natte), 123

Cerise de Volger (syn. of Early Richmond), I32

Cerise Walpurgis (syn. of Bigarreau de Walpurgis), $22 \mathrm{I}$

Cerise de Xavier, 233

Cerise de Zeisberg (syn. of Bigarreau de Zeisberg), 221

Cerisier à Bouquet (syn. of Cluster), I 19

Cerisier Commun à Fruit Rond, 233

Cerisier Commun Pleureur, 233

Cerisier coulard de Holland (syn. of Coularde), 239

Cerisier cuculle (syn. of Griottier à Feuilles Cucullées), 264
Cerisier à Feuilles Laciniées, 234

Cerisier à Feuilles de Saule (syn. of Willow-Leaved), 335

Cerisier à Fruit Ambré, à Fruit Blane (syn. of Choisy), 116

Cerisier à Gros Fruit Blanc, 234

Cerisier à Gros Fruit Rouge-pâle (syn. of Cerise Rouge Pale), 233

Cerisier llätif (syn. of Early Richmond), 132

Cerisier de Hollande (syn. of Coularde), 238

Cerisier de Ilollande à feuilles de saule ou de balsamine (syn. of Willow-Leaved), 335

Cerisier juniat (syn. of June Amarelle), 279

Cerisier de la Madleine (syn. of Madeleine), 294

Cerisier Nain à Fruit Rond Précoce (syn. of Early May), 128

Cerisier Royal Tardif à Fruit Noir, 234

Cerisier Très-fertile, 234

Cerisier de Varenne, 234

Challenge, 234

Champagne, 234

Champion, 235

Chapman, 235

Chapman, Henry, var. orig. by, 116

Chapman, IV. H., var. orig. by, 113, 235, 296, 309

Charozé, var. orig. with, 27 I

Chase, Lewis, var. orig. with, 292

Chase, R. G., var. introduced by, 230

Chatenay, var, orig. with, 163

Cheresoto, 235

Cherries, adaptions of, in America, 55-56; amelioration of, 8-9; ancient history of, 40 ; ancient use of, 39-40; beginning of domestication of, 42-44; blooming dates and season of ripening of, $80-81$; characters of bark, branches and buds of, $1 \mathrm{I}-\mathbf{I} 2$; characters of flowers and fruit of, 13-14; characters of leaves of, I2-13; classification of cultivated varieties of, I5; cultivated, origin of, $44^{1-42 ;}$ diseases of, $88-92$; distribution of cultivated varieties of, 3 ; domestication of, 8 ; early planting of, in America, 56; geographical distribution of species of, 23-24, groups of, by German writers, 49; habit of growth of species of, I0; hardiness of species of, ro; history of, in England, 49-55; history of, in Greece, 42-44; history of, in Italy, $+4^{-4} 8$; history of, in New England, 57-58; history of, in New York, 59-61; history of, in the Middle West, 62; history of. in the Sixteenth Century, $4^{8-49}$; history of, in the South, 61-62; history of, on the Pacific Coast, 62-64; immunity of, to diseases and insects, 10-II; insects detrimental to, 92-96; lack of literature of, 7; list of, growing in America in 1804, 60-61; minor species of, 38; natural environment of, 76-80; number of described varieties of, 8 ; origin of described varieties of, 9; ornamental value of, 6-7; pollination of, $82-83$; productiveness of, 10 ; relation of, to other species, I-2; separation of, from plums, 2; species of, $16-38$; stocks for, 67-76; susceptibility of, to diseases and insects, 10-11; tree and fruit characters of species of, $9-15$; uses of fruit of, $3-6$; uses of leaves and bark of, 6; wood-value of species of, 6 


\section{THE CHERRIES OF NEW YORK}

Cherry culture, commercial magnitude of, in the United States, 65-67

Cherry orchards, their care and management, $83-84$

Cherry-Duck (syn. of Holman Duke), 276

Cherry-growing, commercial status of, in New York, $85-88$

China Bigarreau, 236

China Heart (syn. of China Bigarreau), 236

Choisy, 116

Choque, 236

Christ, var. orig. by, 313

Christbauer, 236

Christiana, 236

Churchill Heart, 236

Cistena, 236

Clark September, 236

Cleveland, I 8

Clingman, A. K., var. orig. with, 292

Cluster, I 19

Cluster Black Heart, 236

Coburger Maiherzkirsche (syn. of Black Guigne), 104

Cocklin, E. H., var. orig. by, I45; var. introduced by, 236

Cocklin Favorite, 236

$\mathrm{Coe}, \mathrm{I} 20$

Coe, Curtis, var. orig. by, $\mathbf{2} 20$

Coe Late Carnation, 237

Coe's Bunte Transparent (syn. of Coe), I20

Coe's Späte Rote Kirsche (syn. of Coe Late Carnation), 237

Coe's Transparent (syn. of Coe), 120

Coeur de Boeuf nouveau (syn. of Ox Heart [of America]), 303

Coeur de Pigeon Gros (syn. of Belle de Rocmont), 212

Coeur de Pigeon Noir, 237

Coeur de Poule, 237

Colarsale d'Hedelfingen (syn. of Hedelfingen), 274

Cole, 237

Collman, A. F., var. orig. with, 238

Colorado Morello (syn. of English Morello), 139

Columbia, 237

Common French Griotte (syn. of Griotte Commune), 262

Common Morello, 237

Common Red Morello (syn. of Common Morello), 237

Como, 237

Comtesse de Médicis Spada, 237

Condé, 237

Conestoga, 237

Constance Maisin, 238

Cook, Steven, var. orig. with, 238, 297

Cook Imperial, 238

Cornelia, 238

Corning, 238

Corone, 238

Corwin, 238

Coularde, 238

Courte-pendu de Gaiberg (syn. of Courte-queue de Gaiberg), 239

Courte-queue de Gaiberg, 239

Courtin, var. orig. with, 320

Coxe, quoted, 68-69
Crawford, 239

Cream (syn, of Honey), 276

Crown Prince, 239

Cserszeger Honigkirsche, 239

Cullen Cherrie, 239

Cumberland, 239

Cumberland Heart (syn. of Cumberland), 239

Cumberland Spice (syn. of Cumberland), 239

Cyclone, 239

Dacotah, 240

Daiber Schwarze Knorpelkirsche, 240

Dankelmannskirsche, 240

Dankelmann's Molkenkirsche (syn. of Dankelmannskirsche), 240

Dankelmann's Weisse Herzkirsche (syn. of Dankelmannskirsche), 240

D'Aout Erfurt (syn. of Erfurter Augustkirsche), 250

D'Aremberg (syn. of Reine Hortense), 179

Datge, $24^{\circ}$

Davenport, 240

Davenport, Edward, var. orig. by, 240

Davenport's Early (syn. of Davenport), 240

Daven port's Early Black (syn. of Davenport), 240

Davenport's Early Red (syn. of Davenport), 240

De Belleu, $24^{\circ}$

De Chaux (syn, of German Morello), 258

De Jacap, 240

De Jonghe, var, orig. by, 327

De Ravaene, 240

De Sibérie (syn. of Dwarf Siberian), 247

De Sibérie à fruit rond (syn. of Dwarf Siberian), 247

De Sibérie à gros fruit et à rameaux pendans, 24 I

De Spa, 24 I

De Vaux, 24I

Dearborn, H. A. S., var. introduced by, $16_{3}$

Dearborn Red French, 24I

Dechenaut, $24 \mathrm{I}$

Delaware Bleeding Heart, 24 I

Delicate, 24I

Délices d'Erfurt (syn, of Erfurter Augustkirsche), 250

Délicieuse, 241

Denner Black, 241

Des Cheneaux, 24 r

Deutsche Belzweichsel, 241

Deutsche Griotte (syn. of German Morello), 258

Deutsche Weichsel (syn. of German Morello), 258

Deutscher Griottier Weichselbaum (syn. of German

Morello), 258

Dikeman, 121

Dikeman, George B., var. orig. with, 121

Disnoder Gewürzkirsche, 24 I

Ditst, 24 I

Dobbeete Moreller, 242

Doctay, 242

Doctor, 242

Dr. Flynn, $24^{2}$

Dr. Wiseman, 242

Doctorkirsche, 242

Doctorknorpelkirsche, 242

Dollaner Schwarze, $2 \neq 2$

Donna Maria, 243 
Dönnissens gelbe Knorpelkirsche (syn. of Bigarreau Dönnissen), 216

Doppelte Amarelle (syn. of Doppelte Weichsel), 24 s

Doppelte Weichsel, 243

Doppelttragende Kleine Rothe Spätkirsche (syn. of Hildesheim), 143

Dorotheenkirsche, 243

Dörrells Neue Himbeerkirsche, $2+3$

Doty, 243

Double Floured Cherry (syn. of Fleurs Doubles), 252

Double Glass, 122

Double Natte, 123

Double Yellow Spanish, 243

Doublet, var. orig. by, 2 I I

Douce de Bardowick, 243

Douce d'Espagne (syn. of Süsse Spanische), 324

Douce de Palatinat (syn. of Velser), 329

Dougall, 243

Dougall, James, var. introduced by, $243,33 \mathbf{I}$; var. orig. with, 198

Doulin Bigarreau, 243

Dove Bank, 243

Downer, 124

Downer, Samuel, var. orig. by, 124

Downer's Late (syn. of Downer), 124

Downer's Red Heart (syn. of Downer), 124

Downing, A. J., life of, 244; quoted, 70, 157; var. orig. by, 244

Downing, Charles, life of, 234-235; var. orig. by, 234

Downing Red Creek, 244

Downing's Sämling (syn. of Downing Red Cheek), 2.44

Downton, 244

Downtoner Molkenkirsche (syn. of Downton), 244

Dresdener Mai Herzkirsche, 245

Drogan, var. orig. by, 245

Drogan White Bigarreau, 245

Drogan Yellow Bigarreau, 245

Drogans Schwarze Knorpelkirsche, 245

Drogan's Weisse Knorpelkirsche (syn. of Drogan White Bigarreau), $2+5$

Drooping Guigne, 245

Du Comte Egger, 245

Du Nord Nouvelle, 245

Duchesse d'Angoulême, 245

Duchesse de Palluau, 246

Dudley, Paul, quoted, $5^{8}$

Duhamel, quoted, 70, 139

Duke Cherry (syn. of May Duke), 164

Duke cherries, characters of, 3 I

Duke of Edinburgh, 246

Dumas, 246

Dunkelrothe Knorpelkirsche, 246

Duraccia, 246

Dure Noir Grosse, 247

Dure de Sauvigny (syn. of Sauvigny Knorpelkirsche), 315

Dutch Weeping (syn. of Dwarf Siberian), 247

Dwarf Double Flowering (syn. of Fleurs Doubles), 253

Dwarf Siberian, 247

Dyehouse, 125

Dyehouse, var. orig. by, 126
Eagle, 126

Early Amarella, 247

Early Amber, 247

Early Black Bigarreau, 247

Early Eugene, 247

Early Griotte (syn. of Early Richmond), 132

Early Guigne (syn. of Flamentine), 252

Early Jaboulay (syn. of Lyons), 161

Early Lamaurie (syn. of Lamaurie), 287

Early Lyons (syn. of Lyons), 16I

Early Mathere (syn. of Guigne Précoce de Mathère), 271

Early May, 128

Early May, 247

Early Morello, 129

Early Prolific, 248

Early Purple, 130

Early Purple Guigne (syn. of Early Purple), 130

Early Red and Yellow, 248

Early Red Bigarreau, 248

Early Red Guigne, 248

Early Richmond, 131

Early Rivers, 248

Early White Bigarreau (syn. of Flamentine), 252

Early White Guigne (syn. of Grosse Guigne Blanche), 266

Early York, 248

Ebenter Cherry, 249

Ecullyer Knorpelkirsche (syn. of Bigarreau Noir d'Ecully), 2 r 9

Edouard Seneclause, 249

Elfner Kirsche, 249

Elizabeth, 249

Elkhorn, 134

Elliott, F. R., life of, 159; quoted, 71, 197; var. introduced by, 159

Elliott's Favorite (syn. of Favorite), $25 \mathrm{I}$

EIton, 135

Emperor Francis, 249

Empress Eugenie, 137

Englische Schwarze Kronherzkirsche (syn. of Corone), 238

Englische Weinkirsche, 249

Englische weisse ganz frühe Herzkirsche (syn. of Englische Weisse Herzkirsche), 250

Englische Weisse Herzkirsche, 250

English Amber, 249

English Bearer, 249

English Gaskin, 249

English Morello, 138; susceptibility of, to leaf spot, I

English Preserve (syn. of English Bearer), 249

Enopa, 250

Épervier Noir (syn. of Black Hawk), ro5

Episcopale, 250

Eppers Weichsel, 250

Erfurt Delicious (syn. of Erfurter Augustkirsche), $25^{\circ}$

Erfurter Augustkirsche, 250

Escl Kirsche (syn. of May Duke), 164

Espagne bigarrée (syn. of Perlknorpelkirsche), 305

Etopa, 250

Eugène Furst, 250 
Eugenie (syn. of Empress Eugenie) 137

Euprunus, sub-genus of Prunus, 15

Everbearing, 25 I

Excellente Douce Tardive, 25I

Eyami, 251

Ezaptan, 251

Faversham Heart, 251

Favorite, 251

Fenno, J. H., var, orig. by, 301

Fenwith, George, quoted, 58

Festfieischige Schwarze Knorpelkirsche, 251

Flagg, 252

Flamentine, 252

Flanders (syn. of Early Richmond), 131

Flanders Cluster (syn. of Cluster), I I 9

Flemish (syn. of Large Montmorency), 153; (syn. of Short-Stem Montmorency), 187

Flemish Gean, 252

Flemish Coloured Bigarreau (syn. of Elton), 135

Fleurs Doubles, 252

Fleurs Semi-doubles, 253

Florence, 140

Florence Heart (syn. of Florence), $\mathbf{r}_{4} 0$

Florianer Kirsche, 253

Flynn, var. orig. with, $2+2$

Folgerkirsche, 253

Folgers Swolfe, 254

Forsyth, quoted, 68

Fouche Morello, 254

Four to the Pound (syn. of Tobacco-Leaved), 326

Französiche Süssweichsel (syn. of Cerise de Soissons), 233

Fraser's White Tartarian (syn. of White Tartarian), 333

Frauendorfer, 254

Frauendorfer Weichsel (syn. of Frauendorfer), 254

French (syn. of Early Richmond), 132

French Amarelle, 254

French Weichsel, 254

Frogmore Bigarreau (syn. of Frogmore Early Bigarreau), 254

Frogmore Early Bigarreau, 254

Frogmore Early Crown, 254

Frogmore Early Prolific (syn. of Frogmore Early Bigarreau), 254

Frogmore Late Bigarrean, 255

Frogmore Norrelo, 255

Fromm, var. orig. by, 255

Fromm Heart, 255

Fromms Schwarze Herzkirsche (syn. of Fromm Heart), 255

Frühe Bernsteinkirsche (syn. of White Heart), 197

Frühe bunte Herzkirsche, 255

Frühe Englische Kirsche aus Löwen (syn. of Löwener Frühkirsche), 292

Frühe Kurzstielige Knorpelkirsche, 255

Frühe Lange Weisse Herakirsche (syn. of Frühe bunte Herzkirsche), 255

Frïhe Lemercier (syn. of Lemercier), 290

Frithe Maiherzkirsche (syn. of Baumann May), 100

Frühe Maikirsche, 255
Frühe Morello, 255

Frühe Natte aus Samen (syn. of Frühe von der Natte), 256

Frühe Sauerkirsche, 256

Frühe Schattenmorelle (syn. of Shadow Amarelle), 318

Frühe Schwarze Herzkirsche (syn. of Black Guigne),

104: (syn. of Black Heart), ro6

Frühe Schwarze Knorpelkirsche, 256

Frühe Süssweichsel von der $N$ att (syr. of Frühe von der Natre), 256

Frühe von der Natte, 256

Frühe Zwergweichsel (syn. of Early May), I28

Früher Gobet, 256

Früheste Bunte Herzkirsche, 256

Früheste bunte Molkenkirsche (syn. of Früheste Bunte

Herzkirsche), 256

Früheste der Mark, 257

Frühkirsche (syn. of Früheste Bunte Herzkirsche), $25^{6}$

Frühzeitige Amarelle (syn. of Early Richmond), 132

Fürst Schwarze Septemberkirsche, 257

Fürst's Herakirsche (syn. of Eugène Furst), $25^{\circ}$

Galopin (syn. of Lutovka), 160

Galusha, 257

Gamdale, 257

Garcine, 257

Garcine, var. orig. by, 257

Gardiner, 257

Gardner, V. R., quoted, $82-83$

Gascoigne (syn. of Bleeding Heart), 109

Gascoigne's Heart (syn. of Bleeding Heart), 109

Gaskins, 257

Gauchers Knorpelkirsche, 257

Géante de Badacson (syn. of Badacsony), 209

Géante d'Iledelfingen (syn. of Hedelfingen), 274

Gedoppelte Amarelle mit halbgefüllter Blïte (syn. of Fleurs Semi-doubles), 253

Geer, 257

Gefüllblühende Amarelle (syn. of Fleurs Doubles), 253

Gefülliblühende Süsskirsche (syn. of Large Double

Flowering), 287

Gefülter Kirschbaume (syn. of Fleurs Semi-doubles), 253

Gelbe Herzkirsche, 257

Gelbe Wachskirsche, $25^{8}$

Gemeine Glaskirsche, 258

Geneine Marmorkirsche (syn. of Yellow Spanish), 202

Gemeine Schwarze Herzkirsche (syn. of Grosse Schwarze Herzkirsche), 267

Gemeine Süsstoeichsel (syn. of Griotte Commune), 262

Genesee, $25^{8}$

George Glass, I4I

Gerarde, quoted, 51, 52, 53, 54, 55

German, 258

German Duke (syn. of German Morello), $25^{8}$

German (Kraus) (syn. of German), 258

German Morello, 258

Germersdorf, 259

Germersdorfer Grosse Kirsche (syn. of Germersdorf), 259

Geschiltztblättrige Süssweichsel, 259

Gestriefte Herzkirsche, 259

Gewöhnliche Muskatellerkirsche, 259 
Giant, 259

Gihb, 259

Gifford, 259

Gilbert, R., var. orig. by, 227

Glanzende goldgelb und roth marmorirte Kramelkirsche

(syn. of Belle de Rocmont), 212

Glasherzkirsche, 259

Glaskirsche mit dickgefüllter Blüthe (syn. of Fleurs

Doubles), 252

Glaskirsche mit halbgefüllter Blüthe (syn. of Fleurs

Semi-doubles), 253

Glaskirsche von der Natte, 260

Glas-Molkenkirsche (syn. of Glasherzkirsche), 259

Glass (syn. of Double Glass), 122

Glasskirsche Kurzstielige, 260

Gloire de France, 260

Gobet à Courte Queue (syn. of Short-Stem Montmorency), 187

Gobet Hâtif (syn. of Frïher Gobet), 256

Golden Knob, 260

Goldgelbe Herzkirsche, 260

Goldsmith Black Heatt, 260

Goodspeed, 260

Gormley, 260

Gormley, John, var. orig. with, 260

Gottorper, 26I

Gottorper Marmorkirsche (syn. of Gottorper), $26 \mathrm{I}$

Gould No. X, 26I

Governor Luce, 26I

Gov. Shannon (syn. of Shannon), 319

Governor Wood (syn. of Wood), 199

Grafenburger Frühkirsche, 26I

Graffion (syn. of Yellow Spanish), 202

Graham, 26I

Grand, var. introduced by, 217

Grande Ronde, 26 I

Great Bearing, 26r

Great Bigarreau (syn. of Mezel), เ67

Great Cornelian (syn. of Double Glass), 122

Great Leafed, 26I

Great rose (syn. of Fleurs Doubles), 252

Grenner Glas, 26I

Gridley, 261

Gridley, Samuel, var. orig. with, $26 \mathbf{I}$

Griotte (syn, of Griotte Commune), 262

Griotte Acher, 262

Griotte d'Allemagne (syn. of German Morello), $25^{8}$

Griotte de Bettenbourg (syn. of Bettenburger Weichsel), 214

Griotte à Bouquet (syn. of Cluster), I 9

Griotte de Büttner, 262

Griotte de Chaux (syn. of German Morello), 258

Griotte Commune, 262

Griotte à Courte Queuc (syn. of Imperial Morello), 278

Griotte Double (syn. of Griotte Acher), 262

Griotte Douce Précoce, 262

Griotte de Frauendorf (sy'n. of Frauendorfer), 254

Griotte à gros fruit noir de Piémont (syn. of Griotte

Noire de Piémont), 263

Griotte à gros fruit rouge de Piémont (syn. of Griotte

Rouge de Piémont), 264
Griotte Guigne (syn. of Cerise Guigne), 232

Grioule Impériale (syn. of Imperial Morello), 278

Griotic Kleparite (syn. of Griotte de Kleparow), 263

Griotte de Kleparow, 263

Griotte de Leopold (syn. of Leopoldskirsche), 290

Griotte Lodigiana, 263

Griotte Noire, 263

Griotte Noire de Piémont, $26_{3}$

Griotte Noire des Vosges (syn. of Noire des Vosges), 301

Griotte du Nord Améliorée, 263

Griotte à Petit Fruit, 263

Griotie de Portugal (syn. of Arch Duke), $9^{8}$

Griotte Précoce, 263

Griotte Précoce d'Espagne (syn. of Spanische Frühweichsel), 320

Griotte rouge foncé (syn. of Braunrore Weichsel), 226

Griotte Rouge de Piémont, 264

Griotte de Schaarbeck, 264

Griotte simple (syn. of Griotte Commune), 262

Griotte Tardive d'Annecy, 264

Griotte Tardive de Büttner (syn. of Büttner Späte

Weichsel), 229

Griotte Tardive de Plombiéres, 264

Griotte de Toscane, 264

Griotte de Turquie, 264

Griotte de Wellington (syn. of Wellington), 332

Griottier à Feuilles Cucullées, 264

Griottier à feuilles de Pêcher (syn. of Willow-Leaved), 335

Griottier à feuilles de Saule (syn. of Willow-Leaved), 335

Griottier à Fruit Aigre, 264

Griottier à Longues Feuilles, 264

Griottier Nain Précoce (syn. of Early May), I 28

Grioltier Weichselbaum (syn. of Griotte Commune), 262

Groll Schwarze Knorpelkirsche, 264

Grolls bunte Knorpelkirsche (syn. of Bigarreau Groll), 217

Gros Bigarreau Blanc (syn. of Napoleon), i7 I

Gros Bigarreau coeur-de-Poule (syn. of Coeur de Poule), 237

Gros Bigarreau Noir (syn. of Elkhorn), 134

Gros Bigarreau pourpré (syn. of Bigarreau Pourpré), 220

Gros Bigarreau Rond, 265

Gros Gobel (syn. of Short-Stem Montmorency), 187

Gros Guindoul Hâtif, 265

Gross blättrige Molkenkirsche (syn. of Tobacco-Leaved), 326

Grosse Blanche Carrée, 265

Grosse Bunte Herzkirsche, 265

Grosse bunte Molkenkirsche (syn. of Grosse Bunte Herzkirsche), $26 ;$

Grosse Cerise à Ratafia (syn. of English Morello), 130

Grosse Cerise des Religieuses (syn. of Grosse Nonnenkirsche), 266

Grosse Cerise Transparente (syn. of Grosse Glaskirsche), 265

Grosse Deutsche Belakirsche (syn. of German Morello), 258

Grosse dunkel braunrothe Kramelkirsche (syn. of Festfleischige Schwarze Knorpelkirsche), 251 
Grosse Friedrichskirsche, 265

Grosse glänzende schwarze Ilerzkirsche (syn. of Guigne

Noir Luisante), 270

Grosse Glas-IIerzkirsche (syn. of Glasherzkirsche), 259

Grosse Glaskirsche, 265

Grosse Glaskirsche von Montmorency (syn. of Large

Montmorency), 153

Grosse Gomballoise, 265

Grosse-Griotte à vin (syn. of Grosse Weinkirsche), 268

Grosse Guigne Blanche, 265

Grosse Guigne Noire à Court Pédicelle, 266

Grosse Guigne noire luisante (syn. of Guigne Norr

Luisante), 270

Grosse Höckerige Marmorkirsche, 266

Grosse Lange Lothkirsche (syn. of English Morello), 139

Grosse Mogulkirsche, 266

Grosse Morelle, 266

Grosse Morelle double (syn. of Grosse Morelle), 266

Grosse Nonnenkirsche, 266

Grosse Picarde, 266

Grosse Schwarze Frühe Herzkirsche, 267

Grosse schwarze Glanzkirsche (syn. of Prinzenkirsche), 308

Grosse Schwarze Herzkirsche, 267

Grosse Schwarze Knorpelkirsche (syn. of Elkhorn), I 34

Grosse schwarze Knorpelkirsche mit festem Fleisch (syn.

of Festfleischige Schwarze Knorpelkirsche), 251

Grosse schwarze ungarische Herzkirsche (syn. of Grosse

Ungarische Kirsche), 267

Grosse Spanische Weichsel (syn. of Spanische Glas-

kirsche), 320

Grosse späte Amarelle (syn. of Grosse Tardive), 267

Grosse Späte Schwarze Knorpelkirsche, 267

Grosse Süsse Maiherzkirsche, 267

Grosse Süsse Maikirsche (syn. of Grosse Süsse Mai-

herzkirsche), 267

Grosse Tardive, 267

Grosse Transparente, 267

Grosse Ungarische Kirsche, 267

Grosse de Verrirées, 267

Grosse de Wagnellee, 268

Grosse Weinkirsche, 268

Grosse Weisse Frühkirsche, 268

Grosse Weisse Marmorkirsche (syn. of Napoleon), 172

Grosse wohltragende holländische Morelle (syn. of Wohltragende Holländische Kirsche), 335

Grosser Gobet (syn. of Large Montmorency), 153

Grosser weisser glänzender Herakirschbaum (syn. of Gelbe

Herzkirsche), 257

Groth Braune Knorpelkirsche, 268

Groth Gelbe Knorpelkirsche, 268

Groth's Wachskirsche (syn. of Groth Gelbe Knorpel-

kirsche), 268

Grünstiel-Kirsche, 268

Guben, 268

Gubener Bernsteinkirsche (syn. of Ambrée de Guben), 207

Gubener Schwarze Knorpel (syn. of Guben), 268

Gubens Ehre, 268

Guigne d'Annonay (syn. of Guigne la Plus Hâtive), 271

Guigne Anglaise Blanche Précoce, 268
Guigne d'Argovie, 268

Guigne de Bettenbourg (syn. of Bettenburger Herzkirsche), 214

Guigne Bigaudelle (syn. of Black Guigne), 104

Guigne Blanche (syn. of Grosse Guigne Blanche), 266

Guigne Blanche de Bordan (syn. of Bigarreau Bordan), 215

Guigne Blanche Précoce, 269

Guigne Blanche de Winkler (syn. of Guigne Carnée

Winkler), 269

Guigne Bonne Alostoise, 269

Guigne brune de Liefeld (syn. of Liefeld Braune), 291

Guigne de Buxeuil, 269

Guigne Carnée Winkler, 269

Guigne de Chamblondes, 269

Guigne Chamonale, 269

Guigne Chavanne, 269

Guigne Choque (syn. of Choque), 236

Guigne Coé (syn. of Coe), 120

Guigne à courte queue (syn. of Guigne Courte-queue d'Oullins), 269

Guigne Courtequeue d'Oullins, 269

Guigne Downton (syn. of Downton), 244

Guigne Early Rivers (syn. of Early Rivers), 248

Guigne Ecarlate, 269

Guigne de l'Escalier, 269

Guigne de Gland, 269

Guigne à gros fruit blanc (syn. of Grosse Guigne Blanche), 265

Guigne à Gros Fruit Noir Hâtif (syn, of Grosse Schwarze Frühe Herzkirsche), 267

Guigne Grosse ambrée (syn. of Gelbe Herzkirsche), 257

Guigne Grosse Rouge Hâtive, 269

Guigne Grosse Rouge Tardive, 270

Guigne Guindole, 270

Guigne Hâtive d'Elsdorf, 270

Guigne-hâtive de Schneider (syn. of Schneider Frühe Herzkirsche), 316

Guigne Hâtive de Werder (syn. of Werder Early Black), 332

Guigne Jaune (syn. of Gelbe Herzkirsche), 257

Guigne de Kruger (syn. of Krüger Herzkirsche), 285

Guigne Lucien (syn. of Lucien), 293

Guigne Ludwig (syn. of Ludwig Bigarreau), 293

Guigne de Mai (syn. of Baumann May), 100

Guigne Marbrée, 270

Guigne marbrée précoce (syn. of Guigne la Plus Hâtive), 271

Guigne Marie Besnard, 270

Guigne Marjolet (syn. of Bigarreau Marjolet), 2r 8

Guigne mûre de Paris (syn. of Späte Maulbeerkirsche), 321

Guigne de Nice, 270

Guigne Noir Luisante, 270

Guigne Noire Ancienne (syn. of Black Heart), 106

Guigne Noire Commune (syn. of Black Guigne), 104

Guigne Noire à Gros Fruit (syn. of Black Tartarian), 107

Guigne Noire Hâtive, 270

Guigne noire hâtive à gros fruits (syn. of Guigne Noir Luisante), 270 
Guigne Noire de Monstreux, 271

Guigne noire Spitz (syn. of Spitzens Herzkirsche), 322

Guigne Nouvelle Espéce, 27 I

Guigne Olive, 27 I

Guigne panachée longue précoce (syn. of Frühe bunte Herzkirsche), 255

Guigne panachée précoce (syn. of Early Amber), 247

Guigne panachée très-précoce (syn. of Früheste Bunte Herzkirsche), 256

Guigne Petite Blanche, 271

Guigne Petite Rouge, 27 I

Guigne la Plus Hâtive, 271

Guigne Précoce Leo d'Ounons, 27 I

Guigne Précoce de Mai (syn, of Baumann May), 100

Guigne Précoce de Mathère, 27 I

Guigne Précoce Ponctuée, 27ı

Guigne de Provence, 27 I

Guigne Ramon Oliva, 27I

Guigne Reinette noire (syn. of Guigne Noir Luisante), 270

Guigne Rose Hâtive, 27I

Guigne Rouge Commune, 272

Guigne Rouge Hâtive (syn. of Bleeding Heart), Iog

Guigne Rouge Poncruée, 272

Guigne Royale (sy'n. of Bigarreau Double Royale), 216

Guigne de Russie à Fruit Blanc, 272

Guigne sucrée de Léon Leclerc (syn. of Sucrée Léon Leclerc), 323

Guigne de Tarascon (syn. of Tarascon Kirsche), 324

Guigne Tardive de Downer (syn. of Downer), I24

Guigne de Tilgener (syn. of Tilgner Rothe Herakirsche), 326

Guigne Très Précoce, 272

Guigne Troprichtz (syn. of Troprichters Schwarze Knorpelkirsche), 328

Guigne van der Broek, 272

Guigne Villeneuve, 272

Guigne de Winkler (syn. of Guigne Carnée Winkler), 269

Guignier à Fruit Noir (syn. of Black Hearr), I06

Guignier à Fruit Noir et Très-long Pédoncule, 272

Guignier à fruit rose hâtif (syn. of Guigne Rose Hâtive), 272

Guignier à Fruit Rouge Tardif (syn. of Hildesheim), 143 Guignicr à gros fruit noir (syn. of Grosse Schwarze Herzkirsche), 267

Guignier à Gros Fruit Noir et Court Pédoncule (syn. of Grosse Guigne Noire à Court Pédicelle), 266

Guignier à Gros Fruit noir hâtif (syn. of Guigne Noire Hâtive), 270

Guignier à gros fruit noir luisant (syn. of Guigne Noir Luisante), 270

Guignier à Petit Fruit Noir, 272

Guignier à rameaux pendans (syn. of Drooping Guigne), 245

Guindoux Noir de Faix, 272

Guindoux du Poitou (syn. of Imperial Morello), 278

Guindoux de Provence (syn. of Cerise de Prusse), 232

Gunsleber Späte Knorpelkirsche, 273

IIalbgefülltblühende Amarelle (syn. of Fleurs Semidoubles), 253
Halbgefülltblühende Weichsel, 273

Halifax, 273

Hallock, 273

Hallock, Nicholas, var. orig. with, 273

Hallowell, 273

Hamell Kirsche, 273

Hamels Arissen, 273

Harrison's Heart (syn. of Napoleon), 172

Hartlib, 273

Hartlippe, 273

Hartz Mountain, 273

Hâtive de Balis, 273

Hâtive de Louvain (syn. of Löwener Frühkirsche), 292

Hâtive de Nattés (syn. of Frühe von der Natte), 256

Hâtive de Prin, 273

Hâtive de St. Jean, 273

Hâtive ou Précoce, 273

Headley, 274

Healy, 274

Heart-Shaped Griotte (syn. of Heart-Shaped Weichsel), I 42

Heart-Shaped Weichsel, $\mathbf{I}_{\mathbf{4} 2}$

Hedelfingen, 274

Hedelfingen Risenkirsche (syn. of Hedelfingen), 274

Hedwigs Kirsche, 274

Heidelberger Kirsche, 274

Heiges, 274

Heintzen (Heintze's) Frïhe Kirsche, 274

Heintzen's (Heintze's) Schwarze Knorpelkirsche (syn. of Bigarteau Noir de Heintzen), 2 I9

Henneberger Grafenkirsche, 274

Henrard, Denis, var. orig. by, 327

Hensel Early, 274

Herrnhäuser neue Ochsenherzkirsche (syn. of Neue Ochsenherzkirsche), 300

Hertogs-Kers (syn. of Elkhorn), 134

Herförmige Sauerkirsche (syn. of Heart-Shaped Weichsel), I $^{2} 2$

Herzförmige Süssweichsel (syn. of Rothe Herakirsche), 313

Herzkirsche Léona Quesnel, 275

Ilerzkirsche Napoléon $I I I$ (syn. of Bigarreau Napoleon Noir), 219

Herzkirsche Trauben, 275

Herzkirsche Wils Frühe, 275

Herzkirschenbaum mit grosse gefullter Blüthe (s!nn. of Large Double Flowering), 287

Herzkirschweichsel, 275

Herzog May, 275

Herzogin von Angouleme (syn. of Duchesse d'Angoulême), 245

Herzogin von Paluau (syn. of Duchesse de Palluau), 246

Herzogskirsche (syn. of Arch Duke), 98

Hildesheim, 143

Hildesheimer Ganz Späte Knorpelkirsche (syn. of Hildesheim), 143

Hildesheimer Späte Knorpelkirsche (syn. of Hildesheim), I 44

Hiller, Casper, var. introduced by, 237

Hoadley, 275 
Hochgenuss Von Erfurt (syn. of Erfurter Augustkirsche), 250

Hockenberg, 275

Hogg Black Gean, 275

Hogg Red Gean, 275

Hoke, 275

IIolland Bigarreau (syn. of Napoleon), 172

Holland Griotte (syn. of Coularde), 239

IIolländische Folgerkirsche (syn, of Folgerkirsche), 253

Holländische grosse Kirsche Coulard (syn. of Coularde), 239

Holländische Grosse Prinzessinkirsche (syn. of Napoleon), $17 \mathbf{I}$

Holländische grosse Weichsel [or] Coulard (syn. of Coularde), 239

IIöllandische Kirsche (syn. of Höllandische Späte Weichsel), 275

Höllandische Späte Weichsel, 275

Holländische Süssweichsel (syn. of Coularde), 239

IIöllandische Weichsel (syn. of Höllandische Späte Weichsel), 275

Holländische Weichselbaum mit sehr grosser Frucht [or] Coulard (syn. of Coularde), 238

Holman Duke, 276

Holme Late Duke, 276

Holstein, 276

Homer, 276

Honey, 276

Honey Dew, 276

Honey Heart (syn. of Sparhawk), I 89

Honeywood, 276

Hoppock, Cornelius, var. orig. by, 277

Hoppock Yellow, 277

llortense (syn. of Reine Hortense), 179

Hoshino, Yugo, quoted, 75

Hoskins, 277

Hoskins, C. E., life of, 277; var. orig. by, 274, 277 , $286,291,296,301,309,323,330$

Houblon, John, var. orig. with, I 4 I

Hovey, 277

Hovey, C. M., var. orig. with, 277

Hoy, 277

Hubbard, 278

Ilungarian Cherry of Zwerts (syn. of Hungarian Gean), 278

Hungarian Gean, 278

Hyde, T. \& G., var. orig. with, 278

Hyde Late Black, $27^{8}$

Hyde Red Heart, 278

Hyde's Seedling (syn. of Hyde Red Heart), 278

Ida, 144

Impératrice Downton (syn. of Downton), 244

Imperial (syn. of Imperial Morello), 278

Imperial Morello, 278

Incomparable en Beauté, 278

Ingram, Thomas, var. orig. by, 254, 255

Intorka, 278

Irwin, var. orig. by, 325

Jaboulay, var. orig. with, I6I

Jahns Durchsichtige (syn. of Transparent Guigne), 328

Jaune de Prusse, 279
Jean Arendsen, 279

Jeffrey Duke, $\mathbf{4}^{6} 6$

Jeffrey's Royal (syn. of Jeffrey Duke), 146

Jenkin Black Heart, 279

Jerusalem Kirsche von der Natte, 279

Jerusalemskirsche, 279

Jockotos (syn. of Jocosot), 279

Jocosot, 279

Joel Keil Kleine Schwarze Herzkirsche, 279

John Tradescantes Cherrie (syn. of Elkhorn), 134

Josselyn, John, quoted, 57

June Amarelle, 279

June Duke, 280

June Morello (syn. of June Amarelle), 279

Juniat Amarelle (syn. of June Amarelle), 279

Junius Amarelle (syn. of June Amarelle), 279

Justinische Amarelle (syn. of Justinische Morello), 280

Justinische Morello, 280

Kaiser Franz Josef (syn. of Emperor Francis), 249

Kaiserliche Weichsel (syn. of Imperial Morello), 278

Kamdesa, 280

Kappenblättrige Süssweichsel, 280

Kapuziner Knorpel (syn. of Bigarreau de Capucins), 2 I 5

Kassin, var. orig. by, 280

Kassin Frühe Herzkirsche, 280

Katie, 280

Kaufmann, 280

Kazan Seedling, 280

Kelly, 280

Kennicott, 28I

Kentish (syn. of Early Richmond), 132; (syn. of Late Kentish), 157

Kentish Bigarreau (syn. of White Heart), 197

Kentish Drier, 28I

Kentish Preserve, 28 I

Kentish Red (syn. of Late Kentish), 157

Keokuk, 28I

Kesterter Frïh Kirsche, $28 \mathbf{I}$

King Amarelle, I47

King George the Second, 281

King Morello, 28 I

King's Cherry (syn. of King Amarelle), I 47

Kinsey, Samuel, var. introduced by, 330

Kirchheimer, 28 $\mathbf{I}$

Kirchheimer Weichsel (syn. of Kirchheimer), 28I

Kirsch von Planchoury (syn. of Planchoury), 305

Kirsche von Basel, 28I

Kirsche von Bénardière (syn. of Cerise de la Besnardière), 23 I

Kirsche von der Natte (syn. of Double Natte), 123

Kirschwasser, manufacture of, 4

Kirtland, $14^{8}$

Kirtland, B. B., var, orig. by, 236, 296

Kirtland, J. P., life of, 200; var. introduced by, I I8; var. orig. by, $105,148,183,200,222,225,230,241$, $242,248,251,275,279,281,282,288,290,291,292$, $294,302,303,306,307,310,319,324,325$

Kirtland Morello, 282

Kirtland's Large Morello (syn. of Kirtland Morello), 282

Kirtland's Mammoth (syn. of Mammoth), 294 
Kirland's Mary (syn. of Kirtland), I 48

Kleindienst, var. orig. by, 282

Kleindienst Braune Knorpel, 282

Kleine Amarelle, 282

Kleine Ambra (syn. of Goldgelbe Herzkirsche), 260

Kleine Ambra, [or] Goldgelber Herzkirschbaum (syn. of Goldgelbe Herzkirsche), 260

Kleine Bunte Fribkirsche, 282

Kleine Bunte Herzkirsche, 282

Kleine bunte Molkenkirsche (syn. of Kleine Bunte Herzkirsche), 282

Kleine Frühe Amarelle, 282

Kleine frühe rothe Herzkirsche (syn. of Guigne Rose Hâtive), 271

Kleine Glaskirsche von Montmorency (syn. of Montmorency), 169

Kleine Natte, 282

Kleine Nonnenkirsche, 283

Kleine Schwarze Frühe Herzkirsche, 283

Kleine Schwarze Herzkirsche, 283

Kleine Schwarze Knorpelkirsche, 283

Kleine Weisse Frühkirsche, 283

Kleine weisse Frühirsche (syn. of Grosse Guigne Blanche), 265

Kleine weisse Perlkirsche (syn. of Dankelmannskirsche), 2 +o

Kleiner Früher Mlay Herzkirschbaum, 283

Kleparavoska (syn. of Griotte de Kleparow), 263

Kleparower Süssweichsel (syn. of Griotte de Kleparow), 263

Knapp, 283

Knapp, George, var. orig. with, 283

$K$ nevett's Late Bigarreau (syn. of Florence), 1 40

Knight, 149

Knight, T. A., var. orig. by, 127, 136, I 50, 196, 245

Knight Late Black, $28_{3}$

Knight's Early Black (syn. of Knight), 149

Knights Frühe Herakirsche (syn, of Knight), 149

Knorpelkirsche von Cleveland (syn. of Cleveland), II 8

Knudson, 283

Knudson, William O., var. orig. with, 283

Knyasnaia Sjevera, 284

Koch Späte Schwarze Knorpelkirsche, 284

Kochs Ostheimer Weichsel, 284

Kochs verbesserie Ostheimer Weichsel (syn. of Kochs

Ostheimer Weichsel), 284

Koehne, species listed by, 16-22

Koeper, 284

Kolaki, 284

Königliche Fleischkirsche (syn. of Bigarreau Double Royale), 216

Königliche Herzkirsche (syn. of Bigarreau Double Royale), 216

Königliche Süsszueichsel (syn. of Jeffrey Duke), ${ }^{1}+6$

Königskirsche (syn. of Royal Duke), 184

Korkovanyer Kirsche, 284

Koslov, 284

Koslov bush Morello (syn. of Koslov), 284

Kosloo-Morello (syn. of Koslov), 284

Kostelnice, 285

Kostelniti, 285
Kramelkirschenbaum mit gross gefullter Blüthe (syn. of Large Double Flowering), 287

$K$ ratos Knorpelkirsche (syn. of Hildesheim), 144

Kreiselkirsche (syn. of Toupie), 327

Kriek van den Broek, 285

Kritzendorfer Einsiedekirsche, 285

Kronberg Black Heart (syn. of Kronberger Kirsche), 285

Kronberger Herzkirsche (syn. of Kronberger Kirsche), 285

Kronberger Kirsche, 285

Kronkirsche (syn. of Kronberger Kirsche), 285

Kronprinz von Hannover, 28 ;

Krüger Herzkirsche, 285

Krügers Ilerzkirsche zu Frankfurt (syn. of Krüger Herzkirsche), 285

Krïgers schwarze llerzkirsche (syn. of Kriiger Herzkirsche), 285

Krüger's Schwarze Knorpelkirsche (syn. of Bigarreau Krïger), 218

La Nappe, 286

Lacure (Large), 286

Lacure (Small ), 286

Ladé, var, orig. by, 286

Ladé Late, 286

Lady of the Lake, 286

Lady Southampton, 286

Lady Southampton's Yellow (syn. of Lady Southampton), 286

Laeder Kirsebaer, 286

Lake, 286

Laker or Loker Bunte Knorpelkirsche, 286

Lamaurie, 287

Lambert, 15 I

Lambert, J. H., var. orig. by, 152

Lampen Schwarze Knorpelkirsche, 287

Lampers Knorpel-Kirsche (syn. of Lampen Schwarze Knorpelkirsche), 287

Lancaster, 287

Lange Marmorkirsche (syn. of Napoleon), 171

Langsurer Brachtweichsel, 287

Large Black Bigarreau of Savoy (syn. of Black Bigarreau of Savoy), 222

Large Black Gean, 287

Large Double Flowering, 287

Large Griotte, 288

Large Guindolle, 288

Large Heart-shaped Bigarreau, 288

Large Honey (syn. of Honey), 276

Large Late Red Bigarreau, 288

Large Montmorency, 153

Large Morello (syn. of English Morello), 139; (syn. of Kirtland Morello), 282

Large Red Bigarreau (syn. of Red Bigarreau), 310

Large Spanish, 288

Larose, var. orig. by, 180,288

Larose (syn. of Laroses Glaskirsche), 288

Laroses Glaskirsche, 2.99

Late Amber (syn. of Cocklin Favorite), 236

Late Imber Gean (syn. of Amber Gean), 207

Late Bigarreau, 288

Late Black Bigarreau, 2\$9 
Late Black Bigarreau (syn. of Guben), 268

Late Duke, 155

Late Gean, 289

Late IIoney (syn. of Honey), 276

Late Kentish, 157

Late Large Black Griotte, 289

Late Purple Guigne, 289

Late Red Guigne (syn. of Hildesheim), 143

Late Richmond, 289

Late Ripe, 289

Late White Guigne, 289

Latham, 289

Lanermannskirsche (syn. of Napoleon), 171

Laura, 289

Lawrence, John, quoted, 68

Lawson, quoted, 62

Leather Stocking, 290

Leclerc, Léon, var. orig. with, 323

I.eib, 290

Leitzkauer, 290

Leitzkauer Einmachweichsel ( $y$ n. of Leitzkawer), 290

Lemercier, 290

Lemercier, var, orig. with, 290

Léon Leclercs Herzkirsche (syn. of Sucrée Léon Leclerc), 323

Léopold (IJ), 290

Leopoldskirsche, 290

Leschken (Leschke's) Schwarze Knorpel Kirsche, 29 I

Lesser rose (syn. of Fleurs Semi-doubles), 253

Lethe, 291

Lervelling (syn. of Republican), I $8 \mathbf{I}$

Lewelling, Henderson, life of, $151-152$

Lewelling, Seth, life of, 151-152; var. orig. by, I03, 181, 291, 335

Liefeld Braune, 291

Liegel's Süsse Frühweichscl (syn. of Griotte Douce Précoce), 262

Lieke, var. orig. with, 285,291

Lieke Bunte Knorpelkirsche, 291

Ligier, var. orig. with, 168

Lincoln (I), 291

Lincoln (II), 291

Lindley, 29I

Lipp, 292

Lipp Late Blood (syn. of Lipp), 292

Litham, 292

Lithaner, 158

Litcle Phil, 292

Logan, 292

Long Finger, 292

Long Stem Montmorency (syn. of Montmorency), 169

Look No Further, 292

Lord Belhaven White Heart, 292

Lothaunner Erfurter, 292

Lothkirsche, 292

Loudon, quoted, 70

Louis Philippe, 158

Lonise, 292

Louisiana Iron Clad, 292

Love Apple (syn. of Tomato), 327

Löwener Frühkirsche, 292
Lowener Frühweichsel, 292

Lucien, 293

Ludwig Bigarreau, 293

Ludwig's Bunte Herzkirsche (syn. of Ludwig Bigarreau), 293

Luigné, M. de, var. orig. with, 296

Lukeward, 293

Lukeward's Heart (sy'n. of Lukeward), 293

Lundie Guigne, 293

Lutovka, 160

Lyons, I6I

McAdow, 293

McAdow, var. orig. by, 293

MacRoach, 293

MacRoach, James, var. orig. with, 293

Madame Courtois, 293

Madame Grégoire, 294

Madeleine, 29.4

Madison, 294

Madison Bigarreau (syn. of Madison), 294

Madison's Bunte Herzirsche (syn. of Madison), 294

Magann, 294

Magèse, 294

Magnifique, 163

Magnifique de Daval, 294

Magog, 294

Mahaleb stock, comparison of, with Mazzard stock, 72-73; history and value of, 69-72

Major Francis (sy'n. of Ox Heart [of America]), 303

Mammoth, 294

Nammoth Oxheart, 295

Mammuthkirsche (syn. of Mammoth), 294

Nanger, 295

Manning, Robert, var. orig. by, 248, 294, 295, 333

Manning Black Bigarreau (syn. of Manning Late Black), 295

Manning Early Black, 295

Manning Early White Heart, 295

Manning Late Black, 295

Manning Mottled, 295

Naple Heart, 295

Maquerlot, var. introduced by, 273

Naraschino, history and manufacture of, $4^{-5}$

Marells Royal, 295

Marguerite (syn. of Bender [of New York]), 213

Maria Gaucher, 295

Marie de Châteauneuf, 295

Marie Thérèse, 296

Marjolets Knorpelkirsche (syn. of Bigarrean Marjolet), $2 \mathbf{I} 8$

Markirsche, 296

Marsotte, 296

Mary, z96

Mary (syn. of Kirtland), 148

Mascall, Leonard, quoted, 68

Master White Heart, 296

Mastodon, 296

Matilda, 296

Matts, 296

May (syn. of Early May), 128

May Bigarreau (syn. of Baumann May), 100 
May Cherry (syn, of May Duke), 164

May Duke, I6 4

May Duke, Willow-leaved (syn. of Willow-Leaved), 335

Mayer's kleine schwarze Merkirsche (syn. of Kleine Schwarze Herzkirsche), 283

Mayo, 296

Mazarine, 296

Mazzard stock, comparison of, with Mahaleb stock, $72-73$; history and value of, $67-69$

Mednyansky, 297

Meininger Späte Knorpelkirsche, 297

Meissener Weisse, 297

Mercer, I 66

Merise à Fleur Double (syn. of Large Double Flowering), 287

Merise Grosse Rose Oblongue, 297

Merise Petite Ronda, 297

Merisier Fastigié, 297

Merisziere (syn. of Large Double Flowering), 287

Merveille de September (syn. of Hildeshein), 143

Meyer, E., var. introduced by, 273, 298

Mezel, 167

Michigan, 297

Mijurin, I. V., var. orig. by, 284

Miller, 297

Miller, David, var, introduced by, 239

Millet, 297

Minnesota, 297

Minnesota Ostheim, 297

Minnie, 298

Moduyansky (syn. of Mednyansky), 297

Monkirsche Rote, 298

Monstreuse de Mezel (syn. of Mezel), I67

Monstrous Duke, 298

Monstrous fleart (syn, of Large Heart-shaped Bigarreau), 288

Monstrueuse d'Vedelfingen (syn. of Hedelfingen), 274

Monstrueuse Hennequine, 298

Montmorency, I69; immunity of, to leaf spot, II

Montmorency (syn. of Large Montmorency), I 53

Montmorency de Bourgueil (syn. of Bourgueil), I09

Montmorency Ordinaire (syn. of Montmorency), 169

Montmorency Pleureur, 298

Montmorency de Sauvigny, 298

Montmorency Stark, 298

Montreuil, 298

Moorhouse, 299

Morella Extra Noir, 299

Morella Wye, 299

Morelle von Wilheimshöhe, 299

Moreller Langstilkede Sode, 299

Morgan, J. A., var. introduced by, 258

Morisco, 299

Morocco, 299

Morten Seedling, 299

Mosely, John, var. orig. by, 300

Mosier Schwarze Herzkirsche, 299

Mottled Bigarreau (syn. of Manning Mottled), 295

Moyer Honey Heart, 299

Mückelberger Grosse, 299

Müller, Hugo M., quoted, 49
Murdock, 299

Murdock, John R. and A., var. orig. by, 299, 313

Murdocks' Bigarreau (syn. of Murdoch), 299

Muscat de Prague (syn. of Pragische Muskateller), 307

Muscat des Larmes (syn. of Thränen Muskatellerkirsche), 326

Nancy, 299

Naples, 300

Napoleon, 17 I

Napoléon Noir (syn. of Bigarreau Napoléon Noir), 2 I 9

Napolitaine (syn. of Neapolitanische Molkenkirsche), 300

Natte hâtive de semis (syn. of Frühe von der Natte), 256

$\mathrm{Ne}$ Plus Ultra, 300

Nenpolitanische Knorpelkirsche (syn. of Naples), 300

Neapolitanische Molkenkirsche, 300

Nebraska Sweet, 300

Nelson Kentish, 300

Neue Englische Kirsche (syn. of Neue Englische Weichsel), 300

Neue Englische Weichsel, 300

Neue Ochsenherzkirsche, 300

Neumann Schwarze Knorpelkirsche, 300

New Century, 300

New Frogmore Morello (syn. of Frogmore Morrelo), 255

New Large Black Bigurreau (syn. of Black Bigarreau of Savoy), 222

New Royal, 301

Nienburger Frühe Bunte Herzkirsche, 301

Noble, 301

Noire des Vosges, $30 \mathbf{r}$

Noire IVâtive de Cobourg (syn, of Black Guigne), 104

Nomblot, Alfred, var. orig. by, 214

Nonpareil, 301

Norfolk, 301

Norma, 301

Northeast, 301

Northern Griotte (syn. of English Morello), 139

Northwest, 30 I

Nouvelle Guigne des Boeufs (syn. of Neue Ochsenherzkirsche), 300

Nouvelle Royale, 174

Occident, 301

Ohio Beauty, 302

Okiya, 302

Oktober-Knorpelkirsche (syn. of Bigarreau d'Octobre), 219

Oliver, 302

Olivet, 175

Opata, 302

Oregon, 302

Orel, 302

Orel No. 23 (syn. of Early Morello), 129

Orel No. 24, 303

Orel No. 26 (syn. of Orel Sweet), 303

Orel Sweet, 303

Orléan Smith, 303

Orleans, 303

Osceola, 303

Ostheim, 176 
Ostheim (syn. of Cerise de Ostheim), 232; (syn. of Minnesota Ostheim), 297

Ostheim (of Morris), 303

Othello, 303

Ounce (syn. of Tobacco-Leaved), 326

Owanka, 303

Ox Heart, 178

Ox Heart (of America), 303

Padus, genus of, 15

Padus cherries, distinguishing characters of, 3 ; use of, 7

Padus mahaleb (syn. of P. Mahaleb), 3I

Pandys Glaskirsche, 304

Paramdam, $30_{4}$

Parent, 304

Paretzer Herzkirsche, 304

Pariser Griotte, 304

Parisian Guindoux, 304

Parkinson, John, quoted 99, 134, 239, 273, 286, 292, 299, 329

Paul, $30_{4}$

Paul, E. V. D., var, orig. with, 304

Pauline de Vigny, 304

Peach-Blossomed, 304

Pease, 304

Pease, Charles, var. orig. by, $238,240,286,289$

Pease, Charles, Sr., var. orig. with, 299, 304

Pelissiers Knorpelkirsche (syn. of Bigarreau Pélissier), 102

Perlkirsche, 304

Perlknorpelkirsche 305

Perlmarmorkirsche (syn. of Perlknorpelkirsche), 305

Petit Bigarreau Hatif (syn. of Kleine Bunte Frühkirsche), 282

Petite Bigarreau hâtif (sy'n. of Flamentine), 252

Petite Morelle, 305

Pfälzer Süssweichsel (syn. of Velser), 329

Pfitzmann Schwarze Herzkirsche, 305

Pie Cherry (syn. of Late Kentish), 157

Pierce, Amos, var. orig. with, 305

Pierce Late, 305

Pigeon Heart Bigarreau (syn. of Belle de Rocmont), 212

Pigeon's Heart (syn. of Belle de Rocmont), 212

Pink Heart, 305

Planchoury, 305

Plattgedrückte Schattenmorelle, 305

Plumstone, 305

Plumstone Morello (syn. of Plumstone), 305

Plymouth (syn. of Plymouth Rock), 306

Plymouth Rock, 306

Podiebrad, 306

Podiebrad Bunte Herakirsche (syn. of Podiebrad), 306

Pohlnische Kirsche (syn. of Griotte de Kleparow), 263

Pointed Guigne, 306

Poitou griotte (syn, of Imperial Morello), 278

Polnische grosse Weichsel (syn. of Griotte de Kleparow), 263

Polnische Weichsel (syn. of Griotte de Kleparow), 263

Polsted, 306

Polton Gean, 306

Pomeranzen, 306

Pomme-d'Amour (syn. of Tomato), 327
Pontiac, 306

Pope, 307

Portugal, 307

Portugiesische Griotte (sy'n. of Arch Duke), 98

Portugiesischer Griottier Weichselbaum (syn. of Arch Duke), 98

Powhattan, 307

Pragische Muskateller, 307

Prague Tardif (Muscadét de) (syn. of Velser), 329

Précoce d' Espagne (syn. of Spanische Frühkirsche), 320

Précoce Lemerciér (syn. of Duchesse de Palluau), 246

Précoce de Marest, 307

Précoce de Montreuil (syn. of Early May), 128

Précoce de Sabaret, 307

President, 307

Prettyman, H. W., var. orig. by, 302

Pride of Washington, 307

Priesche Schwarze Knorpelkirsche, 308

Prince, 308

Prince, William, quoted, 203-204; var. introduced by, I08, 247; var. orig. by, 236, 308

Prince Black Heart, 308

Prince Duke, 308

Prince Englebert, 308

Prince de Hanosre (syn. of Kronprinz von Hannover), $28_{5}$

Prince Roval, 308

Prince Royal du Hanore (syn. of Kronprinz von Hannover), 285

Princess, 308

Priner Frühweichsel (syn. of Hâtive de Prin), 273

Prinzenkirsche, 308

Prinzesskirsche (syn. of Princess), 308

Prödlitzer Elitekirsche, 308

Progress, 308

Prolific Cherry (syn. of Cerisier Très-fertile), 234

Proskauer Knorpelkirsche, 308

Proudfoot, 308

Proudfoot, D., var. orig. by, 308

Provencer Süssweichsel (syn. of Cerise de Prusse), 232

Prunus, division of, 15 ; genus, importance of, in horticulture, I

Prunus acida, 16

Prunus acida (syn. of P. cerasus), 24

Prunus aestiva (syn. of $P$. cerasus), 24

$4+\times t^{8}$ ? Prunus affinis, 18

Prunus ampla, 17

Prunus apetala, 21; (syn. of P. maximosviczii), 16

Prunus apetala isozana (syn. of P. tschonoskii), 20

Prunus apetala typica (syn. of $P$. nipponica), 20

Prunus austera (syn. of P. cerasus), 24

Prunus autumnalis, 20

Prunus avium, 16; characters of, 28-29; comparison of, with Prunus cerasus, 9; distribution and habitat of, 29; division of and how divided, 30; geographic range of, $4^{\mathrm{I}-42}$; specific description of, 28-30; use of wood of, 6 ; value of, as a stock, $67-69$

Prunus avium $\times$ Prunus cerasus, specific description of, 31

Prunus avium decomana, 30

Prunus avium duracina, 30 
Prunus avium regalis, $3 \mathrm{I}$

Prunus batalinii, 22

Prunus besseyi, 21; characters of, 36 ; common names of, 37 ; habitat of, 36 ; hybridism of, with other species, 37 ; specific description of, $36-38$; use of, as a stock, $37-38$

Prunus biloba (syn. of P. herincquiana biloba), 19

Prunus brachypetala, 22

Prunus bracteata (syn. of P. Maximowiczii), I6

Prunus bungei (syn. of $P$. humilis), 2 I

Prunus campanulata, is

Prunus canescens, 20

Prunus carcharias, 22

Prunus caudata, 20

Prunus ceraseidos (syn.. of P. apetala), 2r; (syn. of P. nipponica), 20; (syn. of $P$. tschonoskii), 20

Prunus ceraseidos kurilensis (stn. of P. kurilensis), 20

Prunus cerasoides, 19; (syn. of P. campanulata), 19

Prunus cerasoides tibctica (syn. of $P$. majestica), 19

Prunus cerasus, 16; characters of, 25; comparison of, with Prunus aviun, 9; distribution of, 26; division of and how divided, 26-28; geographic range of, $4 \mathrm{I}$; probable parentage of, 44 ; specific description of, $24^{-28}$

Prunus cerasus austera, 27

Prunus cerasus caproniana, 27

Prunus cerasus flore pleno (syn. of $P$. serrulata), I8; (syn. of $P$. serrulata mucronata), i 8

Prunus cerasus flore simplici (syn. of $P$. serrulata), 17

Prunus cerasus marasca, 28

Prunus cerasus pendula flore roseo (syn. of $P$. pendula), 20

Prunus cinerascens, 22

Prunus clarofolia, 16

Prunus conadenia, 16

Prunus concinna, 19

Prunus conradina, 19

Prunus cuneata, habitat of, 35 ; specific description of, $35^{-36}$

Prunus cyclamina, 17

Prunus cyclamina biflora, 17

Prunus depressa (syn. of $P$. pumila), 34

Prunus dictyoneura, 21

Prunus dielsiana, 17

Prunus dielsiana corferia, 17

Prunus dielsiana laxa, 17

Prunus diffusa, 22

Prunus discadenia, 16

Prunus donarium (syn. of $P$. pseudocerasus virescens), I7; (syn. of $P$. serrulata), 17

Prunus droseracea, 20

Prunus dulcis (syn. of P. avium), 28

Prunus duclouxii, 7

Prunus emarginata, 16; use of, 39

Prunus formosana (syn. of $P$. pogonostyla), 2 I

Prunus fruticosa, I6; use of, 38

Prunus giraldiana, 20

Prunus glabra, 17

Prunus glandulifolia, 17

Prunus glandulosa, 2 I

Prunur glandulosa glabra, 21
Prunus glandulosa glabra alba, 21

Prunus glandulosa glabra albiplena, 2 I

Prunus glandulosa glabra rosea, 21

Prunus glandulosa purdomii, 2 I

Prunus glandulosa salicifoli, 2 I

Prunus glandulosa trichostyla, 2 I

Prunus glandulosa trichostyla faberi, 2 I

Prunus glandulosa trichostyla paokangensis, $2 \mathbf{I}$

Prunus glandulosa trichostyla sinensis, 2 I

Prunus glyptocarya, 20

Prunus gracilifolia, 21

Prunus griffithii, 22

Prunus heleno, 19

Prunus henryi, 17

Prunus herincquiana, 19; (syn. of $P$. pendula), 20

Prunus herincquiana ascendens (syn. of $P$. subhirtella),

19

Prunus herincquiana biloba, 19

Prunus hirifolia, $\mathrm{i}$ ?

Prunus hirtides, 17

Prunus hirtipes glabra (syn. of P. glabra), 17

Prumus hortensis (syn. of P. cerasus), 24

Prunus hosscusii, 19

Prunus humilis, 21

Prunus incana, 22; (syn. of $P$. pumilla), 34; use of, 38

Prunus incisa, 20; (syn. of P. subhirtella), 19

Prunus incisa kurilensis (syn. of $P$. kurilensis), 20

Prunus involucrata, 17

Prunus itosakra ascendens amabilis (syn. of P. sublirtella fukubana), 20

Prunus itosakra pendula (syn. of P. pendula), 20

Prunus itosakra subhirtella (syn. of $P$. subhirtella), 20

Prunus itosakura (syn. of $P$. pendula), 20

Prunus iwagiensis, 20

Prunus involucrata, use of, $3^{8}$

Prunus jacquemontii, 22; use of, 38

Prunus jamasakura (syn. of P. serrulata), 17

Prunus jamasakura borealis (syn. of P. sargentii), 19

Prunus jamasakura clegans compia (syn. of P. sargentii), 19

Prunus jamasakura elegans glabra (syn. of $P$. serrulata), is

Prunus jamasakura elegans parifolia (syn. of $P$. parvifolia), 19

Prunus jamasakura speciosa (syn. of $P$. serrulata), is

Prunus jamasakura speciosa nobilis (syn. of $P$. serrulata lannesiana), 18

Prunus jamasakura speciosa nobilis donarium (syn. of P. serrulata hisakura), 18

Prunus japonica, 2I; (syn. of $P$. glandulosa glabra alba, $2 \mathbf{I}$; of $P$. glandulosa glabra albiplena, 2I; of $P$. glandulosa trichostyla faberi, $2 \mathrm{I}$; of $P$. glandulora trichostyla sinensis, 21 ; of $P$. japonica kerii, 22)

Prunus japonica engleri (syn. of i. japonica gracillima engleri), 22

Prunus japonica eujaponica, 2 I

Prunus japonica eujaponica fauriei, 21

Prunus japonica eujaponica oldhamii, 2I

Prunus japonica flor, simp. (syn. of $P$. glandulosa glabra rosea), 2 I 
Prunus japonica flore albo pleno (syn. of P. glandulosa glabra albiplena), 21

Prunus japonica flore pleno (syn. of $P$. glandulosa glabra albiplena), 21; (syn. of $P$. glandulosa trichostyla sinensis), 2 I

Prunus japonica glandulosa (syn. of $P$. glandulosa glabra), 21; (syn. of $P$. glandulosa glabra rosea), $2 \mathbf{1}$ Prunus japonica gracillima, 22

Prunus japonica gracillima engleri, 22

Prunus japonica gracillima minor, 22

Prunus japonica gracillima sphaerica, 22

Prunus japonica gracillima thunbergii, 22

Prunus japonica japonica (syn. of P. japonica), $2 \mathbf{I}$

Prunus japonica kerii, 22

Prunus japonica multiplex (syn. of P. glandulosa glabra albiplena), 21

Prunus japonica packangensis (syn. of $P$. glandulosa trichostyla paokangensis), 21

Prunus japonica salicifolia (syn. of $P$. glandulosa salicifoli), 21

Prunus japonica sphaerica (syn. of $P$. japonica gracillima sphaerica), 22

Prunus japonica thunbergii (syn. of $P$. japonica gracillima thunbergii), 22

Prunus japonica typica (syn. of $P$. japonica), 21

Prunus japonica typica flore pleno (syn. of $P$. japonica kerii), 22

Prunus japonica typica flore roseo (syn. of $P$. glandulosa glabra rosea), 21

Prunus Juliana (syn. of P. cerasus), 24

Prunus kerii (syn. of P. japonica kerii), 22

Prunus kurilensis, 20

Prunus latidentata, 20

Prunus leveilleana, 19

Prunus litigiosa, 16

Prunus litigiosa abbreviata, 16

Prunus lobulata, 20

Prunus macgregoriana, 17

Prunus macradenia, 16

Prunus mahaleb, 16; characters of, 31-32; habitat of, 32; importance of, in horticulture and commerce, $32-33$; specific description of, 3 I-33; value of, as a stock, $69-72$; value of wood of, 6

Prunus majestica, 19

Prunus malifolia, 17

Prunus malifolia rosthornii, 17

Prunus Mararca (syn. of P. cerasus), 24

Prunus maximowiczii, 16

Prunus maximowiczii adenophora (syn. of P. tatsienensis adenophora), I6

Prunus maximowiczii aperta, 16

Prunus mesadenia, 19

Prunus microcarpa, 22

Prunus microlepis, 20

Prunus microlepis ternata, 20

Prunus micromeloides, 20

Prunus miqueliana, 20; (syn. of P. nipponica), 20; (syn. of P. pendula), zo

Prunus mollis, 16

Prunus mume crasseglandulosa (syn. of $P$. sargentii), 19

Prunus nakii, 22
Prunus neglecta, 17

Prunus nigricans (syn. of $P$. avium), 28

Prunus nikkoensis, 20

Prunus nipponica, 20

Prunus oxycarpa (syn. of $P$. cerasus), 24

Prunus oxyodonta, 20

Prunus padus, 3

Prunus paniculata (syn. of $P$. pseudocerasus sieboldii), 17

Prunus paracerasus, 17

Prunus parvifolia, 19

Prunus parvifolia aomoriensis, 19

Prunus paucifolia, 19

Prunus pendula, 20

Prunus pendula ascendens (syn. of $P$. subhirtella), 19

Prunus pennsylvanica, 16; use of, as a stock, 74

Prunus phyllopoda, 20

Prunus pilosiuscula, 16

Prunus pleiocerasus, 16

Prunus plena (syn. of P. cerasus), 24

Prunus pleuroptera, 20

Prunus plurinervis, 17

Prunus podadenia, 20

Prunus pogonostyla, 21

Prunus pogonostyla globosa, 2I

Prunus pogonostyla obovata, 21

Prunus polytricha, 16

? Prunus praccox, 22

Prunus prostrata, 22

Prunus pseudocerasus, 17; (syn. of P. sargentiz), 19; (syn. of $P$. serrulata albida), 18; use of, 38 ; use of as a stock, 75, use of wood of, 6

Prunus pseudocerasus benifugen (syn. of $P$. serrulata hisakura), 18

Prunus pseudocerasus borealis (syn. of $P$. sargentii), 19

Prunus pseudocerasus flore roseo pleno (syn. of $P$. pseudocerasus sieboldii), 17

Prunus pseudocerasus hisakura (syn. of $P$. serrulata hisakura), 18

Pruntes pseudocerasus hortensis flore carneo suffuso (svn. of $P$. serrulata shidare-sakura), I8

Prunus pseudocerasus hortensis flore pleno viridi (syn. of $P$. serrulata grandifora), 18

Prunus pseudocerasus hortensis flore pulcherrimo pleno candido (syn. of $P$. serrulata mucronata), 18

Prunus pseudocerasus hortensis flore semipleno roseo (syn. of $P$. serrulata hisakura), is

Prunus pseudocerasus hortensis flore simplici albo (syn. of $P$. serrulata albida), 18

Prunus pseudocerasus hortensis flore simplici carneo (syn. of $P$. serrulata lannesiana), is

Prunus pseudocerasus jamasakura I incira, is

Prunus pseudocerasus jamaskura glabra (syn. of $P$. serrulata), 18

Prunus pseudocerasus jamasakura glabra preco: (sуn. of $P$. serrulata), I 8

Prunus pseudocerasus jamasakura pracox (syn. of $P$. serrulata), 18

Prunus pseudocerasus naden (syn. of $P$. pseudocerasus sieboldii), 17 
Prunus pseudocerasus "New Red" (syn. of P. serrulata hisakura), 18

Prunus pseudocerasus ochichima (syn. of $P$. serrulata ochichima), 18

Prunus pseudocerasus parifolia (syn. of $P$. parvifolia), I9

Prunus pseudocerasus sachalinensis (syn. of $P$. sargentii), 19

Prunus pseudocerasus serrulata glabra (syn. of $P$. serrulata), is

Prunus pseudocerasus serrulata glabra fugeño (syn. of $P$. serrulata), 18

Prunus pseudocerasus serrulata glabra viridiflora (syn. of $P$. serrulata grandiflora), 18

Prunus pseudocerasus serrulata sieboldii albida (syn. of $P$. serrulata albida), 18

Prunus pseudocerasus serrulata sicboldtii (syn. of $P$. pseudocerasus sieboldii), 17

Prunus pseudocerasus shidare-sakura (syn. of $P$. serrulata shidare-sakura), is

Prunus pseudocerasus shirofugen (syn. of $P$. serrulata ochichima), i8

Prunus pseudocerasus sieboldii, 17

Prunus pseudocerasus spontanea (syn. of $P$. sargentii), I9

Prunus pseudocerasus spontanea hortensis (syn. of $P$. serrulata), 18

Prunus pseudocerasus typica parvifolia (syn. of $P$. parvifolia), 19

Prunus pseudocerasus typica sieboldii (syn. of $P$. pseudocerasus sieboldii), $\mathbf{I}_{7}$

Prunus pseudocerasus ukon (syn. of $P$. serrulata grandifolia), I 8

Prunus pseudocerasus virescens, 17

Prunus pseudocerasus watereri, 17

Prunus pseudocerasus yoshino (syn. of $P$. serrulato albida, 18

Prunus puddum (syn. of $P$. cerasoides, 19; of $P$. majestica, 19; of $P$. sargentii, 19 ; of $P$. serrulata), 18

Prunus pulchella, 16

Prunus pumila, 21; characters of, 34-35; distribution of. 35 ; specific description of, $34-35$; use of, as a stock, 74

Prunus pumila Besseyi (syn. of P. besseyi), 36

Prunus pumila cuneata (syn. of P. cuneata), 35

Prunus rehderiana, 16

Prunus rosea (syn. of P. cerasus), 24

Prunus rossiana, 21

Prunus rufa, 19; (syn. of P. trichantha), I9

Prunus rufoides, 17

Prunus salicina (syn. of $P$. humilis), 21

Prunus saltuum, is

Prunus sargentii, 19

Prunus schneideriana, 17

Prunus scopulorum, 17

Prunus serotina, value of wood of, 7

Prunus serrula, ig

Prunus serrula tibetica, 19

Prunus serrulata, 17

Prunus serrulata of. supra. (syn. of P. serrulata), i 8

Prunus serrulata albida, 18
Prunus serrulata borealis (syn. of $P$. sargentii), 19

Prunus serrulata flore pleno (syn. of $P$. serrulata mucronata), I8

Prunus serrulata grandiflora, 18

Prunus serrulata hisakura, 18

Prunus serrulata kriegeri, 18

Prunus serrulata lannesiana, 18

Prunus serrulata mucronata, 18

Prunus serrulata ochichima, 18

Prunus serrulata serrulata albida (syn. of $P$. serrulata albida), i 8

Prunus serrulata serrulata fugenzo (syn. of $P$. serrulata ochichima), 18

Prunus serrulata serrulata fugenzo rosea (syn. of $P$. serrulata), I8

Prunus serrulata serrulata lannesiana (syn. of $P$. serrulata lannesiana), 18

Prunus serrulata serrulata sieboldtii (syn. of $P$. pseudocerasus sieboldii), 17

Prunus serrulata serrula'a viridifora (syn. of $P$. serrulata grandiflora), $\mathbf{1} 8$

Prunus serrulata serrulata wattererii (syn. of P. pseudocerasus watereri), I7

Prunus serrulata shidare-sakura, 18

Prunus serrulata veitchiana, i8

Prunus serrulata " $W$.Kou" (syn. of $P$. serrulata hisakura), 18

Prunus serrulata yashino (syn. of $P$. serrulata albida), Is

Prunus setulosa, 20

Prunus sieboldii (syn. of $P$. pseudocerasus), 17; (syn. of $P$. pseudocerasus sieboldii), 17

Prunus silvatica (syn. of $P$. cerasoides), 19

Prunus sinensis (syn. of $P$. glandulosa trichostyla sinensis), 21

Prunus sontagia, 19

Prunus Sp. Zabel (syn. of P. sargentii), 19

Prunus sprengeri, 19

Prunus stipulacea, 20

Prunus subhirtella, 19

Prunus subhirtella autumnalis (syn. of $P$. autumnalis), 20

Prunus subhirtella fukubana, 20

Prunus subhirtella oblongifolia (syn. of P. subhirtella), 19

Prunus subhirtella pendula (syn. of $P$. pendula), 20

Prunus Susquehanae (syn. of P. pumila), 34

Prunus sylvestris (syn. of $P$. asium), 28

Prunus szechuanica, 16

"P. szechuanica, var. ?" (syn. of $P$. dielsiana), 17

“P. szechuanica diclsiana” (syn. of $P$. dielsiana), 17

Prunus taiwaniana, 20

Prunus tatsienensis, 16

Prunus tatsienensis adenophora, 16

Prunus tatsienensis pilosiuscula (syn. of P. pilosiuscula), $\mathbf{1 6}$

Prunus tatsienensis stenadenia, 16

Prunus tenuiflora, 19

Prunus tomentosa, 22; characters of, 33; habitat and distribution of, 33-34; specific description of, 33-34

Prunus tomentosa, ? Batalinii (syn. of P. bataliniz), 22 
Prunus tomentosa brevifiora, 22

Purnus tomentosa endotricha, 22

Prunus tomentosa graebneriana, 22

Prunus tomentosa heter mera, 22

Prunus tomentosa insularis, 22

Prunus tomentosa kashkarovii, 22

Prunus tomentosa souliei, 22

Prunus tomentosa spacthiana, 22

Prunus tomentosa trichocarpa, 22

Prunus tomentosa tsuluensis, 22

Prunus trichantha, 19

Prunus trichocarpa (syn. of $P$. tomentosa trichocarpa), 22

Prunus trichostoma, 20

Prunus tschonoskii, 20

Prunus troymaniana, 19

Prunus varia (syn. of P. avium), 28

Prunus variabilis, 16

Prunus veitchii, 20

Prunus cenusta, 16

Prunus verrucosa, 22

Prunus virginiana, 3

Prunus vulgaris (syn. of P. cerasus), 24

Prunus wildeniana, 19

Prunus yedansis, 19

Prunus yunnanensis, 17

Pranus yunnanensis henryi (syn. of P. henryi), 17;

(syn. of $P$. neglecta), 17

Prunus zappeyana, 20

Prunus zappeyana? subsimplex, 20

Prussian Cherry (syn. of Cerise de Prusse), 232

Puhlmann Frühe, 309

Punctirte Süsskirsche mit festem Fleische (syn. of Punktirte Marmorkirsche), 309

Punktirte Knorpelkirsche (syn. of Punktirte Marmorkirsche), 309

Punktirte Marmorkirsche, 309

Punktirte Molkenkirsche, 309

Purity (I), 309

Purity (II), 309

Purple Cherry (syn. of Early Purple), r30

Purple Guigne (syn. of Early Purple), I 30

Purpurrothe Knorpelkirsche (syn. of Red Bigarreau), 309

Pyramidenkirsche (syn. of Jerusalemskirsche), 279

Pyramidenweichsel (syn. of Jerusalemskirsche), 279

Quaker, 309

Rainier French, 309

Ratafia (syn. of Brusseler Braune), r ro

Ratafia Griotte (syn. of English Morello), I39

Raton, var. orig. with, 21 I

Red Bigarreau, 309

Red Canada, 310

Red-flowered (syn. of Fleurs Semi-doubles), 253

Red Guigne, 310

Red Heart (syn. of Bleeding Heart), 109

Red Jacket, 3 Io

Red Muscatel, 310

Red Oranien, 3 ro

Red Pic Cherry (syn. of Late Kentish), 157

Red Rock, 3 Io
Red Russian, 3 ro

Reichart, 310

Reid, John, quoted, 68

Reina Hortense, 179

Reine-Hortense Hàtive, 3 ro

Remington, $3 \mathrm{t} \mathrm{t}$

Remington Heart (syn. of Remington), 3 I I

Rentz Morello, 3 is

Republican, $\mathbf{1} 8 \mathbf{r}$

Resacks Knorpelkirsche, 3 I I

Richardson, 3 II

Richardson, J. R., var. orig. with, $31 \mathrm{t}$

Richardson, William P., var, orig, with, $3 \mathbf{I}$

Richardson Late Black, 3 I I

Richter Sämling, 3 I r

Riga No. 108, 311

Riga No. rog, $3 \mathbf{I I}$

Riley, quoted, 45

Rival, 31 1

Rivers, Thomas, var. orig. by, $247,248,293,3$ I I

River's Early Amber Heart (syn. of Early Amber), 247

Rivers Early Heare, 3 I I

Roberts, David, var, orig, with, $3 \mathbf{I} 2$

Roberts' Red (syn. of Bowyer Early Heart), 225

Roberts Red Heart, 3 II

Rochaline, $3 \mathbf{I} 2$

Rock, 3 I 2

Rockland, 312

Rockport, $\mathbf{8} 82$

Rocky Hill Honey Heart, $3 \mathbf{1} 2$

Rocky Mountain, 3 I2

Rocky Mountain Cherry, botanical name of, 37

Rocmonter Marmorkirsche (syn. of Belle de Rocmont), 212

Roe, 312

Romaine, $3 \mathbf{1} 2$

Ronald, 312

Ronalt's Large Black Heart (syn. of Black Tartaran), 107

Röschers, var. orig. with, $3 \mathbf{I} 2$

Röschers Kirsche, $3 \mathbf{I} 2$

Rose Charmeux, $3 \mathbf{I} 2$

Rosenobel, 312

Rosenrothe Maikirsche (syn. of Guigne Rose Hâtive), 272

Rostraver Bigarreau, 3 I 3

Rorhe Glanzkirsche, 313

Rothe Herzkirsche, 313

Rothe Maikirsche (syn. of May Duke), 164

Rothe Maiknorpelkirsche, 313

Rothe Molkenkirsche, 3 I 3

Rothe Muskateller (syn. of Cerise Guigne), 232

Rothe Oranienkirsche (syn. of Carnation), IIt

Rothe Soodkirsche, 313

Rothe Spanische Marmorkirsche (syn. of Belle de Rocmont), $2 \mathrm{I} 2$

Rouaanse Kirsche, 313

Rouge de Downing (syn, of Downing Red Cheek), 244

Rouge Pâle Tardive, $3 \mathbf{I} 3$

Rouge des Vosges, 313

Round Sweet, 314 
Royal American, 314

Royal .Inn (syn. of Napoleon), 172

Royal Duke, IS 4

Royal Hâtif, 314

Royale (syn. of Jeffrey Duke), 146

Royale d'Angleterre (syn. of Royal Duke), I 84

Royale Cherry Duke (syn. of May Duke), 164

Royale Hâtive (syn. of Jeffrey Duke), I 46 ; (syn. of

May Duke), 164

Royale Tardive (syn. of Holman Duke), 276

Rumsey, 3I4

Rumsey, J. S., var, orig. by, $3 \mathrm{It}$

Rumsey's Late Morcllo (syn. of Rumsey), 314

Runde Marmorirte Süsskirsche, 3 It

Rupert, 3 I4

Rupp, 3 It

Rupp, Solomon, var, orig. by, $3 \mathrm{I}_{4}$

Russian cherries, value of, for stocks, $73-74$

Russian Morello, 3 I4

Russian 207 (syn. of Russian Morello), 317

Russian Seedlings Nos. 8, 42, 49, 54, 109, 128, 169 and 199,315

Russie à Fruit Blanc, 315

Ryley Black Tartarian, 3 I5

Sächsische Frühe Maikirsche, 315

Sacramento, 3 I 5

Saint-Laurent, 315

St. Lucie cherry, 32

St, Margaret's Ch.rry (syn, of Elkhorn), I34

St. Whalpurgiskirsche (syn. of Bigarreau de Walpurgis), 221

Sand Cherry, botanical name of, 35 ; use of, as a stock, 74

Sansoto, 315

Sapa, 3 I5

Sappington, 315

Sauer Einmach and Backkirsche (sy'n. of Leitzkauer), 290

Sauerjotte, 3I 5

Saure Herzkirsche, 315

Sauvigny Knorpelkirsche, 315

Scharlachkirsche, 316

Schatten Amarelle (syn. of Shadow Amarelle), 318

Scheur-Kers (syn. of Black Guigne), 104

Schleihahn Sweet, 316

Schlössers Schattenmorelle, $3 \mathrm{I} 6$

Schmehls, 316

Schmidt, 185

Schmidt, F., var. orig. by, I $\$ 6,316$

Schmidt Bigarreau No. 2, 316

Schmidt Frühe Herzkirsche, 316

Schneeberger Kirsche, 3 r 6

Schneider Frühe Herzkirsche, 316

Schneider Späte Knorpelkirsche, 316

Schöne Agathe (syn. of Hildesheim), 144

Schöne Audigeoise (syn. of Belle Audigeoise), 211

Schöne aus Sauvigny (syn. of Montmorency de Sauvigny), 298

Schöne von didêche (syn. of Cerise de l'Ardèche), 230

Schöne von Brügge, 317

Schöne von Choisy (syn. of Choisy), I 16
Schöne von Couchey (syn. of Belle de Couchey), 2 I I

Schöne von Marienhohe, 317

Schöne von Montreuil (syn. of Montreuil), 298

Schöne von Ribeaucourt (syn. of Belle de Ribeaucourt), $2 \mathrm{I} 2$

Schöne von Rocmont (syn, of Belle de Rocmont), 2 I 2

Schreckens Kirsche (syn. of Bigarreau de Schrecken), 220

Schröcks Späte Bunte Knorpelkirsche, 317

Schwarzbraune Knorpelkirsche, 318

Schwarze Forellenkirsche, 317

Schwarze Knorpel von Merel (syn. of Mezel), r67

Schwarze Maikirsche (syn. of Schwarze Maiweichsel), 317

Schwarze Maiweichsel, 317

Schwarze Malvasierkirsche (syn. of Schwarze Oranienkirsche), 317

Schwarze Muskateller, 317

Schwarze oder Späte Herakirsche (syn. of Black Spanish), 223

Schwarze Oranienkirsche, 317

Schwarze Soodkirsche, 317

Schwarze Spanische Frühkirsche (syn. of Spanische Frijhkirsche), 320

Schwarze Spanische Knorpelkirsche (syn. of Black Spanish), 223

Schwarze Ungarische Kirsche (syn. of Ungarische Weichsel , 329

Schwarze Weichsel mit halb gefüllter Blute (syn. of Halbgefülltblühende Weichsel), 273

Schwarzes Taubenherz, 3 I 8

Schwefelkirsche (syn. of Dankelmannskirsche), $24^{\circ}$

Sebril, 318

Seckbacher, 318

Seckbacher Knorpelkirsche (syn. of Seckbacher), 318

Seederberger, 318

Select Beauty, 318

Semis de Burr (syn. of Burr), 228

Shadow Amarelle, 318

Shadow Morello (syn, of Shadow Amarelle), 318

Shailer, 3 I 9

Shannon, 319

Shamnon Morello (syn. of Shannon), 3 I9

Shelton, 319

Shelton, William, var. orig. by, 3 I9

Shepler, Louis, var, orig. with, 210

Shippen (syn. of June Duke), 280

Short-stem May, 319

Short-Stem Montmorency, I 87

Short Stem Montmorency (syn. of Large Montmorency), 153

Shubianka, 319

Sibrel, 319

Siebenfreund, var. introduced by, 328

Silver Thorne, 319

Sklanka, I 88

Skublics Weichsel, 319

Sleinhaus, 319

Small Black Guigne, 3 i 9

Small Double Flowering (syn. of Fleurs Doubles), 252

Small Morello, 319 
Smyech, Daniel, var. orig. with, 287

Smidt Yellow, 319

Smith (syn. of Schmidt), 185

Socsany, 320

Soft Sheld (syn. of Soft-stone Cherry), 320

Soft-stone Cherry, 320

Soodamarelle (syn. of Rothe Soodkirsche), 313

Sour Cherry, adaptation of, to culture, 3; comparison of, with the Sweet Cherry, 9; environment of, 76-80; geographic range of, 41 ; group name of, 2 ; probable parentage of, 44

Souths Breite Herzkirsche, 320

Souvenir d'Essonnes, 320

Spanische Frühkirsche, 320

Spanische Frühweichsel, 320

Spanische Glaskirsche, 320

Spanische Herakirsche (sy'n. of Spanische Frühkirsche), 320

Spanish (syn. of Yellow Spanish), 202; (syn. of Black Spanish), 223

Spanish Griotte, 321

Sparhawk, I 89

Sparhawk, Edward, var. introduced by, 190

Sparhavv's Honey (syn. of Sparhawk), 189

Spätblühende Glaskirsche, 32 r

Späte Amarelle, I90

Späte Amarelle (зул. of Süsse Amarelle), 323

Späte braune Spanische Herakirsche (syn. of Braune

Spanische Kirsche), 226

Späte grosse königliche Weichsel (syn. of Jerusalems-

kirsche), 279

Späte Herzogenkirsche (syn. of Late Duke), I 55

Späte Konigliche Weichsel (syn. of Jerusalemskirsche), 279

Späte Maikirsche (syn. of Seckbacher), 318

Späic Maulbeerherzkirsche (syn. of Späte Maulbeerkirsche), 32 I

Späte Maulbeerkirsche, 32 I

Späte Morello (syn. of Späte Amarelle), I9o

Späte Rote Knorpelkirsche, 32 I

Späte Schwarze Forellenkirsche, 32 I

Späte Schwarze Knorpelkirsche, 32 I

Späte Schwarze Spanische Herzkirsche, 321

Speckkirsche, 32 I

Spitzens Herzkirsche, 322

Srdcovka v Skalka, 322

Stanapa, 322

Standard, 322

Starr Prolific, 322

Stäts Blühender Kirschbaum (syn. of Toussaint), 193

Strass Early Black, 322

Strauss, 322

Strauss Weichsel, 322

Strauss Weichsel (syn. of Strauss), 322

Striker, 323

Striped-Leaved, 323

Strong, J. F., var. orig. by, 307

Stuart, 323

Stuart, C. W., var. orig. by, 323

Sucrée Léon Leclerc, 323

Suda, I92
Suda, var. orig. with, 192

Suda IIardy (syn. of Suda), 192

Summer's Honey (syn. of Honey), 276

Summit, 323

Süsse Amarelle, 323

Süsse Frühherzkirsche, 323

Süsse Frühweichsel, 324

Süsse Frühweichsel (svn. of Griotte Douce Précoce), 262

Süsse Maiherzkirsche, 324

Süsse Maiherakirsche (syn. of Baumann May), เо

Süsse Spanische, 324

Süsskirsche mit Gefurster Bluthe, 324

Süsskirschenbaum mit ganz gefüllter Blüte (syt. of

Large Double Flowering), 287

Süssweichsel von Chaux (syn. of German Morello), $25^{8}$

Sweedish, 324

Sweet Cherry, adaptation of, to culture, 3; comparison of, with the Sour Cherry, 9; environment of, 77-80; geographic range of, $t^{[-42 ;}$ group name of, 2

Sweet Montmorency, 324

Sweet Morello, 324

Tabors schwarze Knorpelkirsche (syn. of Bigarreau

Noir de Tabor), 2 I9

Tarascon Kirsche, 324

Tardive d'Avignon, 325

Tardive de Brederode, 325

Tardive Noire d'Espagne, 325

Tardive de Peine, 325

Tartarian (syn. of Black Tartarian), 107

Tecumseh, 325

Temple, 325

Terry, 325

Terry Early (syn. of Terry), 325

Terry, H. A., var. introduced by, 325

Thacher, quoted, 69

Theophrastus, quoted, 43

Thirty Day, 325

Thomas, quoted, 70

Thompson, 325

Thränen Muskatellerkirsche, 326

Tilgner Rothe Herzkirsche, 326

Tilgner Schwarze Knorpelkirsche, 326

Timme, 192

Timme, var. introduced by, 193

Tobacco-Leaved, 326

Toctonne Précoce, 327

Tokeya, 327

Tomato, 327

Toronto, 327

Toupie, 327

Toussaint, 193

Townsend, 327

Townsend, W. P., var. orig. by, 327

Tradescant (syn. of White Bigarreau), 196

Tradescant, John, var. orig, with, $13+$

Tradescant's Black Heart (syn. of Elkhorn), 134

Transparent, 327

Transparent de Bettenburg (syn. of Bettenburger Glaskirsche), 213

Transparent Guigne, 328

Transparent de Jahn (syn. of Transparent Guigne), 328 
Transparente d'Espagne (syn. of Spanische Glaskirsche), 320

Transparente de Meylan, 328

Transparente de Rivers, 328

Transparente de Siebenfreund, 328

Trauben oder Bouquet dmarelle (syn. of Cluster), 119

Trauerknorpelkirsche (syn. of Weeping Black Bigarreau), 33 I

Triomphe de Fausin, 328

Triumph of Cumberland (syn. of Cumberland), 239

Troprichters Schwarze Knorpelkirsche, 328

Tros-Kers (syn. of Cluster), 119

Truchsess, var. orig. by, 213,214

Truchsess Schwarze Herzkirsche, 328

Tubbs, 328

Türkine, 328

Türkine (syn, of Flamentine), 252

Turkirsche Grosse, 329

Turner Late, 329

Twyford, 329

Uellner, var. orig. with, 293

Uhlhorns Trauerkirsche, 329

Ulatis (syn. of California Advance), 113

Ungarische Herakirsche (syn. of Grosse Ungarische Kirsche), 267

Ungarische Süssweichsel (syn. of Royal Duke), 184

Ungarische Weichsel, 329

Urinall, 329

Utha, 329

Vail, Henry, var. orig. with, 209

Iail's August Duke (syn. of August Duke), 209

Van Gaasbeck, 329

Van Mons, var. orig. with, 246

Vanskike, 329

Varenne, var. orig. with, 137

Varrenne, De (syn. of Grosse Nonnenkirsche), 266

Vaughn, 329

Velser, 329

Very Large Heart, 330

Vesta, 330

Villeneuver Herzkirsche (syn. of Guigne Villeneuve), 272

Villennes (syn. of Cerise Rouge Pale), 233

Vilna Sweet, 330

Violet, 330

Virginia May Duke, 330

Vistula, 330

Vladimir, 194

Von Lade's Späte Knorpelkirsche (syn. of Ladé Late), 286

Voronezh No. 27, 330

Wabash, 330

Wachampa, 330

Wachsknorpelkirsche (syn. of Büttner Gelbe Knorpelkirsche), 228

Wagner, 330

Wahre Englische Kirsche (syn. of Late Duke), 155

Walling, G. W., var. orig. by, 304

Walpurgiskirsche (syn. of Bigarreau de Walpurgis), 221

$W$ alsh Seedling (syn. of Black Bigarreau of Savoy), 222

Wanfrieder Weichsel (syn. of Velser), 329

Warner, 33 I
Warner, Mathew G., var, orig. by, 331

Warren, var. orig. by, 33 I

Warren Transparent, $33 \mathbf{I}$

Washington Purple, 33 I

Waterhouse, 33 I

Waterhouse, Warren, var. orig. by, 331

Vaterloo, 196

Weber, R. H., var. orig. by, 301

Weeping, $33 \mathrm{I}$

IVeeping (syn. of Dwarf Siberian), 247

IVeeping or Pendulous Morello (syn. of Weeping), 331

Weeping Black Bigarreau, 33 I

Weeping Napoleon, 33 I

Weichsel mit halbgefülter Blüthe (syn. of Fleurs Semidoubles), 253

Weichselboum mit bündelförmigen Früchten (syn. of Cerisier Très-fertile), 234

Weichselbaum mit gelb, weiss, und rothlich marmorirte Frucht (syn. of Spätblühende Glaskirsche), 321

IVeichselbaum mit sehr gross gefülter Blüthe (syn. of Fleurs Doubles), 252

Weidenblätrige Süssweichsel (syn. of Willow-Leaved), 335

Weis, Roth und Rosenfarbig Marmorirte Krame!kirsche, 33 I

Weiss Herzkirsche (syn. of Grosse Bunte Herzkirsche), 265

Weiss und hellroth gefleckte grosse Kramelkirsche (syn. of Weisse Rosenroth Marmorirte Herzkirsche), 33 I

Weiss und hellroth geflekte grosse Kramelkirsche (syn. of Runde Marmorirte Süsskirsche), 314

Weiss und rothe grosse Herzkirsche (syn. of Früheste Bunte Herzkirsche), 256

Weisse Mandelkirsche, 332

Weisse Rosenroth Marmorirte Herzkirsche, 331

Wellington, 332

IVellington's Weichsel (syn. of Wellington), 332

Weltz, Leo, var. introduced by, 205

Wendell, Herman, var. orig. by, 332

Wendell Mottled, 332

Wenzlecks Bunte Knorpelkirsche, 332

Werder Early Black, 332

VIerdersche Schwarse Allerfrüheste Herzkirsche (syn. of Werder Early Black), 332

Werder'sche Bunte Herzkirsche, 332

Western Sand Cherry, botanical name of, 37

Wheeler, 332

Wheeler, H. J., var. orig. with, 332

White Bigarreau, 196

White Bigarreau, 332

White French, 333

White French Guigne, 333

White Gean, 333

White Heart, 197

White Heart (syn. of Grosse Guigne Blanche), 266

White Hungarian Gean, 333

White Mazzard, 333

White Oxheart (syn. of White Bigarreau), 196

White Spanish, 333

White Tartarian, 333

White Transparent, 333 
Wier, D. B., var. orig. by, 252, 257, 301, 333, 334

Wier No. 2, 333

Wier No. II, 334

Wier No. 12, 334

Wier No. 13, 334

Wier No. 19, 334

Wier No. 24, 334

Wier No. 4t, 334

Wier's Seedlings, 333

IVild Morello (syn. of Common Morello), 237

Wild Ross-shire, 334

Wilde Bunte Marmorkirsche, 334

Wilder, Samson V. S., var. introduced by, 292

Wilding von Kronberg (syn. of Kronberger Kirsche), 285

Wilhelmine Kleindienst, 334

Wilkinson, 334

Willamette, 335

Willis Early, 335

Willow-Leaved, 335

Wincklers schwarze Knorpelkirsche (syn. of Winkler Black), 335

Windsor, 198

Winkler, var. orig. by, 269

Winkler Black, 335
Winkler weisse Herzkirsche (syn. of Guigne Carnée Winkler), 269

IVinkler's schwarze Herzkirsche (syn. of Winkler Black), 335

Winter, Pastor, var. introduced by, 334

Winter Schwarze, 335

Wirt, Henry, var, orig. with, 275

Wohltragende Holländische Kirsche, 335

Wood, I99; immunity of, to powdery mildew, II

Wragg, 201

Yan, 335

Yellow Glass, 336

Yellow Honey (syn. of Honey), 276

Yellow Spanish, 202

Young Large Black Heart, 336

Youngken, Josiah G., var. orig. by, 299

Yuksa, 336

Zahm, G. W., var. orig. with, 274

Zeisbergische Kirsche (syn. of Bigarreau deZeisberg), $22 \mathrm{I}$

Zimmtkirsche, 336

Zweifarbige Kirsche, 336

Zueite Grösser Herakirschweichsel (syn. of Brusseler Braune), 110

Zwitterkirsche, 336

Zzuckser Schwarze Knorpelkirsche, 336 







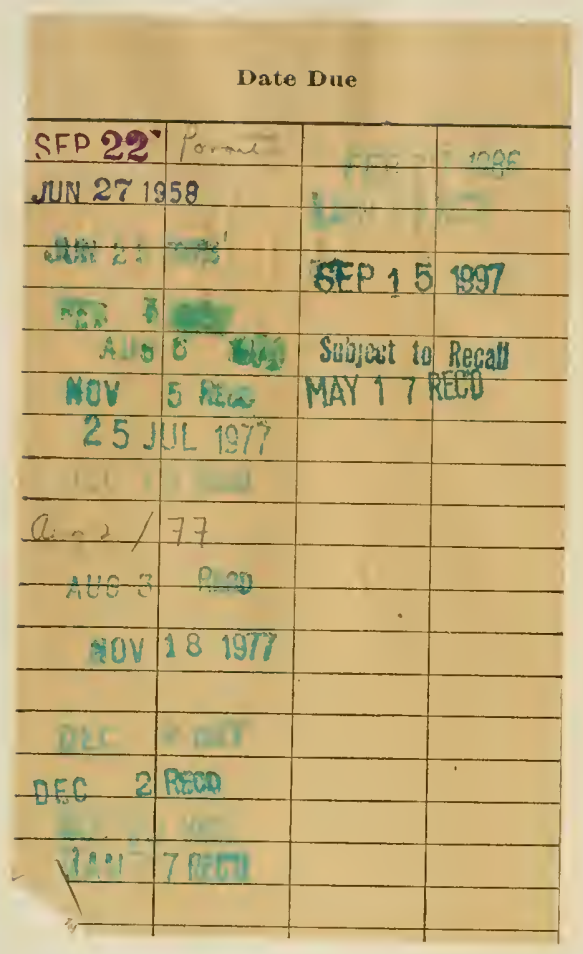




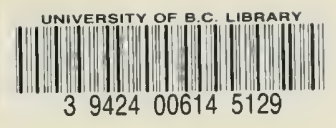

STORAGE

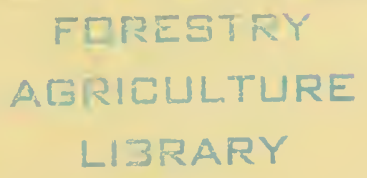


